RUI BARBOSA DE SOUZA

\title{
ESTUDO DA RETRAÇÃO EM FIBROCIMENTO REFORÇADO COM FIBRA POLIMÉRICA
}

\author{
Tese apresentada à Escola Politécnica da \\ Universidade de São Paulo para obtenção \\ do título de Doutor em Engenharia
}

São Paulo 

RUI BARBOSA DE SOUZA

\section{ESTUDO DA RETRAÇÃO EM FIBROCIMENTO REFORÇADO COM FIBRA POLIMÉRICA}

Tese apresentada à Escola Politécnica da Universidade de São Paulo para obtenção do título de Doutor em Engenharia

Área de concentração:

Engenharia de Construção Civil e Urbana

Orientador:

Prof. Dr. Vanderley Moacyr John

São Paulo 
Este exemplar foi revisado e corrigido em relação à versão original, sob responsabilidade única do autor e com a anuência de seu orientador.

São Paulo, 06 de janeiro de 2014.

Assinatura do autor

Assinatura do orientador

FICHA CATALOGRÁFICA

Souza, Rui Barbosa de

Estudo da retração em fibrocimento reforçado com fibra polimérica / R.B. de Souza. - versão corr. -- São Paulo, 2014. $244 \mathrm{p}$.

Tese (Doutorado) - Escola Politécnica da Universidade de São Paulo. Departamento de Engenharia de Construção Civil.

1.Fibrocimento 2.Retração por secagem 3.Pressão capilar I.Universidade de São Paulo. Escola Politécnica. Departamento de Engenharia de Construção Civil II.t. 
DEDICATÓRIA

Dedico à minha mãe. 


\section{AGRADECIMENTOS}

Agradeço à CAPES, pela concessão de bolsa de doutorado.

Agradeço às fábricas de fibrocimento da Infibra e Imbralit, por toda infraestrutura disponibilizada no desenvolvimento deste trabalho, além de informações detalhadas acerca dos produtos e processos, além do livre acesso nas instalações de produção, e apoio dos funcionários da linha de produção, laboratório, P\&D e diretoria.

Agradeço ao meu orientador, Prof. Dr. Vanderley Moacyr John, pela orientação e amizade.

Agradeço aos membros da banca avaliadora de qualificação, Prof. Holmer Savastano Jr, Prof. Rafael Pileggi e Dr. Gustavo Rocha, pela disponibilidade e orientações para melhoria do trabalho.

Agradeço aos membros da banca avaliadora de defesa, Prof. Holmer Savastano Jr, Prof. Wellington Repette, Prof. Romildo Toledo Filho, Dra. Maria do Rosário, pela avaliação e orientações para melhoria do trabalho.

Agradeço aos funcionários do Departamento de Engenharia e Construção Civil da Escola Politécnica da USP, em especial à Engrácia e ao Tecnº Mário Takeashi, além das estagiárias Kelly Kodama, Daisy Okubo, Marina Bento, Verônica Freitas e Beatriz Rodrigues.

Agradeço aos amigos de pós-graduação.

Faço um agradecimento especial à professora Sandra Carla Lima Dórea, minha orientadora de IC (UFS), que foi a pessoa que me encaminhou para esta carreira, me fazendo acreditar que seria capaz de me tornar Doutor em Engenharia. 


\section{RESUMO}

O objetivo do trabalho é analisar e compreender os efeitos das características do fibrocimento reforçado com fibras sintéticas na retração por secagem deste compósito. A importância social do fibrocimento como material de construção, justifica a realização do presente trabalho, de modo a expor como acontece a retração por secagem neste compósito, e desta forma auxiliar o meio técnico na mitigação das manifestações patológicas relacionadas à retração e contribuindo para a redução do importante problema da indústria produtora de fibrocimento, que é a fissuração de borda nas telhas onduladas. Para tal buscou-se demostrar o efeito da porosidade e distribuição de tamanho de poros na retração por secagem. Além disso, foram realizados experimentos onde se variou o tipo de cimento utilizado, as quantidades de todas as matérias-primas envolvidas, além da aplicação de tratamentos modificadores da movimentação higroscópica, manipulando diretamente a tensão capilar causadora da retração. Concluiu-se que a porosidade elevada do fibrocimento faz com que a retração por secagem deste compósito seja fortemente influenciada pela porosidade total do mesmo, com correlação direta com a quantidade de mesoporos. Além disso, no estudo de caso realizado concluiu-se que a redução da retração devido à redução da tensão superficial da água do poro, se refletiu em menor fissuração de borda nas telhas onduladas.

Palavras-chave: Fibrocimento NT; Retração por secagem; Pressão capilar; Fissura de borda; Telha ondulada. 


\begin{abstract}
The objective is to analyze and comprehend the effects of properties of cement based composite reinforced with synthetic fibers, on drying shrinkage of such composite. The social importance of fiber cement as construction material justifies the execution of the present work, in order to expose how drying shrinkage occurs on this composite and by those means to assist the technical community on mitigating pathological manifestations related to shrinkage, thus contributing for the reduction of an important problem on fiber cement industry, the edge cracking on corrugated sheets. In order to achieve this goal, it was sought to demonstrate the effect of porosity and pore size distribution on drying shrinkage. Moreover, experiments were performed, varying the type of cement used and the quantities of all materials involved, in addition to the application of treatments that modify hygroscopic movement, directly manipulating the capillary tension which causes shrinkage. It was concluded that the elevated porosity of the fiber cement causes drying shrinkage of this composite to be strongly influenced by its total porosity, directly correlated to the quantity of mesopores. Furthermore, in the case study performed it was concluded that shrinkage reduction due to the reduction of pore water surface tension was reflected into minor edge cracking on corrugated sheets.
\end{abstract}

Keyword: No-asbesto fiber cement; Drying shrinkage; Capillary pressure; Edge cracking; corrugated sheets. 


\section{LISTA DE ILUSTRAÇÕES}

FIGURA 1 - ESQUEMA DE DUAS PARTÍCULAS SÓLIDAS UNIDAS POR UMA FASE LÍQUIDA, ONDE AS FORÇAS CAPILARES ATUAM. INDICAÇÃO DOS ELEMENTOS $R_{1}$ E $R_{2}$ DA EQUAÇÃO DE LAPLACE. AdAPTADO (HILLEL, 2004)

FIGURA 2 - EXEMPLO dA ALTERAÇÃO DOS RAIOS $R_{1}$ E R $R_{2}$ EM FUNÇÃO DA RUGOSIDADE DAS PARTíCULAS. (A) RAIO R $\mathrm{R}_{1}$ NÃO SOFRE GRANDES ALTERAÇÕES, MAS RAIO R 2 É REDUZIDO SIGNIFICATIVAMENTE EM COMPARAÇÃO COM DUAS PARTÍCULAS ESFÉRICAS; (B) AMBOS OS RAIOS $R_{1}$ E $R_{2}$ SÃO REDUZIDOS EM COMPARAÇÃO COM DUAS PARTÍCULAS ESFÉRICAS; (C) RAIOS $R_{1}$ E $R_{2}$ FORMADOS POR DUAS PARTÍCULAS ESFÉRICAS. ADAPTADO (BUTT, 2003).

FIGURA 3 - CRESCIMENTO DA PRESSÃo CAPILAR NA SECAGEM DA SUSPENSÃO REATIVA. AdAPTAdo (SLOWIK ET AL., 2008) ........... 16

FIGURA 4 - ESQUEMA QUE REPRESENTA A RETRAÇÃo QUÍMICA DE UMA PASTA DE CIMENTO (V - VOLUME). AdAPTADO (TAZAWA, 1998) (KRONLÖF; LEIVO; SIPARI, 1995)

FIGURA 5 - CALORIMETRIA ISOTÉRMICA DE UM CIMENTO CPII F-32 À TEMPERATURA AMBIENTE $\left(23^{\circ} \mathrm{C}\right)$. 18

FIGURA 6 - EVOLUÇÃO DA HIDRATAÇÃO DAS FASES CONSTITUINTES DO CIMENTO EM FUNÇÃO DO TEMPO DE HIDRATAÇÃO (HEWLETT, 2004)

FIGURA 7 - EVOLUÇÃO DA RETRAÇÃO HORIZONTAL E ABATIMENTO VERTICAL EM FUNÇÃO DA PRESSÃO CAPILAR E TEMPO DE HIDRATAÇÃO (SLOWIK ET AL., 2009)

FIGURA 8 - AUTOSSECAGEM DE PASTAS DE CIMENTO COM RELAÇÃO A/C DE 0,25 E 0,50, INDICADA PELA REDUÇÃO DA UMIDADE RELATIVA DA PASTA EM FUNÇÃO DO TEMPO DE HIDRATAÇÃO (HANEHARA ET AL., 1999).

FIGURA 9 - FORÇAS ATUANTES NA TRIPLA INTERFACE ENTRE UMA GOTA LÍQUIDA EM UMA SUPERFÍCIE SÓLIDA.

FIGURA 10 - ÂNGULO DE CONTATO ENTRE UMA GOTA DE ÁGUA DEIONIZADA E (A) UMA SUPERFÍCIE DE FIBROCIMENTO E (B) UMA SUPERFÍCIE DE FIBROCIMENTO PINTADA COM HIDROFUGANTES

FIGURA 11 - FORÇAS QUE ATUAM NAS MOLÉCULAS DE ÁGUA NA SUPERFÍCIE COM RESULTANTE NA DIREÇÃO E SENTIDO DO INTERIOR DA

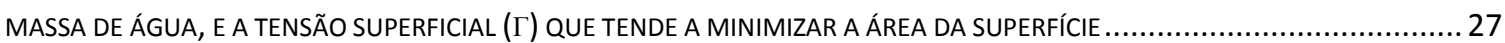

FIGURA 12 - INDICAÇÃO DOS RAIOS R E R DO MENISCO FORMADO NO PORO CAPILAR ..................................................29

FIGURA 13 - VARIAÇÃO NA RETRAÇÃO E NO COMPRIMENTO MÉDIO DA CADEIA DE SILICATO DURANTE A DESCALCIFICAÇÃO DO C-S-H (CHEN ET AL., 2006)

FIGURA 14 - VELOCIDADE DE RETRAÇÃO EM FUNÇÃO DA CONCENTRAÇÃO DE $\mathrm{CO}_{2}$ (MATSUSHITA ET AL., 2004) ..........................35

FIGURA 15 - RETRAÇÃO POR CARBONATAÇÃO EM FUNÇÃO DA UMIDADE RELATIVA DO AR (MINDESS, 1981) .............................35

FIGURA 16 - MATERIAIS QUE COMPÕEM O FIBROCIMENTO 36

FIGURA 17 - CURVAS TíPICAS DE TENSÃO DE TRAÇÃO X DEFORMAÇÃO OBTIDAS ATRAVÉS DE ENSAIOS DE TRAÇÃO DIRETA EM AMOSTRAS EXTRAÍDAS DE TELHAS DISPONÍVEIS NO MERCADO BRASILEIRO (DIAS, 2011)

FIGURA 18 - ETAPAS DO PROCESSO HATSCHEK UTILIZADO NA PRODUÇÃO DE PLACAS PLANAS E TELHAS ONDULADAS DE FIBROCIMENTO

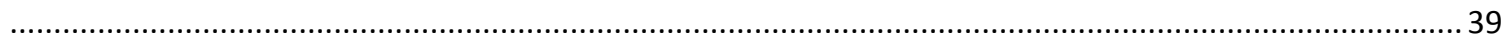

FIGURA 19 - ESPESSURA DA CAMADA DE ÁGUA ADSORVIDA EM FUNÇÃO DA UMIDADE RELATIVA (QUENARD ET AL., 1992) ............ 41

FIGURA 20 - MOVIMENTAÇÃO HIGROSCÓPICA ENTRE POROS COM DIFERENTES UMIDADES RELATIVAS .....................................42

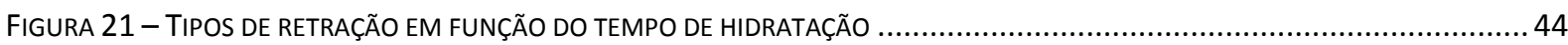

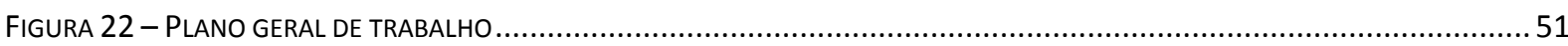

FIGURA 23 - RETALHO DE MANTA FRESCA DE FIBROCIMENTO, COLETADO PARA A EXTRAÇÃO DOS CORPOS-DE-PROVA UTILIZADOS NO ESTUDO .

FIGURA 24 - FIBRAS DE PVA DE 6MM (A) ANTES DA DISPERSÃO, EM FEIXES, E (B) APÓS PROCEDIMENTO DE DISPERSÃO COM APLICAÇÃO DE AR COMPRIMIDO....

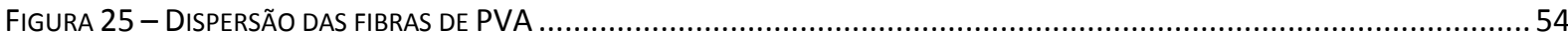

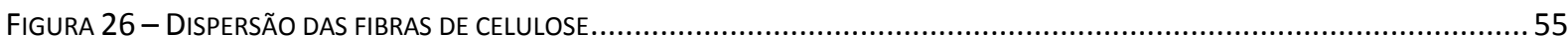

FIGURA 27 - APARATO DE MOLDAGEM DAS PLACAS QUADRADAS DE FIBROCIMENTO, POR FILTRAÇÃO .......................................56

FIGURA 28 - SEQUÊNCIA DE ATIVIDADES REALIZADAS NO ENSAIO DE CALORIMETRIA ISOTÉRMICA. (A) COLOCAÇÃO DA PASTA CIMENTÍCIA NA AMPOLA DE VIDRO; (B) FECHAMENTO HERMÉTICO DA AMPOLA; (C) COLOCAÇÃO DA AMPOLA DE VIDRO COM A AMOSTRA, E DE AMPOLA DE VIDRO VAZIA, NO INTERIOR DO CALORÍMETRO

FIGURA 29 - (A) EQUIPAMENTO UTILIZADO NO ENSAIO DE RETRAÇÃO, (B) QUE É INICIALMENTE ZERADO COM UMA BARRA DE REFERÊNCIA FEITA DE INVAR E (C) EM SEGUIDA É REALIZADA A DETERMINAÇÃO DO COMPRIMENTO DO CORPO-DE-PROVA .......62 
FIGURA 30 - ENSAIO DE RESISTÊNCIA À FLEXÃO COM 4 PONTOS .

FIGURA 31 - RETRAÇÃO POR SECAGEM EM FUNÇÃO DO TEMPO DE AMOSTRAS DE CONCRETO E ARGAMASSA. DADOS DE RETRAÇÃO EM

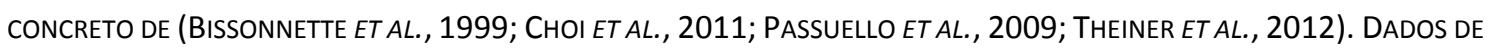
RETRAÇÃo EM ARGAMASSA de (ATIŞ ET AL., 2004; BISSONNETtE ET AL., 1999; RAO, 2001; TOLEdo FILHO ET AL., 2005) ..68

FIGURA 32 - DISTRIBUIÇÃO DE TAMANHO DE POROS DE FIBROCIMENTO REFORÇADO COM FIBRAS DE PVA, POR POROSIMETRIA POR INTRUSÃO DE MERCÚRIO (AMOSTRA PRODUZIDA EM FÁBRICA). I - CAPILARES PEQUENOS (POROS DE GEL); II - CAPILARES MÉDIOS (MESOPOROS); III - CAPILARES GRANDES (MACROPOROS); IV - DEFEITOS E POROS DA CELULOSE ...........................70

FIGURA 33 - DISTRIBUIÇÃO DE TAMANHO DE PARTíCULAS DOS DIFERENTES CALCÁRIOS UTILIZADOS NAS FORMULAÇÕES DE FIBROCIMENTO

FIGURA 34 - PLANO EXPERIMENTAL DO ESTUDO DE INFLUÊNCIA DA POROSIDADE NA RETRAÇÃO POR SECAGEM O FIBROCIMENTO.....74

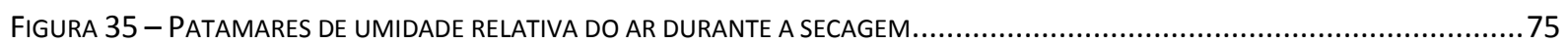

FIGURA 36 - PLANO EXPERIMENTAL PARA A ELABORAÇÃO DAS ISOTERMAS DE SECAGEM DO FIBROCIMENTO .................................76

FIGURA 37 - DIAGRAMA DE RETRAÇÃO POR SECAGEM DE FIBROCIMENTOS REFORÇADOS COM PVA (99 CORPOS-DE-PROVA DE FIBROCIMENTO PRODUZIDOS EM FÁBRICA). (A) RELAÇÃO ENTRE A RETRAÇÃO POR SECAGEM E A UMIDADE DO FIBROCIMENTO;

(B) RETRAÇÃO EM FUNÇÃO DO TEMPO DE SECAGEM; (C) PERDA DE ÁGUA EM FUNÇÃO DO TEMPO DE SECAGEM ....................77

FIGURA 38 - RETRAÇÃO EM FUNÇÃO DA REDUÇÃO DA UMIDADE DOS CORPOS-DE-PROVA. TRECHO I - PERDA DE UMIDADE QUE NÃO CAUSA RETRAÇÃO; TRECHO II - PERDA DE UMIDADE QUE CAUSA RETRAÇÃO SEGUNDO CORRELAÇÃO LOGARÍTMICA. A REGRESSÃO LOGARÍTMICA DESCRITA NO DIAGRAMA DE RETRAÇÃo (FIGURA 37) ESTÁ REPRESENTADA NESTA FIGURA PELA LINHA TRACEJADA

FIGURA 39 - DISTRIBUIÇÃO DE TAMANHO DE POROS DE FIBROCIMENTO REFORÇADO COM FIBRAS DE PVA, POR POROSIMETRIA POR INTRUSÃO DE MERCÚRIO (AMOSTRA PRODUZIDA EM FÁBRICA). I - INTERVALO DE TAMANHO DE POROS QUE NÃO CAUSAM RETRAÇÃO POR SECAGEM; IIA - INTERVALO DE TAMANHO DE POROS QUE RESULTA EM RETRAÇÃO NA SECAGEM EM MENOR INTENSIDADE; IIB - INTERVALO DE TAMANHO DE POROS QUE RESULTA EM RETRAÇÃO NA SECAGEM EM MAIOR INTENSIDADE ..83

FIGURA 40 - PRESSÃO CAPILAR ESTIMADA, CALCULADA A PARTIR DA EQUAÇÃO DE LAPLACE, (A) PARA CADA FAIXA DE TAMANHO DE PORO; (B) PARA O PERCENTUAL DE POROS SATURADOS. O TRECHO EM PONTILHADO EM AMBAS AS CURVAS REPRESENTA A REGIÃO DOS POROS DE GEL E MICROPOROS, ONDE O MECANISMO DE DEPRESSÃO CAPILAR GOVERNADO PELA EQUAÇÃO DE LAPLACE NÃO É VÁLIDO

FIGURA 41 - (A) VOLUME DE POROS PRESENTES NO FIBROCIMENTO, MULTIPLICADO PELA TENSÃO CAPILAR ESTIMADA PARA CADA FAIXA DE DIÂMETRO DE PORO (O TRECHO EM PONTILHADO NA CURVA REPRESENTA A REGIÃO DOS POROS DE GEL E MICROPOROS, ONDE O MECANISMO DE DEPRESSÃO CAPILAR GOVERNADO PELA EQUAÇÃO DE LAPLACE NÃO É VÁLIDO); (B) CORRELAÇÃO DO FATOR 'VOLUME DE POROS X PRESSÃO CAPILAR' COM A RETRAÇÃO POR SECAGEM DO FIBROCIMENTO.....

FIGURA 42 - SECAGEM dO PORO CAPILAR E FORMAÇÃO dO MENISCO. (A) PORO SATURAdO; (B) FORMAÇÃO dE MENISCO; (C) REDUÇÃO DO RAIO DO MENISCO; (D) QUEBRA DA TENSÃO CAPILAR. ADAPTADO (GONÇALVES, 2011)

FIGURA 43 - TAXA DE RETRAÇÃO EM FUNÇÃO DA UMIDADE. DERIVADA DA REGRESSÃO ENCONTRADA PARA A CURVA DE RETRAÇÃO X

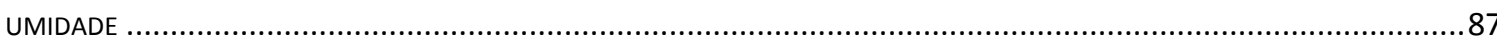

FIGURA 44 - POROSIDADE DO FIBROCIMENTO EM FUNÇÃO DA (A) VARIAÇÃO DA CARGA DE COMPACTAÇÃO APLICADA DURANTE A PRODUÇÃO DAS AMOSTRAS; E (B) GRAU DE EMPACOTAMENTO EM FUNÇÃO DA FINURA DO CALCÁRIO, INDICADA PELO DIÂMETRO

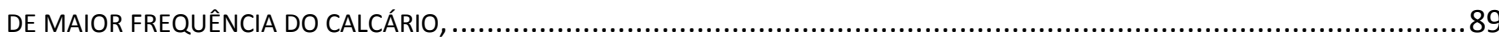

FIGURA 45 - EFEITO DA CARGA DE COMPACTAÇÃO APLICADA DURANTE A PRODUÇÃO DAS AMOSTRAS NA (A) DENSIDADE APARENTE E DENSIDADE REAL DO FIBROCIMENTO. EFEITO DO GRAU DE EMPACOTAMENTO VARIADO PELA FINURA DO CALCÁRIO NA (B) DENSIDADE APARENTE E A DENSIDADE REAL DO FIBROCIMENTO. FINURA INDICADA PELO DIÂMETRO DE MAIOR FREQUÊNCIA DO CALCÁRIO

FIGURA 46 - RELAÇÃO ENTRE A RETRAÇÃO POR SECAGEM E A UMIDADE DO FIBROCIMENTO, EM FUNÇÃO DA CARGA DE COMPACTAÇÃO APLICADA DURANTE A PRODUÇÃO DAS AMOSTRAS .....

FIGURA 47 - RELAÇÃO ENTRE A RETRAÇÃO POR SECAGEM E A UMIDADE DO FIBROCIMENTO, EM FUNÇÃO DO DIÂMETRO MÉDIO DO CALCÁRIO

FIGURA 48 - RETRAÇÃO POR SECAGEM EM FUNÇÃO DA (A) DA CARGA DE COMPACTAÇÃO APLICADA DURANTE A PRODUÇÃO DAS AMOSTRAS; E (B) DO GRAU DE EMPACOTAMENTO EM FUNÇÃO DA FINURA DO CALCÁRIO

FIGURA 49 - RETRAÇÃO AOS 14 DIAS DE SECAGEM EM FUNÇÃO DA (A) DA CARGA DE COMPACTAÇÃO APLICADA DURANTE A PRODUÇÃO DAS AMOSTRAS; E (B) DO GRAU DE EMPACOTAMENTO EM FUNÇÃO DO DIÂMETRO MÉDIO DO CALCÁRIO. 
FigURA 50 - EFEITO dA POROSIDAdE NA (A) PERDA DE ÁGUA E (B) RETRAÇÃO, AOS 14 DIAS DE SECAGEM ...............................94

FIGURA 51 - DISTRIBUIÇÃO DE TAMANHO DE POROS DO FIBROCIMENTO EM FUNÇÃO DA CARGA DE COMPACTAÇÃO ......................95

FIGURA 52 - VOLUME DE POROS DE DIFERENTES TAMANHOS EM FUNÇÃO DA CARGA DE COMPACTAÇÃO APLICADA DURANTE O PROCESSO DE FABRICAÇÃO DO FIBROCIMENTO. TRECHO I: DIÂMETRO DO PORO SUPERIOR A 2,33 $\mu \mathrm{M}$; TRECHO II.A: DIÂMETRO DO PORO ENTRE 0,03 E 2,33 $\mu \mathrm{M}$; TRECHO II.B: DIÂMETRO DO PORO ENTRE 0,03 $\mu \mathrm{M} \mathrm{E} \mathrm{13,2} \mathrm{NM.}$

FIGURA 53 - ESQUEMA DO EFEITO DO TAMANHO DA PARTÍCULA NO GRAU DE EMPACOTAMENTO. O MELHOR EMPACOTAMENTO OCORRE NA CONDIÇÃO (B), ONDE NÃO HÁ AFASTAMENTO DAS PARTÍCULAS E O FILLER PREENCHE AO MÁXIMO OS ESPAÇOS VAZIOS

FIGURA 54 - DISTRIBUIÇÃO DE TAMANHO DE POROS DO FIBROCIMENTO EM FUNÇÃO DA FINURA DO CALCÁRIO ..... 97

FIGURA 55 - VOLUME DE POROS DE DIFERENTES TAMANHOS EM FUNÇÃO DO GRAU DE EMPACOTAMENTO OBTIDO VARIANDO-SE A FINURA DO CALCÁRIO. TRECHO I: DIÂMETRO DO PORO SUPERIOR A 2,33 $\mu \mathrm{M}$; TRECHO II.A: DIÂMETRO DO PORO ENTRE 0,03 E 2,33 $\mu \mathrm{M}$; TRECHO II.B: DIÂMETRO DO PORO ENTRE 0,03 $\mu \mathrm{M}$ E 13,2 NM.

FIGURA 56 - REDUÇÃO DA UMIDADE EM FUNÇÃO DO TEMPO DE SECAGEM DO FIBROCIMENTO E UMIDADE RELATIVA DO AR, QUE VARIOU NOS PATAMARES $70 \%, 50 \%, 40 \%$ E $20 \%$

FIGURA 57 - RETRAÇÃO EM FUNÇÃO DO TEMPO DE SECAGEM DO FIBROCIMENTO E UMIDADE RELATIVA DO AR, QUE VARIOU NOS PATAMARES $70 \%, 50 \%, 40 \%$ E $20 \%$

FIGURA 58 - VARIAÇÃO DA UMIDADE EM FUNÇÃO DO TEMPO DE SECAGEM. SECAGEM DIRETA........................................... 101

FIGURA 59 - RETRAÇÃO EM FUNÇÃO DO TEMPO DE SECAGEM DO FIBROCIMENTO. SECAGEM DIRETA .....................................101

FIGURA 60 - ISOTERMA DE SECAGEM, QUE RELACIONA O EFEITO DA UMIDADE RELATIVA DO AMBIENTE NA UMIDADE DO FIBROCIMENTO. TEMPERATURA DE SECAGEM: $23^{\circ} \mathrm{C}$

FIGURA 61 - RETRAÇÃO POR SECAGEM EM FUNÇÃO DA UMIDADE RELATIVA DO AMBIENTE COM A RETRAÇÃO POR SECAGEM DO FIBROCIMENTO.

FIGURA 62 - PLANO EXPERIMENTAL DO ESTUDO DA INFLUÊNCIA DO CIMENTO NA RETRAÇÃO POR SECAGEM ............................112

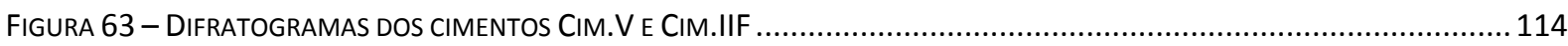

FIGURA 64 - DifRATOGRAMAS DOS CIMENTOS CIM.V E CIM.IIE

FIGURA 65 - (A) TERMOGRAVIMETRIA (TG) E (B) PRIMEIRA DERIVADA DA TERMOGRAVIMETRIA (DTG) DOS CIMENTOS COMPOSTOS

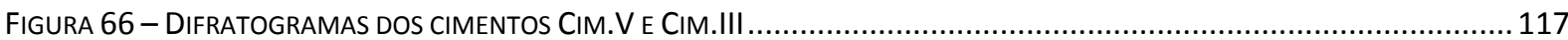

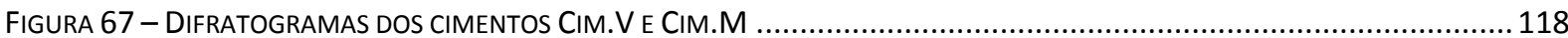

Figura 68 - (A) Termogravimetria (TG) E (B) PRIMeIRA derivada da termograVimetria (DTG) dos Cimentos Cim.III, CIM.V E CIM.M

FIGURA 69 - (A) TERMOGRAVIMETRIA (TG) E (B) PRIMEIRA DERIVADA DA TERMOGRAVIMETRIA (DTG) DO CALCÁRIO E DA SÍLICA.. 119 FIGURA 70 - DISTRIBUIÇÃO ACUMULADA DO TAMANHO DE PARTÍCULAS DOS CIMENTOS ESTUDADOS.....................................120

FIGURA 71 - DISTRIBUIÇÃO DO TAMANHO DE PARTÍCULAS DAS ADIÇÕES MINERAIS ........................................................ 121

FIGURA 72 - FLUXO DE CALOR LIBERADO DURANTE O ENSAIO DE CALORIMETRIA PARA OS CIMENTOS ESTUDADOS .......................122

FIGURA 73 - CALOR ACUMULADO LIBERADO DURANTE O ENSAIO DE CALORIMETRIA PARA OS CIMENTOS ESTUDADOS...................123

FIGURA 74 - POROSIDADE TOTAL DOS FIBROCIMENTOS COM DIFERENTES TIPOS DE CIMENTO .............................................. 125

FIGURA 75 - RETRAÇÃO POR SECAGEM DOS FIBROCIMENTOS COM DIFERENTES TIPOS DE CIMENTO ....................................126

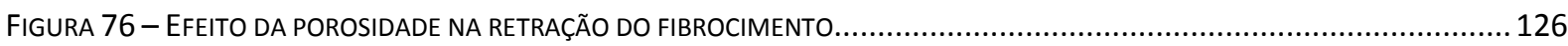

FIGURA 77 - DISTRIBUIÇÃO DE TAMANHO DE POROS DOS FIBROCIMENTOS UTILIZANDO DIFERENTES CIMENTOS, POR POROSIMETRIA POR INTRUSÃO DE MERCÚRIO

FIGURA 78 - DISTRIBUIÇÃO ACUMULADA DE TAMANHO DE POROS DOS FIBROCIMENTOS UTILIZANDO DIFERENTES CIMENTOS, POR POROSIMETRIA POR INTRUSÃO DE MERCÚRIO

FIGURA 79 - CORRELAÇÃO ENTRE A RETRAÇÃO POR SECAGEM E O VOLUME DE POROS DE GEL E MESOPOROS, SEGUNDO CLASSIFICAÇÃO DE TAMANHO DE POROS PROPOSTO POR (MINDESS, 1981)

FIGURA 80 - CORRELAÇÃO ENTRE A RETRAÇÃO POR SECAGEM E O VOLUME DE POROS REFERENTES AOS DEFEITOS, CUJA SECAGEM OCORRE NA PRIMEIRA 1,5 HORA; MACROPOROS E PARCELA DE MESOPOROS, CUJA SECAGEM OCORRE ATÉ 2 DIAS DE EXPOSIÇÃO; GRANDE PARTE DOS MESOPOROS, CUJA SECAGEM OCORRE ENTRE 2 E A4 DIAS DE EXPOSIÇÃO; E POROS DE TAMANHO INFERIOR À

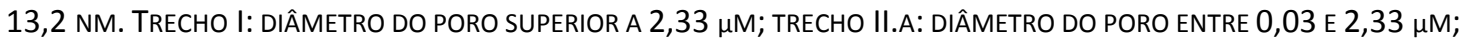


TRECHO II.B: DIÂMETRO DO PORO ENTRE 0,03 $\mu \mathrm{M}$ E 13,2 NM. PONTOS SEM PREENCHIMENTO EQUIVALEM AOS CIMENTOS

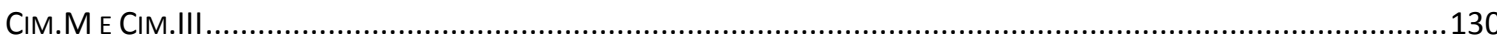

FIGURA 81 - RELAÇÃO ENTRE A RETRAÇÃO ATÉ OS 14 DIAS DE SECAGEM E A UMIDADE DO FIBROCIMENTO ................................131

FIGURA 82 - PLANO EXPERIMENTAL DO ESTUDO SOBRE INFLUÊNCIA DOS MATERIAIS CONSTITUINTES DO FIBROCIMENTO NA RETRAÇÃO

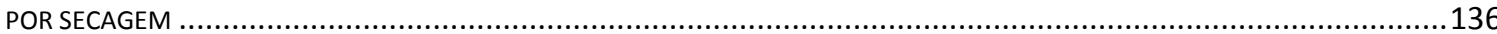

FIGURA 83 - DISTRIBUIÇÃO DO TAMANHO DE PARTÍCULAS DAS ADIÇÕES MINERAIS, COMPARADOS COM O CIMENTO CP II-E.........137

FIGURA 84 - (A) TERMOGRAVIMETRIA (TG) E (B) PRIMEIRA DERIVADA DA TERMOGRAVIMETRIA (DTG) DO CIMENTO, CALCÁRIO,

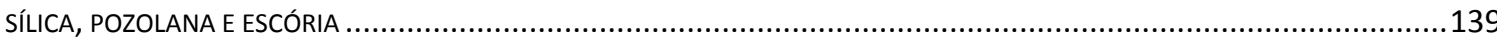

FIGURA 85 - EFEITO DO TEOR DE CIMENTO NA POROSIDADE TOTAL DO FIBROCIMENTO APÓS 14 DIAS DE SECAGEM .....................140

FIGURA 86 - EFEITO DO TEOR DE CIMENTO NAS DENSIDADES APARENTE E REAL DO FIBROCIMENTO .......................................140

FIGURA 87 - RELAÇÃO ENTRE A RETRAÇÃO E POROSIDADE. AMOSTRAS COM A QUANTIDADE DE CIMENTO VARIANDO NOS TEORES DE

$20,35,50,65$ E $80 \%$

FIGURA 88 - EFEITO DO TEOR DE CIMENTO NA RETRAÇÃO EM FUNÇÃO DO TEMPO DE SECAGEM. AMOSTRAS COM A QUANTIDADE DE CIMENTO VARIANDO NOS TEORES DE $20,35,50,65$ E $80 \%$

FIGURA 89 - DISTRIBUIÇÃO DE TAMANHO DE POROS DOS FIBROCIMENTOS EM FUNÇÃO DO TEOR DE CIMENTO PRESENTE NA FORMULAÇÃO

FIGURA 90 - EFEITO DO TEOR DE CIMENTO DO FIBROCIMENTO NO VOLUME DE POROS NAS DIFERENTES FAIXAS DE TAMANHOS. TRECHO I: DIÂMETRO DO PORO SUPERIOR A 2,33 $\mu$ M; TRECHO II.A: DIÂMETRO DO PORO ENTRE 0,03 E 2,33 $\mu$ M; TRECHO II.B: DIÂMETRO DO PORO ENTRE 0,03 $\mu \mathrm{M}$ E 13,2 NM

FIGURA 91 - RELAÇÃO ENTRE A RETRAÇÃO POR SECAGEM E O VOLUME DE MESOPOROS DO FIBROCIMENTO. AMOSTRAS COM A QUANTIDADE DE CIMENTO VARIANDO NOS TEORES DE 20, 35, 50, 65 E 80\% ..................................................144

FIGURA 92 - EFEITO dO TEOR DE CIMENTO NA RELAÇÃO RETRAÇÃO/PERDA DE ÁGUA....................................................145

FIGURA 93 - RELAÇÃO ENTRE A RETRAÇÃO POR SECAGEM E A UMIDADE DO FIBROCIMENTO, EM FUNÇÃO DO TEOR DE CIMENTO ....145

FIGURA 94 - PROPRIEDADES MECÂNICAS (MOR E E) DO FIBROCIMENTO EM FUNÇÃO DA QUANTIDADE DE CIMENTO PRESENTE .....146

FIGURA 95 - EFEITO DA POROSIDADE NO LIMITE DE PROPORCIONALIDADE DO FIBROCIMENTO NA RUPTURA À FLEXÃO ...................146

FIGURA 96 - RETRAÇÃO POR SECAGEM EM FUNÇÃO DO (A) TEOR DE SÍLICA, (B) TEOR DE POZOLANA E (C) TEOR DE ESCÓRIA PRESENTES NO FIBROCIMENTO 147

FIGURA 97 - PERDA DE MASSA DO FIBROCIMENTO EM FUNÇÃO DO (A) TEOR DE SÍlICA, (B) TEOR DE POZOLANA E (C) TEOR DE ESCÓRIA PRESENTES.

FIGURA 98 - EFEITO DO TEOR DE ADIÇÃO NA POROSIDADE TOTAL DO FIBROCIMENTO. AMOSTRAS COM A QUANTIDADE DE ADIÇÃO DE SÍLICA, POZOLANA OU ESCÓRIA VARIANDO NOS TEORES DE 0, 2, 5 E 8\%. 148

FIGURA 99 - RELAÇÃO ENTRE A RETRAÇÃO E POROSIDADE. AMOSTRAS COM A QUANTIDADE DE ADIÇÃO DE SílICA, POZOLANA OU

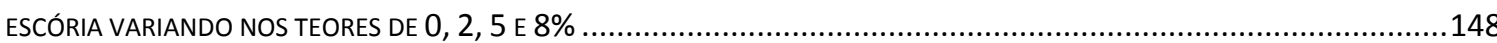

FIGURA 100 - DISTRIBUIÇÃO DE TAMANHO DE POROS EM FUNÇÃO DO TEOR DE SÍLICA PRESENTE NA FORMULAÇÃO......................149

FIGURA 101 - DISTRIBUIÇÃO DE TAMANHO DE POROS EM FUNÇÃO DO TEOR DE POZOLANA PRESENTE NA FORMULAÇÃO ...............149

FIGURA 102 - DISTRIBUIÇÃO DE TAMANHO DE POROS EM FUNÇÃO DO TEOR DE ESCÓRIA PRESENTE NA FORMULAÇÃO ..................150

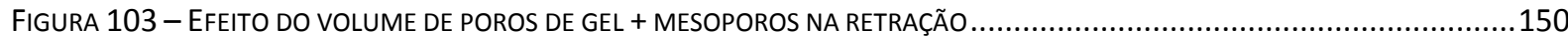

FIGURA 104 - EFEITO DO TEOR DE ADIÇÃO NO VOLUME DE POROS NAS DIFERENTES FAIXAS DE TAMANHO. (A) SÍlICA), (B) POZOLANA, (C) ESCÓRIA. TRECHO I: DIÂMETRO DO PORO SUPERIOR A 2,33 $\mu \mathrm{M}$; TRECHO II.A: DIÂMETRO DO PORO ENTRE 0,03 E 2,33 $\mu \mathrm{M}$; TRECHO II.B: DIÂMETRO DO PORO ENTRE 0,03 $\mu \mathrm{M}$ E 13,2 NM 151

FIGURA 105 - EFEITO DO TEOR DE CELULOSE NA (A) POROSIDADE TOTAL MEDIDA POR PRINCÍPIO DE ARQUIMEDES E (B) DENSIDADES REAL E APARENTE DO FIBROCIMENTO

FiguRA 106 - EFEITO dO TEOR DE CELULOSE NA (A) PERDA DE MASSA E (B) NA RETRAÇÃO EM FUNÇÃO DO TEMPO DE SECAGEM. AMOSTRAS COM A QUANTIDADE DE CIMENTO VARIANDO NOS TEORES DE 1, 3 E 5\% .............................................153

FIGURA 107 - EFEITO POROSIDADE TOTAL NA RETRAÇÃO POR SECAGEM ...............................................................153

FIGURA 108 - RELAÇÃO ENTRE A RETRAÇÃO POR SECAGEM E A UMIDADE DO FIBROCIMENTO, EM FUNÇÃO DO TEOR DE CELULOSE.. 154 FIGURA 109 - DISTRIBUIÇÃO DE TAMANHO DE POROS EM FUNÇÃO DO TEOR DE CELULOSE PRESENTE NA FORMULAÇÃO ................155 FIGURA 110 - EFEITO DO TEOR DE CELULOSE NO FIBROCIMENTO NO VOLUME DE POROS DE GEL + MESOPOROS, CAPILARES GRANDES E

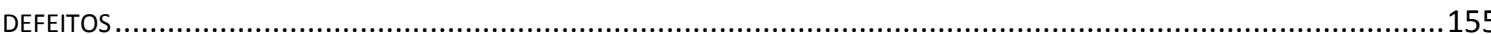

FIGURA 111 - RETRAÇÃO POR SECAGEM EM FUNÇÃO DO (A) TEOR DE PVA E (B) TEOR DE PP PRESENTES NO FIBROCIMENTO........156 
FIGURA 112 - RETRAÇÃO AOS 14 DIAS DE SECAGEM EM FUNÇÃO DAS QUANTIDADES DE PVA OU PP PRESENTES ......................157

FIGURA 113 - POROSIDADE DO FIBROCIMENTO EM FUNÇÃO DAS QUANTIDADES DE PVA OU PP PRESENTES ..............................157

FIGURA 114 - DISTRIBUIÇÃO DE TAMANHO DE POROS EM FUNÇÃO DO TEOR DE PVA PRESENTE NA FORMULAÇÃO.......................158

FIGURA 115 - DISTRIBUIÇÃO DE TAMANHO DE POROS EM FUNÇÃO DO TEOR DE PP PRESENTE NA FORMULAÇÃO .........................158

FIGURA 116 - PROPRIEDADES MECÂNICAS (MOR E LOP) DO FIBROCIMENTO EM FUNÇÃO DAS QUANTIDADES DE PVA OU PP PRESENTES.

FIGURA 117 - CURVAS TENSÃO-DEFORMAÇÃO DOS FIBROCIMENTOS COM (A) 1,2\%, (B) 1,8\% E (C) 2,4\% DE PVA PRESENTE ..... 159

FIGURA 118 - CURVAS TENSÃO-DEFORMAÇÃO DOS FIBROCIMENTOS COM (A) 1,2\%, (B) 1,8\% E (C) 2,4\% DE PP PRESENTE........ 160

FIGURA 119 - PLANO EXPERIMENTAL DO ESTUDO DE RETRAÇÃO POR CARBONATAÇÃO 165

FIGURA 120 - MONTE DE TELHAS EMPILHADAS EXPOSTAS. AMOSTRAS FORAM RETIRADAS DA SEXTA TELHA SUPERIOR (INDICADA PELA LINHA VERMELHA), SENDO UMA AMOSTRA RETIRADA DA BORDA E OUTRA DA REGIÃO CENTRAL DESTA TELHA (INDICADOS PELO SINAL X)

FIGURA 121 - CONDIÇÕES DE EXPOSIÇÃO DAS TRÊS AMOSTRAS ESTUDADAS (SECAGEM; CARBONATAÇÃO APÓS SECAGEM; CARBONATAÇÃO + SECAGEM)

FIGURA 122 - CURVA TíPICA DE TERMOGRAVIMETRIA DE FIBROCIMENTO COM PVA. ESTE RESULTADO É REFERENTE A UMA AMOSTRA

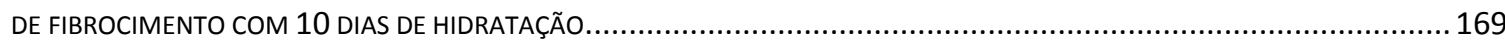

FIGURA 123 - TERMOGRAVIMETRIA DAS AMOSTRAS SUBMETIDAS À SECAGEM EM FUNÇÃO DO TEMPO DE EXPOSIÇÃO ..................169

FIGURA 124 - TERMOGRAVIMETRIA DAS AMOSTRAS SUBMETIDAS À CARBONATAÇÃO APÓS SECAGEM, EM FUNÇÃO DO TEMPO DE EXPOSIÇÃO

FIGURA 125 - TERMOGRAVIMETRIA DAS AMOSTRAS SUBMETIDAS À CARBONATAÇÃO+SECAGEM, EM FUNÇÃO DO TEMPO DE EXPOSIÇÃO

FIGURA 126 - TERMOGRAVIMETRIA DAS AMOSTRAS AO FINAL DOS PERÍODOS DE EXPOSIÇÃO, DEPOIS DE SUBMETIDAS À SECAGEM, CARBONATAÇÃO APÓS SECAGEM E CARBONATAÇÃO+SECAGEM

FIGURA 127 - PERDA DE MASSA REFERENTE AO $\mathrm{CO}_{2}$ COMBINADO. (A) $\mathrm{CO}_{2}$ VOLATILIZADO NA FAIXA DE APROXIMADAMENTE $580^{\circ} \mathrm{C}$ A $980^{\circ} \mathrm{C}$, REFERENTE AO TOTAL DE CARBONATOS PRESENTES NA AMOSTRA. (B) $\mathrm{CO}_{2}$ VOLATILIZADO NA FAIXA DE APROXIMADAMENTE $580^{\circ} \mathrm{C}$ A $790^{\circ} \mathrm{C}$, REFERENTE AOS CARBONATOS FORMANDOS DA REAÇÃO DE CARBONATAÇÃO, COMO A CALCITA MAL CRISTALIZADA. VALORES CALCULADOS NA BASE NÃO-VOLÁTIL

FIGURA 128 - PERDA DE MASSA REFERENTE À ÁGUA COMBINADA DOS COMPOSTOS QUE SOFREM A DESCALCIFICAÇÃO DURANTE A REAÇÃO dE CARBONATAÇÃO. (A) ÁGUA VOLATILIZADA NA FAIXA DE APROXIMADAMENTE $60^{\circ} \mathrm{C}$ A $300^{\circ} \mathrm{C}$, REFERENTE AO C-S-H, ETRINGITA, ALUMINATOS E CARBOALUMINATOS PRESENTES NA AMOSTRA. (B) ÁGUA VOLATILIZADA NA FAIXA DE APROXIMADAMENTE $450^{\circ} \mathrm{C}$ A $550^{\circ} \mathrm{C}$, REFERENTE À PORTLANDITA FORMADA NA HIDRATAÇÃO DO CIMENTO E CONSUMIDA NA REAÇÃO DE CARBONATAÇÃO. VALORES CALCULADOS NA BASE NÃO-VOLÁTIL.

FIGURA 129 - DISTRIBUIÇÃO DE TAMANHO DE POROS DA AMOSTRA SUBMETIDA À SECAGEM.............................................174

FIGURA 130 - DISTRIBUIÇÃO DE TAMANHO DE POROS DA AMOSTRA SUBMETIDA À CARBONATAÇÃO APÓS SECAGEM ...................175

FIGURA 131 - DISTRIBUIÇÃO DE TAMANHO DE POROS DA AMOSTRA SUBMETIDA À CARBONATAÇÃO APÓS SECAGEM ...................176

FIGURA 132 - DISTRIBUIÇÃO DE TAMANHO DE POROS DA AMOSTRA SUBMETIDA À CARBONATAÇÃO+SECAGEM...........................177

FIGURA 133 - EVOLUÇÃO DA POROSIDADE TOTAL DETERMINADA POR POROSIMETRIA POR INTRUSÃO DE MERCÚRIO, EM FUNÇÃO DA CONDIÇÃO DE EXPOSIÇÃO DAS AMOSTRAS.

FIGURA 134 - RETRAÇÃO EM FUNÇÃO DA SECAGEM, CARBONATAÇÃO SIMULTANEAMENTE À SECAGEM, E CARBONATAÇÃO APÓS SECAGEM

FIGURA 135 - PERDA DE MASSA EM FUNÇÃo DA SECAGEM, CARBONATAÇÃO SIMULTANEAMENTE À SECAGEM, E CARBONATAÇÃO APÓS SECAGEM

FIGURA 136 - RELAÇÃO ENTRE A RETRAÇÃo E A PERDA DE MASSA NO PRIMEIRO PERÍOdO DE EXPOSIÇÃo (ATÉ 19 DIAS)

FIGURA 137 - TERMOGRAVIMETRIA DA AMOSTRA EXPOSTA POR 4 MESES AO MEIO AMBIENTE. CURVAS DA AMOSTRA DA BORDA E DO CENTRO DA TELHA

FIGURA 138 - TERMOGRAVIMETRIA DA AMOSTRA EXPOSTA POR 6 MESES AO MEIO AMBIENTE. CURVAS DA AMOSTRA DA BORDA E DO CENTRO DA TELHA.

FIGURA 139 - TERMOGRAVIMETRIA DA AMOSTRA EXPOSTA POR 1 ANO E 1 MÊS AO MEIO AMBIENTE. CURVAS DA AMOSTRA DA BORDA E DO CENTRO DA TELHA. 
FIgURA 140 - TERMOGRAVIMETRIA DA AMOSTRA EXPOSTA POR 2 ANOS E 1 MÊS AO MEIO AMBIENTE. CURVAS DA AMOSTRA DA BORDA E DO CENTRO DA TELHA

FIGURA 141 - PERDA DE MASSA NA FAIXA DE TEMPERATURA DE APROXIMADAMENTE $450^{\circ} \mathrm{C}$ A $550^{\circ} \mathrm{C}$, REFERENTE À PORTLANDITA FORMADA NA HIDRATAÇÃO DO CIMENTO E CONSUMIDA NA REAÇÃO DE CARBONATAÇÃO. VALORES CALCULADOS NA BASE VOLÁTIL.

Figura 142 - PeRda de MASSA NA FAIXA DE TEMPERATURA DE APROXIMADAMENTE $60^{\circ} \mathrm{C}$ A $300^{\circ} \mathrm{C}$, REFERENTE AO C-S-H, ETRINGITA, ALUMINATOS E CARBOALUMINATO. VALORES CALCULADOS NA BASE VOLÁTIL

FIGURA 143 - PERDA DE MASSA NA FAIXA DE TEMPERATURA DE APROXIMADAMENTE $560^{\circ} \mathrm{C}$ A $760^{\circ} \mathrm{C}$, REFERENTE À CALCITA MAL CRISTALIZADA FORMADA A PARTIR DA REAÇÃO DE CARBONATAÇÃO. VALORES CALCULADOS NA BASE VOLÁTIL......................186

FIGURA 144 - (A) POROSIDADE TOTAL E (B) DENSIDADE APARENTE, AMBOS CALCULADOS POR PRINCÍPIO DE ARQUIMEDES...........187

FIGURA 145 - RETRAÇÃO POR SECAGEM DO FIBROCIMENTO APÓS EFEITO DA CARBONATAÇÃO NATURAL ..................................187

FIGURA 146 - FISSURAS NAS BORDAS DAS TELHAS DE FIBROCIMENTO REFORÇADAS COM FIBRAS DE PVA ...............................192

FIGURA 147 - REGIÃO DA BORDA DE UMA TELHA DE FIBROCIMENTO REFORÇADA COM FIBRAS DE PVA, 30 SEGUNDOS APÓS A MESMA TER SIDO RETIRADA DE UMA PILHA DE 90 TELHAS.

FIGURA 148 - (A) ESQUEMA INDICANDO A VARIAÇÃO DE UMIDADE AO LONGO DA TELHA EMPILHADA. A BORDA SECA MAIS RAPIDAMENTE E A REGIÃO CENTRAL DA TELHA PERMANECE MAIS ÚMIDA, DEVIDO À RESTRIÇÃO À EVAPORAÇÃO IMPOSTA PELAS

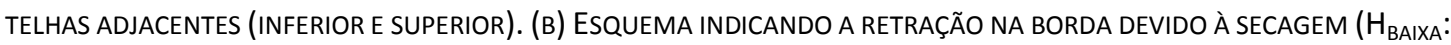

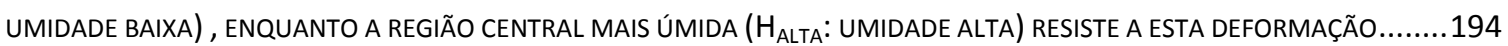

FIGURA 149 - FAIXA DE APLICAÇÃO DO ADITIVO SRA (6CM A PARTIR DA BORDA DA TELHA) ............................................198

FIGURA 150 - (A) GOTA DE ÁGUA DEIONIZADA E (B) GOTA DE ÁGUA DEIONIZADA COM 6\% DE ADITIVO SRA ...........................199

FIGURA 151 - EFEITO DO ADITIVO SRA E PROPILENO GLICOL NA TENSÃO SUPERFICIAL DA ÁGUA ........................................199

FIGURA 152 - ÂNGULO DE CONTATO DA ÁGUA DEIONIZADA (A) COM UM FIBROCIMENTO PADRÃO, SEM TRATAMENTO, E (B) EM UM FIBROCIMENTO HIDROFUGADO, TRATADO COM UMA SOLUÇÃO DE ÁGUA E 10\% DE HIDROFUGANTE ................................200

FIGURA 153 - REGIÃO DA BORDA DA TELHA ONDE FOI REALIZADA A LEITURA DA RETRAÇÃO POR SECAGEM...............................202

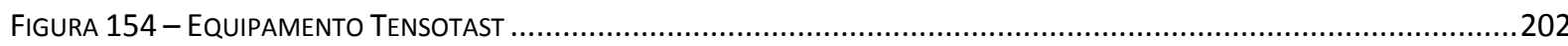

FIGURA 155 - MONTE DE TELHAS EXPOSTAS AO MEIO AMBIENTE PARA MONITORAMENTO DA EVOLUÇÃO DA FISSURAÇÃO. DIVISÃO DAS REGIÕES NA FACE LATERAL DO MONTE, ONDE FOI CONTADA A QUANTIDADE DE FISSURAS NA BORDA DA ONDA DE COBERTURA

FIGURA 156 - FLUXOGRAMA DE ATIVIDADES DO ESTUDO DE ESTRATÉGIA PARA REDUÇÃO DA RETRAÇÃO E FISSURAÇÃO EM TELHAS DE FIBROCIMENTO NT PRODUZIDAS INDUSTRIALMENTE

FIGURA 157 - PRESSÃO CAPILAR ESTIMADA, CALCULADA A PARTIR DA EQUAÇÃO DE LAPLACE, PARA O PERCENTUAL DE POROS SATURADOS. O TRECHO EM PONTILHADO EM AMBAS AS CURVAS REPRESENTA A REGIÃO DOS POROS DE GEL E MICROPOROS, ONDE O MECANISMO DE DEPRESSÃO CAPILAR GOVERNADO PELA EQUAÇÃO DE LAPLACE NÃO É VÁLIDO. A CURVA COM SRA É A ESTIMATIVA DA PRESSÃO CAPILAR CONSIDERANDO A CONCENTRAÇÃO DESTE PRODUTO APLICADO NAS AMOSTRAS, QUE FOI DE $6 \%$

FIGURA 158 - PERDA DE MASSA DOS FIBROCIMENTOS TRATADOS COM MODIFICADORES DA MOVIMENTAÇÃO HIGROSCÓPICA (SRA, PROPILENO GLICOL, HIDROFUGANTES)

FIGURA 159 - EFEITO DOS TRATAMENTOS MODIFICADORES DA MOVIMENTAÇÃO HIGROSCÓPICA (APLICAÇÃO DE SRA, PROPILENO GLICOL, HIDROFUGANTES) NA RETRAÇÃO POR SECAGEM DO FIBROCIMENTO REFORÇADO COM FIBRAS DE PVA....................207

FIGURA 160 - RELAÇÃO ENTRE A RETRAÇÃO POR SECAGEM E A UMIDADE DO FIBROCIMENTO ..............................................208

FIGURA 161 - POROSIDADE DOS FIBROCIMENTOS TRATADOS COM MODIFICADORES DA MOVIMENTAÇÃO HIGROSCÓPICA (SRA, PROPILENO GLICOL, HIDROFUGANTES)

FIguRA 162 - CURVAS TENSÃO-DEFORMAÇÃO. (A) AMOSTRAS dE REFERÊNCIA E (B) COM APLICAÇÃO DE SRA

FIGURA 163 - CURVAS TENSÃO-DEFORMAÇÃO. AMOSTRAS DE FIBROCIMENTO COM APLICAÇÃO DE (A) PROPILENO GLICOL, (B) HIDROFUGANTES

FIGURA 164 - PROPRIEDADES MECÂNICAS (MOR E LOP) DOS FIBROCIMENTOS TRATADOS COM MODIFICADORES DE MOVIMENTAÇÃO HIGROSCÓPICA (SRA, PROPILENO GLICOL, HIDROFUGANTES)

FIGURA 165 - ENERGIA ESPECÍFICA DOS FIBROCIMENTOS TRATADOS COM MODIFICADORES DE MOVIMENTAÇÃO HIGROSCÓPICA (SRA, PROPILENO GLICOL, HIDROFUGANTES) 
FIGURA 167 - EFEITO DO TEOR DE SRA NA (A) VELOCIDADE DE FORMAÇÃO DO C-S-H E NO (B) TEMPO DE INÍCIO DA FORMAÇÃO DE C-S-H DURANTE A HIDRATAÇÃO DO CIMENTO

FIGURA 168 - RETRAÇ̃̃o POR SECAGEM NA REGIÃO DA BORDA DE COBERTURA DE TELHAS DE FIBROCIMENTO. (A) AMOSTRA dE REFERÊNCIA E (B) COM APLICAÇ̃̃̃O DE SRA

FIGURA 169 - RETRAÇÃO AOS 14 DIAS DE SECAGEM MEDIDA NA BORDA DE COBERTURA DE TELHAS DE FIBROCIMENTO DE REFERÊNCIA

E COM APLICAÇÃO DE SRA, EM FUNÇÃO DA DISTÂNCIA DA BORDA.

FIGURA 170 - QUANTIDADE DE FISSURAS EXISTENTES NA BORDA DE COBERTURA DE TELHAS DE FIBROCIMENTO DE REFERÊNCIA E COM

APLICAÇÃO DE SRA, DURANTE 6 MESES DE EXPOSIÇÃO. (A) PILHAS EM EXPOSIÇ̃̃o E (B) MÉDIA DAS PILHAS EM EXPOSIÇÃ̃o 217

FIGURA 171 - ESTRATÉGIAS PARA A REDUÇÃO DA RETRAÇÃO POR SECAGEM NO FIBROCIMENTO NT.

219

FIGURA 172 - INTERVALO DE VARIAÇÃO DA RETRAÇÃO POR SECAGEM EM FUNÇÃO DA ESTRATÉGIA APLICADA PRA A MODIFICAÇÃO DAS

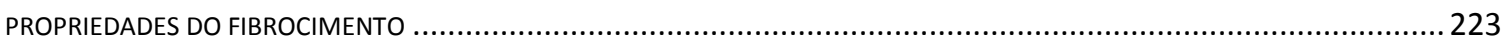

FIGURA 173 - ESQUEMA DESTACANDO A FASE LÍQUIDA CONTÍNUA FORMADA QUANDO A SECAGEM É LENTA ............................227 


\section{LISTA DE TABELAS}

TABELA 1 - RETRAÇÃO QUíMICA ORIUNDA DA FORMAÇÃO DE ETRINGITA E ALUMINATO DE CÁLCIO HIDRATADO A PARTIR DO C 3 A..... 19

TABELA 2 - RETRAÇÃO QUÍMICA ORIUNDA DA HIDRATAÇÃO DO $C_{3} S, C_{2} S, C_{3} A$ (FORMAÇÃO DE MONOSSULFOALUMINATO) E $C_{4} A F$.

DENSIDADES DAS FASES, SEGUNDO (MOUNANGA ET AL., 2004)

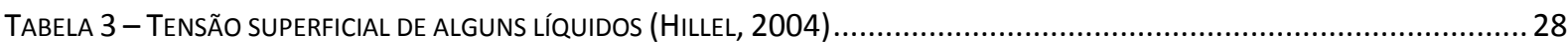

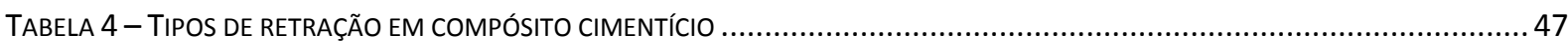

TABELA 5 - CLASSIFICAÇÃO DO DIÂMETRO DE POROS EM PASTAS DE CIMENTO HIDRATADO (MINDESS, 1981) .............................70

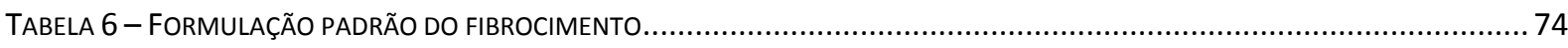

TABELA 7 - UMIDADE E RETRAÇÃO DO FIBROCIMENTO NA SATURAÇÃO, NO INÍCIO DA RETRAÇÃO, APÓS 2 DIAS DE SECAGEM E APÓS 14 DIAS DE SECAGEM. UMIDADE EM RELAÇÃO AO VOLUME DO FIBROCIMENTO CALCULADA ADOTANDO-SE DENSIDADE APARENTE DE $1,5 \mathrm{G} / \mathrm{CM}^{3}$ ... 80

TABELA 8 - FoRMULAÇÃO PADRÃO DOS FIBROCIMENTOS, ONDE A VARIÁVEL É O CIMENTO UTILIZADO....................................111

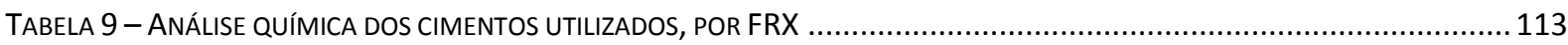

TABELA 10 - VALORES MÉDIOS DA COMPOSIÇÃO QUÍMICA DE CIMENTOS NACIONAIS, SEGUNDO DADOS FORNECIDOS PELA ABCP

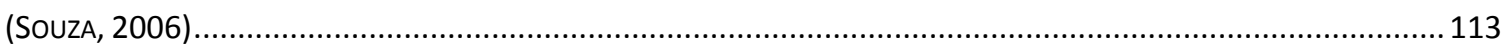

TABELA 11 - PERDAS DE MASSA CALCULADAS A PARTIR DA TERMOGRAVIMETRIA DAS MATÉRIAS-PRIMAS (G/100G) ....................118

TABELA 12 - PARÂMETROS D10, D50 E D90 OBTIDOS A PARTIR DA CURVA DE DISTRIBUIÇÃO DO TAMANHO DE PARTíCULAS DOS CIMENTOS ESTUDADOS

TABELA 13 - PARÂMETROS D10, D50 E D90 OBTIDOS A PARTIR DA CURVA DE DISTRIBUIÇÃo DO TAMANHO DE PARTíCULAS DAS ADIÇÕES MINERAIS UTILIZADAS

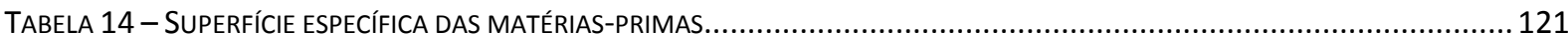

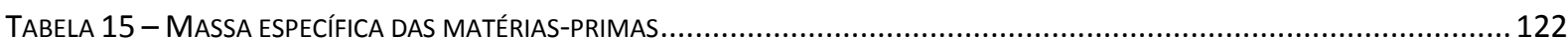

TABELA 16 - TEMPO DE INÍCIO DO PERÍODO DE ACELERAÇÃO, VELOCIDADE (TAXA) DA REAÇÃO DE HIDRATAÇÃO DURANTE O PERÍODO DE ACELERAÇÃO E CALOR ACUMULADO EM 72 HORAS DE HIDRATAÇÃO

TABELA 17 - VOLUME DE MERCÚRIO INTRUDIDO NAS FAIXAS DE TAMANHO DE POROS SUSCETÍVEIS À TENSÃO CAPILAR E POROS DE GEL

TABELA 18 - FORMULAÇÕES COM VARIAÇÃO NOS TEORES DE CIMENTO, SÍLICA ATIVA, POZOLANA E ESCÓRIA.............................134

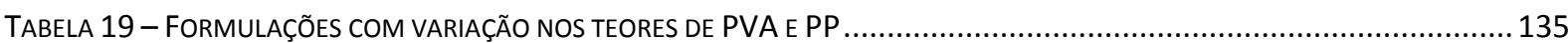

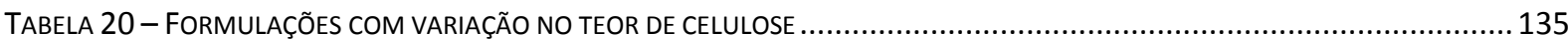

TABELA 21 - PARÂMETROS D10, D50 E D90 OBTIDOS A PARTIR DA CURVA DE DISTRIBUIÇÃO DO TAMANHO DE PARTíCULAS DAS ADIÇÕES MINERAIS UTILIZADAS, EM COMPARAÇÃO COM O CIMENTO CP II-E ..................................................... 136

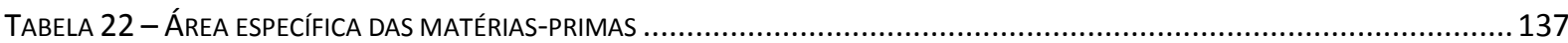

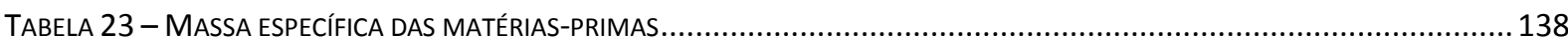

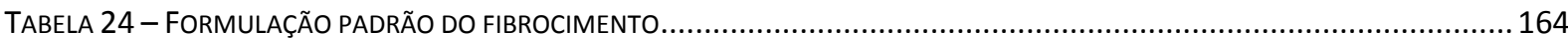

TABELA 25 - INTERVALOS DOS TEORES DOS MATERIAIS COMPONENTES DOS FIBROCIMENTOS EXPOSTOS À CARBONATAÇÃO NATURAL

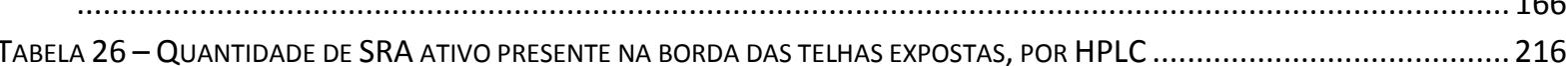




\section{SUMÁRIO}

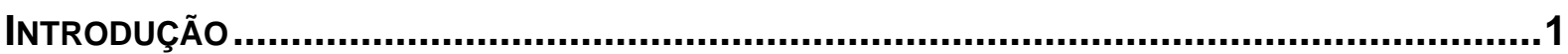

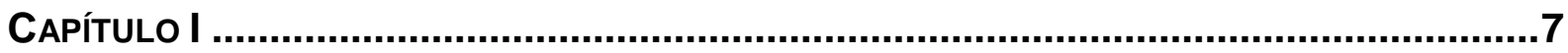

1. RetraÇÃo em Compósito CimentícIo...................................................................

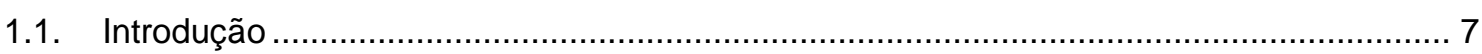

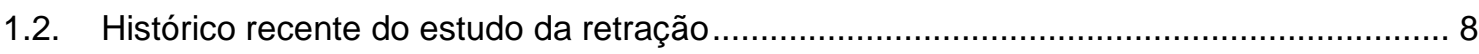

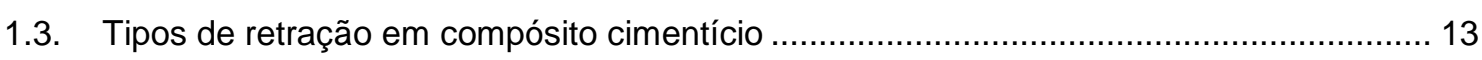

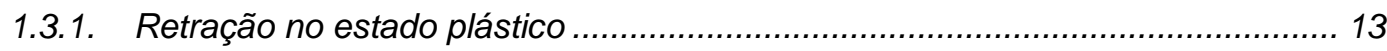

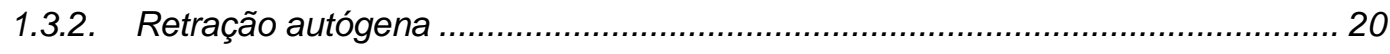

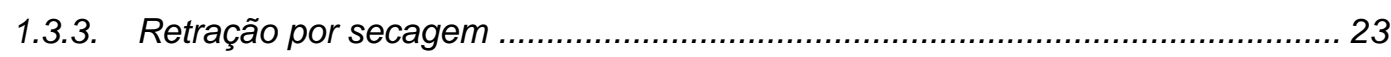

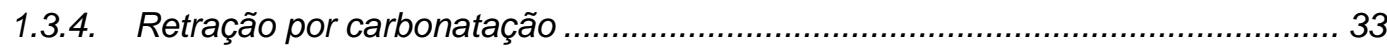

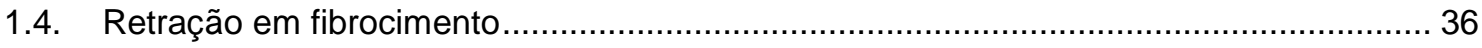

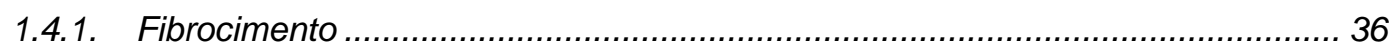

1.4.2. Processo Hatschek de fabricação de fibrocimento ......................................... 38

1.4.3. Movimentação higroscópica - secagem ........................................................ 40

1.4.4. Mecanismos de retração atuantes no fibrocimento em função do tempo............ 44

Capítulo ll .49

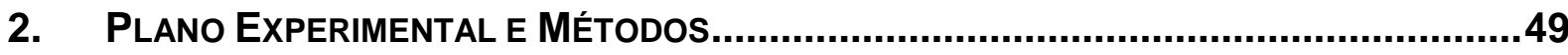

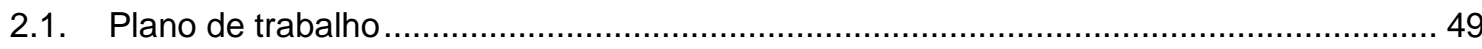

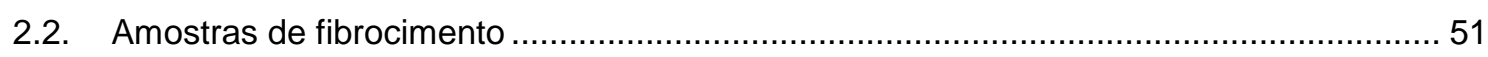

2.2.1. Coleta de fibrocimento na fábrica ............................................................. 51

2.2.2. Moldagem de fibrocimento em laboratório ................................................... 53

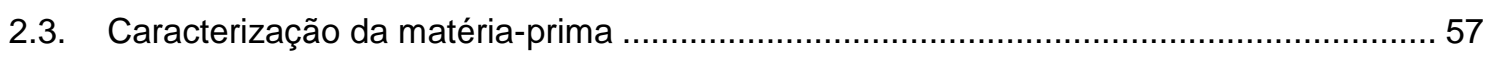

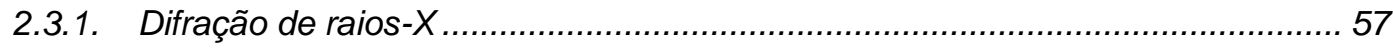

2.3.2. Calorimetria de condução isotérmica ........................................................ 58

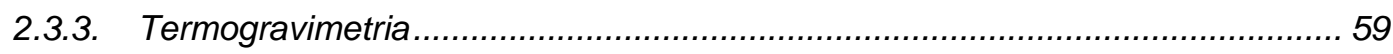

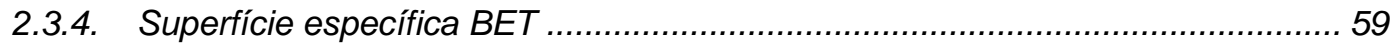

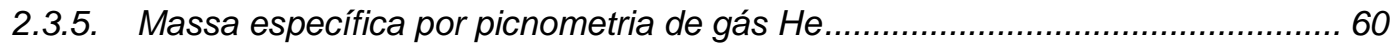

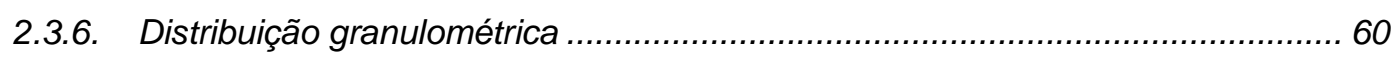

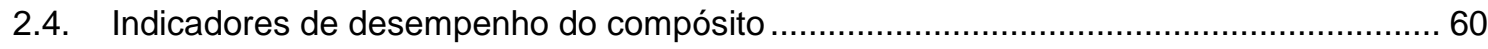

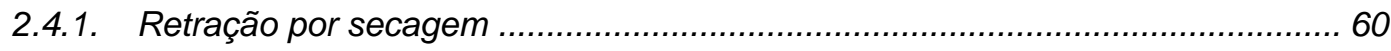

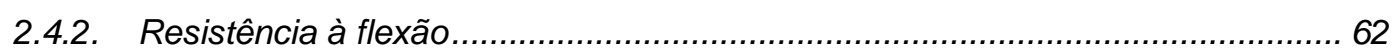


2.4.3. Porosidade e densidade por princípio de Arquimedes .....................................64

2.4.4. Porosimetria por intrusão de mercúrio .......................................................... 64

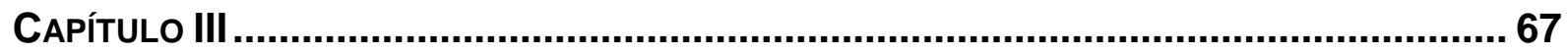

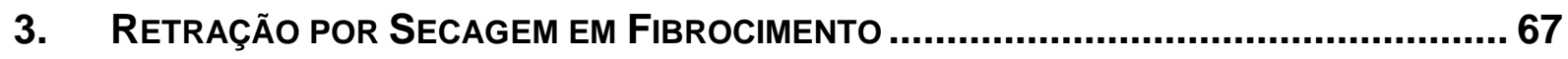

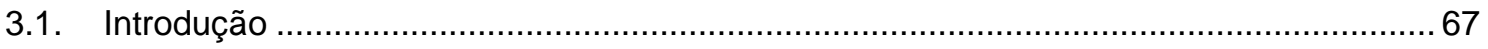

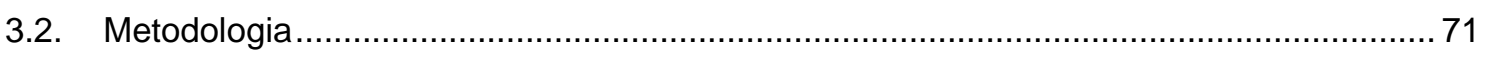

3.2.1. Retração por secagem em fibrocimento industrial ......................................... 71

3.2.1. Estratégias para reduzir a retração variando a porosidade do fibrocimento ....... 72

3.2.1. Influência da umidade relativa do ar na retração por secagem .......................... 74

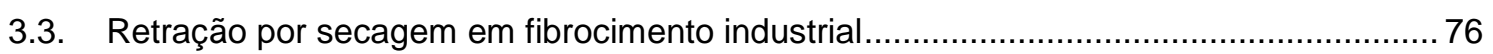

3.4. Influência da porosidade na retração do fibrocimento ................................................. 87

3.5. Influência da umidade relativa na retração (Isoterma de secagem) ...............................97

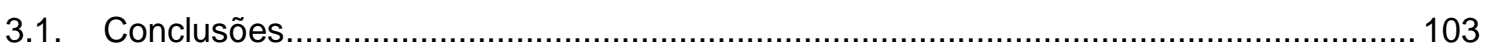

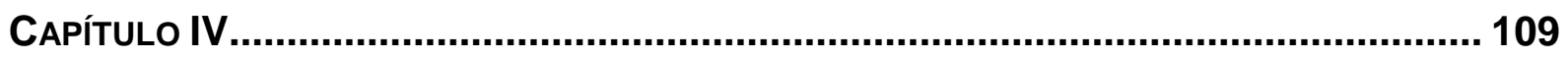

4. Influencia do Cimento e da Formulação na Retração por SecaGem do

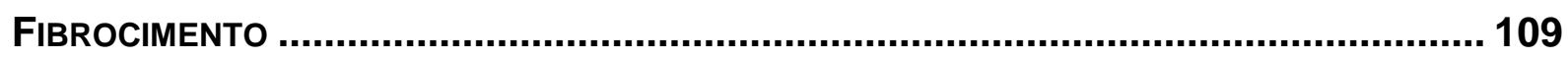

4.1. Influência do cimento na retração por secagem ......................................................... 109

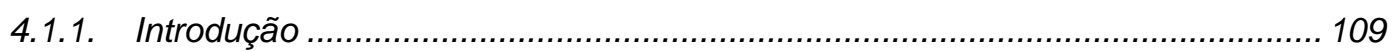

4.1.2. A influência do cimento na retração............................................................. 109

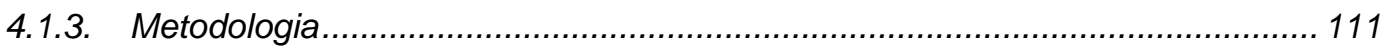

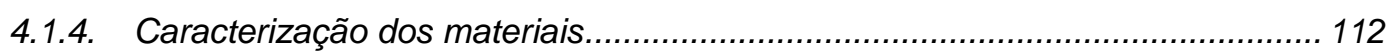

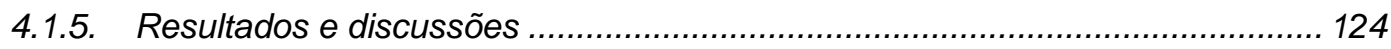

4.2. Influência da formulação na retração por secagem ................................................... 132

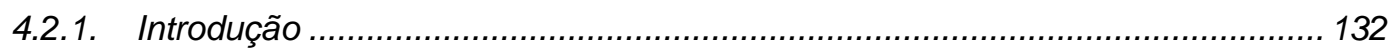

4.2.2. Influência de cada constituinte do fibrocimento na retração.............................. 132

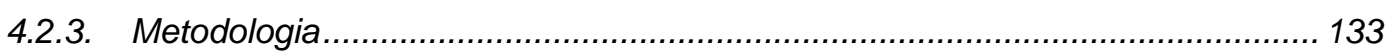

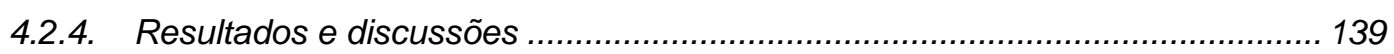

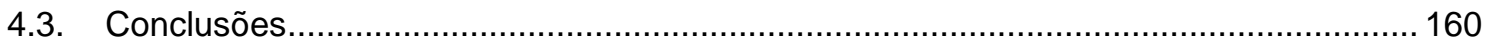

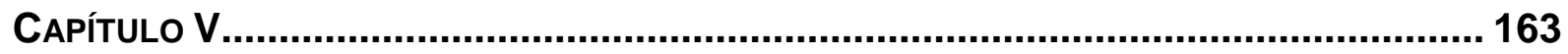

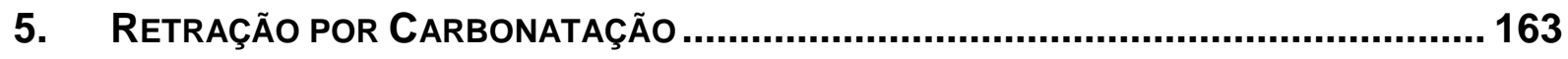

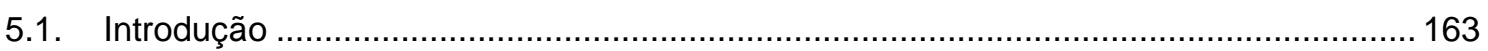

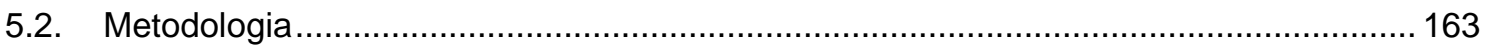

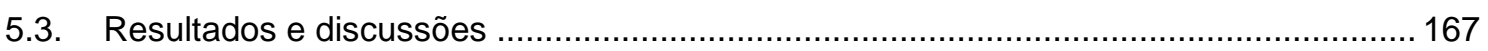


5.3.1. Efeito da carbonatação na microestrutura do fibrocimento com PVA 167

5.3.2. Retração por carbonatação ........................................................................ 177

5.3.3. Gradiente de carbonatação nas telhas empilhadas ...................................... 180

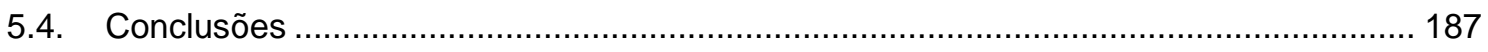

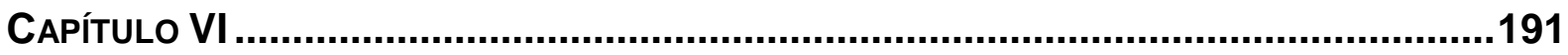

6. Efeito da Pressão Capilar na Retração por Secagem .............................191

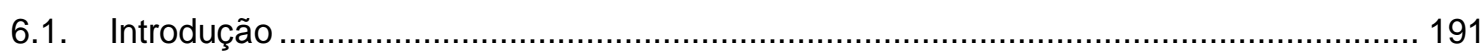

6.2. Redução da retração devido à modificação pressão capilar do líquido ......................... 195

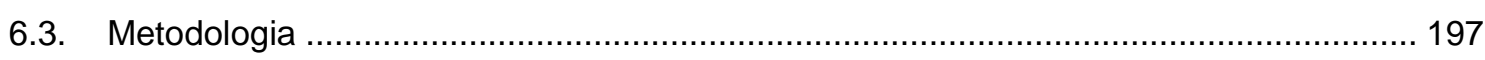

6.3.1. Efeito dos modificadores da movimentação higroscópica na retração .............. 197

6.3.2. Aplicação em escala industrial do aditivo SRA .............................................. 200

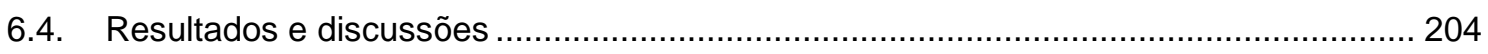

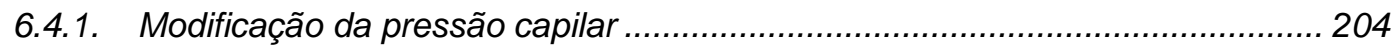

6.4.2. Efeito do tratamento com SRA na redução da retração do fibrocimento produzido industrialmente ................................................................................................... 212

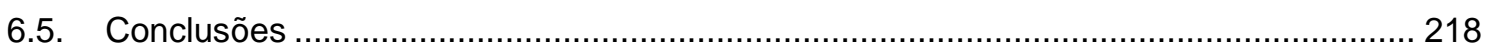

CAPÍTULO VII ...................................................................................................219

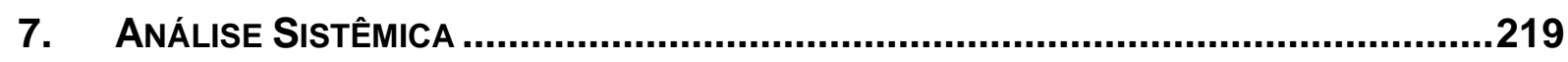

CAPÍTULO VIII .............................................................................................229

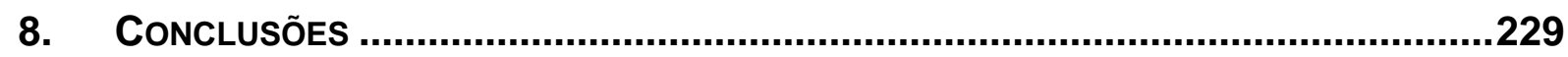

CAPÍTULO IX ........................................................................................................233

9. SugESTÕES DE TRABALhOS FUtUROS .......................................................233

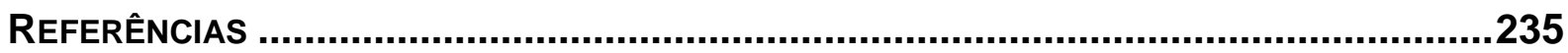




\section{INTRODUÇÃO}

O fibrocimento é o material de construção mais utilizado nos sistemas de cobertura das edificações brasileiras. Considerando o mercado total de coberturas, o fibrocimento é aplicado em $49 \%$ das edificações, seguido pelas telhas cerâmicas (35\%) e de aço (11\%) (Silva; Etulain, 2010). Apesar da sua grande utilização, esta é mais concentrada na população de baixa renda, que consome cerca de $50 \%$ do fibrocimento produzido no Brasil (Dias; Giordano; John, 2008), sendo a outra metade dividida entre as faixas da população com renda maior, obras institucionais públicas e privadas, galpões de agropecuária, e demais aplicações.

Este compósito cimentício é normalmente reforçado com fibras de amianto ou fibras sintéticas de $\mathrm{PVA}^{1}, \mathrm{PP}^{2}$ ou $\mathrm{PAN}^{3}$. Atualmente há no Brasil um movimento de migração do uso de fibras de amianto crisotila para as fibras sintéticas, uma vez que a primeira é considerada cancerígena pela Organização Mundial da Saúde (Ivanov; Straif, 2006). Este movimento tem levado algumas indústrias de fibrocimento a migrarem para esta nova tecnologia que, no entanto, ainda está no processo de consolidação no país. Atualmente há 10 empresas que produzem fibrocimento no Brasil, sendo que 2 grupos produzem somente fibrocimento sem amianto, e em 2008 detinham 24\% do mercado nacional (Silva et al., 2010). Outros 3 grupos empresariais comercializam produtos com amianto, mas também comercializam fibrocimento sem amianto como produtos alternativos. Estes 5 grupos totalizavam $75 \%$ do mercado nacional de fibrocimento em 2010.

\footnotetext{
${ }^{1}$ Polivinil-álcool

${ }^{2}$ Polipropileno

${ }^{3}$ Poliacrilonitrila
} 
Os fibrocimentos com fibras sintéticas têm apresentado resultados de desempenho inferiores comparados ao fibrocimento com amianto (Dias, 2005), especialmente no que se refere à resistência à tração e flexão, todavia, o inverso ocorre com a tenacidade, que é maior nos compósitos sem amianto. A tecnologia empregada hoje pelas indústrias brasileiras já é capaz de conferir aos fibrocimentos sem amianto propriedades de desempenho dentro dos requisitos ditados pelas normas técnicas vigentes no país. No caso das telhas, que compõem $74 \%$ dos produtos de fibrocimento comercializados no Brasil (Dias et al., 2008), os produtos sem amianto possuem resistência mecânica satisfatória em acordo com a norma técnica da (ABNT, 2013a), tenacidade superior ao produto com amianto, estanqueidade satisfatória, no entanto, há uma manifestação patológica muito comum, que é a fissuração de borda (Akers, 2010).

Por ser composto essencialmente por uma pasta cimentícia reforçada como fibras, o consumo de cimento do fibrocimento é muito elevado, quando comparado com outros compósitos cimentícios. Enquanto um concreto convencional possui em torno de $17 \%$ de cimento, podendo atingir valores extremos de até 30\% (Damineli et al., 2010), o fibrocimento possui até $80 \%$ de cimento em massa em sua formulação (Dias, 2011). Uma importante consequência deste elevado consumo de cimento é a retração ocorrida durante as fases de hidratação e durante a vida útil do fibrocimento. Desde a retração química que ocorre durante a formação dos compostos hidratados do cimento, passando pela retração por secagem, que ocorre desde o momento em que a cura não é mais realizada eficientemente e prossegue por todo o período de vida útil dos artefatos, toda vez que este é solicitado a ciclos de umedecimento e secagem, até a retração por carbonatação por exposição ao ar.

A principal consequência enfrentada devido à elevada retração observada no fibrocimento é o aparecimento de fissuras quando ocorre secagem preferencial das bordas das telhas por empilhamento. Esta fissura é originada do processo industrial, e mais precisamente, do manejo e condições de exposição das telhas ainda dentro da fábrica. Esta fissuração nas bordas das telhas é apresentada pelos fibrocimentos reforçados com fibras poliméricas, problema este enfrentado pela maioria das empresas produtoras de fibrocimento sem amianto, fato confirmado pelos produtores que participam deste projeto de pesquisa. Este problema também é enfrentado por empresas em outros países, segundo relatos de pesquisadores e produtores durante 
o International Inorganic-Bonded Fiber Composites Conference 2010, realizado em Aalborg - Dinamarca, e artigos publicados sobre 0 assunto em revistas internacionais (Akers, 1990). A fissuração é um defeito do material, que afeta predominantemente o aspecto visual (exemplo da fissura de borda, que não altera o desempenho em uso da telha, mas cria rejeição do produto), sem efeito comprovado no desempenho.

Apesar da grande importância do tema, não existe uma grande massa de dados publicados sobre o assunto, sendo que os artigos do Stephen A.S. Akers são as mais importantes referências sobre o assunto. Além disso, não há estudos publicados acerca das soluções, ou ações no sentido de mitigar a fissuração de borda, mostrando sua eficácia e limites. No sentido de preencher esta lacuna, a presente tese irá abordar os fatores que influenciam na retração por secagem e consequentemente na fissuração, e apontar ações no sentido da mitigação deste problema industrial.

As ações para a mitigação da retração, e consequentemente da fissuração, podem ocorrer em diferentes vertentes. A primeira é a alteração da forma como a água molha o fibrocimento, ou melhor, a forma como esta se difunde, permeia e sai do fibrocimento. Isso ocorre alterando, por exemplo, o ângulo de contato entre a água e o fibrocimento, alteração da tensão superficial da água, ou ainda alteração das características dos poros. Outra vertente é a alteração das características microestruturais do fibrocimento, através das proporções de suas matérias-primas, em especial seu material aglomerante, o cimento. Alterando as quantidades dos compostos cimentícios formados e a distribuição do tamanho de poros na matriz, consequentemente é possível alterar a tensão capilar causadora da retração. Além disso, melhores propriedades mecânicas do compósito favorecem a resistência à fissuração.

\section{Objetivo}

O objetivo principal desta tese é medir o potencial de redução da retração alterando o processo e a formulação, usando variáveis com possibilidade de aplicação na indústria.

Para alcançar este objetivo maior, este trabalho apresenta como objetivos específicos: 
- Determinar o efeito da formulação do fibrocimento na retração por secagem do compósito, variando as características físico-químicas do ligante e quantidades de todas as matérias-primas;

- Mostrar qual é a parcela da retração por carbonatação, em relação à retração total em fibrocimento exposto a condições ambientais típicas, suscetíveis à secagem e interação química com o ar contendo $\mathrm{CO}_{2}$;

- Realizar estudo de caso aplicando como estratégia para redução da retração e fissuração a redução da tensão capilar, que é o princípio causador da retração, observando os efeitos na redução da retração por secagem e redução da fissuração em telhas de fibrocimento reforçado com fibras de PVA, comercializados pela indústria da construção.

\section{Justificativa}

A importância social do fibrocimento como material de construção, tanto pela quantidade de material comercializado no mercado brasileiro, como pela sua participação como cobertura das edificações, como ainda pela alternativa mais atrativa economicamente para a faixa de população com menor renda no nosso país, justificam a realização do presente trabalho, de modo e expor como acontece a retração por secagem neste compósito, e desta forma auxiliar o meio técnico na mitigação das manifestações patológicas relacionadas à retração por secagem.

O presente trabalho se justifica também no sentido de contribuir com a mitigação de um importante problema tecnológico enfrentado pelos produtores de telhas de fibrocimento reforçado com fibras poliméricas, em nível mundial, que é a fissuração nas bordas das telhas. Este defeito da telha corrugada de fibrocimento, que pode acontecer quando o produto ainda está em estoque nos pátios das fábricas, como quando aplicado na cobertura (Akers, 2010), tem maior impacto na aceitação ou rejeição do produto, que passa a ser associado a um material de baixa qualidade devido à ocorrência de fissuras, do que ao seu desempenho em uso e durabilidade. É certo que a fissuração pode ser um meio de propagação de agentes deletérios relacionados às intempéries, no entanto isto nunca foi comprovado em estudos científicos com fibrocimento, de modo que existe uma rejeição do mercado por produtos fissurados, segundo relatos de produtores de telhas de fibrocimento, cuja motivação é unicamente cultural. 
Por fim, o presente trabalho contribui para o meio científico, trazendo como originalidade a apresentação do panorama de como as propriedades do fibrocimento podem contribuir para a retração por secagem, bem como os efeitos da sua formulação e a parcela da carbonatação na retração total.

\section{Estrutura do trabalho}

A estrutura desta tese está dividida em 7 capítulos, com os seguintes conteúdos:

Capítulo $1 \rightarrow$ Neste capítulo é apresentada uma revisão da bibliografia sobre o tema, com a análise sobre retração em compósitos cimentícios de modo geral, histórico da evolução dos estudos sobre retração ao longo do tempo, e mecanismos de retração associados aos materiais cimentícios.

Capítulo $2 \rightarrow \mathrm{A}$ metodologia da tese é apresentada neste capítulo, com a descrição das técnicas utilizadas na caracterização dos materiais e indicadores de desempenho, apresentação da estrutura do trabalho e descrição dos procedimentos experimentais.

Capítulo $3 \rightarrow$ O capitulo 3 apresenta o panorama de como as características do fibrocimento influenciam na retração por secagem. Este capítulo tem estrutura dividida em introdução, metodologia, desenvolvimento do trabalho e conclusão, com objetivo de medir o potencial de redução da retração alterando o processo e a formulação, usando variáveis com potencial de aplicação na indústria, além de mostrar o efeito da porosidade e distribuição de tamanho de poros característicos do fibrocimento na retração por secagem, de modo a verificar a teoria de formação de menisco e tensão capilar como fonte geradora de retração.

Capítulo $4 \rightarrow$ Este capítulo apresenta os efeitos de todas as matérias-primas do fibrocimento na sua retração por secagem. Do mesmo modo que no capítulo anterior, este capítulo tem estrutura dividida em introdução, metodologia, desenvolvimento do trabalho e conclusão, com objetivo de determinar o efeito da formulação do fibrocimento, variando as características físico-químicas do ligante, e quantidades de todas as matérias-primas, na retração por secagem do compósito.

Capítulo $5 \rightarrow$ O capítulo 5 apresenta os efeitos da reação de carbonatação de fibrocimentos exposto à secagem e ao $\mathrm{CO}_{2}$, na retração total do compósito, com a verificação dos resultados medidos sob condições controladas de laboratório, com dados analisados de amostras de telhas expostas a condições naturais, típicas de 
uma fábrica de telhas corrugadas de fibrocimento. Este capítulo tem estrutura dividida em introdução, metodologia, desenvolvimento do trabalho e conclusão, com objetivo de mostrar qual é a parcela da retração por carbonatação, em relação à retração total em fibrocimento exposto a condições ambientais típicas, suscetíveis à secagem e interação química com o ar contendo $\mathrm{CO}_{2}$.

Capítulo $6 \rightarrow$ Neste capítulo é apresentado um estudo de caso, realizado dentro de uma indústria produtora de telhas corrugadas de fibrocimento, onde aplicando-se os conceitos envolvidos nas causas primárias da retração por secagem, que é a tensão atuante nos poros de dimensão capilar, na retração por secagem das telhas produzidas, bem como no surgimento de fissuras de borda. Este capítulo tem estrutura dividida em introdução, metodologia, desenvolvimento do trabalho e conclusão, com objetivo de aplicar o princípio da redução da tensão superficial da água do poro do fibrocimento como estratégia industrial para a redução da retração e fissuração de telhas onduladas de fibrocimento reforçado com fibras de PVA, comercializados pela indústria da construção.

Capítulo $7 \rightarrow$ Neste capítulo foi realizada uma análise sistêmica abrangendo todos os resultados da tese, como forma de união das análises e conclusões encontradas.

Capítulo $8 \rightarrow 0$ capítulo 8 apresenta as conclusões gerais da tese.

Capítulo $9 \rightarrow$ Neste capítulo são apresentadas sugestões para trabalhos futuros. 


\section{CAPÍtULO I}

\section{Retração em Compósito Cimentício}

\subsection{Introdução}

A retração em compósitos cimentícios está frequentemente relacionada à ocorrência de defeitos e manifestações patológicas em peças, artefatos e estruturas. Grandes áreas em concreto como pisos, calçadas e lajes, podem apresentar fissuração devido à retração no estado plástico, ou ainda devido à retração por secagem no estado endurecido (Melo Neto; Cincotto; Repette, 2008). Fachadas em argamassa também apresentam fissuração aparente devido à retração por secagem. Os artefatos de fibrocimento não são diferentes, apresentando manifestações patológicas devido à retração, como a fissuração nas bordas de telhas onduladas.

A movimentação higroscópica é uma das causas primárias da retração, aliás, a mais importante, uma vez que está envolvida praticamente em todos os mecanismos de retração conhecidos. No estado plástico a retração está diretamente relacionada com a variação de umidade da suspensão reativa, e consequentemente com a distância de separação interparticular - IPS ${ }^{4}$ (Slowik et al., 2009); e no estado endurecido a variação de umidade no interior dos poros do compósito pode gerar tensões internas de retração, devido à força capilar (Mehta, 2008).

A umidade no interior de um poro frequentemente vai variar, por diferentes razões: secagem ou umedecimento do compósito, consumo ou liberação de água em reações químicas, tendência de equilíbrio de umidade entre os poros etc. Nos casos desta movimentação higroscópica ocorrer nos poros de pequena dimensão,

\footnotetext{
${ }^{4}$ IPS - Interparticle size
} 
entre 5 e $50 \mathrm{~nm}$ (Mehta, 2008), uma força capilar atuará no interior do mesmo, causando retração na secagem, e expansão no umedecimento.

Na retração autógena, que está relacionada com a reação química de hidratação do cimento, e resulta em compostos hidratados de menor volume, também ocorre movimentação higroscópica devido ao consumo da água do poro capilar pela reação química citada. A retração por carbonatação também está relacionada a uma reação química, que é suprida por $\mathrm{CO}_{2}$ (presente no meio ambiente) e água (presente no interior dos poros capilares), causando assim movimentação higroscópica. A retração por secagem é a redução de volume do compósito oriunda da perda de umidade para o ambiente, devido às forças capilares. Em suma, toda a movimentação higroscópica ocorrida nos poros do compósito cimentício pode colaborar para a ocorrência da retração, se houver a secagem dos poros de dimensões capilares ou menores.

\subsection{Histórico recente do estudo da retração}

O estudo da retração em compósito cimentício conta com um grande número de publicações, especialmente aplicadas ao concreto como objeto de estudo. Isto se deve ao fato da retração estar diretamente relacionada com uma importante manifestação patológica do concreto, que é a fissuração (Shah; Weiss, 2006; Weiss; Yang; Shah, 1998).

A retração por secagem sempre foi avaliada como a mais importante do ponto de vista da engenharia, uma vez que a sua magnitude é muito maior que a retração autógena para concretos convencionais. Embora C. G. Lyman já tenha realizado estudo sobre retração autógena em 1934, até o começo da década de 1990 os trabalhos publicados sobre este tema em sua maioria abordavam a retração por secagem. Somente a partir desta data que a importância da retração autógena foi considerada, quando os concretos de alto desempenho tornaram-se factíveis com relativa facilidade, devido ao desenvolvimento de aditivos superplastificantes e aplicação de adições minerais como a sílica ativa. A partir de então, a retração autógena passou a receber maior interesse dos pesquisadores, resultando em uma grande quantidade de trabalhos publicados, que são justificados devido à importância do tema. Há trabalhos publicados que mostram que a retração autógena é maior nos concretos de alto desempenho, podendo inclusive ser maior 
que a retração por secagem (Tazawa et al., 2000), contribuindo desta forma para a fissuração da estrutura.

O advento da tecnologia dos concretos de alto desempenho renovou o interesse por este tema, especialmente nas seguintes vertentes (Bentur, 2000): desenvolvimento de uma variedade de novos concretos com melhor desempenho nos estados fresco e endurecido, que em contrapartida são mais sensíveis à fissuração nas primeiras idades (exemplo: concretos de alta resistência, com baixa relação a/c, e concretos autoadensáveis), e aplicação de novos métodos de controle da fissuração (exemplo: reforço mecânico com fibras e utilização de aditivos redutores de retração).

Uma vez que os temas "concreto" e "retração" sofreram esta renovação de interesse de estudo, entre os anos de 1997 e 2000 ocorreram importantes eventos científicos, pois reuniram o estado da arte até então sobre retração em compósito cimentício, especialmente o concreto. Em 1997 e 1999 ocorreram duas edições do International research seminars on self-desiccation and its importance in concrete technology, na Suécia, e reuniram o conhecimento existente sobre retração por autossecagem. $\mathrm{O} \mathrm{JCl}^{5}$ foi um importante agente no estudo e disseminação do conhecimento sobre retração, quando instituiu o Technical committee on autogenous shrinkage em 1995. Este comitê investigou (1) a definição de retração autógena, (2) métodos de ensaio para medir retração autógena, tensão e fissuração, (3) mecanismos e modelos de retração autógena e (4) modelos de fissuração a partir da retração autógena. A partir deste comitê realizou-se em 1998 em Hiroshima o International workshop on autogenous shrinkage of concrete (Autoshrink' 98). Em 2000, o RILEM 6 realizou o International RILEM Workshop on Shrinkage of Concrete (Shrinkage 2000), com maior abrangência que os eventos anteriores citados, uma vez que reuniu o estado da arte da retração do concreto de forma mais ampla, incluindo a retração autógena e a retração por secagem.

Em seguida, após este período onde o conhecimento sobre retração foi reunido nestes eventos e publicações, o RILEM realizou a International conference on early age cracking in cementitious systems (EAC'01), em Israel, no ano de 2001. O foco deste evento foi a fissuração, e sua relação com a retração dos compósitos

\footnotetext{
${ }^{5}$ Japan Concrete Institute

${ }^{6}$ Réunion Internationale des Laboratoires et Experts des Matériaux
} 
cimentícios. O mesmo comitê técnico que realizou este evento publicou em 20030 Report of RILEM technical committee 181-EAS, Early age shrinkage induced stresses and cracking in cementitious systems, que reuniu o estado da arte sobre o tema.

A partir destes eventos e publicações, que foram os mais importantes até então sobre retração, estabeleceu-se uma clara e precisa definição do que são retração autógena e retração por secagem, o que não era o caso até então. Definitivamente foi estabelecido que a retração autógena e a retração por secagem possuem a mesma origem. Ambas resultam do aparecimento de forças de tensão devido à formação de meniscos nos poros da matriz.

A origem de ambos os mecanismos de retração é a movimentação higroscópica que ocorre no interior da matriz cimentícia. Definiu-se que a retração por secagem é aquela que ocorre devido à perda de umidade do compósito cimentício para o ambiente. Esta variação dimensional é induzida pela movimentação higroscópica que ocorre na tendência do equilíbrio hídrico entre o interior do compósito cimentício e o ambiente externo (Burlion; Bourgeois; Shao, 2000). Isso ocorre quando o concreto é submetido a um ambiente com umidade relativa menor do que aquela que prevalece dentro dos poros. Consequentemente, efeitos capilares induzem um gradiente de pressão de água líquida entre a região próxima à superfície e o miolo da estrutura, e então uma movimentação higroscópica de dentro para fora (Tazawa et al., 2000). A evaporação da água contida nos poros da matriz cimentícia causa uma força de atração entre as paredes sólidas dos poros (pressão capilar), que têm seu volume reduzido, refletindo em retração em escala macroscópica.

Já a retração autógena é a redução macroscópica de volume do material cimentício quando o cimento hidrata (Tazawa et al., 2000). A retração autógena não inclui a variação de volume devido à perda ou ingresso de água, variação de temperatura, aplicação de força externa ou restrição. Uma vez que a retração autógena é geralmente usada para a previsão de fissuração, a retração gerada no período em que o material cimentício está fresco é excluída. Desta forma, o tempo de início de pega do cimento é especificado como o ponto inicial da retração autógena. A origem desta deformação advém dos processos químicos e físicos relacionados à hidratação do cimento. 
Há outros tipos de retração, além da autógena e por secagem, e vários fatores que as influenciam. Desta forma, o estudo da retração em compósito cimentício pode ser reunido em grupos ou linhas de pesquisa, sendo que os principais são:

- Retração nas primeiras idades (retração química, autossecagem e retração autógena);

- Retração por secagem;

- Métodos de determinação da retração;

- Efeito dos materiais constituintes na retração;

- Mitigação da retração;

- Modelagem.

Uma vez que passou a receber maior importância do ponto de vista da engenharia, a quantidade de publicações sobre retração nas primeiras idades cresceu, sendo que a maior parte dos trabalhos estuda de alguma forma a retração química e a retração por autossecagem. Por exemplo, há estudos que mostram que existe variação volumétrica devido à reação química mesmo no período de indução, na hidratação do cimento (Justnes; Sellevold; et al., 1999). A retração química que ocorre no concreto ainda no estado fresco é diferente da retração química que ocorre durante a pega e rápida formação de $\mathrm{C}-\mathrm{S}-\mathrm{H}^{\mathrm{ver} 7}$, com o concreto no estado endurecido (Beltzung; Wittmann, 2000), especialmente para os concretos com alto consumo de cimento. Há estudos que provam que ocorre a autossecagem dos poros, pois a água é consumida na hidratação do cimento (Hanehara; Hirao; Uchikawa, 1999); ou ainda que a retração autógena é influenciada pela idade e relação a/c (Persson, 1999).

Devido ao fato da movimentação higroscópica ou ocorrer internamente, ou haver troca de umidade com o ambiente, há uma linha de estudos específicos de desenvolvimento de métodos para determinar corretamente a retração (Hedlund; Westman, 1999). Estes estudos mostram que existem diferentes maneiras de medir a retração autógena, cada uma com suas particularidades e imperfeições, mas nenhuma normatizada (Fourdrin; Guigou; Chappuis, 2000; Holt; Leivo, 1999; Miao, 2000). Existem muitos fatores que interferem nesta determinação, como a

\footnotetext{
${ }^{7} \mathrm{x} \mathrm{CaO} \cdot \mathrm{SiO}_{2} \cdot \mathrm{yH}_{2} \mathrm{O}$ : silicato de cálcio hidratado
} 
exsudação, por exemplo, que pode gerar erros na determinação da retração no estado plástico, uma vez que esta água exsudada pode ser perdida ou reabsorvida (Hammer, 1999). No caso da retração por secagem, um fator importante que altera nas leituras da retração é a geometria das amostras, uma vez que a secagem ocorre por difusão da água na amostra (Miyazawa; Tazawa, 2000).

Uma das linhas de pesquisa de maior importância, talvez por este motivo seja a que apresenta maior volume de trabalhos publicados, é o estudo dos efeitos dos materiais constituintes do compósito cimentício na retração. Normalmente são estudadas as adições minerais incorporadas, por exemplo, a cinza volante, que reduz a retração autógena, principalmente aquelas que possuem elevado teor de $\mathrm{SO}_{3}$ e maiores tamanhos de partículas (Tangtermsirikul, 1999), mas que pode aumentar a retração por secagem (Chan; Liu; Lu, 1999). Já a escória de alto forno aumenta a retração autógena em concreto de alto desempenho (Chan et al., 1999), principalmente as mais finas (Han; Zhang; $\mathrm{Li}, 2000$ ). A sílica ativa aumenta a retração autógena (Justnes; Hammer; et al., 1999) (Kanstad et al., 2000) (BaroghelBouny; Kheirbek, 2000) (Brooks; Cabrera; Megat Johari, 1999), e por secagem, com o agravante de não melhorar as propriedades mecânicas do compósito quando esta sílica não for bem dispersa na matriz (Souza; John, 2010). Entretanto, quanto à retração no estado plástico, a adição de sílica ativa não causa alterações significativas no concreto (Hammer, 2000).

Além dos materiais constituintes, a composição do cimento pode interferir na retração. O composto anidro do cimento que mais contribui como causa da retração química é o $\mathrm{C}_{3} \mathrm{~S}$ (Justnes; Sellevold; et al., 1999), enquanto que a presença em grande quantidade de $\mathrm{C}_{3} \mathrm{~A}$ e gipsita reduzem esta retração (Jensen, 2000).

A mitigação da retração normalmente é estudada com a utilização de aditivos redutores da tensão superficial da água do poro, aditivos expansivos compensadores de retração, aditivos hidrofugantes que alteram o ângulo de contato da água do poro com suas paredes sólidas e cura interna com retentores de água. Os aditivos redutores de retração, chamados de $\mathrm{SRA}^{8}$, reduzem substancialmente a retração no estado plástico (Mora-Ruacho; Gettu; Aguado, 2009), a retração autógena e por secagem (Passuello; Moriconi; Shah, 2009), retardando e reduzindo a fissuração (Passuello et al., 2009). Há aditivos compensadores de retração,

\footnotetext{
${ }^{8}$ Shrinkage Reducing Admixtures
} 
chamados de $\mathrm{SCA}^{9}$, cujo princípio de atuação é a formação de compostos expansivos, como a etringita, na matriz cimentícia. Estes aditivos reduzem a retração total (Sun et al., 2001). Os aditivos expansivos compostos por cal livre são efetivos na compensação da retração autógena (Hori et al., 1999), mas dependem do tipo de cimento, sendo menos eficazes para cimentos contendo escória de alto forno (Hori et al., 1999). Os aditivos redutores de retração, que reduzem a tensão superficial da água do poro, e os aditivos compensadores de retração, que são baseados na formação de compostos expansivos na matriz, ambos podem ser usados simultaneamente no concreto, potencializando os efeitos de redução da retração (Meddah; Suzuki; Sato, 2011). A adição de agregado leve saturado também reduz significativamente a retração (Takada et al., 1999) (Cusson; Hoogeveen, 2008), uma vez que atua como uma cura interna, liberando água para a matriz para a hidratação do cimento.

Em virtude dos aspectos mencionados, vimos que apesar de muitas vezes estar relacionada com a movimentação higroscópica, a retração em materiais cimentícios é complexa, com a possibilidade de diferentes causas de origem. Até aqui ainda não foram consideradas outras parcelas contribuintes para a variação volumétrica, como a retração por carbonatação e variação volumétrica de origem térmica. Contudo, especialmente considerando o objeto de estudo desta tese que é o fibrocimento, a retração por secagem ainda é o mecanismo de maior relevância para o meio técnico, uma vez que sua magnitude e seus efeitos na qualidade dos produtos são grandes.

\subsection{Tipos de retração em compósito cimentício}

\subsubsection{Retração no estado plástico}

Desde a mistura do compósito cimentício, quando este ainda está no estado fresco, a primeira retração que o material sofre é chamada de retração no estado plástico (ou retração plástica), cuja principal causa é a rápida velocidade de secagem da suspensão reativa (Cohen; Olek; Dolch, 1990). Durante o estado fresco, a suspensão reativa possui muita água, sendo que parte dela será consumida pela reação química de hidratação e parte dela está presente somente para que o compósito no estado fresco tenha consistência adequada à aplicação e

\footnotetext{
${ }^{9}$ Shrinkage Compensating Admixture
} 
moldagem das estruturas. Com a exposição ao ambiente, parte da água livre é perdida por evaporação, reduzindo a umidade entre as partículas sólidas da superfície. Ao passo que esta quantidade de água diminui, o equilíbrio de forças entre as partículas sólidas é alterado, causado aproximação destas, que se reflete em retração em macro escala (Cohen et al., 1990).

\section{Retração interparticular por tensão capilar}

Quando a superfície da suspensão reativa começa a secar, os poros superficiais deixam de estar saturados, até o ponto onde se forma um sistema de meniscos próximo à superfície (Figura 3), a partir de então, forças de atração começam a atuar no sistema, gerando uma pressão negativa na suspensão reativa (Saliba et al., 2011). A magnitude desta pressão negativa $(P)$ depende da tensão superficial $(\gamma)$ do líquido e dos raios do menisco nas duas direções principais $\left(R_{1}\right.$ e $\left.R_{2}\right)$ indicadas na Figura 1, expressa pela equação de Laplace (Equação 1) (Slowik; Schmidt; Fritzsch, 2008).

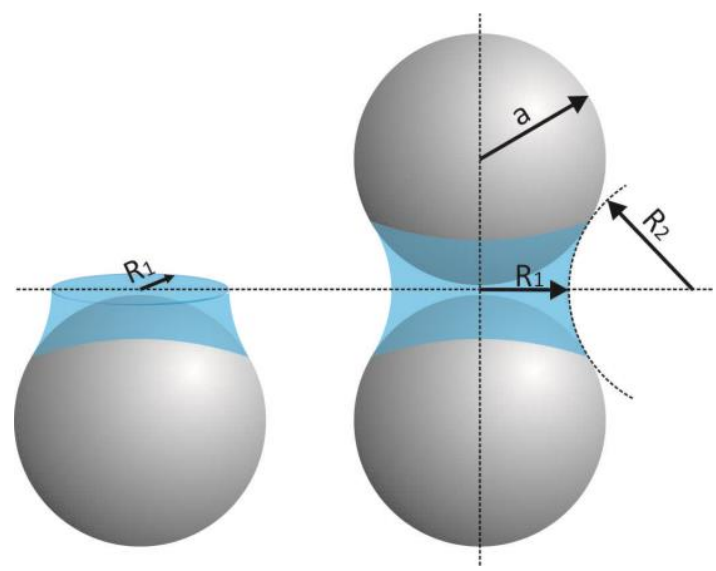

Figura 1 - Esquema de duas partículas sólidas unidas por uma fase líquida, onde as forças capilares atuam. Indicação dos elementos $\boldsymbol{R}_{1}$ e $\boldsymbol{R}_{2}$ da equação de Laplace. Adaptado (Hillel, 2004)

$$
P=-\gamma\left(\frac{1}{R_{1}}+\frac{1}{R_{2}}\right)
$$

Equação 1 - Equação de Laplace

$P$ - Pressão capilar

$\gamma$-Tensão superficial do líquido

$$
F=\pi R_{1}{ }^{2} \cdot P
$$

Equação 2 - Força de atração entre duas partículas sólidas unidas por uma fase líquida, em função da área de atuação da tensão capilar

A força de atração que causa a aproximação entre duas partículas da suspensão é indicada pela pressão capilar $(P)$ multiplicada pela área de atuação da tensão $\left(\pi R_{1}^{2}\right)$ (Figura 1) (Equação 2).

Uma vez que os fatores $R_{1}$ e $R_{2}$ têm relação direta com o tamanho da partícula, mantidas a tensão superficial do líquido e ângulo de contato entre o líquido e a partícula sólida, pode-se afirmar que quanto menor o tamanho da partícula, maior 
será a tensão capilar de atração entre elas, uma vez que os fatores $R_{1}$ e $R_{2}$ estão no denominador da equação e Laplace (Equação 1). Isso explica o fato da incorporação de partículas mais finas nas misturas cimentícias reativas, como aumento no consumo de cimento ou adição de cal, aumentar a plasticidade das pastas no estado fresco.

A força de atração entre as partículas também pode ser influenciada pela forma e rugosidade das mesmas, uma vez que a área de contato entre duas partículas e os raios $R_{1}$ e $R_{2}$ do menisco podem ser aumentados ou diminuídos, em comparação a duas partículas esféricas, alterando a área de atuação da tensão, alterando consequentemente a força de atração entre elas (Equação 2), como pode ser observado pela Figura 2.

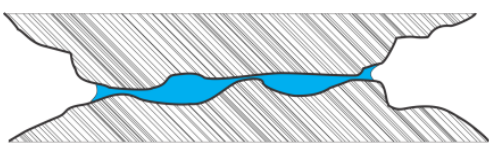

(a)

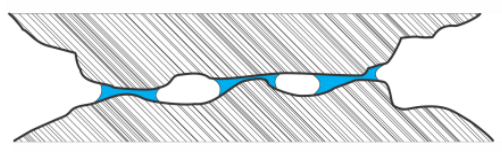

(b)

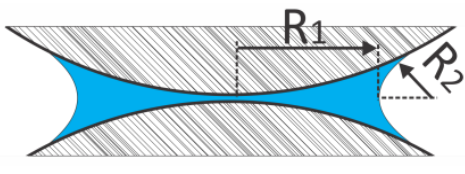

(c)

Figura 2 - Exemplo da alteração dos raios $R_{1}$ e $R_{2}$ em função da rugosidade das partículas. (a) raio $R_{1}$ não sofre grandes alterações, mas raio $R_{2}$ é reduzido significativamente em comparação com duas partículas esféricas; (b) ambos os raios $R_{1}$ e $R_{2}$ são reduzidos em comparação com duas partículas esféricas; (c) raios $R_{1}$ e $R_{2}$ formados por duas partículas esféricas. Adaptado (Butt, 2003)

A Figura 3 mostra que nesta fase de secagem do compósito cimentício, que ocorre gradualmente, a pressão capilar cresce rapidamente até atingir um ponto máximo chamado de "quebra da tensão capilar" (Wittmann, 1976). Esta quebra ocorre porque a umidade entre as partículas sólidas é muito baixa, ao ponto de não haver água suficiente para a formação de meniscos, portanto, anulando a tensão capilar no poro. Há estudos que comprovam esta teoria, com a determinação da pressão capilar, que aumenta com a secagem ao mesmo tempo em que a retração por redução da distância interparticular também cresce (Slowik et al., 2009, 2008; Wittmann, 1976). 


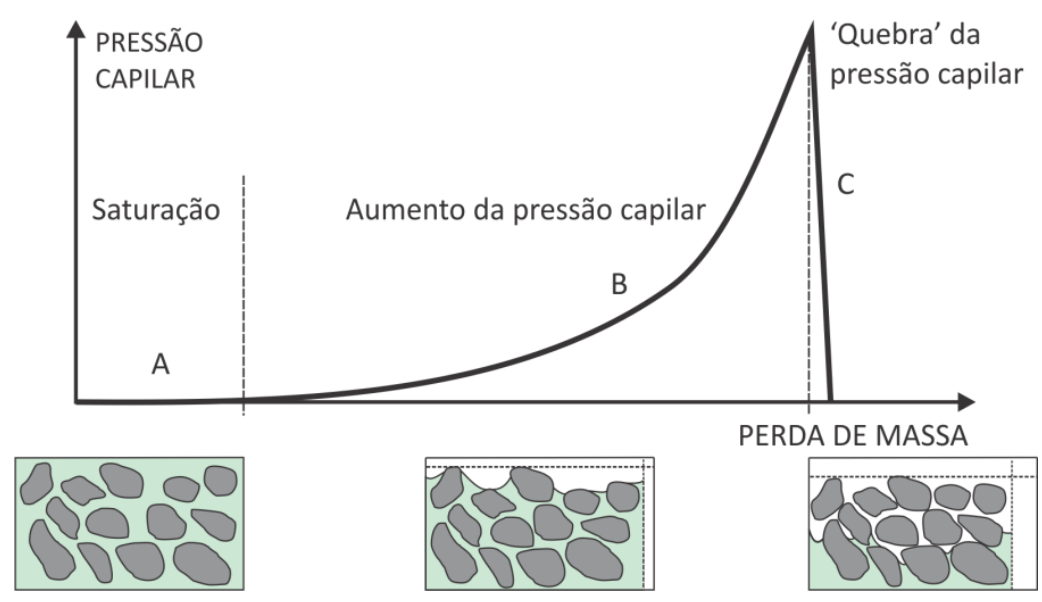

Figura 3 - Crescimento da pressão capilar na secagem da suspensão reativa. Adaptado (Slowik et al., 2008)

\section{Retração química}

Ao mesmo tempo em que ocorre a retração por redução da distância interparticular, reações químicas chamadas de hidratação do cimento também ocorrem em taxa elevada enquanto o compósito ainda está no estado fresco. Como consequência há formação dos compostos resistentes do cimento, mas há também uma redução volumétrica total, chamada de retração química. Este tipo de retração é o fenômeno em que o volume absoluto dos produtos de hidratação é menor que o volume total do cimento anidro e a água da mistura a serem combinados quimicamente, como mostram a Figura 4 e Equação 3.

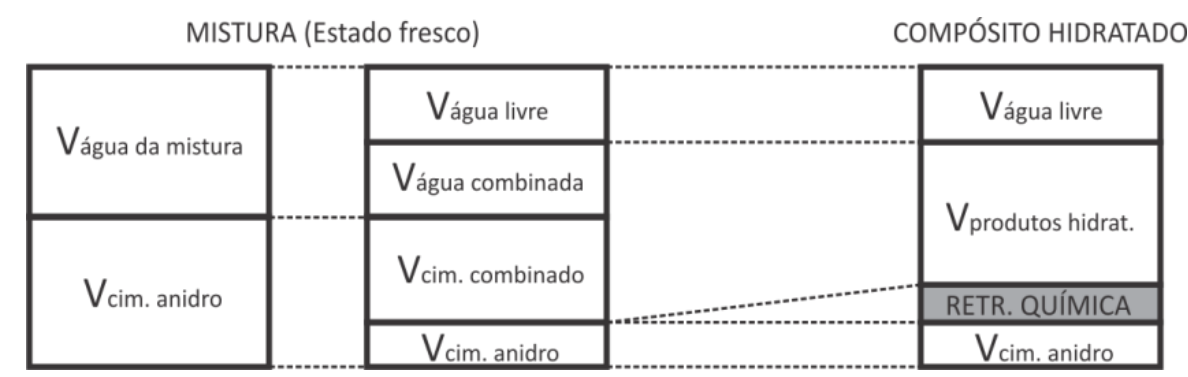

Figura 4 - Esquema que representa a retração química de uma pasta de cimento (V - volume). Adaptado (Tazawa, 1998) (Kronlöf; Leivo; Sipari, 1995)

$$
R_{\text {química }}=\frac{\left(V_{\text {cim combinado }}+V_{\text {água combinada }}\right)-V_{\text {prod hidratação }}}{V_{\text {cim anidro }}+V_{\text {água antes da mistura }}} \times 100
$$

Equação 3 - Retração química (V - volume) (Tazawa et al., 2000) 
As reações químicas fundamentais do cimento são bem conhecidas e geralmente definidas pela hidratação dos seus principais compostos constituintes, que são $\circ \mathrm{C}_{3} \mathrm{~S}, \mathrm{C}_{2} \mathrm{~S}, \mathrm{C}_{3} \mathrm{~A}$ e $\mathrm{C}_{4} \mathrm{AF}$. A magnitude da retração química pode ser estimada usando as massas moleculares e densidades dos compostos anidros, e suas alterações a partir das reações químicas fundamentais envolvidas.

Com uma abordagem simplificada, a hidratação do cimento pode ser dividida em duas etapas principais: a primeira é referente à dissolução do cimento e formação de etringita e aluminato de cálcio hidratado, com o compósito cimentício ainda no estado fresco; e a segunda é referente à formação dos principais compostos hidratados do cimento, que são o C-S-H e portlandita, entre outros, com o endurecimento do compósito. Através do ensaio de calorimetria, é possível observar o calor liberado nestas reações químicas exotérmicas citadas, como indicador da cinética de hidratação do cimento (Figura 5). No contato do cimento com a água todas as fases iniciam a sua solubilização. Esta etapa da hidratação é chamada de pré-indução, onde grande quantidade de calor é liberado em um curto espaço de tempo, referente ao molhamento das partículas, dissolução inicial (Cincotto, 2011) e formação de etringita e aluminato de cálcio hidratado (Kirchheim et al., 2011) (Figura 5.A). Somente após a dissolução dos compostos atingir o nível de supersaturação de íons $\mathrm{Ca}^{2+}$ na suspensão reativa, começa a ser formado o C-S-H e a portlandita (Cincotto, 2011), com grande liberação de calor indicado pela calorimetria (Figura 5.B). Neste instante o compósito passa para o estado endurecido, sendo que com algumas horas depois se reinicia a formação de etringita e monossulfoaluminato (Taylor, 1997), indicados por um pico de menor intensidade na calorimetria (Figura 5.C). 


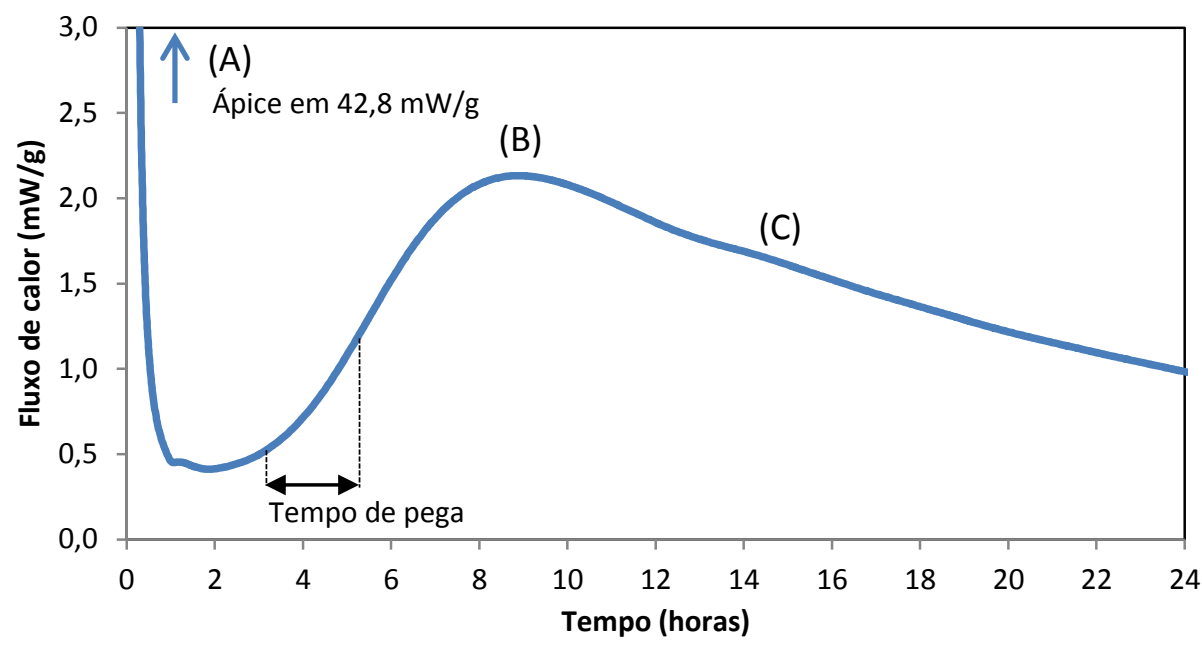

Figura 5 - Calorimetria isotérmica de um cimento CPII F-32 à temperatura ambiente $\left(23^{\circ} \mathrm{C}\right)$

Destas reações químicas envolvidas na cinética de hidratação do cimento, a formação de etringita e aluminato de cálcio hidratado nos instantes iniciais da mistura são as parcelas contribuintes para a retração química que ocorre no compósito no estado fresco. $\mathrm{O}_{3} \mathrm{~A}$ é o composto do cimento de maior reatividade, por isso forma etringita imediatamente quando misturado com a água, no entanto, devido à elevada concentração de íons sulfato $\mathrm{SO}_{4}{ }^{2-}$ na suspensão, parte deste é adsorvido na superfície do $\mathrm{C}_{3} \mathrm{~A}$, dificultando a sua dissolução, e consequente formação de etringita (Kirchheim et al., 2011). Desta forma, somente parte do $C_{3} A$ contido no cimento é hidratado imediatamente, conforme é mostrado por Hewlett (2004) na Figura 6, que mostra o progresso da hidratação das fases constituintes do cimento.

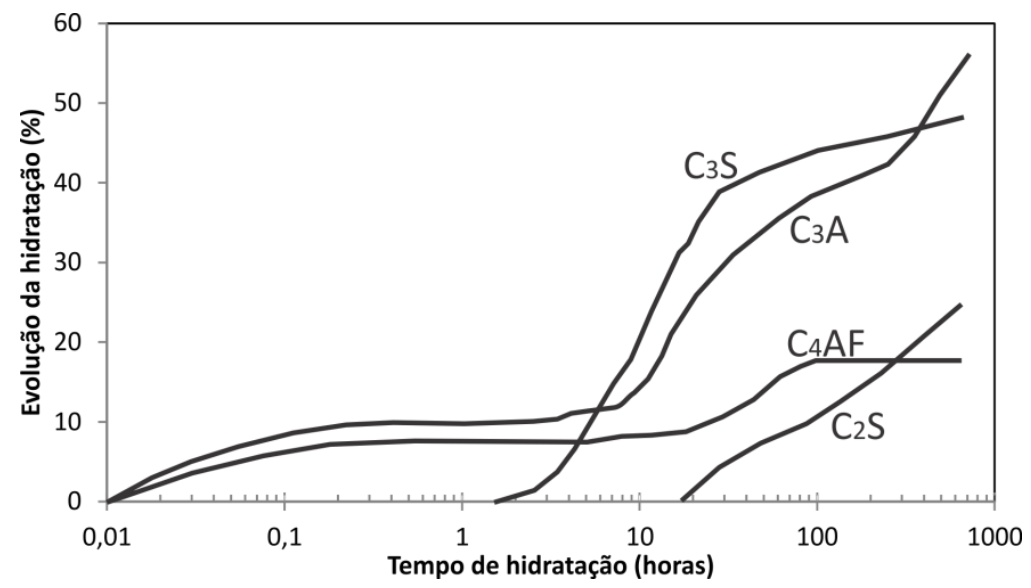

Figura 6 - Evolução da hidratação de fases constituintes do cimento em função do tempo de hidratação (estudo realizado com fases sintéticas) (Hewlett, 2004) 
As principais reações de hidratação do $\mathrm{C}_{3} \mathrm{~A}$ que influenciam na retração química no estado fresco do compósito são a formação de etringita, indicada na Equação 4.a, e que causa retração de $0,2045 \mathrm{~cm}^{3} / g$ de $C_{3} A$; e formação do aluminato de cálcio, indicada pela Equação 4.b, e que causa retração de $0,1741 \mathrm{~cm}^{3} / \mathrm{g}$ de $C_{3} A$. Estes valores de retração química apresentados foram calculados a partir das reações químicas de formação (Equação 4), massas moleculares e densidades dos compostos, como indicado nas Tabela 1 e Equação 5.

$$
\begin{gathered}
C_{3} A+3 C \bar{S} H_{2}+26 H \rightarrow C_{6} A \bar{S}_{3} H_{32} \text { (etringita) } \\
C_{3} A+6 H \rightarrow C_{3} A H_{6} \text { (aluminato de cálcio hidratado) }
\end{gathered}
$$

Equação 4 - Reação química de formação de (a) etringita e

(b) aluminato de cálcio hidratado, a partir do $C_{3} A$
Equação 5 - Retração química a partir da redução de volume (V) na formação do composto hidratado

Tabela 1 - Retração química oriunda da formação de etringita e aluminato de cálcio hidratado a partir do $\mathrm{C}_{3} \mathrm{~A}$

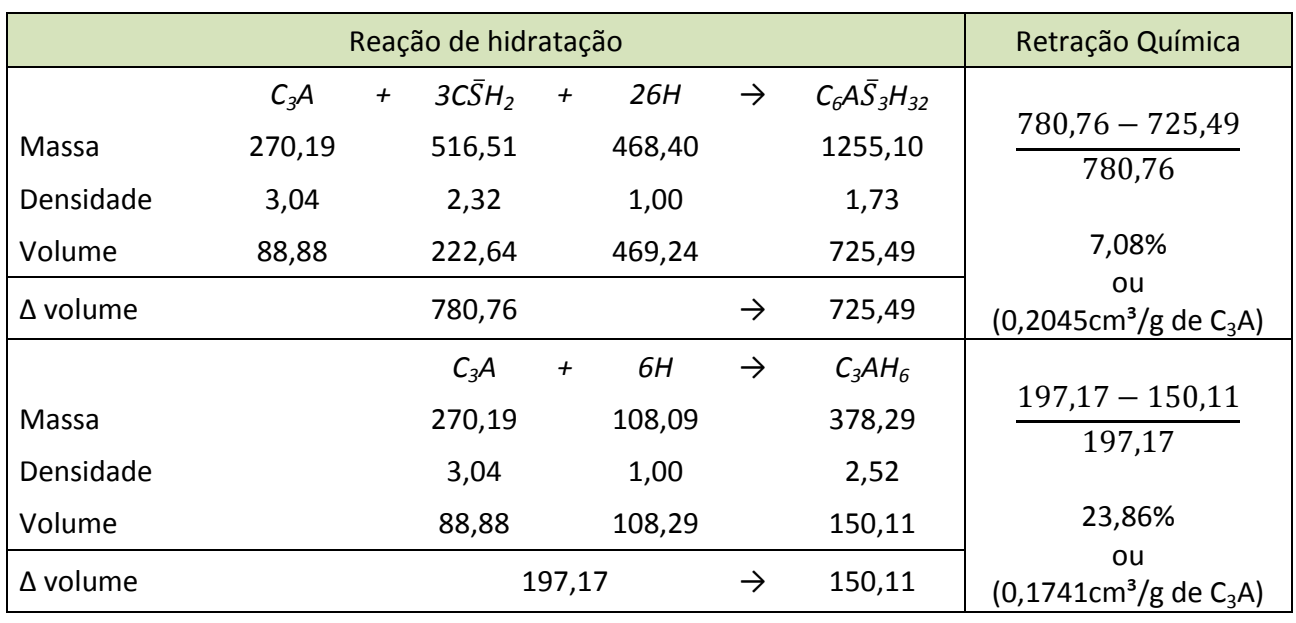

Embora a retração seja um fenômeno isotrópico, ou seja, ocorre de maneira uniforme em todas as direções no espaço, a gravidade pode interferir neste processo quando o compósito ainda está no estado fresco, causando um abatimento na direção vertical antes do início de pega (Tazawa et al., 2000). No caso do concreto fresco, em que a estrutura monolítica resistente de produtos de hidratação não está formada, as partículas de cimento são rearranjadas pelo efeito da gravidade, de modo que a retração ocorre na direção vertical. Este abatimento não ocorre somente pela sedimentação das partículas na água, mas também pela retração química e exsudação. Os trabalhos publicados (Kronlöf et al., 1995) 
(Slowik et al., 2009) mostram que, devido à ação da gravidade, o abatimento vertical é iniciado imediatamente após a mistura, antes mesmo de haver forças capilares atuando na suspensão reativa, em estudos realizados em argamassa e concreto (Figura 7). Entretanto, a retração horizontal é desencadeada somente pelo crescimento da tensão capilar.

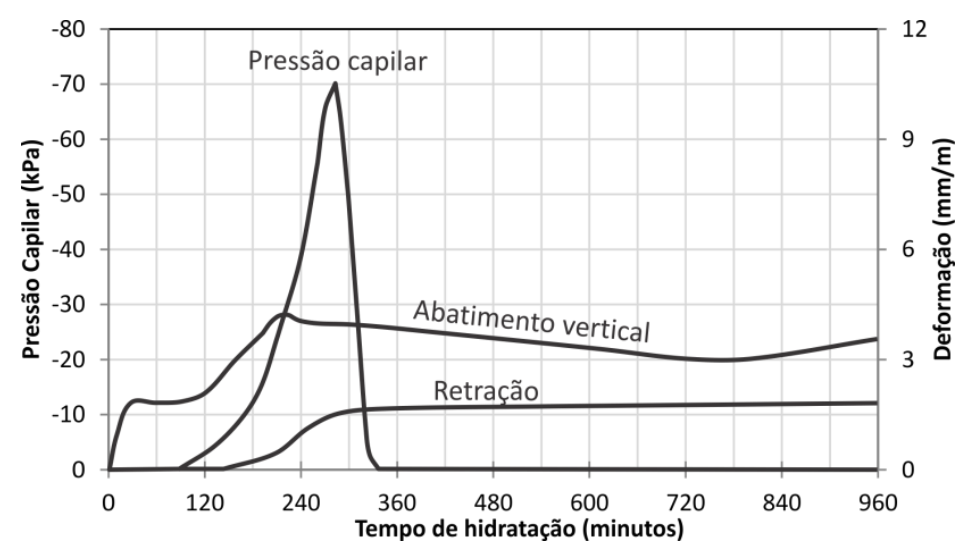

Figura 7 - Evolução da retração horizontal e abatimento vertical em função da pressão capilar e tempo de hidratação (Slowik et al., 2009)

A terceira parcela da retração no estado plástico se deve ao consumo de água da suspensão reativa pela reação química de hidratação, similarmente ao que acontece na autossecagem do compósito endurecido. Este mecanismo aumenta a taxa de secagem da suspensão e formação de pressão capilar negativa. Uma vez que a reação química de hidratação é a combinação de fases reativas do cimento (compostos anidros) com a água, formando os compostos hidratados resistentes, esta consome a água que está contida entre as partículas na suspensão reativa, repetindo o mesmo mecanismo de formação de meniscos e aumento da pressão capilar que gera retração.

\subsubsection{Retração autógena}

Após o início de pega, ou seja, no instante em que o compósito começa a se tornar um sólido monolítico resistente, os fenômenos que causam retração se modificam (Beltzung et al., 2000). A partir deste momento se inicia a retração autógena, por definição. A retração autógena é a redução volumétrica do compósito cimentício quando o cimento hidrata, a partir do início de pega (Tazawa et al., 2000). Este tipo de retração não compreende fatores externos como a perda ou ingresso de água, variação de temperatura, aplicação de força externa ou restrição. 
A origem da retração autógena é a somatória dos efeitos da retração química e autossecagem, oriundos das reações de hidratação do cimento. Na cinética de hidratação do cimento, o início de pega é marcado pelo instante em que as reações de hidratação do $\mathrm{C}_{3} \mathrm{~S}$ para formação de $\mathrm{C}-\mathrm{S}$-H e portlandita começam ocorrer em taxa elevada. Da mesma forma que acontece na retração no estado plástico, no caso da retração autógena as reações químicas de formação dos compostos resistentes do cimento geram uma redução volumétrica total, chamada de retração química (Figura 4 e Equação 3).

Após o período de indução, a concentração de $\mathrm{Ca}^{2+}$ na suspensão reativa atinge o ponto de supersaturação, iniciando a formação do C-S-H e portlandita a partir do $\mathrm{C}_{3} \mathrm{~S}$ (Equação 6.a) (Cincotto, 2011), com grande liberação de calor indicado pela calorimetria (Figura 5.B) e consequente endurecimento do compósito. Como discutido anteriormente, após a primeira formação de etringita e aluminato de cálcio hidratado, a taxa de hidratação do $\mathrm{C}_{3} \mathrm{~A}$ diminui, pois há adsorção de íons $\mathrm{SO}_{4}{ }^{2-} \mathrm{em}$ sua superfície dificultando a dissolução (Kirchheim et al., 2011). Entretanto, quando o sulfato é completamente consumido (Minard et al., 2007), ou quando a camada adsorvida que cobre o $\mathrm{C}_{3} \mathrm{~A}$ é reduzida, a dissolução do $\mathrm{C}_{3} \mathrm{~A}$ é novamente facilitada (Figura 6), sendo retomada a formação de etringita e monossulfoaluminato (Equação 6.d e Equação 6.e) (Taylor, 1997), indicados por um pico de menor intensidade na calorimetria (Figura 5.C). Quando o sulfato é completamente consumido, a partir do $\mathrm{C}_{3} \mathrm{~A}$ remanescente ocorre a formação de aluminato de cálcio hidratado (Equação 6.c). Há ainda a hidratação do $\mathrm{C}_{2} \mathrm{~S}$ (Equação 6.b) e $\mathrm{C}_{4} \mathrm{AF}$ (Equação 6.f), que por serem menos reativos, ocorrem com maior idade da mistura cimentícia. Desta forma, as principais reações químicas causadoras da retração química no estado endurecido do cimento são as seguintes (Equação 6).

$$
\begin{gathered}
2 C_{3} S+6 H \rightarrow C_{3} S_{2} H_{3}+3 C H \quad \text { (a) } \\
2 C_{2} S+4 H \rightarrow C_{3} S_{2} H_{3}+C H \quad \text { (b) } \\
C_{3} A+6 H \rightarrow C_{3} A H_{6} \quad \text { (c) } \\
C_{3} A+3 C \bar{S} H_{2}+26 H \rightarrow C_{6} A \bar{S}_{3} H_{32} \quad \text { (d) } \\
2 C_{3} A+C_{6} A \bar{S}_{3} H_{32}+4 H \rightarrow 3 C_{4} A \bar{S} H_{12} \quad \text { (e) } \\
C_{4} A F+2 C H+10 H \rightarrow C_{3} A H_{6}+C_{3} F H_{6}
\end{gathered}
$$

Equação 6 - Reações químicas de hidratação dos principais compostos constituintes do cimento

(Taylor, 1997) (Hewlett, 2004) (Mehta; Monteiro, 2008) 
Estas reações químicas envolvidas na hidratação do cimento contribuem para a retração química total em diferentes proporções, como mostram os cálculos da retração química, expostos nas Tabela 1 e Tabela 2. Todas as reações químicas apontadas afetam em alguma proporção na retração química final, no entanto podese apontar a hidratação do $\mathrm{C}_{3} \mathrm{~S}$ como a mais significativa, uma vez que o seu teor no cimento costuma ser elevado, superior a 50\%. Esta análise mostra que a retração química é fortemente dependente das propriedades do cimento, especialmente da composição química, uma vez que a retração química total será a soma dos produtos da retração química individual em função da quantidade de cada composto anidro constituinte do cimento.

Tabela 2 - Retração química oriunda da hidratação do $C_{3} S, C_{2} S, C_{3} A$ (formação de monossulfoaluminato) e $C_{4} A F$. Densidades das fases, segundo (Mounanga et al., 2004)

\begin{tabular}{|c|c|c|c|c|c|c|c|c|c|c|}
\hline \multicolumn{10}{|c|}{ Reação de hidratação } & \multirow{3}{*}{$\begin{array}{l}\text { Retração Química } \\
\frac{254,18-229,88}{254,18}\end{array}$} \\
\hline \multirow{3}{*}{$\begin{array}{l}\text { Massa } \\
\text { Densidade }\end{array}$} & & & $2 C_{3} S$ & + & $6 H$ & $\rightarrow$ & $\mathrm{C}_{3} \mathrm{~S}_{2} \mathrm{H}_{3}$ & + & $3 \mathrm{CH}$ & \\
\hline & & & 456,63 & & 108,09 & & 342,45 & & 222,28 & \\
\hline & & & 3,13 & & 1,00 & & 2,63 & & 2,23 & \\
\hline Volume & & & 145,89 & & 108,29 & & 130,21 & & 99,68 & $9,56 \%$ \\
\hline \multicolumn{3}{|l|}{$\Delta$ volume } & \multicolumn{3}{|c|}{254,18} & $\rightarrow$ & \multicolumn{3}{|c|}{229,88} & $0,053 \mathrm{~cm}^{3} / \mathrm{g}$ de $\mathrm{C}_{3} \mathrm{~S}$ \\
\hline \multirow{4}{*}{$\begin{array}{l}\text { Massa } \\
\text { Densidade } \\
\text { Volume }\end{array}$} & & & $2 \mathrm{C}_{2} \mathrm{~S}$ & + & $4 H$ & $\rightarrow$ & $\mathrm{C}_{3} \mathrm{~S}_{2} \mathrm{H}_{3}$ & + & $\mathrm{CH}$ & \multirow{3}{*}{$\frac{177,21-163,43}{177,21}$} \\
\hline & & & 344,48 & & 72,06 & & 342,45 & & 74,09 & \\
\hline & & & 3,28 & & 1,00 & & 2,63 & & 2,23 & \\
\hline & & & 105,02 & & 72,19 & & 130,21 & & 33,23 & $7,78 \%$ \\
\hline \multicolumn{2}{|l|}{$\Delta$ volume } & & \multicolumn{3}{|c|}{177,21} & $\rightarrow$ & \multicolumn{3}{|c|}{163,43} & $0,040 \mathrm{~cm}^{3} / g$ de $C_{2} S$ \\
\hline & $2 C_{3} A$ & + & $C_{6} A \bar{S}_{3} H_{32}$ & + & $4 H$ & $\rightarrow$ & \multicolumn{3}{|c|}{$3 C_{4} A \bar{S} H_{12}$} & \\
\hline Massa & 540,39 & & 1255,10 & & 72,06 & & \multicolumn{3}{|c|}{1867,55} & $\frac{915,44-938,4 /}{2754}$ \\
\hline Densidade & 3,04 & & 1,73 & & 1,00 & & \multicolumn{3}{|c|}{1,99} & \\
\hline Volume & 177,76 & & 725,49 & & 72,19 & & \multicolumn{3}{|c|}{938,47} & $3,79 \%$ \\
\hline \multicolumn{3}{|l|}{$\Delta$ volume } & 975,44 & & & $\rightarrow$ & \multicolumn{3}{|c|}{938,47} & $0,174 \mathrm{~cm}^{3} / \mathrm{g}$ de $C_{3} A$ \\
\hline \multirow{4}{*}{$\begin{array}{l}\text { Massa } \\
\text { Densidade } \\
\text { Volume }\end{array}$} & $C_{4} A F$ & + & $2 \mathrm{CH}$ & + & $10 \mathrm{H}$ & $\rightarrow$ & $\mathrm{C}_{3} \mathrm{AH}_{6}$ & + & $\mathrm{C}_{3} \mathrm{FH}_{6}$ & \multirow{3}{*}{$\frac{369,34-315,27}{369,34}$} \\
\hline & 485,96 & & 148,19 & & 180,15 & & 378,29 & & 436,01 & \\
\hline & 3,97 & & 2,23 & & 1,00 & & 2,52 & & 2,64 & \\
\hline & 122,41 & & 66,45 & & 180,48 & & 150,11 & & 165,16 & \multirow{2}{*}{$\begin{array}{c}14,64 \% \\
\text { ou } \\
0,111 \mathrm{~cm}^{3} / \mathrm{g} \text { de } \mathrm{C}_{4} \mathrm{AF}\end{array}$} \\
\hline$\Delta$ volume & & & 369,34 & & & $\rightarrow$ & & 27 & & \\
\hline
\end{tabular}

Ao mesmo tempo em que ocorre a retração química com o avanço da hidratação do cimento, as reações químicas envolvidas neste processo consomem água presente nos poros do compósito. A partir de um determinado grau de hidratação, que depende da quantidade de água inicial presente e da composição da mistura, o 
compósito sofre autossecagem, ou seja, uma interna, homogênea e isotrópica secagem. O processo de autossecagem é relacionado com a redução da água líquida presente devido à alteração na água quimicamente combinada.

A autossecagem ocorre em qualquer compósito cimentício, independentemente da relação $\mathrm{a} / \mathrm{c}$, entretanto, o seu efeito será diferente dependendo da quantidade inicial de água da mistura. Em concretos convencionais, com elevada relação a/c, a autossecagem não será significativa (Figura 8), enquanto que em concretos de alto desempenho, com relação a/c baixa, a autossecagem se inicia em menor idade de hidratação, e seus efeitos são importantes na contribuição para a retração autógena (Persson, 2002a) (Figura 8).

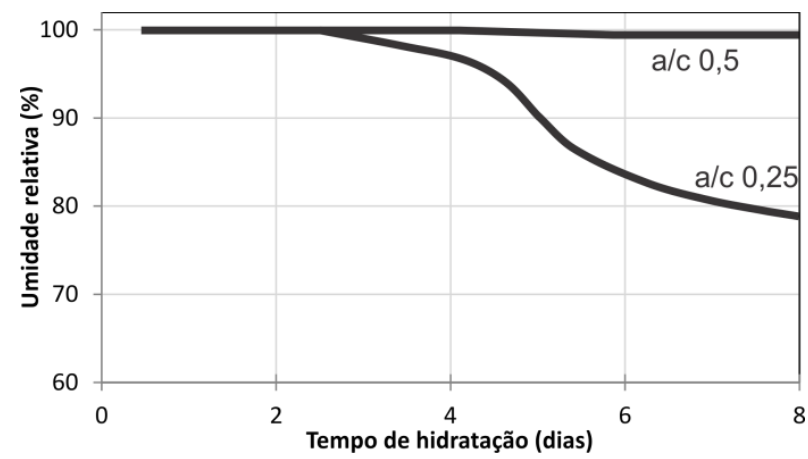

Figura 8 - Autossecagem de pastas de cimento com relação a/c de 0,25 e 0,50, indicada pela redução da umidade relativa da pasta em função do tempo de hidratação (Hanehara et al., 1999)

A autossecagem causa a redução da umidade relativa do compósito cimentício, que consequentemente gera retração devido ao aumento da pressão capilar atuante nos poros. O princípio causador da retração é a pressão capilar, ou seja, o mesmo princípio a ser discutido no item 1.3.3 (Retração por secagem). Diferentemente do mecanismo de acréscimo da pressão capilar que ocorre na retração no estado plástico, em que as partículas sólidas têm grande mobilidade na suspensão, afastando-se ou aproximando-se umas das outras, no caso da retração autógena o compósito cimentício é um sólido monolítico resistente, com uma estrutura de poros contendo umidade. Neste caso, a variação de umidade também gera tensão capilar, que resultarão em pressões internas, podendo causar fissuração na estrutura.

\subsubsection{Retração por secagem}

A retração por secagem acontece simultaneamente à retração autógena, desde que haja perda de água para o ambiente. Uma vez que a taxa de hidratação do cimento é bastante reduzida, ou nula, nas idades mais avançadas de hidratação, 
pode-se afirmar que neste estágio atuam no compósito cimentício apenas a retração por secagem, uma vez que o material será submetido à secagem e molhagem continuamente por toda a vida útil, e a retração por carbonatação, uma vez que o gás carbônico do ar reage com a portlandita da matriz cimentícia, gerando retração. A retração por secagem possui elevada magnitude, comparada com os demais tipos de retração atuantes nos compósitos cimentícios, sendo grande causa de fissuração nestes materiais, como nos concretos convencionais (Maruyama, 2010).

A retração por secagem pode ser definida como a redução volumétrica de compósitos cimentícios associada com a evaporação de água quando este está exposto em ambiente com umidade relativa inferior à umidade da sua estrutura de poros.

Os mecanismos envolvidos no processo de secagem são complexos e estão frequentemente inter-relacionados. Isso ocorre principalmente devido ao grande intervalo de tamanhos de poros existentes nos materiais cimentícios, que determinam os diferentes mecanismos de transporte durante a secagem (Idiart, 2009). A movimentação higroscópica dentro dos poros do compósito cimentício envolve diferentes mecanismos, que dependem destes estarem na condição saturada ou não-saturada, envolvendo neste caso a água líquida da mesma forma como vapor d'água. Quando os poros estão totalmente preenchidos por água, atuam na movimentação higroscópica os mecanismos como permeação devido a uma diferença de pressão e difusão devido a um gradiente de concentração. A secagem ocorre quando os poros se encontram na condição não-saturada, e esta movimentação higroscópica envolve mecanismos como a sucção capilar devido aos fenômenos de capilaridades associados à tensão superficial do fluido, e fenômenos de adsorção-dessorção, envolvendo fixação e liberação de moléculas na superfície sólida dos poros devido a forças de massa (Idiart, 2009).

Tradicionalmente a retração por secagem é fundamentada em quatro mecanismos principais (Barcelo; Moranville; Clavaud, 2005); (Hua; Acker; Ehrlacher, 1995):

- Variação da pressão capilar (depressão capilar);

- Variação da tensão superficial de partículas coloidais;

- Variação da pressão de desligamento; 
- Perda de água interlamelar do C-S-H.

\subsubsection{Variação da pressão capilar (depressão capilar)}

A retração devido à perda de água condensada no interior do poro capilar, tanto para o ambiente como para a hidratação do C-S-H, está fundamentada no efeito físico de depressão capilar (Melo Neto, 2008). A pressão capilar, que é a pressão dentro dos poros capilares, exerce uma força de atração entre as superfícies das paredes do capilar, ou outras superfícies separadas por uma camada fina de água. Esta pressão capilar é significativa somente em poros com diâmetros inferiores a 50nm (Mindess, 1981).

Este fenômeno pode ser descrito como uma tensão gerada nos poros capilares da matriz cimentícia, devido à formação de um menisco no interior destes poros capilares quando estes são sujeitos à secagem (Idiart, 2009). A equação de Kelvin explica como a forma do menisco se configura com a variação da umidade relativa, e está fundamentado nos conceitos de tensão superficial, ângulo de contato e equação de Laplace.

\section{Ângulo de contato}

Quando uma gota líquida é colocada sobre uma superfície sólida, a tripla interface formada entre o sólido, líquido e gás irá mover-se em resposta às forças resultantes das três tensões superficiais atuantes, até que uma posição de equilíbrio é estabelecida (Hillel, 2004). O ângulo formado entre a superfície sólido-líquido e a tangente à superfície líquido-ar, é conhecido como ângulo de contato $(\theta)$ (Figura 9). Esta condição de equilíbrio é atingida quando o somatório das forças atuantes na direção horizontal é nulo, como na Equação 7.

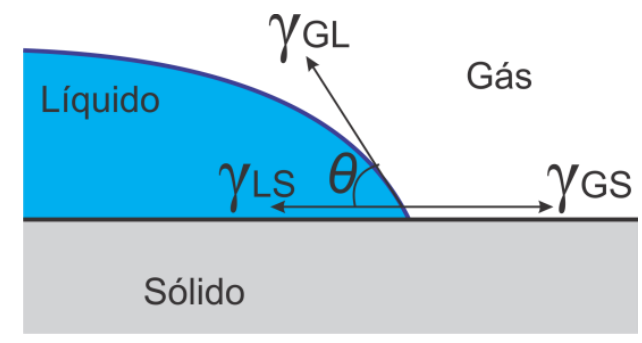

Figura 9 - Forças atuantes na tripla interface entre uma gota líquida em uma superfície sólida

$$
\gamma_{G S}=\gamma_{L S}+\gamma_{G L} \cos \theta
$$

Equação 7 - Equilíbrio das tensões superficiais atuantes na tripla interface entre as fases sólida, líquida e gasosa

$\theta-$ Ângulo de contato

$\gamma$-Tensão superficial

A origem da formação do ângulo de contato tem relação com o equilíbrio de forças entre as moléculas do líquido (forças coesivas) e entre as moléculas do 
líquido e a superfície (forças adesivas). Uma superfície composta por grupos polares, tais como grupos hidroxila, terá uma boa afinidade com a água e, por conseguinte, forças adesivas intensas e um ângulo de contato reduzido (superfície hidrófila) (Figura 10.a). Se a superfície é constituída por grupos não polares, o que é comum para as superfícies de polímeros ou superfícies recobertas por uma camada orgânica, podemos dizer que esta é hidrófoba, com ângulo de contato grande (Figura 10.b) (Barnes, 2011).

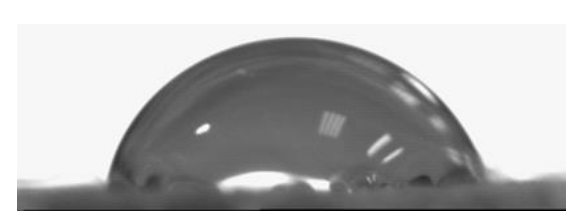

(a)

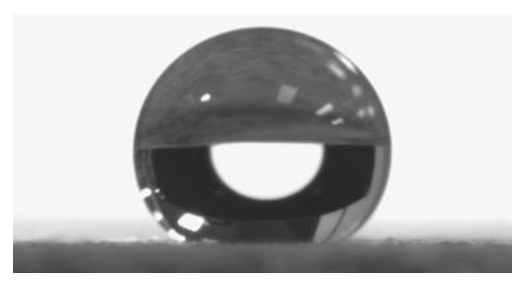

(b)

Figura 10 - Ângulo de contato entre uma gota de água deionizada e (a) uma superfície de fibrocimento e (b) uma superfície de fibrocimento pintada com hidrofugantes

\section{Tensão superficial}

O conceito de tensão superficial explica o comportamento das superfícies (interfaces entre uma fase líquida e uma fase gasosa) que tendem a se contrair para o estado onde sua área é mínima. Esta tensão superficial controla o molhamento de uma superfície sólida por uma gota líquida, a força de adesão de um líquido sobre uma superfície sólida, a ascensão de um líquido em um tubo capilar, a tensão capilar no interior de poros não-saturados, entre outros fenômenos (Barnes, 2011).

A origem da tensão superficial pode ser entendida considerando as forças atuantes nas moléculas de água quando estas estão no interior de toda a sua massa em comparação àquelas que estão na superfície. As forças de atração atuantes nas moléculas de água são isotrópicas, entretanto, quando estas estão na superfície, encontram-se em uma condição de desequilíbrio, devido à escassez de moléculas adjacentes na direção da fase gasosa, o que se reflete em uma força resultante (Figura 11). Como consequência, ocorre uma tendência de movimentação das moléculas da superfície na direção e sentido da força resultante, para o interior da massa de água. A força que tende a minimizar a área da superfície, equilibrando a força resultante citada, é a tensão superficial $(\gamma)$, que atua na direção tangencial à superfície (Barnes, 2011). 

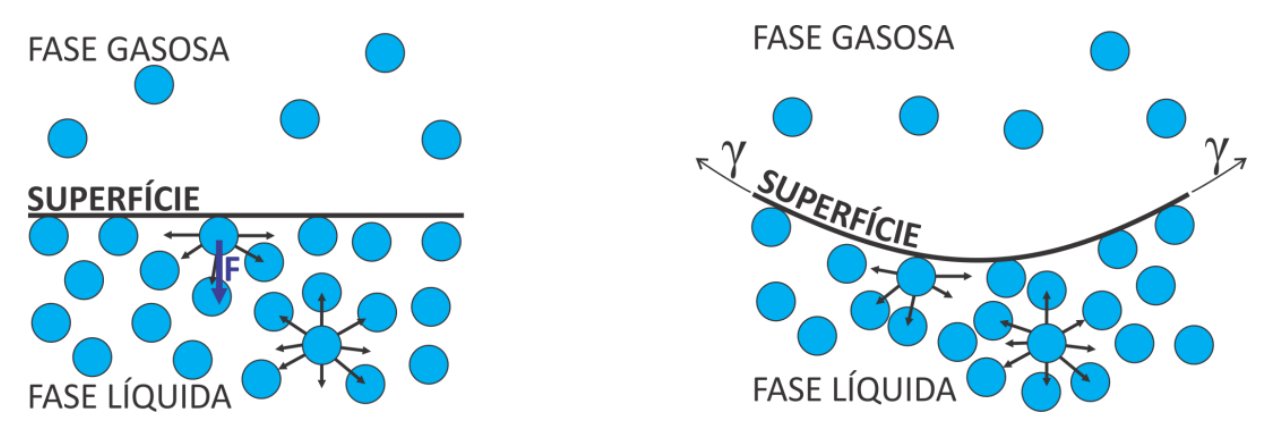

Figura 11 - Forças que atuam nas moléculas de água na superfície com resultante na direção e sentido do interior da massa de água, e a tensão superficial $(\gamma)$ que tende a minimizar a área da superfície

Quando a superfície submetida à ação da tensão superficial for curva, isto indica que há uma diferença de pressão entre os dois lados da superfície (entre a fase líquida e a fase gasosa), que é descrita pela equação de Laplace (Equação 8). Esta configuração também possui ligação com a equação de Kelvin (Equação 9), que descreve como a curvatura de uma superfície líquida muda o equilíbrio da pressão de vapor (Barnes, 2011), o que governa fenômenos como a condensação capilar e a correlação entre a umidade relativa da fase gasosa e a pressão capilar.

Dentro de um capilar esta curvatura da superfície é chamada de menisco, e está sujeita à ação de outras forças decorrentes do ângulo de contato entre as fases líquida, gasosa e sólida (paredes do menisco). A geometria do menisco formado no poro capilar tem relação com a tensão superficial do líquido, que procura equilibrar as forças coesivas das moléculas do meio líquido (Figura 11), como também com o ângulo de contato, relacionado às forças adesivas. A afinidade entre a fase líquida e as paredes sólidas do poro capilar determinará a intensidade das forças adesivas na superfície sólido-líquido, e consequentemente do ângulo de contato, que influenciará na curvatura do menisco. Se a afinidade da superfície sólido-líquido for grande, o líquido tende a molhar as paredes do capilar, configurando um menisco côncavo; no caso contrário, onde esta afinidade é pequena, o menisco pode ser formado com superfície convexa (bolha).

A tensão superficial entre um meio líquido e o ar é uma propriedade intrínseca do material, que varia com as condições do ambiente (Hua et al., 1995) como temperatura e pressão, sendo que a água possui em $20^{\circ} \mathrm{C}$ tensão superficial de $72,94 \mathrm{mN} / \mathrm{m}$. A Tabela 3 indica a tensão superficial de alguns líquidos, variando entre 9,89 e $486,5 \mathrm{mN} / \mathrm{m}$. 
Tabela 3 - Tensão superficial de alguns líquidos (Hillel, 2004)

\begin{tabular}{lcc}
\hline Líquido & Temperatura $\left({ }^{\circ} \mathbf{C}\right)$ & Tensão superficial $(\mathbf{m N} / \mathbf{m})$ \\
\hline Mercúrio & 20 & 486,5 \\
Água & 20 & 72,9 \\
Glicerina & 25 & 72,1 \\
Etileno glicol & 24 & 62,6 \\
Benzeno & 25 & 47,3 \\
Clorofórmio & 20 & 28,9 \\
Butil acetato & 25 & 26,7 \\
Metanol & 20 & 25,1 \\
Etanol & 20 & 22,5 \\
Éter & 20 & 22,4 \\
Perfluoroheptano & 25 & 20,1 \\
Perfluoropentano & 20 & 13,2 \\
\hline
\end{tabular}

Pressão capilar

Com base no conceito de tensão superficial apresentados, vimos que quando a pressão na fase líquida é igual à pressão de vapor satudado, ocorre um equilíbrio entre as fases líquida e gasosa no interior de um poro. Nesta situação, a quantidade de moléculas de água evaporadas para o meio gasoso é igual à quantidade de moléculas de água que retornam para o meio líquido, caracterizando a condição de equilíbrio, que corresponde à umidade relativa de $100 \%$.

Quando a umidade relativa da fase gasosa é inferior a 100\%, a pressão de vapor nesta fase é inferior à pressão da fase líquida. Enquanto a condição de equilíbrio não é reestabelecida, esta diferença de pressão favorece evaporação de água do meio líquido para o gasoso (Kovler; Zhutovsky, 2006), caracterizando o processo de secagem do poro capilar. Uma vez iniciada a secagem, um menisco é formado no poro, indicando a diferença de pressão entre as fases, e desta forma a condição de equilíbrio do sistema ocorre em umidade relativa da fase gasosa inferior a $100 \%$. Isto ocorre, pois nesta condição as forças coesivas da massa sólida têm tal monta que a evaporação é inibida (Kovler et al., 2006), uma vez que a quantidade de moléculas é muito maior na fase líquida do que na gasosa. Em virtude disso, a condição de equilíbrio da pressão capilar nos poros varia em função da umidade relativa do mesmo.

Este mecanismo supracitado é fundamentalmente o princípio da depressão capilar, que é a pressão existente dentro dos poros, que aumenta ao passo que este sofre secagem, causando retração em escala macroscópica. Este fenômeno é 
descrito pela equação de Laplace (Equação 8), que é apresentada aqui expressando a relação entre a diferença de pressão nas fases líquida e gasosa, com a tensão superficial do líquido e os raios formados no menisco.

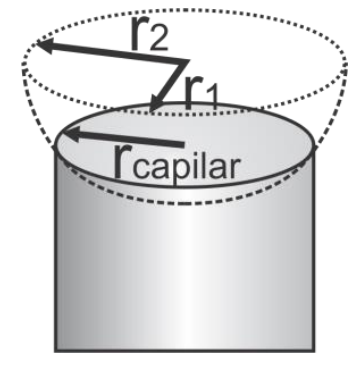

Figura 12 - Indicação dos raios $r_{1}$ e $r_{2}$ do menisco formado no poro capilar

$$
\sigma=P_{G}-P_{L}=\gamma\left(\frac{1}{r_{1}}+\frac{1}{r_{2}}\right)
$$

$\sigma=P_{G}-P_{L}=\frac{2 \gamma}{r} \quad$ (poro de seção circular)

Equação 8 - Equação de Laplace

$\sigma-$ Pressão capilar

$P_{G}-$ Pressão na fase gasosa

$P_{L}$ - Pressão na fase líquida

$\gamma$ - Tensão superficial do líquido

$r_{1}$ e $r_{2}$ - raios do menisco

A equação de Laplace sustenta a base teórica para a equação de Kelvin, que descreve o efeito da curvatura da superfície na pressão de vapor da fase gasosa (Barnes, 2011). Desta forma, uma vez que a pressão de vapor está diretamente relacionada com a umidade relativa da fase gasosa, a equação de Kelvin descreve como a esta umidade realtiva se reflete na pressão capilar atuante no poro. A dedução da equação de Kelvin parte da geometria existente na formação do menisco, envolvendo a tensão superficial e o ângulo de contato, e da equação de Laplace. A relação entre a pressão de vapor quando há um menisco formado, com a pressão de vapor quando a superfície é plana, está diretamente relacionada com a umidade relativa da fase gasosa, de modo que a equação de Kelvin pode ser expressa de duas formas, como mostra a Equação 9.

$$
\begin{gathered}
\ln \frac{P_{G}^{m}}{P_{G}^{\infty}}=\left(\frac{V_{m o l}}{R T}\right)\left(\frac{2 \gamma}{r_{m}}\right) \\
\sigma=P_{L}-P_{G}=\frac{R T \rho}{V_{m o l}} \ln (H) \\
\text { (relação com pressão capilar) }
\end{gathered}
$$

Equação 9 - Equação de Kelvin

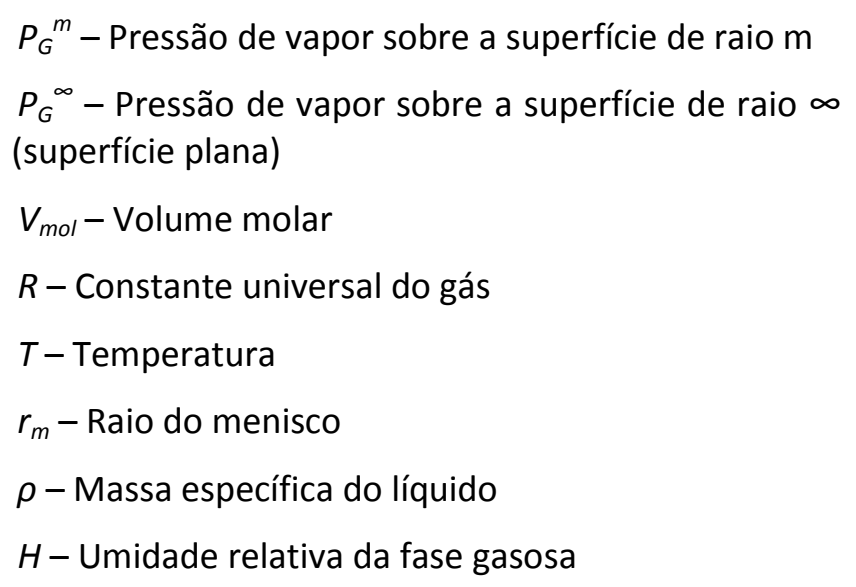


Em resumo, o mecanismo de depressão capilar descreve a partir das equações de Laplace e Kelvin, como que as tensões geradas nos poros capilares são formadas, e desta forma, causam retração em escala macroscópica nos compósitos cimentícios.

Este mecanismo ocorre apenas quando há uma fase contínua de umidade pela estrutura de poros capilares do material. Esta condição é obtida somente a partir de um nível de umidade superior a 40\% (Kovler et al., 2006), uma vez que não se consegue explicar a retração ocorrida em umidade relativa baixa, pois não há formação de um menisco estável (Taylor, 1997).

\subsubsection{Variação da tensão superficial de partículas coloidais}

Da mesma forma como foi ilustrado para uma superfície de um líquido com uma fase gasosa, na Figura 11, as moléculas que compõem um material sólido estão em equilíbrio entre si, uma vez que as forças de atração e repulsão atuantes entre elas estão em equilíbrio em todas as direções (Idiart, 2009). No caso das moléculas da superfície do material, devido à falta de simetria, existe uma força resultante perpendicular à superfície que provoca a sua contração, comportando-se como uma película elástica esticada. Esta força produz uma pequena variação nas distâncias moleculares que induzem uma tensão tangente à superfície (Hua et al., 1995).

Em partículas de tamanho coloidal ( $1 \mathrm{a} 100 \mathrm{~nm}$ ), como as do gel de cimento hidratado, estas possuem grande área específica, de modo que a tensão superficial pode induzir tensões da ordem de 250MPa (Kovler et al., 2006). Em função disso, a retração em escala macroscópica do material cimentício pode ser significativa, sendo que este mecanismo não pode ser negligenciado dentre os mecanismos causadores de retração que envolvem movimentação higroscópica.

A tensão superficial de um material depende do meio ambiente; ela é maior quando a superfície é situada em um vácuo e é nula quando a superfície esta em contato com o mesmo material (Hua et al., 1995). Em geral, a adsorção de átomos ou de moléculas por uma superfície sólida provoca uma relaxação da tensão superficial. Ao contrário, a dessorção aumenta a tensão na superfície, inferindo compressão ao sólido, podendo se manifestar como retração em escala macroscópica (Hua et al., 1995; Idiart, 2009). 
Desta forma a retração oriunda do mecanismo de variação da tensão superficial de partículas coloidais ocorre devido à variação da umidade relativa no poro. A tensão superficial, ou energia de superfície do sólido, varia com a pressão de vapor da fase gasosa no poro, que governa os fenômenos de adsorção e dessorção de água nas superfícies sólidas, que por sua vez determinam a espessura de água adsorvida. A Equação 10 mostra que se um filme líquido de espessura $\varepsilon$ é formado sobre uma superfície sólida, sob pressão de vapor $P$, a energia de superfície diminui $\Delta \gamma$ (Kovler et al., 2006):

$$
\Delta \gamma=\gamma_{0}-\gamma=R T \int_{0}^{P} \varepsilon d(\ln (P))
$$

Equação 10 - Variação da tensão superficial em função da espessura de água adsorvida na superfície sólida

Observa-se a partir da Equação 10 que durante a secagem, ou redução da pressão de vapor, ou redução da umidade relativa, que por sua vez estão todos inter-relacionados, ocorre um aumento da tensão superficial, causando retração (Kovler et al., 2006).

Entretanto, apenas a água adsorvida fisicamente na superfície sólida ativa este mecanismo de retração, e uma vez que a espessura de uma camada de água adsorvida é muito pequena, este mecanismo ocorre primordialmente em baixa umidade relativa. A partir de determinada espessura de água adsorvida, esta não surte mais efeito na tensão superficial, e a variação da umidade relativa não interfere mais na tensão superficial. Por esta razão é que o mecanismo de variação da tensão superficial é válido somente em regimes de baixa umidade relativa, de até 40\% (Kovler et al., 2006; Wittmann, 1976).

\subsubsection{Variação da pressão de desligamento}

A pressão de desligamento ocorre quando a água está retida entre superfícies sólidas muito próximas, mais próximas do que as admitidas no mecanismo de depressão capilar. Este mecanismo compreende a interação entre estas duas superfícies sólidas, muito próximas entre si, na presença de moléculas adsorvidas de água. No caso destas superfícies serem hidrófilas, separadas por uma fina camada de água, a resultante de forças é geralmente repulsiva e chama-se pressão de desligamento. 
A espessura da camada de água adsorvida depende da umidade relativa, no entanto, esta camada não se movimenta livremente sobre uma dada umidade relativa porque a distância entre as duas superfícies é muito pequena (Hua et al., 1995). Quando a umidade relativa é aumentada, a adsorção de água tende a separar as duas superfícies sólidas aumentando a espessura da camada adsorvida. As duas superfícies sólidas então sofrem a pressão de desligamento. Esta pressão atinge seu máximo valor no estado saturado, então quando o sistema migra do estado saturado para o não-saturado ocorre retração porque a pressão de desligamento diminui e as duas superfícies sólidas se aproximam (Hua et al., 1995; Idiart, 2009).

Este mecanismo foi proposto na década de 60 por Powers, a fim de explicar a retração contínua abaixo da umidade relativa de $40 \%$ e foi recentemente reconhecido como o mecanismo dominante por trás da expansão higroscópica acima de $50 \%$ de umidade relativa, já que a solução dos poros em escala nanométrica não pode formar um menisco capilar (Beltzung; Wittmann, 2005).

\subsubsection{Perda de água das lamelas do C-S-H}

A estrutura do C-S-H é composta por placas lamelares, segundo o modelo de Feldman e Sereda (Taylor, 1997), com grande área superficial polarizada, ou seja, com grande força de atração com as moléculas polarizadas da água entre as monocamadas do C-S-H (Kovler et al., 2006). Segundo este modelo proposto, a água pode estar presente na porosidade do C-S-H de três formas, ou como água em poros capilares (espaços vazios maiores), ou adsorvido nas superfícies do C-S-H, em poros de tamanho dos poros de gel, ou ainda localizada entre as camadas de C-S-H, em microporos (Taylor, 1997). Considerando os poros de gel e microporos, segundo os cálculos de Powers e Brownyard, um terço do volume de poros de C-S-H é referente aos espaços entre as suas camadas (Taylor, 1997), ou seja, região onde se localiza a água interlamelar.

A movimentação higroscópica dentro e fora das camadas de C-S-H causam variação volumétrica no material cimentício, ou por depressão capilar, ou por pressão de desligamento ou variação da tensão superficial, sendo que no caso da perda de água localizada entre as camadas do C-S-H, haverá aproximação destas camadas, e consequente retração em escala macroscópica (Jennings, 2008; Kovler et al., 2006). Quando a umidade relativa da fase gasosa dos poros atinge o nível de 
$10 \%$ na secagem, a água interlamelar tende a migrar para fora das camadas de C-S-H, gerando retração (Hua et al., 1995). No entanto, a maioria dos autores afirma que este mecanismo de secagem e retração ocorre em níveis de umidade relativa inferiores a 35\% (Kovler et al., 2006).

\subsubsection{Retração por carbonatação}

A carbonatação é um processo de descalcificação, no qual o hidróxido de cálcio e o C-S-H perdem o cálcio de sua composição através de uma reação química. Ocorre pela reação destes produtos do cimento já hidratado, o hidróxido de cálcio $\left(\mathrm{Ca}(\mathrm{OH})_{2}\right)$, com o dióxido de carbono $\left(\mathrm{CO}_{2}\right)$, resultando no carbonato de cálcio mais água $\left[\mathrm{Ca}(\mathrm{OH})_{2}+\mathrm{CO}_{2} \rightarrow \mathrm{CaCO}_{3}+\mathrm{H}_{2} \mathrm{O}\right]$. Esta reação ocorre com consequente diminuição de volume da matriz cimentícia e perda de água.

O mecanismo de carbonatação necessita de água, uma vez que acontece a interação do dióxido de carbono com os compostos hidratados do cimento ocorre na solução intersticial (Houst; Wittmann, 2002). Na presença de umidade, o anidrido carbônico difunde na estrutura porosa do fibrocimento e dissolve na solução dos poros, produzindo íons $\mathrm{CO}_{3}{ }^{-2}$ (Taylor, 1997). Estes por sua vez, combinam com o íon $\mathrm{H}^{+}$, proveniente da hidrólise da água, formando ácido carbônico $\left(\mathrm{H}_{2} \mathrm{CO}_{3}\right)(\mathrm{Hoppe}$ Filho, 2008). De forma simplificada, o ácido carbônico reage com hidróxido de cálcio para formar carbonato de cálcio. Uma vez que no balanço final da reação, uma molécula de dióxido de carbono substitui uma molécula de água, a massa do compósito aumenta, uma vez que peso molecular do dióxido de carbono $(44,01 \mathrm{~g} / \mathrm{mol})$ é substancialmente maior do que o da água $(18,02 \mathrm{~g} / \mathrm{mol})$ (Persson, 2002b).

$$
\begin{aligned}
& \mathrm{CO}_{2}+\mathrm{H}_{2} \mathrm{O} \rightarrow \mathrm{H}_{2} \mathrm{CO}_{3} \ldots \ldots \ldots \ldots \ldots \ldots \ldots \ldots \ldots \ldots \ldots \ldots \ldots \text { formação de ácido carbônico } \\
& 2 \mathrm{H}_{2} \mathrm{CO}_{3}+\mathrm{Ca}(\mathrm{OH})_{2} \rightarrow \mathrm{Ca}\left(\mathrm{HCO}_{3}\right)_{2}+2 \mathrm{H}_{2} \mathrm{O} \ldots \ldots \ldots \text { carbonatação do hidróxido de cálcio } \\
& \mathrm{Ca}\left(\mathrm{HCO}_{3}\right)_{2}+\mathrm{Ca}(\mathrm{OH})_{2} \rightarrow 2 \mathrm{CaCO}_{3}+2 \mathrm{H}_{2} \mathrm{O} \ldots \ldots \ldots \text { carbonatação do bicarbonato de cálcio }
\end{aligned}
$$

Equação 11 - Reações químicas envolvidas no processo de carbonatação

Além do hidróxido de cálcio, a decomposição de outros compostos hidratados do cimento ocorre simultaneamente, como a etringita, o monossulfoaluminato, a hidrogranada (aluminato de cálcio hidratado) e o C-S-H (Hoppe Filho, 2008; Houst et al., 2002). A reação que causa retração em escala macroscópica é a descalcificação do $\mathrm{C}-\mathrm{S}-\mathrm{H}$, que tem sua relação $\mathrm{Ca} / \mathrm{Si}$ reduzida paulatinamente até 
formar carbonato de cálcio e sílica gel. O aumento da retração é observado nos valores abaixo de 1,2 da relação $\mathrm{Ca} / \mathrm{Si}$. A Figura 13 mostra que o surgimento da retração em uma pasta de cimento aconteceu somente quando a relação $\mathrm{Ca} / \mathrm{Si}$ saiu originalmente de 3,0 para 1,1 (Chen; Thomas; Jennings, 2006).

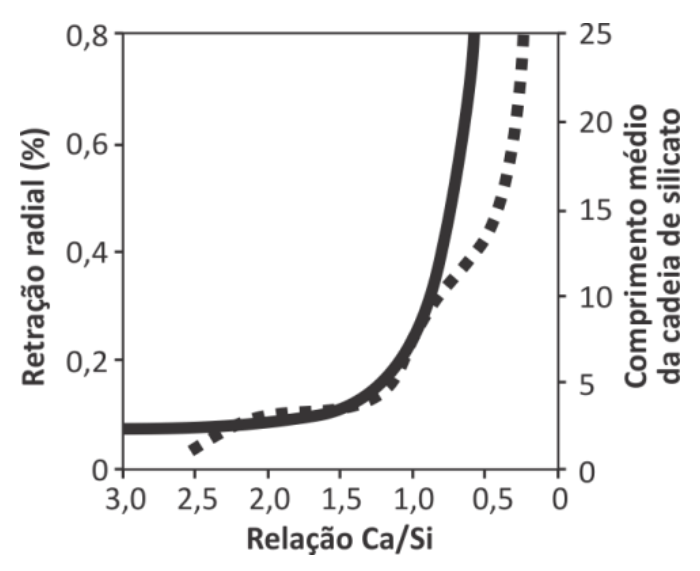

Figura 13 - Variação na retração e no comprimento médio da cadeia de silicato durante a descalcificação do C-S-H (Chen et al., 2006)

Para os valores baixos de relação $\mathrm{Ca} / \mathrm{Si}$ ocorre alteração no arranjo microestrutural do C-S-H. A média do comprimento da cadeia principal de silicato em C-S-H aumenta progressivamente com a evolução da carbonatação e consequente descalcificação do silicato de cálcio hidratado (Chen et al., 2006). O mesmo autor (Chen et al., 2006) explica que a remoção dos íons $\mathrm{Ca}^{2+}$ do C-S-H contribui para formação de grupos de $\mathrm{Si}-\mathrm{OH}$, caracterizados por cadeias de longos comprimentos, ligadas por pontes de siloxano. Este processo é denominado de polimerização da cadeia de silicato do C-S-H.

A descalcificação do C-S-H, e mais especificamente a elevação da densidade do C-S-H, é a causa primária responsável pela retração por carbonatação (Groves et al., 1991). A alteração ocorrida no arranjo estrutural do C-S-H reduz o seu volume.

Um importante fator que influencia na carbonatação é a quantidade de $\mathrm{CO}_{2}$ disponível para a reação. Quanto maior a concentração de $\mathrm{CO}_{2}$ disponível no meio ambiente, mais rápido ocorre a reação de carbonatação, e consequentemente a retração. A quantidade de dióxido de carbono presente na atmosfera $(\sim 0,04 \%)$ é suficiente para causar reações significativas em toda pasta de cimento, se esta ficar exposta por um longo período de tempo (Mindess, 1981). No entanto, concentrações maiores de $\mathrm{CO}_{2}$ contribuem para maiores valores de retração em 
curto prazo de tempo (Matsushita; Aono; Shibata, 2004), como demonstra o gráfico a seguir.

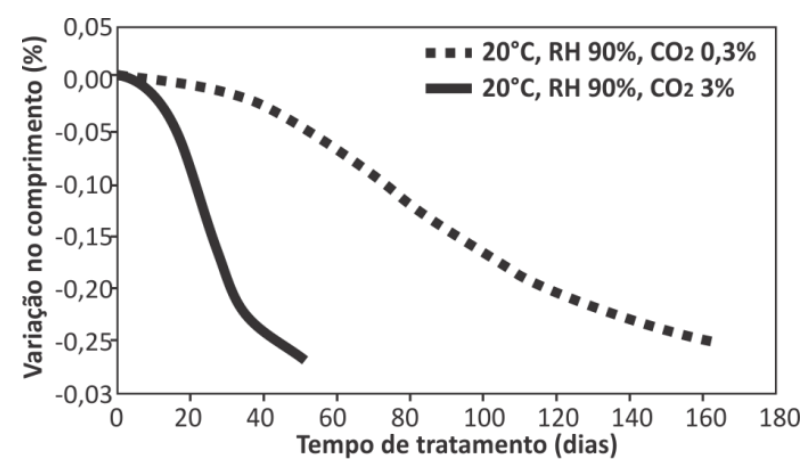

Figura 14 - Velocidade de retração em função da concentração de $\mathrm{CO}_{2}$ (Matsushita et al., 2004)

A umidade do ambiente e do compósito cimentício também influenciam na velocidade das reações químicas com $\mathrm{O} \mathrm{CO}_{2}$ do ar. Nas condições extremas de umidade, de material totalmente seco ou totalmente saturado, não conferem condição propícia para a ocorrência da carbonatação. Como foi dito, a carbonatação é uma reação que necessita de água, de modo que no caso do compósito estar completamente seco, a reação não vai acontecer. A carbonatação é mais intensa em ambiente com 50\% de umidade (Mindess, 1981), pois em níveis muito elevados de umidade os poros se encontram preenchidos por água, o que reduz fortemente a difusão do $\mathrm{CO}_{2}$ para o interior do material. A difusão do dióxido de carbono na água é de $10^{4}$ a $10^{6}$ vezes menos que no ambiente (Neville, 1997).

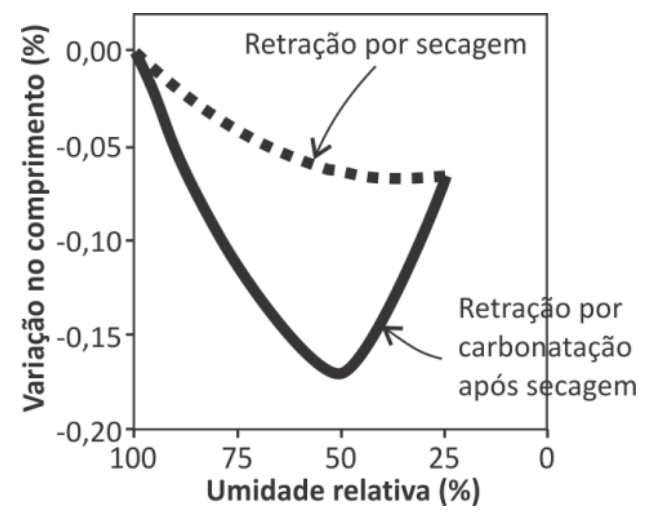

Figura 15 - Retração por carbonatação em função da umidade relativa do ar (Mindess, 1981)

Uma importante alteração nas propriedades da matriz cimentícia é a redução observada no volume total de poros, que pode ser associada com o depósito de $\mathrm{CaCO}_{3}$ formado durante a carbonatação, chamada na bibliografia de colmatação dos 
poros. $\mathrm{O}$ volume de $\mathrm{CaCO}_{3}$ formado excede o dos hidratados partir do qual é formada, provocando assim uma redução da porosidade total (Ngala; Page, 1997).

\subsection{Retração em fibrocimento}

\subsubsection{Fibrocimento}

O fibrocimento é um compósito cimentício, ou seja, material à base de cimento Portland, composto por duas fases: matriz cimentícia e fibras. A matriz cimentícia é uma pasta composta por cimento e adições minerais de escória, pozolânicas e/ou calcíticas, sem agregados. Para aumentar a resistência mecânica final e a tenacidade do compósito, e para viabilizar o processo produtivo, o fibrocimento possui fibras distribuídas discretamente pela matriz, que normalmente são de celulose, amianto ou fibras sintéticas de PVA, PP ou PAN.

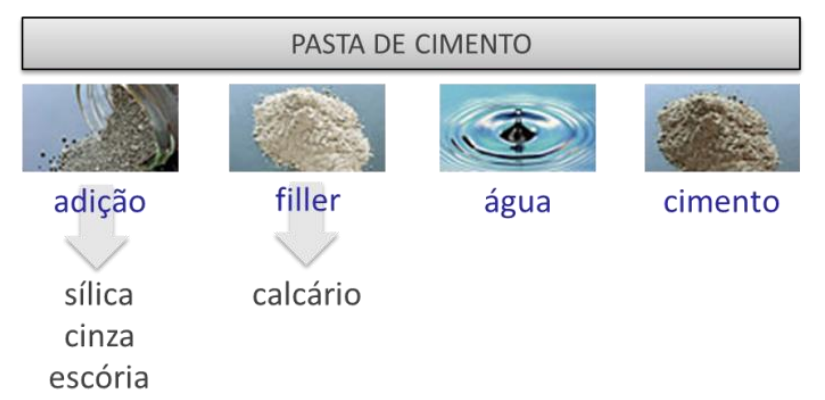

escória

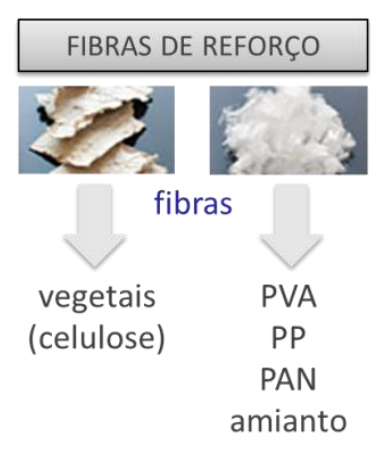

Figura 16 - Materiais que compõem o fibrocimento

A incorporação de fibras de reforço é a principal particularidade do fibrocimento, que o torna um compósito cimentício diferenciado, em comparação com os demais materiais à base de cimento Portland. $O$ amianto é uma fibra mineral natural sedosa, com propriedades físico-químicas com grande potencial para ser utilizada como reforço mecânico em fibrocimento, como: alta resistência mecânica, durabilidade, flexibilidade, resistência ao ataque de ácidos e álcalis etc. As fibras vegetais, como reforço das matrizes frágeis do fibrocimento, têm despertado grande interesse dos produtores, especialmente devido seu baixo custo, grande disponibilidade, economia de energia na produção, além do apelo ecológico de preservação ambiental. No entanto, a viabilização do emprego deste tipo de fibras, especialmente na forma de polpas de celulose, passa por problemas de durabilidade. Para se contornar esta deficiência, a solução mundialmente encontrada foi o seu emprego conjunto com outras fibras sintéticas para reforço. As 
fibras sintéticas usualmente empregadas em fibrocimento são as de PVA, PP e PAN. As fibras sintéticas são cortadas com comprimento entre 6 e $12 \mathrm{~mm}$, empregadas em pequenas porcentagens em volume e sendo distribuídas aleatoriamente ou com certo grau de orientação na matriz, dependendo do processo de produção. Da comparação entre as fibras de PVA e PP, as mais utilizadas entre as sintéticas no Brasil, as fibras de PVA possuem elevada resistência mecânica, são duráveis em meio alcalino, têm alta adesão à matriz cimentícia, no entanto possuem maior custo, uma vez que são importadas do Japão ou China. As fibras de PP possuem menor resistência à tração, menor módulo de elasticidade, fraca adesão à matriz cimentícia, no entanto seu custo é menor, pois são produzidas no Brasil.

A fibra de amianto pode ser nociva à saúde quando respirada, pois atende a 3 requisitos fundamentais: é respirável, biopersistente no organismo e tem geometria pontiaguda. Atualmente há no Brasil um movimento de migração do uso de fibras de amianto crisotila para as fibras sintéticas, uma vez que a primeira é considerada cancerígena pela Organização Mundial da Saúde, pois pode desenvolver asbestose, que evolui para câncer (Ivanov et al., 2006). Este movimento tem levado parte das indústrias de fibrocimento a migrarem para esta nova tecnologia, que está em processo de consolidação no país, havendo inclusive normas técnicas vigentes para estes produtos (ABNT, 2013a) (NBR 15210, referente a telhas onduladas para cobertura) (ABNT, 2013b) (NBR 15498, referente a placas planas).

Os fibrocimentos com amianto, também conhecidos como cimento-amianto, possuem propriedades diferentes dos fibrocimentos NT ${ }^{10}$, que são aqueles reforçados com outros tipos de fibra. A Figura 17 mostra que a resistência à tração do cimento-amianto é maior, sendo quase $2 x$ superior entre as amostras analisadas, enquanto que a tenacidade foi maior na amostra de fibrocimento NT (Dias, 2011). No caso das telhas, que compõem $74 \%$ dos produtos de fibrocimento comercializados no Brasil (Dias et al., 2008), os produtos sem amianto possuem resistência mecânica satisfatória em acordo com a norma técnica (ABNT, 2013a), tenacidade superior ao produto com amianto, estanqueidade satisfatória, no entanto, há uma manifestação patológica muito comum neste fibrocimento, que é a fissuração de borda (Akers, 2010).

\footnotetext{
${ }^{10}$ Non-asbestos Technology
} 


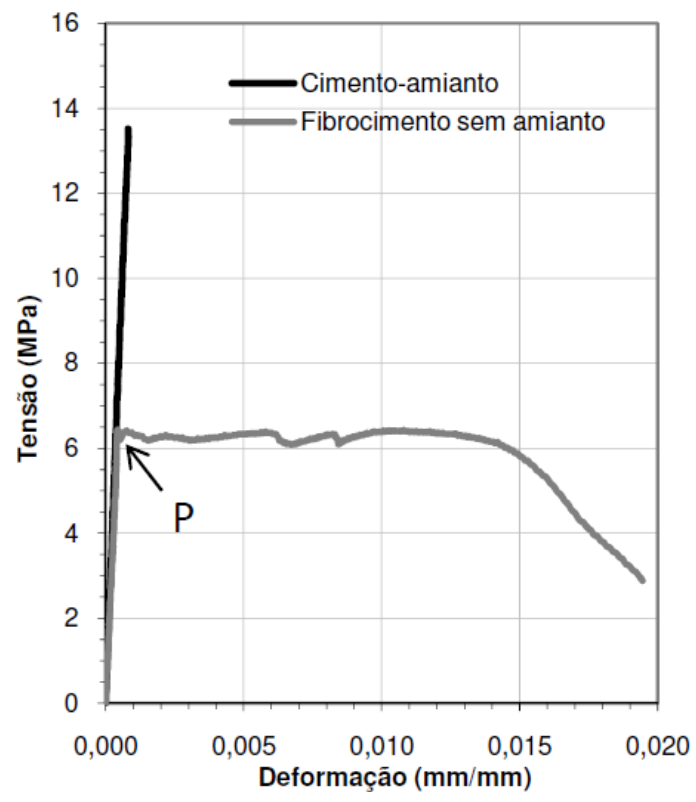

Figura 17 - Curvas típicas de tensão de tração $x$ deformação obtidas através de ensaios de tração direta em amostras extraídas de telhas disponíveis no mercado brasileiro (Dias, 2011)

\subsubsection{Processo Hatschek de fabricação de fibrocimento}

O processo Hatschek é o mais empregado na produção de componentes de fibrocimento para a construção civil (Dias, 2011). Este processo consiste produzir monocamadas de fibrocimento através de filtração e prensagem, que são sobrepostas até a obtenção da espessura final desejada. A Figura 18 mostra as etapas de produção de fibrocimento pelo processo Hatschek. 
1. Dispersão das fibras

Refino das fibras de celulose.

Dispersão das fibras de reforço.

2. Mistura da suspensão de fibrocimento

Preparo da suspensão no misturador, que consiste em misturar em proporções adequadas o material sólido em água, em uma baixa concentração de sólidos (20\%). A mistura inicial é por bateladas. A suspensão é homogeneizada em reservatório pulmão.

3. Filtração da suspensão reativa através das telas do tamis para a formação da monocamada

Filtração contínua na caixa de tamis, onde o excesso de água é o filtrado e a torta fica aderida na tela do tamis. O giro do tamis transfere o fibrocimento, que fica aderido no feltro, formando a monocamada de aproximadamente $1 \mathrm{~mm}$ de espessura.

4. Compactação e sobreposição das monocamadas até a obtenção da espessura final

A monocamada é uma manta contínua, de modo que a quantidade de voltas dadas pela prensa equivale ao número de monocamadas sobrepostas para a formação da manta fresca.

5. Compactação da manta fresca de fibrocimento

6. Conformação

7. Cura
Caixa de tamis

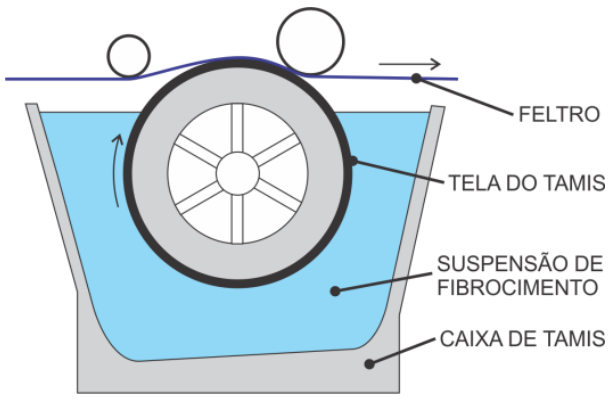

Prensa (rolo formador)

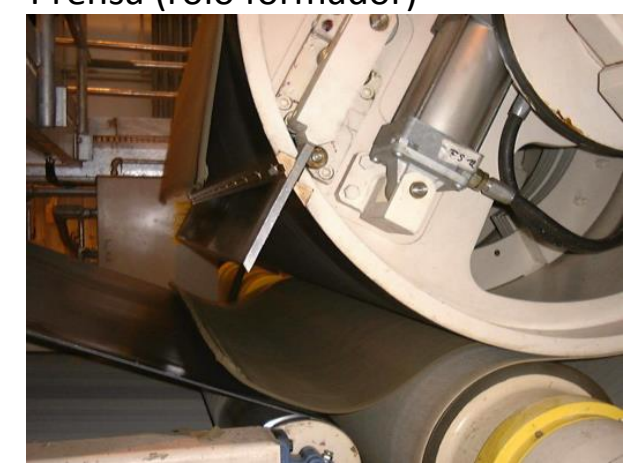

http://www.mfl-fc.at/MFLEquipment/MFLEquipment.htm

Telhas empilhadas

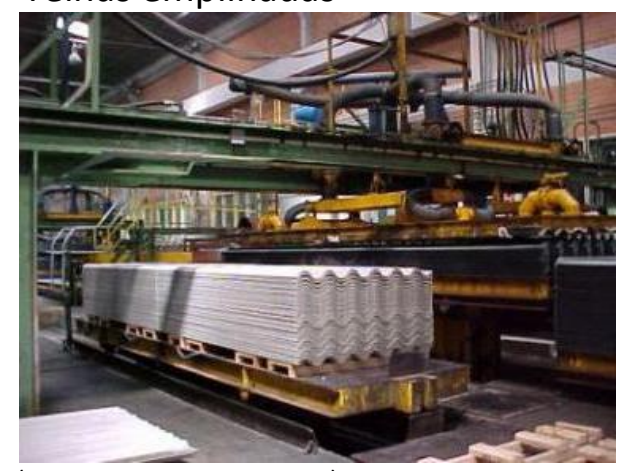

(Savastano Jr.; Santos, 2007)

Figura 18 - Etapas do processo Hatschek utilizado na produção de placas planas e telhas onduladas de fibrocimento

O processo Hatschek possui muitas particularidades em comparação com outros processos de fabricação de compósitos cimentícios, como a formação da placa plana por filtração, a formação de placas de fibrocimento por sobreposição de camadas e a baixa concentração de sólidos da suspensão reativa, que gira em torno de 20\% (Savastano Jr. et al., 2007). Somando a estas, outras particularidades do processo Hatschek o tornam seletivo. Por exemplo, as fibras necessariamente não podem sedimentar ou aglomerar em suspensão aquosa com cimento, têm que reter finos durante a filtração, não podem danificar o feltro. 
No final do processo, as placas de fibrocimento são empilhadas e curadas em câmara de cura, cuja atuação é apenas impedir que a umidade do fibrocimento seja evaporada. Devido à grande massa de fibrocimento curada ao mesmo tempo, criase uma condição semi-adiabática na câmara de cura, que impede parcialmente a dissipação do calor gerado pelo cimento devido às reações de hidratação. Desta forma, a cura inferida aos artefatos é úmida e térmica, com umidade relativa elevada e temperatura que pode girar em torno de $60^{\circ} \mathrm{C}$.

Os produtos fabricados por este processo são placas planas, ou placas corrugadas para coberturas, além das peças especiais de concordância, como cumeeiras, rufos etc.

\subsubsection{Movimentação higroscópica - secagem}

A secagem de um compósito cimentício é basicamente um processo de equilíbrio, tendo como fatores intervenientes a este processo a umidade relativa do ar, a velocidade de secagem e o tamanho dos poros. Soma-se a estes fatores a afinidade entre a fase líquida e o corpo sólido, que no estudo de fibrocimento, e outros compósitos cimentícios, torna-se uma constante. Estes fatores influenciam no nível de secagem e consequentemente também na retração oriunda deste processo, devido à pressão capilar nos poros.

A força motriz das massas de água e vapor d'água por entre a estrutura de poros, na busca pelas condições de equilíbrios, são os fenômenos de adsorção e dessorção de água nas paredes dos poros. A curva de adsorção isotérmica de água pode ser entendida como a espessura da camada de água aderida por forças físicas de atração com a parede sólida devido à energia de superfície, em função da umidade relativa do ar (Baroghel-Bouny, 2007a). A curva de dessorção isotérmica de água pode ser entendida pela curva de pressão de capilaridade do material na secagem, que representa a pressão capilar em relação ao grau de saturação do poro (Baroghel-Bouny, 2007a).

No sentido de umedecimento dos poros, o fenômeno de adsorção física de vapor de água pela superfície dos poros advém das interações físicas que ocorrem entre as moléculas de gás e a superfície sólida. A água adsorvida consiste em camadas de moléculas que aderem sobre a superfície dos poros. O processo de adsorção é contínuo até que se estabeleça o equilíbrio termodinâmico entre o meio gasoso e a 
camada adsorvida, expressado pela equação de Kelvin (Equação 9). A espessura média da camada de água adsorvida é estimada conforme a equação de Bradley (Quenard; Sallee, 1992), e tem relação com a umidade relativa, como mostra a Figura 19.

$$
\begin{array}{l|l}
e_{a}(U R)=k_{1}+k_{2} \ln (-\ln U R) & \begin{array}{l}
e_{a}(U R)-\text { Espessura da camada adsorvida } \\
U R-U \text { midade relativa } \\
k_{1} \text { e } k_{2}-\text { constantes que dependem da área específica } \\
\text { Equação 12 - Equação de Bradley poroso, da afinidade entre o vapor de água e } \\
\text { a matriz sólida e a temperatura }
\end{array}
\end{array}
$$

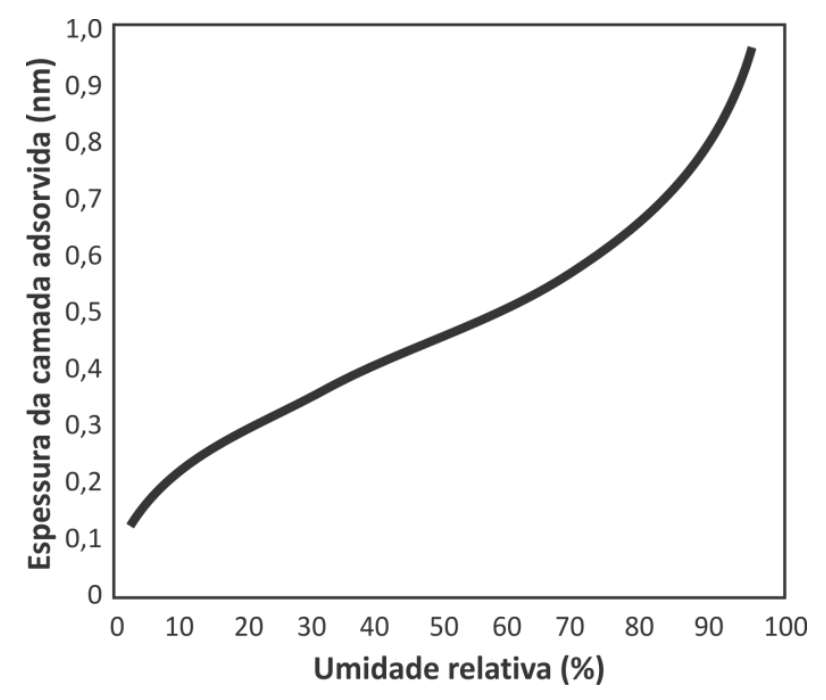

Figura 19 - Espessura da camada de água adsorvida em função da umidade relativa (Quenard et al., 1992)

A camada de água adsorvida aumenta, ao passo que a umidade relativa no poro também se eleva. Quando esta atinge níveis elevados, o poro é completamente preenchido por água. Este processo é denominado de condensação capilar. De acordo com as equações de Kelvin (Equação 9) e de Laplace (Equação 8), esta condensação ocorre nos poros de raios menores que o raio de equilíbrio, ou raio crítico (Sato, 1998):

$$
r_{\text {equilíbrio }}=\frac{-2 M \sigma \cos \theta}{\rho R T \ln U R}
$$

\section{Equação 13 - Raio de equilíbrio}

No sentido da secagem dos poros, como já discutino no item 1.3.3.1, quando a umidade relativa da fase gasosa é inferior a 100\%, a pressão de vapor nesta fase é inferior à pressão da fase líquida, e esta diferença de pressão favorece evaporação de água do meio líquido para o gasoso (Kovler et al., 2006), caracterizando o 
processo de secagem do poro capilar. Com isso há formação de menisco, indicando a diferença de pressão entre as fases, e desta forma a condição de equilíbrio do sistema ocorre em umidade relativa da fase gasosa inferior a $100 \%$. Isto ocorre, pois nesta condição as forças coesivas da massa sólida têm tal intensidade que a evaporação é inibida (Kovler et al., 2006). Em virtude disso, a condição de equilíbrio da pressão capilar nos poros varia em função da umidade relativa do mesmo.

As condições de umidade que um poro pode estar submetido são as seguintes:

$\rightarrow$ Poros saturados, completamente preenchidos por água (fase líquida);

$\rightarrow$ Poros com fase líquida e fase gasosa, com umidade relativa da fase gasosa igual a 100\%. Nesta condição não há formação de menisco;

$\rightarrow$ Poros com fase líquida e fase gasosa, com umidade relativa da fase gasosa inferior a 100\%. Nesta condição há formação de menisco, e consequentemente ocorrência de tensão capilar e retração por secagem;

$\rightarrow$ Ocorrência apenas de fase gasosa, com pequeno volume de fase líquida apenas adsorvida nas paredes dos capilares. Não há formação de menisco nesta condição, portanto não há ação de tensão capilar.

A movimentação higroscópica que caracteriza a secagem ocorre uma vez que na estrutura de poros do compósito cimentício há poros nestas diferentes condições de umidade. Na tendência ao equilíbrio de umidade relativa da fase líquida, a água migra de um poro para o outro, como ilustra o esquema a seguir (Sato, 1998):

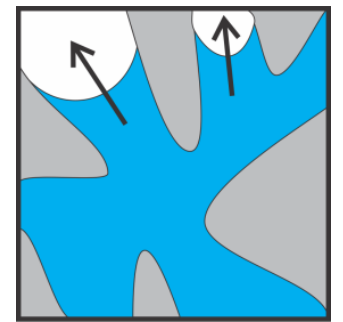

$\rightarrow$ Na condição de poros saturados, a movimentação higroscópica entre os poros se dá por capilaridade

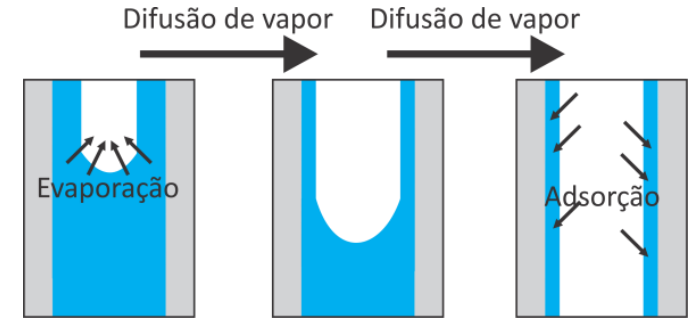

$\rightarrow$ evaporação e difusão de vapor, no sentido do poro de menor UR

$\rightarrow$ diferença de pressão da fase líquida $\rightarrow$ evaporação e difusão de vapor, no sentido do poro de menor UR $\rightarrow$ adsorção física

Figura 20 - Movimentação higroscópica entre poros com diferentes umidades relativas

$\mathrm{Na}$ condição de poros saturados, ou seja, completamente preenchidos por água, a movimentação higroscópica durante a secagem ocorre através do mecanismo de 
ascensão capilar (capilaridade). Na condição onde há fase líquida e gasosa no poro, a movimentação higroscópica ocorre por difusão de vapor no sentido do poro com menor umidade relativa. Desta forma, a redução da umidade relativa do poro favorece a evaporação de água, até este voltar a atingir o equilíbrio. Por fim, a movimentação higroscópica para poros mais secos, sem fase líquida com formação de menisco, ocorre por difusão de vapor, e adsorção de água nas paredes do poro.

O processo de secagem é a tendência ao estado de equilíbrio entre a fase gasosa do poro e as condições ambientais de exposição (humidade relativa e temperatura). Portanto, para atingir esta condição de equilíbrio a cinética de transporte de umidade é muito lenta, uma vez que os materiais cimentícios possuem poros de tamanho na faixa dos mesoporosos, onde o processo de transporte é ainda retardado por interações água-matriz (Baroghel-Bouny, 2007b). Segundo dados experimentais de artigos publicados (Baroghel-Bouny, 2007b), o chamado estado de equilíbrio é assumido quando a massa de amostra encontra-se estabilizado por várias semanas. O tempo necessário para atingir o equilíbrio de umidade depende principalmente da espessura da amostra, das características da estrutura de poros e do gradiente de umidade relativa (Garboczi, 1990).

Os modelos matemáticos para transporte de umidade em materiais porosos seguem a equação de Darcy, para material saturado (Sato, 1998), e as leis de Fick (Baroghel-Bouny, 2007b), para o transporte de fase gasosa. Como a permeabilidade à água é uma grandeza derivada de uma condição de material saturado, situação em que se encontram somente as estruturas que ficam constantemente em contato com a água, este não é o parâmetro mais indicado a ser considerado nos casos em que os materiais estão submetidos a outras condições de exposição (Sato, 1998). Nas situações onde o compósito está sujeito à secagem, por exemplo, o material não se encontra saturado e portanto a lei de Darcy na sua forma original não se aplica. Neste caso, é sugerida a aplicação da equação de Darcy estendida para meios não-saturados (Hall; Hoff; Skeldon, 1983):

$$
\begin{array}{c|l}
u=-k(C) \nabla_{\Psi} & \mathrm{u} \text { - velocidade específica de escoamento (m/s) } \\
\begin{array}{c}
\text { Equação 14 - Equação de Darcy } \\
\text { estendida para meios não-saturados }
\end{array} & \begin{array}{l}
\Psi \text { - potencial capilar por unidade de massa do líquido (m) } \\
\text { (Hall et al., 1983) }
\end{array} \\
\begin{array}{l}
\text { volume de líquido contido no corpo e volume do corpo) } \\
\mathrm{K}(\mathrm{C}) \text { - permeabilidade em condições não saturadas (m/s) }
\end{array}
\end{array}
$$

\footnotetext{
$\mathrm{u}$ - velocidade específica de escoamento $(\mathrm{m} / \mathrm{s})$ $\Psi$ - potencial capilar por unidade de massa do líquido $(\mathrm{m})$ C - teor de umidade contida no corpo (razão entre o volume de líquido contido no corpo e volume do corpo) $\mathrm{K}(\mathrm{C})$ - permeabilidade em condições não saturadas $(\mathrm{m} / \mathrm{s})$
} 


\subsubsection{Mecanismos de retração atuantes no fibrocimento em função do tempo}

A retração é um fenômeno que ocorre desde o primeiro momento em que o compósito cimentício é produzido, estendendo-se por toda a vida útil do material. No fibrocimento, devido às particularidades do seu processo produtivo, métodos de cura, condições de estoque e expedição, até sua aplicação e uso, os diferentes mecanismos de retração podem ocorrer simultaneamente, em menor ou maior intensidade em função do tempo. A Figura 21 ilustra os tipos de retração que atuam no fibrocimento em função do tempo de hidratação.

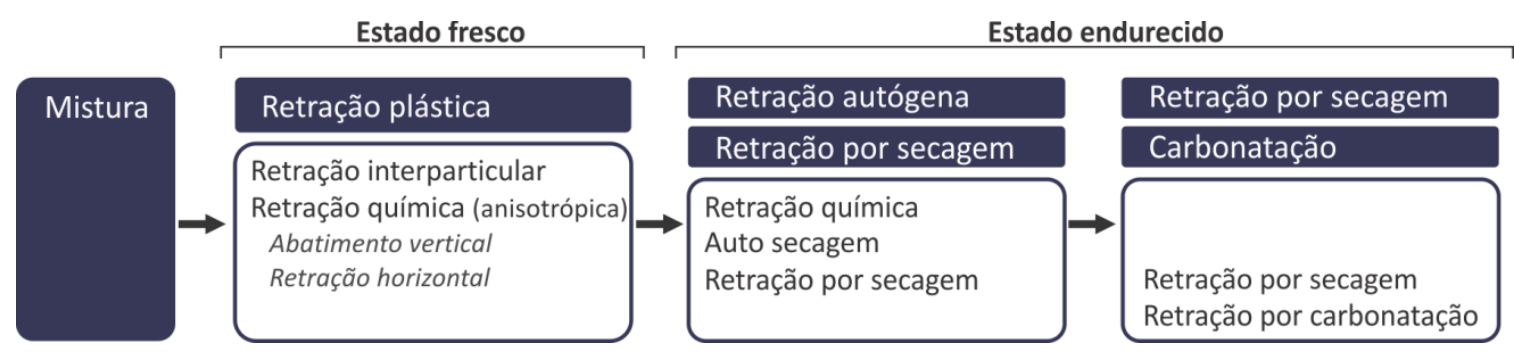

Figura 21 - Tipos de retração em função do tempo de hidratação

Desde o primeiro momento, ainda no estado fresco, um compósito cimentício qualquer já sofre retração no estado plástico (Figura 21) devido às reações químicas de hidratação (Tabela 4). Além disso, a secagem e autossecagem também causam retração por redução da distância interparticular (Tabela 4), que é a aproximação das partículas sólidas da suspensão reativa, ainda nesta fase prematura do compósito.

O alto consumo de cimento na sua formulação, além da grande quantidade de partículas muito finas, favorecem a retração no estado plástico nos fibrocimentos. Segundo a equação de Laplace que governa o mecanismo de retração por aproximação interparticular devido à secagem (Equação 1), quanto menor o tamanho das partículas, maior é a magnitude da força de atração entre elas. No entanto, este mecanismo atua somente em uma determinada faixa de umidade, pois para níveis baixos de umidade, ocorre a queda da tensão capilar (Figura 3). A manta fresca de fibrocimento, no momento da conformação dos artefatos, não se encontra na condição de saturação (Figura 3.A), uma vez que durante o processo Hatschek a manta fresca é submetida à secagem por aplicação de vácuo, além da compactação, que removem mecanicamente parte da água excedente dos poros. 
Soma-se a isto, o fato do compósito conter fibras, que atuam como uma estrutura resistente do fibrocimento, minimizando os efeitos da retração no estado plástico. A umidade da manta fresca no momento da conformação é menor que $25 \%$, enquanto que a porosidade total do compósito endurecido gira em torno de $35 \%$, corroborando o estado não saturado da manta fresca.

O processo de cura, que compreende estoque em câmara de cura, embalagem das telhas com filme plástico, além do efeito de barreira de secagem que o empilhamento causa, faz com que a umidade do fibrocimento se mantenha sempre elevada enquanto este se encontra no estado fresco.

Assim que o compósito começa a enrijecer, ou seja, se tornar um sólido monolítico, a retração autógena passa a atuar (Figura 21). Esta retração é composta em parte pela retração química, uma vez que as reações de hidratação ainda estão ocorrendo em taxa elevada, em parte por autossecagem, uma vez que o consumo de água para a hidratação reduz a umidade da estrutura de poros da matriz (Tabela 4), e por fim pela retração por secagem, uma vez que a troca de umidade com o ambiente reduz a umidade nos poros, causando tensão capilar e consequentemente retração.

No fibrocimento esta etapa temporal ocorre no término da cura, empilhamento das telhas prontas, e estoque inicial no pátio da empresa. A retração química sempre será uma parcela intrínseca do compósito, que vai depender do teor e características do cimento utilizado na formulação. A autossecagem e retração por secagem são mecanismos com o mesmo princípio, que é a redução da umidade relativa nos poros do fibrocimento. No entanto, no caso da retração por secagem, esta sofre influência do manejo das telhas nas suas idades iniciais. No término da cura, as placas de fibrocimento são retiradas dos moldes e empilhadas, sendo que neste instante ocorre grande perda de água e consequente retração por secagem.

Com o avanço do tempo, as reações químicas ocorrem em taxa muito menor, não interferindo significativamente na retração, no entanto a retração por secagem pode ocorrer (Tabela 4) por toda a vida útil do material, uma vez que este estará sempre submetido ora à secagem ora ao umedecimento. Além disso, estando em contato com o ar, haverá carbonatação da matriz cimentícia, fenômeno que também causa retração (Tabela 4). 
Durante o estoque das placas planas ou telhas onduladas, empilhadas em conjuntos de aproximadamente 100 unidades, esta configuração favorece uma condição de gradiente de umidade ao longo do material. As telhas atuam como barreira contra a secagem das regiões centrais das peças, enquanto que as bordas ficam livres para a evaporação. Este arranjo cria uma secagem diferencial, que induz a pressões na região da borda devido à retração por secagem nesta região, que pode causar fissuração. O mesmo fenômeno é observado para a interação da matriz com $\circ \mathrm{CO}_{2}$, que causa uma condição de retração por carbonatação nas bordas maior do que no centro, pela dificuldade de difusão do $\mathrm{CO}_{2}$ do ar na região central das placas.

Durante qualquer fase da vida útil do compósito cimentício, se este for submetido à variação de temperatura, consequentemente ocorrerá retração no resfriamento (Tabela 4). Em estruturas com grande volume, o calor gerado da reação química de hidratação atua na variação de temperatura do compósito. Ainda no período de cura é comum as estruturas e peças cimentícias serem submetidas à cura térmica, que também causará retração no resfriamento. Por fim, as estruturas expostas às intempéries estão submetidas a ciclos de calor e resfriamento diários e sazonais, que geram retração térmica e danos às mesmas.

A Tabela 4 mostra os tipos de retração que ocorrem em materiais cimentícios, com descrição e origem. 
Tabela 4 - Tipos de retração em compósito cimentício

\begin{tabular}{|c|c|c|}
\hline Tipo de retração & Descrição & Origem \\
\hline no Estado Plástico & $\begin{array}{l}\text { Toda a retração que ocorre no compósito cimentício } \\
\text { quando este se encontra no estado fresco. }\end{array}$ & $\begin{array}{l}\text { Secagem } \\
\text { Reação química de } \\
\text { hidratação } \\
\text { Autossecagem }\end{array}$ \\
\hline Autógena & $\begin{array}{l}\text { Toda a retração que ocorre a partir do início de pega, } \\
\text { sem a interferência de perda ou ingresso de água, } \\
\text { variação de temperatura, aplicação de força externa ou } \\
\text { restrição. }\end{array}$ & $\begin{array}{l}\text { Reação química de } \\
\text { hidratação } \\
\text { Autossecagem }\end{array}$ \\
\hline por Secagem & $\begin{array}{l}\text { Retração que ocorre em qualquer tempo, devido à } \\
\text { perda de umidade do compósito cimentício para o } \\
\text { ambiente. }\end{array}$ & Secagem \\
\hline por Carbonatação & $\begin{array}{l}\text { Retração que ocorre devido à redução no volume dos } \\
\text { compostos hidratados do cimento após reação química } \\
\text { de carbonatação. }\end{array}$ & $\begin{array}{l}\text { Reação química de } \\
\text { carbonatação }\end{array}$ \\
\hline Térmica & $\begin{array}{l}\text { Retração que ocorre com o resfriamento do compósito } \\
\text { cimentício. }\end{array}$ & $\begin{array}{l}\text { Variação de } \\
\text { temperatura }\end{array}$ \\
\hline
\end{tabular}




\section{Capítulo II}

\section{Plano Experimental e Métodos}

O presente trabalho foi realizado com o apoio do Departamento de Engenharia de Construção Civil da Escola Politécnica da USP, em parceria com as empresas produtoras de fibrocimento Infibra Ltda e Imbralit Ltda, sendo parte integrante do projeto intitulado "Aprimoramento de processos industriais para melhoria de novas tecnologias de produção de fibrocimento", também tratado por projeto "CimentoCelulose". O objetivo geral do projeto é desenvolver continuamente nova tecnologia de produção de telhas onduladas de cimento reforçado com fibras de celulose, associadas a fibras sintéticas, pelo processo Hatschek.

\subsection{Plano de trabalho}

O fluxograma apresentado na Figura 22 resume as etapas de trabalho que compõem esta tese, que está dividida em 4 partes:

Efeito da distribuição de tamanho de poros - Esta etapa do estudo buscou avaliar as possibilidades de modificar o efeito da porosidade e distribuição de tamanho de poros característicos do fibrocimento na retração por secagem, e deste modo estimar o efeito de dois métodos viáveis industrialmente para variar os poros de um fibrocimento produzido por filtração e prensagem. Para tal foi reunida uma massa de dados correspondente a ensaios de retração realizados durante vários estudos contidos no projeto Cimento-Celulose, durante pelo menos 5 anos de acompanhamento desta propriedade das amostras produzidas industrialmente. 
Além disso, foi gerada a isoterma de secagem característica do fibrocimento NT, além da variação da porosidade total do fibrocimento, com intuito de verificar seus efeitos na retração.

Efeito da formulação na retração por secagem - Esta etapa do trabalho buscou determinar o efeito primeiramente do cimento utilizado na formulação, adotando para isso 6 diferentes cimentos com propriedades físico-químicas distintas, na retração por secagem do compósito. Também se buscou determinar como a variação da quantidade de cada matéria-prima isoladamente, se reflete na retração por secagem do fibrocimento. Esta etapa do trabalho foi realizada em laboratório, com amostras produzidas por filtração e prensagem em laboratório.

Retração por carbonatação - Nesta etapa buscou-se mostrar qual é a parcela da retração por carbonatação, em relação à retração total em fibrocimento exposto a condições ambientais típicas, suscetíveis à secagem e interação química com o ar contendo $\mathrm{CO}_{2}$, criando desta forma dois gradientes de deformação, o primeiro por secagem diferencial e o segundo por carbonatação diferencial na região do centro e da borda da telha empilhada.

Redução da tensão superficial - Com intuito de aplicar o conceito de tensão capilar como principal causa da retração por secagem do fibrocimento, nesta etapa do estudo foi aplicada uma medida de mitigação da retração baseado na redução da tensão superficial da água do poro, e consequente redução da tensão capilar atuante nos mesmos, como preconizam as equações de Laplace e Kelvin. Para medir tais efeitos, foi aplicado um produto que reduz a tensão superficial da fase líquida (aditivo SRA), e foi medido o efeito desta ação na retração por secagem e fissuração de telhas empilhadas, expostas ao meio ambiente, no pátio da fábrica de fibrocimento. 


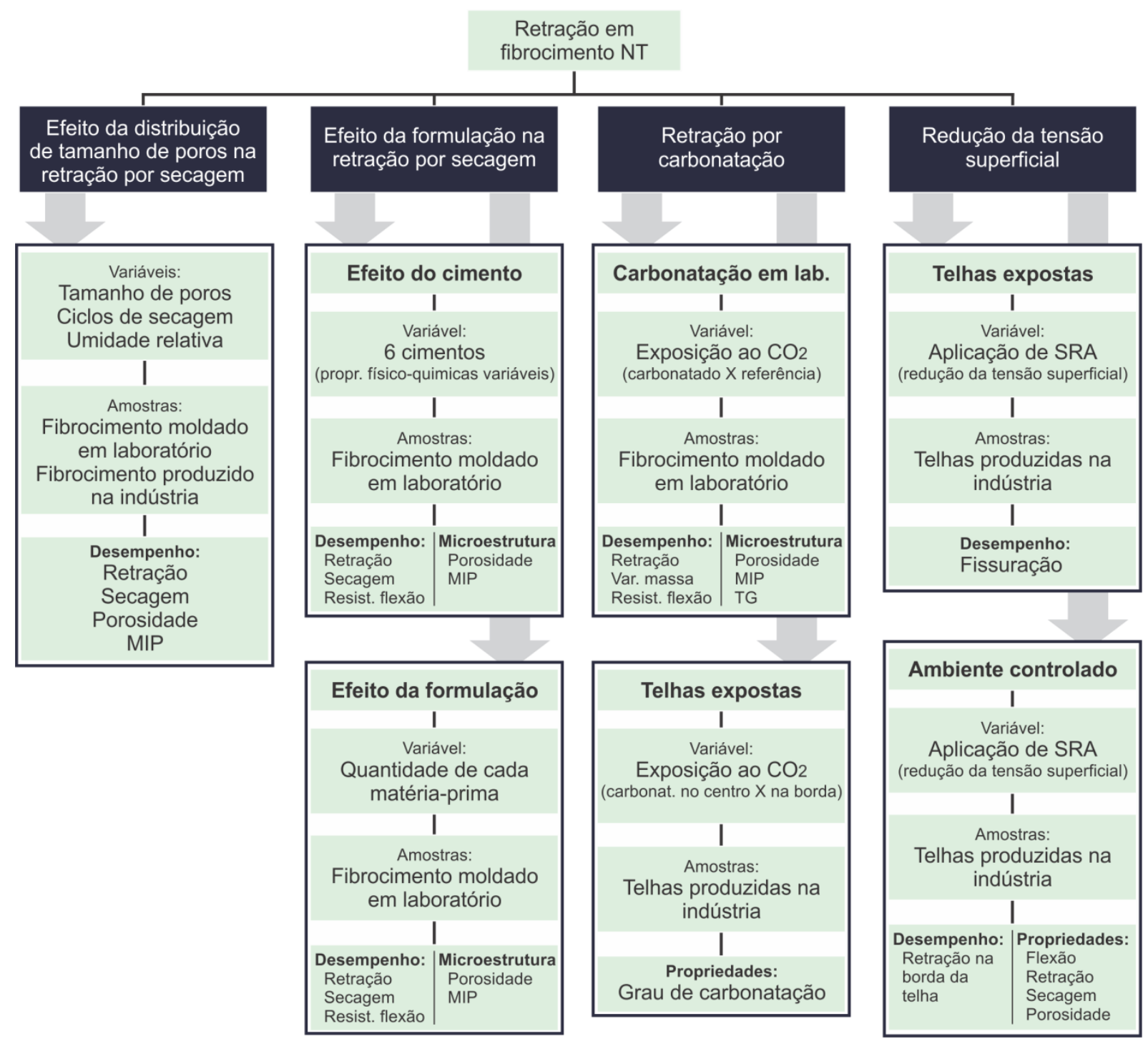

Figura 22 - Plano geral de trabalho

\subsection{Amostras de fibrocimento}

\subsubsection{Coleta de fibrocimento na fábrica}

Como mostrado no plano geral de trabalho (Figura 22), os estudos que compõem esta tese foram realizados utilizando amostras produzidas por fábricas de fibrocimento durante sua produção regular de telhas onduladas; amostras de telhas de fibrocimento produzidas pelas fábricas; ou ainda amostras de fibrocimento produzidas em laboratório.

No caso da utilização de amostras de fibrocimento produzidas industrialmente, seguiu-se um procedimento padronizado de coleta e cura inicial destas amostras, 
com intuito especialmente de não causar danos no fibrocimento em seu manuseio, e o mantimento da umidade da manta sempre elevado, conferindo a cura do material, e evitando a primeira secagem. Estas amostras foram coletadas em fábricas produtoras de fibrocimento de São Paulo e Santa Catarina. O procedimento completo de coleta de amostras consistiu em:

\section{a) Coleta}

A coleta das amostras foi realizada a partir da manta de fibrocimento ainda no estado fresco, na etapa final de produção pelo processo Hatschek. Logo após o corte da manta nas dimensões da telha a ser produzida, sobram retalhos nas laterais da mesma que voltam para o processo, para voltar a incorporar a suspensão de fibrocimento. As amostras de interesse foram coletadas a partir destes retalhos (Figura 23), com o cuidado de não deformá-las, pois estas ainda se encontravam maleáveis e sem resistência mecânica.

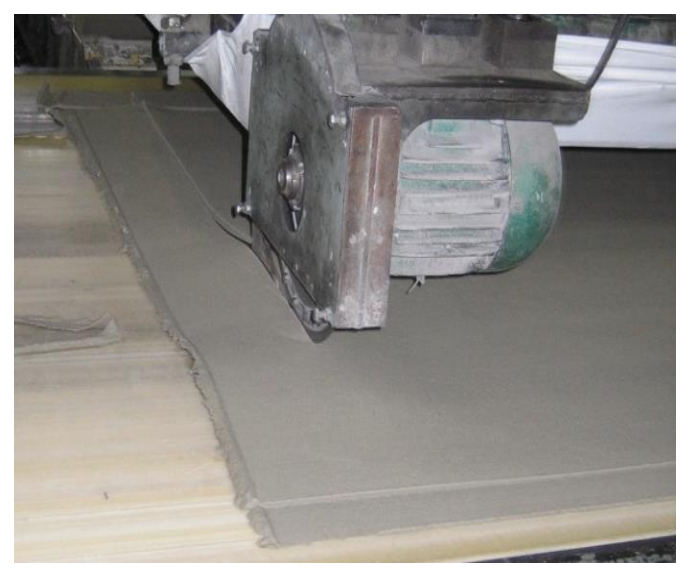

Figura 23 - Retalho de manta fresca de fibrocimento, coletado para a extração dos corpos-deprova utilizados no estudo

b) Cura térmica

As amostras coletadas foram armazenadas juntamente com as telhas produzidas, na câmara úmida da fábrica. O procedimento completo de cura envolveu a manutenção da umidade alta das amostras por embalagem plástica impermeável e temperatura de $\sim 60^{\circ} \mathrm{C}$, por período de $\sim 10$ horas. A temperatura de cura não foi precisa, pois a câmara de cura retém o calor liberado pelo próprio fibrocimento durante a reação de hidratação do cimento, ao invés de possuir fontes geradoras de calor. Por este motivo, o calor dentro da câmara depende de alguns fatores, como o tipo de cimento utilizado, ou a velocidade de 
produção, ou a quantidade de fibrocimento dentro da câmara, por exemplo. O tempo de cura também não foi constante, uma vez que foi dependente da velocidade de produção da fábrica, que em alguns momentos sofreu interrupções.

\subsubsection{Moldagem de fibrocimento em laboratório}

O processo Hatschek de fabricação de fibrocimento é bastante complexo, e possui inúmeras variáveis de processo que interferem nas características do produto final produzido. Como exemplo, são algumas das variáveis independentes os parâmetros de processo como pressão de vácuo no feltro, velocidade do feltro, concentração de sólidos nas diferentes etapas do processo, periodicidade de limpeza do feltro, entre outros. Estes parâmetros influenciam um segundo nível de variáveis, chamadas de intervenientes, que são a densidade da manta, umidade da monopelícula, entre outros, que se refletem nas propriedades do produto final.

No intuito de reproduzir ao máximo o processo produtivo adotado pelas fábricas, as amostras de fibrocimento produzidas em laboratório seguiram o método de moldagem descrito por Savastano Jr. (Savastanojr; Warden; Coutts, 2005), cujo princípio de formação da placa plana de fibrocimento é o mesmo que fundamenta o processo Hatschek: filtração e compactação.

O procedimento de mistura e moldagem foi adaptado do descrito por Savastano Jr, com intuito de garantir a dispersão das fibras sintéticas, e consequentemente a homogeneidade do fibrocimento. $\mathrm{O}$ procedimento de mistura e moldagem foi o seguinte:

a) Dispersão das fibras

As fibras sintéticas (PVA e PP) encontram-se aglomeradas em pequenos feixes antes da utilização (Figura 24.a). A dispersão destas fibras é um procedimento crítico na produção de fibrocimento em laboratório, uma vez que a energia de mistura dos agitadores mecânicos comuns não é eficiente na dispersão destes feixes de fibras, ainda mais pela tendência de aglomeração das fibras quando úmidas, devido à afinidade destas com a água. No processo Hatschek, além da utilização de aditivos dispersores, a grande energia de mistura envolvida no processo garante a dispersão das fibras, no entanto, em laboratório a solução encontrada para a desagregação dos feixes de fibras foi a dispersão a seco, com 
aplicação de jatos de ar comprimido nas fibras aglomeradas (Figura 25), com pressão e tempo de aplicação padronizados (Figura 24.b).

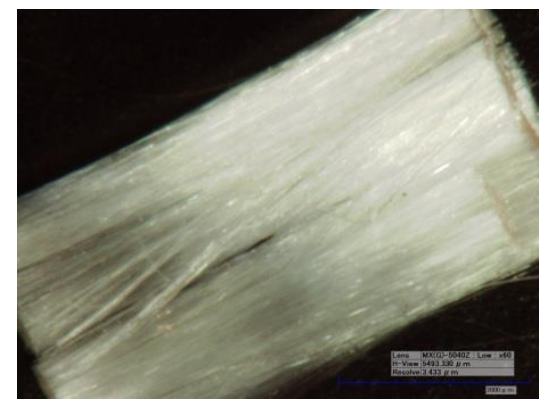

(a)

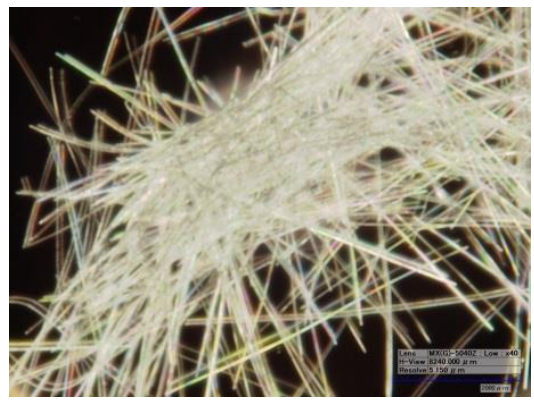

(b)

Figura 24 - Fibras de PVA de $6 \mathrm{~mm}$ (a) antes da dispersão, em feixes, e (b) após procedimento de dispersão com aplicação de ar comprimido

As fibras de celulose passam por um tratamento de refino para uso no processo Hatschek, formando uma polpa celulósica dispersa, e com a superfície das fibras tratadas de modo a apresentarem retenção de finos adequada ao processo de fabricação do fibrocimento (Savastano Jr. et al., 2007). Para a utilização em laboratório, as fibras curtas branqueadas de celulose utilizadas na produção dos fibrocimentos, encontram-se na forma de folhas. Devido à limitação na infraestrutura do laboratório, que não possui os refinadores de disco similares aos da fábrica, as fibras de celulose foram desagregadas para o uso utilizando-se um equipamento dispersor, cujo princípio de funcionamento é a recirculação da mistura de fibras e água até a sua completa dispersão (Figura 26).

Dispersão das fibras de PVA com aplicação de ar comprimido:

$\rightarrow$ Em saco plástico

$\rightarrow$ Pressão de 3 bar (300 kPa)

$\rightarrow$ Período de 2 minutos

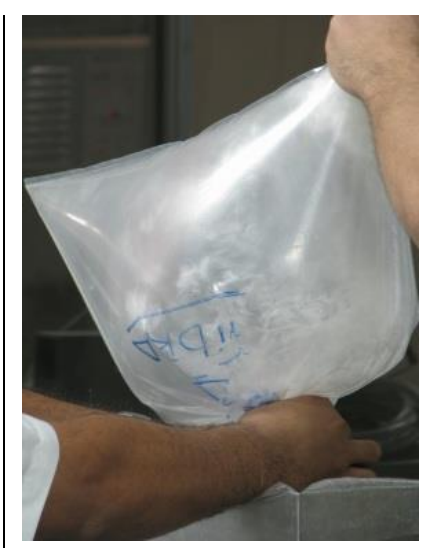

Figura 25 - Dispersão das fibras de PVA 
Desagregação das fibras de celulose em dispersor por recirculação:

$\rightarrow$ Frequência da bomba 3000 rpm

$\rightarrow$ Período de 3 minutos

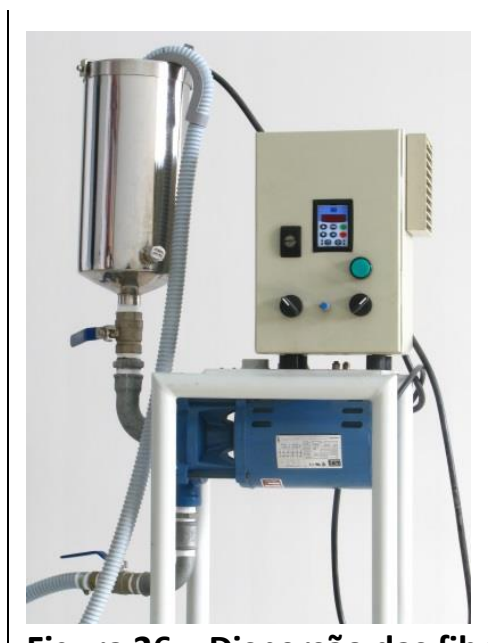

Figura 26 - Dispersão das fibras de celulose

b) Mistura dos materiais

A mistura da suspensão reativa com todas as matérias-primas do fibrocimento, somada à circulação desta suspensão no processo Hatschek, é eficiente ao ponto de manter as partículas dispersas, sem ocorrência de sedimentação.

Para realizar em laboratório uma mistura eficiente da suspensão com baixa concentração de sólidos, foi utilizado o mesmo dispersor da Figura 26, cujo princípio de mistura é a recirculação da suspensão, onde a passagem dos materiais pela bomba juntamente com a turbulência dentro das tubulações, são responsáveis pela mistura homogênea de toda a massa. Com o dispersor sempre ligado, a sequência de mistura foi a seguinte:

Desagregação e dispersão das fibras de celulose, como descrito anteriormente (Figura 26);

$\rightarrow$ Período de desagregação: 3 minutos

Adição dos pós (cimento e adições) previamente homogeneizados, à suspensão de celulose + água, com o dispersor ligado;

$\rightarrow$ Pré-homogeneização dos pós secos, com agitação em saco plástico

$\rightarrow$ Adição lenta dos pós à suspensão em circulação (1 minuto)

$\rightarrow$ Período de mistura: 3 minutos

Adição das fibras poliméricas dispersas à suspensão reativa (celulose + cimento + adições + água), com o dispersor ligado;

Adição lenta das fibras à suspensão em circulação (1 minuto)

Período de mistura: 3 minutos

Em uma mesma batelada, foi misturada quantidade de material suficiente para a moldagem de várias placas de fibrocimento. Com o dispersor em funcionamento, 
foram realizadas coletas da quantidade de suspensão necessária para a produção de uma única placa, sendo esta controlada pela determinação da massa em balança digital (precisão $0,01 \mathrm{~g}$ ). Desta forma, após o término da mistura, o dispersor continuou ligado na mesma velocidade até que todas as coletas de suspensão reativa fossem realizadas, para evitar a separação das fases por sedimentação da suspensão em repouso.

c) Moldagem das placas de fibrocimento

O processo Hatschek compreende a formação contínua de uma película de fibrocimento, pela filtração da suspensão reativa através da tela do tamis. Uma vez que o tamis é um cilindro, a sua movimentação (giro) infere uma orientação preferencial das fibras de reforço na direção do movimento, tornando o fibrocimento um material anisotrópico.

Na moldagem em laboratório, o processo é por batelada, também por filtração, no entanto sem orientação preferencial das fibras. A moldagem das placas quadradas de fibrocimento foi realizada baseada no método apresentado por Savastano; Warden; Coutts (2005), através de filtração da suspensão cimentícia; para isso foi utilizado um molde quadrado de $20 \mathrm{~cm}$ de lado, com uma placa acrílica perfurada como base, com uma folha de papel filtro de gramatura $80 \mathrm{~g} / \mathrm{m}^{2}$ (Figura 27). A suspensão reativa foi vertida no molde, e em seguida foi iniciada a filtração forçada por bomba de vácuo, com uma sucção de $200 \mathrm{mmHg}(26,7 \mathrm{kPa})$.
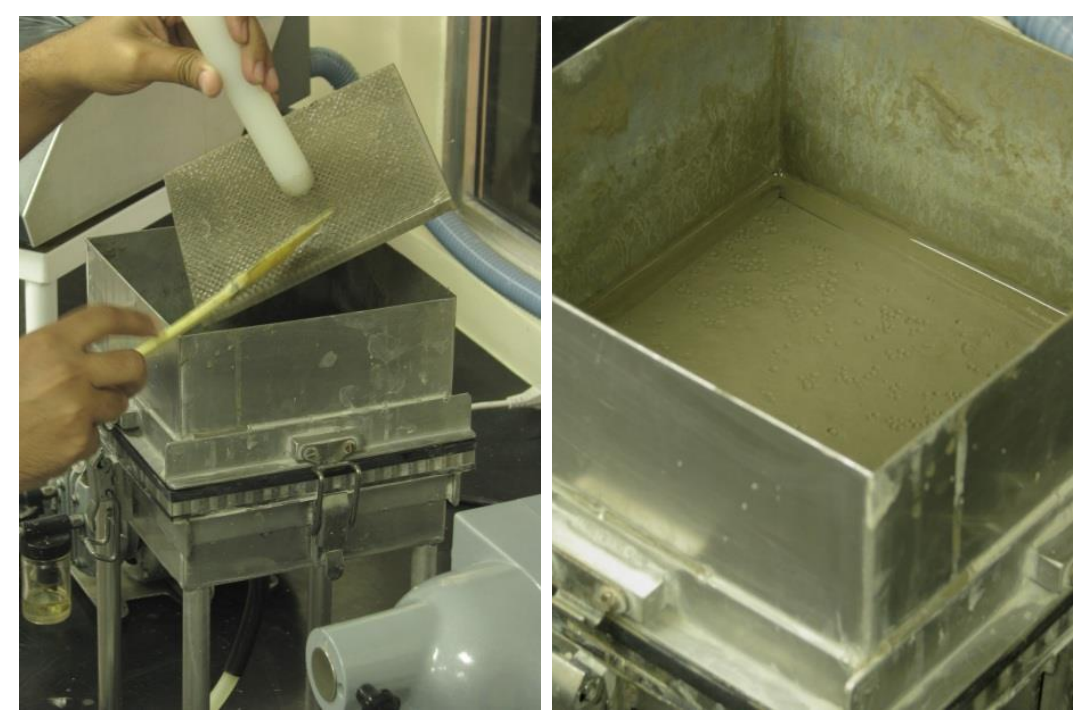

Figura 27 - Aparato de moldagem das placas quadradas de fibrocimento, por filtração 
Cada placa de fibrocimento foi moldada em 4 camadas, sendo que cada camada foi filtrada separadamente, e depois sobrepostas para a formação da placa de fibrocimento com espessura desejada.

d) Compactação das placas moldadas

Após a moldagem, cada camada individualmente, e por fim a placa de fibrocimento ainda no estado fresco, foram compactadas em prensa eletromecânica universal, da marca Instron, modelo 3365, com célula de carga de $50 \mathrm{kN}$, por período de tempo aproximado de 2 minutos. Esta operação foi realizada com intuito de retirar o excesso de água remanescente nas amostras e para simular a compactação ocorrida na fábrica ao término do processo de fabricação de fibrocimento; no mesmo procedimento foi realizado o ensaio de squeeze-flow em duas etapas, como forma de caracterização da placa no estado fresco: na primeira etapa a carga de compactação foi aumentando a partir do zero, até atingir $40 \mathrm{kN}$ (ou $20 \mathrm{kN}$ para o caso da compactação das camadas individualmente), com velocidade de $3 \mathrm{~mm} / \mathrm{s}$; na segunda etapa a célula de carga da prensa não se deslocou, e o equipamento coletou a redução da carga de compressão devido ao escoamento lateral da amostra.

\subsection{Caracterização da matéria-prima}

\subsubsection{Difração de raios- $X$}

As matérias-primas utilizadas neste estudo foram caracterizadas quanto à identificação qualitativa das fases cristalinas através da difração de raios-X (DRX). Esta técnica, como qualquer outra, tem limite de sensibilidade, sendo difícil a deteç̧ão de fases cristalinas com concentração abaixo de $5 \%$. A preparação das amostras em pó foi a secagem das mesmas em estufa a vácuo, à temperatura de $60^{\circ} \mathrm{C}$, por período de 24 horas.

As amostras secas foram encaminhadas para $0 \mathrm{LCT}^{11}$ para a realização dos ensaios de DRX. A análise foi efetuada através do método do pó, mediante o emprego de difratômetro de raios-X, marca Philips, modelo MPD 1880, sendo que 0 espectro foi coletado de 3 a $70^{\circ} 2 \theta$ e tempo de passo de 2,5s. A identificação das fases cristalinas foi obtida utilizando o software Philips X'Pert HighScore versão

\footnotetext{
${ }^{11}$ Laboratório de Caracterização Tecnológica, do Departamento de Engenharia de Minas e de Petróleo, da Escola Politécnica da USP
} 
1.0b, por comparação do difratograma das amostras com o banco de dados do ano de 2003 do ICCD - International Centre for Diffraction Data.

\subsubsection{Calorimetria de condução isotérmica}

Para a determinação da cinética de hidratação dos cimentos, e possíveis interferências das demais matérias-primas e aditivos, foi realizado o ensaio de calorimetria isotérmica de condução. Esta técnica consiste na medida do calor gerado na amostra devido às reações químicas exotérmicas de hidratação do cimento. Esta técnica analítica é bastante sensível às alterações na cinética de hidratação, sendo que o equipamento utilizado nestes experimentos possui grande precisão e exatidão.

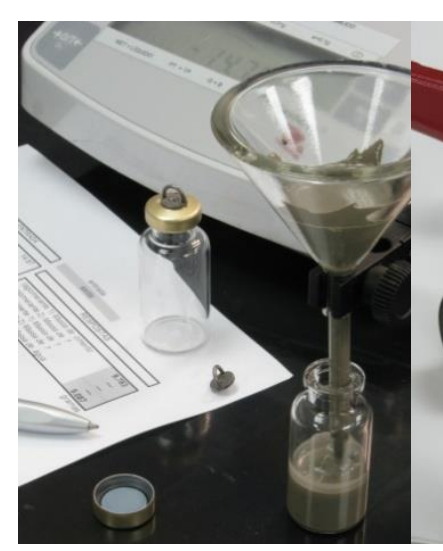

(a)

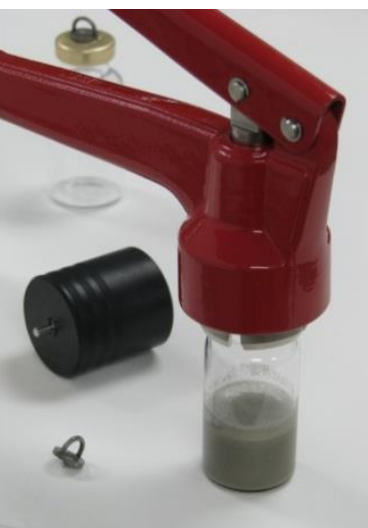

(b)

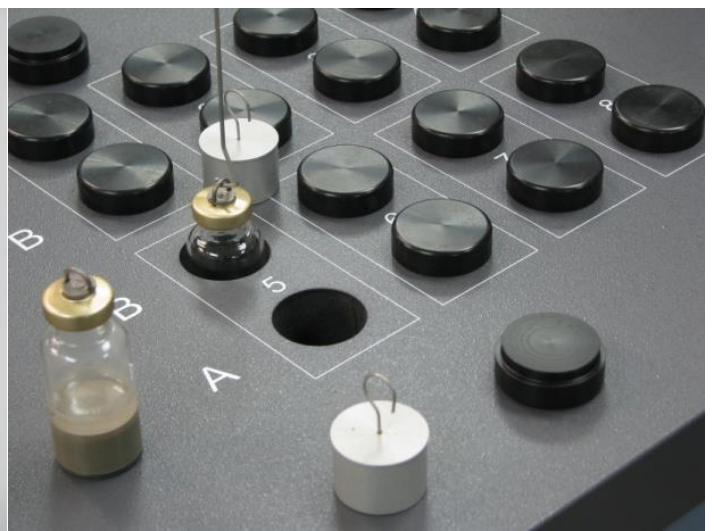

(c)

Figura 28 - Sequência de atividades realizadas no ensaio de calorimetria isotérmica. (a) colocação da pasta cimentícia na ampola de vidro; (b) fechamento hermético da ampola; (c) colocação da ampola de vidro com a amostra, e de ampola de vidro vazia, no interior do calorímetro

O ensaio foi realizado em pasta, à temperatura de interesse do estudo, que pode variar entre $5^{\circ} \mathrm{C}$ e $90^{\circ} \mathrm{C}$, por um período de 72 horas. O equipamento utilizado foi um calorímetro isotérmico da marca TA Instruments, modelo TAM Air. O procedimento de ensaio adotado consistiu em misturar manualmente, com espátula flexível, os pós com a água por período de 3 minutos. Uma quantidade entre 4 e 20 gramas da pasta cimentícia foi colocada, com auxílio de um funil, na ampola de vidro específica para este ensaio (Figura 28.a), e a massa de amostra foi determinada em balança analítica. A ampola de vidro foi fechada hermeticamente com uma ferramenta específica, como mostrado na Figura 28.b. Completados 4 minutos desde o instante em que a água entrou em contato com o cimento, a ampola com a 
amostra, e uma ampola idêntica vazia, foram colocadas no interior do calorímetro (Figura 28.c), e o ensaio foi iniciado via software LabAssistant.

\subsubsection{Termogravimetria}

A termogravimetria é uma técnica de análise térmica bastante empregada, consistindo em aquecer uma amostra a uma taxa geralmente constante, e em medir a variação de sua massa ao longo do aquecimento. As curvas geradas pelo ensaio fornecem informações a respeito da composição e estabilidade tanto da amostra inicial, como dos produtos intermediários que possam ser formados e do resíduo. As reações de transformação que ocorrem no aquecimento são de desidratação e de carbonatação, amplamente conhecidas e divulgadas na literatura internacional. Assim, pela faixa de temperatura em que ocorrem as transformações térmicas, ou seja, sua variação de massa, é possível analisar o perfil da curva resultante, $\Delta m=f(T)$, tanto qualitativa como quantitativamente.

As amostras estudadas foram ensaiadas em termobalança da marca Netzsch, modelo TG 409-PC, do Laboratório de Microestrutura e Ecoeficiência - LME, após moagem e secagem por liofilização.

Amostras de aproximadamente $1,5 \mathrm{~g}$ foram adicionadas em cadinho de alumina, pesadas em balança analítica e posicionada dentro do forno da termobalança. equipamento foi então ligado a uma taxa de aquecimento de $10^{\circ} \mathrm{C} / \mathrm{min}$, em ambiente de nitrogênio com taxa de $60 \mathrm{ml} / \mathrm{min}$, até atingir $1000^{\circ} \mathrm{C}$.

\subsubsection{Superfície específica BET}

A superfície específica dos materiais estudados foi determinada pelo método BET $^{12}$, realizada em um equipamento Micromeritics ASAP 2010. Este método baseia-se na adsorção física de moléculas de um gás inerte na superfície externa e na superfície interna de todos os poros abertos e interligados das partículas do sólido ensaiado. Os ensaios foram realizados com gás nitrogênio, sendo que para a obtenção da curva de adsorção isotérmica a pressão de nitrogênio foi incrementada gradativamente no conjunto amostra/porta amostra, determinando-se as quantidades de gás adsorvido equivalentes para cada pressão de equilíbrio. A

\footnotetext{
${ }^{12}$ Sigla dos nomes Stephen Brunauer, Paul Hugh Emmet e Edward Teller, que foram os pesquisadores que desenvolveram este método em 1938
} 
hipótese adotada pelo método BET é que há formação de uma monocamada de moléculas de nitrogênio por toda a área específica da amostra.

\subsubsection{Massa específica por picnometria de gás He}

A técnica de determinação da massa específica por picnometria de gás hélio emprega a lei de Boyle $(P 1 \cdot V 1=P 2 \cdot V 2)$ para medir o volume ocupado por uma massa conhecida de sólido dentro de um recipiente calibrado. O hélio possui, adicionalmente, comportamento muito próximo de um gás ideal e, por ser gás nobre, não é reativo. Maiores informações sobre o método podem ser obtidas na normalização existente, como a ASTM D5965-02 ${ }^{\text {ver13 }}$ e ASTM B923-02 ${ }^{\text {ver14 }}$.

No presente estudo as amostras foram ensaiadas em um picnômetro de gás hélio, modelo Multitycnometer, da marca Quantachrome Instruments. A quantidade de amostra ensaiada foi de aproximadamente $3 / 4$ do volume total do cadinho (volume do cadinho $=1,0772 \mathrm{~cm}^{3}$ ). Após a colocação da amostra no equipamento, a câmara de ensaio é fechada. A seguir, aplica-se uma pressão de aproximadamente 17 psi com gás hélio na câmara de referência. Abrindo-se o registro que conecta a câmara de referência com a que contém a amostra provoca-se uma queda na pressão, que é medida. Esta queda de pressão é proporcional à variação do volume, definido como o volume da câmara de amostra quando vazia, menos o volume absoluto da amostra. Sabendo-se a massa da amostra, que foi previamente pesada e o volume das câmaras, calcula-se a massa específica.

\subsubsection{Distribuição granulométrica}

A análise de distribuição de tamanho de partículas foi realizada através da técnica de espalhamento de luz laser de baixo ângulo mediante equipamento Mastersizer S, marca Malvern. Cada amostra foi dispersa em água, com a aplicação de ultrassom antes da realização da aquisição dos resultados.

\subsection{Indicadores de desempenho do compósito}

\subsubsection{Retração por secagem}

Os corpos-de-prova utilizados no ensaio de retração por secagem foram cortados nas dimensões de $40 \times 160 \mathrm{~mm}$ a partir das amostras de fibrocimento

\footnotetext{
${ }^{13}$ ASTM D5965-02 - Standard test methods for specific gravity of coating powders

${ }^{14}$ ASTM B923-02 - Standard test method for metal powder skeletal density by helium on nitrogen pycnometry
} 
coletadas nas fábricas, ou a partir das placas de $200 \times 200 \mathrm{~mm}$ produzidas em laboratório, utilizando uma serra circular com disco diamantado.

Para tornar possível a leitura do comprimento dos corpos-de-prova de fibrocimento no aparato de determinação da retração, foi colada em cada extremidade do corpo-de-prova uma peça metálica de superfície cônica e côncava, para que fosse possível o perfeito encaixe com as pontas convexas do equipamento. Esta geometria de encaixe foi definida para que haja o perfeito encaixe do corpo-deprova no equipamento, e também para que não sofra interferências de possíveis grãos de sujeira nos encaixes metálicos.

Os pinos metálicos foram colados nos corpos-de-prova com adesivo epóxi bicomponente de secagem rápida. Este procedimento foi realizado com os corposde-prova úmidos, para que estes não sejam submetidos à primeira secagem. Para isso, os pinos metálicos foram colados de um dos lados dos corpos-de-prova, que foram colocados em câmara úmida durante o período de secagem do adesivo. Passados 30 minutos, foi realizada a colagem dos pinos metálicos no outro lado dos corpos-de-prova, que voltaram em seguida para a câmara úmida.

A retração por secagem é o principal indicador de desempenho desta tese, de modo que foi adotada uma técnica bastante simples, no entanto, bastante precisa para a determinação desta propriedade física do fibrocimento. O método adotado consiste na determinação do comprimento e da massa dos corpos-de-prova em função do tempo de secagem. Para a determinação da massa, que sempre diminui com o passar do tempo, foi utilizada uma balança analítica de precisão 0,01 g; e para a determinação da variação dimensional foi utilizado um aparato específico para esta finalidade, composto por um extensômetro (precisão 0,001 mm) afixado em um aparato vertical, com a ponta esférica convexa (Figura 29). Primeiramente é realizada a tara do micrômetro, com o posicionamento de uma barra de referência composta de invar (liga metálica à base de níquel e ferro, que apresenta a propriedade de baixo coeficiente de dilatação térmica) de $160 \mathrm{~mm}$. Com o micrômetro zerado, cada corpo-de-prova é posicionado no equipamento e é realizada a leitura de comprimento. A leitura do micrômetro indica a diferença de comprimento entre o corpo-de-prova e a barra de referência de $160 \mathrm{~mm}$. 


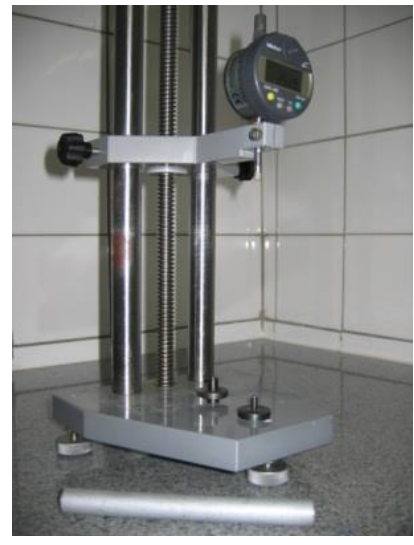

(a)

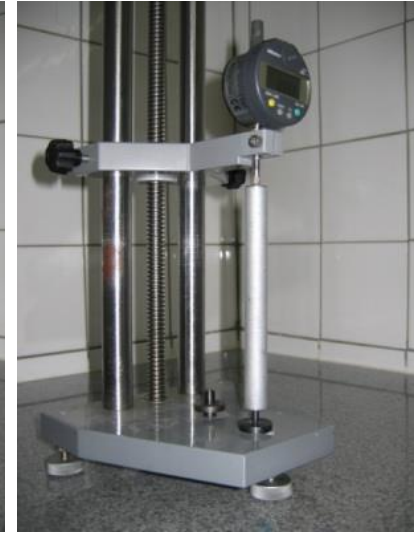

(b)

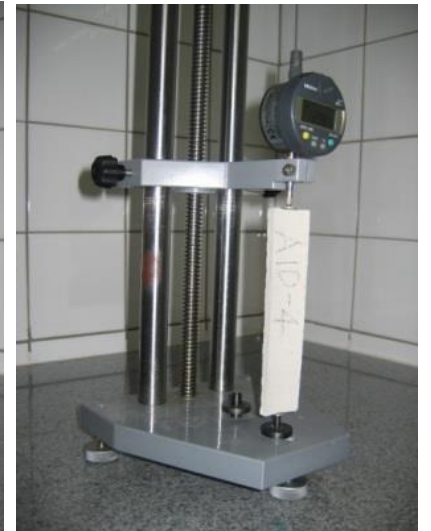

(c)

Figura 29 - (a) Equipamento utilizado no ensaio de retração, (b) que é inicialmente zerado com uma barra de referência feita de invar e (c) em seguida é realizada a determinação do comprimento do corpo-de-prova

A secagem dos corpos-de-prova foi iniciada após o período de cura dos mesmos, quando estes estão com grande umidade, em equilíbrio com as condições ambientais da câmara úmida (temperatura de $23^{\circ} \mathrm{C}$ e umidade relativa do ar superior à $95 \%$ ). A primeira leitura de comprimento foi realizada com os corpos-de-prova úmidos, imediatamente antes do início da secagem, e serve como a referência, sendo que todos os dados de retração foram calculados em relação a esta medida.

A secagem dos corpos-de-prova foi realizada em câmara climática Thermotron, modelo SM-3.5S, ajustada para os seguintes parâmetros:

$\rightarrow$ Temperatura: $23^{\circ} \mathrm{C}$

Umidade relativa do ar: $50 \%$

\subsubsection{Resistência à flexão}

A resistência mecânica das amostras foi determinada através de ensaios de flexão com quatro pontos, conforme esquema exposto na Figura 30. Foram determinados o módulo de ruptura $(M O R)$ (Equação 15), módulo de elasticidade $(E)$

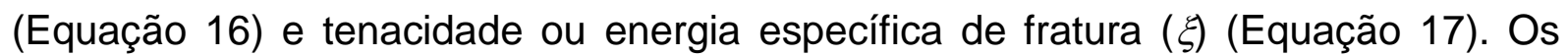
ensaios de flexão foram feitos com corpos-de-prova depois de estes terem sido submetidos à imersão em água por $24 \mathrm{~h}$. 


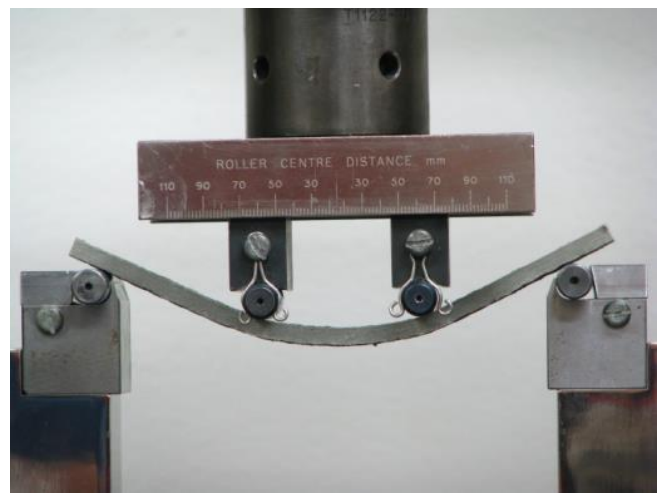

Figura 30 - Ensaio de resistência à flexão com 4 pontos

Onde:

$$
\text { MOR }=\frac{P_{\text {máx }} \cdot L}{b \cdot e^{2}} \quad \begin{array}{ll} 
& P_{\text {máx }}-\text { carga máxima de ensaio }(\mathrm{N}) \\
& b-\text { distância entre os cutelos }(\mathrm{mm}) \\
& e-\text { largura do corpo-de-prova }(\mathrm{mm}) \\
&
\end{array}
$$

Equação 15 - Módulo de ruptura (MPa)

Onde:

$$
E=\frac{23 \cdot L^{3}}{1296 \cdot I}\left(\frac{P}{\delta}\right) \quad \begin{aligned}
& L-\text { distância entre os cutelos }(\mathrm{mm}) \\
& I-\text { momento de inércia da seção transversal, dado por } \frac{b e^{3}}{12}\left(\mathrm{~mm}^{4}\right) \\
& \begin{array}{l}
P / \delta \text { - coeficiente angular do trecho elástico da curva carga } \\
\text { versus flecha }(\mathrm{N} / \mathrm{mm})
\end{array}
\end{aligned}
$$

Equação 16 - Módulo de elasticidade (MPa)

Onde:

$$
\begin{array}{ll}
\xi=\frac{A_{P-\delta}}{b \cdot e} & A_{P-\delta}-\text { área total sob a curva carga versus flecha }(\mathrm{N} \cdot \mathrm{mm}) \\
& b-\text { largura do corpo-de-prova }(\mathrm{mm}) \\
& e-\text { espessura do corpo-de-prova }(\mathrm{mm})
\end{array}
$$

Equação 17 - Tenacidade ou energia específica $\left(\mathrm{kJ} / \mathrm{m}^{2}\right)$

Para a realização dos ensaios de flexão foi utilizada uma prensa da marca INSTRON (modelo 5569) com célula de carga com capacidade de $1 \mathrm{kN}$. Para a determinação do coeficiente angular e módulo de elasticidade dos corpos-de-prova, a flecha no meio do vão foi medida utilizando-se um sensor LVDT Solatron com curso de $5 \mathrm{~mm}$. A velocidade de deslocamento da célula de carga foi igual a $5 \mathrm{~mm} / \mathrm{min}$. 


\subsubsection{Porosidade e densidade por princípio de Arquimedes}

As mesmas amostras utilizadas nos ensaios de retração por secagem e resistência à flexão foram utilizadas para a determinação da porosidade total por Arquimedes. A saturação das amostras para a determinação da porosidade total foi realizada depois de terminado o período de secagem do ensaio de retração, com a imersão das amostras em água saturada de cal, para a completa saturação das mesmas. O período de imersão foi de 48 horas, sendo que ao término deste período as amostras foram submetidas a 1 hora de imersão com vácuo.

Uma vez saturados, foram determinadas a massa saturada e a massa imersa dos corpos-de-prova. Para a determinação da massa imersa foi utilizada uma balança digital de precisão $0,01 \mathrm{~g}$, com um gancho na parte inferior da mesma, onde foi conectado um porta-amostra de tela metálica, que ficou totalmente imerso em água.

Como os mesmos corpos-de-prova foram utilizados para a determinação da resistência à flexão, estes foram encaminhados para a ruptura na condição saturada. Após o rompimento à flexão das amostras, estas foram secas em estufa, para a determinação da massa seca. O procedimento de secagem foi realizado em 2 etapas: secagem em estufa com circulação (temperatura de $50^{\circ} \mathrm{C}$ ) por 24 horas, seguida de secagem em estufa à vácuo (temperatura de $60^{\circ} \mathrm{C}$ e aplicação de vácuo) por 24 horas.

As equações para a determinação da porosidade, densidade aparente, densidade real e absorção de água, está apresentadas a seguir (Equação 18).

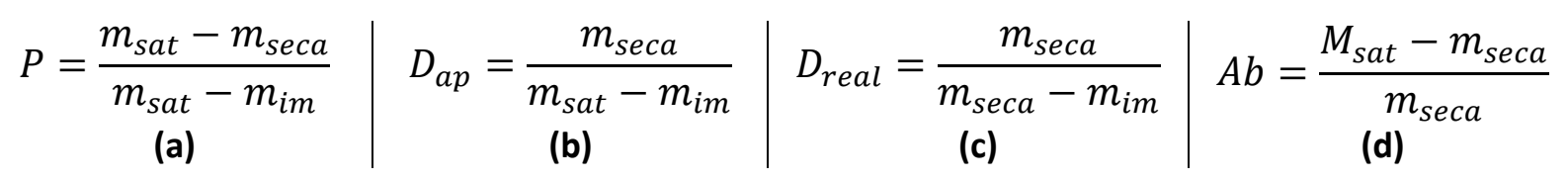

Equação 18 - Equações de determinação da (a) porosidade, (b) densidade aparente, (c) densidade real e (d) absorção de água, determinadas pelo princípio de Arquimedes

\subsubsection{Porosimetria por intrusão de mercúrio}

A análise da distribuição do tamanho de poros foi realizada por porosimetria por intrusão de mercúrio $\left(\mathrm{MIP}^{15}\right)$. O ensaio foi realizado em um equipamento porosímetro da marca Micromeritics, modelo Auto Pore III 9492. Os parâmetros

\footnotetext{
${ }^{15}$ MIP - Mercury Intrusion Porosimetry
} 
fixos deste ensaio são a Equação de Washuburn, utilizada para a determinação da distribuição dos tamanhos dos poros, o ângulo de contato e tensão superficial do mercúrio, iguais a $130^{\circ}$ e $0,485 \mathrm{~N} / \mathrm{m}$; e pressão máxima aplicada durante o ensaio de $412 \mathrm{MPa}$.

Da mesma forma ocorrida para os demais ensaios, os corpos-de-prova foram cortados a partir das placas de fibrocimento moldadas, em serra portátil de disco diamantado. A massa das amostras, previamente liofilizadas, foi de aproximadamente 1,0 grama, para adequar o volume intrudido com os limites de precisão da haste de mercúrio do penetrômetro. 


\section{Capítulo III}

\section{Retração por Secagem em Fibrocimento}

\subsection{Introdução}

O fibrocimento produzido pelo processo Hatschek é um compósito bastante comum na construção civil. No entanto, possui particularidades que o diferem dos demais compósitos cimentícios, como a ausência de agregados na sua composição, elevado consumo de cimento, elevada porosidade, adição de altos teores de fibras minerais ou orgânicas para reforço mecânico, grande quantidade de matérias-primas na composição, espessuras reduzidas das peças (artefatos de fibrocimento normalmente possuem pequena espessura, em torno dos 4 a $8 \mathrm{~mm}$ ), processo produtivo por filtração etc.

Apesar dos mecanismos que causam retração no fibrocimento possuírem modelos clássicos que os representem, comuns aos demais materiais porosos utilizados na construção, as particularidades do fibrocimento fazem com que a cinética de secagem e retração deste material seja diferenciada, e até hoje sem o completo domínio do meio técnico, uma vez que conta com pouca literatura publicada.

O fibrocimento é composto quase que em sua totalidade (mais de $90 \%$ da massa) por uma pasta, que além de cimento pode conter fillers como sílica e calcário. Esta característica se reflete em níveis de retração superiores aos das argamassas e concretos, por exemplo. Enquanto os fibrocimentos apresentam retração da ordem dos $3,0 \mathrm{~mm} / \mathrm{m}$, os concretos retraem em torno de $0,5 \mathrm{~mm} / \mathrm{m}$ (Bissonnette; Pierre; Pigeon, 1999; Choi; Park; Jung, 2011; Passuello et al., 2009; Theiner; Hofstetter, 2012), e as argamassas em torno $1,5 \mathrm{~mm} / \mathrm{m}$ até os 100 dias de 
secagem (Atiş; Kiliç; Sevim, 2004; Bissonnette et al., 1999; Rao, 2001; Toledo Filho et al., 2005) (Figura 31).
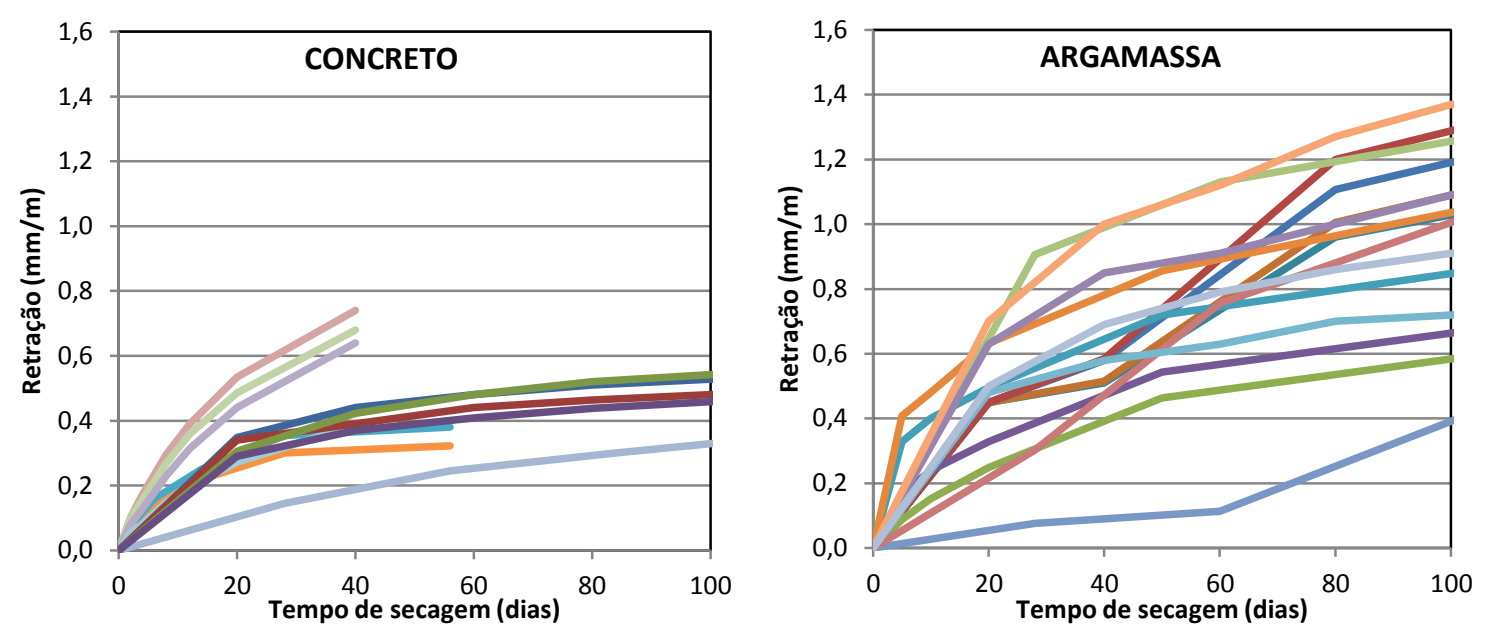

Figura 31 - Retração por secagem em função do tempo de amostras de concreto e argamassa. Dados de retração em concreto de (Bissonnette et al., 1999; Choi et al., 2011; Passuello et al., 2009; Theiner et al., 2012). Dados de retração em argamassa de (Atiş et al., 2004; Bissonnette et al., 1999; Rao, 2001; Toledo Filho et al., 2005)

A movimentação higroscópica, a carbonatação com $0 \mathrm{CO}_{2}$ do ar e a redução volumétrica ocorrida na formação dos compostos hidratados do cimento, são os três fatores desencadeadores da retração nos materiais cimentícios. Visto que estes fatores estão diretamente relacionados com o consumo de cimento, tanto pelo fato da distribuição de tamanho de poros presente na matriz cimentícia hidratada causar retração na secagem, como pelo fato das reações de carbonatação e a própria hidratação do cimento serem causas de retração; observa-se o grande potencial de retração do fibrocimento, que tem grande volume de matriz cimentícia, com consumo de cimento de até $80 \%$ (Dias et al., 2009), frente a um consumo de cimento entre 10 e $22 \%$ nos concretos, podendo atingir valores extremos de até $30 \%$, por exemplo (Damineli et al., 2010).

A porosidade total do fibrocimento gira entre 30 e $45 \%$, que é da mesma ordem de grandeza das argamassas, que varia de $30 \%$ a $50 \%$ (Cardoso, 2009), e bastante superior a dos concretos, que possuem em torno de 15\% (Sato; Agopyan, 1998). O grande potencial de retração dos fibrocimentos, e consequentes manifestações patológicas, vem do fato dos seus artefatos possuírem sempre geometria fina, com grande área de secagem, com todas as suas superfícies livres para a perda de água; além do fato da sua formulação conter grande quantidade de cimento, que gera uma distribuição de tamanho de poros propícia para a ocorrência de tensão 
capilar durante a secagem, como pode ser visto a partir de curvas de porosimetria por intrusão de mercúrio.

Uma importante particularidade do fibrocimento em relação a outros compósitos cimentícios é a presença de fibras na sua composição. As fibras poliméricas reforçam mecanicamente e atuam na redução da fissuração (Sales, 2006) oriunda da retração. A fibra de celulose, necessária para o processo, possui como principal característica a capacidade de retenção de água e finos. Durante a filtração no processo Hatschek, a fibra de celulose é fundamental na retenção de finos, formando aglomerados retidos na tela do tamis, sendo que diferenças nesta retenção de finos se refletem diretamente nas propriedades do fibrocimento em uso. Por ser oca e dúctil, facilita a compactação durante o processo produtivo.

A retração por secagem que ocorre no fibrocimento tem como causa os mesmos mecanismos observados em outros materiais de construção porosos, como o concreto e argamassa. Ou seja, primordialmente a perda de água para o ambiente, e a movimentação higroscópica ocorrida no sentido dos poros menores para os poros maiores, causam tensão capilar que se reflete em retração em escala macroscópica.

Por apresentar um volume de pasta cimentícia muito elevado, a distribuição de tamanho de poros torna este compósito suscetível à retração por secagem, visto que a quantidade de poros capilares e poros de gel é relativamente grande, como mostra o resultado de porosimetria por intrusão de mercúrio a seguir, realizado em uma amostra de fibrocimento produzida em fábrica de telhas onduladas (Figura 32). A Figura 32 mostra a distribuição de tamanho de poros de um fibrocimento produzido industrialmente, com formulação em volume de 58,3\% de cimento, 27,0\% de filler calcário, 6,6\% de sílica; $8,1 \%$ de fibras de PVA e celulose somadas. Estas amostras foram coletadas na fábrica e curadas segundo procedimento padrão apresentado no item 2.2.1. Estas passaram por período de 14 dias de secagem em câmara seca $\left(23^{\circ} \mathrm{C}\right.$ e $\left.U R=50 \%\right)$, e aos 28 dias de hidratação foram submetidas ao ensaio de porosimetria por intrusão de mercúrio, com preparação de amostra e procedimento de ensaios descritos no item 2.4.4. 

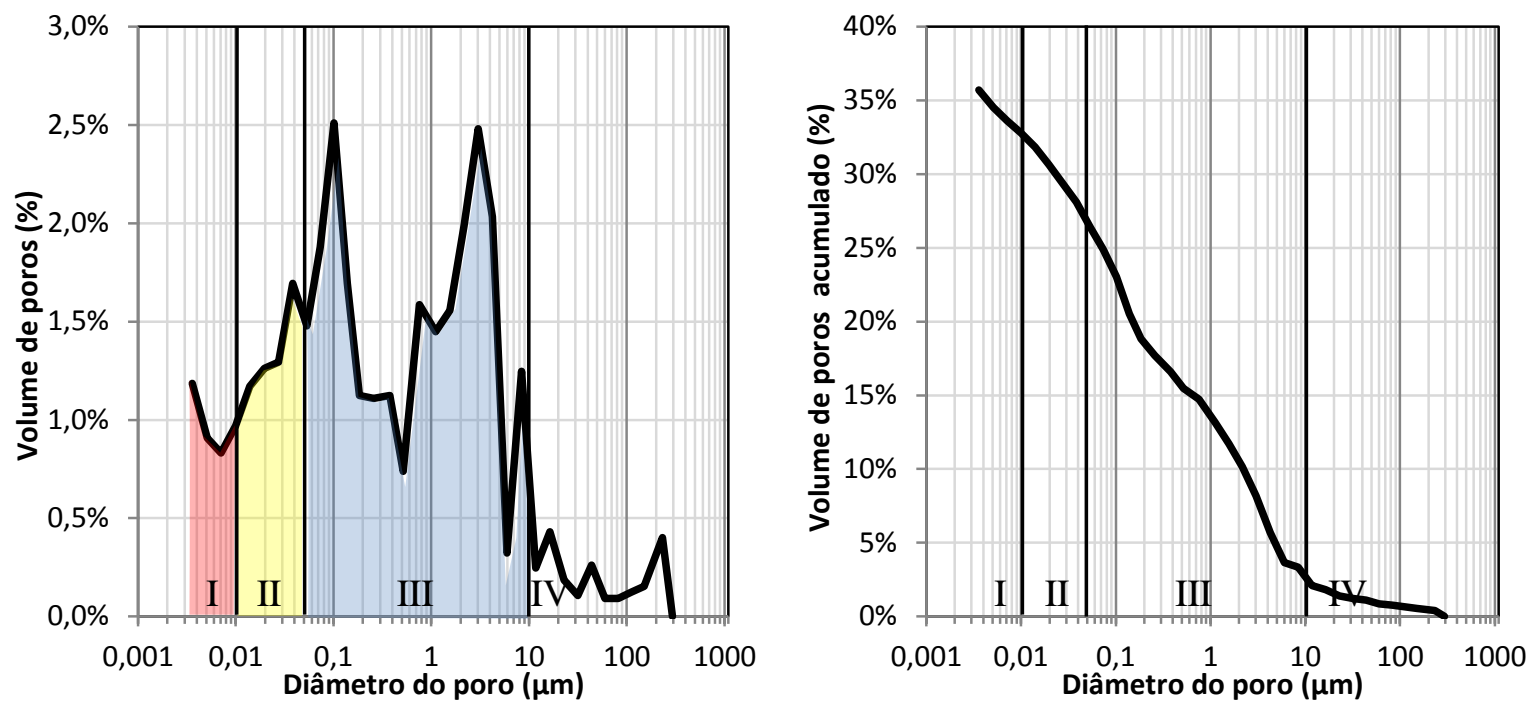

Figura 32 - Distribuição de tamanho de poros de fibrocimento reforçado com fibras de PVA, por porosimetria por intrusão de mercúrio (amostra produzida em fábrica). I - Capilares pequenos (poros de gel); II - Capilares médios (mesoporos); III - Capilares grandes (macroporos); IV Defeitos e poros da celulose

Segundo (Mindess, 1981), a distribuição de tamanho de poros comuns em pastas cimentícias pode ser classificada conforme apresentado na Tabela 5, sendo que as faixas de poros de gel e mesoporos geram forças capilares capazes de resultar em retração em escala macroscópica nos compósitos produzidos.

Tabela 5 - Classificação do diâmetro de poros em pastas de cimento hidratado (Mindess, 1981)

\begin{tabular}{|c|c|c|c|c|}
\hline Designação & Diâmetro & Descrição & Função da água & $\begin{array}{c}\text { Propriedade da pasta } \\
\text { afetadas }\end{array}$ \\
\hline $\begin{array}{c}\text { Poros } \\
\text { Capilares }\end{array}$ & $10 \mu \mathrm{m}-0,05 \mu \mathrm{m}$ & $\begin{array}{c}\text { Capilares grandes } \\
\text { (macroporos) }\end{array}$ & $\begin{array}{c}\text { Comporta como água } \\
\text { de enchimento }\end{array}$ & $\begin{array}{c}\text { Resistência mecânica } \\
\text { Permeabilidade }\end{array}$ \\
\cline { 2 - 5 } & $0,05 \mu \mathrm{m}-0,01 \mu \mathrm{m}$ & $\begin{array}{c}\text { Capilares médios } \\
\text { (mesoporos) }\end{array}$ & $\begin{array}{c}\text { Gera moderadas } \\
\text { forças de tensão } \\
\text { superficial }\end{array}$ & $\begin{array}{c}\text { Resistência mecânica } \\
\text { Permeabilidade } \\
\text { Retração em umidades } \\
\text { elevadas }\end{array}$ \\
\cline { 2 - 5 } Poros de Gel & $2,01 \mu \mathrm{mm}-2,5 \mathrm{~nm}$ & $\begin{array}{c}\text { Capilares pequenos } \\
\text { (gel) }\end{array}$ & $\begin{array}{c}\text { Gera fortes forças de } \\
\text { tensão superficial }\end{array}$ & $\begin{array}{c}\text { Retração em umidade } \\
\text { relativa de } 50 \%\end{array}$ \\
\cline { 2 - 5 } & $<0,5 \mathrm{~nm}$ & Microporos & $\begin{array}{c}\text { Forte adsorção de } \\
\text { água sem formação } \\
\text { de meniscos }\end{array}$ & $\begin{array}{c}\text { Retração } \\
\text { Fluência }\end{array}$ \\
\hline
\end{tabular}

Considerando o equipamento utilizado na determinação da distribuição de tamanho de poros por intrusão de mercúrio, cujo diâmetro mínimo mensurável é de 3,6 nm, observa-se na Figura 32 que o volume de mercúrio intrudido na faixa de poros entre 3,6 e $10 \mathrm{~nm}$ é grande (capilares pequenos). Somando-se a estes, também os poros capilares médios, que abrange a faixa entre 10 e $50 \mathrm{~nm}$ 
(mesoporos), o volume total destes poros é $8,9 \%$, o que confere ao fibrocimento grande potencial de retração na secagem devido às forças capilares geradas nos poros destas dimensões (poros de gel e mesoporos). Considerando as limitações desta técnica, há poros de dimensões abaixo do detectável pela porosimetria por intrusão de mercúrio, denominados de microporos. No entanto, segundo (Mindess, 1981) nesta faixa de poros não há formação de meniscos, causadores de pressão capilar.

O objetivo principal deste capítulo é medir o efeito da porosidade e distribuição de tamanho de poros característicos do fibrocimento na retração por secagem, de investigar as possibilidades de interferir na retração manipulando o tamanho dos poros por empacotamento de partículas ou carga de compressão durante a etapa de compactação do processo produtivo.

\subsection{Metodologia}

Para analisar e compreender os efeitos das características do fibrocimento reforçado com fibras de celulose e sintéticas de PVA na retração por secagem deste compósito, este capítulo está dividido em 4 partes:

- Medir como ocorre a retração por secagem de amostras de fibrocimento fabricadas industrialmente, a fim de observar a variação desta propriedade do fibrocimento, a partir de um grande número de amostras;

- Medir o potencial de redução da retração alterando o processo e a formulação, usando variáveis com potencial de aplicação na indústria;

- Elaboração da isoterma de secagem do fibrocimento, de modo a verificar a influência da umidade relativa do ar na retração por secagem.

\subsubsection{Retração por secagem em fibrocimento industrial}

Para demonstrar como ocorre a retração por secagem no fibrocimento reforçado com fibras de PVA, foi elaborado um diagrama de retração por secagem a partir de uma grande massa de dados de estudos realizados em pelo menos de 5 anos de atividade do projeto Cimento-Celulose.

Durante o período de 5 anos de atividades do projeto Cimento-Celulose, foram realizados muitos estudos com diferentes objetivos, aonde se estudou a retração por secagem do fibrocimento. De modo a observar de maneira representativa qual é a 
magnitude da retração por secagem e qual é a variabilidade desta propriedade ao longo do tempo, em escala industrial, foi reunida uma grande massa de dados destes vários estudos que foram expressos como um diagrama de retração. Ao todo foram ensaiadas 99 amostras de fibrocimentos submetidas à secagem e determinação da retração, com condições ambientais de secagem idênticas (temperatura: $23^{\circ} \mathrm{C}$; umidade relativa: $50 \%$ ), no entanto, com umidade inicial das amostras que variou entre aproximadamente 18 e $28 \%$ em função de variações nos procedimentos de ensaio ocorridas durante este longo período de testes.

Este estudo foi realizado com amostras de fibrocimento produzidos industrialmente pelo processo Hatschek, por uma fábrica de telhas de fibrocimento reforçado com fibras de celulose e fibras poliméricas de PVA. Os procedimentos de coleta e cura das amostras foram padronizados, sendo que estas foram coletadas a partir da manta fresca, antes da conformação das telhas (ondulação), em placas de aproximadamente $25 \times 25 \mathrm{~cm}$ (procedimento detalhado descrito no item 2.2.1).

Devido ao extenso período de acompanhamento da retração por secagem, e por se tratar de amostras produzidas em fábricas de fibrocimento, a formulação das amostras testadas e outros parâmetros de processo de fabricação sofreram variações ao longo do tempo. Estas variações incluem formulações com e sem adição de sílica ativa, mudança do tipo de cimento, pequenas variações nas quantidades de todas as matérias-primas, ensaios realizados na direção longitudinal e na direção transversal das fibras de reforço, amostras tratadas com hidrofugantes, amostras curadas em temperatura ambiente e submetidas à cura térmica à temperatura de $60^{\circ} \mathrm{C}$.

\subsubsection{Estratégias para reduzir a retração variando a porosidade do} fibrocimento

Com o objetivo de medir esta correlação da porosidade com a retração por secagem, foram produzidas 2 séries de amostras, onde a primeira variou a carga de compactação aplicada na produção das amostras de fibrocimento, e a segunda variou a finura do calcário utilizado na formulação. Ambas as estratégias foram adotadas com intuito de obter amostras de fibrocimento com diferentes níveis de porosidade. 
Série $1 \rightarrow$ Foram produzidos fibrocimentos com formulações idênticas (formulação padrão - Tabela 6), no entanto, a carga de compactação das amostras durante o processo de fabricação variou nos níveis a seguir. $O$ tempo de carregamento foi em todos os casos, 1 minuto de acréscimo de carga, e mais 1 minuto com a deformação constante:

- $5 \mathrm{kN}$ (tensão 0,125 MPa)

- $20 \mathrm{kN}$ (tensão 0,5 MPa)

- $40 \mathrm{kN}$ (tensão 1,0 MPa)

- 100 kN (tensão 2,5 MPa)

Série $2 \rightarrow$ Foram produzidos fibrocimentos com formulações idênticas quanto às proporções (formulação padrão - Tabela 6), no entanto o tipo de calcário usado nas amostras variou, em função da finura, nos seguintes níveis (dimensão equivalente ao diâmetro de maior frequência na distribuição de tamanho de partículas), conforme exposto na Figura 33:

- $4,0 \mu \mathrm{m}$

- $26,8 \mu \mathrm{m}$

- $65,5 \mu \mathrm{m}$

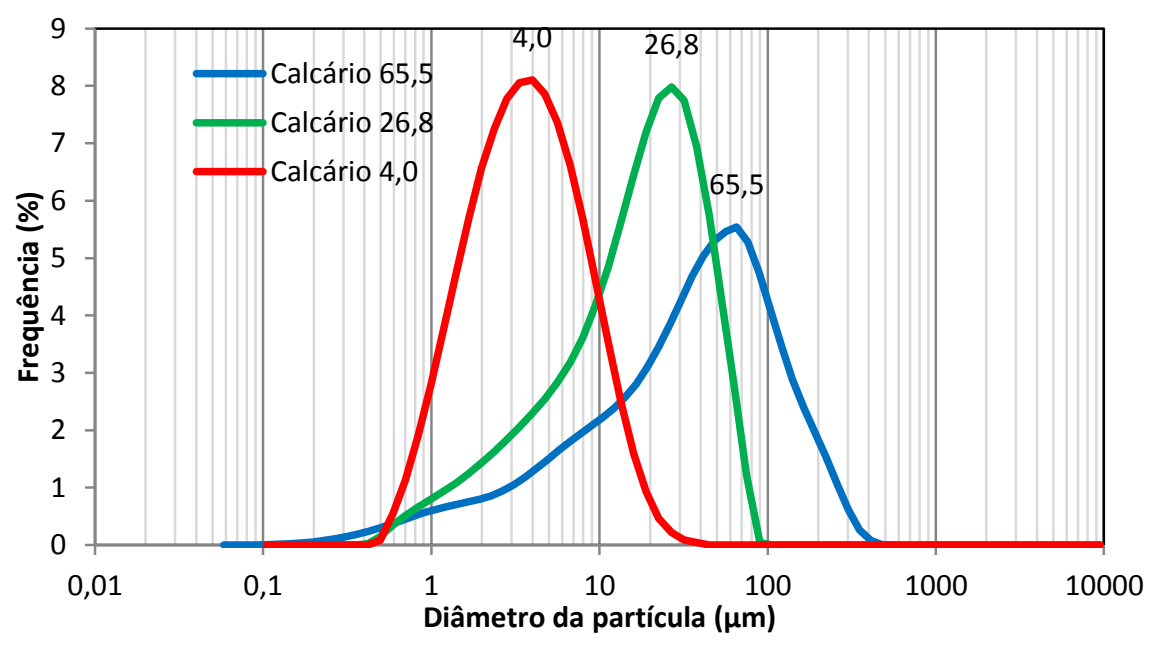

Figura 33 - Distribuição de tamanho de partículas dos diferentes calcários utilizados nas formulações de fibrocimento

A formulação adotada nestes estudos foi denominada de formulação padrão, composta por cimento Portland CPII E-32, calcário, sílica ativa, fibras de celulose e PVA (Tabela 6). A caracterização destes materiais está exposta no item 4.1.4.2. 
Tabela 6 - Formulação padrão do fibrocimento, em massa

\begin{tabular}{|c|c|c|c|}
\hline Cimento & Sílica ativa & Calcário & Celulose + PVA \\
\hline $60 \%$ & $5 \%$ & $30,2 \%$ & $4,8 \%$ \\
\hline
\end{tabular}

As amostras estudadas foram produzidas em laboratório e foram submetidas ao plano experimental exposto na Figura 34. Foram moldados 8 corpos-de-prova de cada amostra, sendo que estes foram submetidos ao ensaio de retração por secagem, com a determinação da retração na primeira secagem no período de 14 dias. Após o ciclo da primeira secagem, foi determinada a porosidade total por princípio de Arquimedes dos mesmos corpos-de-prova, que em seguida foi rompido à flexão, para determinação da resistência mecânica. De dois corpos-de-prova, antes da ruptura à flexão, foram extraídas duas amostras de aproximadamente $1 \mathrm{~g}$, para o ensaio de porosimetria por intrusão de mercúrio (MIP). Os métodos de ensaio estão detalhados nos itens 2.2.2, 2.4.1, 2.4.2 e 2.4.4.

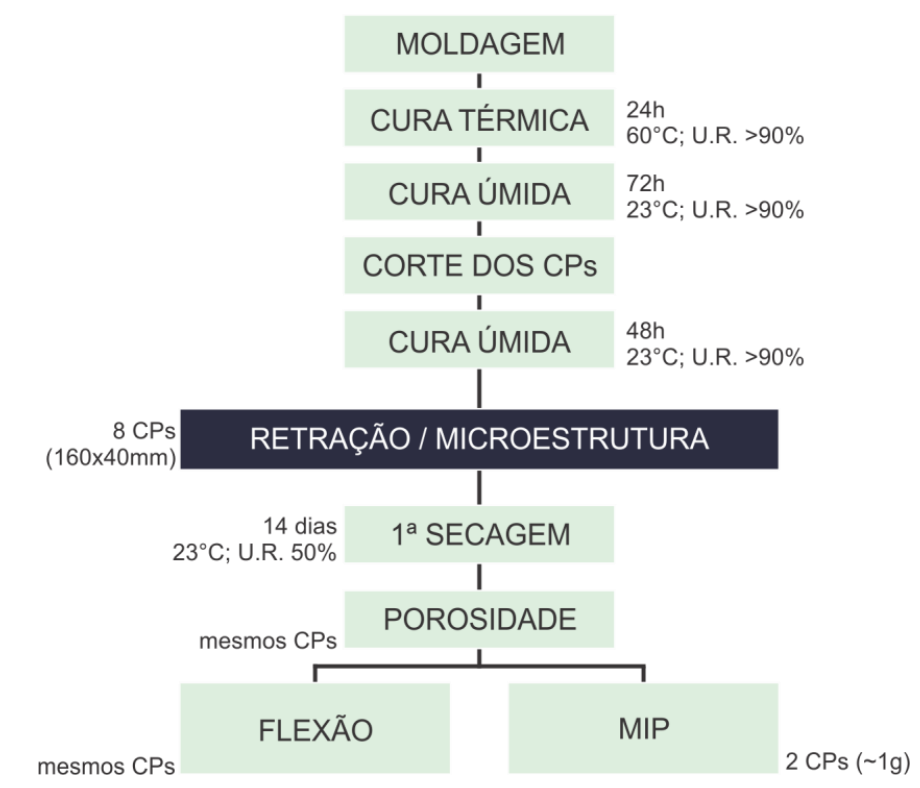

Figura 34 - Plano experimental do estudo de influência da porosidade na retração por secagem o fibrocimento

3.2.1. Influência da umidade relativa do ar na retração por secagem

No mesmo intuito de descrever como ocorre a retração por secagem no fibrocimento reforçado com fibras de PVA, foram geradas duas isotermas de secagem do fibrocimento. 
A primeira isoterma de secagem foi gerada a partir de um conjunto de 8 corposde-prova foi submetido à secagem em câmara climática, a $23^{\circ} \mathrm{C}$ e com umidade relativa variável. A umidade relativa do ar variou nos seguintes patamares, segundo a rampa descrita na Figura 35. O valor de umidade relativa foi alterado quando as amostras atingiram constância de massa, que no primeiro patamar (70\%) aconteceu em após 11 dias de secagem, enquanto que nos demais dias ocorreu após 7 dias de secagem.

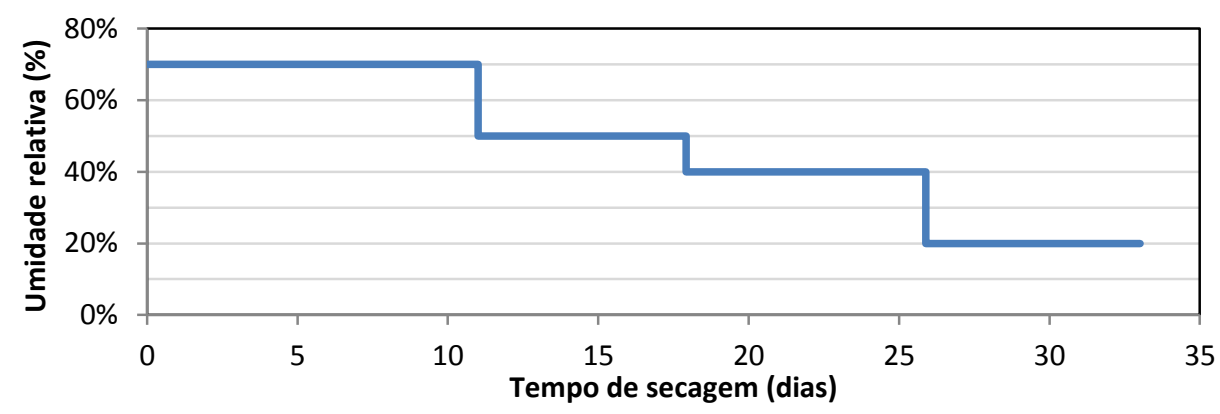

Figura 35 - Patamares de umidade relativa do ar durante a secagem

A segunda isoterma de secagem foi gerada a partir de 4 amostras de fibrocimento, compostas por 8 corpos-de-prova cada uma. Cada amostra foi submetida à secagem em câmara climática sob condições ambientais diferentes:

- Amostra UR70 $\rightarrow$ temperatura $23^{\circ} \mathrm{C}$; U.R. $70 \%$

- Amostra UR50 $\rightarrow$ temperatura $23^{\circ} \mathrm{C}$; U.R. $50 \%$

- Amostra UR40 $\rightarrow$ temperatura $23^{\circ} \mathrm{C}$; U.R. $40 \%$

- Amostra UR20 $\rightarrow$ temperatura $23^{\circ} \mathrm{C}$; U.R. $20 \%$

Todas as amostras adotaram a mesma formulação, denominada de formulação padrão, composta por cimento Portland CPII E-32, calcário, sílica ativa, fibras de celulose e PVA (Tabela 6).

As amostras estudadas foram produzidas em laboratório e foram submetidas ao plano experimental exposto na Figura 36. Foram moldados 8 corpos-de-prova de cada amostra, sendo que estes foram submetidos ao ensaio de retração por secagem, com a determinação da retração na primeira secagem no período de 14 dias, conforme descrição detalhada no item 2.4.1. 


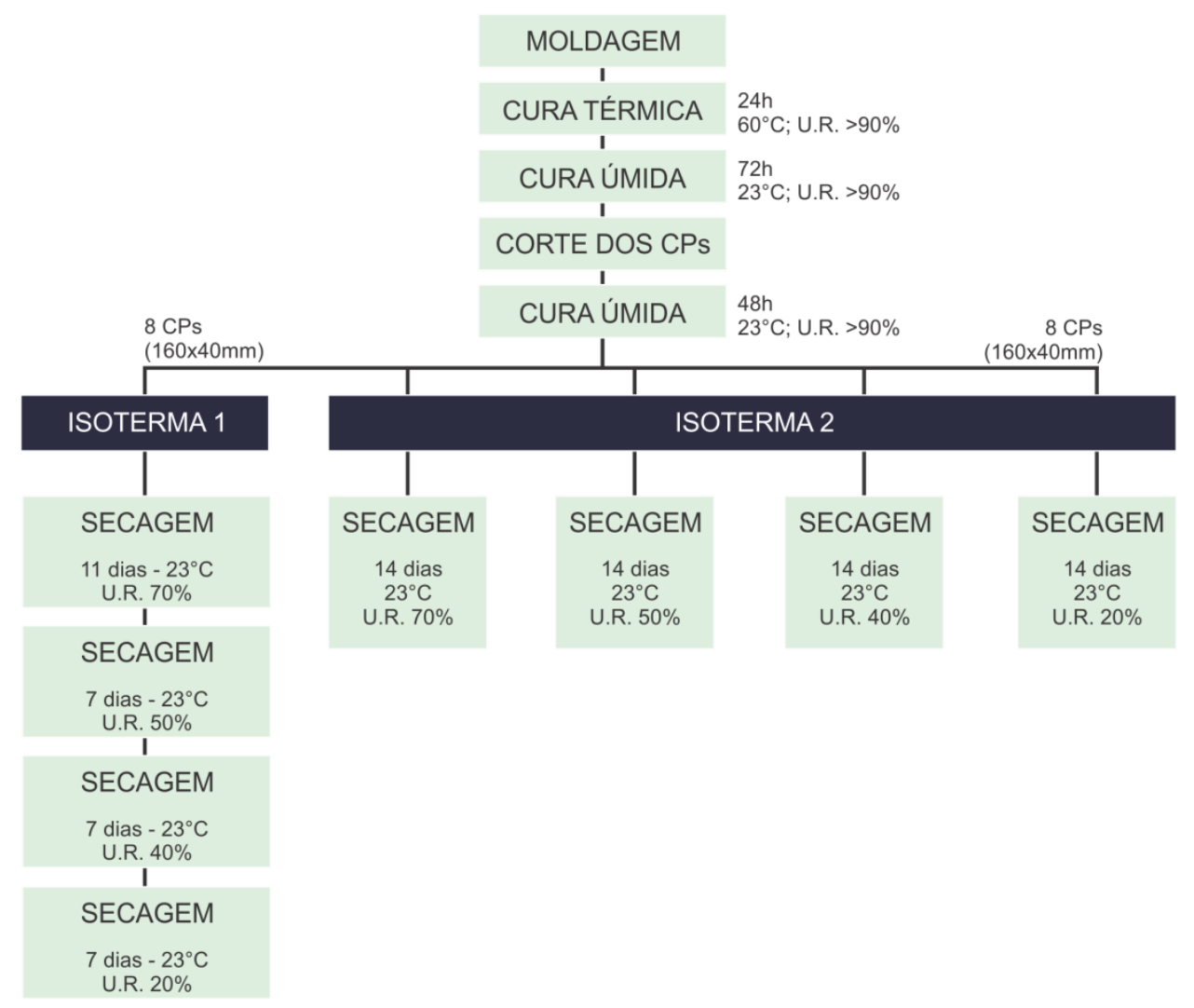

Figura 36 - Plano experimental para a elaboração das isotermas de secagem do fibrocimento

\subsection{Retração por secagem em fibrocimento industrial}

$\mathrm{Na}$ busca de um valor médio representativo da retração por secagem do fibrocimento NT, reforçado com fibras de celulose e PVA, foi realizado extenso estudo de acompanhamento dos valores de retração por secagem deste compósito produzido por uma unidade industrial fabricante de telhas onduladas de fibrocimento. Dentro das atividades do projeto Cimento-Celulose, durante um período de 5 anos de acompanhamento, foi realizado o ensaio de retração por secagem de diversos estudos isolados ${ }^{16}$, sempre com procedimentos padronizados de coleta, cura e manejo das amostras, de modo a compor uma grande massa de dados. Ao todo foram ensaiados 99 corpos-de-prova de fibrocimento produzido em escala industrial, pelo processo Hatschek, que ficaram expostos em condições idênticas de secagem (temperatura: $23^{\circ} \mathrm{C}$; umidade relativa: $50 \%$ ), por período variável de tempo, dependendo dos objetivos de cada estudo. A partir da análise destes resultados, definiu-se o período de secagem para a determinação da retração, a exposição por

\footnotetext{
${ }^{16}$ Estudos realizados dentro do projeto Cimento Celulose, de acompanhamento de diversas propriedades do fibrocimento, incluindo a retração por secagem, em situações de mudança de matérias-primas, parâmetros de processo, formulação, ou outras variáveis inerentes ao processo de produção de telhas onduladas de fibrocimento NT
} 
14 dias nas condições ambientais citadas, período no qual a perda de água já estabilizou e a retração ocorre em taxa bastante reduzida. Uma vez que não houve qualquer restrição ao contato com o dióxido de carbono do ar, todos os resultados possuem a interferência da retração por carbonatação, que majora um pouco o valor final. Entretanto, esta parcela é pequena devido à baixa concentração de $\mathrm{CO}_{2}$ no ar (condição de carbonatação natural) e devido ao curto período de exposição.
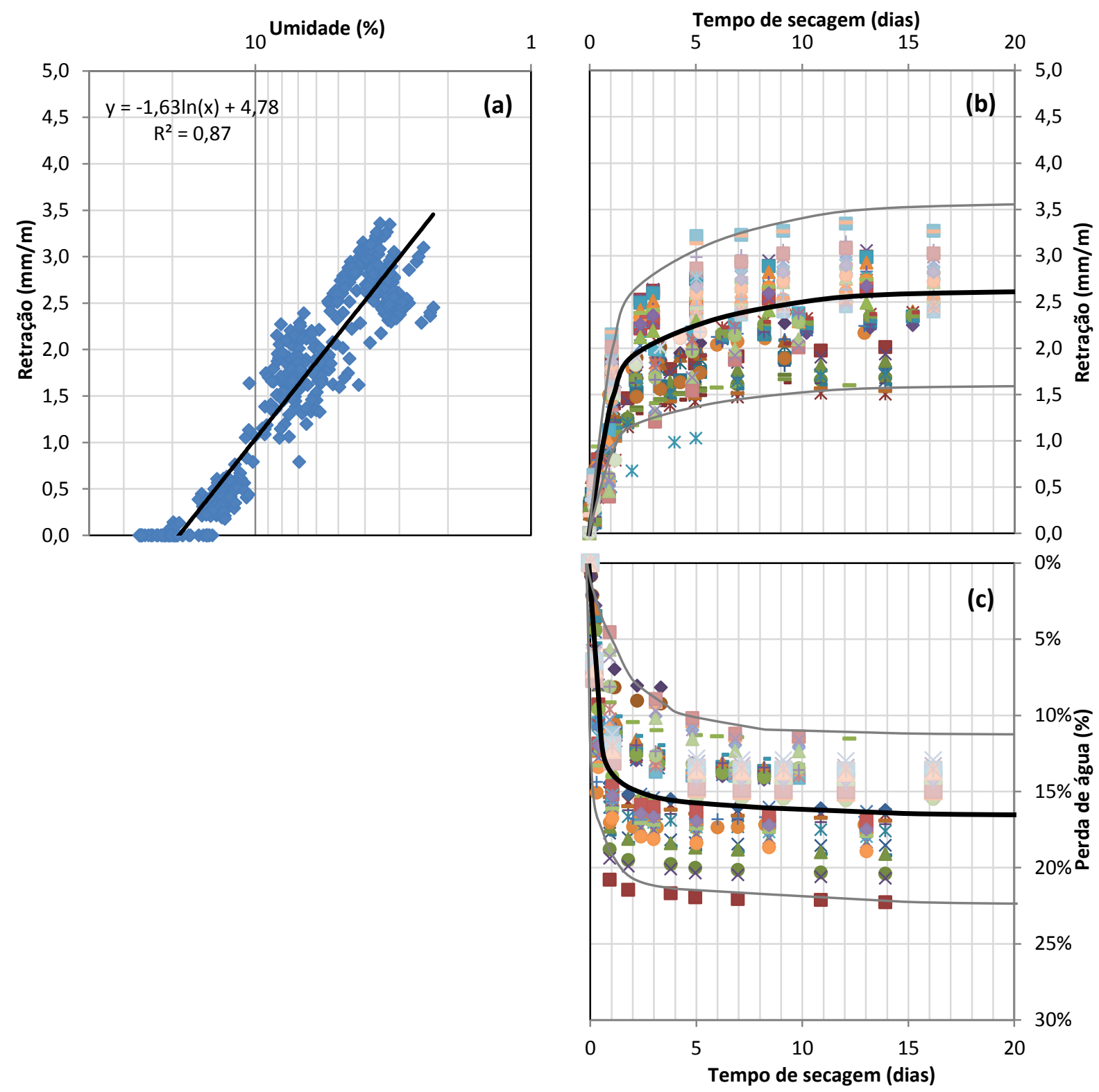

Figura 37 - Diagrama de retração por secagem de fibrocimentos reforçados com PVA (99 corposde-prova de fibrocimento produzidos em fábrica). (a) Relação entre a retração por secagem e a umidade do fibrocimento; (b) Retração em função do tempo de secagem; (c) Perda de água em função do tempo de secagem

A compilação desta massa de dados está apresentada na Figura 37, através de um diagrama de retração por secagem, que mostra como ocorre a perda de água 
em função do tempo de secagem (Figura 37.c), a retração em função do tempo de secagem (Figura 37.b) e a relação entre a umidade do fibrocimento e a retração por secagem (Figura 37.a).

A cinética de secagem do fibrocimento é o modo como este perde água para o ambiente em função do tempo, e pode ser descrita em duas etapas, sendo a primeira referente à perda de água nos dois primeiros dias de secagem, que é muito intensa. Neste período a perda de água do fibrocimento é de $14,9 \%$ da massa de amostra (média dos valores apresentados na Figura 37.c aos 2 dias de secagem), o que equivale a $92 \%$ de toda a perda de água no período de 14 dias. A segunda etapa se refere à secagem nos dias subsequentes, que equivale à perda de água de $1,3 \%$, em relação à massa de amostra.

O intervalo entre os valores mínimos e máximos de perda de água é bastante grande, de aproximadamente $11 \%$. Esta grande amplitude reflete a variabilidade das propriedades do fibrocimento produzido industrialmente, especialmente a porosidade. Durante o longo período de teste, a formulação e alguns parâmetros de processo sofreram alterações, que podem ter refletido em diferenças na porosidade. Algumas destas fontes de variabilidade são o consumo de cimento nas formulações, o tipo de cimento utilizado, a quantidade de adições minerais da formulação, como exemplo a sílica que aumenta significativamente a retração, e foi utilizada em quantidades que variaram de 0 a $5 \%$ entre as amostras ensaiadas, o teor de fibras na formulação, além do teor de água, e outros ajustes intrínsecos ao processo. Desta forma, a variabilidade exposta na Figura 37.c representa as alterações inerentes ao processo produtivo quando este funciona em regime constante, somada às alterações às quais o processo produtivo de modo geral está sujeito ao longo do tempo, como a necessidade da troca do tipo de cimento a ser utilizado na produção, por exemplo.

A cinética de retração obviamente está relacionada com a perda de água, e também possui um perfil dividido em duas etapas. A primeira etapa é a retração que acontece nos dois primeiros dias de secagem, onde esta variação dimensional ocorre com taxa elevada, reduzindo seu comprimento em 1,95 mm/m (média dos valores apresentados na Figura 37.b aos 2 dias de secagem). Esta retração equivale a $76 \%$ do total medido aos 14 dias de secagem. A segunda etapa é aquela 
retração ocorrida nos dias subsequentes, onde o fibrocimento ainda retrai mais $0,60 \mathrm{~mm} / \mathrm{m}$.

A retração por secagem também apresentou grande variabilidade nos resultados durante todo o teste, com amplitude de aproximadamente $2 \mathrm{~mm} / \mathrm{m}$. Esta variabilidade também é decorrente das diferenças nas propriedades do fibrocimento durante o período de acompanhamento deste teste, e reflete a grande amplitude dos valores de perda de água, uma vez que a retração é função da tensão capilar gerada na secagem.

As diferenças na velocidade de secagem e velocidade de retração mostram que a correlação entre ambas não é linear. Embora seja direta, ou seja, quanto maior é a perda de água, maior é a retração, esta correlação não é linear porque a velocidade de secagem nos instante iniciais é muito maior que a velocidade de retração. Em dois dias de secagem a perda de água é superior a $90 \%$ do total, enquanto a retração nesta etapa é de aproximadamente $75 \%$ do total. A correlação entre a retração e a secagem é representada através da curva de retração em função do nível de umidade do fibrocimento, exposta na Figura 37.a. A retração por secagem apresenta uma correlação contínua logarítmica com a variação de umidade, que mostra que ao passo que o nível de umidade decresce, a retração aumenta em taxa mais elevada.

Das curvas apresentadas no diagrama de retração por secagem, somente a partir da Figura 37.a é possível perceber que vários pontos se agrupam entre 20 e $28 \%$ de umidade, com retração nula. Este comportamento induz à conclusão de que a perda de água nesta faixa de umidade não causa retração, e que esta ocorre primeiro em poros de maior dimensão, em concordância com a teoria publicada sobre tensão capilar, que diz que ocorre retração somente a partir da secagem de poros pequenos, de dimensões capilares (Mindess, 1981).

A curva retração $X$ umidade (Figura 37.a) mostra que dentre todas as amostras ensaiadas, a umidade inicial variou desde 17 até $29 \%$, mas que independente disso, a redução volumétrica das amostras só se iniciou quando estas atingiram umidade em torno de 17 a $20 \%$. A partir da teoria publicada sobre a tensão capilar como causa da retração, este comportamento na secagem dos fibrocimentos se dá pela hipótese de que tanto as amostras com umidade inicial próxima da condição de saturação, como aquelas com umidade mais baixa, iniciaram seus processos de 
retração a partir do momento em que os poros de dimensão capilar começaram a sofrer secagem, e esta condição aconteceu no mesmo nível de umidade entre todas as amostras. A partir destes resultados, nota-se que variações na umidade inicial das amostras não se refletem em variabilidade nos valores de retração medidos, desde que estas variações ocorram em nível de umidade acima de aproximadamente $20 \%$, em relação à massa da amostra.

A Figura 38 é a representação de um dos estudos contidos no diagrama de retração por secagem (Figura 37), e ilustra bem a perda de água inicial. Dentre todos os estudos que compõem o diagrama de retração, neste estudo foram feitas leituras de retração nos primeiros minutos de secagem, até o período de 9 dias de exposição. Foi possível observar que na primeira 1h30min não houve retração, mesmo para uma secagem de aproximadamente 6\%. A representação gráfica em escala logarítmica foi feita para evidenciar a faixa de perda de umidade sem resultar em retração, e mostrar que a regressão logarítmica calculada é adequada, uma vez que os dados se agrupam segundo uma tendência linear. Uma vez que estes dados são referentes a um único estudo, com menor número de corpos-de-prova, a regressão adotada para explicar como a retração é influenciada pela perda de umidade apresentou pequena diferença àquela exposta no diagrama de retração por secagem (Figura 37.a).

Tabela 7 - Umidade e retração do fibrocimento na saturação, no início da retração, após 2 dias de secagem e após 14 dias de secagem. Umidade em relação ao volume do fibrocimento calculada adotando-se densidade aparente de $1,5 \mathrm{~g} / \mathrm{cm}^{3}$

\begin{tabular}{cccc}
\hline \multirow{2}{*}{ Evento } & \multicolumn{2}{c}{ Umidade (\%) } & Retração \\
\cline { 2 - 3 } & $\begin{array}{c}\text { em relação à massa } \\
\text { do fibrocimento }\end{array}$ & $\begin{array}{c}\text { em relação ao volume } \\
\text { do fibrocimento }\end{array}$ & $\begin{array}{c}\mathrm{mm} / \mathrm{m}) \\
\text { Início secagem (CP saturado) }\end{array}$ \\
Início retração & $25 \%$ & $38 \%$ & 0 \\
2 dias de secagem & $18,8 \%$ & $28,2 \%$ & 0 \\
14 dias de secagem & $5,9 \%$ & $8,9 \%$ & 1,9 \\
\hline
\end{tabular}




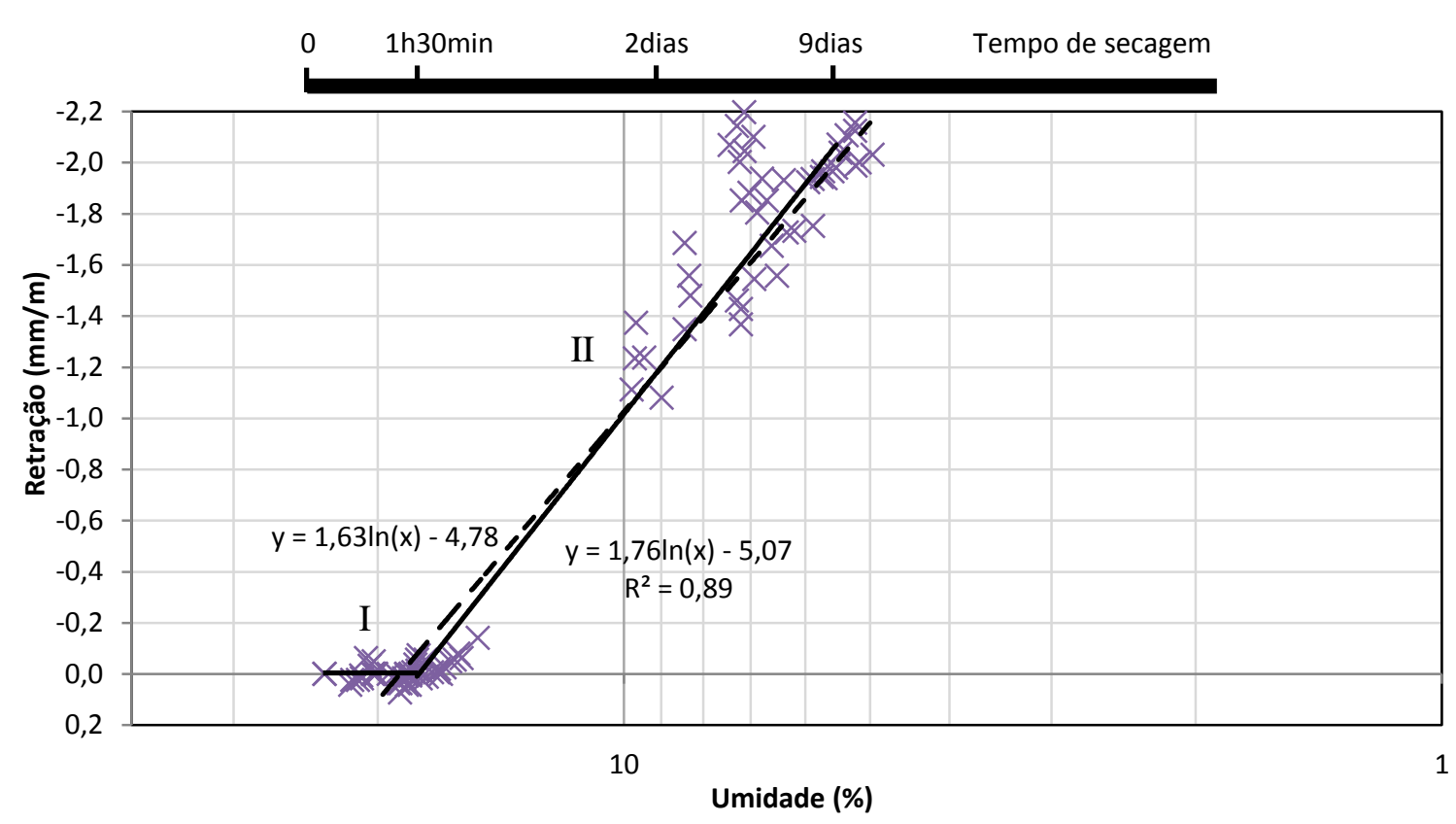

Figura 38 - Retração em função da redução da umidade dos corpos-de-prova. Trecho I - perda de umidade que não causa retração; Trecho II - Perda de umidade que causa retração segundo correlação logarítmica. A regressão logarítmica descrita no diagrama de retração (Figura 37) está representada nesta figura pela linha tracejada

A Tabela 7 reúne os dados de retração e umidade nos instantes considerados importantes na cinética de secagem e de retração do fibrocimento. Para a correlação direta com a porosidade do fibrocimento, os valores de umidade estão apresentados em relação ao volume da amostra. Desta forma, é possível observar que aos dois dias de secagem o fibrocimento atinge um nível de umidade de 5,9\% em massa (equivalente a $8,9 \%$ do volume do fibrocimento), e se reflete em retração de $1,95 \mathrm{~mm} / \mathrm{m}$. Segundo a regressão encontrada para este conjunto de amostras, a retração aos 14 dias de secagem é de $2,5 \mathrm{~mm} / \mathrm{m}$, para um nível de umidade de $4,0 \%$ em massa $(6,0 \%$ em volume).

A partir da distribuição de tamanho de poros de um fibrocimento NT (com fibras de PVA), apresentada nas Figura 32 e Figura 39, em conjunto com as informações apresentadas na Tabela 7, observa-se que um grande volume de poros do fibrocimento pode ser submetido à secagem, sem inferir retração ao compósito. Esta secagem ocorre nos poros com diâmetro superior a 2,33 $\mu \mathrm{m}$, e compreende aqueles poros referentes aos defeitos, à porosidade da celulose e parte dos poros classificados como macroporos (Figura 39.I). A partir de um determinado nível de umidade, a secagem do fibrocimento passa a se refletir em retração. Até os 2 dias 
de exposição em ambiente com umidade relativa do ar de 50\%, a secagem causa grande retração e ocorre nos poros com diâmetro entre 0,03 e 2,33 $\mu \mathrm{m}$. Esta faixa de poros compreende parte dos macroporos e parte dos mesoporos (Figura 39.II.a). Entre 2 e 14 dias de exposição, a secagem passa a ocorrer nos poros de menor dimensão, com maior potencial de retração pois a pressão capilar atuante é significativamente maior. A faixa de poros em que esta secagem é aquela entre $13,2 \mathrm{~nm}$ e $0,03 \mu \mathrm{m}$, e equivale à grande parte dos mesoporos (Figura 39.II.b).

A tensão capilar atuante em nos poros do compósito durante a secagem pode ser estimada, em função do tamanho do poro, aplicando a Equação 8 - Equação de Laplace. Para esta estimativa, de modo a correlacionar a tensão capilar estimada com os níveis de retração atingidos experimentalmente e expostos no diagrama de retração por secagem (Figura 37), e para a análise apresentada no parágrafo anterior, é necessário fazer algumas considerações e simplificações:

- A secagem ocorre primeiramente nos poros de maior volume, para depois acontecer nos poros imediatamente menores, e assim por diante;

- A pressão capilar causadora da retração considera apenas as variáveis contidas na equação de Laplace, apresentada na Equação 8;

- Os poros têm geometria cilíndrica;

- A porosidade total do fibrocimento é aquela determinada por porosimetria por intrusão de mercúrio. 


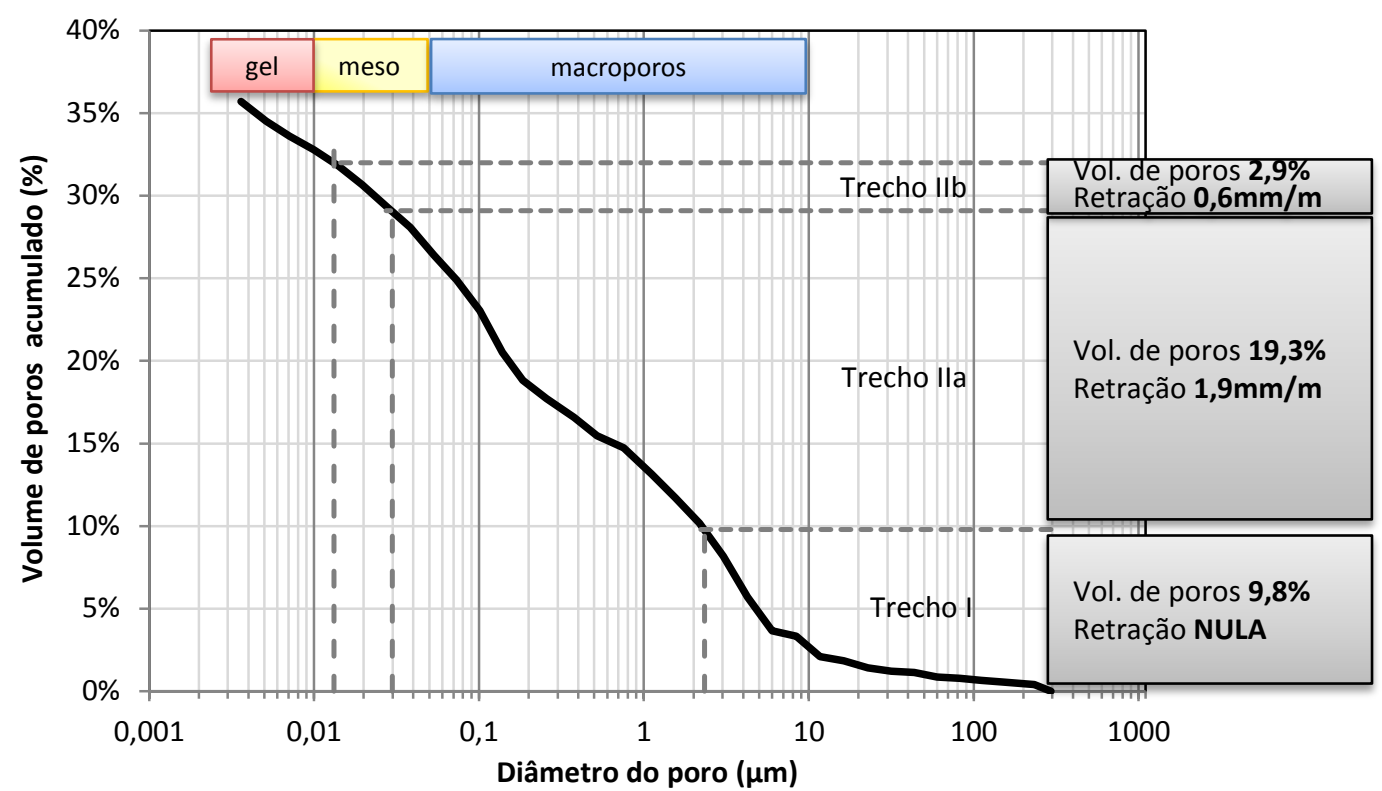

Figura 39 - Distribuição de tamanho de poros de fibrocimento reforçado com fibras de PVA, por porosimetria por intrusão de mercúrio (amostra produzida em fábrica). I - Intervalo de tamanho de poros que não causam retração por secagem; lla - Intervalo de tamanho de poros que resulta em retração na secagem em menor intensidade; llb - Intervalo de tamanho de poros que resulta em retração na secagem em maior intensidade

A primeira secagem, que ocorre na primeira 1,5 hora de exposição em ambiente com umidade relativa de 50\%, apesar de ocorrer em curto espaço de tempo, equivale a uma grande perda de água, em torno de $10 \%$ do volume do fibrocimento. Esta perda de água equivale a $28 \%$ do total de poros presentes no material, e não se reflete em retração, pois não há tensão capilar atuando nos poros em processo de secagem, segundo a estimativa de tensão capilar calculada e exposta na Figura 40. Considerando que esta secagem acontece predominantemente nos poros maiores (para efeito da estimativa realizada, a consideração é que a secagem ocorre exclusivamente nos poros maiores), a tensão capilar atuante é nula para esta faixa de poros, garantindo a estabilidade dimensional dos corpos-de-prova estudados.

Ao passo que a secagem progride, os poros de menor dimensão começam a perder água, e a tensão capilar começa a atuar nos poros, se refletindo em retração. A magnitude desta tensão capilar não é a mais elevada, no entanto, o volume de água evaporada é muito grande, equivalente a $53 \%$ dos poros existentes no material no trecho Il.a indicado na Figura 40. Nos níveis menores de umidade do fibrocimento a tensão capilar atua em maior intensidade (Figura 40), explicando o 
fato de uma perda de água pequena, de aproximadamente $8 \%$ do total de poros, se refletir em grande retração por secagem.

Para correlacionar como a perda de água e a tensão capilar atuante nos poros com a retração por secagem, foi calculado um fator, que corresponde à multiplicação da pressão capilar estimada pela equação de Laplace com o volume de poros que sofreram secagem. Desta forma faz-se a ponderação que considera que nos poros submetidos à menor pressão capilar ocorre maior secagem, enquanto que nos poros onde a tensão capilar tem maior intensidade, o volume de água evaporada é menor. Este fator de ponderação mostra que a parcela da tensão capilar que ocorre nos dois primeiros dias de secagem (trecho II.a; fator 0,13) tem mesma magnitude da parcela da tensão capilar que ocorre nos dias subsequentes, até 14 dias de secagem (trecho II.b; fator 0,11) (Figura 41.a).

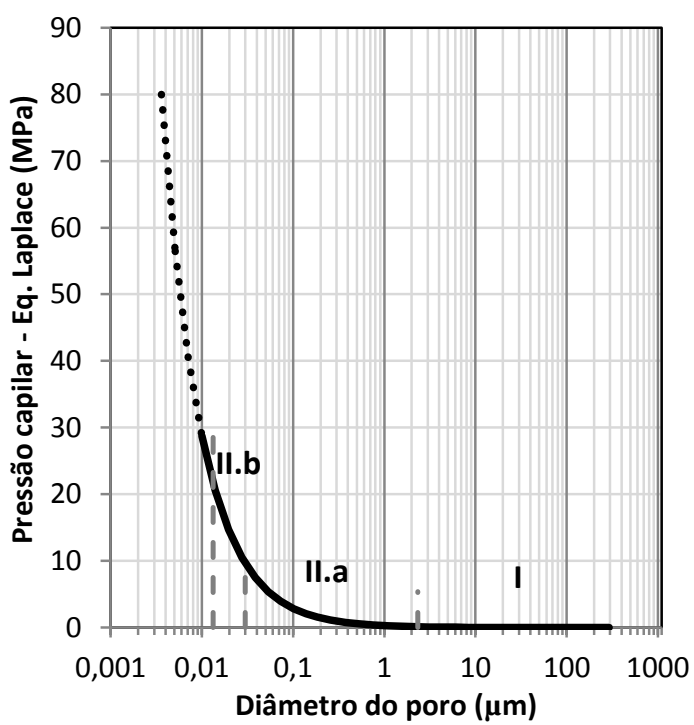

(a)

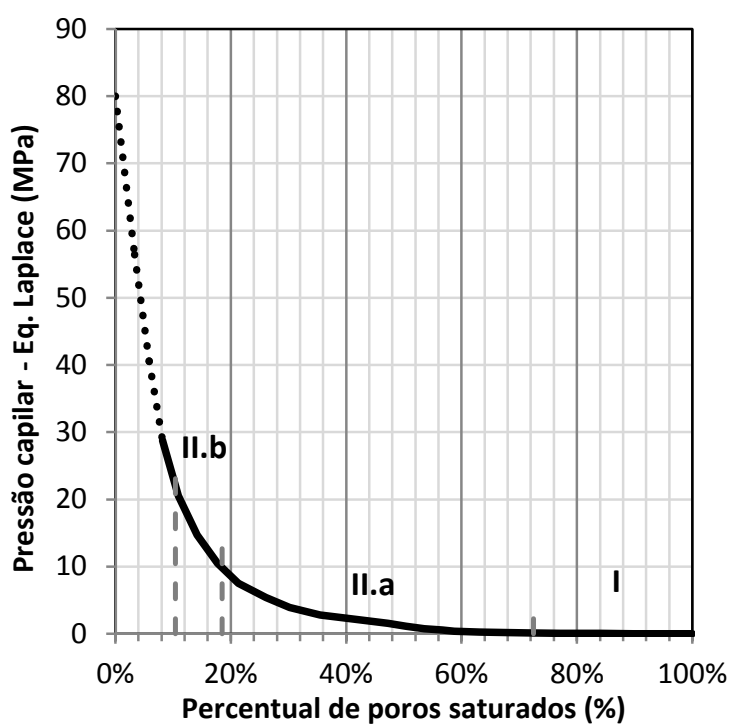

(b)

Figura 40 - Pressão capilar estimada, calculada a partir da equação de Laplace, (a) para cada faixa de tamanho de poro; (b) para o percentual de poros saturados. 0 trecho em pontilhado em ambas as curvas representa a região dos poros de gel e microporos, onde o mecanismo de depressão capilar governado pela equação de Laplace não é válido 


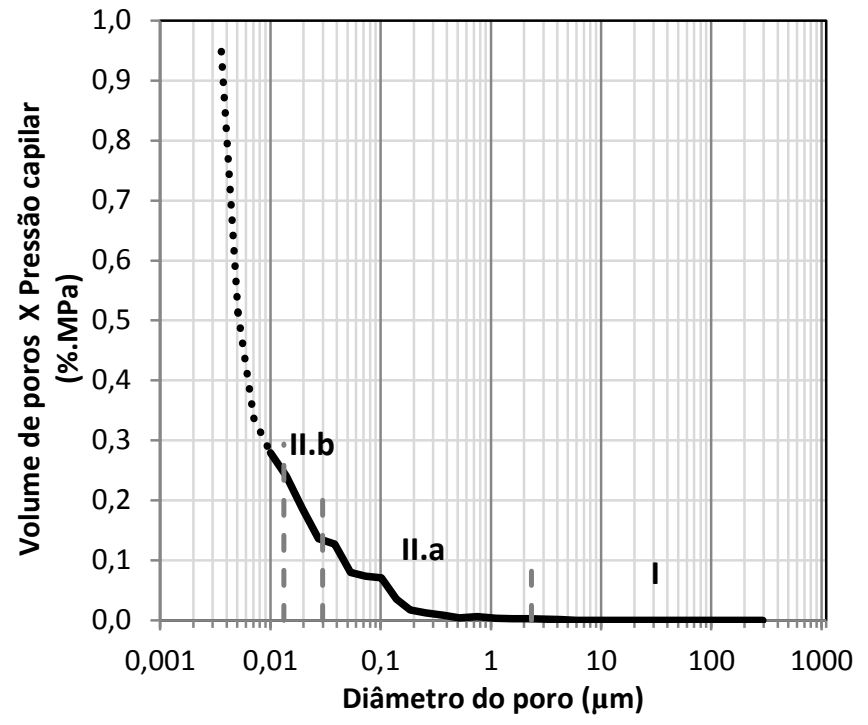

(a)

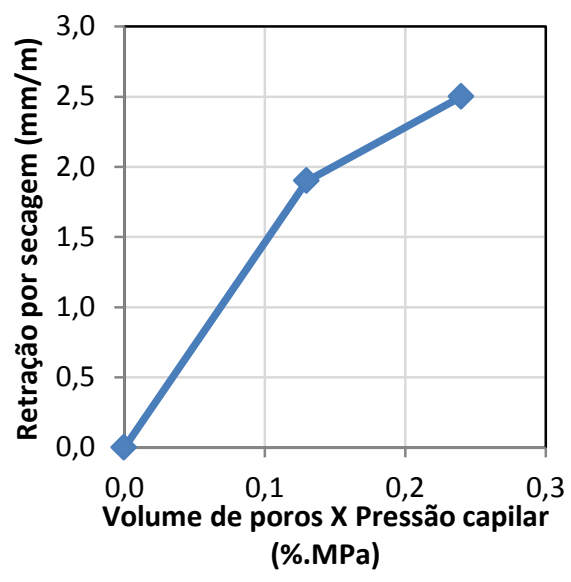

(b)

Figura 41 - (a) Volume de poros presentes no fibrocimento, multiplicado pela tensão capilar estimada para cada faixa de diâmetro de poro (o trecho em pontilhado na curva representa a região dos poros de gel e microporos, onde o mecanismo de depressão capilar governado pela equação de Laplace não é válido); (b) Correlação do fator 'volume de poros $\mathrm{X}$ pressão capilar' com a retração por secagem do fibrocimento

Toda esta análise realizada para gerar a correlação entre o fator 'volume de poros X tensão capilar' com a retração por secagem considerou a simplificação de que a secagem não ocorre simultaneamente entre os poros de diferente tamanho. Por este motivo, a correlação apresentada na Figura 41.b não foi linear. A curvatura do gráfico apresentado na Figura 41.b indica que este modelo simplificado de análise minora a tensão capilar inicial, ocorrida nos níveis maiores de umidade, e majora a retração final, nos níveis menores de umidade do fibrocimento.

No entanto, considerando o mecanismo de transporte de água nos poros de uma matriz cimentícia, entre a condição saturada e seca há os poros com diferentes níveis de umidade, com água adsorvida nas paredes sólidas e formação de meniscos (Gonçalves, 2011; Sato, 1998), o que indica que o processo de secagem ocorre simultaneamente em poros de diferentes diâmetros, incluindo os mesoporos, se refletindo em retração. O processo de secagem consiste na tendência constante do equilíbrio de pressão e umidade relativa dentro dos poros, conforme descreve a equação de Kelvin (Equação 9), sendo que esta condição de equilíbrio se modifica com a queda da umidade. Ao passo que os poros em contato com o ambiente secam, na tendência do equilíbrio da umidade relativa do ar, os poros internos interconectados a estes, também têm seus processo de secagem iniciado. 
$\mathrm{Na}$ secagem, quando os poros perdem a condição de saturação, ocorre a formação de meniscos, dividindo o volume do poro e duas regiões: uma com água e outra com ar e vapor d'água (Figura 42). Quando a umidade relativa do ar do poro é elevada, ocorre uma camada grande de água adsorvida nas paredes do poro (Sato, 1998) (Gonçalves, 2011) devido às forças adesivas da matriz cimentícia com a água, que pode preencher o poro formando menisco. Com o avanço da secagem, o vapor d'água dos poros é perdido para a atmosfera (ou para poros maiores), o que tem como consequência a evaporação de parte da camada de água adsorvida nas paredes do poro, e diminuição dos raios dos meniscos (Figura 42), aumentando consequentemente a tensão capilar.

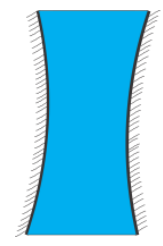

(a)

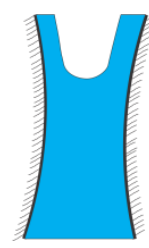

(b)

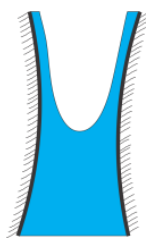

(c)

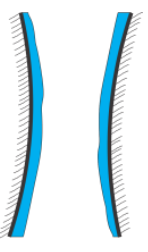

(d)

Figura 42 - Secagem do poro capilar e formação do menisco. (a) Poro saturado; (b) formação de menisco; (c) redução do raio do menisco; (d) quebra da tensão capilar. Adaptado (Gonçalves, 2011)

A taxa de retração é a inclinação da curva de retração $X$ umidade apresentada na Figura 37. Este índice reflete o que a teoria sobre tensão capilar preconiza e modela segundo a equação de Kelvin (Equação 9), onde a tensão capilar causadora de retração aumenta com a redução da umidade relativa dentro dos poros da matriz. A taxa de retração foi calculada a partir da derivada da regressão logarítmica apresentada na Figura 37, e mostra que para níveis maiores de umidade da amostra, a retração por unidade de umidade perdida é menor em comparação com a amostra mais seca, com nível de umidade inferior (Figura 43). Em outras palavras, no início do processo de retração, as amostras encolhem aproximadamente $0,1 \mathrm{~mm} / \mathrm{m}$ para cada $1 \%$ de umidade perdida na secagem, enquanto que a partir do segundo dia de secagem, quando a umidade da amostra já é baixa $(\leq 7 \%)$, o fibrocimento pode encolher até $0,6 \mathrm{~mm} / \mathrm{m}$ para cada $1 \%$ de umidade perdida na secagem (Figura 43).

Além do nível de umidade relativa dentro do poro, segundo a equação de Laplace a tensão capilar é função do raio dos poros. Apesar do processo de secagem incidir simultaneamente em poros de diferentes tamanhos, no caso dos 
poros maiores a secagem ocorre mais facilmente (Groot; Larbi, 1999), pois a velocidade de evaporação é menor nos poros menores porque estes têm menor área para a evaporação da água. Além disso, proporcionalmente ao volume do poro, há mais água absorvida nas paredes, dificultando a movimentação higroscópica nestes poros de pequeno tamanho.

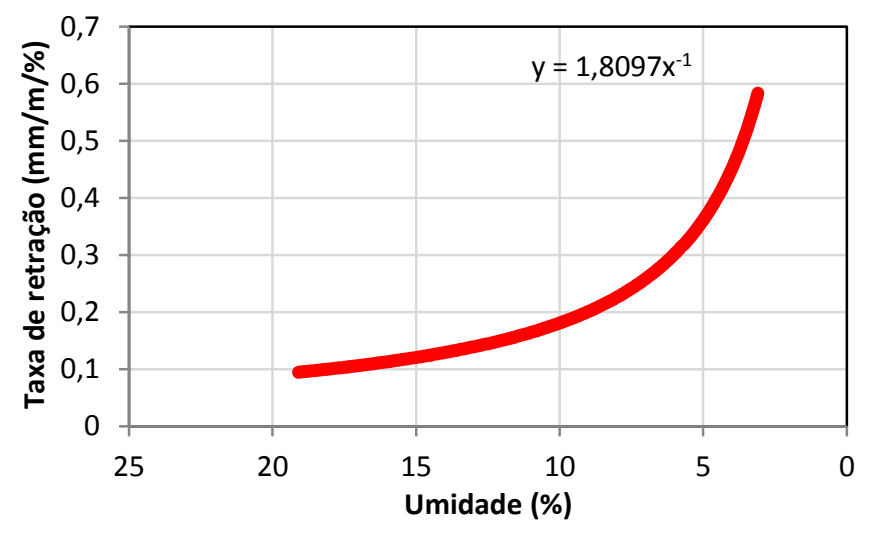

Figura 43 - Taxa de retração em função da umidade. Derivada da regressão encontrada para a curva de retração $X$ umidade

\subsection{Influência da porosidade na retração do fibrocimento}

Como discutido anteriormente, o fato do fibrocimento ser um compósito constituído em grande parte por uma matriz cimentícia, este possui um elevado volume de poros de dimensões capilares, ou seja, suscetíveis à ação da tensão capilar. Em função disso, a porosidade do fibrocimento é a sua propriedade que apresenta melhor correlação com a retração, uma vez que durante a sua secagem a tensão capilar gerada é a causa da retração em escala macroscópica.

Uma vez que uma parte significativa dos poros do fibrocimento é suscetível à pressão capilar, a redução da porosidade total deste compósito se reflete em redução da retração por secagem. No processo industrial é possível adotar medidas que podem reduzir a porosidade dentro de certos limites, como o aumento da pressão aplicada durante a compactação da manta fresca, ou ainda melhorando o empacotamento de partículas com a utilização de matérias-primas com diferentes tamanhos, ou ainda reduzindo o consumo de cimento e o teor de fibras de celulose.

Dentre estas quatro estratégias apresentadas, a redução no consumo de cimento e do teor de celulose, não são viáveis. O cimento é o ligante do compósito, 
de modo que as propriedades mecânicas do fibrocimento estão diretamente relacionadas com 0 consumo de cimento. A sua redução pode comprometer 0 desempenho do fibrocimento em uso. A celulose é uma fibra de processo, ou seja, ela é necessária dentro do processo Hatschek para ajustar a reologia da manta e para reter finos no momento da filtração. O teor de celulose é ajustado de modo que o processo produtivo seja realizado adequadamente, sendo que qualquer alteração na sua quantidade se reflete diretamente no processo produtivo.

Com o objetivo de medir o potencial que a redução de porosidade tem na retração por secagem, foram produzidas duas séries de amostras, onde a primeira variou a carga de compactação aplicada na produção das amostras de fibrocimento, e a segunda variou o diâmetro médio do calcário utilizado na formulação, de modo a melhorar o empacotamento.

Ambas as estratégias geraram amostras com porosidades distintas, como mostra a Figura 44. O aumento da carga de compactação entre $5 \mathrm{kN}$ e $40 \mathrm{kN}$ resultou em uma redução da porosidade total do fibrocimento de 52,46\% para $38,05 \%$ (redução de 27\%) (Figura 44.a). Quando se alterou a finura do calcário, com a diminuição do tamanho de partículas entre $65,5 \mu \mathrm{m}$ até $4,0 \mu \mathrm{m}$, a porosidade total do fibrocimento caiu de $47,94 \%$ para $38,84 \%$ (redução de 19\%) (Figura 44.b).

As cargas aplicadas na compactação do fibrocimento no estado fresco foram de $5 \mathrm{kN}, 20 \mathrm{kN}, 50 \mathrm{kN}$ e $100 \mathrm{kN}$, que equivalem às tensões aproximadas de $0,12 \mathrm{MPa}$, 0,50 MPa, 1,00 MPa e 2,50 MPa, respectivamente. A aplicação da carga em todos os casos foi realizada por 2 minutos (1 minuto para atingir a carga máxima +1 minuto mantendo a deformação final da manta fresca). A formulação do fibrocimento foi a mesma em todas as amostras, indicada na Tabela 6, com consumo de calcário de $30,2 \%$ em massa. Nas amostras onde se variou o diâmetro médio do calcário, a formulação entre as amostras também foi a mesma, sendo apenas utilizado em cada amostra um calcário diferente. 


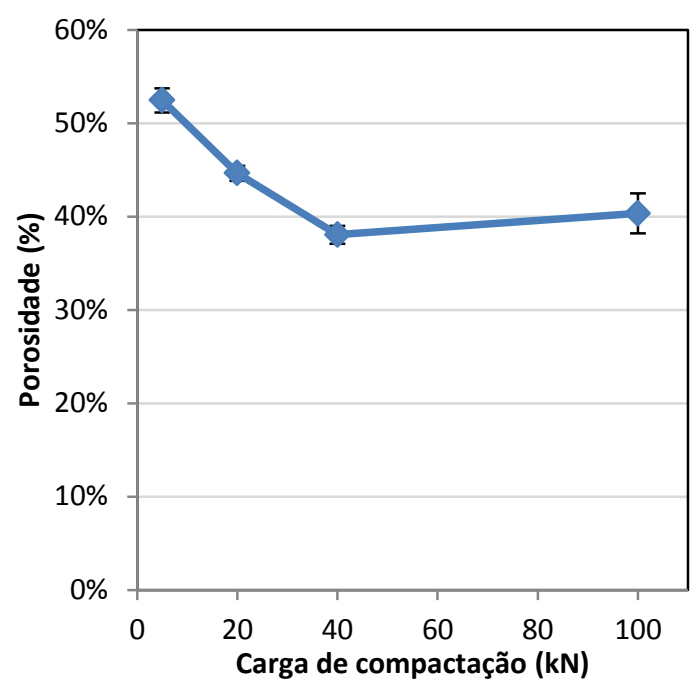

(a)

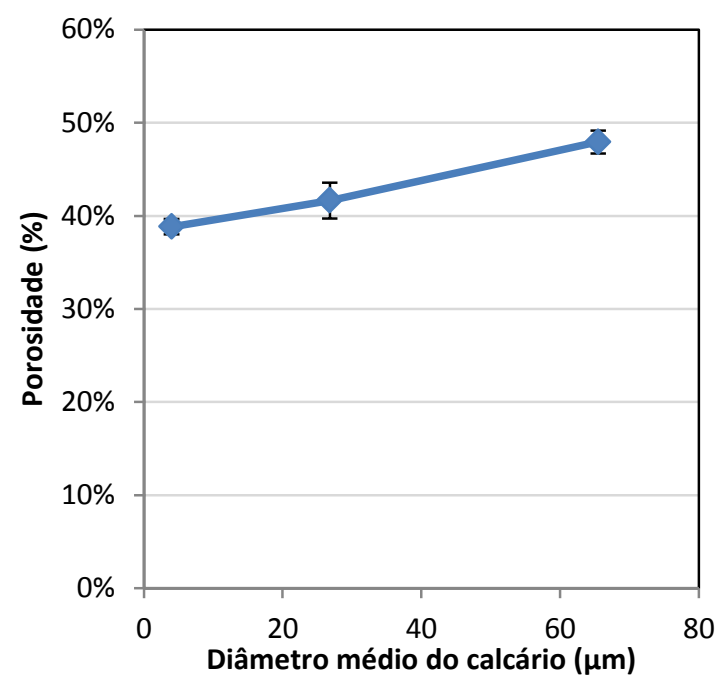

(b)

Figura 44 - Porosidade do fibrocimento em função da (a) variação da carga de compactação aplicada durante a produção das amostras; e (b) grau de empacotamento em função da finura do calcário, indicada pelo diâmetro de maior frequência do calcário,

Com o aumento da carga de compactação durante o processo de fabricação do fibrocimento, uma maior quantidade de água foi eliminada da amostra fresca, reduzindo uniformemente a sua porosidade no estado endurecido, como foi medido na Figura 44.a. O efeito do aumento da carga de compactação foi efetivo na redução da porosidade total do fibrocimento até o nível de $40 \mathrm{kN}$, pois acima deste patamar não houve redução na porosidade, o que pode ser atribuído ao fato deste nível de carga ter atingido o limite de deformação plástica do fibrocimento no estado fresco, com ocorrência de recuperação elástica. Este comportamento ocorreu, pois a redução da porosidade obtida foi reflexo da diminuição dos poros de tamanhos maiores, referentes aos defeitos e provavelmente ao lúmen da celulose (Dias, 2005), sendo que estes poros reduziram em quantidade até o carregamento de $40 \mathrm{kN}$, patamar em que se observou que estes poros foram eliminados.

A densidade aparente, que é aquela que considera a porosidade do material, também apresentou correlação com o aumento da carga de compactação. Para as maiores cargas, os mais elevados níveis de densidade aparente foram atingidos (Figura 45.a). Uma vez que a formulação se manteve constante entre todas as amostras, a microestrutura da fase sólida, desconsiderando a sua porosidade, não apresentou diferença na sua densidade (densidade real), como mostra a Figura 45.a. Variando a finura do calcário, o mesmo comportamento foi observado, com a melhoria do empacotamento da matriz ao passo que foi diminuído o tamanho das 
partículas, se refletindo em aumento da densidade aparente (Figura 45.b), sem apresentar grandes alterações na densidade real (Figura 45.b).

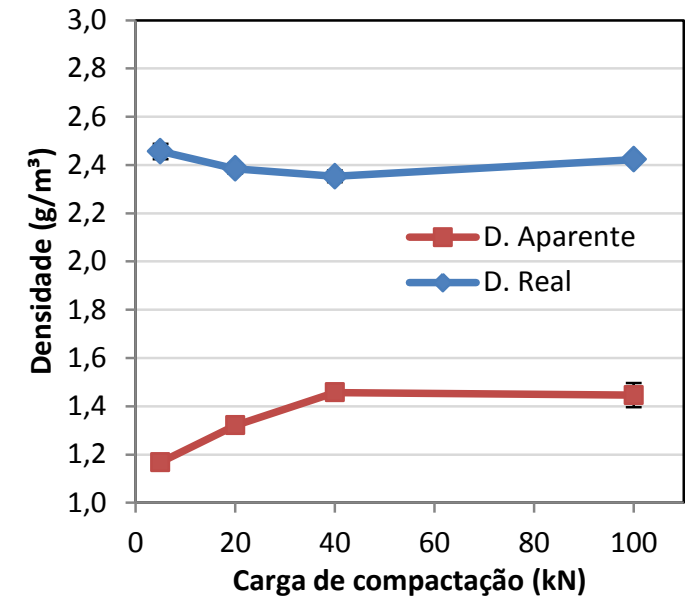

(a)

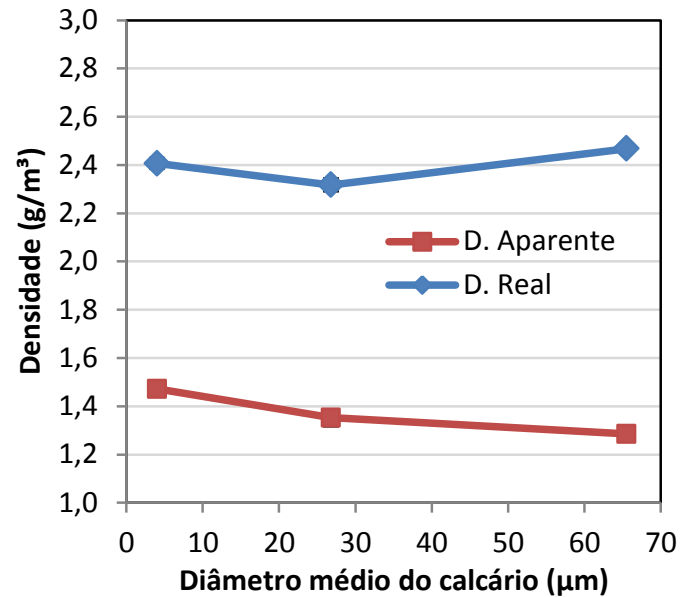

(b)

Figura 45 - Efeito da carga de compactação aplicada durante a produção das amostras na (a) densidade aparente e densidade real do fibrocimento. Efeito do grau de empacotamento variado pela finura do calcário na (b) densidade aparente e a densidade real do fibrocimento. Finura indicada pelo diâmetro de maior frequência do calcário

O primeiro efeito direto da variação da porosidade das amostras foi a maior umidade no início da secagem observada nas amostras mais porosas. Isto ocorreu, pois o aumento da porosidade se refletiu em maior quantidade de água armazenada na saturação, aumentando desta forma a umidade inicial das amostras, como mostra a Figura 46 e Figura 47. Apesar da umidade inicial do ensaio ter sido diferente entre as amostras, a tendência do equilíbrio na secagem se deu no mesmo nível de umidade para todos os fibrocimentos, em torno de 6,8\% para todos os níveis de carregamento na compactação. No caso da série onde se variou o diâmetro do calcário, a amostra com calcário 65,5 $\mu \mathrm{m}$ também atingiu equilíbrio em um nível de umidade final em torno de 6,8\%. No entanto, nos casos onde se utilizou calcários mais finos, o nível de umidade final foi maior aos 14 dias de secagem, atingindo equilíbrio em $8,0 \%$ e 8,5\% com o uso dos calcários $26,8 \mu \mathrm{m}$ e $4,0 \mu \mathrm{m}$, respectivamente. Este comportamento é um indício que os calcários mais finos causaram um refinamento dos poros, mais precisamente um aumento da quantidade de microporos, comprovado através dos resultados de porosimetria por intrusão de mercúrio (Figura 55.b). Os microporos não causam retração, pois em umidade relativa de $50 \%$ estes não sofrem secagem (Sato, 1998), daí os maiores níveis de umidade final das amostras com calcários mais finos. 
Como já foi discutido no item 3.3, a perda de umidade do fibrocimento acima de aproximadamente $19 \%$ não causa retração, no entanto, este comportamento não pôde ser observado nos resultados de retração em função da umidade do fibrocimento, uma vez que a primeira leitura de retração foi realizada com 24 horas de secagem. Desta forma a regressão foi calculada a partir das leituras de todas as idades de secagem, excluindo-se aquelas do tempo zero (instante em que se iniciou a secagem).

As curvas de retração $\mathrm{X}$ umidade mostram que toda umidade acima do intervalo de 20 a 25\% não causa retração, uma vez que as regressões logarítmicas que descrevem como ocorre a retração com a variação da umidade, cruzam o eixo das abscissas neste intervalo. A perda de água do fibrocimento em níveis elevados de umidade não causa retração, como mostrado na Figura 38. Baseado na teoria de tensão capilar, a retração do material acontece a partir do momento que poros de menor dimensão, aqueles sujeitos à ação da tensão capilar, começam a secar. A Figura 46 mostra que este nível de umidade varia em função da porosidade do material, mais precisamente em função da quantidade de poros sujeitos à ação de tensão capilar. Segundo (Mindess, 1981) estes poros são aqueles com diâmetro entre $2,5 \mathrm{~nm}$ e $0,05 \mu \mathrm{m}$, e segundo os resultados obtidos no item 3.2.1 para fibrocimentos produzidos industrialmente, os poros sujeitos à tensão capilar são aqueles com diâmetro menor que 2,33 $\mu$ m (Figura 39). Os fibrocimentos compactados com as menores cargas apresentaram maior porosidade total, e maior quantidade de mesoporos (Figura 52.a), por este motivo a umidade a partir da qual a retração começou a acontecer foi maior. As cargas de $40 \mathrm{kN}$ e $100 \mathrm{kN}$ não apresentaram diferenças significativas na porosidade, e por este motivo a correlação entre retração e umidade foi praticamente o mesmo.

A representação gráfica em escala logarítmica torna possível a visualização das regressões calculadas expressas como retas. Desta forma, é possível observar através das equações expostas na Figura 47 que a inclinação da regressão da amostra calcário 26,8 é maior que as demais, indicando que este fibrocimento é mais suscetível à retração para uma mesma unidade de umidade evaporada. 


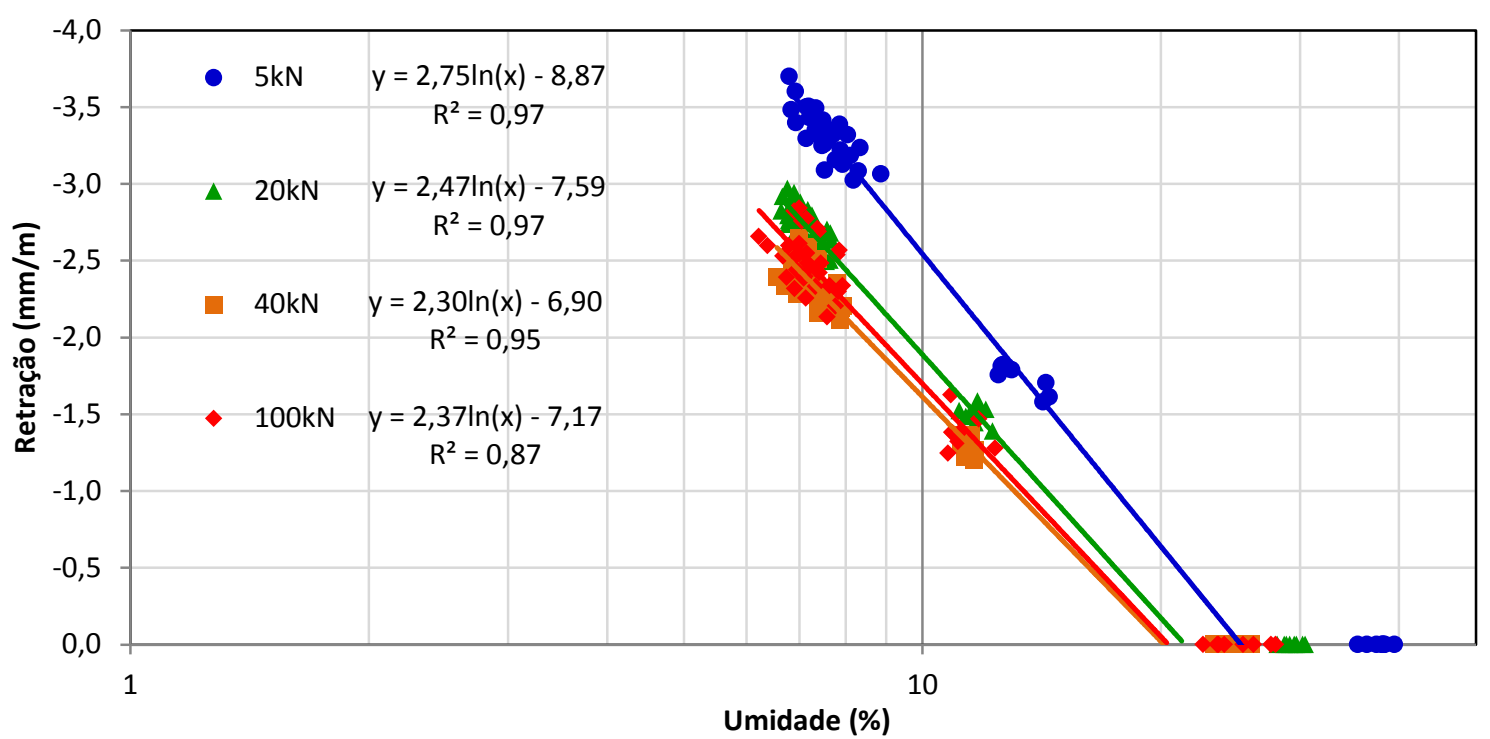

Figura 46 - Relação entre a retração por secagem e a umidade do fibrocimento, em função da carga de compactação aplicada durante a produção das amostras

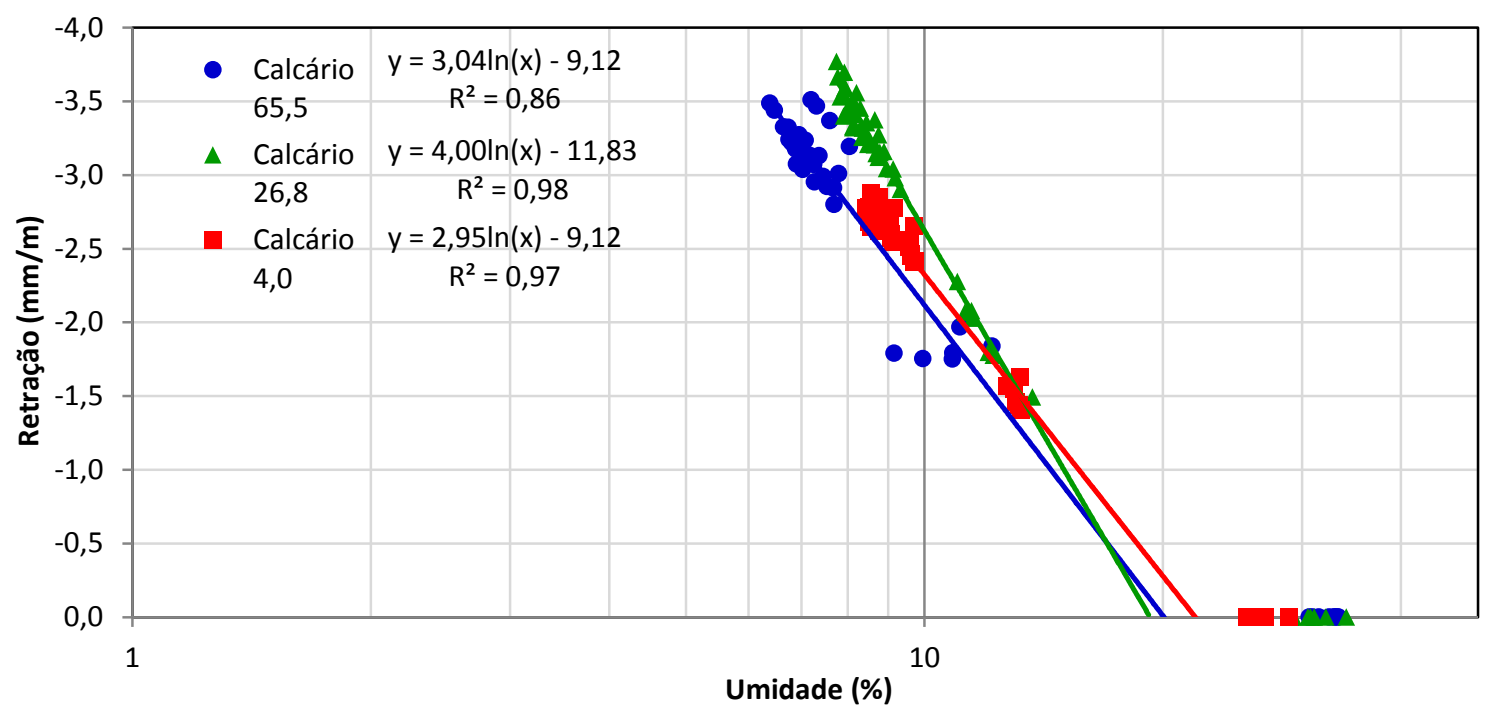

Figura 47 - Relação entre a retração por secagem e a umidade do fibrocimento, em função do diâmetro médio do calcário

A amplitude dos gráficos de retração em função do tempo de secagem (Figura 48) mostra o potencial de alteração da retração para cada uma das duas estratégias adotadas. Alterando a carga de compactação, a retração final diferiu até $1 \mathrm{~mm} / \mathrm{m}$ entre as amostras, sendo que quanto maior foi a carga de compactação, menor foi a retração por secagem. Este comportamento foi observado no intervalo de $20 \mathrm{kN}$ até $40 \mathrm{kN}$, uma vez que para a carga máxima de $100 \mathrm{kN}$, esta tendência de redução da retração não foi mais observada (Figura 49.a). Alterando o empacotamento de partículas através da utilização de calcários com diferentes diâmetros médios, a retração final diferiu até $0,75 \mathrm{~mm} / \mathrm{m}$ entre as amostras. Neste caso não foi 
observada uma variação linear da retração em função do tamanho das partículas do calcário. O calcário de tamanho intermediário (calcário 26,8 $\mu \mathrm{m}$ ) apresentou retração de $3,5 \mathrm{~mm} / \mathrm{m}$, ligeiramente maior que o calcário $65,5 \mu \mathrm{m}$ com $3,3 \mathrm{~mm} / \mathrm{m}$, que é o mais grosso entre todos os calcários utilizados. O calcário $4 \mu \mathrm{m}$ foi o que apresentou menor valor de retração, $2,75 \mathrm{~mm} / \mathrm{m}$ (Figura 49.b).

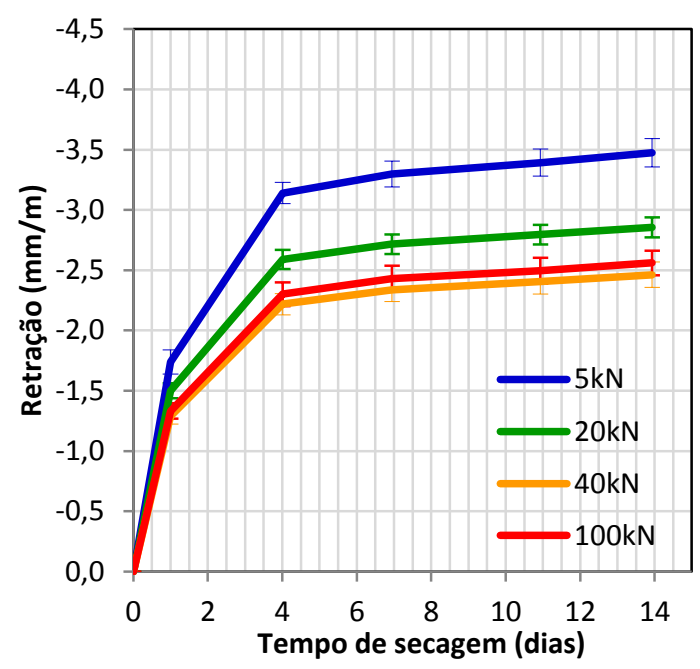

(a)

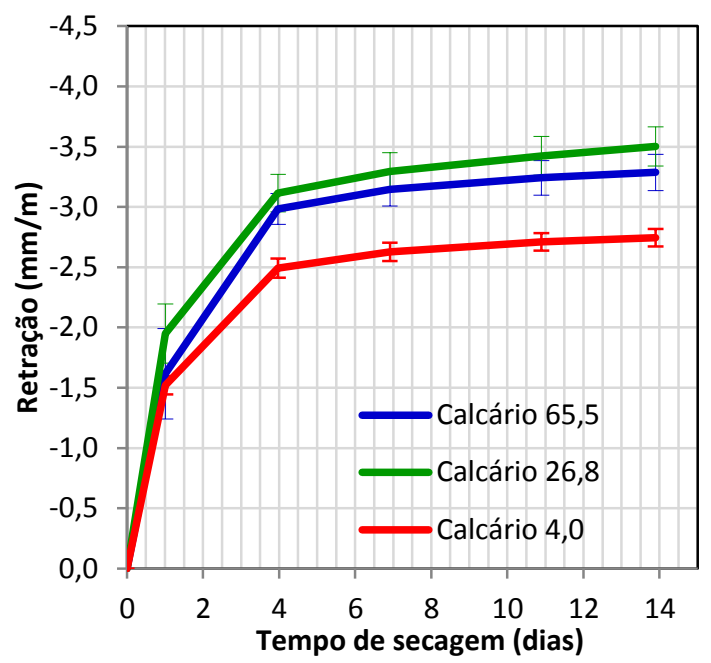

(b)

Figura 48 - Retração por secagem em função da (a) da carga de compactação aplicada durante a produção das amostras; e (b) do grau de empacotamento em função da finura do calcário

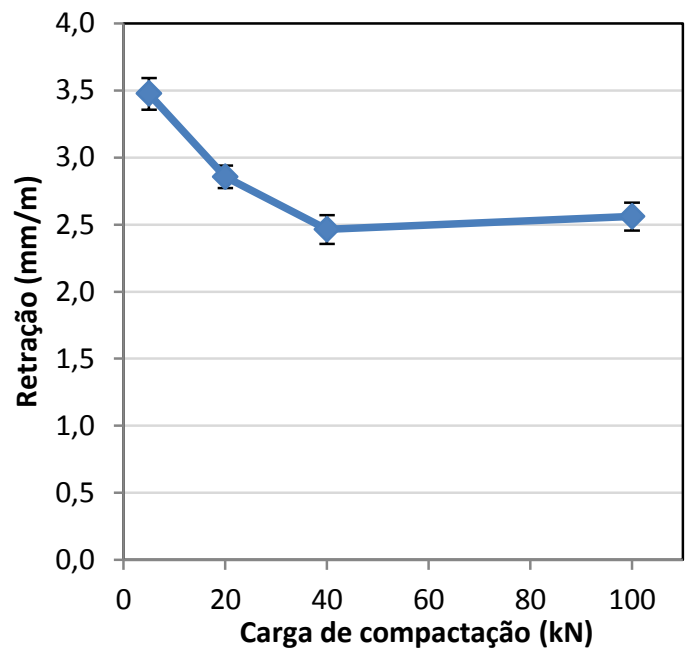

(a)

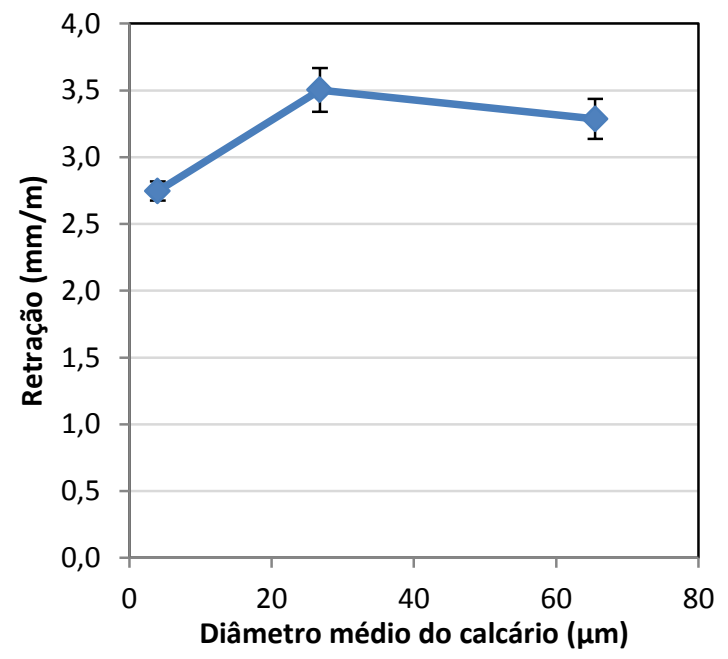

(b)

Figura 49 - Retração aos 14 dias de secagem em função da (a) da carga de compactação aplicada durante a produção das amostras; e (b) do grau de empacotamento em função do diâmetro médio do calcário

Analisando todos os dados conjuntamente, a perda de massa apresentou uma correlação direta com a porosidade do fibrocimento, como mostra a Figura 50.a, 
independente da estratégia de variação da porosidade (por compactação ou por empacotamento). A porosidade total foi uma importante causa que explica os níveis de retração medidos nas amostras estudadas, uma vez que esta reflete também a quantidade de poros de dimensões capilares. O efeito da porosidade na retração por secagem foi direto. No entanto, não foi calculada uma correlação envolvendo todos os dados conjuntamente, haja vista que as variações oriundas da variação no empacotamento não apresentaram desvios constantes que equivalham à variabilidade da tendência (Figura 50.b). A boa correlação entre a porosidade e a retração nas amostras onde se variou a carga de compactação indica que a redução da porosidade total pelo carregamento reduziu proporcionalmente os volumes de poros de dimensões capilares e aumentou o volume de poros grandes, que pouco contribuem para a retração, mas que em grande volume, interferem no valor final. Em contrapartida, a variação da porosidade total em função do grau de empacotamento não é proporcional às alterações na distribuição de tamanho de poros, especialmente nas quantidades de poros capilares.

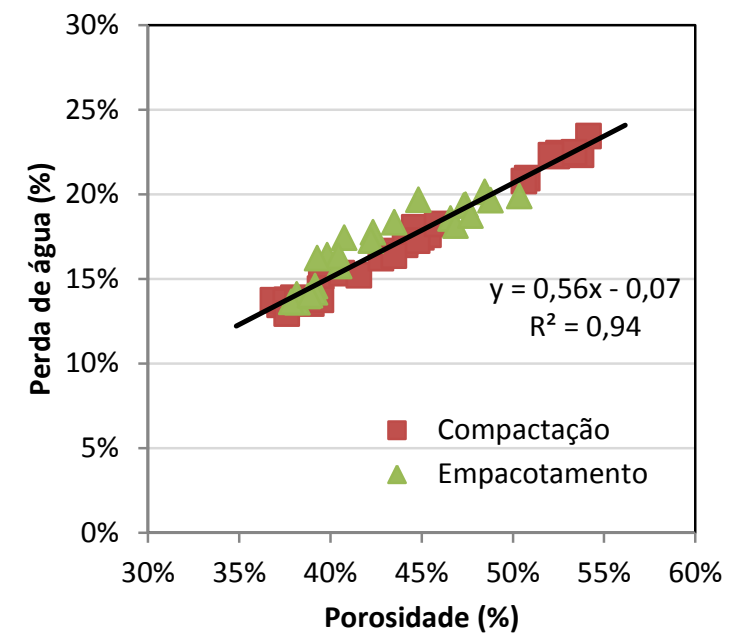

(a)

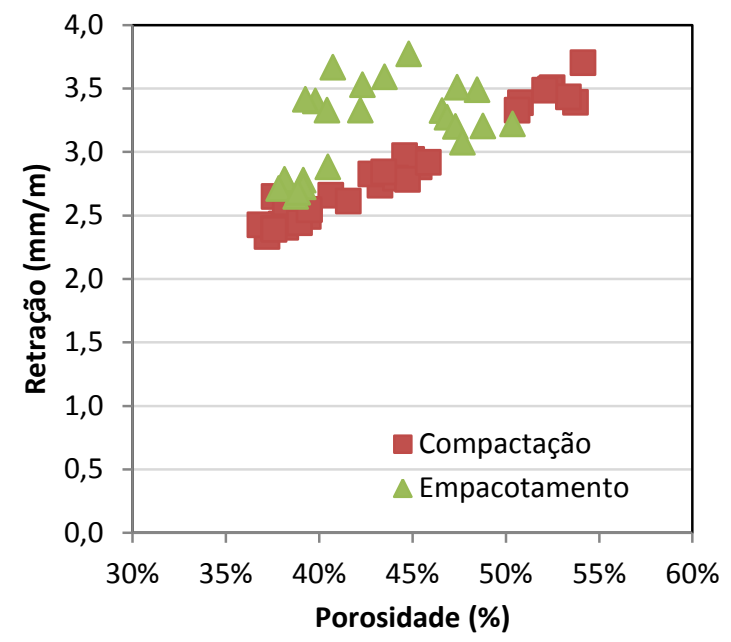

(b)

Figura 50 - Efeito da porosidade na (a) perda de água e (b) retração, aos 14 dias de secagem

Analisando a maneira como o aumento da carga de compactação interfere na porosidade, esta ação elimina defeitos (poros de maior dimensão) e causa deformação plástica na celulose, como o esmagamento do lúmen (Motta, 2005). A Figura 51 ilustra o que foi dito, sendo possível observar que para as maiores cargas houve principalmente a redução da quantidade de poros maiores, aqueles equivalentes aos defeitos e poros causados pela celulose. A partir da carga de 
$40 \mathrm{kN}$, praticamente toda a porosidade maior foi eliminada, por este motivo a compactação com 100 kN não reduziu mais a porosidade total, uma vez que não havia mais defeitos a serem eliminados do fibrocimento. Em menor proporção, o aumento da carga de compactação, além de causar uma redução na porosidade total do fibrocimento, causou reduções da quantidade de poros causadores de retração por serem suscetíveis à tensão capilar, que são os mesoporos. A Figura 52 mostra que o volume de poros entre 13,2 nm e 0,03 $\mu \mathrm{m}$ (trecho II.b na Figura 39, composta por mesoporos) caiu de aproximadamente $7,15 \%$ para quase $5,75 \%$, variando a carga de compactação de 5 a $40 \mathrm{kN}$, o que se refletiu em redução da retração por secagem.
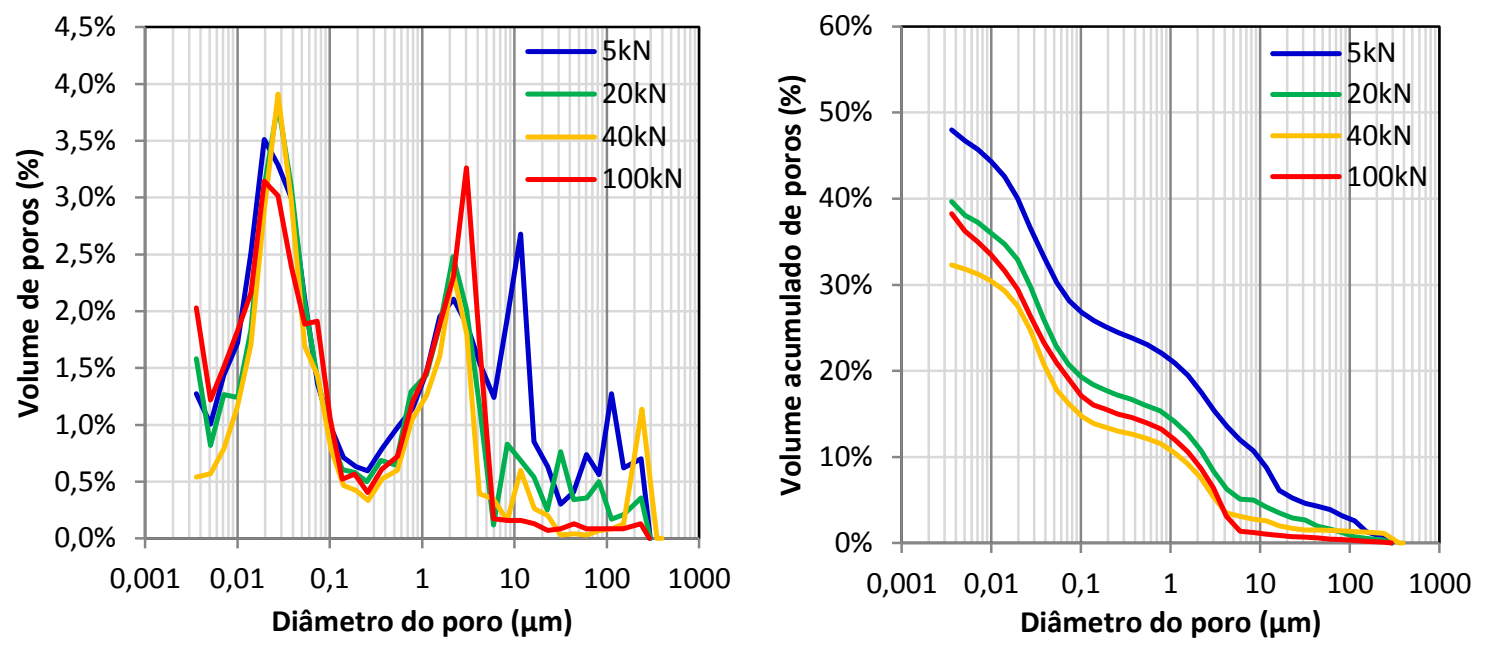

Figura 51 - Distribuição de tamanho de poros do fibrocimento em função da carga de compactação

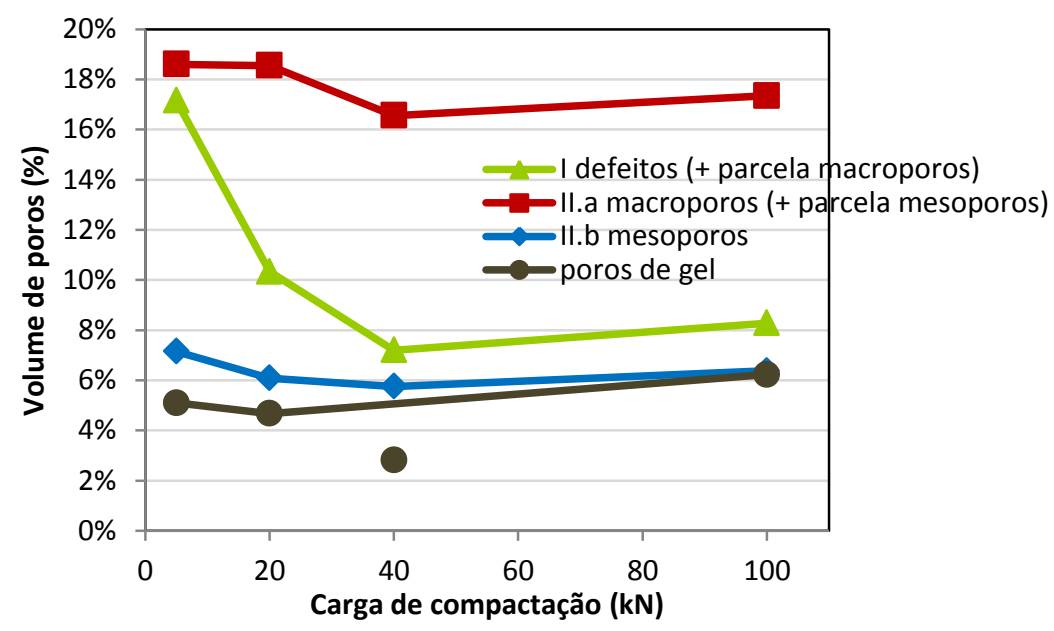

Figura 52 - Volume de poros de diferentes tamanhos em função da carga de compactação aplicada durante o processo de fabricação do fibrocimento. Trecho I: diâmetro do poro superior a 2,33 $\mu \mathrm{m}$; trecho II.a: diâmetro do poro entre 0,03 e 2,33 $\mu \mathrm{m}$; trecho II.b: diâmetro do poro entre 0,03 $\mu \mathrm{m}$ e $13,2 \mathrm{~nm}$ 
A variação do teor de partículas finas alterou o empacotamento de partículas do fibrocimento. Desta forma, as alterações na distribuição de tamanho de poros da matriz não ocorrem uniformemente. A redução do tamanho da partícula não se reflete em aumento linear do grau de empacotamento, conforme mostra a Figura 53, pois há faixas de tamanhos de partículas onde o arranjo entre elas será ótimo. Nesta série, o efeito do refinamento dos poros tornou os fibrocimentos com calcários mais finos mais suscetíveis à retração, especialmente no caso do calcário $26,8 \mu \mathrm{m}$, elevando o nível de retração por secagem medido ao longo dos 14 dias de secagem (Figura 48.b).

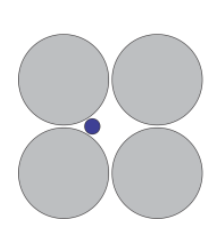

(a)

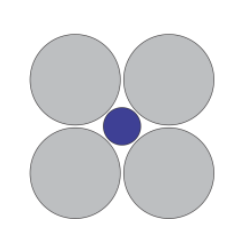

(b)

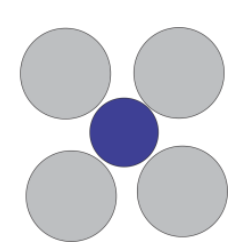

(c)

Figura 53 - Esquema do efeito do tamanho da partícula no grau de empacotamento. 0 melhor empacotamento ocorre na condição (b), onde não há afastamento das partículas e o filler preenche ao máximo os espaços vazios

A Figura 54 mostra que para as amostras com calcário mais fino, o volume de poros maiores reduz enquanto que a quantidade de poros capilares aumenta, refletindo o refinamento de poros citado e discutido até então. A troca de calcários mais grossos por materiais mais finos reduziu a porosidade total, como esperado. No entanto, neste caso ocorreu um aumento na quantidade de poros entre menores que 2,33 $\mu \mathrm{m}$ quando se utilizou calcários mais finos, o que favorece a retração. Esta faixa de poros compreende tanto os mesoporos quanto parte dos macroporos, sendo mais acentuado este aumento para o calcário 26,8. Estes resultados indicam e confirmam que mesmos poros de grande tamanho (macroporos menores que 2,33 $\mu \mathrm{m}$ ), cuja bibliografia afirma que não sofrem ação capilar, são desencadeadores de retração.

A Figura 54 mostra que o calcário $26,8 \mu \mathrm{m}$ atuou no aumento do empacotamento reduzindo o volume de poros na faixa entre 0,1 e 2,33 $\mu \mathrm{m}$, que são os poros de menor dimensão na faixa dos macroporos. O calcário $4 \mu \mathrm{m}$ reduziu o volume de poros entre 0,1 e $300 \mu \mathrm{m}$. Estes intervalos de tamanho de poros são referentes aos macroporos e poros grandes. Mas, apesar da definição teórica dizer que $0,05 \mu \mathrm{m}$ é o diâmetro limite dos poros onde há incidência de tensão capilar, a redução desta 
tensão entre os mesoporos e macroporos é uma transição gradual, que decresce com o aumento do tamanho do poro. Desta forma, a explicação para a influência dos macroporos na retração é o reflexo desta pequena tensão capilar que pode atuar nos macroporos, que quando multiplicado pela grande quantidade de poros deste tamanho e volume de água evaporada, se reflete em retração significativa em escala macroscópica.
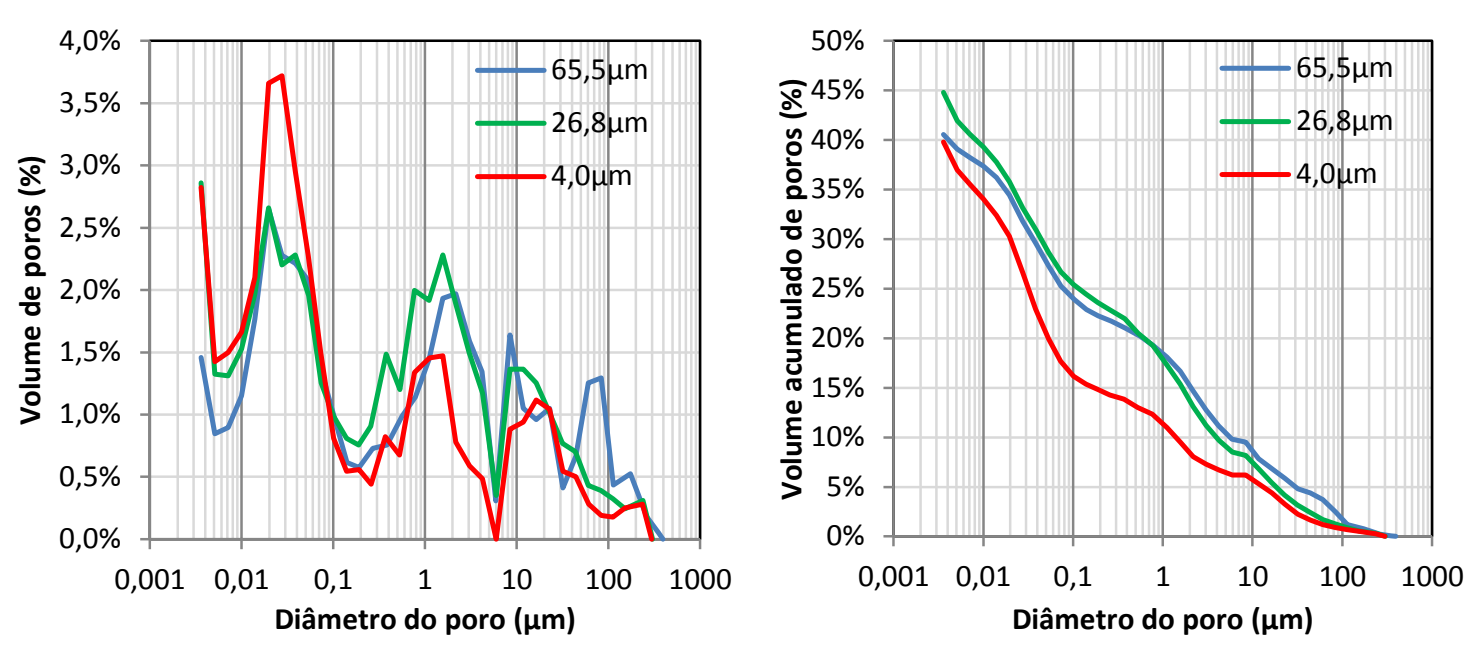

Figura 54 - Distribuição de tamanho de poros do fibrocimento em função da finura do calcário

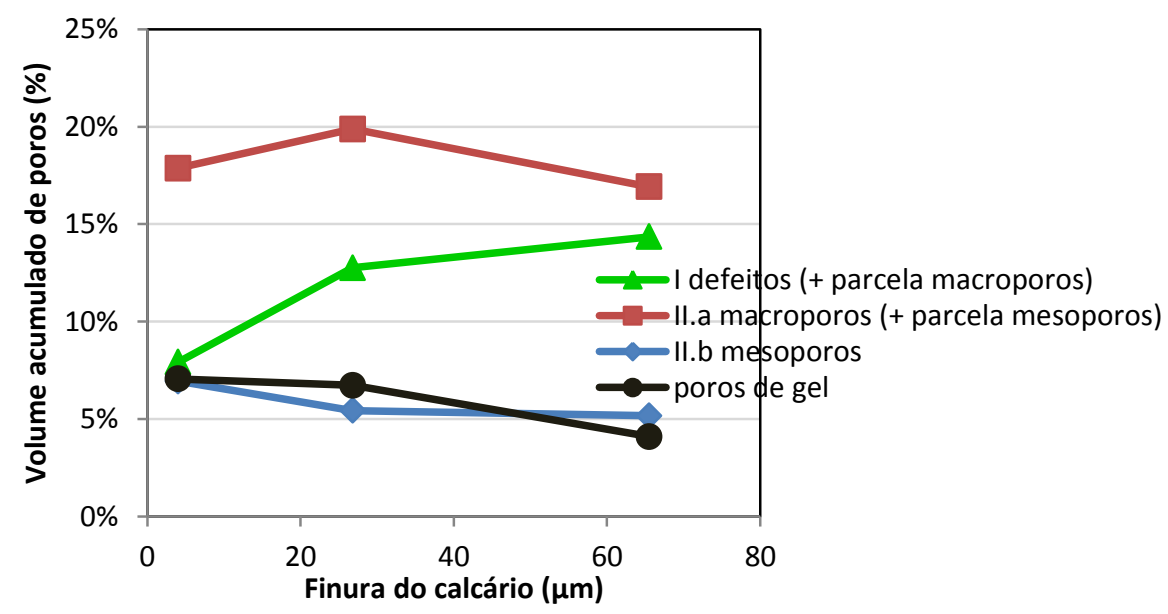

Figura 55 - Volume de poros de diferentes tamanhos em função do grau de empacotamento obtido variando-se a finura do calcário. Trecho I: diâmetro do poro superior a 2,33 $\mu \mathrm{m}$; trecho II.a: diâmetro do poro entre 0,03 e 2,33 $\mu \mathrm{m}$; trecho Il.b: diâmetro do poro entre 0,03 $\mu \mathrm{m}$ e 13,2 nm

\subsection{Influência da umidade relativa na retração (Isoterma de secagem)}

A retração total do fibrocimento vai depender de fatores dinâmicos, como a idade do compósito, o histórico de secagens etc, como também das propriedades 
intrínsecas do material (porosidade total, distribuição de tamanho de poros...), e especialmente das condições ambientais de secagem, como temperatura e umidade relativa do ar. Os resultados apresentados no início do item 3.3 mostram que independente da umidade inicial do fibrocimento, sob mesma condição ambiental de secagem (umidade relativa de 50\%), o compósito tende a atingir uma umidade final estável no mesmo patamar, que naqueles resultados foi em torno de $6,8 \%$. Isso ocorre porque a umidade relativa dentro dos poros tende a estabilizar em uma condição de equilíbrio com a umidade relativa do ar, de modo que no caso desta condição de exposição ser alterada, a umidade dentro dos poros também tende a se alterar, mudando os níveis medidos de retração por secagem.

Para montar a isoterma de secagem, ou seja, a curva que mostra a correlação da umidade relativa do ar com a perda de água do fibrocimento, e consequentemente com a sua retração, foram seguidas duas rotas de ensaios:

- Variação progressiva da umidade relativa do ar

- Variação direta da umidade relativa do ar

Na primeira rota, o mesmo conjunto de 8 corpos-de-prova foi submetida à quatro patamares de umidade relativa, que variou progressivamente de 70 até $20 \%$. A Figura 56 e Figura 57 mostram como variou a umidade do fibrocimento, a perda de água na secagem, e a retração, em função do tempo de exposição e condição de exposição (nível de umidade relativa).

$\mathrm{Na}$ segunda rota, 4 amostras compostas por 8 corpos-de-prova cada, foram submetidas à quatro condições de exposição distintas, onde a secagem ocorreu diretamente nos níveis de umidade relativa de $70,50,40$ ou 20\%. A Figura 58 e Figura 59 mostram como variou a umidade do fibrocimento, a perda de água e a retração, em função do tempo de exposição em cada diferente nível de umidade relativa do ar.

Quando submetidos à mesma condição de exposição, fibrocimentos com formulação constante tendem a atingir o equilíbrio de secagem no mesmo nível de umidade da amostra. Entretanto, quando as condições ambientais são alteradas, como com a redução da umidade relativa do ambiente, esta condição de equilíbrio se altera, como mostra a Figura 56. A cada decréscimo da umidade relativa do ar, a umidade da amostra no final da secagem também diminuiu. 
A maior parte da secagem ocorreu em ambiente com $70 \%$ de umidade relativa, sendo que quase $3 / 4$ de toda a água evaporada no experimento evaporou nesta condição. A perda de agua ao final da secagem a UR $70 \%$ foi de $14,7 \%$, o que equivale à umidade da amostra de $8,6 \%$ (Figura 56). Como visto anteriormente, o fibrocimento começa a sofrer os efeitos da retração em níveis de umidade da amostra abaixo de $20 \%$, de modo que a secagem em umidade relativa do ar de $70 \%$ causa importante retração, de $2,5 \mathrm{~mm} / \mathrm{m}$ nas amostras ensaiadas (Figura 57). Nos demais patamares de umidade relativa do ar, as perdas de água foram menores, de $2,07 \%, 2,17 \%$ e $1,23 \%$ nas condições de exposição de UR iguais a 50\%, 40\% e $20 \%$, respectivamente.

A retração por secagem medida nestas amostras também foi maior na primeira condição de exposição, com umidade relativa do ar de $70 \%$. A grande retração medida se deu em função da grande perda de água durante a secagem. Ocorre que, no segundo patamar de umidade relativa, quando esta ficou programada em $50 \%$, a retração medida ao final dos 7 dias de exposição foi relativamente grande, de $1,03 \mathrm{~mm} / \mathrm{m}$, acumulando uma retração total de $3,58 \mathrm{~mm} / \mathrm{m}$. Isto ocorre porque neste nível de umidade relativa ocorre a secagem dos poros de dimensões capilares, causadores de retração devido à formação de menisco e atuação de tensão capilar (Kovler et al., 2006). Em níveis de umidade relativa abaixo de 50\%, os mecanismos causadores são diferentes da teoria apresentada sobre depressão capilar. Os resultados apresentados na Figura 57 comprovam o que foi dito.

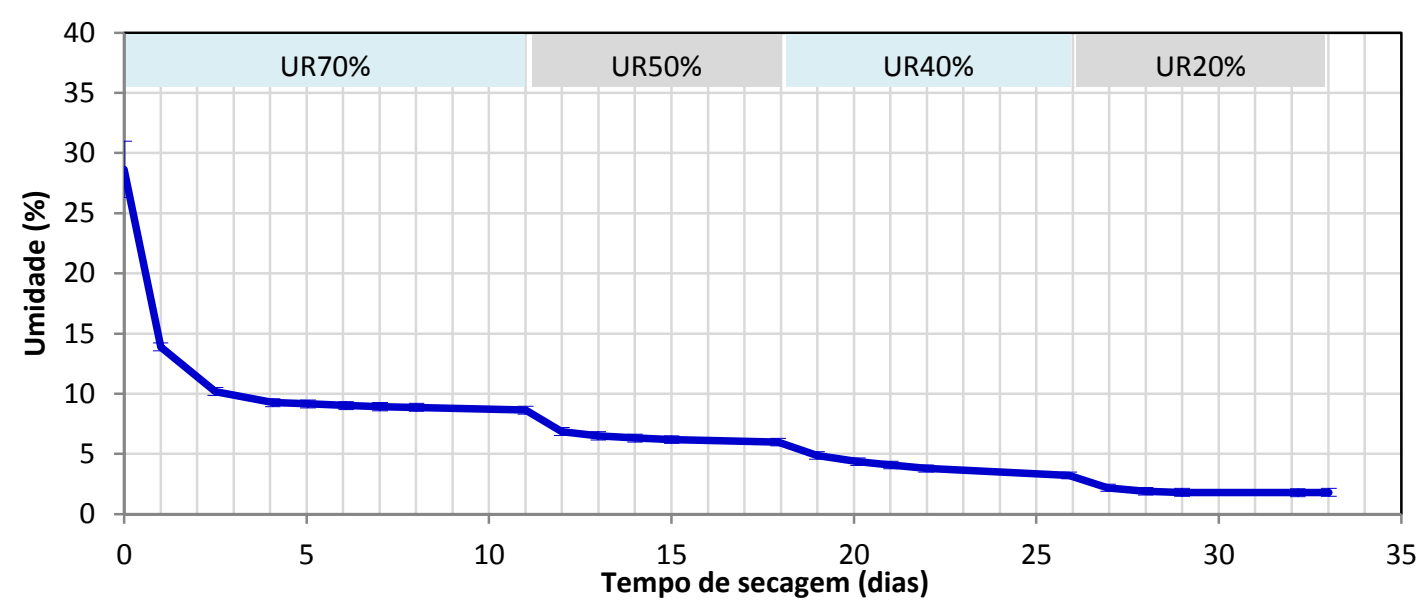

Figura 56 - Redução da umidade em função do tempo de secagem do fibrocimento e umidade relativa do ar, que variou nos patamares $70 \%, 50 \%, 40 \%$ e $20 \%$ 


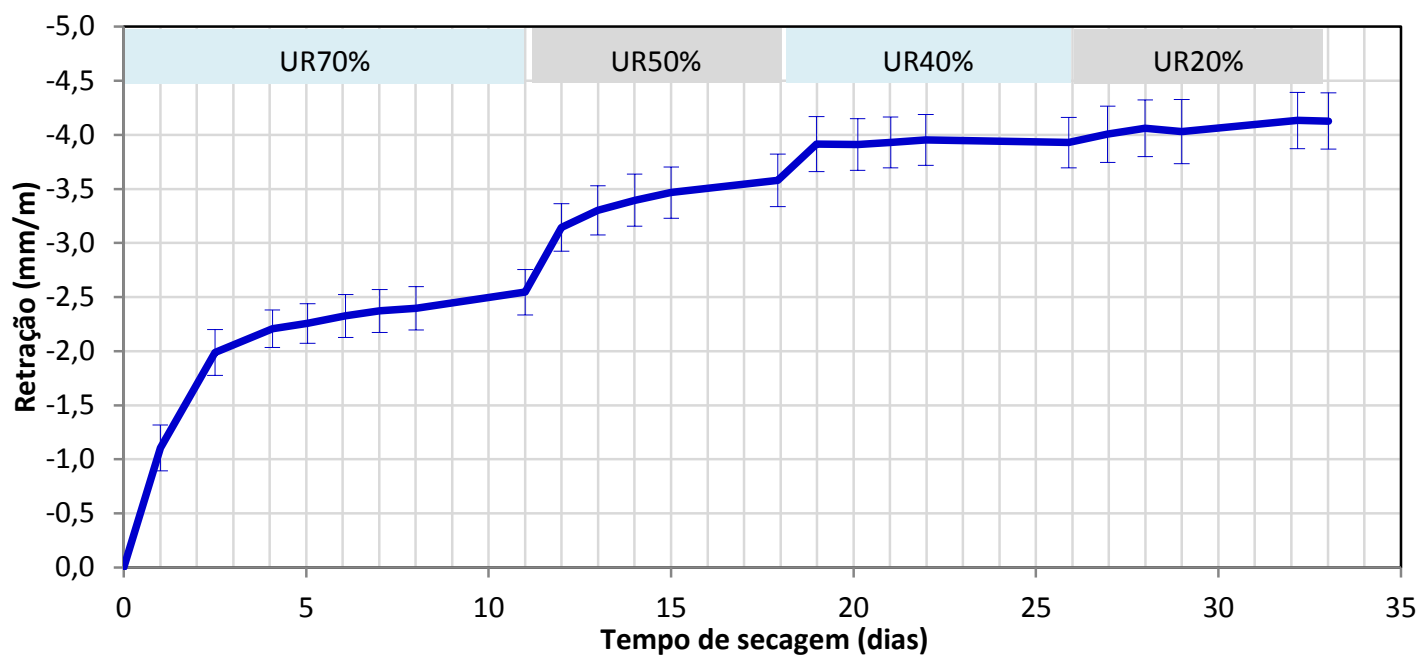

Figura 57 - Retração em função do tempo de secagem do fibrocimento e umidade relativa do ar, que variou nos patamares $70 \%, 50 \%, 40 \%$ e $20 \%$

Quando amostras de fibrocimento foram submetidas à secagem direta sob cada nível de umidade relativa, estas apresentaram uma menor secagem (Figura 58) quando comparadas com aquelas onde a redução da umidade relativa do ar foi progressiva. A umidade de equilíbrio das amostras submetidas à variação progressiva da UR foi menor ao final de cada patamar de secagem (Figura 58.a). Isto significa que quando a secagem é progressiva, esta é mais efetiva, uma vez que se dá tempo para os poros de diferentes tamanhos sofram a movimentação higroscópica necessária para entrarem em equilíbrio. Quando se submete uma amostra à secagem direta em níveis muito baixos de umidade relativa, os poros maiores secam rapidamente, quebrando a continuidade do meio líquido dentro de toda a estrutura de poros do material, desfazendo esta condição essencial para 0 avanço da secagem nos poros menores.

Uma vez que a perda de água foi menor nas amostras submetidas à secagem direta nos diferentes níveis de umidade relativa, consequentemente a retração também foi menor (Figura 59). No menor nível de umidade relativa, que foi de $20 \%$, a retração por secagem iniciou rapidamente, no entanto ao final do período de secagem foi inferior à medida em condições menos severas de secagem como em umidade relativa de 40 e de $50 \%$. A retração tem relação direta com a perda de massa, e a Figura 58.b mostra que sob UR de $20 \%$ a secagem foi a maior entre as amostras estudadas, o que resultou em patamares muito baixos de umidade da amostra. No entanto, em umidade relativa de $20 \%$ poros de diâmetro muito pequeno, como os microporos, que não sofrem a ação da tensão capilar, são 
submetidos à secagem. Por este motivo a maior secagem destas amostras não se refletiu em maior retração. Este comportamento observado também se justifica pelo fato de, em condições de umidade relativa inferiores a $40 \%$, não se formar uma fase contínua de umidade pela estrutura de poros do compósito, de modo que não há formação de um menisco estável, reduzindo desta forma os níveis de tensão capilar nos poros (Taylor, 1997).

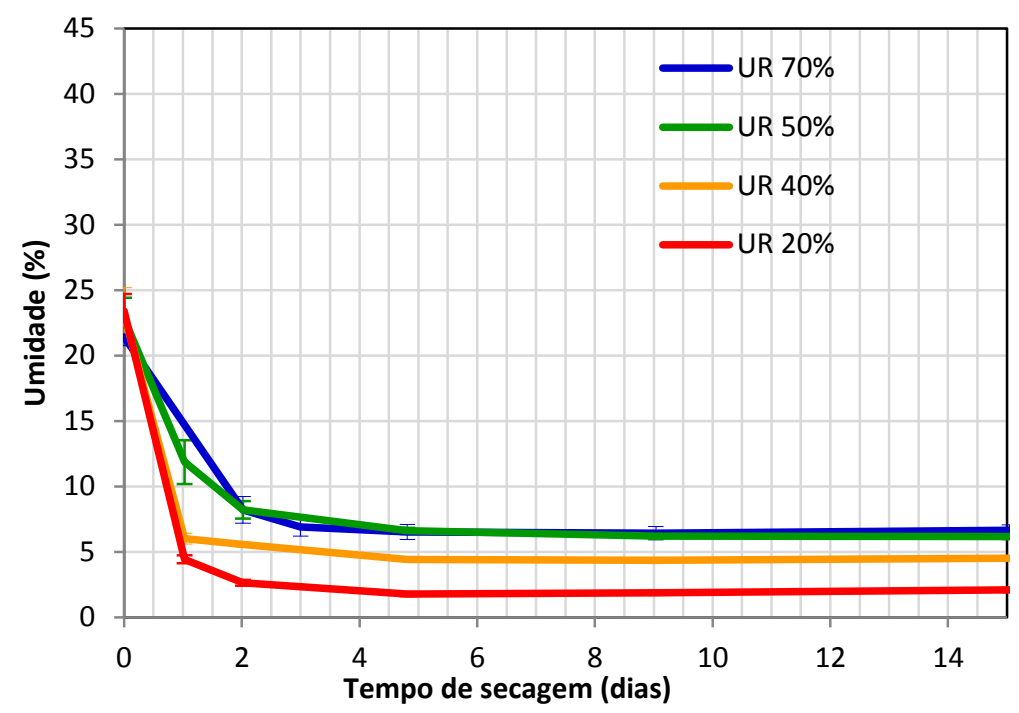

Figura 58 - Variação da umidade em função do tempo de secagem. Secagem direta

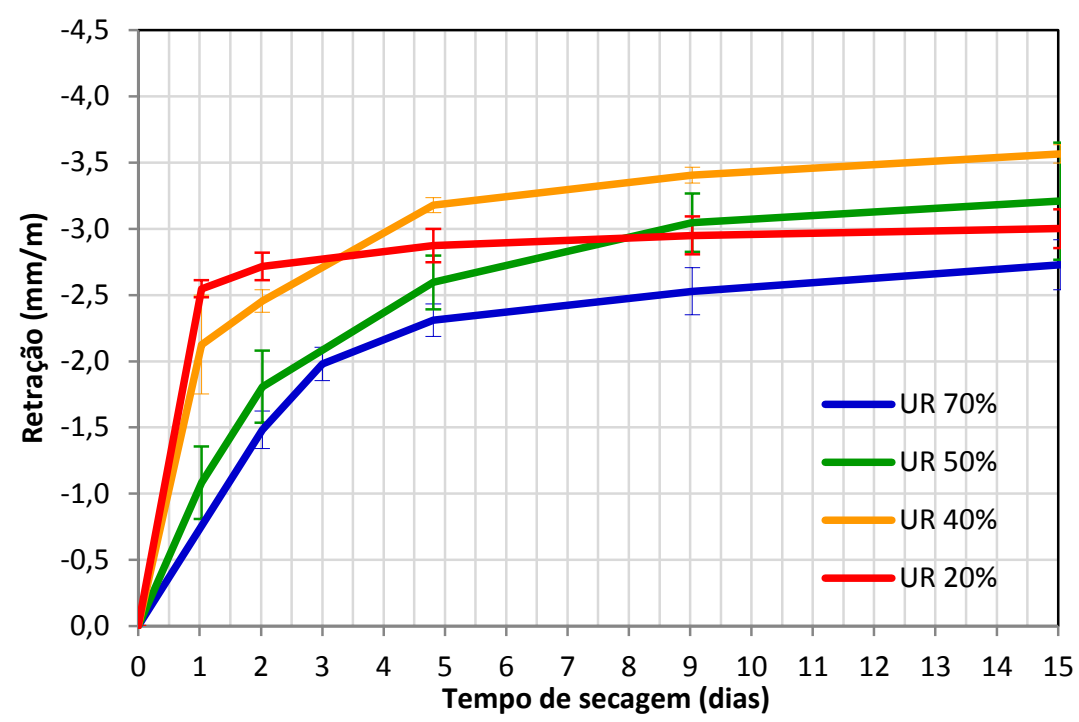

Figura 59 - Retração em função do tempo de secagem do fibrocimento. Secagem direta

Apesar de algumas diferenças terem sido apresentadas entre as amostras submetidas à secagem com variação progressiva da umidade relativa ou com variação direta da umidade relativa do ar, quando se correlaciona o efeito da umidade relativa do ar na umidade do fibrocimento, observa-se que há uma 
correlação grande e direta entre elas. A Figura 60 mostra que quanto maior a umidade relativa do ar, maior é a umidade da amostra de fibrocimento, sendo que a maior inclinação da curva nos níveis mais altos de umidade relativa indica que nesta faixa o material é mais suscetível à secagem, havendo uma maior variação de umidade da amostra quando se altera a umidade relativa do ar.

Quando medido o efeito da umidade relativa do ar na retração do fibrocimento, observou-se que a forma como é realizada a secagem interfere na retração por secagem do fibrocimento. No caso onde a variação da umidade relativa do ar foi progressiva, criou-se uma condição favorável à secagem e formação de menisco nos poros capilares, o que se refletiu em aumento da retração ao passa que se reduziu a umidade relativa do ar (Figura 61). No entanto, quando ocorre a secagem direta da amostra sob a condição de umidade relativa mais severa, que foi de $20 \%$, a retração ao final da secagem foi menor do que em níveis superiores de umidade relativa, confirmando o observado na revisão da bibliografia, que explica este fenômeno ao fato de sob umidade relativa muito baixa, não há condição favorável para a formação de tensão capilar. Conclui-se desta maneira que a condição ótima, ou seja, a mais severa para se medir a retração por secagem de fibrocimento é em umidade relativa do ar em $50 \%$.

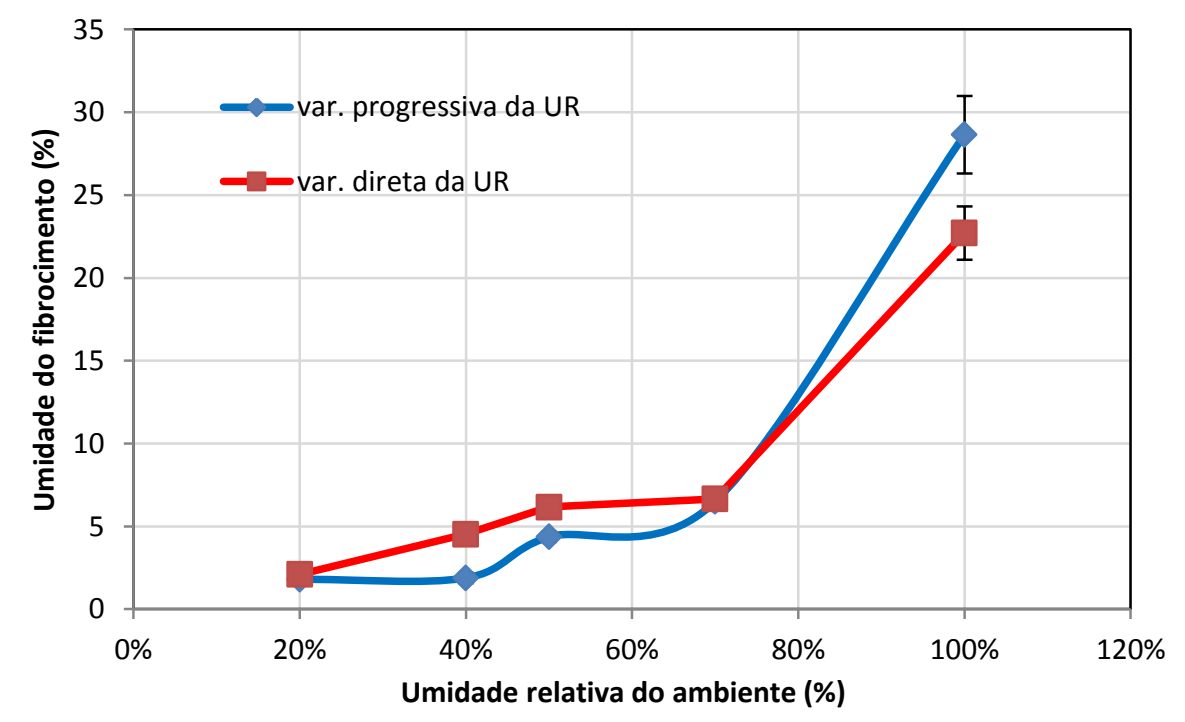

Figura 60 - Isoterma de secagem, que relaciona o efeito da umidade relativa do ambiente na umidade do fibrocimento. Temperatura de secagem: $23^{\circ} \mathrm{C}$ 


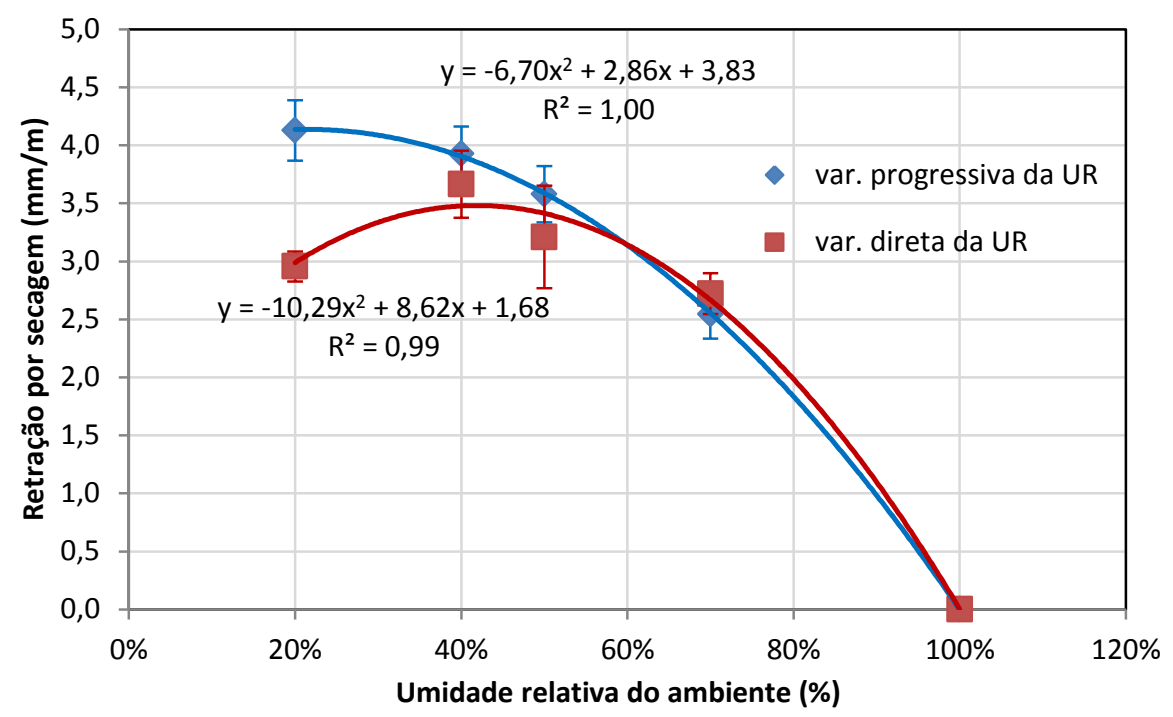

Figura 61 - Retração por secagem em função da umidade relativa do ambiente com a retração por secagem do fibrocimento.

\subsection{Conclusões}

Este capítulo da tese demonstra o efeito da porosidade e distribuição de tamanho de poros característicos do fibrocimento na retração por secagem, verificando a teoria de formação de menisco e tensão capilar como fonte geradora de retração.

A cinética de retração em fibrocimento NT produzido industrialmente foi estudada e exposta neste capítulo, sendo obtidas as seguintes conclusões:

- A distribuição de tamanho de poros do fibrocimento é favorável à ocorrência da retração por secagem, uma vez que o volume de mesoporos e macroporos menores que 2,33 $\mu \mathrm{m}$, que são aqueles onde a tensão capilar atua, é bastante grande, em torno de $3 / 4$ da porosidade total do compósito;

- A retração volumétrica do fibrocimento tem grande magnitude quando comparada com outros compósitos cimentícios de grande importância para a indústria da construção civil, podendo atingir níveis de até $3,4 \mathrm{~mm} / \mathrm{m}$ aos 14 dias quando exposto em ambiente com $23^{\circ} \mathrm{C}$ de temperatura e umidade relativa do ar de $50 \%$; 
- A cinética de secagem do fibrocimento pode ser descrita em duas etapas, sendo a primeira referente à perda de água nos dois primeiros dias de secagem, que é muito intensa - equivale a $92 \%$ de toda a perda de água. A segunda etapa se refere à secagem nos dias subsequentes, que equivale à perda de água de $1,3 \%$;

- O intervalo entre os valores mínimos e máximos de perda de água é bastante grande, de aproximadamente 11\%. Esta grande amplitude reflete a variabilidade das propriedades do fibrocimento produzido industrialmente, especialmente a porosidade;

- A cinética de retração obviamente está relacionada com a perda de água, e também possui um perfil dividido em duas etapas. A primeira etapa é a retração que acontece nos dois primeiros dias de secagem, onde esta variação dimensional ocorre com taxa elevada - equivale a $76 \%$ do total medido. A segunda etapa é aquela retração ocorrida nos dias subsequentes;

- A retração por secagem também apresentou grande amplitude nos resultados durante todo o teste. Esta variabilidade também é decorrente das diferenças nas propriedades do fibrocimento, e reflete a grande amplitude dos valores de perda de água, uma vez que a retração é função da tensão capilar gerada na secagem;

- A correlação entre a retração e a secagem é representada através da curva de retração em função do nível de umidade do fibrocimento. Neste caso, a retração por secagem apresenta uma correlação contínua logarítmica com a variação de umidade - nível de umidade decresce, a retração aumenta em taxa mais elevada;

- As variações na umidade inicial das amostras não se refletem em variabilidade nos valores de retração medidos, desde que estas variações ocorrem em nível de umidade acima de aproximadamente 19\%, em relação à massa da amostra. Este comportamento na secagem dos fibrocimentos se dá pela hipótese de que tanto as amostras com umidade inicial próxima da condição de saturação, como aquelas com umidade 
mais baixa, iniciaram seus processos de retração a partir do momento em que os poros de dimensão capilar começaram a sofrer secagem;

- A taxa de retração calculada a partir da derivada da regressão logarítmica da curva de retração $X$ umidade, reflete a teoria sobre tensão capilar - a tensão capilar causadora de retração aumenta com a redução da umidade relativa dentro dos poros da matriz. A causa está relacionada com o nível de umidade relativa dentro do poro e o raio dos poros;

- A secagem dos dois primeiros dias de exposição, de aproximadamente 1,5 horas até 2 dias, ocorre em taxa mais elevada, sendo que os poros submetidos à secagem neste período são predominantemente aqueles com diâmetro entre 0,03 e 2,33 $\mu \mathrm{m}$. Nesta faixa de poros, que compreende parte dos macroporos e uma parcela dos mesoporos, a tensão capilar estimada pela equação de Laplace não apresenta grande magnitude, no entanto, devido ao grande volume de poros nesta faixa, a retração por secagem passa a ser significativa, compreendendo a maior parcela da retração total medida nos fibrocimentos estudados;

- A secagem nos dias subsequentes ao segundo dia de secagem ocorre predominantemente nos poros entre $13,2 \mathrm{~nm}$ e 0,03 $\mu \mathrm{m}$, faixa esta compreendida por mesoporos. Apesar da secagem ocorrer em pequena taxa, a retração neste período é significativa devido à grande tensão capilar atuante nestes poros na secagem, conforme estimado pela equação de Laplace.

Sobre as estratégias de redução da retração por secagem, usando como variáveis parâmetros com potencial na aplicação da indústria, as conclusões deste capítulo foram:

- A redução da porosidade total deste compósito se refletiu em redução da retração por secagem;

- A estratégia de redução da porosidade com aumento da carga de compactação apresentou bom potencial na mitigação da retração por secagem do fibrocimento. Entre os diferentes níveis de carregamento, a retração final do fibrocimento diferiu em até $1 \mathrm{~mm} / \mathrm{m}$, sendo que quanto maior for a carga de compactação, menor foi a retração por secagem; 
- O aumento da carga de compactação durante o processo de fabricação do fibrocimento reduziu uniformemente a sua porosidade no estado endurecido. Contudo, a efetividade da redução da porosidade total do fibrocimento ocorreu até determinado nível de carga de compactação aquele nível de carga que atingiu o limite de deformação plástica do fibrocimento no estado fresco, devido à completa eliminação dos poros maiores, característicos dos defeitos e lúmen da celulose;

- A estratégia de melhoria no empacotamento das partículas que compõem o fibrocimento também apresentou potencial de redução da retração, com intervalo máximo de retração por secagem de $0,75 \mathrm{~mm} / \mathrm{m}$ entre as amostras estudadas;

- A melhoria do empacotamento de partículas com a utilização de matériasprimas com diferentes tamanhos resultou na redução da porosidade total conjuntamente com o refinamento dos poros, medido pela redução da porosidade total e aumento da quantidade dos poros de menor tamanho, que são os poros de gel. Como os poros de gel não sofrem secagem em umidade relativa até $50 \%$, então esta variação não se refletiu em retração. A faixa de poros que apresentou melhor correlação com a retração por secagem foi aquela entre 0,03 e 2,33 $\mu \mathrm{m}$, que é a faixa presente em maior volume dentro do fibrocimento;

- A secagem do fibrocimento tende a estabilizar ao final do período de 14 dias de secagem, atingindo um nível de umidade de equilíbrio. Este nível é constante para uma mesma formulação de fibrocimento, no entanto, sofre influência do grau de empacotamento, quando se mudam as matérias-primas, alterando o volume de poros muito pequenos.

Sobre o modo como a umidade relativa do ar influencia na retração, discutida a partir da isoterma de secagem elaborada, as conclusões deste capítulo foram:

- Independente da umidade inicial do fibrocimento, sob mesma condição ambiental de secagem (umidade relativa de 50\%), o compósito tende a atingir uma umidade final estável no mesmo patamar. Isso ocorre porque a umidade relativa dentro dos poros tende a estabilizar em uma condição de equilíbrio com a umidade relativa do ar. No entanto, quando se altera 
a umidade relativa do ar, o nível de umidade de equilíbrio também se altera;

- A condição de exposição (nível de umidade relativa) e a velocidade de secagem contribuíram para a variação da umidade do fibrocimento, da perda de água na secagem e da retração;

- Quando amostras de fibrocimento foram submetidas à secagem direta sob cada nível de umidade relativa, estas apresentaram uma menor secagem quando comparadas com aquelas onde a redução da umidade relativa do ar foi progressiva;

- Na secagem progressiva, os poros de diferentes tamanhos têm mais tempo para sofrerem a movimentação higroscópica necessária para entrarem em equilíbrio. Na secagem direta em níveis muito baixos de umidade relativa, os poros maiores secam rapidamente, quebrando a continuidade do meio líquido dentro de toda a estrutura de poros do material, desfazendo esta condição essencial para o avanço da secagem nos poros menores. 


\section{Capítulo IV}

\section{Influencia do Cimento e da Formulação na Retração por SeCAGEM do Fibrocimento}

\subsection{Influência do cimento na retração por secagem}

\subsubsection{Introdução}

O elevado consumo de cimento torna o fibrocimento um material muito suscetível à retração devido à movimentação higroscópica, podendo resultar em fissuração dos artefatos produzidos. O teor de cimento nas formulações de fibrocimento produzido pelo processo Hatschek pode ser de até $80 \%$ (Dias et al., 2009). A maior tendência à fissuração, quando comparado a um concreto cujo consumo de cimento é menor, ocorre porque os poros existentes na matriz cimentícia hidratada tem distribuição de tamanhos (Figura 32), incluindo o distanciamento entre as lamelas do $\mathrm{C}-\mathrm{S}-\mathrm{H}$, suscetível à solicitação de tensão capilar, capaz de produzir retração no compósito.

O objetivo do deste estudo desenvolvido é determinar a influência de diferentes cimentos, com características físico-químicas distintas, na retração por secagem do fibrocimento reforçado com fibras poliméricas e celulósicas.

\subsubsection{A influência do cimento na retração}

A utilização do ligante adequado a fim de se obter o melhor desempenho técnico, econômico e também ambiental, deve ser fortemente considerada pelos produtores de fibrocimento, devido ao seu grande consumo. Atualmente os cimentos Portland compostos, cuja principal diferença na composição é a substituição de parte do clínquer por escória (CP II-E), pozolana (CP II-Z) ou calcário (CP II-F), é largamente utilizado pela indústria de artefatos de fibrocimento. No entanto, cada vez mais se 
tem buscado a utilização de cimentos com maiores teores de substituição, como o CP III, com até $70 \%$ de adição de escória (ABNT, 1991a), e o CP IV, com até $50 \%$ de adição de pozolana (ABNT, 1999), cujo potencial para a redução de emissões de $\mathrm{CO}_{2}$ na produção de cimento é grande.

As variações dos diferentes tipos de cimento provocam mudanças importantes nas propriedades do fibrocimento. Variações na distribuição do tamanho de partículas dos cimentos podem mudar o empacotamento, e consequentemente a porosidade final do compósito; ou ainda diferentes composições químicas provocam alterações na velocidade de ganho de resistência, essencialmente devido às alterações ocorridas na cinética de hidratação da matriz cimentícia (observável através do fluxo de calor liberado pelas reações exotérmicas de hidratação) e consequentemente modificando as fases mineralógicas e microestrutura do compósito endurecido (Scrivener; Wieker, 1992).

A distribuição do tamanho de poros do compósito é uma propriedade importante no fibrocimento, uma vez que tem relação direta com a tensão capilar causadora de retração. Esta distribuição é fortemente influenciada pelo tipo de cimento, uma vez que a quantidade de C-S-H formado pode variar bastante em função da quantidade e tipo de adição mineral presente no cimento. O C-S-H é o composto resistente do cimento, no entanto, este composto hidratado possui poros entre suas lamelas com dimensão muito pequena, que com a secagem geram tensão de retração em grande magnitude (Idiart, 2009). O mecanismo de movimentação de água do C-S-H é atribuído à estrutura lamelar deste composto hidratado resistente no gel de cimento (Jennings, 2008; Majorana, 1989). No entanto, há pesquisas que afirmam que somente nos casos onde a umidade relativa cai para cerca de $10 \%$, é geralmente aceito que a água intercalar pode migrar para fora das lamelas do $\mathrm{C}-\mathrm{S}-\mathrm{H}$, reduzindo consequentemente a distância entre estas camadas e causando retração em escala macroscópica (Idiart, 2009).

Sabe-se que a retração autógena é fortemente dependente do tipo de cimento, no entanto, não há muitos dados para o caso da retração por secagem. A retração autógena de cimento de moderado calor e baixo calor de hidratação é muito menor que para o cimento Portland comum (Tazawa et al., 2000), por exemplo. A partir do cálculo da retração química de cada componente do cimento, demonstrada no item 1.3.2, observa-se que a retração correspondente ao $C_{3} A$ e $C_{4} A F$, é muito maior que 
aquela correspondente ao $\mathrm{C}_{2} \mathrm{~S}$ e $\mathrm{C}_{3} \mathrm{~S}$ por uma ou duas ordens de grandeza (Tazawa et al., 2000), corroborando que a composição do cimento pode influenciar na retração do compósito.

Além das alterações microestruturais inferidas pelos cimentos durante a hidratação, os tamanhos das partículas dos cimentos utilizados também influenciam fortemente os resultados finais, pois mudam o empacotamento do sistema, interferindo na porosidade final. Uma vez que a retração por secagem tem como causa primária a tensão capilar que ocorre durante o processo de secagem no interior dos poros da matriz cimentícia, a distribuição de tamanho de poros é uma importante alteração inferida pelos diferentes cimentos a influenciar nesta propriedade física do fibrocimento, que se trata da propriedade de maior interesse do estudo.

\subsubsection{Metodologia}

A influência do cimento foi estudada através da comparação das propriedades de fibrocimentos com uma mesma formulação padrão, indicada na Tabela 8, mas com diferentes cimentos, com propriedades físico-químicas distintas.

Tabela 8 - Formulação padrão dos fibrocimentos, onde a variável é o cimento utilizado

\begin{tabular}{|c|c|c|c|c|c|}
\hline \multirow{2}{*}{ Formulação } & \multirow{2}{*}{ Tipo de cimento } & \multicolumn{4}{|c|}{ Componente (teor em massa) } \\
\cline { 2 - 4 } & Cim.IIE & CP II E-32 & & & \\
Cim.IIF & CP II F-32 & \multirow{2}{*}{$60 \%$} & $5 \%$ & $30,2 \%$ & $4,8 \%$ \\
\hline Cim.III & CP III-40 & \multirow{2}{*}{$60 \%$} & & & \\
\hline Cim.V & CP V-ARI & & & & \\
\hline Cim.M & Microcimento & & & & \\
\hline
\end{tabular}

As amostras estudadas foram produzidas em laboratório, segundo o método de moldagem descrito no item 2.2.2, e foram submetidas ao plano experimental exposto na Figura 62. Depois de moldados, os corpos-de-prova foram submetidos a duas rotas de ensaios, a primeira determinou as diferenças na retração higroscópica e resistência mecânica; e a segunda caracterizou as formulações em relação aos aspectos microestruturais, como a distribuição de poros (por porosimetria por intrusão de mercúrio e porosidade pelo método de Arquimedes) e as quantificações de compostos hidratados formados (por termogravimetria). 
O ensaio de retração higroscópica foi realizado conforme detalhado no 2.4.1, e determinou a retração na primeira secagem no período de 3 meses, e em seguida após 4 ciclos de molhagem/secagem. Ao término da última secagem, os mesmos corpos-de-prova foram rompidos à flexão, conforme detalhado no item 2.4.2.

O plano experimental realizado está exposto na Figura 62.

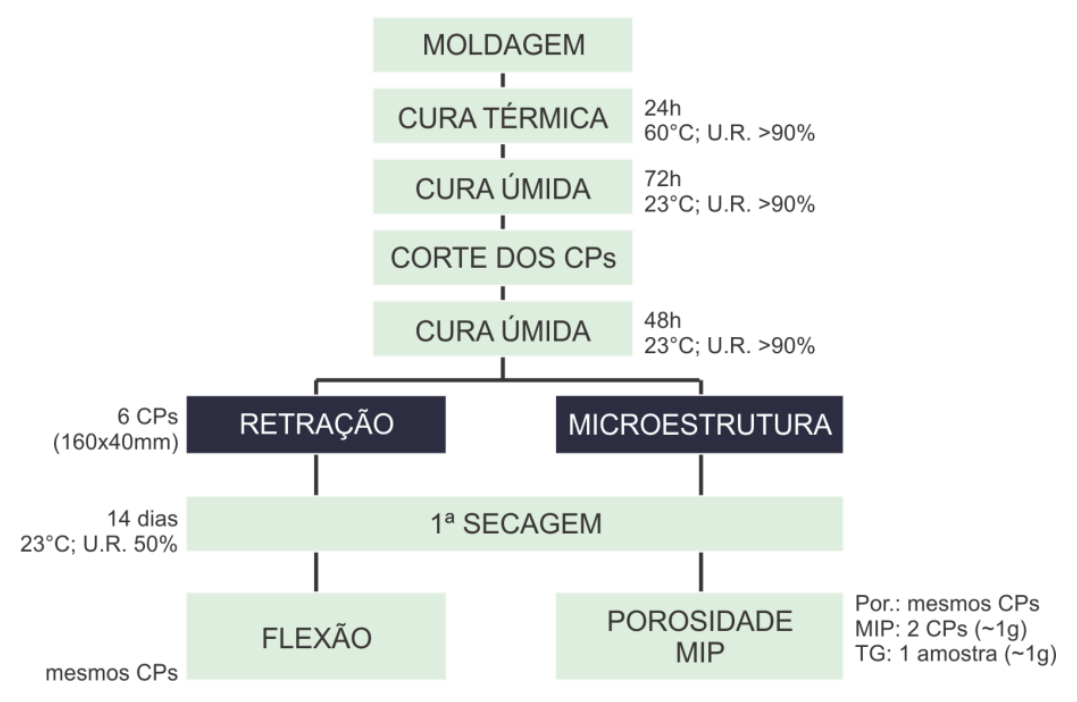

Figura 62 - Plano experimental do estudo da influência do cimento na retração por secagem

\subsubsection{Caracterização dos materiais}

\subsubsection{Composição}

A composição das matérias-primas foi determinada através das técnicas de análise química por fluorescência de raios-X (FRX), difração de raios-X e termogravimetria.

Dentre os cimentos utilizados neste estudo, o cimento CPV-ARI (Cim.V) é aquele cuja composição contém maior teor de clínquer, uma vez que a norma brasileira (ABNT, 1991b) especifica que o teor máximo de filler deve ser de $5 \%$, ou seja, entre $95 \%$ e $100 \%$ de sua composição em massa é de clínquer e sulfato de cálcio. Segundo os resultados de termogravimetria, o teor de carbonatos do Cim.V é de $4,09 \%$ (Tabela 11).

A análise química por FRX aponta que $65,90 \%$ da composição do Cim.V é de $\mathrm{CaO}$, teor mais alto entre todos os cimentos. Estes valores estão em acordo com 
dados de 2006 fornecidos pela $A B C P^{17}$, sobre a composição química de cimentos nacionais, enquadrando-se nos níveis referentes ao CPI-S, cuja composição é similar ao CPV-ARI. As fases cristalinas identificadas através da difração de raios- $X$ foram aquelas típicas do cimento anidro, como o $\mathrm{C}_{3} \mathrm{~S}, \mathrm{C}_{2} \mathrm{~S}, \mathrm{C}_{3} \mathrm{~A}$ e $\mathrm{C}_{4} \mathrm{AF}$, além de calcita referente ao filler, e o sulfato de cálcio foi identificado na fase hemidrato, não sendo identificados picos isolados referentes à gipsita (Figura 63).

Tabela 9 - Análise química dos cimentos utilizados, por FRX

\begin{tabular}{|c|c|c|c|c|c|}
\hline Composição (\%) & Cim.IIE & Cim.IIF & Cim.III & Cim.V & Cim.M \\
\hline CaO - óxido de cálcio & 59,70 & 56,40 & 55,20 & 65,90 & 56,60 \\
\hline $\mathrm{SiO}_{2}$ - anidrido silícico & 20,50 & 12,90 & 24,80 & 17,30 & 22,00 \\
\hline $\mathrm{Al}_{2} \mathrm{O}_{3}$ - óxido de alumínio & 5,76 & 3,28 & 7,66 & 3,99 & 7,08 \\
\hline $\mathrm{Fe}_{2} \mathrm{O}_{3}-$ óxido férrico & 2,29 & 3,16 & 1,81 & 3,29 & 2,48 \\
\hline MgO - óxido de magnésio & 2,36 & 4,94 & 3,46 & 0,58 & 1,71 \\
\hline $\mathrm{SO}_{3}-$ anidrido sulfúrico & 3,90 & 5,00 & 3,09 & 4,59 & 6,64 \\
\hline $\mathrm{Na}_{2} \mathrm{O}-$ óxido de sódio & 0,31 & 0,09 & 0,20 & 0,30 & 0,16 \\
\hline $\mathrm{K}_{2} \mathrm{O}$ - óxido de potássio & 0,91 & 0,33 & 0,69 & 0,94 & 0,73 \\
\hline PF - perda ao fogo & 2,98 & 11,60 & 1,91 & 1,91 & 1,42 \\
\hline
\end{tabular}

Tabela 10 - Valores médios da composição química de cimentos nacionais, segundo dados fornecidos pela ABCP (Souza, 2006)

\begin{tabular}{|c|c|c|c|c|c|c|c|c|}
\hline \multirow{2}{*}{ Composição (\%) } & \multirow{2}{*}{$\begin{array}{l}\text { CP I } \\
\text { S-32 }\end{array}$} & \multicolumn{4}{|c|}{ CPII } & \multicolumn{2}{|c|}{ CP III } & \multirow{2}{*}{$\begin{array}{c}\text { CP IV } \\
32 \\
\end{array}$} \\
\hline & & $E-32$ & $E-40$ & F-32 & Z-32 & 32 & 40 & \\
\hline CaO - óxido de cálcio & 62,90 & 56,94 & 56,79 & 61,18 & 54,01 & 50,43 & 52,88 & 43,17 \\
\hline $\mathrm{SiO}_{2}$ - anidrido silícico & 18,39 & 23,01 & 21,46 & 19,01 & 22,62 & 27,83 & 26,06 & 32,31 \\
\hline $\mathrm{Al}_{2} \mathrm{O}_{3}$ - óxido de alumínio & 4,52 & 7,20 & 5,95 & 4,47 & 6,21 & 8,52 & 8,22 & 9,82 \\
\hline $\mathrm{Fe}_{2} \mathrm{O}_{3}-$ óxido férrico & 2,46 & 2,44 & 2,27 & 2,97 & 3,65 & 1,87 & 1,82 & 3,35 \\
\hline MgO - óxido de magnésio & 5,65 & 3,43 & 4,81 & 3,29 & 3,29 & 5,29 & 4,70 & 3,60 \\
\hline $\mathrm{SO}_{3}-$ anidrido sulfúrico & 3,62 & 2,00 & 2,82 & 2,64 & 2,80 & 1,92 & 2,46 & 2,65 \\
\hline PF - perda ao fogo & 3,11 & 4,53 & 4,50 & 5,21 & 5,17 & 2,38 & 2,36 & 3,01 \\
\hline $\mathrm{RI}$ - resíduo insolúvel & 0,83 & 1,17 & 0,93 & 1,43 & 10,85 & 0,70 & 0,47 & 27,83 \\
\hline
\end{tabular}

A composição do cimento CPII-F, segundo a norma brasileira (ABNT, 1997), pode conter maior quantidade de adição mineral carbonática, dentro do intervalo de $6 \%$ a $10 \%$, o que significa que a quantidade total de clínquer e sulfatos de cálcio será de $90 \%$ a $94 \%$. Segundo os resultados de termogravimetria, a quantidade total de carbonato de cálcio presente no cimento Cim.IIF é de 18,22\% (Tabela 11), acima

\footnotetext{
${ }^{17}$ Associação Brasileira de Cimento Portland
} 
do especificado por norma, o que resulta uma menor quantidade de $\mathrm{CaO}$ medida na análise química (Tabela 9), no entanto, mantendo a relação $\mathrm{CaO} / \mathrm{SiO}_{2}$ alta, em 4,37\%, acima do valor encontrado para o Cim.V, devido ao cálcio contido no carbonato.

As fases cristalinas identificadas no cimento Cim.IIF por DRX foram as mesmas presentes no Cim.V, no entanto, as fases sulfato de cálcio foram identificadas tanto na forma de hemidrato como na forma de gipsita, como esta destacado na Figura 63. Esta maior quantidade de gipsita pode ser confirmada pela perda de massa medida por termogravimetria, em torno de $150^{\circ} \mathrm{C}$, região onde ocorre a perda de voláteis do $\mathrm{C}-\mathrm{S}-\mathrm{H}$, aluminatos hidratados e gipsita (Tabela 11). A intensidade dos picos referentes aos compostos anidros do cimento, como o $\mathrm{C}_{3} \mathrm{~S}, \mathrm{C}_{2} \mathrm{~S}, \mathrm{C}_{3} \mathrm{~A}$ e $\mathrm{C}_{4} \mathrm{AF}$ (entre 32 e $35^{\circ} 2$ th), não apresentaram grande diferença de intensidade, no entanto os picos da calcita foram mais intensos no Cim.IIF, indicando a maior quantidade deste carbonato presente na amostra.

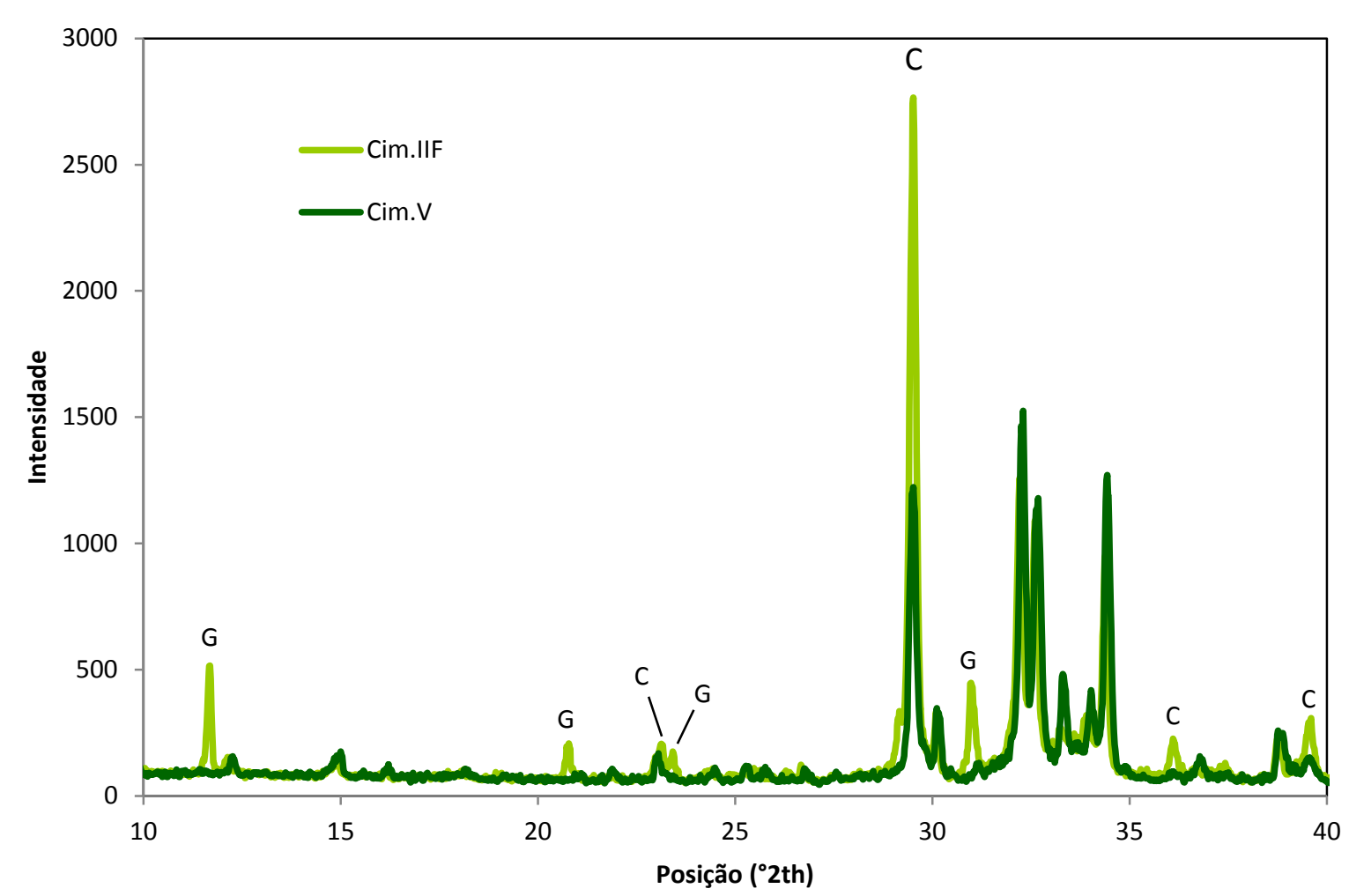

Figura 63 - Difratogramas dos cimentos Cim.V e Cim.IIF

O cimento CPII-E (Cim.IIE), segundo a norma brasileira (ABNT, 1997), pode conter pequena quantidade de filler carbonático, de até $10 \%$, sendo medido através da termogravimetria um teor de $8,6 \%$ (Tabela 11). Mas, este cimento pode conter 
também adição de escória granulada de alto-forno em grande quantidade, entre 6\% e $34 \%$ segundo a norma, o que significa que a quantidade de clínquer é menor neste cimento. A análise química indica um teor de $59,7 \%$ de $\mathrm{CaO}$, no entanto, parte deste cálcio é referente à escória, que se soma ao cálcio do clínquer, uma vez que a escória é composta essencialmente de $\mathrm{CaO}$ (24 a 45\%), $\mathrm{SiO}_{2}$ (30 a 55\%), $\mathrm{Al}_{2} \mathrm{O}_{3}$ (8 a $19 \%$ ) e $\mathrm{MgO}$ (1,5 a 9\%) (John; Agopyan, 2000). Uma vez que a relação $\mathrm{CaO} / \mathrm{SiO}_{2}$ da escória é inferior à do clínquer, as alterações na análise química nestes dois óxidos, acabam por reduzir a relação $\mathrm{CaO} / \mathrm{SiO}_{2}$ do cimento para 2,91, como está verificado nos resultados de análise química (Tabela 9).

As fases cristalinas identificadas por DRX no cimento Cim.IIE foram as mesmas contidas no Cim.IIF, com a observação de picos isolados referentes à gipsita, e com intensidade dos picos da calcita inferiores ao Cim.IIF, porém superiores ao Cim.V. Neste cimento foi identificada a presença de quartzo, com pico característico em torno de $26,6^{\circ} 2$ th. Não foram identificados picos isolados que caracterizasse a presença de melilita, merwinita ou mayenita, compostos comuns em cimentos contendo escória, no entanto, é possível que haja hidrotalcita, fase em que o Mg da escória está presente. O principal indicativo observado do difratograma do Cim.IIE, que caracteriza a presença de escória neste cimento, é o aumento do halo amorfo na região entre 25 e $35^{\circ} 2$ th, característico da escória, além da redução da intensidade dos picos referentes ao $\mathrm{C}_{3} \mathrm{~S}, \mathrm{C}_{2} \mathrm{~S}, \mathrm{C}_{3} \mathrm{~A}$ e $\mathrm{C}_{4} \mathrm{AF}$, indicando a menor quantidade de clínquer neste cimento.

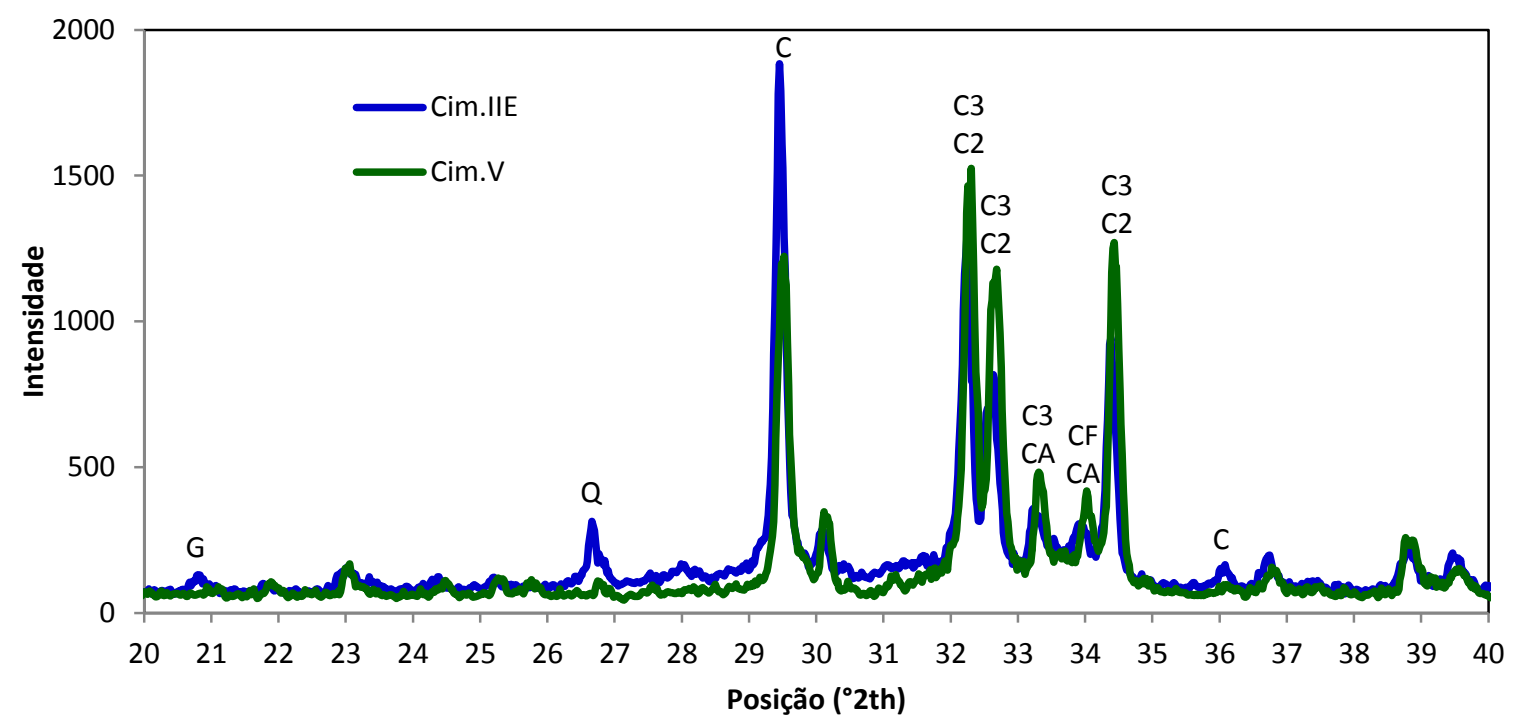

Figura 64 - Difratogramas dos cimentos Cim.V e Cim.IIE 


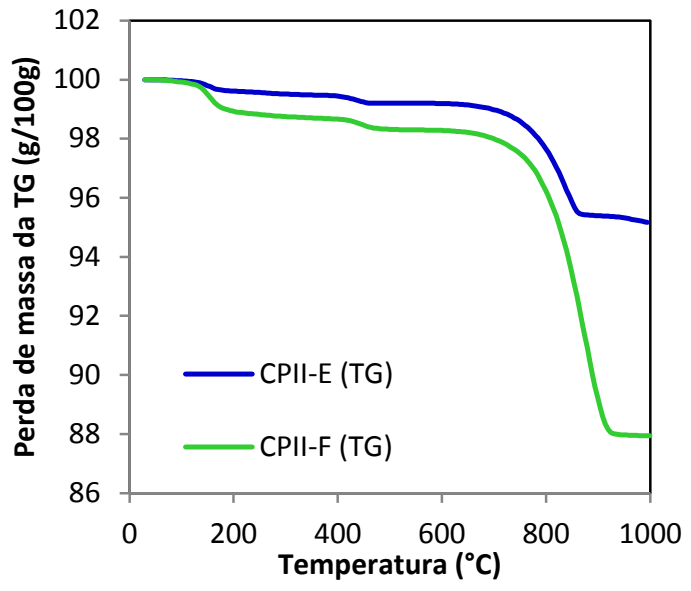

(a)

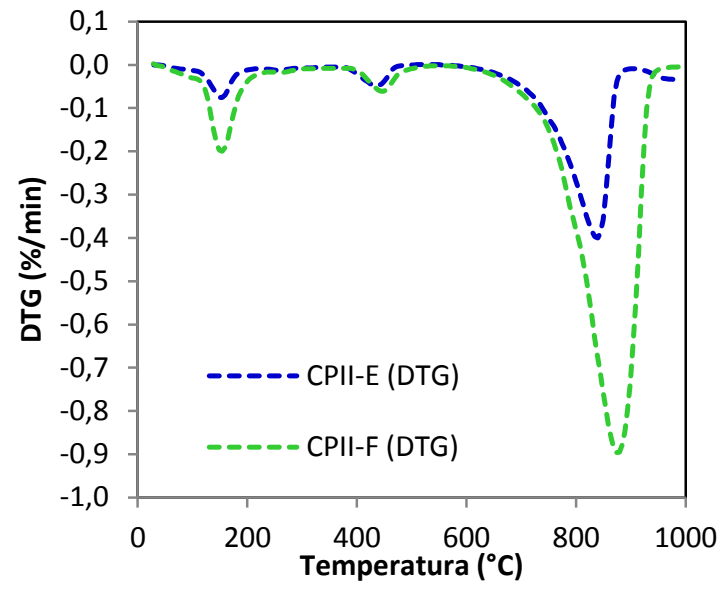

(b)

Figura 65 - (a) Termogravimetria (TG) e (b) primeira derivada da termogravimetria (DTG) dos cimentos compostos

O cimento CPIII (Cim.III) é similar ao CPII-E, no entanto, com maior quantidade de escória de alto forno em sua composição, que segundo a norma brasileira(ABNT, 1991a) pode variar entre $35 \%$ e $70 \%$, o que significa que a quantidade de clínquer e sulfato de cálcio é menor neste cimento (de 25 a 65\%). Além da escória, a norma brasileira permite a adição de pequena quantidade de filler carbonático, até o teor de $5 \%$, sendo medido através da termogravimetria um teor de $6,62 \%$ para o cimento estudado (Tabela 11). A análise química indica um teor de $55,2 \%$ de $\mathrm{CaO}$, no entanto, do mesmo modo observado para o Cim.IIE, parte deste cálcio é referente à escória, que se soma ao cálcio do clínquer. Neste caso, também houve uma redução da relação $\mathrm{CaO} / \mathrm{SiO}_{2}$ do cimento (Tabela 9).

As fases cristalinas identificadas por DRX no cimento Cim.III foram as mesmas contidas no Cim.IIE, sem a identificação de quartzo. A intensidade dos picos da calcita foram bastante inferiores ao Cim.IIE, no mesmo patamar do observado no difratograma do Cim.V. Apesar da adição em grande quantidade de escória, não foram identificados picos isolados que caracterizasse a presença de melilita, merwinita ou mayenita, compostos comuns em cimentos contendo este tipo de adição, no entanto, também é possível que haja hidrotalcita em sua composição, fase em que o $\mathrm{Mg}$ da escória está presente. O principal indicativo observado do difratograma do Cim.III, que caracteriza a presença de escória neste cimento, é o aumento do halo amorfo na região entre 25 e $35^{\circ} 2$ th, que para este cimento foi bastante evidente, além da considerável redução da intensidade dos picos 
referentes ao $\mathrm{C}_{3} \mathrm{~S}, \mathrm{C}_{2} \mathrm{~S}, \mathrm{C}_{3} \mathrm{~A}$ e $\mathrm{C}_{4} \mathrm{AF}$, indicando a menor quantidade de clínquer neste cimento (Figura 66).

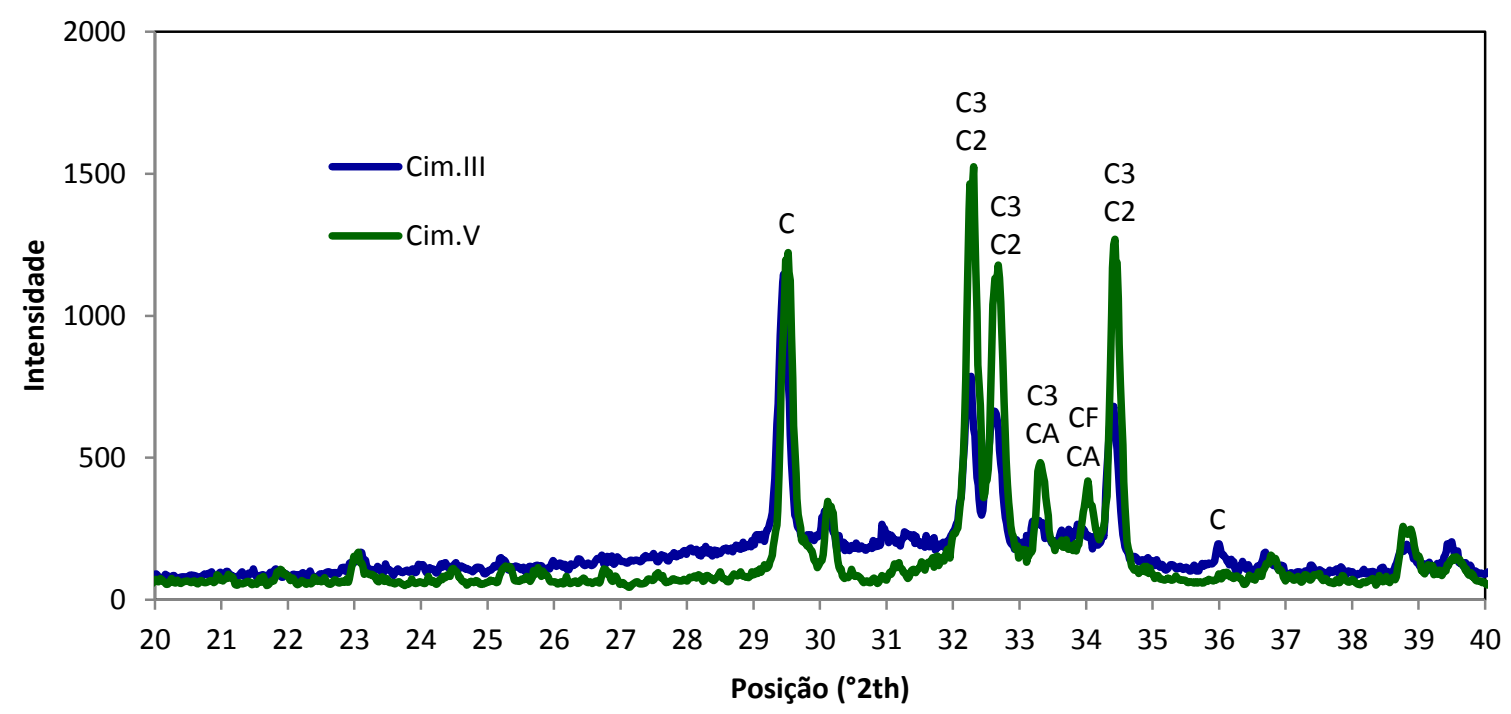

Figura 66 - Difratogramas dos cimentos Cim.V e Cim.III

O microcimento (Cim.M) não possui normalização nacional com especificação de sua composição. Este cimento é comercializado como um produto de granulometria diferenciada, ultrafina, no entanto sem especificação quanto à composição. Os resultados de FRX observados indicam que o Cim.M não é composto essencialmente de clínquer e carbonato de cálcio (como é o caso do Cim.V), pois a quantidade de $\mathrm{CaO}$ medida é baixa $(56,6 \%)$. A pequena quantidade de material carbonático presente, medida por termogravimetria (Tabela 11), e a baixa relação $\mathrm{CaO} / \mathrm{SiO}_{2}$ (Tabela 9) são indicativos de que a adição incorporada à formulação deste cimento pode ser escória, hipótese que é validada pelos resultados de DRX, que apresenta perfil similar ao do Cim.III, com halo amorfo destacado, porém em menor intensidade, e com a redução das intensidades dos picos referentes ao $\mathrm{C}_{3} \mathrm{~S}, \mathrm{C}_{2} \mathrm{~S}$, $\mathrm{C}_{3} \mathrm{~A}$ e $\mathrm{C}_{4} \mathrm{AF}$ (entre 32 e $35^{\circ} 2$ th) (Figura 67). 


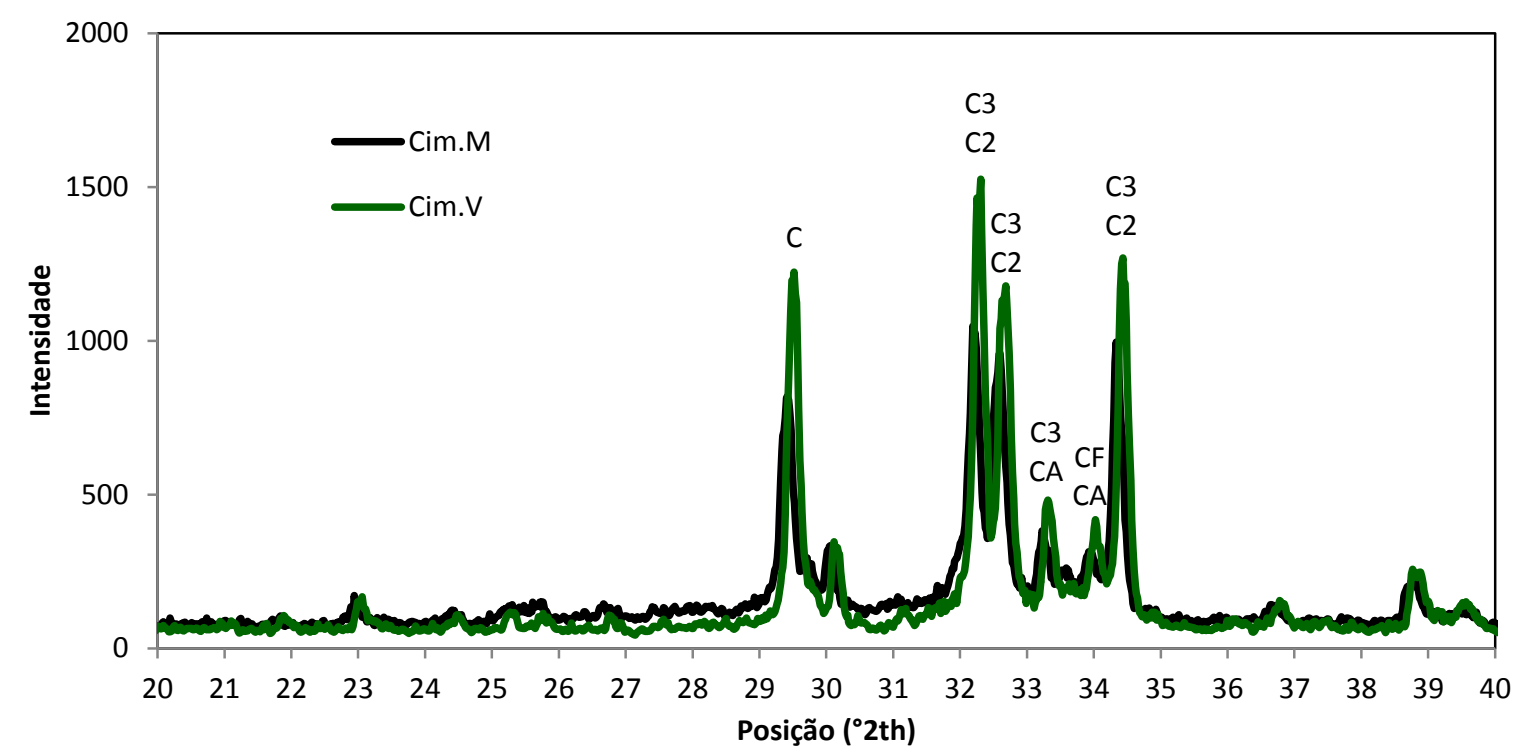

Figura 67 - Difratogramas dos cimentos Cim.V e Cim.M

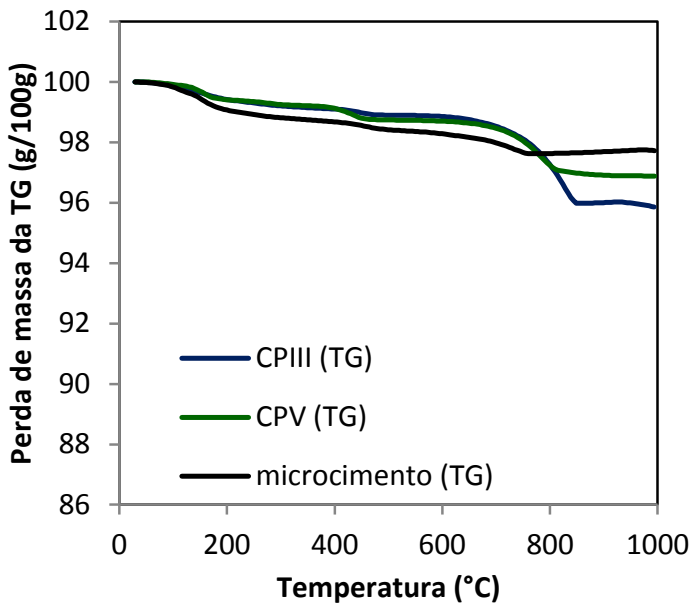

(a)

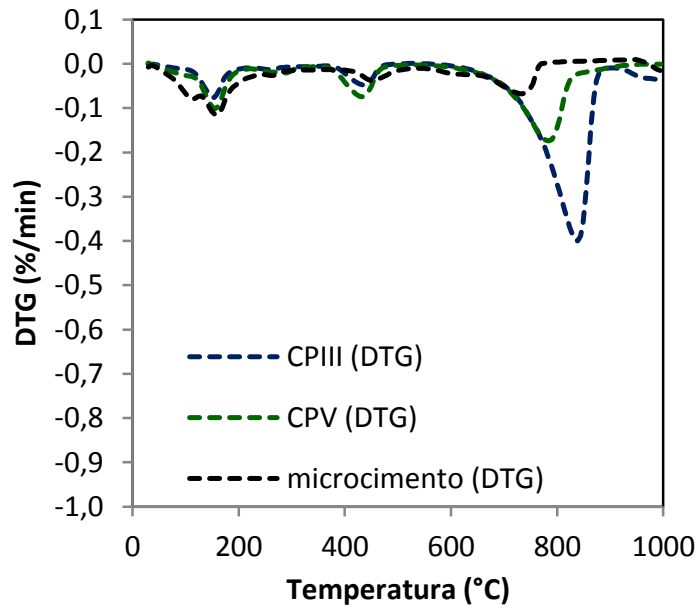

(b)

Figura 68 - (a) Termogravimetria (TG) e (b) primeira derivada da termogravimetria (DTG) dos cimentos Cim.III, Cim.V e Cim.M

Tabela 11 - Perdas de massa calculadas a partir da termogravimetria das matérias-primas $(\mathrm{g} / 100 \mathrm{~g})$

\begin{tabular}{|ll|c|c|c|c|c|}
\hline FASE & Cim.IIE & Cim.IIF & Cim.III & Cim.V & Cim.M \\
\hline $\begin{array}{l}\text { C-S-H } \\
\begin{array}{l}\text { Aluminatos } \\
\text { Gipsita }\end{array}\end{array}$ & 0,34 & 1,11 & 0,37 & 0,50 & 0,71 \\
\hline \multirow{2}{*}{ Portlandita } & voláteis & 0,28 & 0,38 & 0,20 & 0,45 & 0,26 \\
\cline { 2 - 7 } & $\mathrm{Ca}(\mathrm{OH})_{2}{ }^{*}$ & 1,11 & 1,36 & 0,78 & 1,81 & 1,03 \\
\hline Carbonatos & voláteis & 3,97 & 9,11 & 3,04 & 1,86 & 0,75 \\
\hline $\mathrm{CaCO}_{2}{ }^{*}$ & 8,60 & 18,22 & 6,62 & 4,09 & 1,66 \\
\hline residual & 95,15 & 87,94 & 95,84 & 96,88 & 97,72 \\
\hline
\end{tabular}

* calculado na base volátil 
A Figura 69 mostra a termogravimetria do calcário e da sílica utilizados na confecção dos fibrocimentos. Observa-se por estes resultados que o calcário utilizado é dolomítico, pois aparecem dois picos de perda de voláteis na TG, o primeiro em torno de $750^{\circ} \mathrm{C}$ e o segundo em torno de $900^{\circ} \mathrm{C}$.

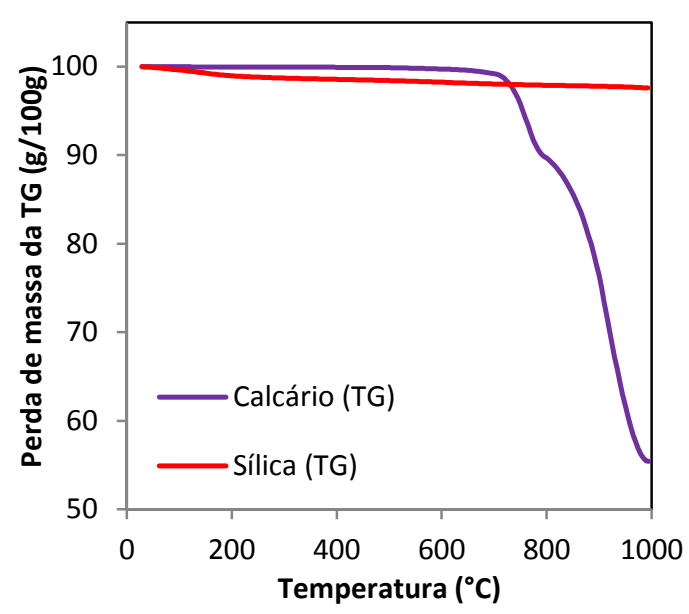

(a)

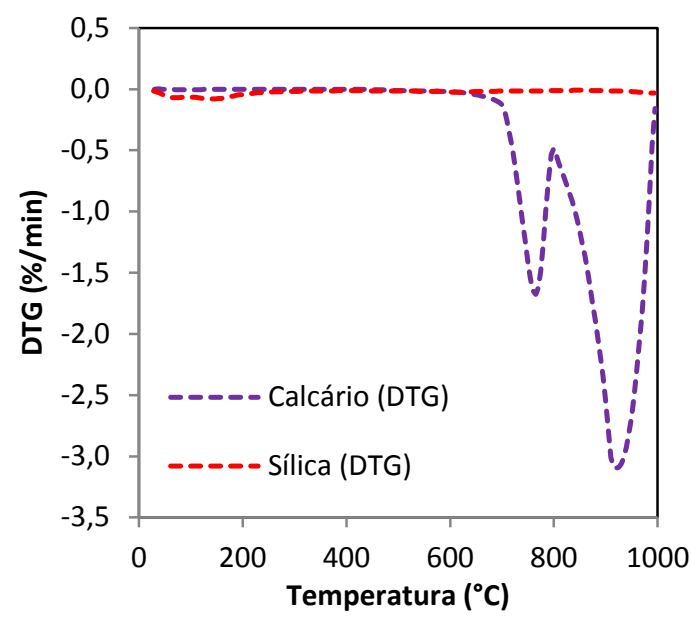

(b)

Figura 69 - (a) Termogravimetria (TG) e (b) primeira derivada da termogravimetria (DTG) do calcário e da sílica

\subsubsection{Propriedades físicas}

As propriedades físicas dos materiais utilizados neste estudo foram avaliadas segundo a distribuição de tamanho de partículas (granulometria a laser), área específica BET e massa específica real por picnometria de gás hélio.

Os resultados de distribuição de tamanho de partículas determinada em granulômetro laser mostraram que houve grande variação na finura dos 5 cimentos estudados. A Figura 70, que mostra a distribuição acumulada, é mais fácil visualizar que os cimentos estudados estão agrupados em 3 níveis de tamanho de partículas, sendo os cimentos Cim.M e Cim.III os mais finos, os cimentos Cim.V e Cim.IIF com tamanho intermediário, e o cimento Cim.IIE o mais grosso. As características dos cimentos estão na Tabela 12 e Figura 70. 
Tabela 12 - Parâmetros D10, D50 e D90 obtidos a partir da curva de distribuição do tamanho de partículas dos cimentos estudados

\begin{tabular}{|c|c|c|c|c|c|}
\hline \multirow{2}{*}{ Parâmetros } & \multicolumn{5}{|c|}{ Tipo de cimento (diâmetros em $\boldsymbol{\mu m}$ ) } \\
\cline { 2 - 6 } & Cim.IIE & Cim.IIF & Cim.III & Cim.V & Cim.M \\
\hline D10 & 5,2 & 3,1 & 2,3 & 3,4 & 1,6 \\
\hline D50 & 36,0 & 18,9 & 13,5 & 18,6 & 12,8 \\
\hline D90 & 97,1 & 59,5 & 34,4 & 47,1 & 41,7 \\
\hline
\end{tabular}

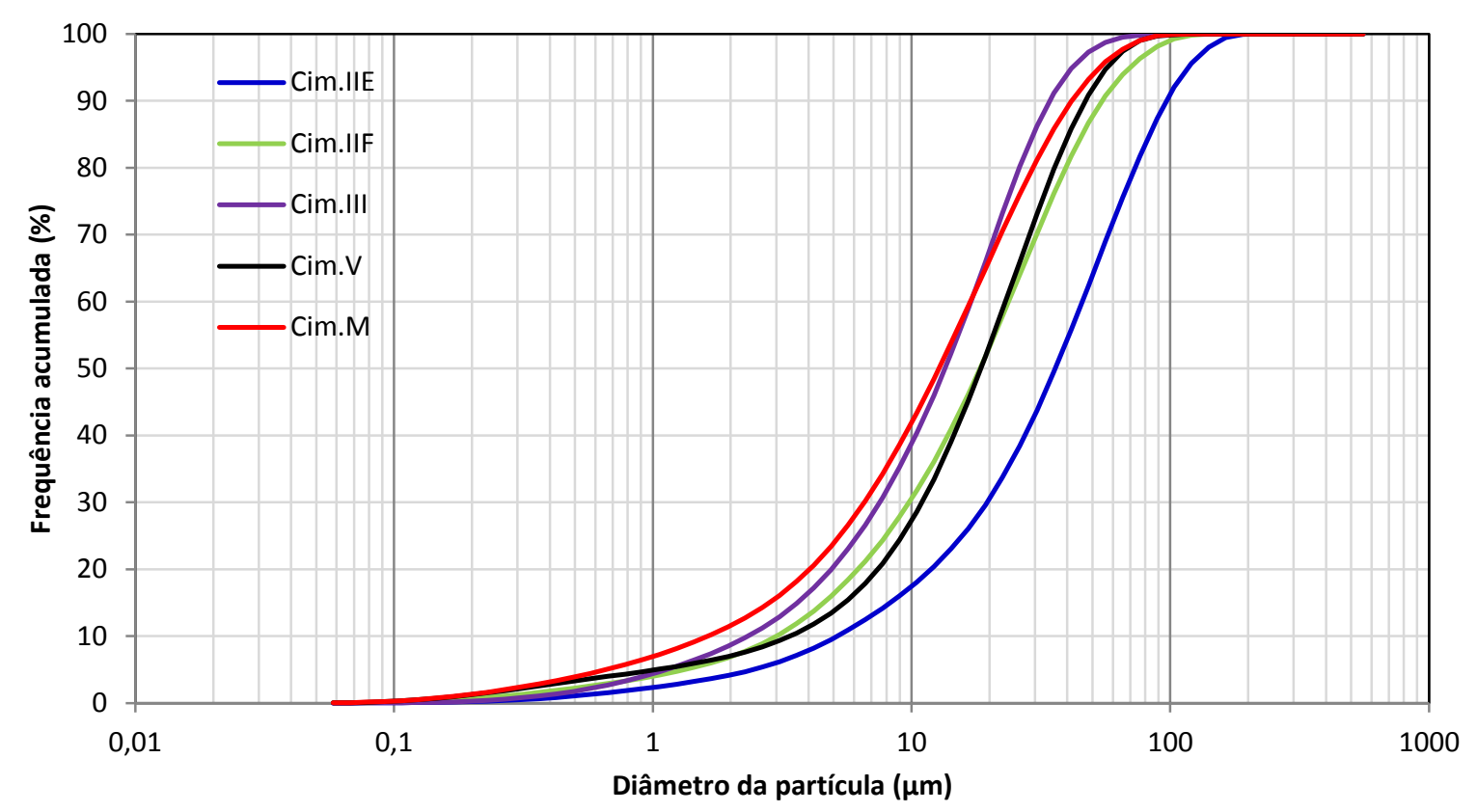

Figura 70 - Distribuição acumulada do tamanho de partículas dos cimentos estudados

As adições minerais que compõe o fibrocimento possuem distribuições de tamanho de grãos distintas, sendo que o calcário tem grãos de tamanho similar ao do cimento Cim.IIE, com diâmetro D50 de 35,3 $\mu \mathrm{m}$, no entanto, com uma maior quantidade de partículas mais grossas, como pode ser observado pela Figura 71 na faixa entre 200 e $400 \mu \mathrm{m}$. A sílica é uma adição mineral com partículas mais finas que as demais matérias-primas (Figura 71), apesar de se encontrar aglomerada no momento do uso, com maior diâmetro D50 $(9,3 \mu \mathrm{m})$, o que certamente melhorará o empacotamento das partículas do compósito (Tabela 13).

Tabela 13 - Parâmetros D10, D50 e D90 obtidos a partir da curva de distribuição do tamanho de partículas das adições minerais utilizadas

\begin{tabular}{|c|c|c|}
\hline \multirow{2}{*}{ Parâmetros } & \multicolumn{2}{|c|}{ Tipo de cimento (diâmetros em $\boldsymbol{\mu m}$ ) } \\
\cline { 2 - 3 } & Calcário & Sílica \\
\hline D10 & 3,3 & 2,7 \\
\hline D50 & 35,3 & 9,3 \\
\hline D90 & 126,2 & 19,2 \\
\hline
\end{tabular}




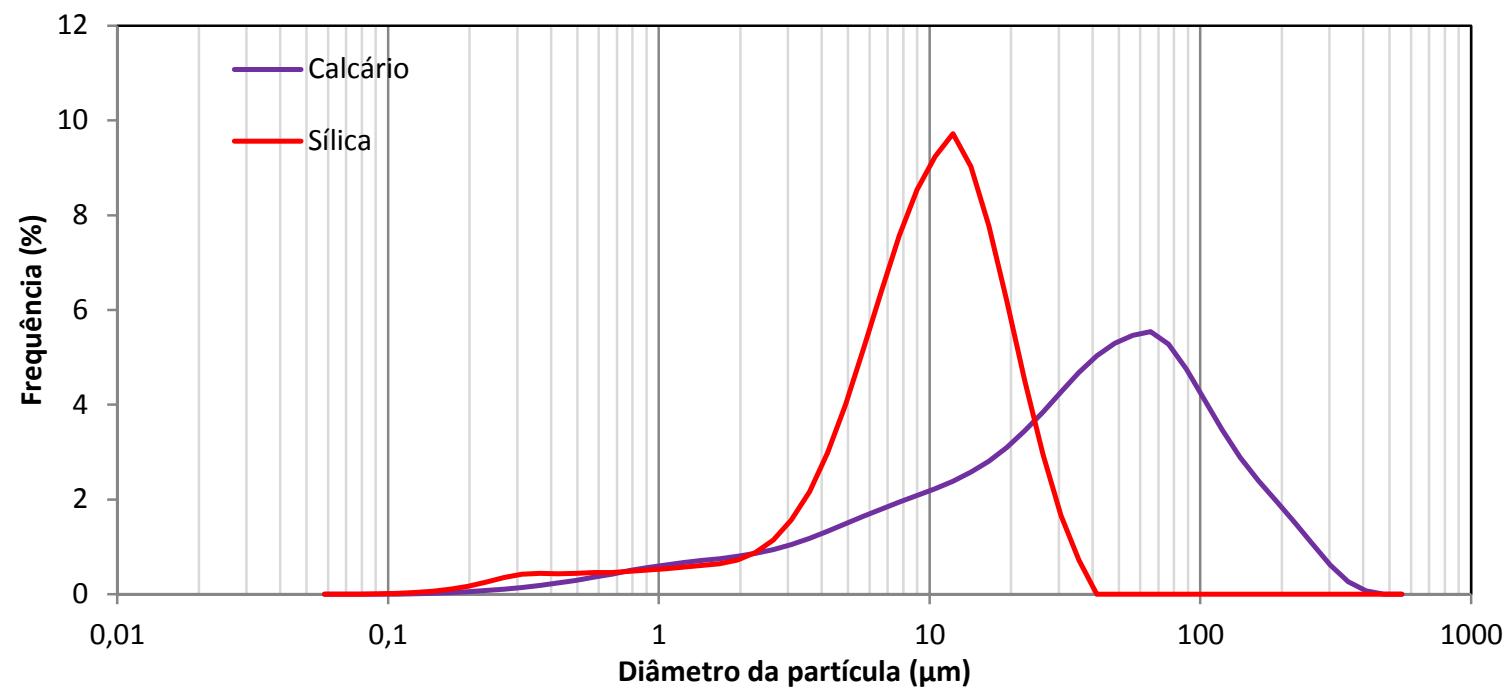

Figura 71 - Distribuição do tamanho de partículas das adições minerais

A superfície específica dos materiais foi determinada pelo método BET, cujo procedimento experimental está detalhado no item 2.3.4, e tem relação com o tamanho das partículas e rugosidade dos materiais. A sílica ativa é o material mais fino dentre as matérias-primas, e também é o material com maior área específica, em torno de 10 vezes maior que os demais materiais (Tabela 14), o que confere grande reatividade a este material.

Tabela 14 - Superfície específica das matérias-primas

\begin{tabular}{|c|c|c|}
\hline & Amostra & Superfície específica $\left(\mathrm{m}^{2} / \mathrm{g}\right)$ \\
\hline \multirow{5}{*}{ Cimentos } & Cim.IIE & 1,3034 \\
\hline & Cim.IIF & 2,1542 \\
\hline & Cim.III & 1,6142 \\
\hline & Cim.V & 2,3072 \\
\hline & Cim.M & 2,7669 \\
\hline \multirow{2}{*}{$\begin{array}{l}\text { Adições } \\
\text { minerais }\end{array}$} & Calcário & 1,1505 \\
\hline & Sílica & 15,6657 \\
\hline
\end{tabular}

A densidade real dos materiais foi determinada por picnometria de gás hélio, cuja descrição do procedimento experimental está relatada no item 2.3.5. Os resultados mostraram que a densidade dos materiais que compõe o fibrocimento varia pouco, sendo que o cimento que contém maior quantidade de adição mineral incorporada (Cim.III) é menos denso. A sílica é o material menos denso entre todos os pós (Tabela 15). As fibras possuem densidade menor que os pós, desta forma, apesar 
de serem adicionadas em pequena quantidade em massa, ocupam grande volume do compósito pronto.

Tabela 15 - Massa específica das matérias-primas

\begin{tabular}{|c|c|c|c|}
\hline & Material & Massa específica $\left(\mathrm{g} / \mathrm{cm}^{3}\right)$ & Desvio padrão $\left(\mathrm{g} / \mathrm{cm}^{3}\right)$ \\
\hline \multirow{6}{*}{ Cimentos } & Cim.IIE & 2,90 & 0,01 \\
\hline & Cim.IIF & 2,94 & 0,01 \\
\hline & Cim.III & 2,88 & 0,01 \\
\hline & Cim.IV & 2,72 & 0,06 \\
\hline & Cim.V & 3,00 & 0,01 \\
\hline & Cim.M & 2,92 & 0,04 \\
\hline \multirow{2}{*}{$\begin{array}{l}\text { Adições } \\
\text { minerais }\end{array}$} & Calcário & 2,73 & 0,01 \\
\hline & Sílica & 2,04 & 0,07 \\
\hline \multirow{2}{*}{ Fibras } & Celulose & 0,89 & 0,01 \\
\hline & PVA & 1,49 & 0,02 \\
\hline
\end{tabular}

\subsubsection{Cinética de hidratação}

Outro importante indicador de desempenho dos cimentos é a determinação do fluxo de calor liberado durante a sua hidratação, medida por calorimetria isotérmica de condução, que reflete a cinética de reações químicas durante o enrijecimento da matriz cimentícia.

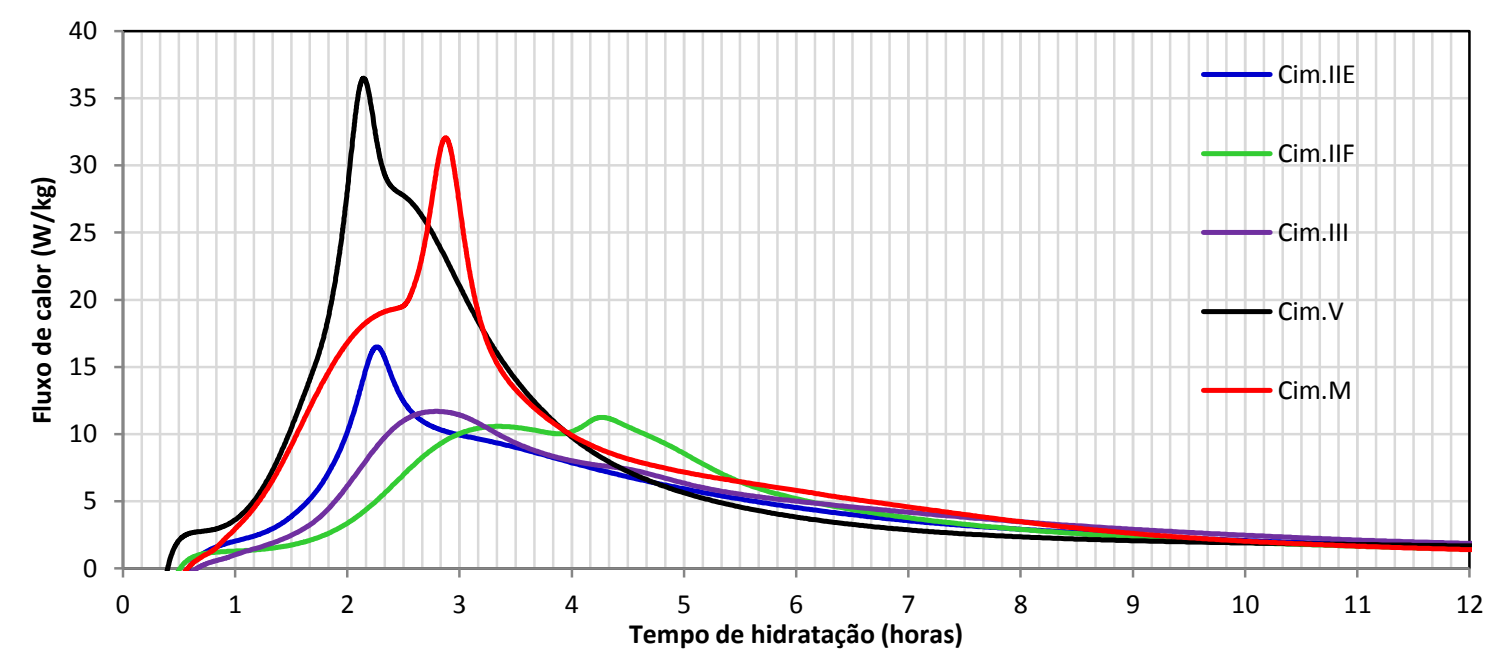

Figura 72 - Fluxo de calor liberado durante o ensaio de calorimetria para os cimentos estudados 


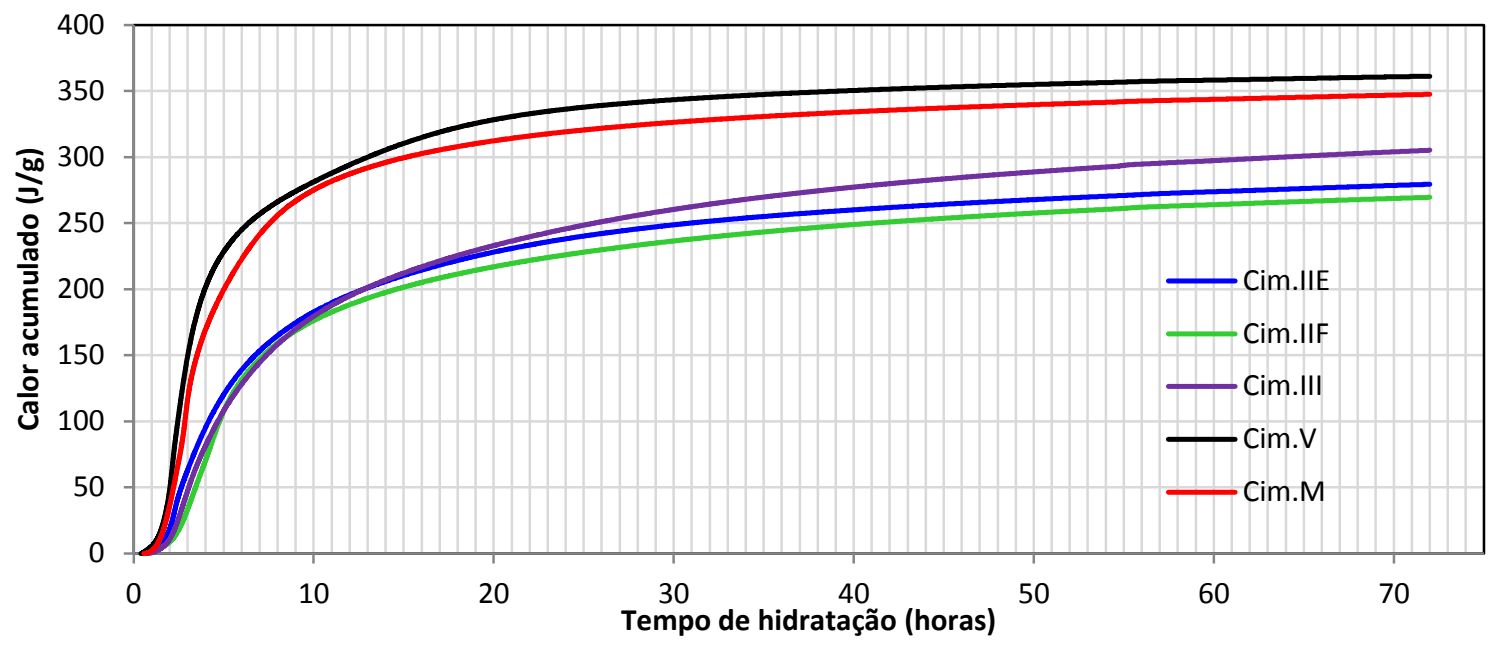

Figura 73 - Calor acumulado liberado durante o ensaio de calorimetria para os cimentos estudados

Os resultados de calorimetria realizados em ambiente com temperatura de $60^{\circ} \mathrm{C}$ indicam que há 2 níveis de reatividade entre os cimentos estudados, sendo que os cimentos Cim.V e Cim.M são os mais reativos entre todos (Figura 72). O tempo de início do período de aceleração da formação de C-S-H ocorre de 12 a 46 minutos antes para estes cimentos (reações de hidratação são iniciadas em menor tempo), com tempos de 44 (Cim.V) e 45 minutos (Cim.M) (Tabela 16). Além disso, a taxa de aceleração é elevada, indicando que as reações de hidratação ocorrem em maior velocidade durante a aceleração (Cim.V $=16,03 \mathrm{~W} / \mathrm{kg} / \mathrm{h}$; Cim.M $=15,18 \mathrm{~W} / \mathrm{kg} / \mathrm{h}$ ) (Tabela 16).

Os cimentos Cim.IIE, Cim.IIF e Cim.III apresentaram um nível intermediário de reatividade, como apresenta a Figura 72 . Os tempos de início do período de aceleração foram de $1 \mathrm{~h} 04 \mathrm{~min}, 1 \mathrm{~h} 10 \mathrm{~min}$ e 56 minutos, respectivamente, com taxa de reação no período de aceleração de 9,33 W/kg/h (Cim.IIE), 8,01 W/kg/h (Cim.IIF) e 10,79 W/kg/h (Cim.III) (Tabela 16).

Tabela 16 - Tempo de início do período de aceleração, velocidade (taxa) da reação de hidratação durante o período de aceleração e calor acumulado em 72 horas de hidratação

\begin{tabular}{|c|c|c|c|}
\hline Cimento & $\begin{array}{c}\text { Taxa de hidratação } \\
\text { (W/kg/h) }\end{array}$ & $\begin{array}{c}\text { Início do período de aceleração } \\
\text { (h:min) }\end{array}$ & $\begin{array}{c}\text { Calor acumulado em 72 horas } \\
\text { (J/g) }\end{array}$ \\
\hline Cim.IIE & 9,32 & $01: 04$ & 279,4 \\
\hline Cim.IIF & 8,01 & $01: 10$ & 269,5 \\
\hline Cim.III & 10,79 & $00: 56$ & 305,1 \\
\hline Cim.V & 16,03 & $00: 44$ & 361,2 \\
\hline Cim.M & 15,18 & $00: 45$ & 347,5 \\
\hline
\end{tabular}




\subsubsection{Resultados e discussões}

Os cimentos Cim.III, Cim.V e Cim.M utilizados neste estudo possuem composição distintas, como mostrado na caracterização dos materiais (item 4.1.4.1). O Cim.III se trata de um cimento com grande adição de escória, que pode ser superior à 50\% da composição do cimento, enquanto que o Cim.V é um cimento de alta resistência inicial, com mais de $95 \%$ de sua composição constituída de clínquer e sulfato de cálcio. O Cim.M tem composição intermediária, com possível adição de escória em teor inferior ao Cim.III.

Apesar das grandes diferenças apresentadas entre estes 3 cimentos, todos possuem alta reatividade, determinada por calorimetria isotérmica, com reduzido tempo de início das reações de formação de C-S-H (índice que possui boa correlação com o tempo de início de pega), e com grande taxa (velocidade) de formação dos principais compostos hidratados do cimento, como mostrado na Tabela 16. A reatividade elevada destes cimentos não tem mesma causa, entretanto, em todos os casos o tamanho médio de partículas é pequeno, segundo os índices D10 e D50, em comparação com os demais cimentos estudados, o que favorece a alta reatividade. Como consequência da elevada finura, a porosidade total dos fibrocimentos foi menor em comparação com os compósitos produzidos com os demais cimentos, tanto quando se analisam os dados obtidos pelo ensaio de absorção de água como pelo volume total de mercúrio intrudido por MIP (Figura 74); comportamento este que é resultado de um melhor empacotamento de partículas.

Os cimentos Cim.IIE e Cim.IIF são classificados como cimentos compostos segundo a norma técnica brasileira (ABNT, 1997). Isso significa dizer que a quantidade de adições minerais em suas formulações é menor, mantendo o teor de clínquer em patamares mais elevados. Ainda assim, no caso do Cim.IIE, este pode conter até $35 \%$ de escória adicionada. A caracterização destes cimentos mostra que as suas composições são distintas, sendo identificado por DRX que a quantidade de clínquer presente no Cim.IIE é menor que nos demais, devido à adição de escória (Figura 64). O cimento Cim.IIF é o único que contém apenas adição carbonática em sua composição. Este é o mais fino, entre estas 2 amostras analisadas (Tabela 12), com superfície específica de $1,95 \mathrm{~m}^{2} / \mathrm{g}$, no entanto, não apresentou grande reatividade. 
Apesar destas diferenças apresentadas entre os cimentos, estes apresentaram tamanho médio de partículas maiores, segundo o índice D50, em comparação com os demais cimentos estudados. Como consequência do grande tamanho de partículas, a porosidade total dos fibrocimentos foi maior (Figura 74); pois o empacotamento de partículas foi pior.

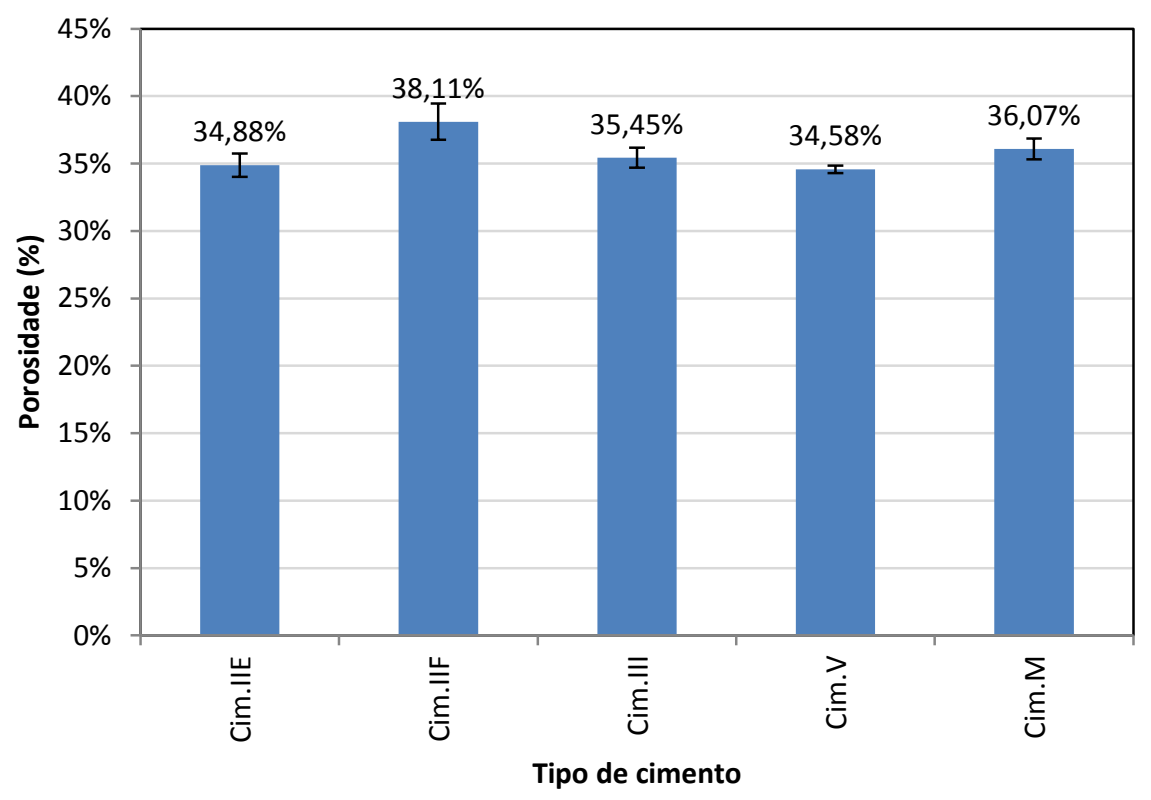

Figura 74 - Porosidade total dos fibrocimentos com diferentes tipos de cimento

Quando se varia o tipo de cimento, a porosidade total não apresenta boa correlação com a retração, uma vez que esta variação volumétrica é função da quantidade de poros suscetíveis à tensão capilar. $O$ intervalo de porosidade entre as amostras foi de 34,58 a $39,62 \%$, e não apresentou correlação com a retração por secagem, como pode ser visto na Figura 76. 


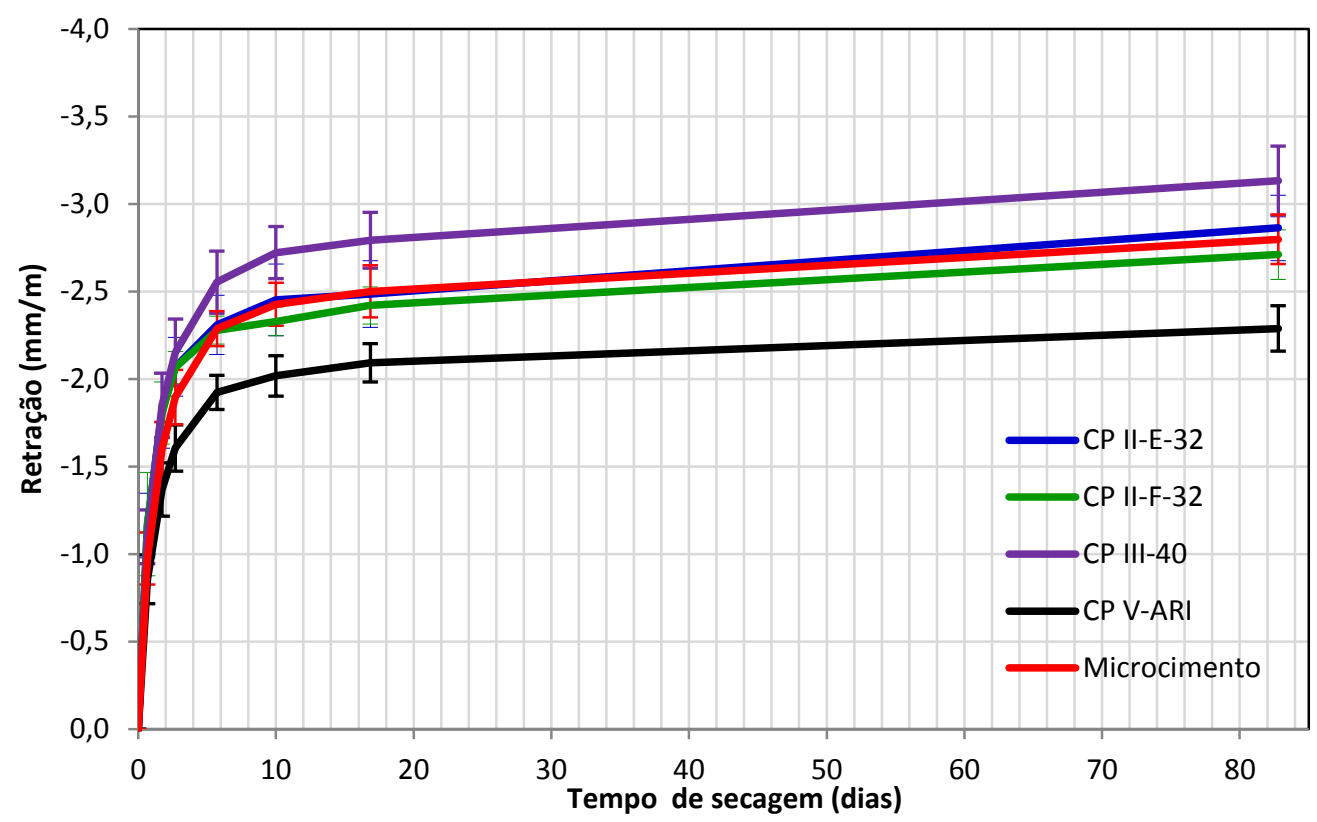

Figura 75 - Retração por secagem dos fibrocimentos com diferentes tipos de cimento

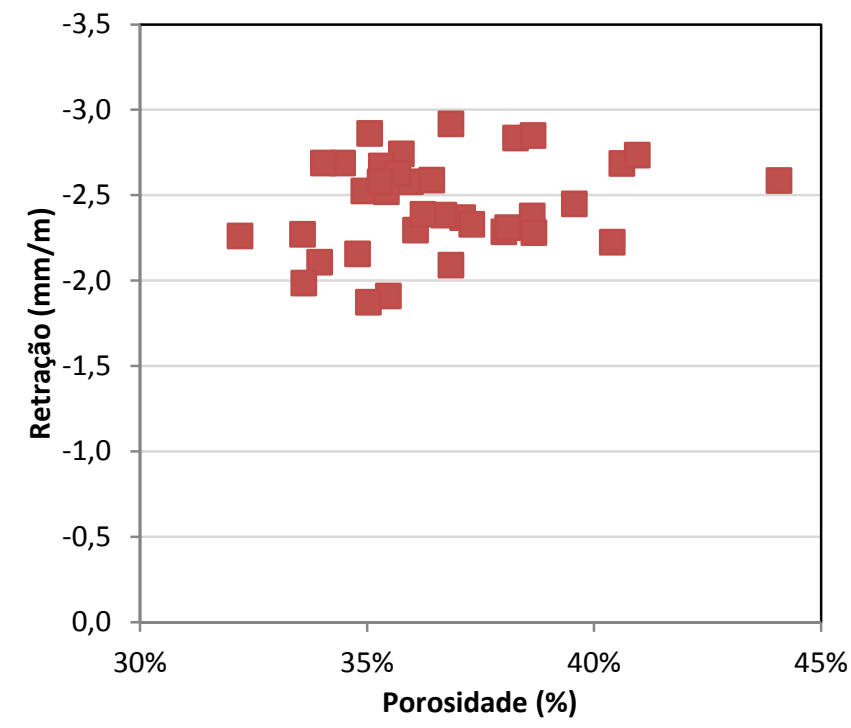

Figura 76 - Efeito da porosidade na retração do fibrocimento, aos 14 dias de secagem

O fibrocimento Cim.III apresentou elevada retração aos 83 dias de secagem, reduzindo em média seu comprimento em $3,13 \mathrm{~mm} / \mathrm{m}$ (Figura 75 ) para uma perda de água de 12,63\%. Esta elevada variação volumétrica é atribuída à escória incorporada à formulação, que segundo a bibliografia consultada (Giordano; Souza; John, 2009), aumenta a retração por secagem dos compósitos cimentícios devido a alterações na distribuição de tamanho de poros do mesmo. Segundo a equação de Laplace (Equação 1), quanto menor o diâmetro do poro, maior será a tensão capilar atuante no mesmo. Os resultados de distribuição de tamanho de poros por 
porosimetria por intrusão de mercúrio mostram este refinamento dos poros, confirmando os dados bibliográficos, com maior volume de poros nas faixas de mesoporos e poros de gel (Figura 77 e Tabela 17), que são aqueles com potencial de ocorrência da tensão capilar.

O fibrocimento Cim.V apresentou retração pequena, a menor entre todos os cimentos estudados, com valor médio aos 83 dias de secagem de $2,29 \mathrm{~mm} / \mathrm{m}$ (Figura 75) para uma perda de água de $12,13 \%$. Apesar da porosidade total estar no mesmo nível da medida para o Cim.III, a distribuição de tamanho de poros nos fibrocimentos com Cim.V é menos favorável à ação da tensão capilar, uma vez que o volume de poros de gel e mesoporos é menor nestas amostras (Figura 77 e Tabela 17).

Os valores de retração medidos no fibrocimento Cim.M foram intermediários às duas amostras anteriores, com redução linear de 2,80 mm/m (Figura 75), para uma perda de água de $12,43 \%$. Este comportamento ocorreu, uma vez que o cimento Cim.M também contém adição de escória em sua composição, porém em teor inferior ao contido no Cim.lll, segundo interpretação dos difratogramas destas amostras (Figura 67). Como consequência, a distribuição de tamanho de poros do fibrocimento Cim.M apresentou volume de mercúrio intrudido em nível intermediário aos demais (Figura 77), mantendo a correlação observada de que a maior quantidade de poros capilares pequenos e médios (poros de gel e mesoporos) se reflete em maior retração por secagem.

A retração por secagem do fibrocimento Cim. IIE foi grande, com valor médio aos 83 dias de secagem de 2,86 mm/m (Figura 75) para uma perda de água de 12,91\%, que equivale à segunda maior retração observada entre todas as amostras estudadas. Esta elevada variação volumétrica é decorrente da composição do cimento Cim.IIE que contém escória em sua composição. Como já observado nos demais cimentos contendo escória analisados anteriormente, esta adição mineral forma na matriz cimentícia uma rede de poros com distribuição de tamanho favorável à ação de tensão capilar. Os resultados de porosimetria por intrusão de mercúrio mostram isso, com o grande volume de mercúrio intrudido nos poros de gel e mesoporos (Figura 78).

Os valores de retração referentes ao fibrocimento Cim.IIF foram inferiores às duas amostras anteriores. A retração linear foi de $2,71 \mathrm{~mm} / \mathrm{m}$ (Figura 75 ), para uma 
perda de água de 15,23\%. Este melhor desempenho desta amostra se deu especialmente pela composição do cimento utilizado, que contém apenas adições carbonáticas, que não favorecem a formação de poros de gel.

A granulometria mais fina do cimento (Tabela 12) não foi efetiva na melhoria do empacotamento, pois a porosidade total do fibrocimento produzido foi grande, refletindo em grande perda de água na secagem. No entanto, a distribuição de tamanho de poros apresentada na Figura 78 mostra que o volume de mercúrio intrudido na faixa de poros de gel foi menor em comparação com os outros fibrocimentos, o que reduz a ação da tensão capilar na secagem, e consequentemente a suscetibilidade à retração. Apesar da grande perda de água medida, a retração por secagem medida não foi grande, e por este motivo a relação entre retração e perda de água foi a menor entre as três amostras analisadas (Figura 81).

Tabela 17 - Volume de mercúrio intrudido nas faixas de tamanho de poros suscetíveis à tensão capilar e poros de gel

\begin{tabular}{|l|c|c|c|c|}
\hline \multirow{2}{*}{ Amostra } & \multicolumn{3}{|c|}{ Faixa de diâmetro do poro } & \multirow{2}{*}{ TOTAL } \\
\cline { 2 - 5 } & $\begin{array}{c}\mathbf{0 , 0 0 3 6} \text { a 0,01} \boldsymbol{\mu m} \\
\text { Poros de gel }\end{array}$ & $\begin{array}{c}\mathbf{0 , 0 1} \text { a 0,5 } \boldsymbol{\mu m} \\
\text { Mesoporos }\end{array}$ & $\begin{array}{c}\mathbf{0 , 0 0 3 6} \text { a 0,5 } \boldsymbol{\mu m} \\
\text { Poros de gel + Mesoporos }\end{array}$ & \\
\hline Cim.IIE & $7,97 \%$ & $12,85 \%$ & $20,82 \%$ & $41,32 \%$ \\
\hline Cim.IIF & $6,40 \%$ & $13,48 \%$ & $19,88 \%$ & $43,16 \%$ \\
\hline Cim.III & $6,82 \%$ & $12,66 \%$ & $19,48 \%$ & $36,62 \%$ \\
\hline Cim.V & $4,91 \%$ & $9,13 \%$ & $14,04 \%$ & $35,79 \%$ \\
\hline Cim.M & $5,84 \%$ & $10,64 \%$ & $16,49 \%$ & $30,64 \%$ \\
\hline
\end{tabular}

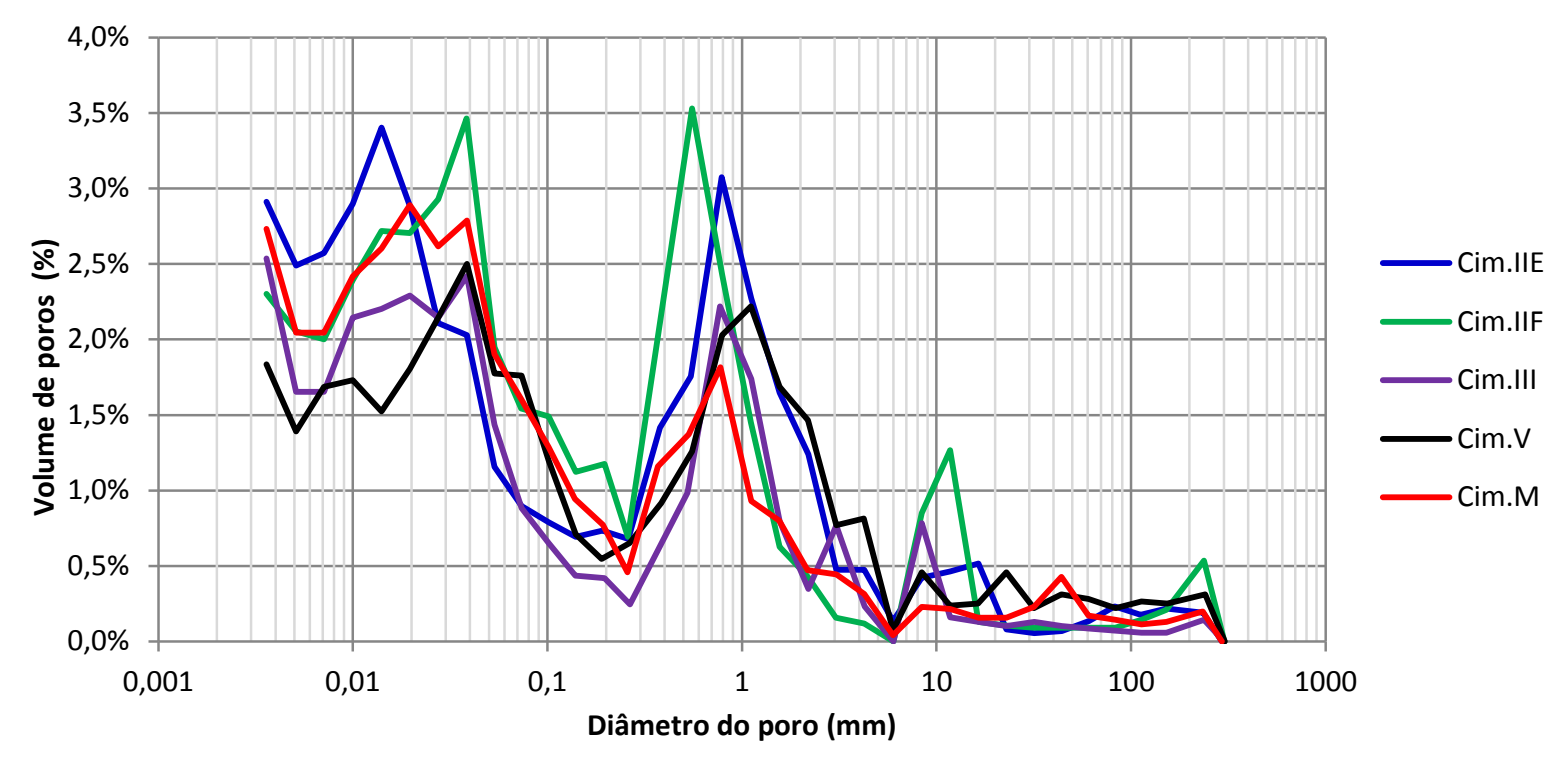

Figura 77 - Distribuição de tamanho de poros dos fibrocimentos utilizando diferentes cimentos, por porosimetria por intrusão de mercúrio 


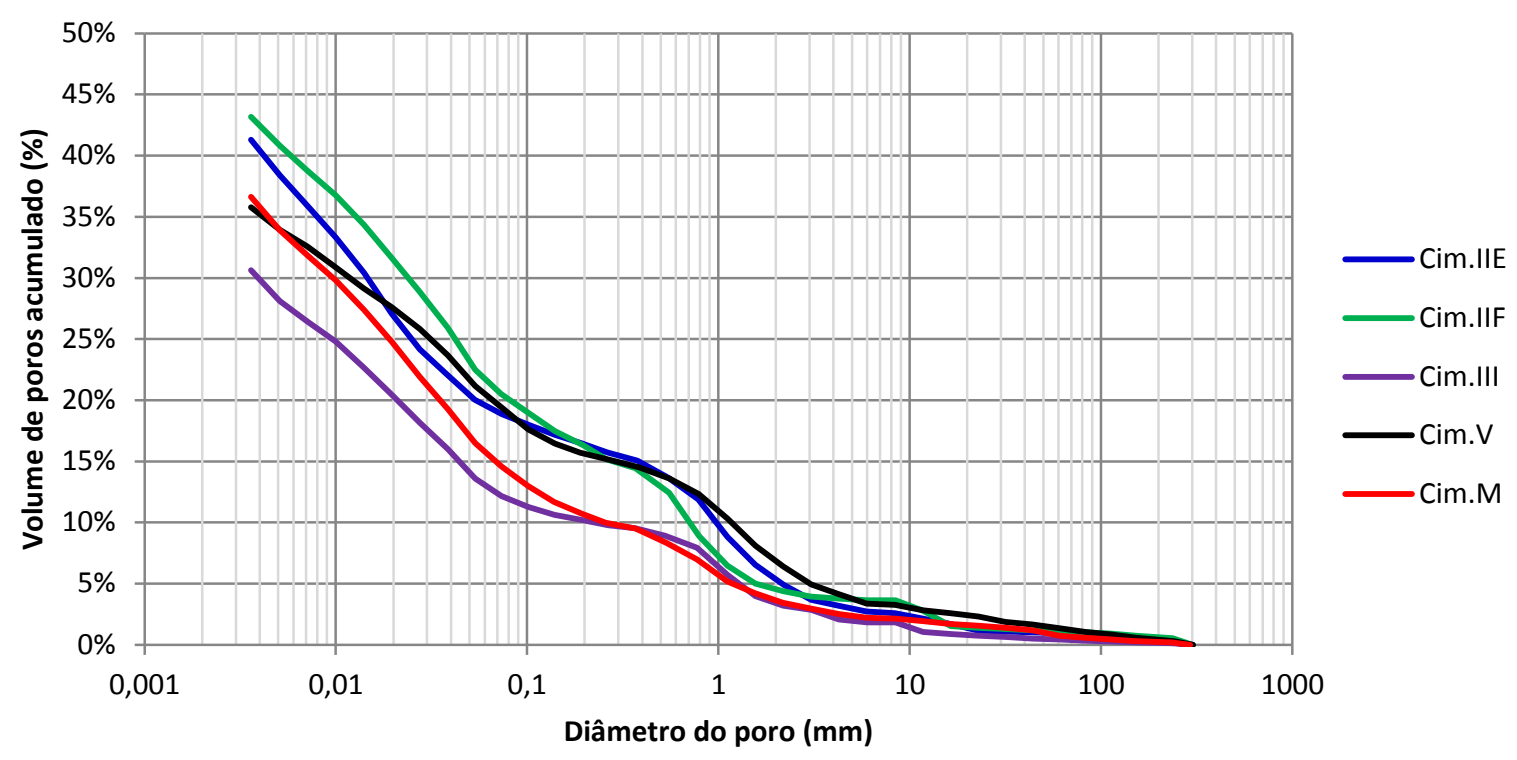

Figura 78 - Distribuição acumulada de tamanho de poros dos fibrocimentos utilizando diferentes cimentos, por porosimetria por intrusão de mercúrio

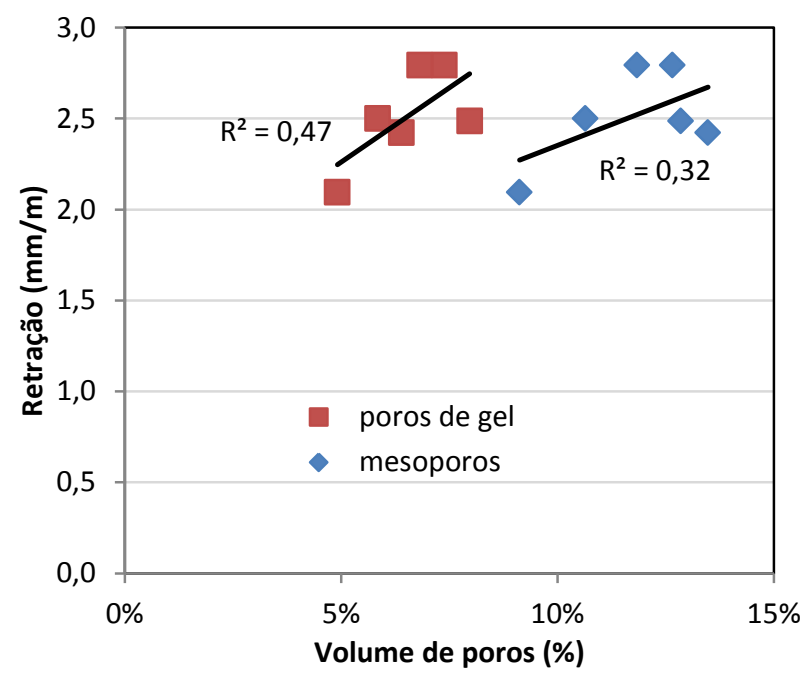

Figura 79 - Correlação entre a retração por secagem (14 dias de secagem) e o volume de poros de gel e mesoporos, segundo classificação de tamanho de poros proposto por (Mindess, 1981)

A correlação apresentada na Figura 79 não é grande, mas mostra a tendência, onde quanto maior o volume de mesoporos, maior foi a retração medida. Analisando estes mesmos dados, mas dividindo as faixas de poros com base na análise realizada no item 3.3, através do diagrama de retração por secagem (Figura 37), obtém-se a mesma conclusão. A primeira secagem, que ocorre na primeira 1,5 hora, acontece nos poros de maior dimensão, classificados como defeitos da matriz (poros com diâmetro superior a 2,33 $\mu \mathrm{m}$ ), sendo que o volume deste tipo de poros 
não apresentou qualquer correlação com a retração por secagem, pois não há atuação de tensão capilar no interior de poros deste volume (Figura 80). A maior parcela da secagem ocorre até os 2 dias de exposição, e a faixa de poros que sofre perda de umidade predominantemente é aquela entre 0,03 e 2,33 $\mu \mathrm{m}$, que compreende macroporos e uma parcela de mesoporos. Esta faixa de poros também não apresentou correlação com a retração medida, talvez por conta dos cimentos Cim.III e Cim.M que contém adição de escória na sua composição, apresentarem reduzido volume de poros nesta faixa dimensional, mas com elevados níveis de retração por secagem (Figura 80). A secagem final, dos 2 dias de exposição até atingir a umidade de equilíbrio aos 14 dias de exposição acontece em menor velocidade, mas tem magnitude considerável na retração total. Esta secagem ocorre predominantemente nos poros menores, entre 13,2 nm e 0,03 $\mu \mathrm{m}$, e apesar de também ter baixa correlação $\mathrm{R}^{2}=0,44$, apresentou uma tendência direta com a relação por secagem.

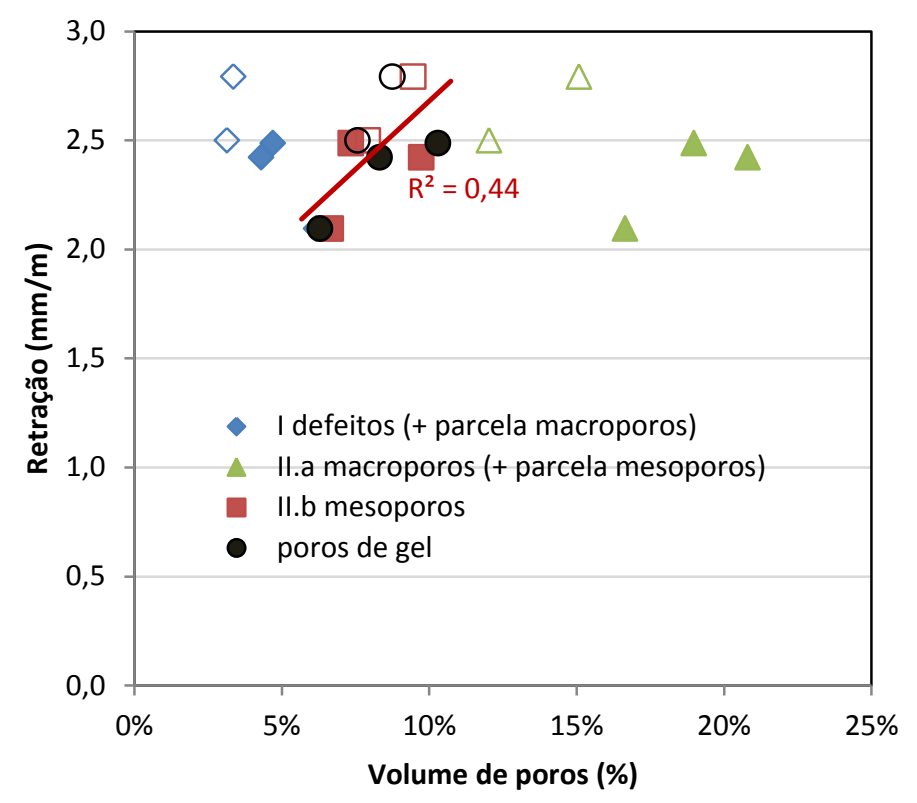

Figura 80 - Correlação entre a retração por secagem e o volume de poros referentes aos defeitos, cuja secagem ocorre na primeira 1,5 hora; macroporos e parcela de mesoporos, cuja secagem ocorre até $\mathbf{2}$ dias de exposição; grande parte dos mesoporos, cuja secagem ocorre entre 2 e a4 dias de exposição; e poros de tamanho inferior à $13,2 \mathrm{~nm}$. Trecho I: diâmetro do poro superior a

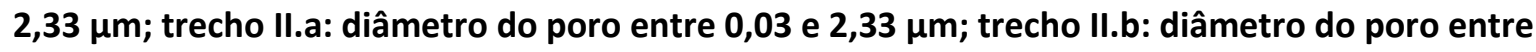
$0,03 \mu \mathrm{m}$ e 13,2 nm. Pontos sem preenchimento equivalem aos cimentos Cim.M e Cim.III

A correlação entre a retração por secagem e a umidade do fibrocimento é logarítmica, como mostra a Figura 81. A diferença entre os cimentos está na inclinação da reta representada na escala logarítmica. Quanto maior a inclinação da 
reta, o mais suscetível à retração é o fibrocimento, indicando que para uma mesma redução de umidade, o fibrocimento sofrerá maior retração. Os fibrocimentos Cim.III e Cim.M apresentaram maior inclinação. Através da Figura 81 observa-se que os cimentos com maior porosidade total (Cim.IIF e Cim.IIE) apresentaram uma umidade de equilíbrio menor, no entanto, a distribuição de tamanho de poros destes cimentos não favorece à tensão capilar e por este motivo os níveis de retração total foram menores. O Cim.V é um cimento de alta reatividade, e para isso apresenta reduzido tamanho de partículas. Desta forma, a pasta endurecida apresenta um menor nível de porosidade em relação aos cimentos comuns, que ocorreu de maneira distribuída entre todas as faixas de poros, como mostra a Figura 77. O resultado desta menor porosidade é um menor nível de umidade de equilíbrio, e pelo fato de não favorecer a formação de poros na faixa dos mesoporos, este cimento apresentou menor retração por secagem (Figura 81). Os cimentos Cim.III e Cim.M apresentaram maior cinética de retração, ou seja, maior tendência à retração para uma mesma perda de umidade, indicada pela inclinação das regressões logarítmicas calculadas. $\mathrm{O}$ reduzido tamanho de partículas destes cimentos se refletiu em baixa porosidade da pasta endurecida, no entanto, provavelmente pela adição de escória na composição destes cimentos (adição incorporada ao cimento que favorece a retração por secagem em grande proporção - (Giordano et al., 2009)), os níveis de retração por secagem medidos foram grandes, mesmo para reduzidos níveis de umidade de equilíbrio (Figura 81).

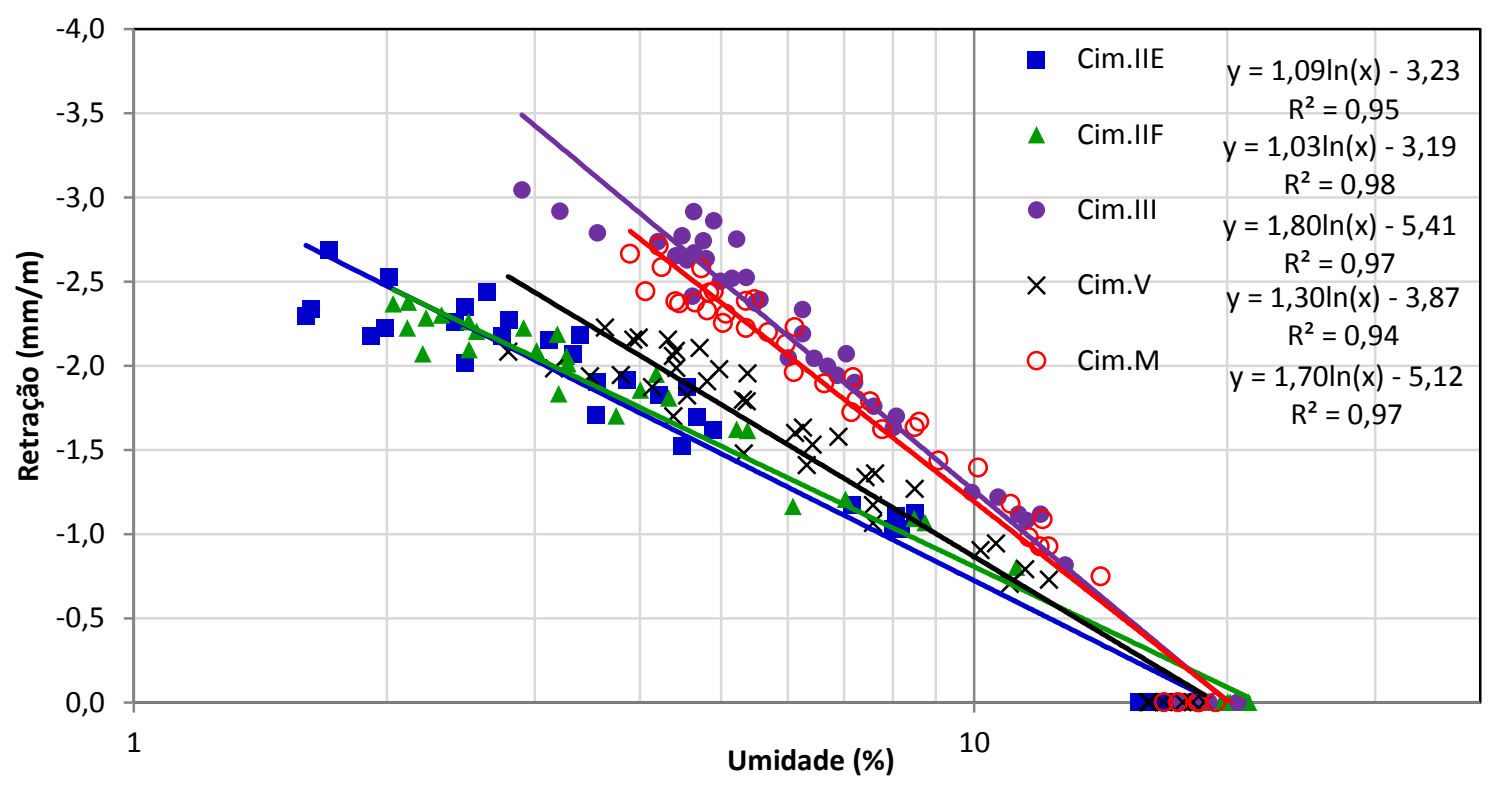

Figura 81 - Relação entre a retração até os 14 dias de secagem e a umidade do fibrocimento 


\subsection{Influência da formulação na retração por secagem}

\subsubsection{Introdução}

Além do elevado consumo de cimento, o fibrocimento é um compósito com muitos materiais constituintes, que obviamente exercem influência nas propriedades deste material, em maior ou menor grau. O fibrocimento reforçado com fibras poliméricas produzido atualmente pela indústria nacional é normalmente composto por mais de cinco matérias-primas, que vão desde o cimento Portland e adições minerais, até diferentes tipos de fibras e aditivos orgânicos (Negro et al., 2006). O grande número de materiais componentes dificulta o planejamento das misturas, de modo a variar a quantidade destes materiais e avaliar o seu efeito nas propriedades finais do fibrocimento.

O objetivo deste estudo desenvolvido foi a observação da influência de cada material constituinte na retração por secagem do fibrocimento reforçado com fibras poliméricas.

\subsubsection{Influência de cada constituinte do fibrocimento na retração}

O fibrocimento é um compósito cimentício formado por vários materiais constituintes, como o cimento e as adições minerais, que podem ser reativas como a sílica, pozolana, escória e calcário; além das fibras de reforço como o amianto, PVA e PP; e fibras de processo como a celulose, que exercem influência nas propriedades deste material.

A influência do cimento já foi comentada, e é muito grande devido ao elevado consumo do ligante. Ocorre que, além do cimento, as demais adições minerais que compõem o fibrocimento também podem ser reativas, e na maioria das vezes influenciam na retração por secagem. Assim, a matriz cimentícia pode sofrer grandes alterações a depender da adição mineral incorporada na formulação do fibrocimento, influenciando todas as suas propriedades físicas e mecânicas.

O efeito das adições minerais como a cinza volante, metacaulim, sílica ativa e escória, na retração de compósitos cimentícios, é bastante estudado. Uma visão geral dos estudos aponta que a cinza volante (Darquennes et al., 2011) e o metacaulim reduzem a retração do concreto (Güneyisi; Gesoğlu; Özbay, 2010). Embora haja estudos que apontem redução da retração com a adição de escória de alto forno (Güneyisi et al., 2010), sabe-se da maior parte dos trabalhos publicados 
(John, 1995) (Melo Neto, 2008) (Giordano et al., 2009), que esta adição mineral aumenta a quantidade de $\mathrm{C}$-S-H na matriz cimentícia, e aumenta significativamente a retração por secagem do concreto. A sílica ativa já é estudada faz bastante tempo, e sempre resulta em aumento da retração no concreto (Güneyisi et al., 2010), sem promover melhorias no desempenho mecânico em alguns casos, no fibrocimento (Souza et al., 2010).

A maioria dos estudos publicados sobre a influência das adições minerais em compósito cimentício tem como objeto o concreto, que como já comentado, possui matriz cimentícia em volume muito inferior à do fibrocimento. Por este motivo, justifica-se a realização deste estudo da influência das adições minerais nas propriedades físicas e mecânicas do fibrocimento.

Há estudos que tratam do efeito da adição de fibras de reforço nas propriedades de compósitos cimentícios, especialmente o concreto. Considerando a perfeita aderência entre fibra e matriz, as fibras propiciam aumento da tenacidade e módulo de ruptura.

A fibra de celulose é considerada uma fibra de processo pela indústria de fibrocimento, pois este material é necessário para o processo de produção deste compósito, mais do que para uma contribuição na sua resistência mecânica. No entanto, sua capacidade de retenção de água resulta em maior porosidade do fibrocimento, que pode se refletir em retração por secagem.

Como está presente no próprio nome deste compósito, a incorporação de fibras é a grande responsável por grande parte das propriedades comuns do fibrocimento. O perfeito funcionamento do compósito de matriz rígida com fibras tenazes resulta em um compósito capaz de suportar deformações, antes de entrar em colapso. Por este conceito envolvido, justifica-se o estudo da influência das fibras nas propriedades do fibrocimento.

\subsubsection{Metodologia}

\subsubsection{Plano experimental}

O estudo do efeito dos materiais componentes do fibrocimento em suas propriedades foi realizado a partir de um planejamento de misturas, onde cada componente variou em quantidade na formulação. A elaboração do planejamento de misturas deve considerar compósitos processáveis, economicamente viáveis e 
com propriedades físicas e mecânicas adequadas ao uso (Dias, 2011). Deste modo, este planejamento exige o conhecimento prévio da relação entre a proporção das matérias-primas e as propriedades do produto.

Em virtude destes fatores mencionados, foi realizado um estudo, cujo objetivo foi observar o efeito das matérias-primas nas propriedades do fibrocimento, especialmente na retração por secagem, sem a necessidade da produção de grande número de amostras. Para isso um projeto de mistura foi calculado, onde a quantidade de cada componente foi modificada isoladamente. Neste projeto de mistura também foram testadas as influências da pozolana e da escória, como adições minerais reativas, e da fibra sintética de PP, como fibra de reforço mecânico.

A partir de análises de estudos exploratórios e bibliografia consultada, observouse que a influência do calcário na retração higroscópica é pequena, deste modo o projeto de mistura considerou a variação do cimento e da sílica ativa, em substituição ao calcário. A variação das quantidades de cinza volante e escória também foi realizada em substituição ao calcário. Desta forma não se variou as quantidades dos demais materiais constituintes do fibrocimento, melhorando a análise. A Tabela 18 expõe as formulações calculadas.

Tabela 18 - Formulações com variação nos teores de cimento, sílica ativa, pozolana e escória

\begin{tabular}{|c|c|c|c|c|c|c|c|c|}
\hline \multirow{2}{*}{ Form. } & \multirow{2}{*}{ Variável } & \multicolumn{7}{|c|}{ Componente (fração em massa) } \\
\hline & & Cimento & Sílica ativa & Pozolana & Escória & Calcário & Celulose & PVA \\
\hline Cim.20 & \multirow{5}{*}{ cimento } & 0,20 & \multirow{5}{*}{0,05} & \multirow{5}{*}{--- } & \multirow{5}{*}{---} & 0,702 & \multirow{5}{*}{0,030} & \multirow{5}{*}{0,018} \\
\hline Cim.35 & & 0,35 & & & & 0,552 & & \\
\hline Cim.50 & & 0,50 & & & & 0,402 & & \\
\hline Cim.65 & & 0,65 & & & & 0,252 & & \\
\hline Cim. 80 & & 0,80 & & & & 0,102 & & \\
\hline Sil.0 & \multirow{4}{*}{ sílica } & \multirow{4}{*}{0,6} & 0 & \multirow{4}{*}{--} & \multirow{4}{*}{--- } & 0,352 & \multirow{4}{*}{0,030} & \multirow{4}{*}{0,018} \\
\hline Sil.2 & & & 0,02 & & & 0,332 & & \\
\hline Sil.5 & & & 0,05 & & & 0,302 & & \\
\hline Sil.8 & & & 0,08 & & & 0,272 & & \\
\hline Poz.0 & \multirow{4}{*}{$\begin{array}{c}\text { pozolana } \\
\text { (cinza } \\
\text { volante) }\end{array}$} & \multirow{4}{*}{0,6} & \multirow{4}{*}{---} & 0 & \multirow{4}{*}{--} & 0,352 & \multirow{4}{*}{0,030} & \multirow{4}{*}{0,018} \\
\hline Poz.2 & & & & 0,02 & & 0,332 & & \\
\hline Poz.5 & & & & 0,05 & & 0,302 & & \\
\hline Poz.8 & & & & 0,08 & & 0,272 & & \\
\hline Esc.0 & \multirow{4}{*}{ escória } & \multirow{4}{*}{0,6} & \multirow{4}{*}{---} & \multirow{4}{*}{---} & 0 & 0,352 & \multirow{4}{*}{0,030} & \multirow{4}{*}{0,018} \\
\hline Esc. 2 & & & & & 0,02 & 0,332 & & \\
\hline Esc.5 & & & & & 0,05 & 0,302 & & \\
\hline Esc. 8 & & & & & 0,08 & 0,272 & & \\
\hline
\end{tabular}


A influência das fibras de reforço mecânico (PVA e PP) na retração higroscópica foi analisada primeiramente variando o teor de cada tipo de fibra isoladamente com relação ao fibrocimento, deste modo os teores de todos os demais materiais variam ao mesmo tempo, no entanto mantém a mesma relação entre eles. As formulações calculadas estão expostas na Tabela 19.

Tabela 19 - Formulações com variação nos teores de PVA e PP

\begin{tabular}{|c|c|c|c|c|c|c|c|}
\hline \multirow{2}{*}{ Form. } & \multirow{2}{*}{ Variável } & \multicolumn{6}{|c|}{ Componente (fração em massa) } \\
\hline & & Cimento & Sílica ativa & Calcário & Celulose & PVA & PP \\
\hline PVA.1,2 & \multirow{3}{*}{ PVA } & 0,604 & 0,050 & 0,304 & 0,030 & 0,012 & \multirow{3}{*}{---} \\
\hline PVA.1,8 & & 0,600 & 0,050 & 0,302 & 0,030 & 0,018 & \\
\hline PVA.2,4 & & 0,596 & 0,050 & 0,300 & 0,030 & 0,024 & \\
\hline PP.1,2 & \multirow{3}{*}{ PP } & 0,604 & 0,050 & 0,304 & 0,030 & \multirow{3}{*}{---} & 0,012 \\
\hline PP.1,8 & & 0,600 & 0,050 & 0,302 & 0,030 & & 0,018 \\
\hline PP.2,4 & & 0,596 & 0,050 & 0,300 & 0,030 & & 0,024 \\
\hline
\end{tabular}

A fibra de celulose tem função específica no fibrocimento, relacionada ao processo de produção, por este motivo ela é chamada de "fibra de processo" no meio produtivo. Em virtude deste aspecto particular, optou-se por variar a quantidade desta fibra isoladamente, em relação ao fibrocimento. Deste modo, as quantidades de todos os demais materiais variam ao mesmo tempo, no entanto mantém a mesma relação entre eles. As formulações variando o teor de fibra de celulose estão expostas na Tabela 20.

Tabela 20 - Formulações com variação no teor de celulose

\begin{tabular}{|c|c|c|c|c|c|c|}
\hline \multirow{2}{*}{ Form. } & \multirow{2}{*}{ Variável } & \multicolumn{5}{|c|}{ Componente (fração em massa) } \\
\cline { 4 - 7 } & & Cimento & Sílica ativa & Calcário & Celulose & PVA \\
\hline \multirow{3}{*}{ Cel.1 } & \multirow{3}{*}{ celulose } & 0,612 & 0,051 & 0,308 & 0,010 & 0,018 \\
\cline { 3 - 7 } Cel.3 & 0,600 & 0,050 & 0,302 & 0,030 & 0,018 \\
\cline { 3 - 7 } & & 0,588 & 0,049 & 0,296 & 0,050 & 0,018 \\
\hline Cel.5 & & &
\end{tabular}

O acompanhamento das alterações na porosidade e nos compostos formados foi realizado como mostra o plano experimental (Figura 82). Os métodos de ensaio estão detalhados nos itens 2.3.3, 2.4.3 e 2.4.4. 


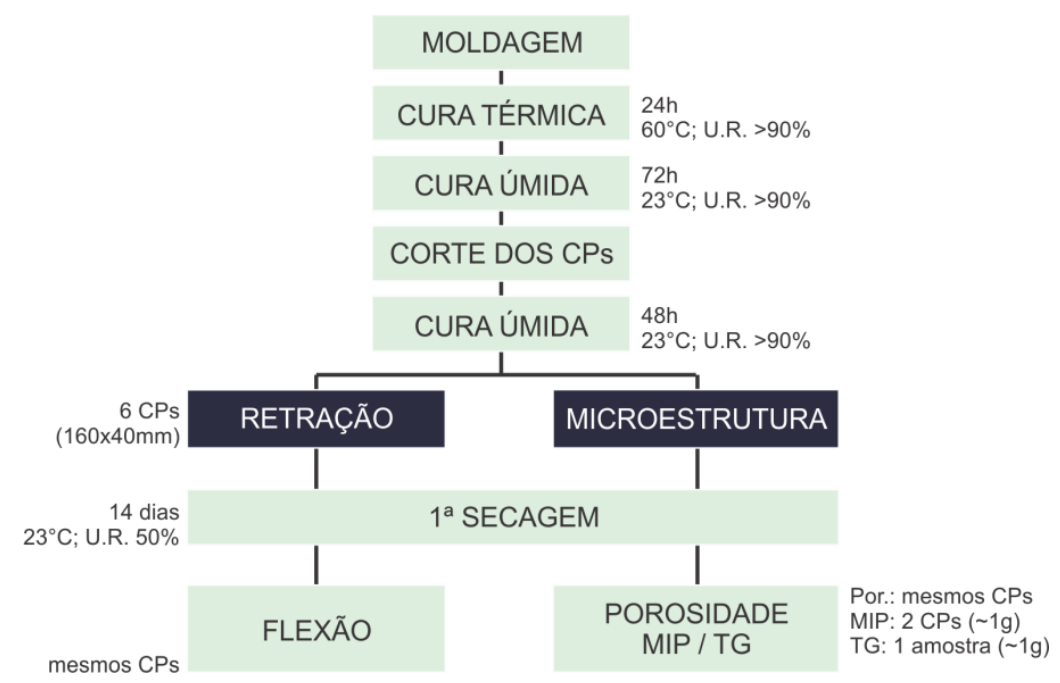

Figura 82 - Plano experimental do estudo sobre influência dos materiais constituintes do fibrocimento na retração por secagem

\subsubsection{Caracterização dos materiais}

Os resultados de distribuição de tamanho de partículas determinada em granulômetro laser mostraram que as adições minerais que compõe o fibrocimento possuem distribuições de tamanho de grãos distintas, sendo que o calcário tem grãos de tamanho similar ao do cimento CP II-E, com maior frequência de partículas de diâmetro $65,5 \mu \mathrm{m}$, no entanto, com uma maior quantidade de partículas mais grossas, como pode ser observado pela Figura 83 na faixa entre 200 e $400 \mu \mathrm{m}$. A sílica é uma adição mineral com partículas mais finas que as demais matériasprimas, com maior frequência de partículas de diâmetro 12,2 $\mu \mathrm{m}$ (Figura 83) e D90 igual a $19,2 \mu \mathrm{m}$, o que certamente melhorará o empacotamento das partículas do compósito.

Tabela 21 - Parâmetros D10, D50 e D90 obtidos a partir da curva de distribuição do tamanho de partículas das adições minerais utilizadas, em comparação com o cimento CP II-E

\begin{tabular}{|c|c|c|c|c|c|}
\hline \multirow{2}{*}{ Parâmetros } & \multicolumn{5}{|c|}{ Matéria-prima (diâmetros em $\boldsymbol{\mu m}$ ) } \\
\cline { 2 - 6 } & CPII-E & Calcário & Sílica & Pozolana & Escória \\
\hline D10 & 5,2 & 3,3 & 2,7 & 3,9 & 2,0 \\
\hline D50 & 36,0 & 35,3 & 9,3 & 43,0 & 13,4 \\
\hline D90 & 97,1 & 126,2 & 19,2 & 194,1 & 40,9 \\
\hline
\end{tabular}




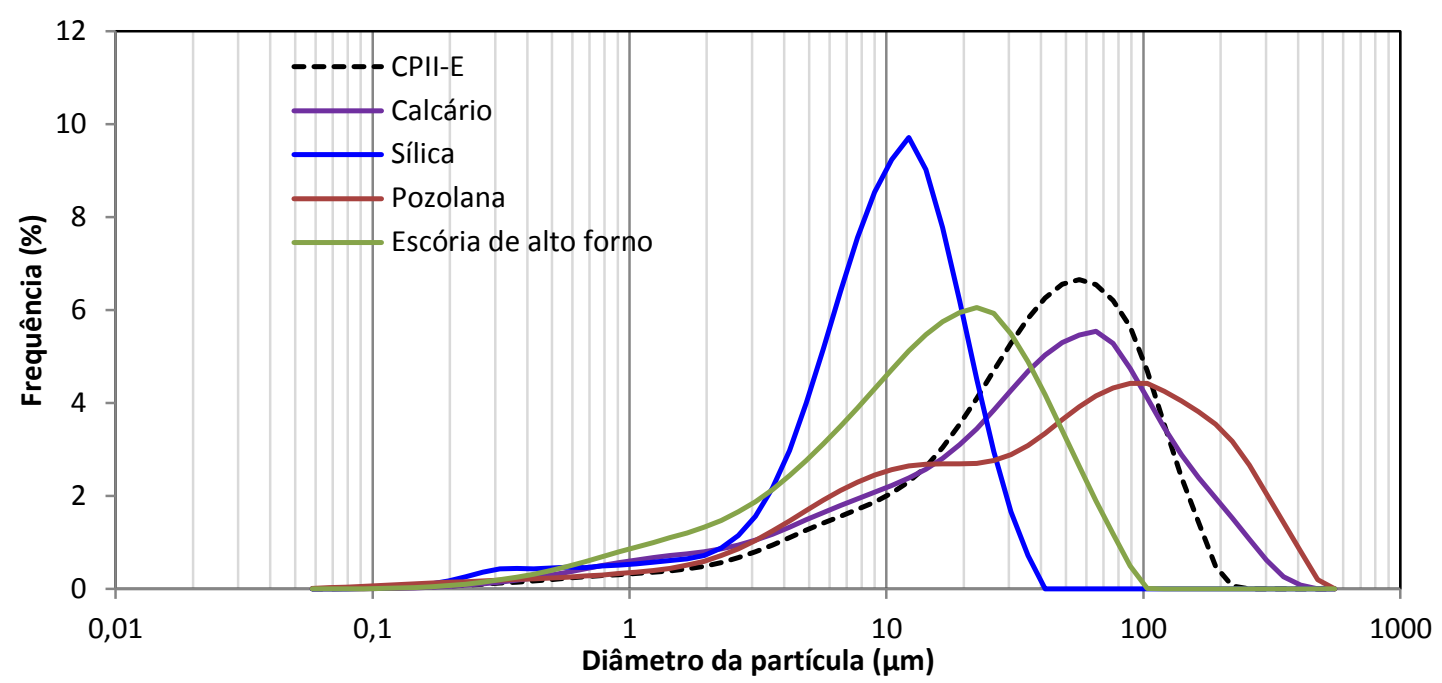

Figura 83 - Distribuição do tamanho de partículas das adições minerais, comparados com o cimento CP II-E

Além das adições minerais que constituem a formulação padrão, adotada neste estudo, também foram estudados os efeitos da adição de escória e de uma pozolana (cinza volante) nas propriedades do fibrocimento. A distribuição do tamanho de partículas destes materiais apresenta-se distintas entre si e em comparação com o cimento CP II-E, como pode ser observado pela Figura 83. A escória de alto forno é mais fina que os demais materiais, com D10 igual a 2,0 $\mu \mathrm{m}$ e D90 igual a 40,9 $\mu \mathrm{m}$. A pozolana apresenta um perfil bimodal bastante conveniente para um bom empacotamento, com partículas mais finas que a do cimento CP II-E (D10 = 3,9 $\mu \mathrm{m}$ ), e também partículas mais grossas (D90 = 194,1 $\mu \mathrm{m}$ ).

A superfície específica dos materiais foi determinada pelo método BET, cujo procedimento experimental está detalhado no item 2.3.4, e tem relação com o tamanho das partículas e rugosidade dos materiais. A sílica ativa é o material mais fino dentre as matérias-primas, e também é o material com maior área específica, em torno de 10 vezes maior que os demais materiais (Tabela 22), o que confere grande reatividade a este material.

Tabela 22 - Área específica das matérias-primas

\begin{tabular}{|c|c|}
\hline Amostra & Área específica $\left(\mathrm{m}^{2} / \mathrm{g}\right)$ \\
\hline CP II-E & 1,3034 \\
\hline Calcário & 1,1505 \\
\hline Sílica & 15,6657 \\
\hline Pozolana & 1,0468 \\
\hline Escória & 1,2134 \\
\hline
\end{tabular}


A densidade dos materiais foi determinada por picnometria de gás hélio, cuja descrição do procedimento experimental está relatada no item 2.3.5. Os resultados mostraram que a densidade dos materiais que compõe o fibrocimento varia pouco, sendo o cimento a matéria-prima mais densa presente no fibrocimento. A sílica e a pozolana os materiais menos densos entre todos os pós (Tabela 23). As fibras possuem densidade menor que os pós, desta forma, apesar de serem adicionadas em pequena quantidade em massa, ocupam grande volume do compósito pronto.

Tabela 23 - Massa específica das matérias-primas

\begin{tabular}{|c|c|c|c|}
\hline & Material & Massa específica $\left(\mathrm{g} / \mathrm{cm}^{3}\right)$ & Desvio padrão $\left(\mathrm{g} / \mathrm{cm}^{3}\right)$ \\
\hline Cimento & CPII-E & 2,90 & 0,01 \\
\hline \multirow{4}{*}{$\begin{array}{l}\text { Adições } \\
\text { minerais }\end{array}$} & Calcário & 2,73 & 0,01 \\
\hline & Sílica & 2,04 & 0,07 \\
\hline & Pozolana & 2,10 & 0,02 \\
\hline & Escória & 2,82 & 0,02 \\
\hline \multirow{3}{*}{ Fibras } & Celulose & 1,35 & 0,03 \\
\hline & PVA & 1,49 & 0,02 \\
\hline & PP & 0,89 & 0,01 \\
\hline
\end{tabular}

Segundo norma técnica da ABNT, o cimento CP II-E pode conter até $10 \%$ de filler calcário em sua composição. Os resultados da termogravimentria indicam que a quantidade de carbonato de cálcio é de $8,60 \%$ no cimento CP II-E (Figura 84). A Figura 84 mostra que o calcário utilizado é dolomítico, pois aparecem dois picos de perda de voláteis na $\mathrm{TG}$, o primeiro em torno de $750^{\circ} \mathrm{C}$ e o segundo em torno de $900^{\circ} \mathrm{C}$. 


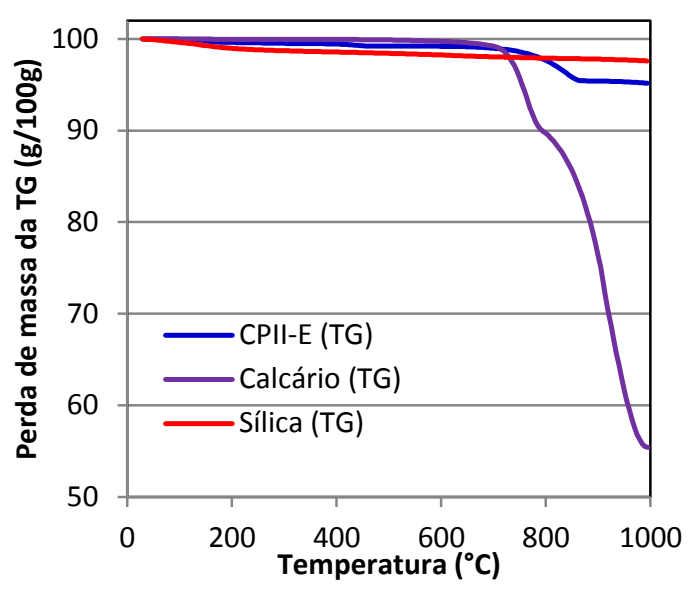

(a)

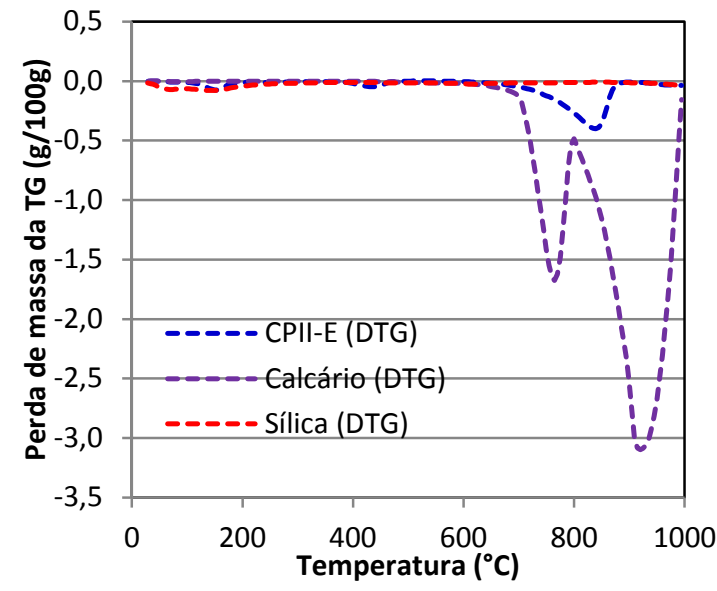

(b)

Figura 84 - (a) Termogravimetria (TG) e (b) primeira derivada da termogravimetria (DTG) do cimento, calcário, sílica, pozolana e escória

\subsubsection{Resultados e discussões}

\subsubsection{Efeito da quantidade de cimento na retração por secagem}

O cimento é o componente presente em maior quantidade no fibrocimento, e como já foi discutido, a sua composição e características físicas influenciam fortemente na retração por secagem. No entanto, a fim de avaliar o efeito apenas da quantidade de cimento presente na formulação, se optou por variar somente o teor de uma mesma amostra de cimento, em substituição ao calcário, mantendo-se constante o restante da formulação do fibrocimento.

A primeira influência verificada foi a redução da porosidade total do fibrocimento à medida que se aumenta o teor de cimento (Figura 85). A umidade final da manta fresca de fibrocimento não é determinada em função do consumo de cimento, ou outra matéria-prima, mas sim em função de parâmetros de processo e das propriedades reológicas adequadas do material. Em virtude disso, as amostras produzidas em laboratório foram filtradas a vácuo e compactadas sob condições padronizadas, de modo que ao se aumentar o consumo de cimento, ao mesmo tempo a relação a/c foi diminuída como consequência, o que se refletiu em redução da porosidade total medida a partir do ensaio de absorção de água (princípio de Arquimedes).

A Figura 85 mostra que a porosidade total do fibrocimento caiu com o aumento do consumo de cimento, de $43,48 \%$ para as amostras com $20 \%$ de cimento 
(amostra CIM20), para $35,20 \%$ quando este consumo foi de $80 \%$ em massa (amostra CIM80). Como reflexo desta alteração, a densidade aparente, que é aquela que considera a quantidade de vazios presentes na matriz, aumentou ligeiramente com o acréscimo de cimento (Figura 86), enquanto que a densidade real diminuiu (Figura 86).

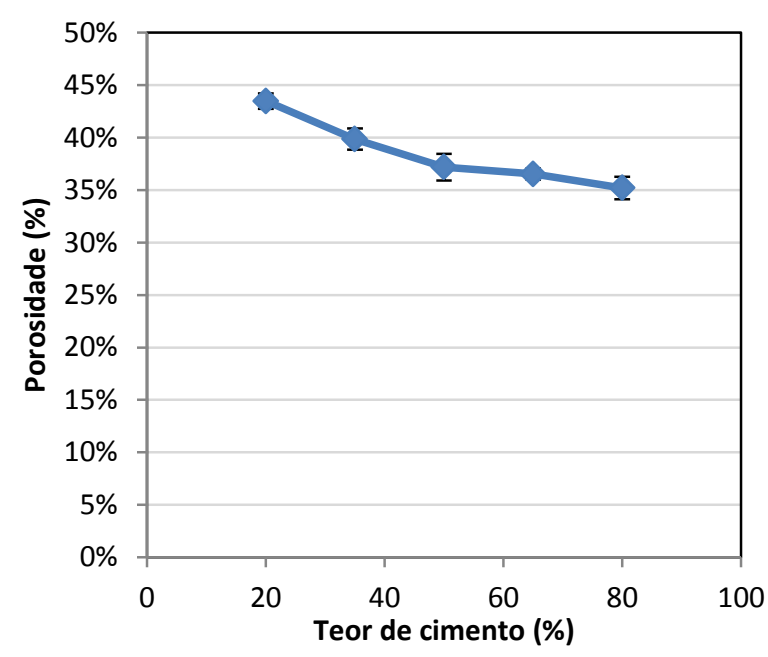

Figura 85 - Efeito do teor de cimento na porosidade total do fibrocimento após 14 dias de secagem

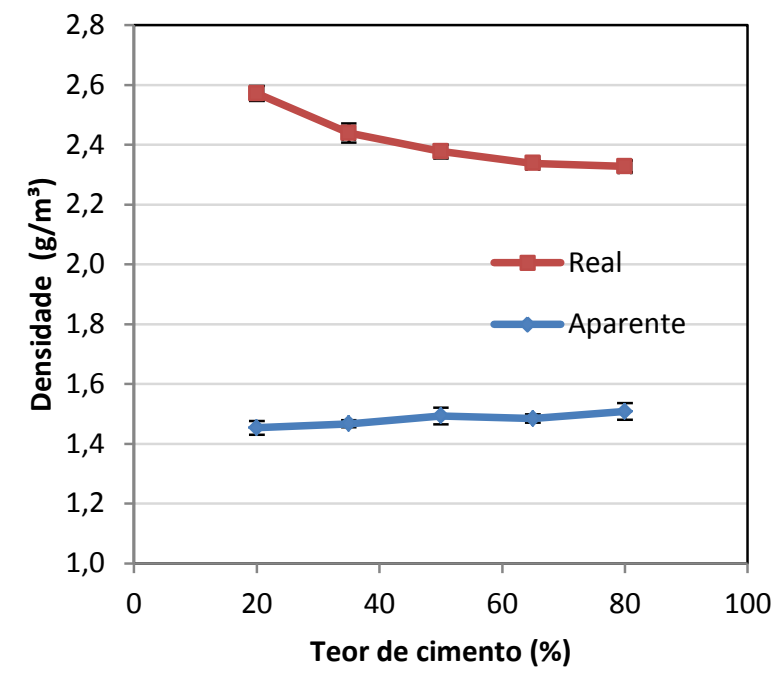

Figura 86 - Efeito do teor de cimento nas densidades aparente e real do fibrocimento

A umidade contida no fibrocimento fica armazenada nos seus poros, de modo que a perda de água durante a secagem apresenta correlação direta com a porosidade total medida através do ensaio de absorção de água, ou seja, para as amostras com maior porosidade, a perda de água aos 14 dias de secagem foi maior. Diferente do que foi observado no item 3.4, onde a porosidade do fibrocimento foi manipulada através da compactação da manta fresca, a correlação entre porosidade 
e retração não foi linear na Figura 87. Esta diferença de comportamento ocorre porque com o aumento do teor de cimento na formulação, a porosidade da matriz decresce devido à menor presença de água livre no compósito no estado fresco, somado ao refinamento dos poros devido à formação de compostos hidratados do cimento. Como consequência deste refinamento, é observada uma curvatura na correlação entre porosidade de retração, que indica que para os menores níveis de porosidade a matriz tem distribuição de tamanho de poros que favorece a retração.

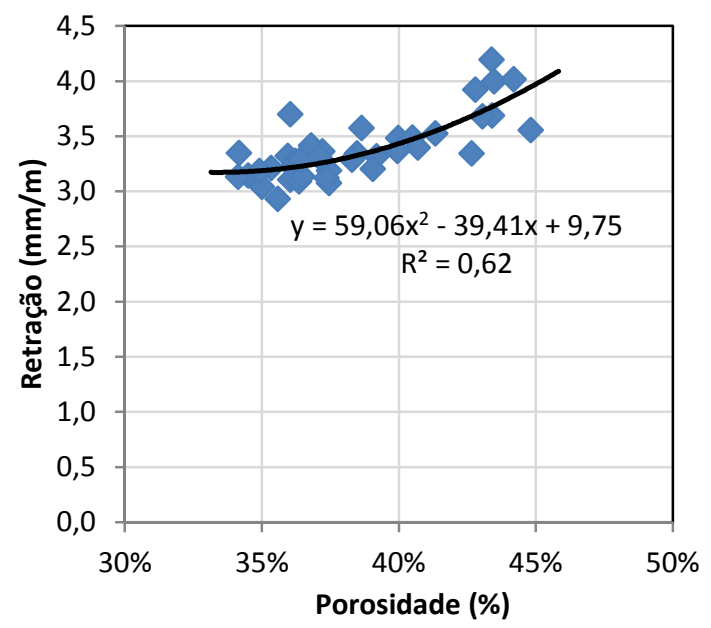

Figura 87 - Relação entre a retração e porosidade. Amostras com a quantidade de cimento variando nos teores de $20,35,50,65$ e $80 \%$

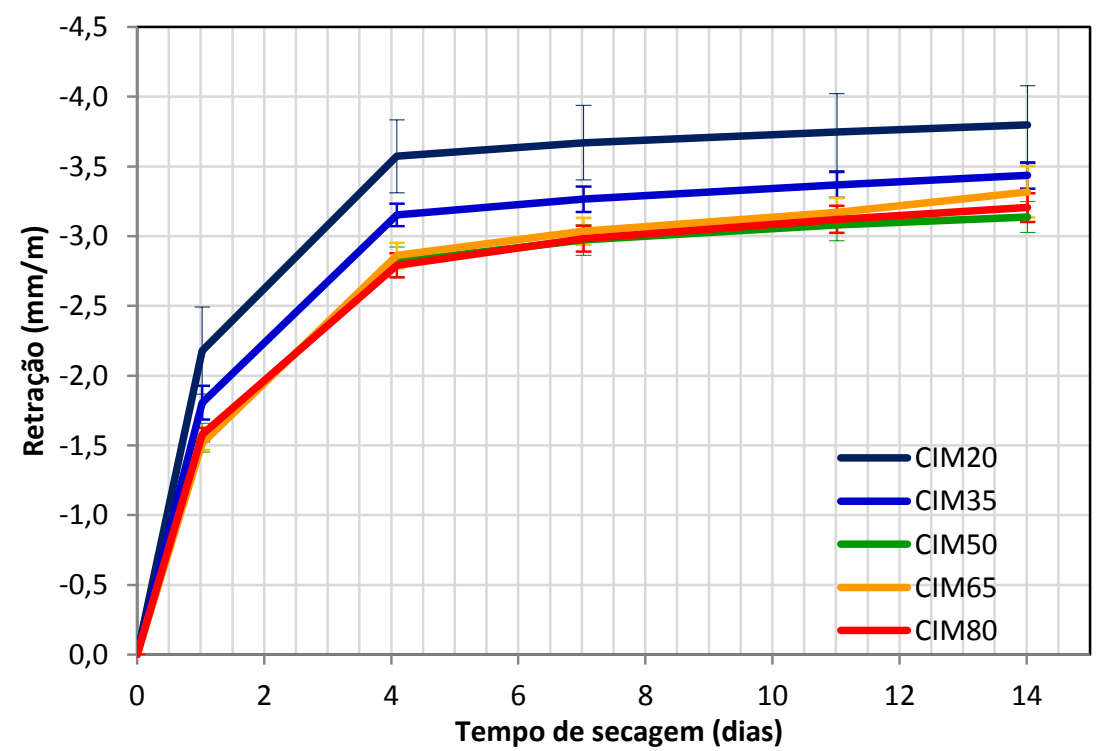

Figura 88 - Efeito do teor de cimento na retração em função do tempo de secagem. Amostras com a quantidade de cimento variando nos teores de $20,35,50,65$ e $80 \%$

A retração apresentou relação com a porosidade do fibrocimento, como mostra a Figura 87. No entanto, com o aumento do teor de cimento, a perda de água diminui, 
enquanto que a retração decresce somente até o teor de $50 \%$ de cimento, o que pode ser observado na Figura 88. A partir deste patamar, mesmo para valores maiores de perda de massa, a retração por secagem aos 14 dias se manteve constante, sem grandes diferenças entre as curvas de retração para os teores 50, 65 e $80 \%$. Estes resultados confirmam que, além da redução da porosidade total do fibrocimento, também ocorreu um refinamento dos poros, com o aumento da quantidade de mesoporos, cujas dimensões são suscetíveis à ação de tensão capilar (Figura 90).

A distribuição de tamanho de poros de cada amostra, apresentada na Figura 89, varia com o aumento do teor de cimento na formulação. Através da distribuição discreta de tamanho de poros (Figura 89) é possível observar que o fibrocimento CIM20 apresenta maior volume de poros na faixa dos mesoporos (diâmetro entre 0,01 e $0,5 \mu \mathrm{m}$ ), que compreende a faixa de poros com secagem predominante entre 2 e 14 dias de secagem (entre 0,0132 $\mu \mathrm{m}$ e 0,03 $\mu \mathrm{m}$ ). Com o aumento do teor de cimento, a alteração na distribuição de tamanho de poros observada foi a redução do volume de mesoporos e o aumento do volume de poros de gel. Esta tendência ocorreu até o teor de $50 \%$ de cimento, sendo que para os teores mais altos $65 \%$ e $80 \%$ ) os perfis das curvas apresentadas na Figura 89 não apresentaram diferenças significativas entre si. A maior porosidade total medida por intrusão de mercúrio na amostra CIM50 em comparação às amostras CIM65 e CIM80, é referente a um maior volume de poros na faixa de diâmetro entre 1 e $3 \mu \mathrm{m}$, que por sua vez não é suscetível à ação de tensão capilar (Mindess, 1981).

Desta forma, na análise dos poros suscetíveis à tensão capilar, a Figura 90 mostra que o menor consumo de cimento favoreceu a formação de poros na faixa de diâmetro dos mesoporos, cujo volume decresceu com o aumento do consumo de cimento, até o teor de $50 \%$, a partir de então a redução foi pequena. Os poros de gel são pouco frequentes nos menores teores de consumo de cimento, aumentando com o acréscimo de cimento na formulação. Deste modo, a porosidade total do fibrocimento não controla a forma como este retrai quando o teor de cimento na formulação é elevado, sendo que o volume de poros de dimensões capilares entre 13,2 nm e 0,03 $\mu \mathrm{m}$ (mesoporos) apresenta a melhor correlação com a retração observada (Figura 91). 

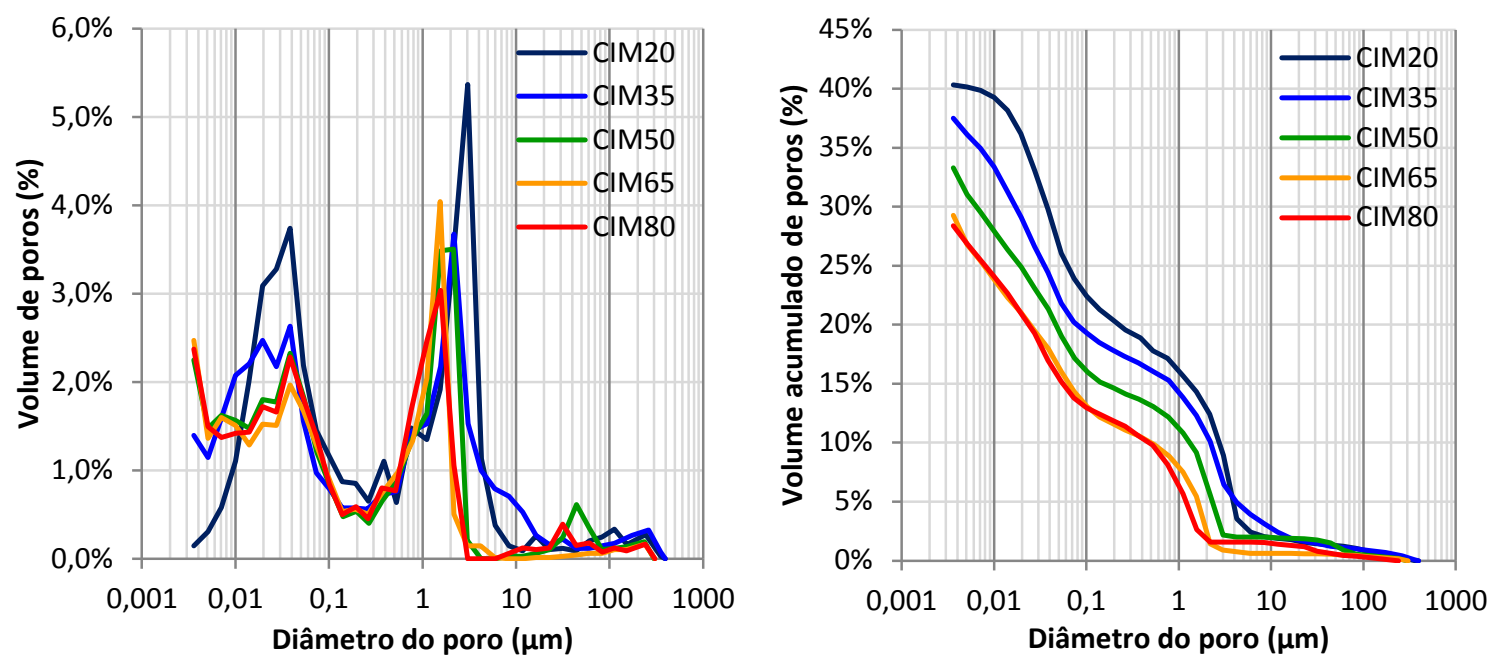

Figura 89 - Distribuição de tamanho de poros dos fibrocimentos em função do teor de cimento presente na formulação

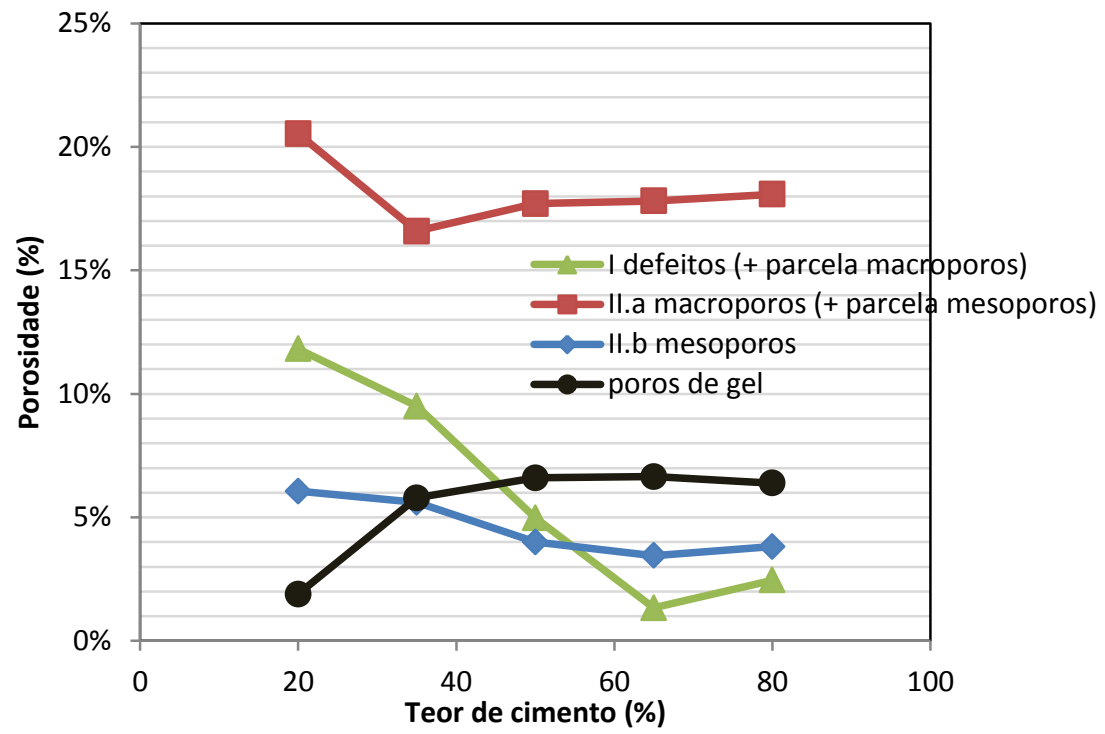

Figura 90 - Efeito do teor de cimento do fibrocimento no volume de poros nas diferentes faixas de tamanhos. Trecho I: diâmetro do poro superior a 2,33 $\mu \mathrm{m}$; trecho II.a: diâmetro do poro entre 0,03 e 2,33 $\mu \mathrm{m}$; trecho II.b: diâmetro do poro entre 0,03 $\mu \mathrm{m}$ e 13,2 nm 


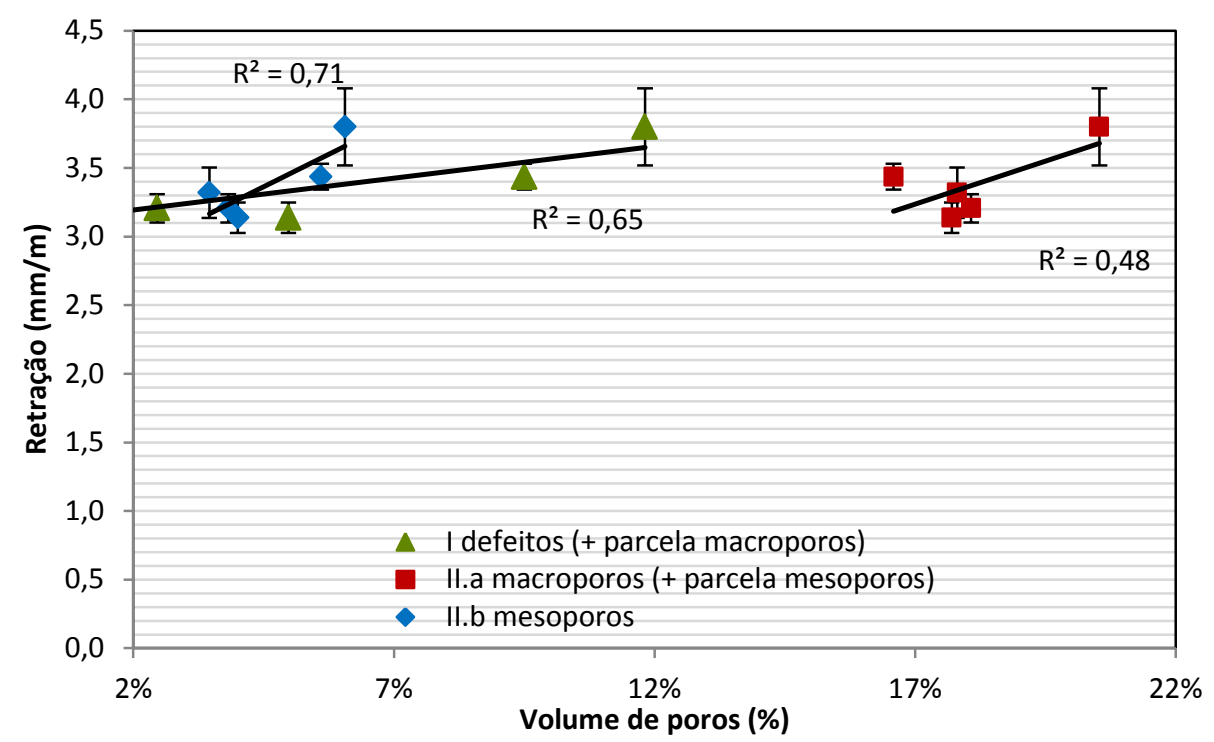

Figura 91 - Relação entre a retração por secagem e o volume de mesoporos do fibrocimento.

Amostras com a quantidade de cimento variando nos teores de 20, 35, 50, 65 e $80 \%$

O refinamento dos poros ocorrido nas amostras com maior consumo de cimento foi no sentido da diminuição da quantidade de defeitos e mesoporos para o aumento da quantidade de poros de gel. Como efeito principal, a retração total do fibrocimento foi maior nas amostras com menor consumo de cimento. No entanto, segundo a equação de Laplace, quanto menor o tamanho do poro, maior é a tensão capilar atuante. Do modo como a faixa de poros de gel foi definida nas análises, esta compreende o intervalo entre 3,6 nm e 13,2 nm. Esta faixa é mais ampla do que o definido na maioria das publicações acerca do assunto (Mindess, 1981). Deste modo, o que é denominado poros de gel, compreende o que a bibliografia trata como poros de gel (de 3,6 a $10 \mathrm{~nm}$ ), e uma pequena parte dos mesoporos (de 10 a 13,2 nm). Os poros de gel não sofrem a tensão capilar na secagem, por este motivo a umidade de equilíbrio para as amostras com maior consumo de cimento foi menor, como mostra a Figura 93. Mesmo apresentando menor retração total aos 14 dias de secagem, a relação retração / perda de água foi maior para as amostras com maior consumo de cimento, que são aquelas com maior quantidade de poros de gel (Figura 92), indicando maior suscetibilidade à retração para uma mesma perda de umidade, para as amostras com maior consumo de cimento. Este comportamento pode ser observado pela maior inclinação das curvas de correlação logarítmicas indicadas na Figura 93. 


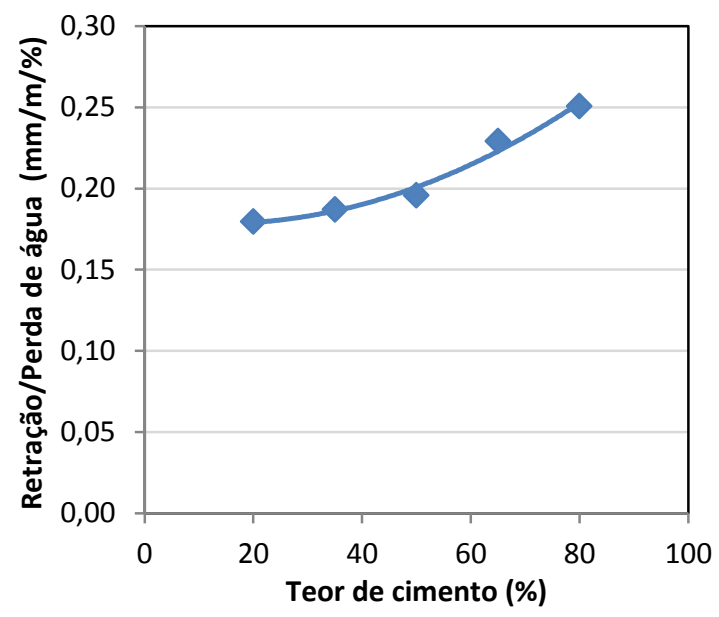

Figura 92 - Efeito do teor de cimento na relação Retração/Perda de água

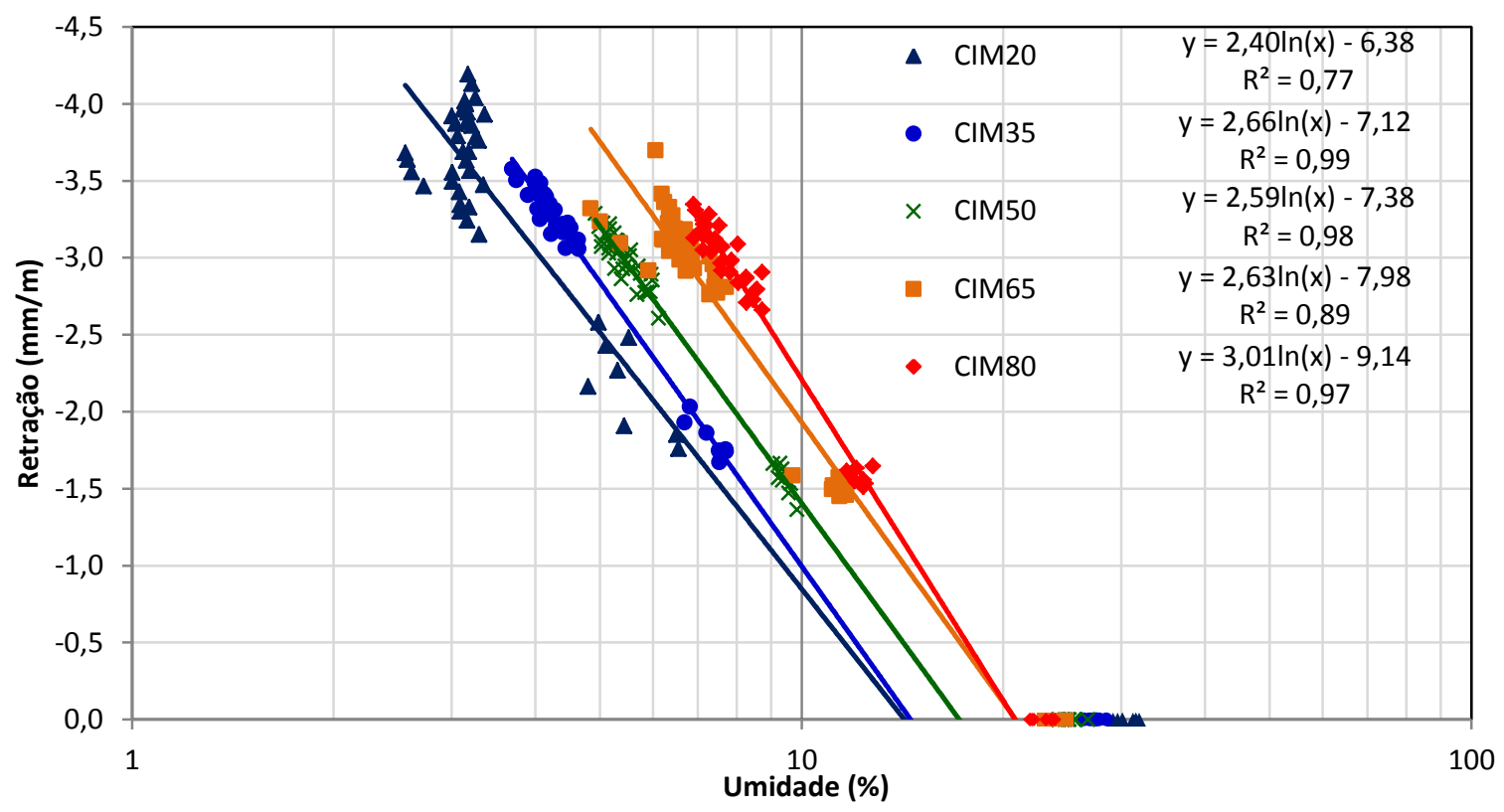

Figura 93 - Relação entre a retração por secagem e a umidade do fibrocimento, em função do teor de cimento

A retração total destas amostras não foi maior, porque a mesma tensão capilar que atua mais intensamente na redução volumétrica do compósito, dificulta a secagem dos poros de gel. A secagem dos poros menores é mais difícil uma vez que a área de evaporação é menor. Independente da umidade inicial da amostra, a umidade final de equilíbrio foi maior nas amostras com poros mais refinados, devido à dificuldade de secagem de poros de diâmetro tão reduzido nestas condições ambientais de secagem (U.R. 50\%).

As propriedades mecânicas do fibrocimento foram melhoradas com o aumento da quantidade de cimento na formulação, como mostram os resultados de LOP e 
módulo de elasticidade - E (Figura 94). O LOP aumentou, uma vez que a matriz cimentícia foi melhorada com o aumento da quantidade de ligante. O aumento da quantidade de cimento tornou a matriz mais rígida, o que não é desejável, uma vez que resulta em maiores valores de tensão interna aumentando a suscetibilidade à fissuração (Figura 94).

Estes resultados de melhora das propriedades mecânicas têm relação direta com a porosidade total do compósito, como mostra a Figura 95. Este incremento da resistência está relacionado com a maior formação de compostos hidratados resistentes formados devido à maior quantidade de cimento presente, e consequente redução da porosidade.
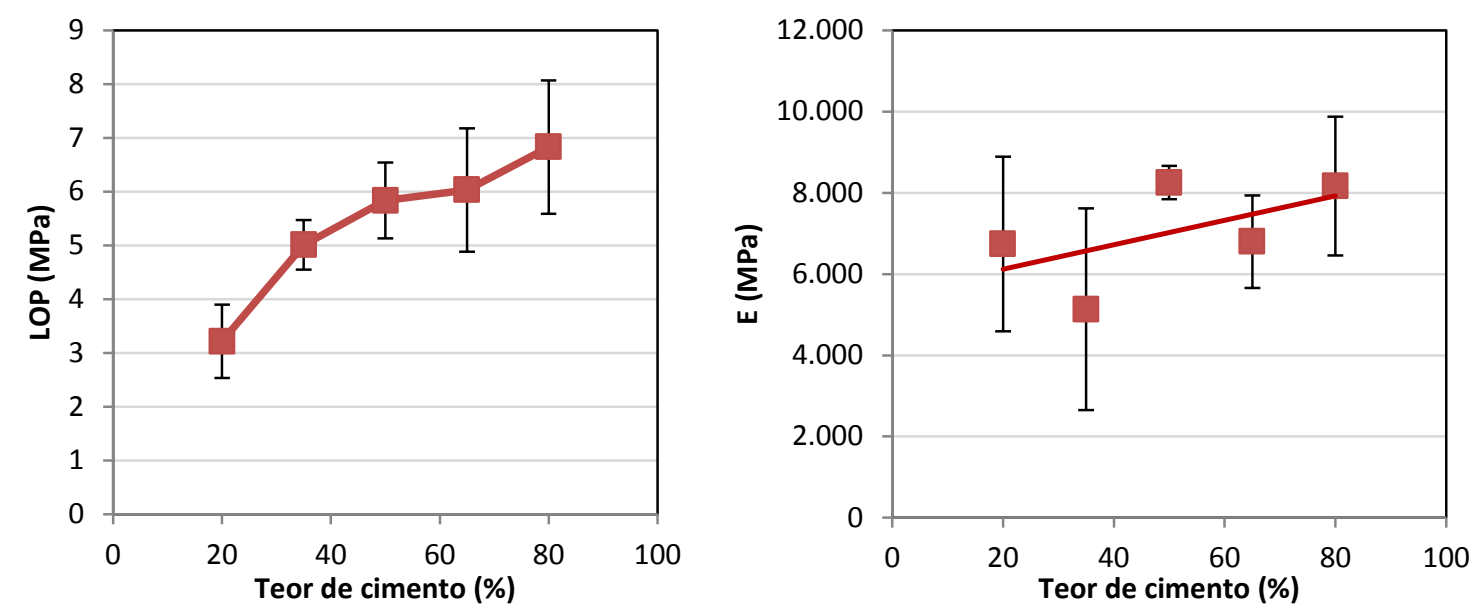

Figura 94 - Propriedades mecânicas (MOR e E) do fibrocimento em função da quantidade de cimento presente

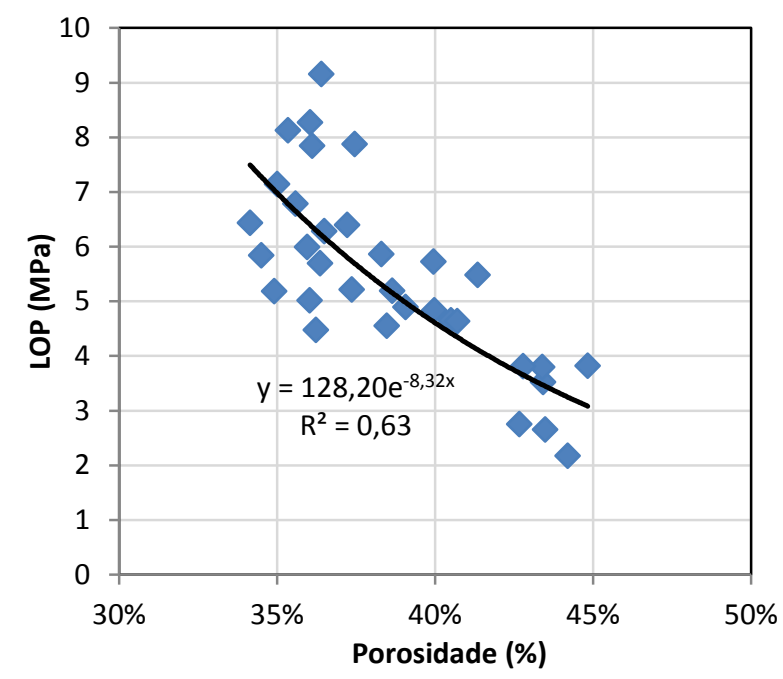

Figura 95 - Efeito da porosidade no limite de proporcionalidade do fibrocimento na ruptura à flexão 


\subsubsection{Influência das adições minerais na retração por secagem}

Apesar de normalmente estarem presentes em menor quantidade nos fibrocimentos utilizados na construção, as adições minerais apresentam influência na retração por secagem deste compósito. Dentre as adições de sílica, pozolana e escória, que foram aplicadas no teor máximo de $8 \%$ da formulação, a sílica ativa foi o material que mais influenciou na retração por secagem, aumentando o seu valor em mais de $1 \mathrm{~mm} / \mathrm{m}$ nos teores mais elevados (Figura 96).

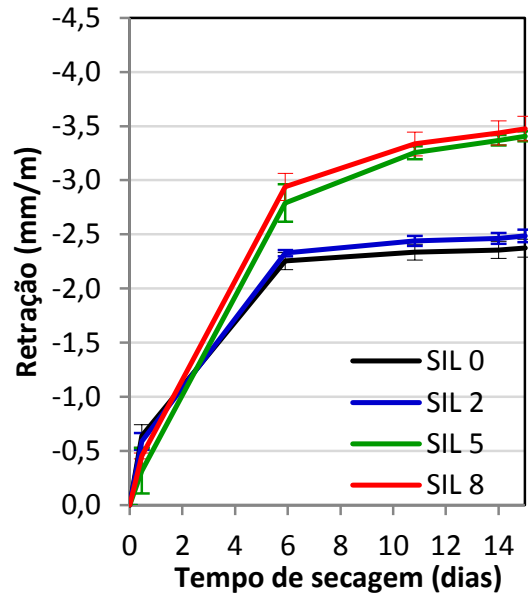

(a)

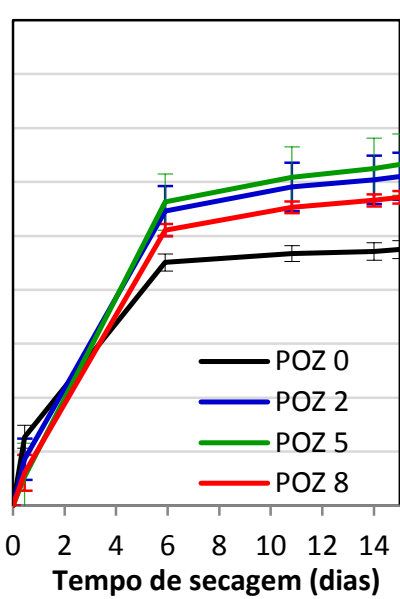

(b)

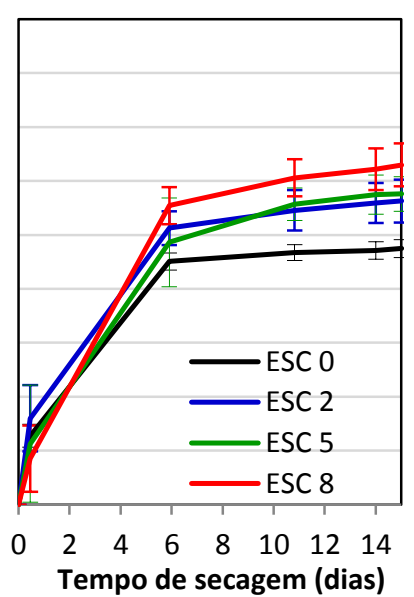

(c)

Figura 96 - Retração por secagem em função do (a) teor de sílica, (b) teor de pozolana e (c) teor de escória presentes no fibrocimento

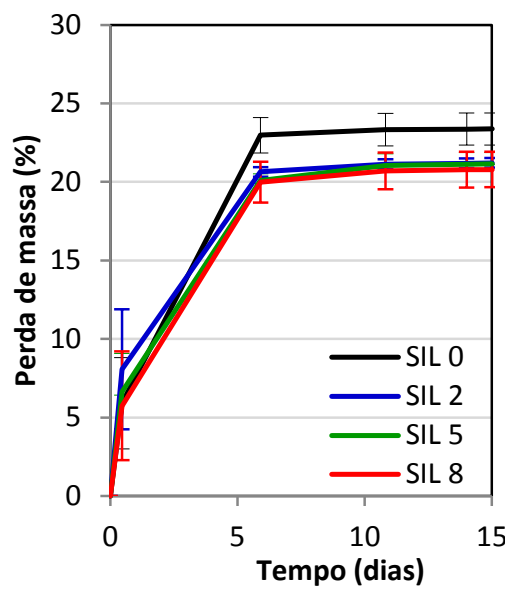

(a)

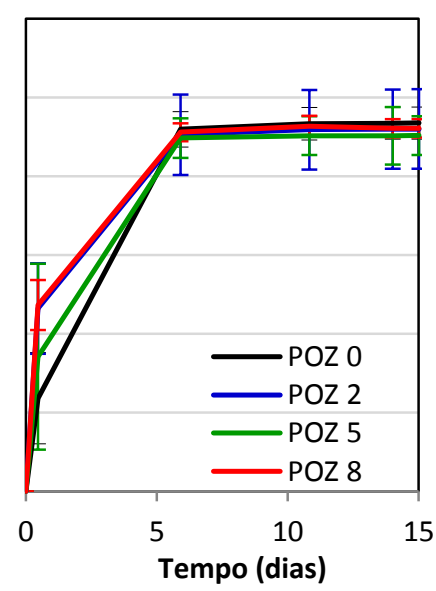

(b)

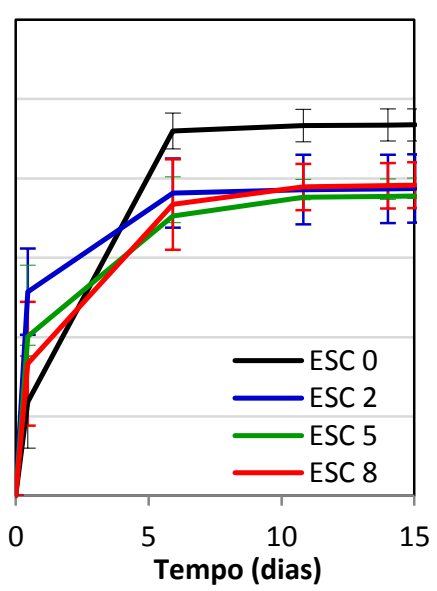

(c)

Figura 97 - Perda de massa do fibrocimento em função do (a) teor de sílica, (b) teor de pozolana e (c) teor de escória presentes

A incorporação destas adições minerais na formulação do fibrocimento reduziu a porosidade total do material, segundo os resultados obtidos através do ensaio de absorção de água por princípio de Arquimedes (Figura 98). A perda de água, que 
por princípio causa a retração por secagem, foi proporcional à porosidade total dos fibrocimentos com adição. No entanto, a correlação entre a porosidade e a retração por secagem não foi observada (Figura 99), mostrando que a porosidade não governou o modo como o fibrocimento variou seu volume.

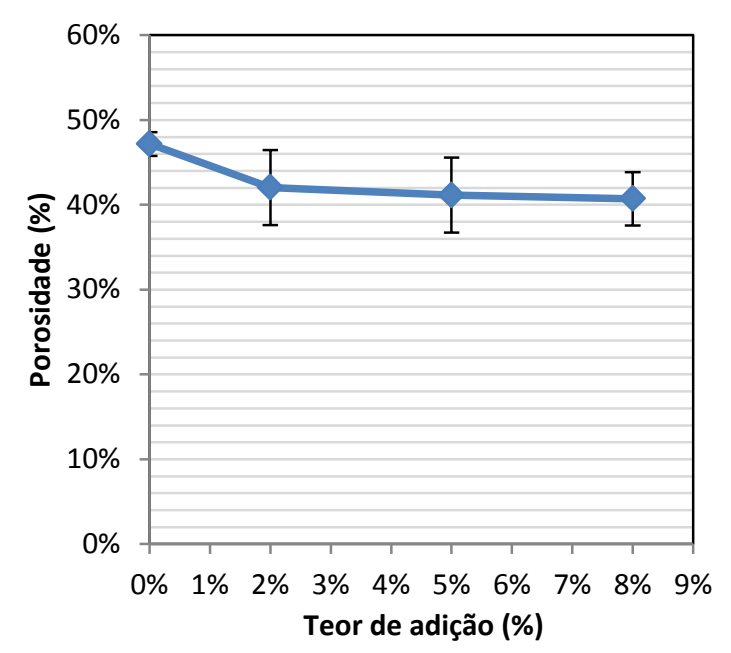

Figura 98 - Efeito do teor de adição na porosidade total do fibrocimento. Amostras com a quantidade de adição de sílica, pozolana ou escória variando nos teores de 0, 2, 5 e 8\%

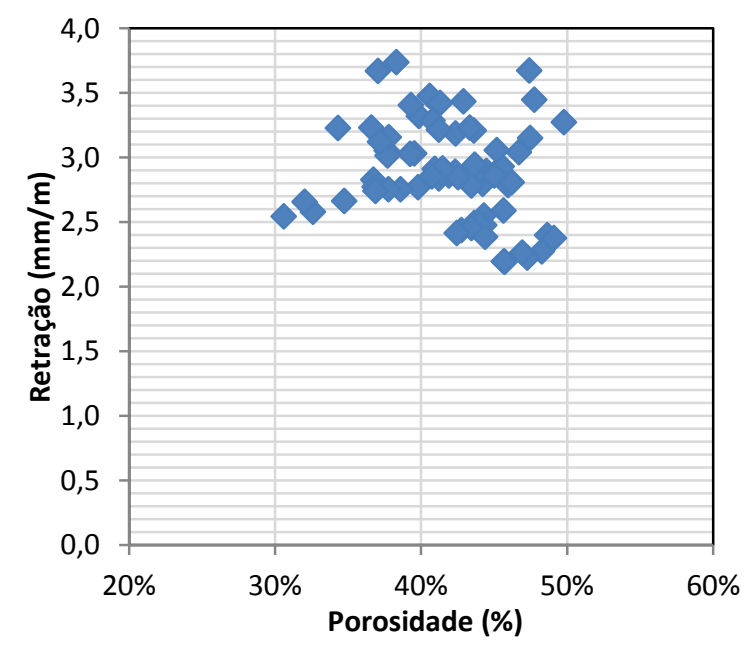

Figura 99 - Relação entre a retração e porosidade. Amostras com a quantidade de adição de sílica, pozolana ou escória variando nos teores de $0,2,5$ e $8 \%$

Os resultados de porosimetria por intrusão de mercúrio mostraram que as adições minerais atuaram na porosidade reduzindo a quantidade de poros de 0,2 a $1 \mu \mathrm{m}$, e aumentando o volume de poros capilares na faixa de $3,6 \mathrm{~nm}$ a $0,2 \mu \mathrm{m}$ (Figura 100, Figura 101 e Figura 102). Este refinamento dos poros foi a causa do aumento da retração por secagem medida nas amostras contendo adições. Estas análises são mais evidentes nas amostras contendo sílica, cujo acréscimo de 
retração foi maior. Isto ocorreu devido ao fato desta adição mineral ser mais fina em comparação com a escória e pozolana, o que se refletiu em um maior refinamento dos poros, comprovado pelos resultados de porosimetria (Figura 100).
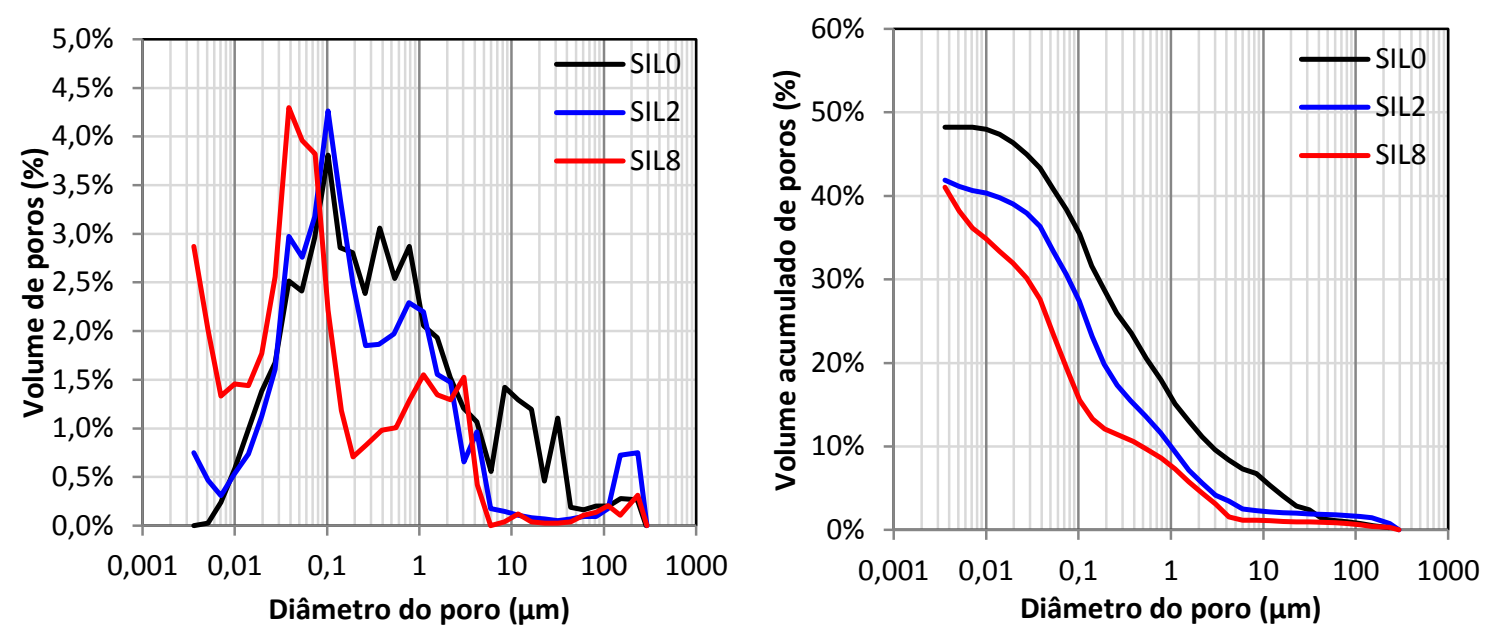

Figura 100 - Distribuição de tamanho de poros em função do teor de sílica presente na formulação
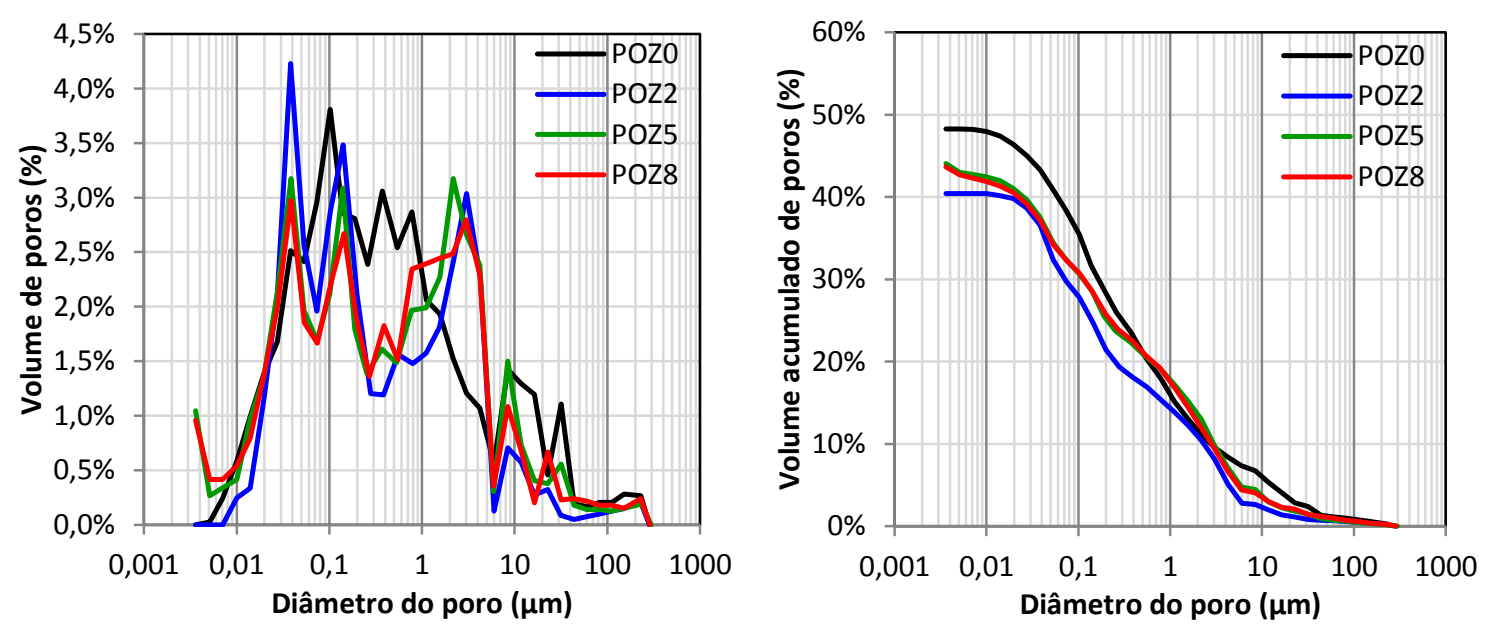

Figura 101 - Distribuição de tamanho de poros em função do teor de pozolana presente na formulação 

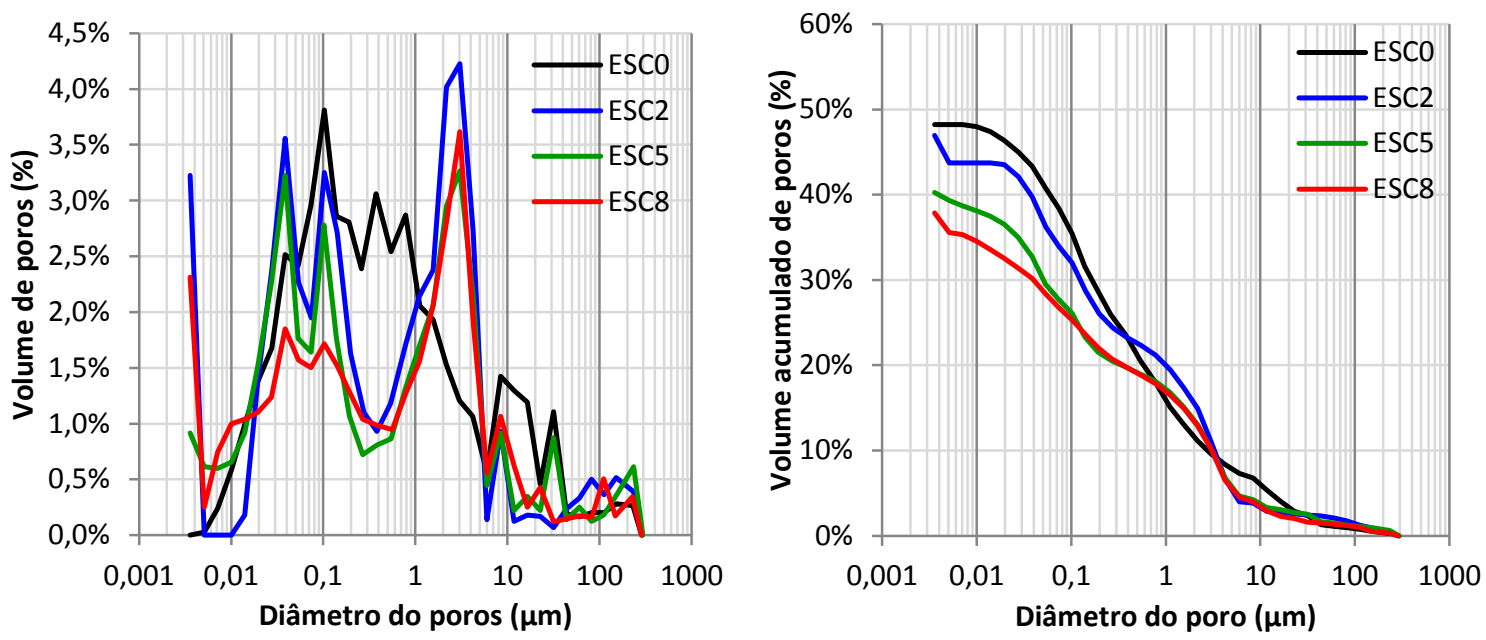

Figura 102 - Distribuição de tamanho de poros em função do teor de escória presente na formulação

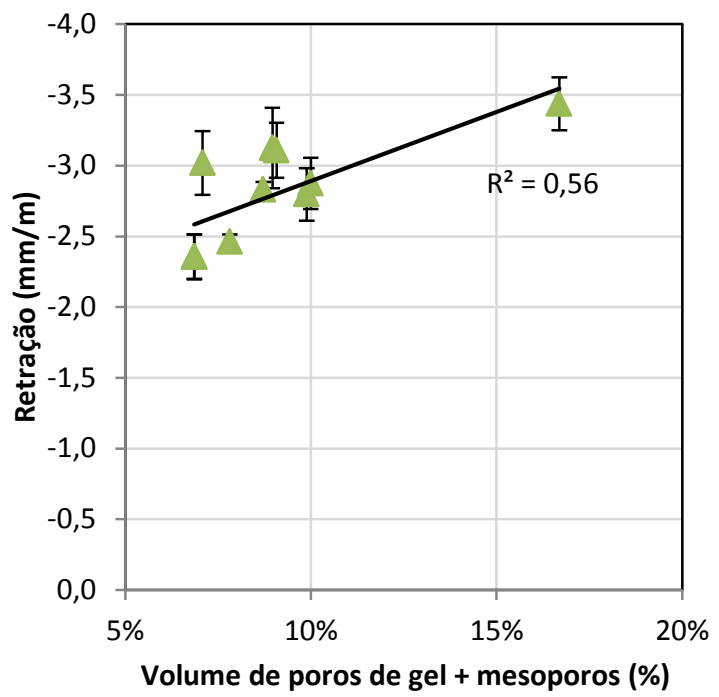

Figura 103 - Efeito do volume de poros de gel + mesoporos na retração 


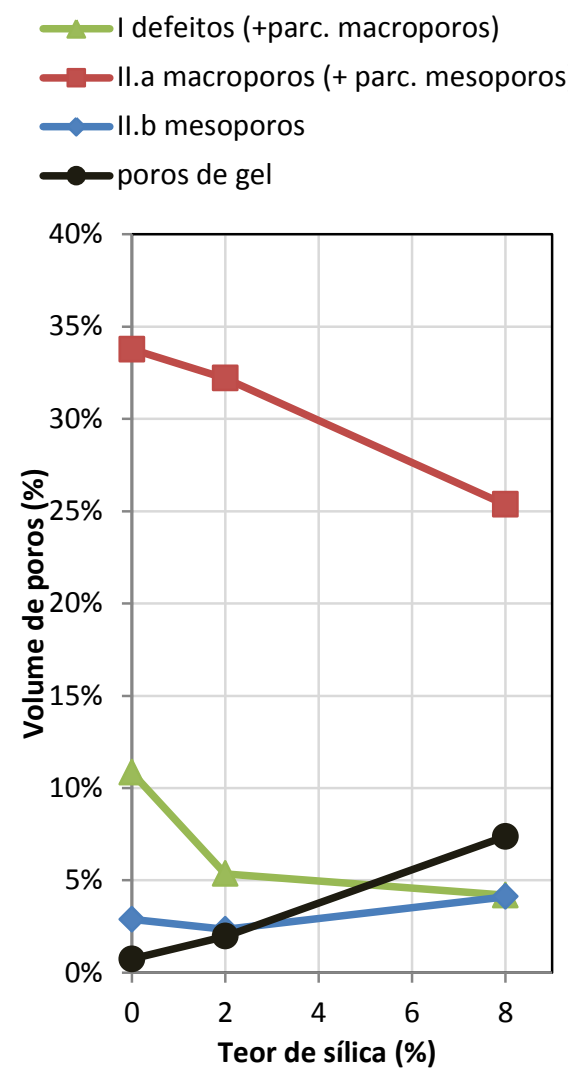

(a)

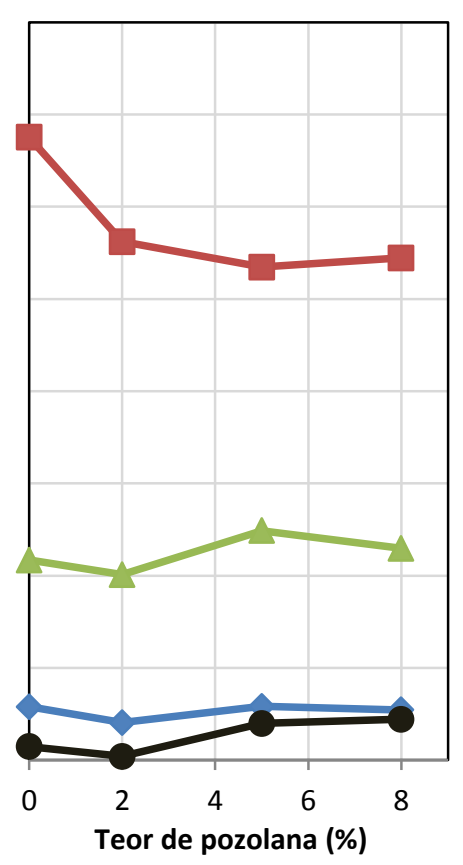

(b)

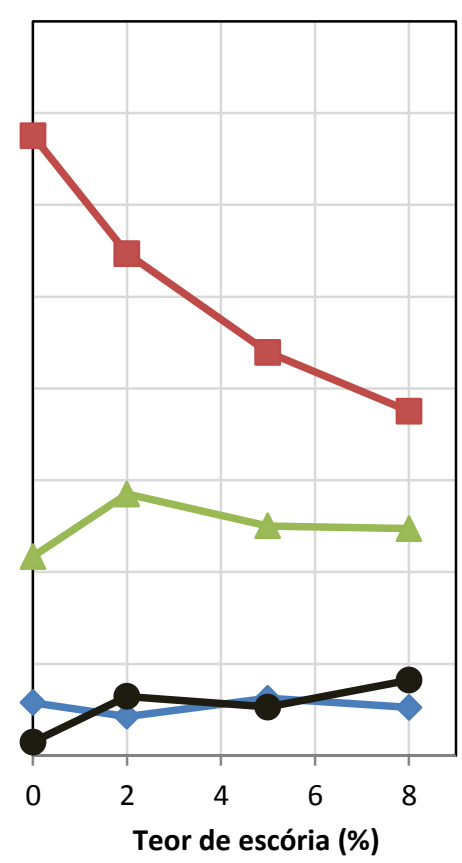

(c)

Figura 104 - Efeito do teor de adição no volume de poros nas diferentes faixas de tamanho. (a) sílica), (b) pozolana, (c) escória. Trecho I: diâmetro do poro superior a 2,33 $\mu \mathrm{m}$; trecho II.a: diâmetro do poro entre 0,03 e 2,33 $\mu \mathrm{m}$; trecho Il.b: diâmetro do poro entre 0,03 $\mu \mathrm{m}$ e 13,2 nm

A Figura 104 mostra o efeito de cada adição mineral na quantidade de poros de gel e mesoporos, que são os poros capilares que causam retração. Estes resultados mostram que o efeito somado da variação da quantidade de mesoporos, que são aqueles submetidos à ação de tensão capilar, juntamente com as alterações no volume de poros de gel, que neste caso apresentou correlação com a retração medida, indicam que uma parcela desta faixa de poros de gel pode contribuir para a retração sob o efeito de tensão capilar. As adições de escória e pozolana aumentaram o volume destes poros capilares. A sílica proporcionou ao fibrocimento um aumento mais intenso no volume destes tipos de poros. A Figura 103 é a comprovação do efeito da adição destes materiais minerais na retração por secagem o fibrocimento, pois mostra que o refinamento de poros causado, com aumento nas quantidades de poros de gel e mesoporos, têm relação direta com o aumento da retração. O aumento na retração foi de até $1 \mathrm{~mm} / \mathrm{m}$, para o intervalo de 0 a $8 \%$ de adição. 


\subsubsection{Influência da quantidade de celulose na retração por secagem}

A celulose é uma fibra natural, componente presente no fibrocimento com duas finalidades principais, sendo a primeira conferir o reforço mecânico da fibra, aumentando a tenacidade e módulo de ruptura à flexão; o segundo é reter água e finos durante o processo produtivo, durante a fabricação de artefatos pelo processo Hatschek, e manter a reologia adequada da manta por todo o processo produtivo.

Ocorre que, esta propriedade de retenção de água, necessária para o bom funcionamento do processo Hatschek, faz com que a porosidade do fibrocimento no estado endurecido seja grande. A água retida nas fibras, depois do fibrocimento endurecido, evapora e deixa os espaços vazios responsáveis pelo elevado nível de porosidade. A Figura 105.a mostra que quanto maior foi a quantidade de celulose adicionada na amostra, maior foi a porosidade resultante. No mesmo sentido, a densidade real e aparente diminuem com o aumento da adição de celulose na formulação (Figura 105.b).

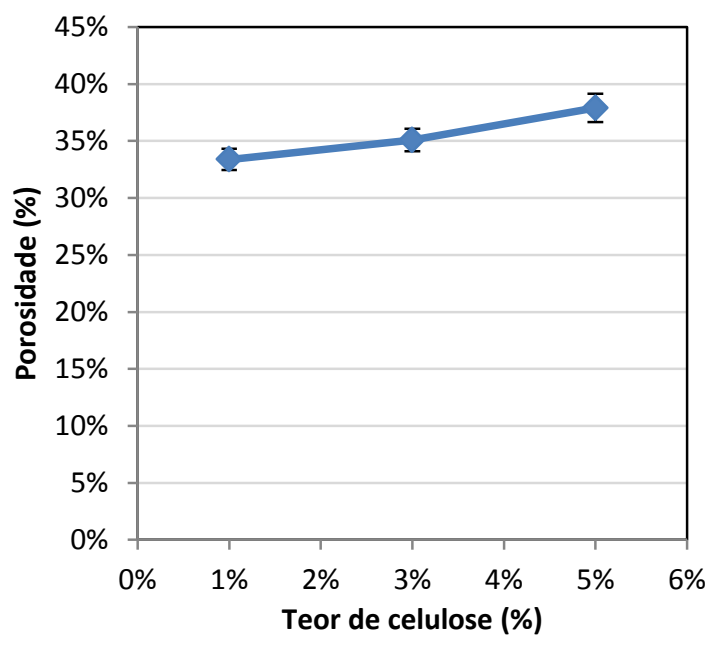

(a)

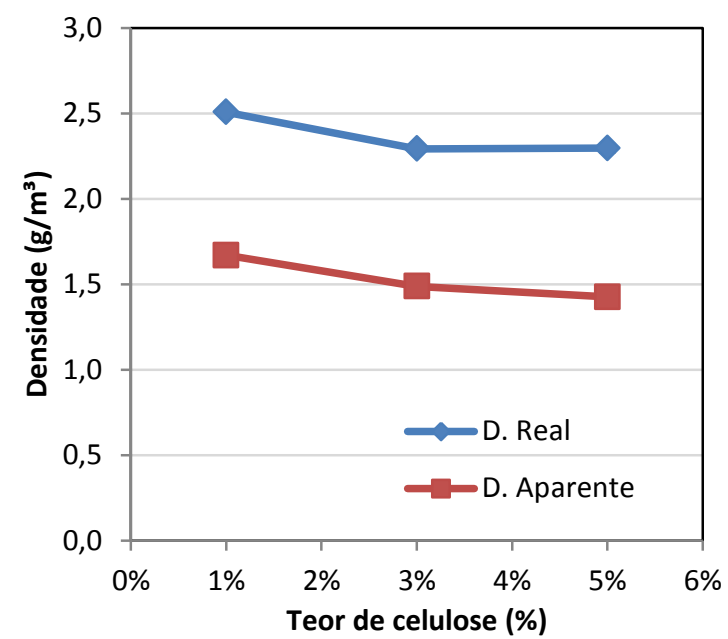

(b)

Figura 105 - Efeito do teor de celulose na (a) porosidade total medida por princípio de Arquimedes e (b) densidades real e aparente do fibrocimento

Uma vez que a retração por secagem está relacionada com a porosidade total do fibrocimento, a Figura 106 mostra que a retração por secagem aumentou até $0,65 \mathrm{~mm} / \mathrm{m}$ quando se aumentou o teor de celulose até $5 \%$. A maior retração se deu devido à retenção de água promovida pela fibra enquanto o fibrocimento está sendo produzido, que se refletiu em uma perda de água ao final da secagem, maior na amostra com maior teor de celulose. A maior retenção de água promovida pela celulose foi de $4,9 \%$ de perda de massa ao final da secagem (Figura 106.b). 


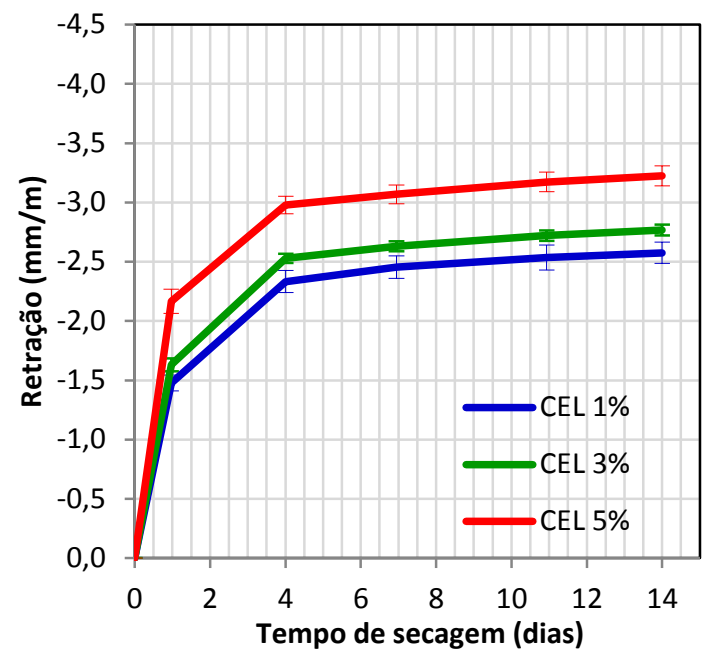

(a)

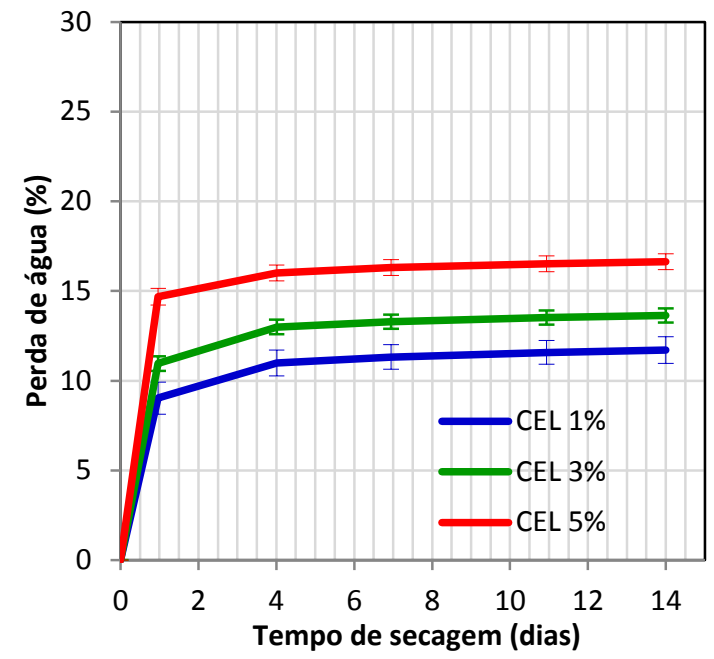

(b)

Figura 106 - Efeito do teor de celulose na (a) perda de massa e (b) na retração em função do tempo de secagem. Amostras com a quantidade de cimento variando nos teores de 1, 3 e 5\%

A maior porosidade promovida pela adição de celulose apresentou correlação direta com a perda de água durante a secagem, e por consequência com a retração. O intervalo de aproximadamente $7 \%$ de variação na porosidade resultou uma diferença de até $1 \mathrm{~mm} / \mathrm{m}$ na retração por secagem (Figura 107).

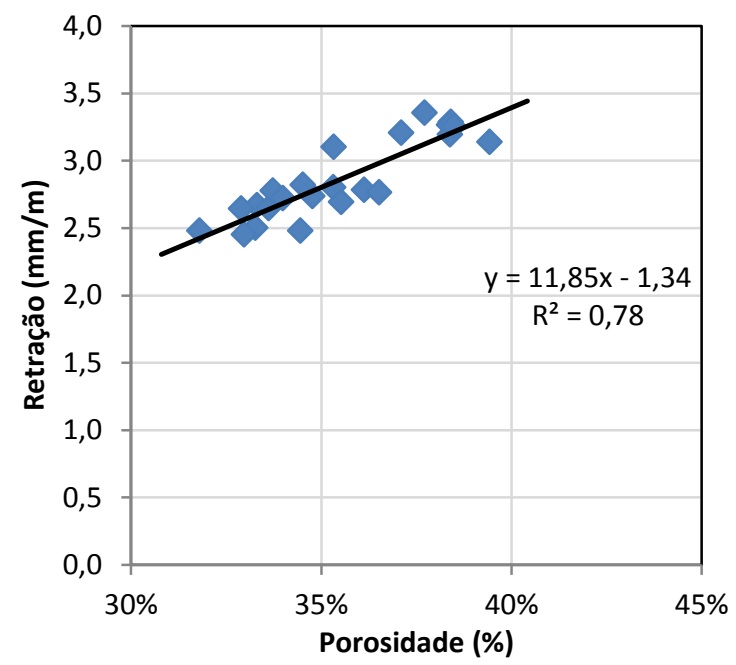

Figura 107 - Efeito porosidade total na retração por secagem 


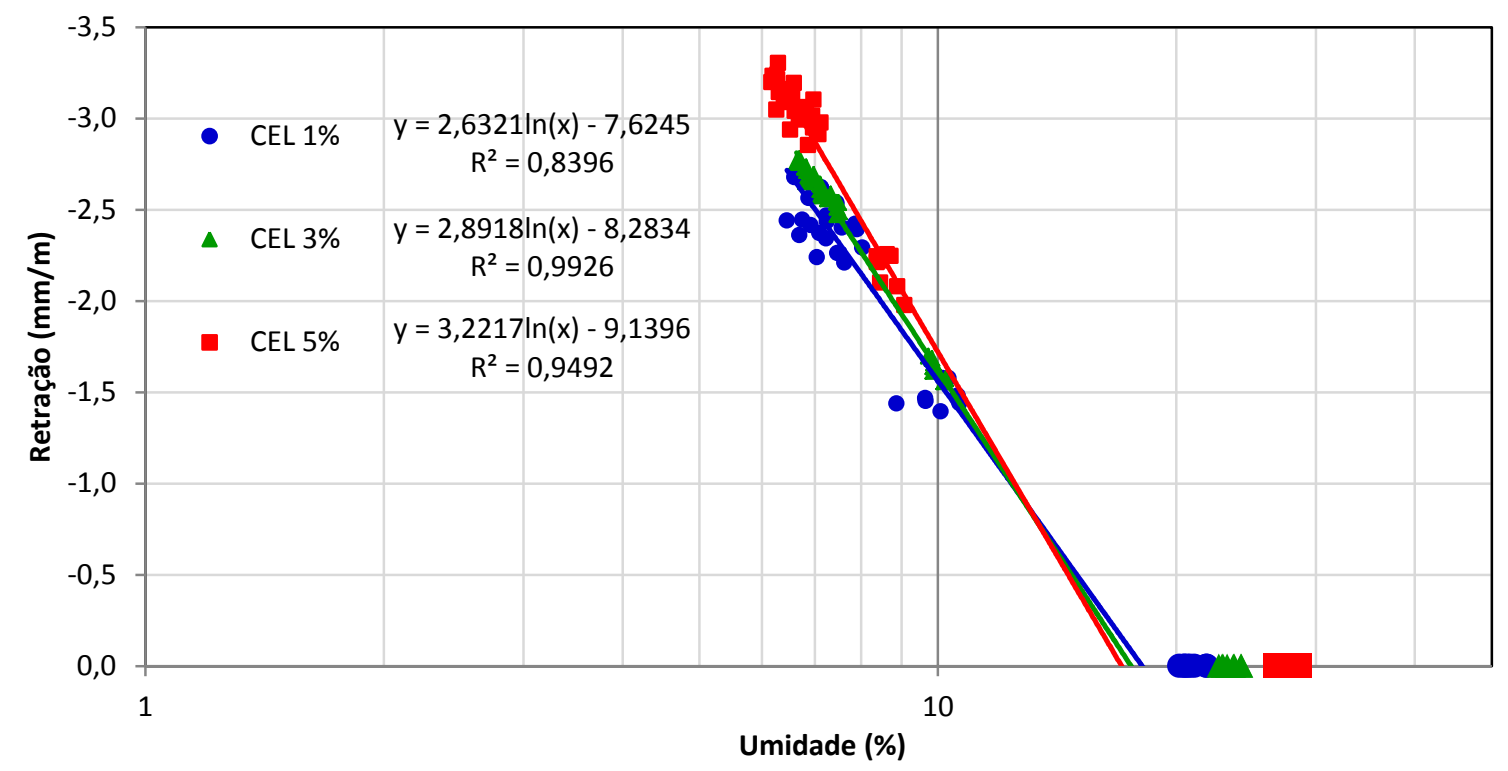

Figura 108 - Relação entre a retração por secagem e a umidade do fibrocimento, em função do teor de celulose

Através da relação entre umidade e retração por secagem observa-se que a aumento no teor de celulose reduziu a umidade de equilíbrio, aumentou a retração total, além de aumentar a inclinação da curva, indicando maior suscetibilidade à retração destas amostras. Isto ocorreu devido ao grande incremento de volume de poros em torno de $1 \mu \mathrm{m}$, que é uma faixa de tamanho de poros que contribui para a retração, especialmente pela grande perda de água.

$O$ aumento da porosidade total causado pela celulose influenciou uniformemente a distribuição de tamanho de poros. A Figura 109 mostra que a celulose aumenta especialmente $o$ volume de poros de tamanho entre 0,1 e $4 \mu \mathrm{m}$, aumentando também a quantidade de poros capilares entre $3,6 \mathrm{~nm}$ e $0,5 \mu \mathrm{m}$. A Figura 110 mostra que o aumento no volume de poros suscetíveis à ação de pressão capilar, que são os mesoporos e poros de gel, foi pequeno com a adição de celulose, no entanto, o volume de poros capilares grandes, e consequentemente todo o intervalo de poros entre 3,6 nm e $10 \mu \mathrm{m}$, sofreu grande aumento. Mesmo que a parcela da tensão capilar seja pequena nos poros capilares grandes (Mindess, 1981), o volume total deste tipo de poros é grande, com resultante que apresentou correlação com a retração por secagem medida. 

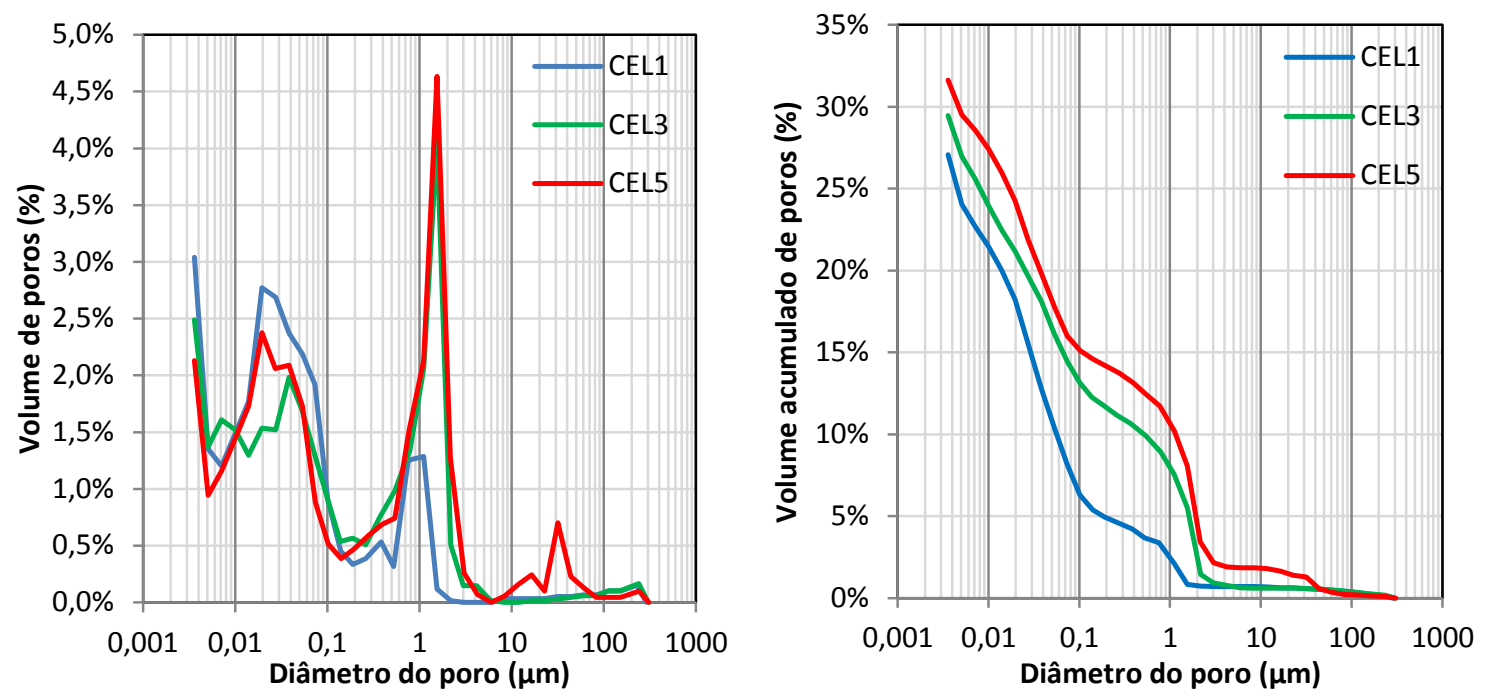

Figura 109 - Distribuição de tamanho de poros em função do teor de celulose presente na formulação

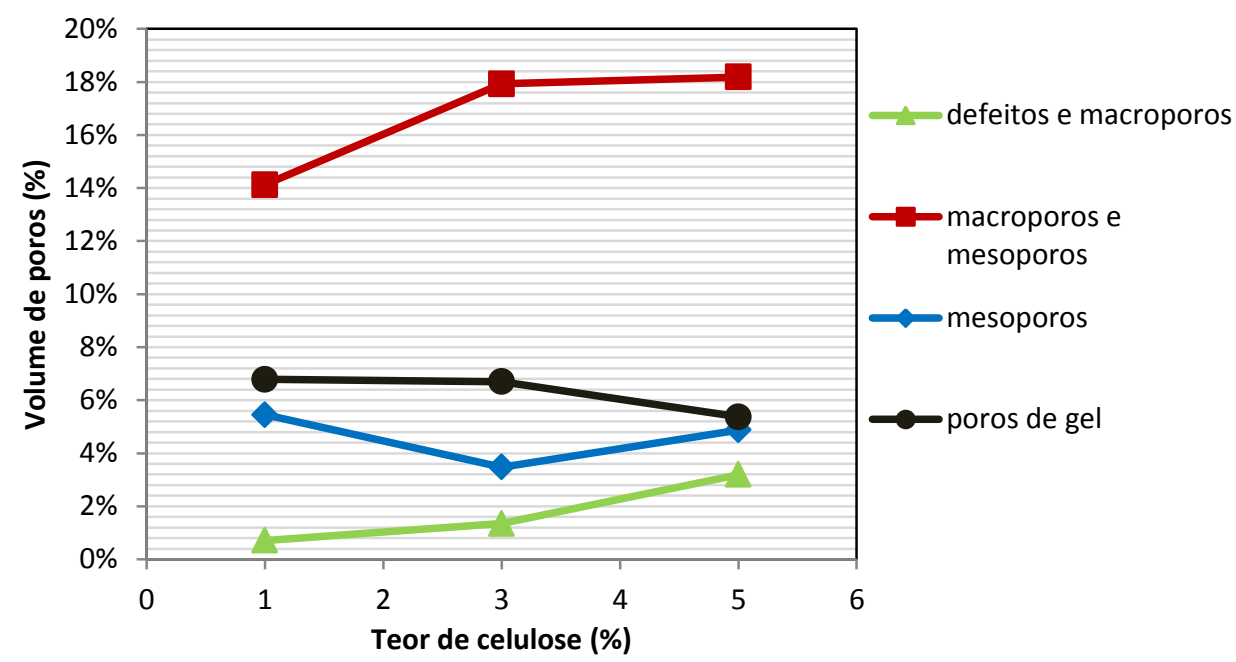

Figura 110 - Efeito do teor de celulose no fibrocimento no volume de poros de gel + mesoporos, capilares grandes e defeitos

\subsubsection{Influência da quantidade de fibras de PVA e PP na retração por secagem}

As fibras poliméricas de reforço são adicionadas ao fibrocimento para melhorar suas propriedades mecânicas, conferindo resistência mecânica e tenacidade ao compósito. As fibras de reforço atuam mecanicamente no compósito, tanto no incremento de resistência mecânica, como no impedimento da variação volumétrica quando o fibrocimento tende a retrair na secagem. Esta ação mecânica é válida quando se considera uma matriz cimentícia com mesmas características. 
Teoricamente fibras de reforço como PVA e PP não alteram as características da matriz cimentícia. No entanto, a perturbação mecânica que a presença da fibra causa na manta fresca, aumenta a quantidade de poros no fibrocimento, que por sua vez podem ser fonte geradora de retração por secagem. Nas amostras estudadas foi verificado um aumento na retração com o aumento do teor de fibras sintéticas na formulação (Figura 111), pois o efeito da variação de porosidade oriundo da incorporação de fibras se sobrepôs à resistência mecânica imposta por ela, que poderia impedir esta variação volumétrica.

A maior retração por secagem medida para os maiores teores de fibras é devido à maior perda de água durante a secagem. Esta perda de massa superior é a confirmação do que foi dito, onde o aumento da quantidade de fibras gera maior porosidade no compósito (Figura 113). Estas tendências comentadas são mais evidentes nas formulações com PP, pois o aumento na porosidade foi mais evidente nesta amostra.

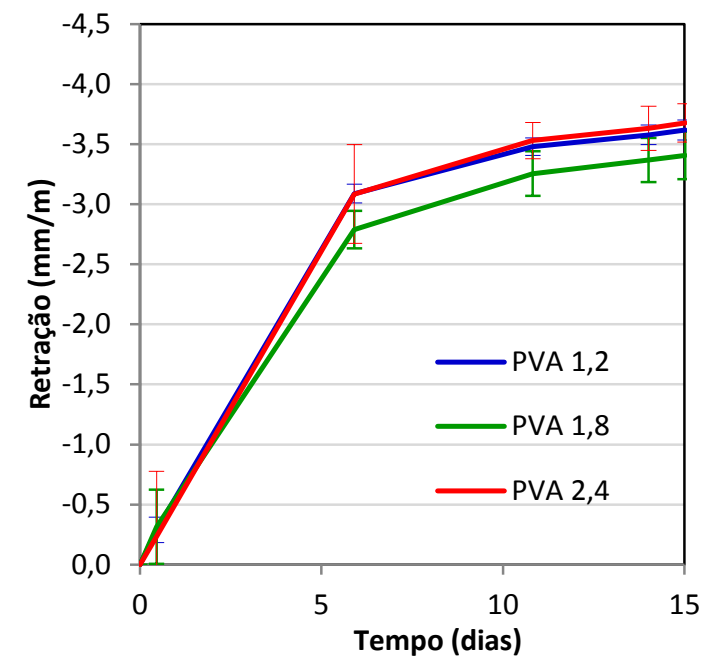

(a)

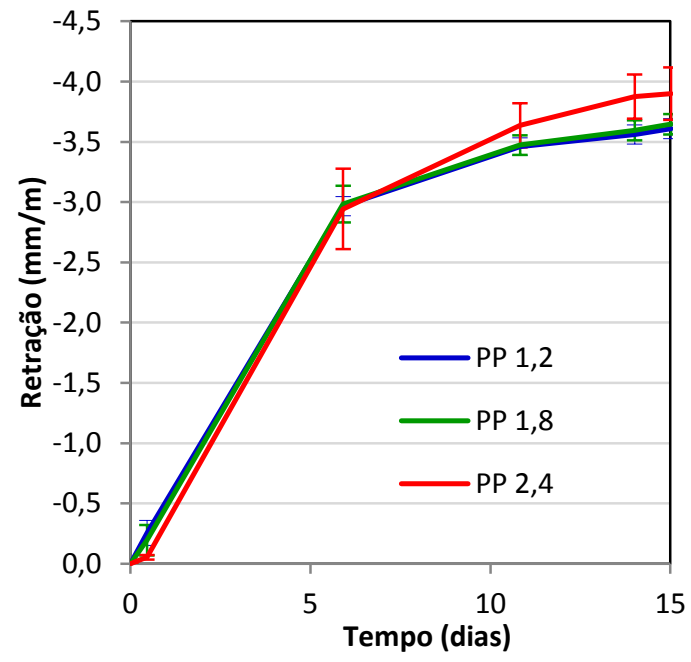

(b)

Figura 111 - Retração por secagem em função do (a) teor de PVA e (b) teor de PP presentes no fibrocimento 


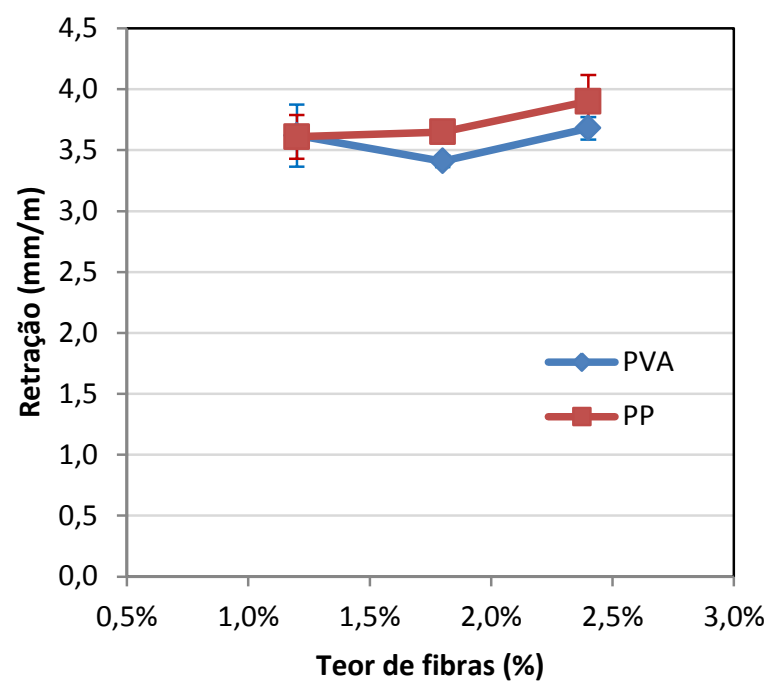

Figura 112 - Retração aos 14 dias de secagem em função das quantidades de PVA ou PP presentes

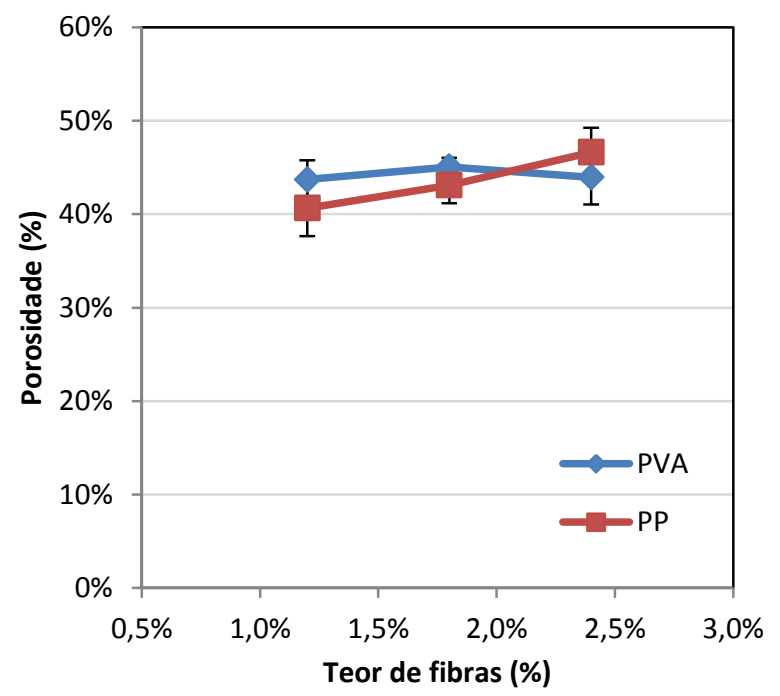

Figura 113 - Porosidade do fibrocimento em função das quantidades de PVA ou PP presentes

Os resultados apresentados nos itens anteriores desta tese mostram que a relação do aumento da porosidade com o aumento da retração está relacionada com o aumento no volume de poros causadores de retração, que não primeiramente os mesoporos, ou ainda a quantidade de mesoporos + poros de gel, e até mesmo a quantidade de poros capilares grandes, quando a variação no volume destes poros for grande. Neste caso, o aumento na porosidade total acompanha um aumento na quantidade de mesoporos, na faixa de 0,01 a 0,05 $\mu \mathrm{m}$, causadores de retração, como pode ser visto na Figura 114 e na Figura 115. 

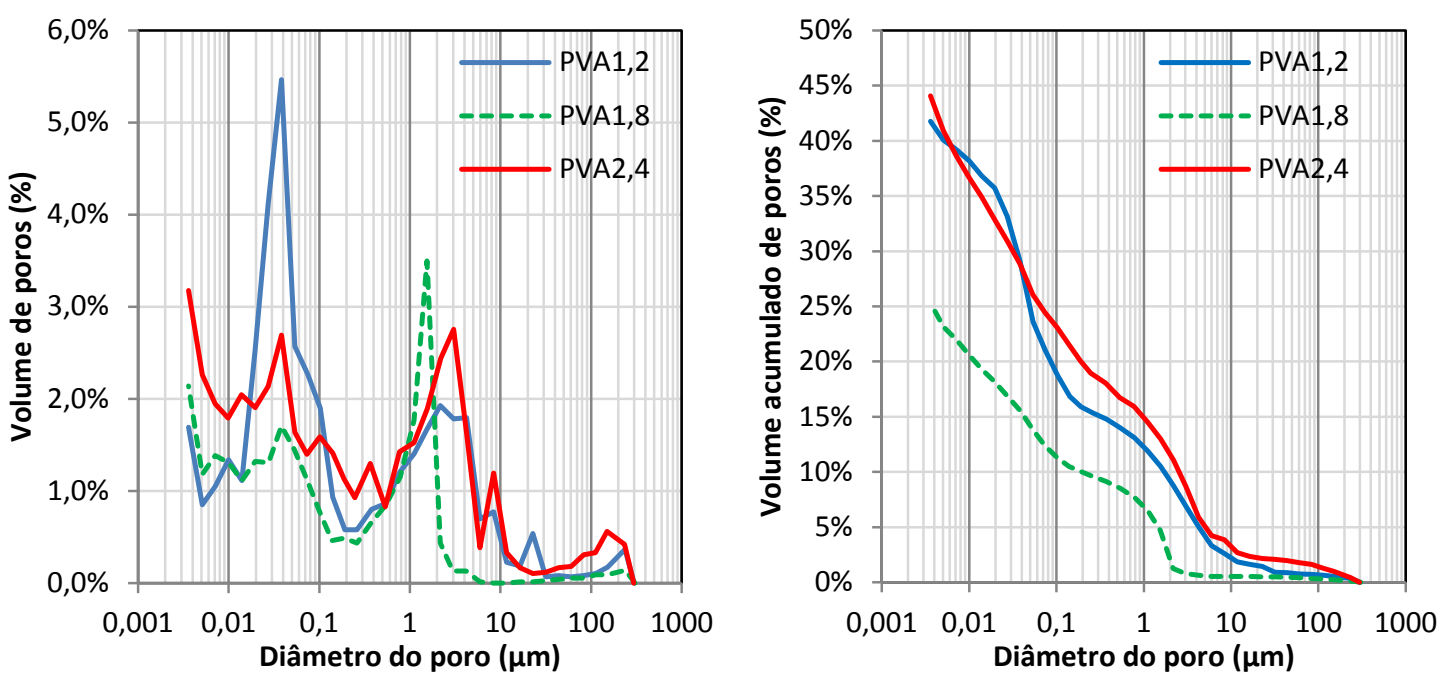

Figura 114 - Distribuição de tamanho de poros em função do teor de PVA presente na formulação
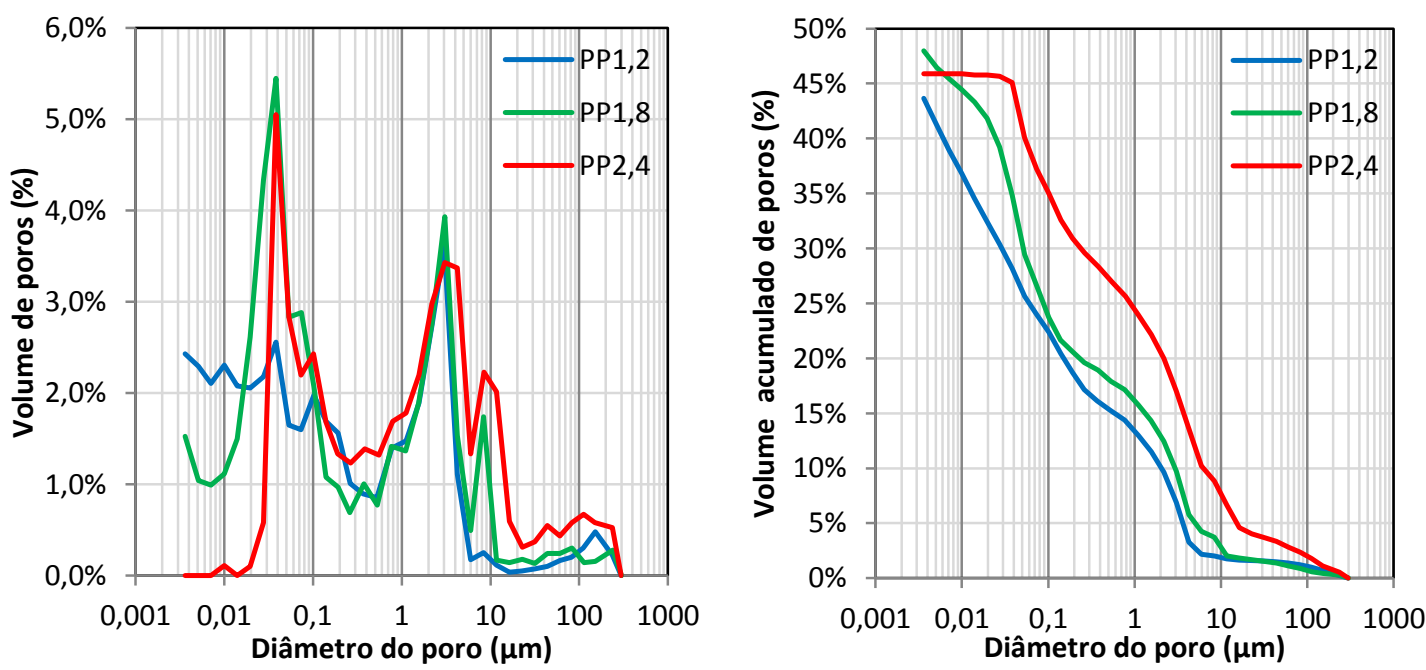

Figura 115 - Distribuição de tamanho de poros em função do teor de PP presente na formulação

As fibras poliméricas de reforço aumentaram a resistência mecânica do fibrocimento tanto para o caso do PVA como do PP. A Figura 116 mostra que houve melhora no MOR com o aumento da quantidade de fibras, enquanto que o LOP se manteve constante, indicando que este incremento se deve principalmente pelo aumento de energia específica. Além disso, o aumento na incorporação das fibras reduziu a rigidez do fibrocimento, o que é bom, pois reduz as tensões geradas devido à retração por secagem.

Mesmo que as fibras poliméricas não sejam capazes de reduzir a retração por secagem, estas são necessárias ao compósito, pois não permitem que ocorra fissuração devido à retração, e inibem a propagação de fissuras, quando estas 
ocorrem, de modo que seus benefícios são necessários para o bom desempenho do fibrocimento.

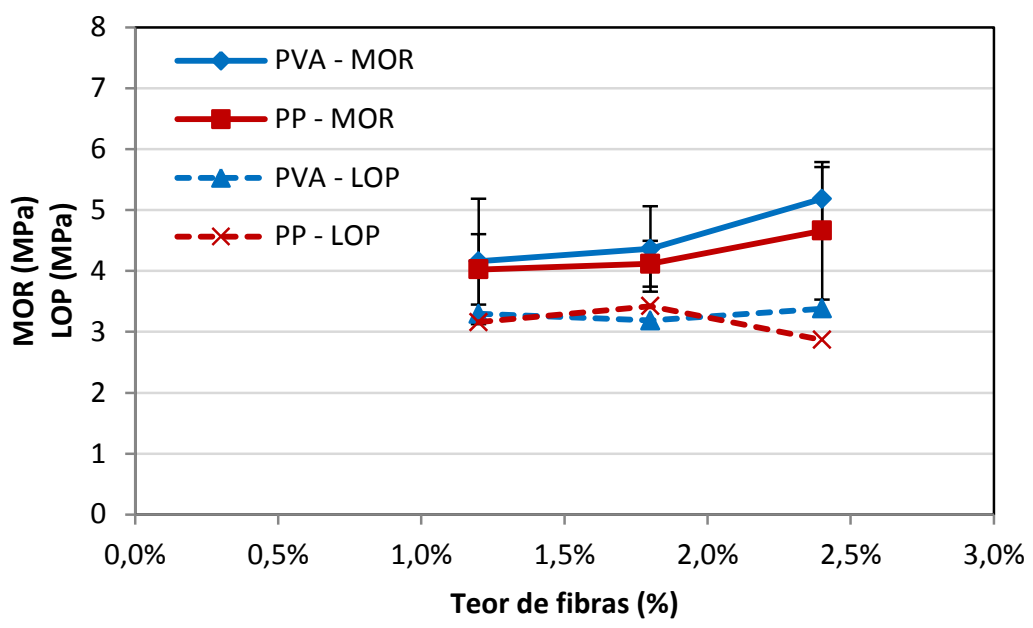

Figura 116 - Propriedades mecânicas (MOR e LOP) do fibrocimento em função das quantidades de PVA ou PP presentes

As curvas de tensão deformação dos ensaios de flexão estão expostos a seguir, nas Figura 117 e Figura 118.

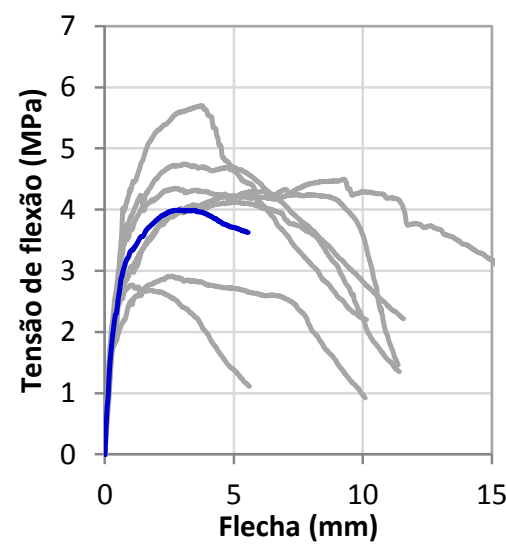

(a)

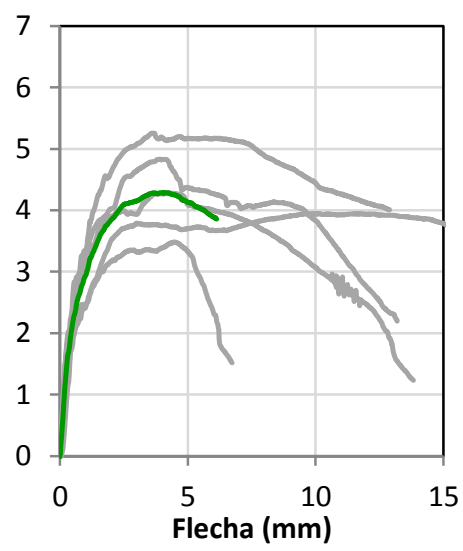

(b)

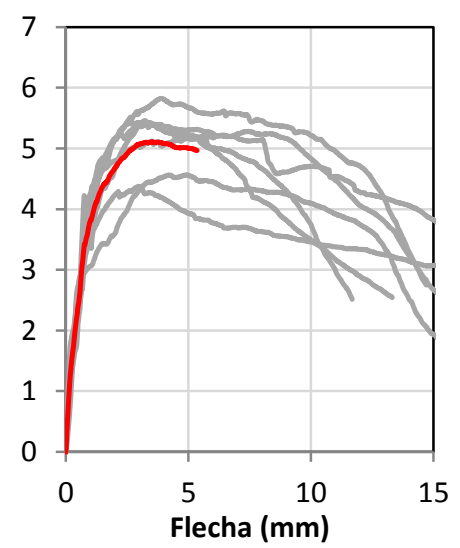

(c)

Figura 117 - Curvas tensão-deformação dos fibrocimentos com (a) 1,2\%, (b) 1,8\% e (c) 2,4\% de PVA presente 


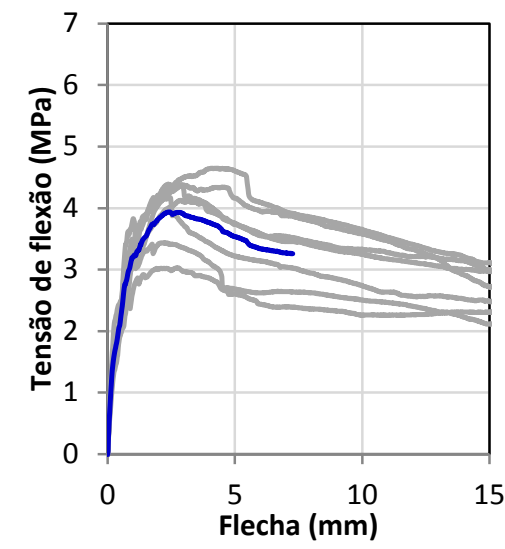

(a)

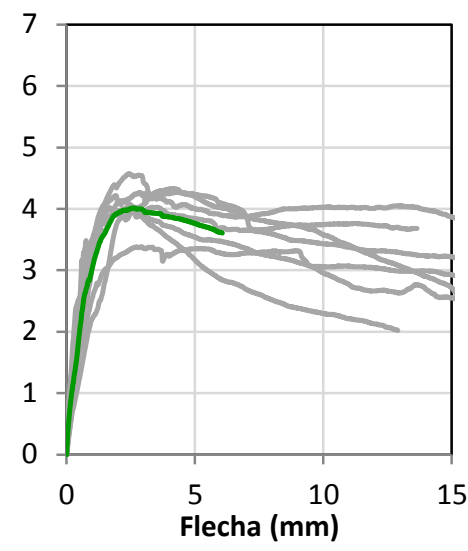

(b)

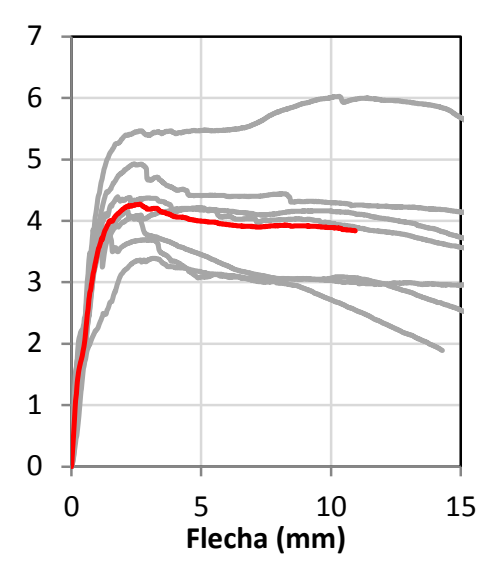

(c)

Figura 118 - Curvas tensão-deformação dos fibrocimentos com (a) 1,2\%, (b) $1,8 \%$ e (c) $2,4 \%$ de PP presente

\subsection{Conclusões}

Este capítulo da tese mostra como os materiais que compõem o fibrocimento NT influenciam na sua retração por secagem, de modo a utilizar esta estratégia como ferramenta de mitigação da fissuração decorrente da retração por secagem.

As conclusões deste capítulo foram:

- As propriedades físico-químicas entre diferentes cimentos variam em um grande intervalo, desde o tamanho de partículas, superfície específica, composição química, reatividade, adições minerais incorporadas etc;

- Nenhuma das propriedades caracterizadas dos cimentos utilizados apresentou correlação isoladamente com a retração por secagem. Isto ocorreu uma vez que, quando se muda o tipo de cimento, mais de uma variável que podem influenciar na retração, podem atuar aleatoriamente, como:

- Tamanho de partículas, que muda o empacotamento;

- Quantidade de C-S-H, e demais compostos hidratados formados, que varia em função do teor de clínquer do cimento; 
- Efeito da adição mineral presente no cimento, uma vez que a escória favorece a retração (Giordano et al., 2009), diferente do calcário.

- De qualquer forma, isolada ou simultaneamente, todos estes fatores devem refletir na distribuição de tamanho de poros da matriz cimentícia, para que haja reflexo na retração por secagem, uma vez que esta é função da pressão capilar. A correlação entre a retração e o volume de poros capilares foi fraca, impossibilitando a aplicação de uma regressão. No entanto, a tendência observada foi que quanto maior a quantidade de mesoporos, maior foi a retração;

- As adições de sílica, pozolana ou escória influenciaram na retração em concordância ao observado na bibliografia existente, aumentando a retração por secagem, pois devido ao tamanho de partículas da sílica utilizada, esta refinou os poros da matriz, aumentando a quantidade destes na faixa dos mesoporos;

- A adição de fibras de celulose pode ser o fator determinante deste comportamento particular do fibrocimento, uma vez que esta fibra vegetal atua como retentor de água durante a conformação do fibrocimento, o que se reflete em porosidade do compósito no estado endurecido, e em grande retração durante a secagem;

- No intervalo de teores estudados, as fibras poliméricas de reforço (PVA e PP) não foram capazes de reduzir a retração por ação mecânica de impedimento desta variação volumétrica. As perturbações na matriz cimentícia geradas pela movimentação destas fibras quando o fibrocimento está no estado fresco, resultaram em aumento na porosidade, que por sua vez se refletiu em aumento na retração. 


\section{Capítulo V}

\section{Retração por Carbonatação}

\subsection{Introdução}

A carbonatação é uma reação química do dióxido de carbono com os compostos hidratados do cimento. Esta reação causa retração nos compósitos cimentícios. Da mesma forma como a retração por secagem pode causar danos aos artefatos de fibrocimento, a grande magnitude da retração causada pela carbonatação pode ser causa importante de manifestações patológicas, como a fissuração de borda das telhas onduladas.

O objetivo deste capítulo é mostrar qual é a parcela da retração por carbonatação, em relação à retração total em fibrocimento exposto a condições ambientais típicas, suscetíveis à secagem e interação química com o ar contendo $\mathrm{CO}_{2}$.

\subsection{Metodologia}

Para mostrar qual é a parcela da retração por carbonatação, em relação à retração total em fibrocimento suscetível à secagem e interação química com o ar contendo $\mathrm{CO}_{2}$, amostras de fibrocimento foram expostas a três condições distintas de secagem:

- Secagem em ambiente protegido do $\mathrm{CO}_{2}$, de modo a sofrer apenas a ação da secagem na retração e propriedades microestruturais do fibrocimento;

- Secagem em ambiente protegido de $\mathrm{CO}_{2}$ por 14 dias, seguido de exposição em ambiente rico em $\mathrm{CO}_{2}$, de modo a medir somente os efeitos 
da carbonatação na retração e propriedades microestruturais do fibrocimento;

- Secagem em ambiente rico de $\mathrm{CO}_{2}$, de modo a observar o efeito conjunto da secagem e carbonatação na retração e propriedades microestruturais do fibrocimento.

A formulação adotada neste estudo foi denominada de formulação padrão, composta por cimento Portland CPII E-32, calcário, sílica ativa, fibras de celulose e PVA (Tabela 24).

Tabela 24 - Formulação padrão do fibrocimento, em massa

\begin{tabular}{|c|c|c|c|}
\hline Cimento & Sílica ativa & Calcário & Celulose + PVA \\
\hline $60 \%$ & $5 \%$ & $30,2 \%$ & $4,8 \%$ \\
\hline
\end{tabular}

As amostras estudadas foram produzidas em laboratório, segundo o método de moldagem descrito no item 2.2.2, e foram submetidas ao plano experimental exposto na Figura 119. Depois de moldados e curados, os corpos-de-prova foram submetidos às três condições de exposição supracitadas, e descritas no plano experimental. Como indicadores de desempenho foram realizados os ensaios de retração, variação de massa e resistência à flexão. As alterações na microestrutura do fibrocimento foi medida através dos ensaios de porosidade total por princípio de Arquimedes, alteração nos compostos presentes por termogravimetria e distribuição de tamanho de poros por porosimetria por intrusão de mercúrio. Os métodos de ensaio estão detalhados nos itens 2.4.1, 2.4.2, 2.4.3, 2.3.3 e 2.4.4.

A Figura 119 mostra o plano experimental deste estudo, sendo que inicialmente todas as amostras foram submetidas ao mesmo processo de cura, em câmara climática. Após iniciado o processo de secagem, cada amostra foi submetida a uma condição distinta de exposição. No primeiro intervalo de tempo de secagem, que durou 19 dias, as amostras denominadas SECAGEM e CARBONATAÇÃO APÓS SECAGEM foram expostas à secagem em câmara climática com circulação de ar, em temperatura de $23^{\circ} \mathrm{C}$ e U.R. de $50 \%$. Com intuito de minimizar os efeitos da carbonatação natural pelo contato das amostras com 0 ar, estas ficaram armazenadas em recipiente contendo cal sodada. A amostra SECAGEM + 
CARBONATAÇÃO foi submetida à exposição em câmara de carbonatação, com temperatura de $23^{\circ} \mathrm{C}$, umidade relativa de $50 \%$ e concentração de $\mathrm{CO}_{2}$ de $5 \%$.

No segundo intervalo de tempo de secagem, somente a amostra SECAGEM permaneceu em câmara climática, sob as mesmas condições ambientais $\left(23^{\circ} \mathrm{C}\right.$; U.R. 50\%), enquanto que a amostra CARBONATAÇÃO APÓS SECAGEM foi transferida para a câmara de carbonatação, juntamente com a amostra SECAGEM + CARBONATAÇÃO, pelo período de 63 dias.

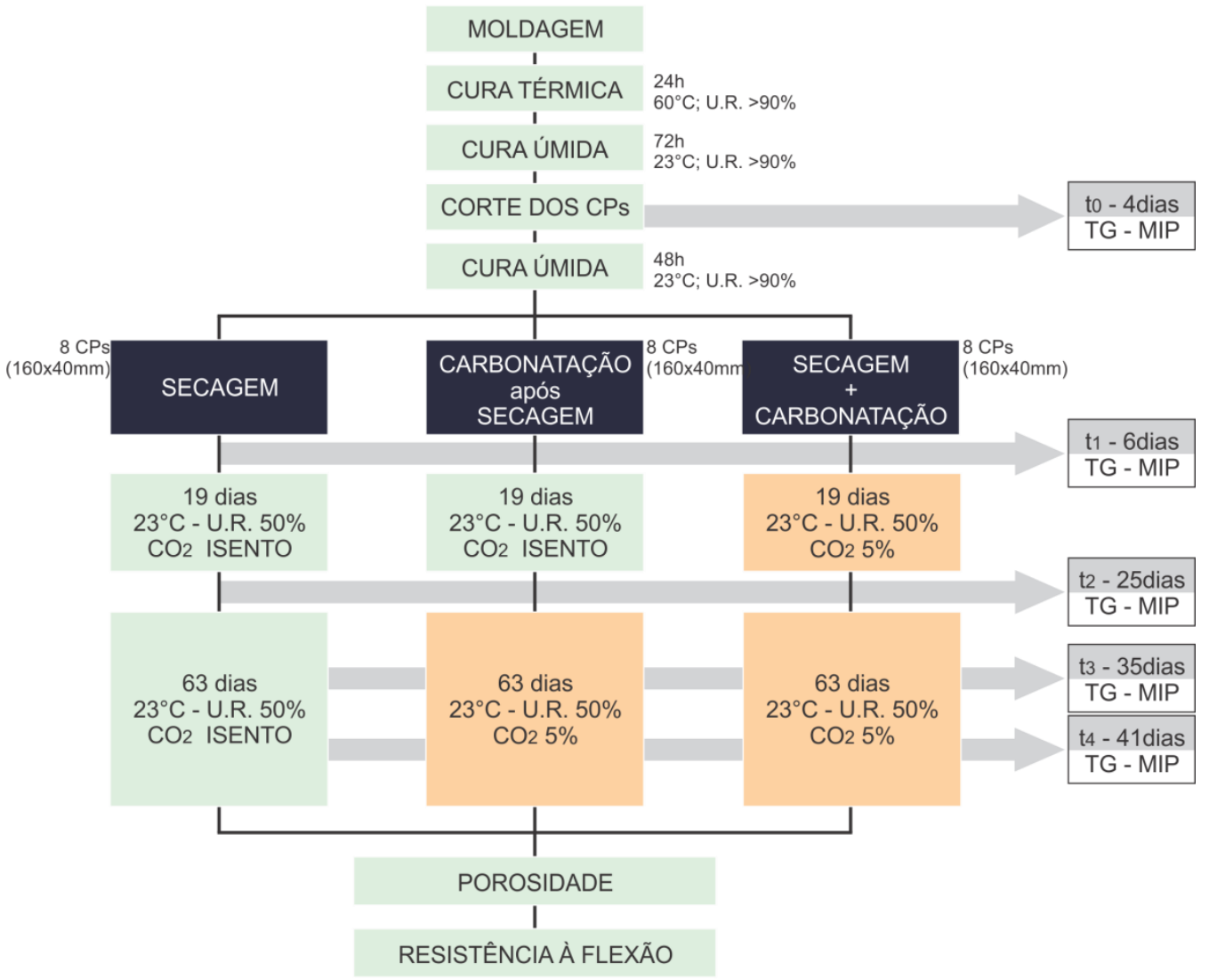

Figura 119 - Plano experimental do estudo de retração por carbonatação

\subsubsection{Carbonatação de telhas expostas}

Paralelamente ao estudo realizado em laboratório, foram coletadas amostras de telhas de fibrocimento NT empilhadas, expostas ao tempo no pátio de uma fábrica de fibrocimento, de modo a verificar a diferença no grau de carbonatação entre as regiões da borda e centro das telhas.

Foram analisadas amostras em 4 idades de exposição: 4 meses; 6 meses; 1 ano e 1 mês; 2 anos e 1 mês. Estas amostras foram fabricadas industrialmente pelo processo Hatschek, e submetidas às mesmas condições de cura e exposição. Haja vista que no período de 2 anos de produção a formulação de fibrocimento sofreu 
modificações em suas matérias-primas, formulação e parâmetros de processo, as 4 amostras de fibrocimento coletadas possuem formulações diferentes, que variaram dentro dos seguintes intervalos indicados na Tabela 25:

Tabela 25 - Intervalos dos teores dos materiais componentes dos fibrocimentos expostos à carbonatação natural

\begin{tabular}{lc}
\hline Material & Intervalo (\%) \\
\hline \multirow{2}{*}{ Cimento } & CPII-F ou CPII-E \\
\cline { 2 - 2 } & 58,9 a $61,1 \%$ \\
\hline Calcário & 31,7 a $34,1 \%$ \\
\hline Sílica & 0 a $5 \%$ \\
\hline Fibras orgânicas (celulose + PVA) & 4,3 a $5,8 \%$ \\
\hline
\end{tabular}

As amostras analisadas foram coletadas sempre da sexta telha superior, como indicado na Figura 120, de modo que a borda da telha ficou exposta as intempéries, incluindo a reação de carbonatação, durante todo o período de exposição. O empilhamento das telhas cria uma condição onde a região central fica protegida das ações do tempo, sendo menores os efeitos de secagem e de carbonatação nesta região, devido à maior dificuldade de difusão do ar externo até esta região.

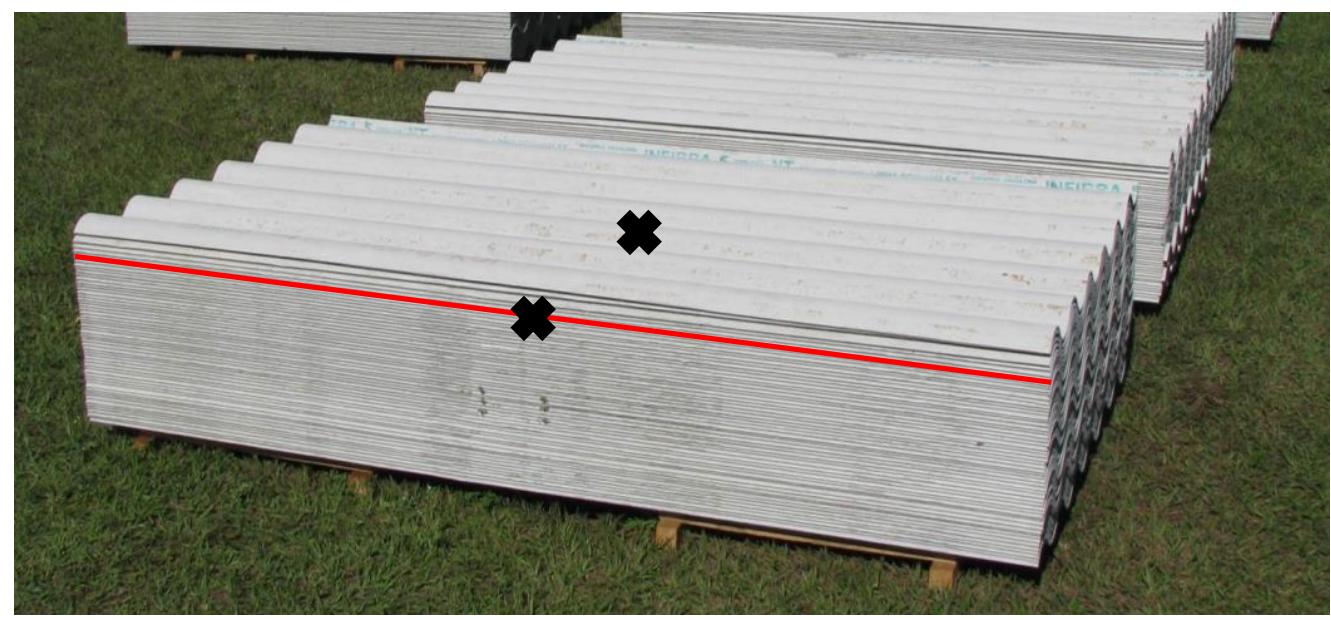

Figura 120 - Monte de telhas empilhadas expostas. Amostras foram retiradas da sexta telha superior (indicada pela linha vermelha), sendo uma amostra retirada da borda e outra da região central desta telha (indicados pelo sinal $\mathrm{X}$ )

A partir das amostras coletadas foram determinadas as alterações nos compostos hidratados do cimento, de modo a verificar o grau de carbonatação nas duas diferentes regiões, em função do tempo, por termogravimetria; foi medida a porosidade total por princípio de Arquimedes; distribuição de tamanho de poros por porosimetria por intrusão de mercúrio, retração por secagem após período de 
exposição; resistência mecânica à flexão. A descrição detalhada dos métodos de ensaio consta nos itens 2.3.3, 2.4.1, 2.4.2, 2.4.3 e 2.4.4.

\subsection{Resultados e discussões}

5.3.1. Efeito da carbonatação na microestrutura do fibrocimento com PVA

Com o intuito de medir a retração por carbonatação, sem o efeito da retração por secagem, e desta forma medir qual é a parcela e magnitude da retração por carbonatação em comparação com a retração por secagem, foram testadas três amostras de fibrocimento de mesma formulação, que foram submetidas a condições de exposição diferentes. A primeira amostra foi submetida somente à secagem durante todo o período de exposição, atuando como amostra de referência. A segunda amostra foi submetida à secagem durante um primeiro período de 19 dias, até a constância de massa. Após a secagem, esta amostra foi exposta em ambiente com concentração de $5 \%$ de $\mathrm{CO}_{2}$ no ar, de modo a inferir uma condição de carbonatação acelerada, por um segundo período de 63 dias. A terceira amostra foi exposta diretamente à secagem e carbonatação simultaneamente, como mostra a Figura 121.

\begin{tabular}{|c|c|c|}
\hline & Período 1 - 19 dias & Período 2 - 63 dias \\
\hline Secagem & $\begin{array}{c}\text { Secagem } \\
23^{\circ} \mathrm{C}-\text { UR } 50 \%\end{array}$ & $\begin{array}{c}\text { Secagem } \\
23^{\circ} \mathrm{C}-\text { UR50\% }\end{array}$ \\
\hline $\begin{array}{l}\text { Carbonatação } \\
\text { após Secagem }\end{array}$ & $\begin{array}{c}\text { Secagem } \\
23^{\circ} \mathrm{C}-\text { UR } 50 \%\end{array}$ & $\begin{array}{c}\text { Carbonatação } \\
23^{\circ} \mathrm{C}-\text { UR } 50 \% \text { - CO } 25 \%\end{array}$ \\
\hline $\begin{array}{c}\text { Carbonatação } \\
+ \\
\text { Secagem }\end{array}$ & $\begin{array}{c}\text { Carbonatação + Secagem } \\
23^{\circ} \mathrm{C} \text { - UR50\% - CO25\% }\end{array}$ & $\begin{array}{c}\text { Carbonatação } \\
23^{\circ} \mathrm{C}-\text { UR } 50 \% \text { - CO } 25 \%\end{array}$ \\
\hline
\end{tabular}

Figura 121 - Condições de exposição das três amostras estudadas (Secagem; Carbonatação após secagem; Carbonatação + Secagem)

A carbonatação é uma interação química entre o dióxido de carbono com os compostos hidratados do cimento. Simplificadamente, as principais reações envolvidas na carbonatação são a descalcificação do C-S-H e consumo da portlandita, para a formação de calcita. A retração ocorre porque as cadeias de C-S-H ficam mais compridas, no entanto, ficam mais densas. Desta forma, através dos resultados de termogravimetria, as análises realizadas foram no sentido de observar as variações nos teores de $\mathrm{C}-\mathrm{S}-\mathrm{H}$, portlandita e fases carbonáticas presentes no fibrocimento. 
A Figura 122 mostra o resultado típico de termogravimetria - TG - de um fibrocimento reforçado com fibras de PVA, com 10 dias de hidratação. A partir da temperatura de $70^{\circ} \mathrm{C}$ ○ C-S-H já se decompõe perdendo massa volátil, que é detectada pela TG, e é melhor representada no gráfico pelo primeiro pico da DTG. Somada à perda de massa volátil do $\mathrm{C}-\mathrm{S}-\mathrm{H}$, na faixa de temperatura compreendida pelo primeiro pico da DTG também se decompõem a etringita, o monossulfoaluminato, outros aluminatos hidratados, além da gipsita. Antes mesmo do término da perda de massa do primeiro pico da DTG, ocorre a decomposição do PVA, entre aproximadamente 210 e $315^{\circ} \mathrm{C}$. Sempre que há uma situação como essa, onde dois picos da DTG se sobrepõem, os valores de perda de massa obtidos da TG são aproximados, uma vez que na sobreposição dos picos, há perda de massa volátil de ambos os compostos referentes aos dois picos. Para facilitar a análise das interferências da carbonatação do $\mathrm{C}-\mathrm{S}-\mathrm{H}$, as amostras destinadas ao ensaio de termogravimetria foram moldadas sem a fibra de PVA, uma vez que estas não foram submetidas a outros ensaios.

A Figura 122 mostra que a celulose se decompõe entre 315 e $390^{\circ} \mathrm{C}$, seguida da decomposição do hidróxido de magnésio (brucita), entre 390 e $450^{\circ} \mathrm{C}$. A portlandita (hidróxido de cálcio - $\mathrm{Ca}(\mathrm{OH})_{2}$ ) se decompõe liberando voláteis entre 450 e $560^{\circ} \mathrm{C}$. A perda de voláteis nesta faixa de temperatura facilita as análises de alterações ocorridas da portlandita, uma vez que não há interferências de outras fases. A partir de $560^{\circ} \mathrm{C}$ até temperaturas superiores a $900^{\circ} \mathrm{C}$ ocorrem as perdas de dióxido de carbono das fases carbonáticas do fibrocimento, tanto aquelas referentes aos fillers de calcário adicionado na formulação ou na composição do cimento, como calcita bem cristalizada (entre aproximadamente 760 e $950^{\circ} \mathrm{C}$ ), como os carbonatos de adição de filler dolomítico e também os carbonatos formados nas reações de carbonatação, na forma de calcita mal cristalizada (Dias, 2005). 


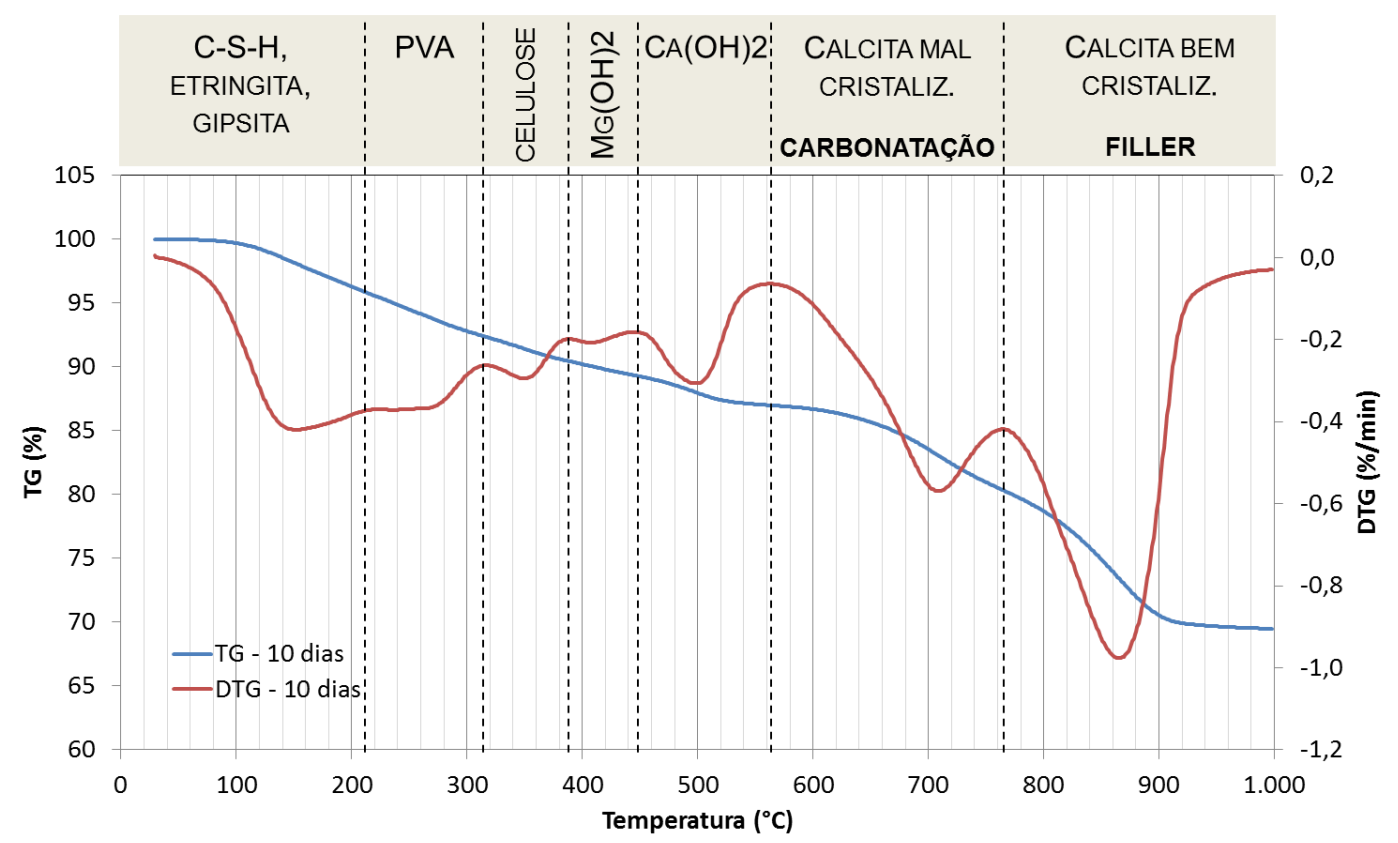

Figura 122 - Curva típica de termogravimetria de fibrocimento com PVA. Este resultado é referente a uma amostra de fibrocimento com 10 dias de hidratação

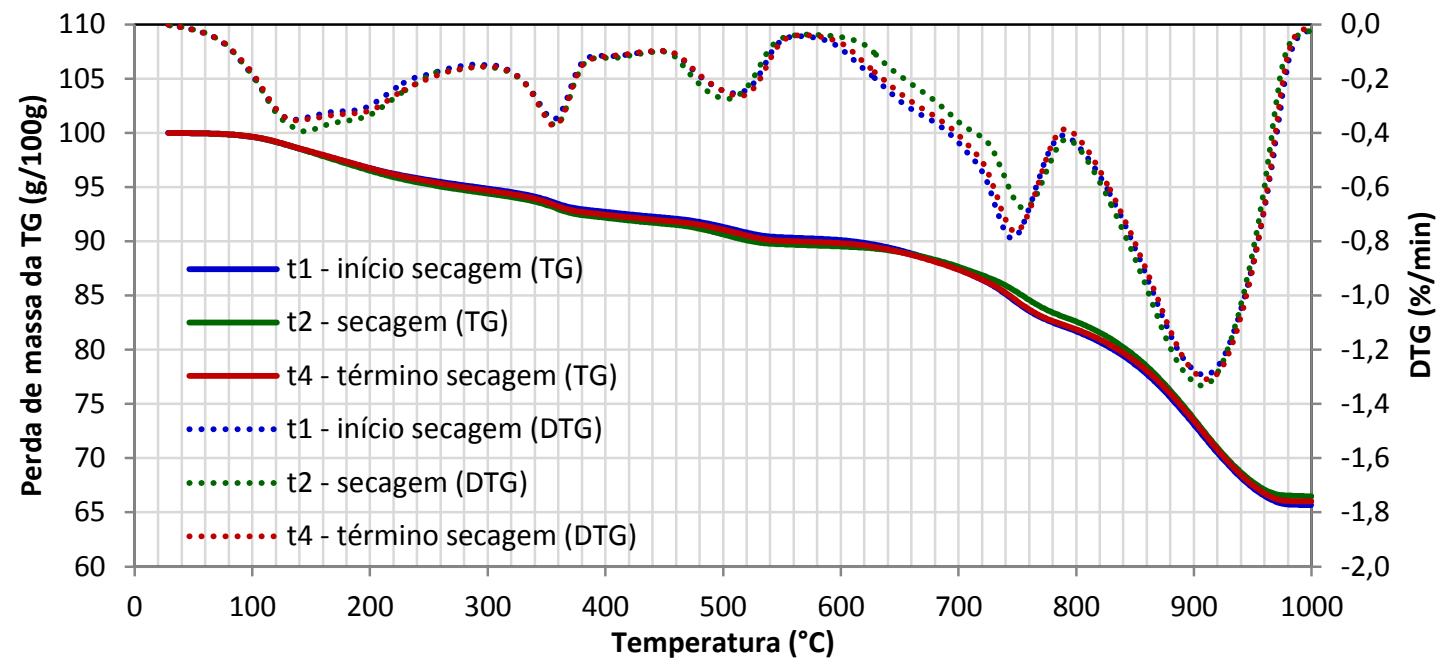

Figura 123 - Termogravimetria das amostras submetidas à secagem em função do tempo de exposição 


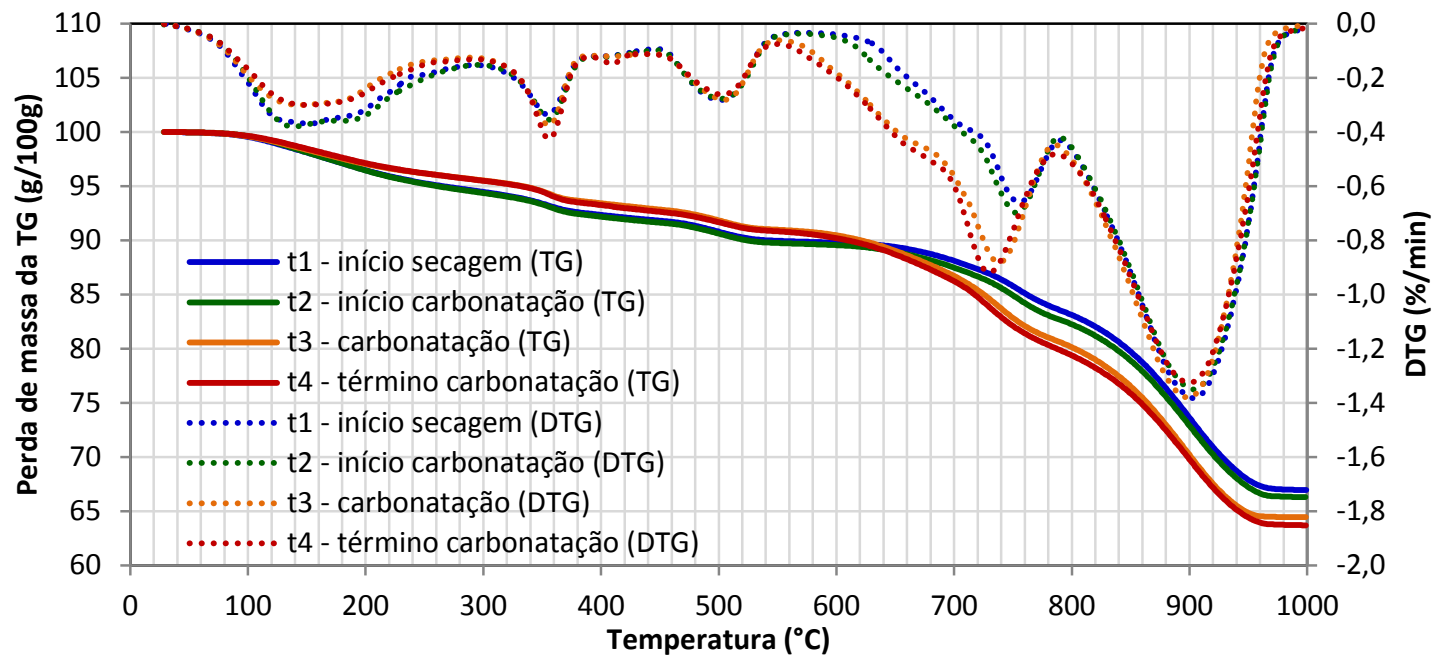

Figura 124 - Termogravimetria das amostras submetidas à carbonatação após secagem, em função do tempo de exposição

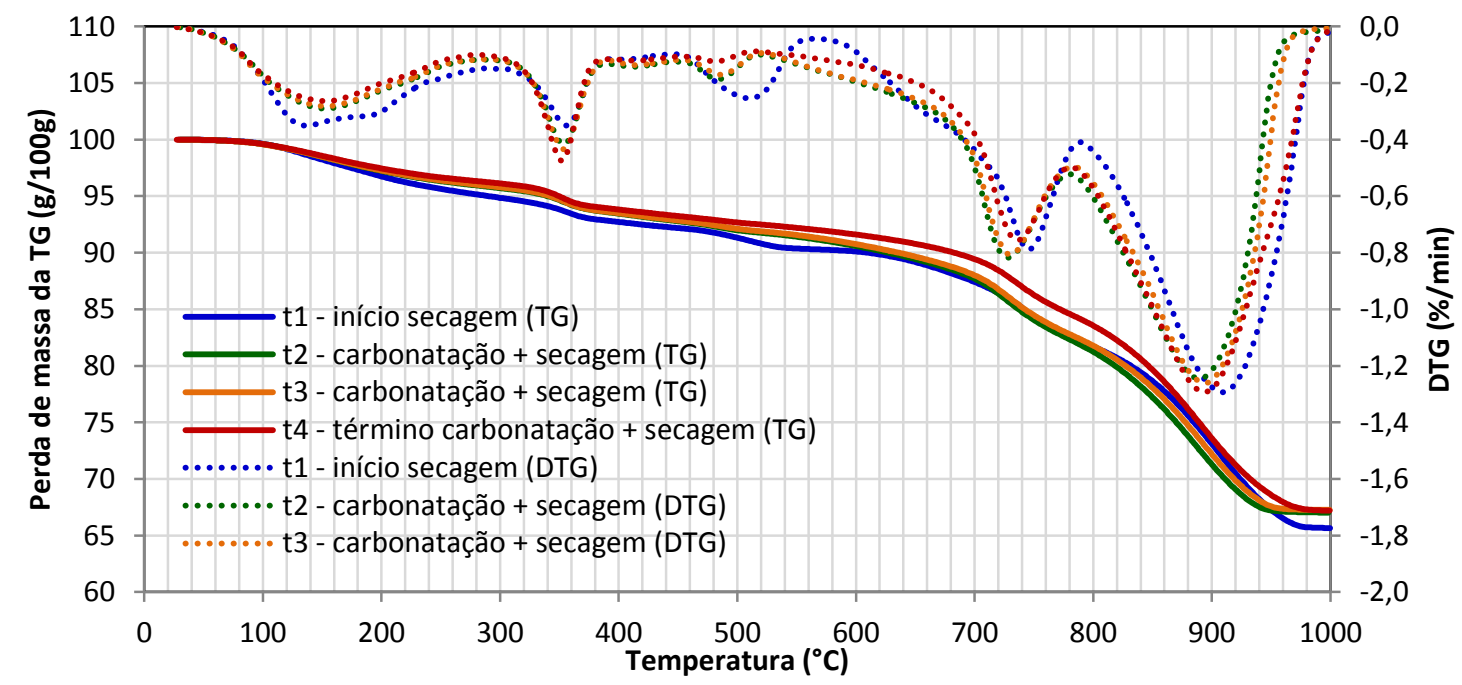

Figura 125 - Termogravimetria das amostras submetidas à carbonatação+secagem, em função do tempo de exposição

A Figura 123 mostra as curvas de termogravimetria da amostra submetida à secagem. Observa-se que o calcário utilizado na fabricação do fibrocimento é dolomítico, pois há ocorrência de um pico da DTG em torno de $750^{\circ} \mathrm{C}$. Os resultados da Figura 123 mostram as curvas de TG nos diferentes tempos de secagem, identificados como $\mathrm{t}_{1}=$ início de secagem (6 dias de hidratação), $\mathrm{t}_{2}=$ durante o processo de secagem (25 dias de hidratação, o que equivale a 19 dias de secagem) e $t_{4}=$ término do período de secagem monitorado por TG (41 dias de hidratação, o que equivale a 35 dias de secagem). Não se observam diferenças significativas nesta amostra em função do tempo de secagem, indicando que neste período de exposição não houve carbonatação detectada pela TG. A Figura 127.b 
mostra que houve um aumento na quantidade de calcita mal cristalizada no final do período de secagem, que pode ser oriunda de uma pequena carbonatação natural, porém esta variação não se refletiu em alteração nas quantidades de C-S-H ou portlandita (Figura 128).

A amostra submetida à carbonatação após a secagem tem os efeitos da carbonatação explícitos pelo aumento da quantidade de carbonatos na amostra durante (tempo $t_{3}$ ) e após a carbonatação (tempo $t_{4}$ ), visível pela grande perda de voláteis na faixa de temperatura de 550 a $760^{\circ} \mathrm{C}$ na termogravimetria (Figura 124). $\mathrm{Na}$ comparação com a amostra submetida somente à secagem, a quantidade de calcita mal cristalizada é superior a partir do instante em que esta amostra foi submetida à carbonatação acelerada, com aumento equivalente a 9,01 g de calcita na amostra, calculada na base volátil. A Figura 128 mostra que a reação de carbonatação ocorreu no sentido da descalcificação do C-S-H, cuja quantidade na amostra reduziu consideravelmente após a exposição das amostras à carbonatação acelerada. As quantidades de portlandita não se alteraram, como mostra a Figura 128.b, cujos valores estão calculados na base não-volátil, o que indica que a interação do $\mathrm{CO}_{2}$ com a matriz cimentícia não afetou a quantidade deste composto.

A amostra exposta à ação conjunta de secagem e carbonatação, certamente foi aquela que apresentou maiores discrepâncias em comparação com as duas anteriores. Os resultados apresentados na Figura 125 mostram que as alterações ocorridas na matriz cimentícia quando esta é submetida à carbonatação nestas condições de secagem simultânea, e especialmente em idade de hidratação prematura, são certamente diferentes daquelas observadas para a segunda amostra, onde a carbonatação ocorreu após a secagem e com grau de hidratação superior, com os compostos hidratados do cimento como C-S-H e portlandita em grande parte já formados. A quantidade de calcita mal cristalizada, oriunda das reações de carbonatação, sofreu acréscimo rápido, atingindo seu valor máximo após 19 dias de exposição (segunda leitura de quantidade de compostos por TG). Neste caso a reação de carbonatação agiu tanto na descalcificação do C-S-H como no consumo de portlandita, como mostra a Figura 128.

A comparação das três amostras, através do resultado de termogravimetria do último dia de exposição das amostras, mostra que a carbonatação tem como principal efeito na microestrutura da matriz cimentícia o aumento na quantidade de 
calcita mal cristalizada, que é o produto resultante da reação de carbonatação. Além disso, nota-se que a carbonatação atua na descalcificação do C-S-H com principal mecanismo, sendo mais severa no caso da amostra carbonatada simultaneamente à secagem. Esta condição também se mostrou mais severa, uma vez que houve consumo de portlandita na reação (Figura 126).

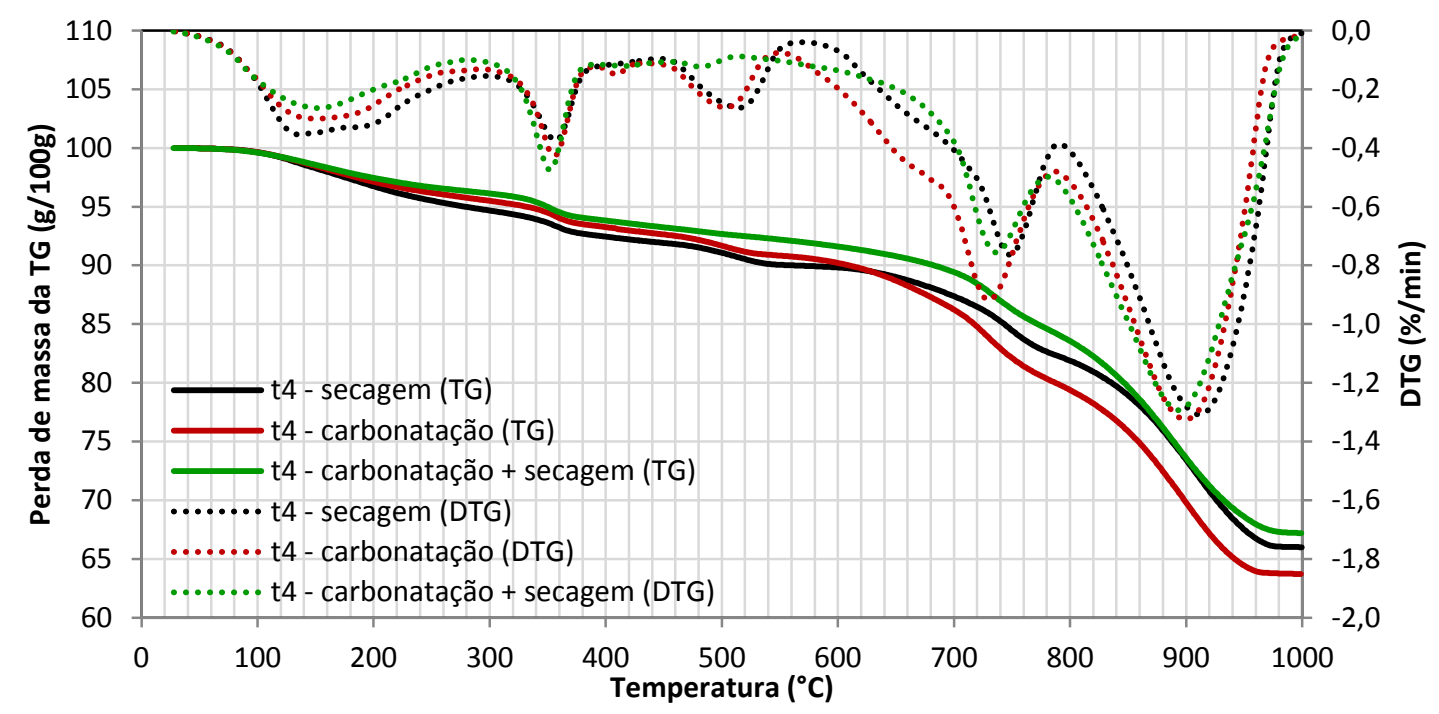

Figura 126 - Termogravimetria das amostras ao final dos períodos de exposição, depois de submetidas à secagem, carbonatação após secagem e carbonatação+secagem

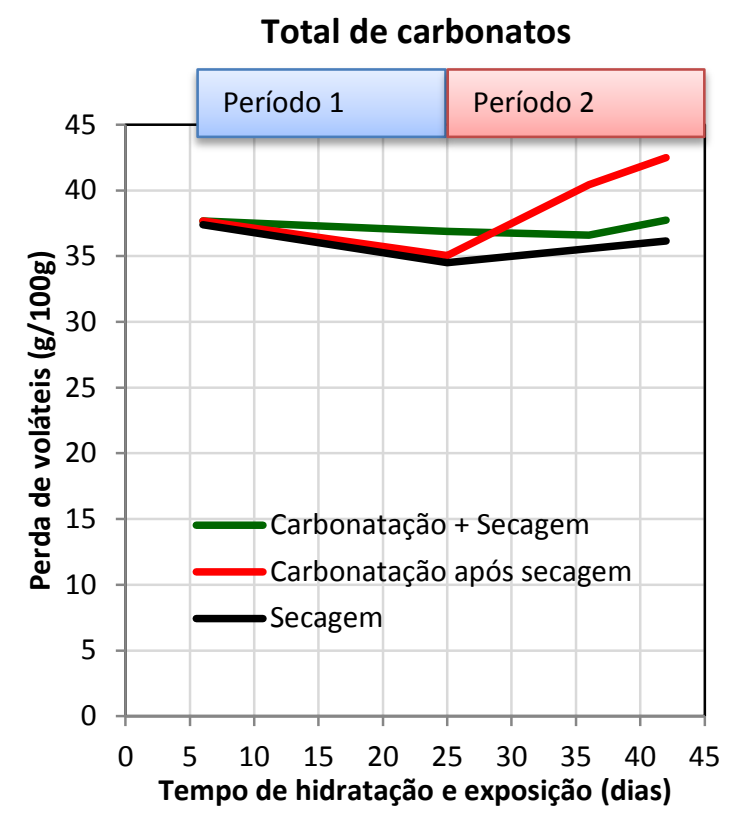

(a)

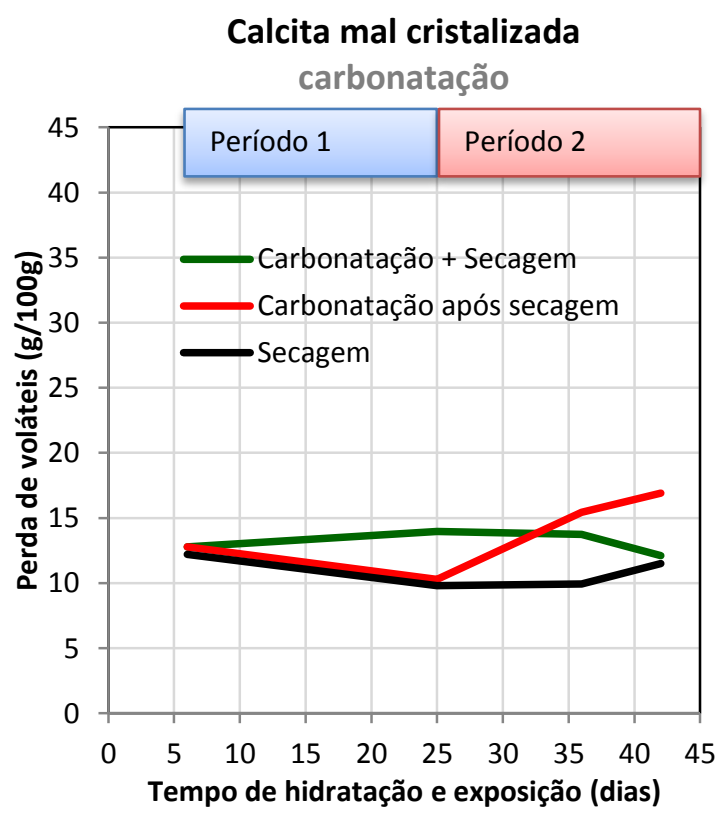

(b)

Figura 127 - Perda de massa referente ao $\mathrm{CO}_{2}$ combinado. (a) $\mathrm{CO}_{2}$ volatilizado na faixa de aproximadamente $580^{\circ} \mathrm{C}$ a $980^{\circ} \mathrm{C}$, referente ao total de carbonatos presentes na amostra. (b) $\mathrm{CO}_{2}$ volatilizado na faixa de aproximadamente $580^{\circ} \mathrm{C}$ a $790^{\circ} \mathrm{C}$, referente aos carbonatos formandos da reação de carbonatação, como a calcita mal cristalizada. Valores calculados na base não-volátil 
C-S-H, etringita, aluminatos, carboaluminato

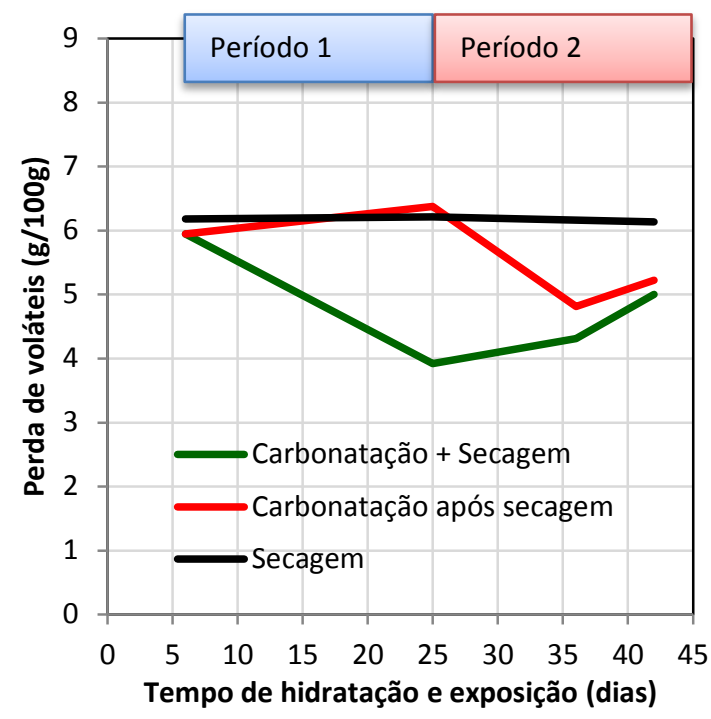

(a)
Portlandita

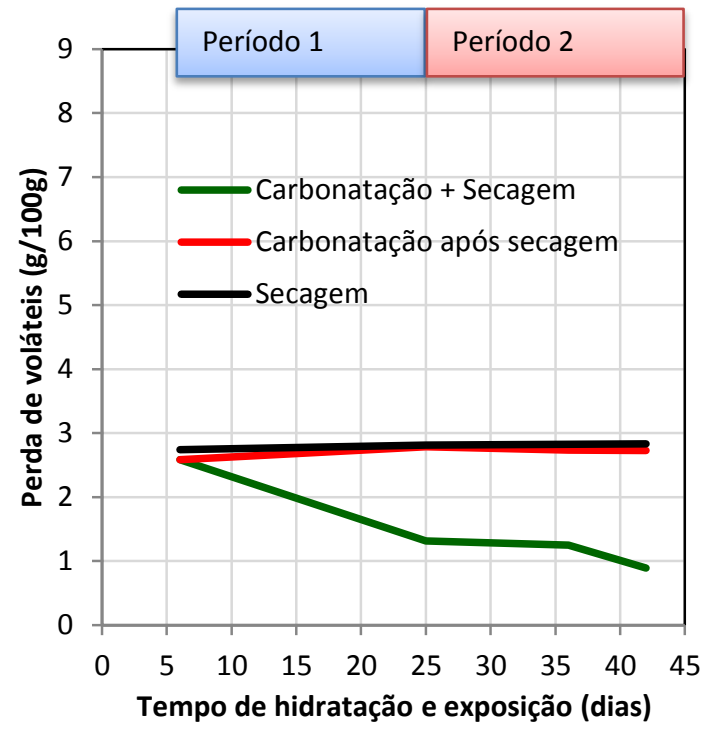

(b)

Figura 128 - Perda de massa referente à água combinada dos compostos que sofrem a descalcificação durante a reação de carbonatação. (a) Água volatilizada na faixa de aproximadamente $60^{\circ} \mathrm{C}$ a $300^{\circ} \mathrm{C}$, referente ao $\mathrm{C}-\mathrm{S}-\mathrm{H}$, etringita, aluminatos e carboaluminatos presentes na amostra. (b) Água volatilizada na faixa de aproximadamente $450^{\circ} \mathrm{C}$ a $550^{\circ} \mathrm{C}$, referente à portlandita formada na hidratação do cimento e consumida na reação de carbonatação. Valores calculados na base não-volátil

Como exposto na metodologia deste capítulo, o acompanhamento das alterações na porosidade dos fibrocimentos estudados foi realizado através de resultados de porosimetria por intrusão de mercúrio - MIP. Esta abordagem exclui as variações ocorridas na faixa dos microporos, e consequentemente na porosidade total do material, uma vez que esta técnica está limitada a poros de diâmetro a partir de $3,6 \mathrm{~nm}$.

A Figura 129 mostra que o avanço da hidratação, uma vez que no tempo denominado $t_{0} 0$ fibrocimento estava com apenas 4 dias de hidratação, juntamente com a secagem a partir do sexto dia, causou um refinamento dos poros da matriz, com aumento no volume de poros na faixa de $3,6 \mathrm{~nm}$ até $0,1 \mu \mathrm{m}$, e redução no volume de poros maiores, na faixa de 0,1 a $4 \mu \mathrm{m}$. A porosidade total medida por MIP reduziu de 30,05\% para 29,65\%, e isto ocorreu devido ao avanço da hidratação, com a formação dos compostos hidratados do cimento. Esta análise é a diferença observada nas curvas de distribuição de tamanho de poros nos tempos $t_{2}$ e $t_{0}$, referente ao primeiro período de secagem. Quando a análise é estendida até o término de todo o experimento, o efeito da carbonatação sofrida pela amostra de 
referência, mesmo que em pequena intensidade, se refletiu em redução da porosidade total para $25,33 \%$. A bibliografia sobre a ação da carbonatação se refere a esta redução da porosidade da matriz cimentícia como colmatação dos poros, que é o preenchimento dos poros por fases carbonáticas formadas durante a reação (Hoppe Filho, 2008). A Figura 129 mostra que esta colmatação de poros ocorreu com a diminuição do volume de poros capilares na faixa de $3,6 \mathrm{~nm}$ a $0,1 \mu \mathrm{m}$. Estes resultados comprovam que mesmo sem esta intenção, a condição de exposição considerada como referência, também se dividiu em dois períodos de exposição, sendo o primeiro com proteção efetiva à ação da carbonatação, e o segundo período com ação da carbonatação natural, em pequena taxa.

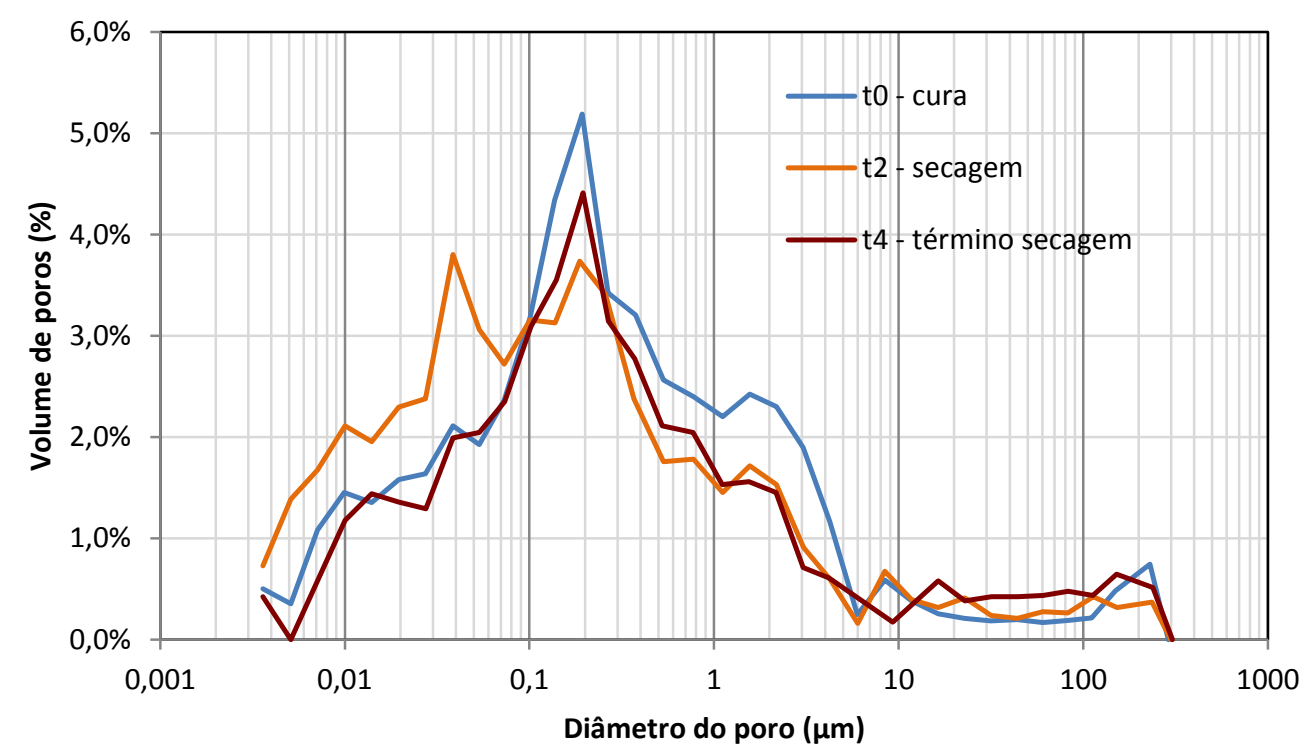

Figura 129 - Distribuição de tamanho de poros da amostra submetida à secagem

Na segunda amostra testada, o fibrocimento permaneceu exposto à condição de secagem isolada durante o primeiro período de tempo, de 19 dias. Assim como na amostra anterior, o que se observou foi que com o avanço da hidratação a porosidade total medida por MIP diminuiu (Figura 133), e o volume de poros maiores, na faixa de 0,05 a $6 \mu \mathrm{m}$, diminuiu, enquanto que 0 volume de poros capilares menores aumentou (de 3,6 $\mathrm{nm}$ a $0,05 \mu \mathrm{m}$ ), caracterizando o refinamento dos poros devido à formação das fases hidratadas do cimento. A partir do tempo $t_{2}$, após os 19 dias de secagem, observam-se os efeitos da carbonatação na porosidade do fibrocimento, uma vez que estas amostras foram submetidas às condições ambientais de carbonatação acelerada. A distribuição de tamanho de poros do compósito nos tempos $t_{3}$ e $t_{4}$ reflete que a carbonatação acelerada atuou 
na redução do volume de poros na faixa de 0,1 a $2 \mu \mathrm{m}$, com aumento dos poros menores, de 3,6 nm a 0,1 $\mu \mathrm{m}$. Com a evolução da hidratação, a porosidade do fibrocimento diminui devido à formação dos compostos hidratados do cimento (Figura 133). Esta redução da porosidade total pode ser observada pela redução do volume de macroporos, presentes em grande quantidade no fibrocimento, e aumento no volume de poros de menor dimensão, como os mesoporos e poros de gel (Figura 131). Com a exposição ao ambiente contendo $\mathrm{CO}_{2}$, as alterações na porosidade são nítidas no sentido do refinamento dos poros pela formação de carbonato de cálcio, pois é detectada a formação deste composto em maior quantidade pela TG (Figura 127.b), com redução do volume de macroporos e aumento mais acentuado no volume de poros capilares, os mesoporos (Figura $130 \mathrm{e}$ Figura 131). A redução da porosidade total medida por MIP foi mais acentuada, em comparação com a amostra anterior, submetida à secagem (Figura 133), confirmando que o mecanismo de carbonatação reduz a porosidade do compósito cimentício.

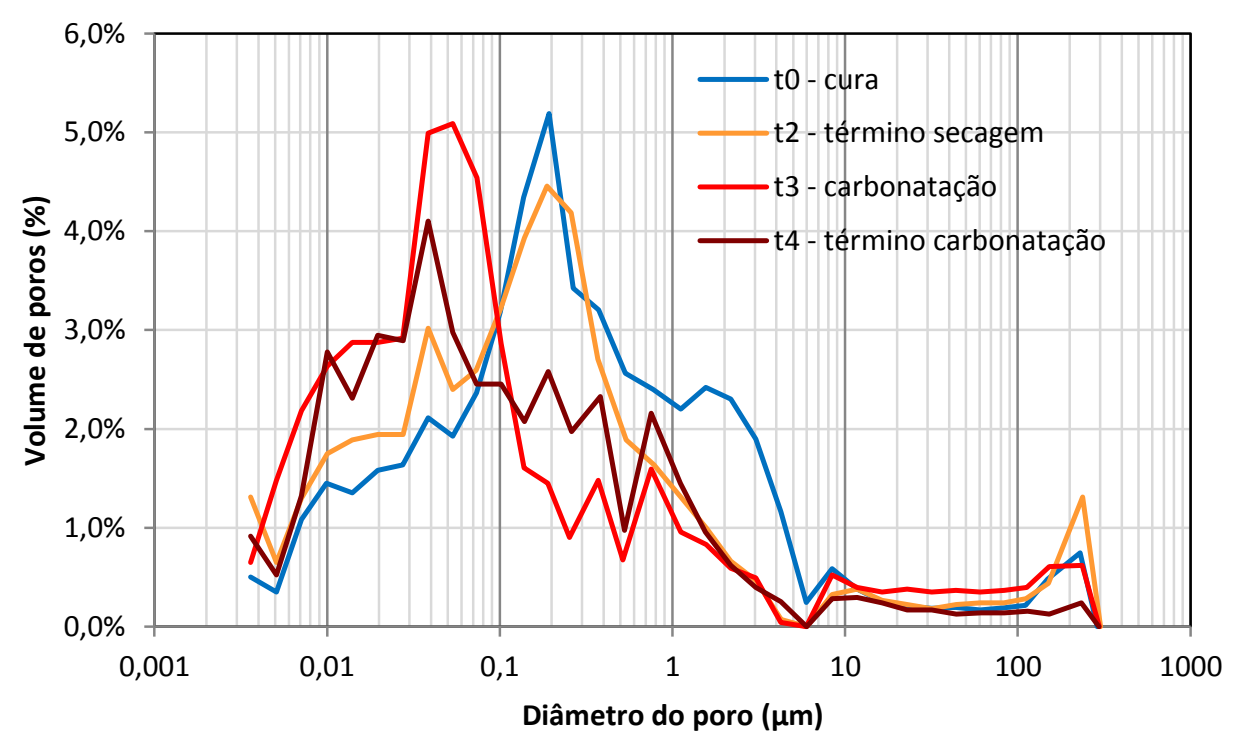

Figura 130 - Distribuição de tamanho de poros da amostra submetida à carbonatação após secagem 


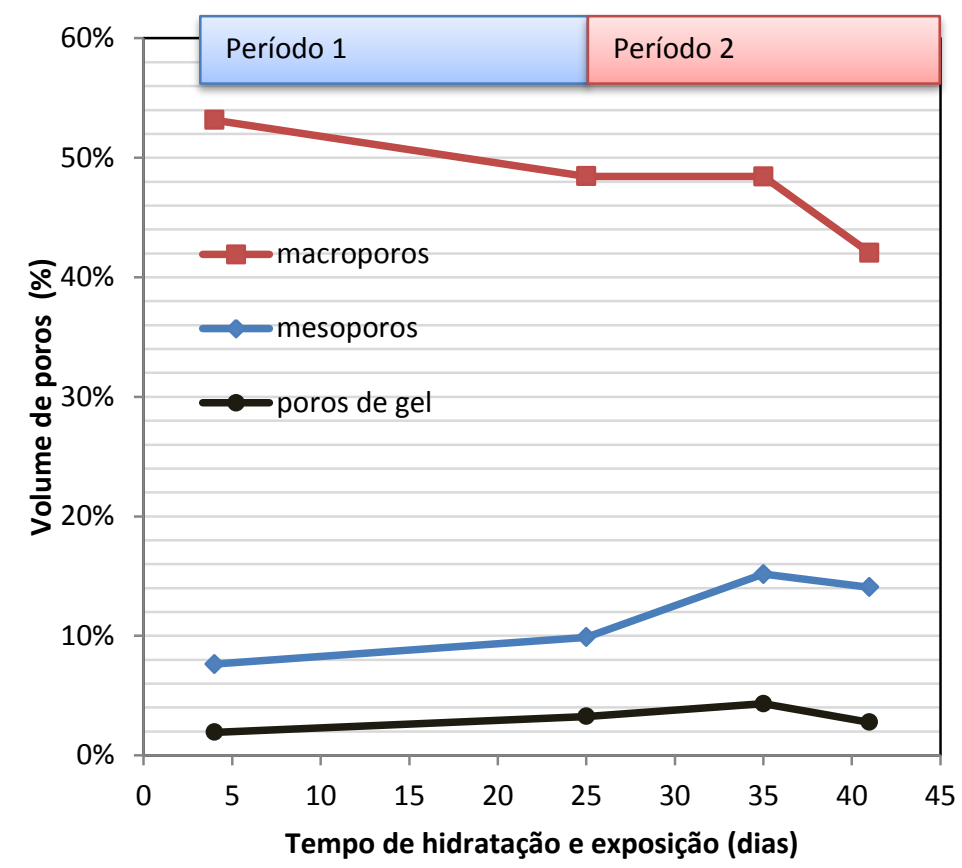

Figura 131 - Distribuição de tamanho de poros da amostra submetida à carbonatação após secagem

A Figura 132 mostra as alterações na distribuição de tamanho de poros da amostra submetida à secagem simultaneamente à carbonatação. A porosidade total medida por MIP foi menor com comparação com as demais, como mostra a Figura 133. No entanto, as alterações na distribuição de tamanho de poros não foi nítida, uma vez que as reações acontecem simultaneamente. Ao passo que o cimento forma seus compostos hidratados como o C-S-H e a portlandita, o mecanismo de carbonatação atua consumindo estes compostos em suas reações químicas, de modo que não é clara a observação das alterações na microestrutura da matriz cimentícia referente a cada mecanismo isoladamente. As curvas de distribuição de tamanho de poros foram semelhantes ao longo do tempo de exposição, com uma redução na porosidade total, e uma diminuição no volume de poros menores, entre $3,6 \mathrm{~nm}$ e $0,04 \mu \mathrm{m}$. 


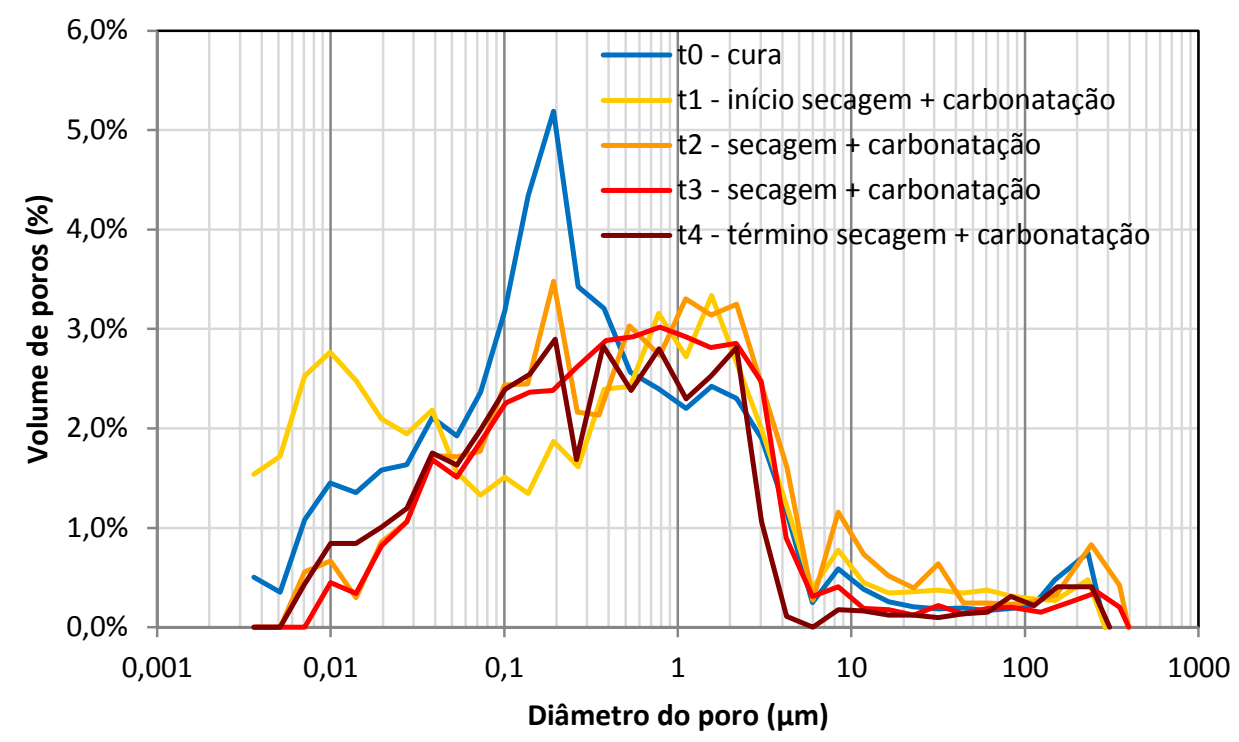

Figura 132 - Distribuição de tamanho de poros da amostra submetida à carbonatação+secagem

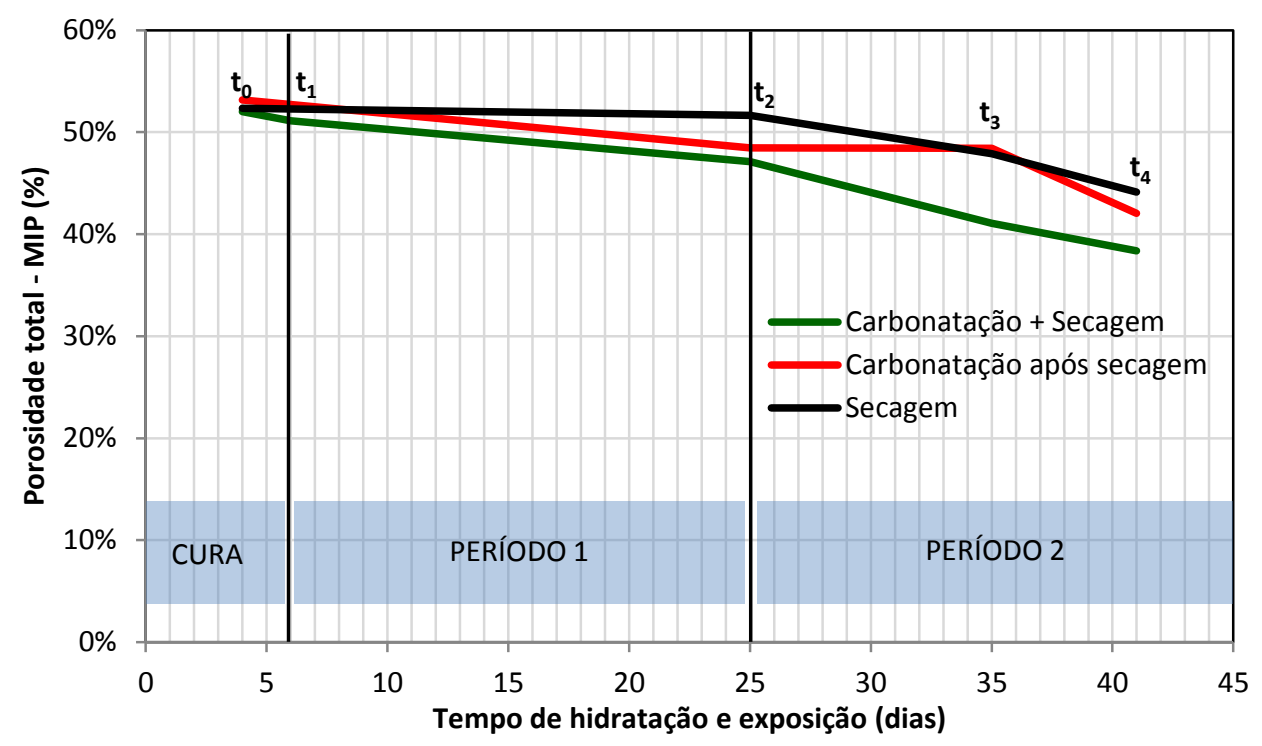

Figura 133 - Evolução da porosidade total determinada por porosimetria por intrusão de mercúrio, em função da condição de exposição das amostras

\subsubsection{Retração por carbonatação}

A retração por carbonatação é uma parcela importante da retração total sofrida pelos artefatos de fibrocimento, como as placas planas e telhas onduladas. Uma vez que se trata de um processo que envolve a difusão do ar contendo $\mathrm{CO}_{2}$ nos poros do compósito cimentício, a geometria dos artefatos se torna uma característica importante para a ocorrência da carbonatação. Como os artefatos de fibrocimento normalmente possuem pequena espessura e consequentemente uma grande área 
de exposição ao ar, o potencial da ocorrência da carbonatação é grande. Soma-se também o fato do fibrocimento fabricado pelo processo Hatschek ser um material com elevada porosidade.

A reação de carbonatação, apesar de formar compostos no interior dos poros da matriz cimentícia, reduzindo sua porosidade, causa redução volumétrica isotrópica no compósito, chamada de retração por carbonatação. Uma vez que a retração por carbonatação se trata de uma interação química entre $\mathrm{o} \mathrm{CO}_{2}$ do ar e os compostos hidratados do cimento, ela está diretamente relacionada com a quantidade de cimento presente na matriz. Como é sabido, o fibrocimento possui consumo de cimento bastante elevado, podendo atingir até $80 \%$ da massa de material sólido da formulação (Dias, 2011).

Os resultados da retração por carbonatação obtidos a partir de amostras de fibrocimento com fibras de PVA comprovam que este tipo de retração química do compósito cimentício endurecido tem grande magnitude, da mesma ordem de grandeza da retração por secagem (Figura 134).

A amostra Secagem foi submetida durante todo o tempo de exposição ao ambiente de secagem com umidade relativa de $50 \%$ e temperatura de $23^{\circ} \mathrm{C}$, em câmara climática (Figura 121). Desta forma, foi medida a retração por secagem do fibrocimento, com o mínimo de influência da carbonatação. Os resultados de perda de massa expostos na Figura 135 mostraram que a secagem completa destas amostras aconteceu até o quinto dia de secagem, com a estabilização da perda de massa. A partir do $25^{\circ}$ dia de exposição, observou-se um ganho de massa discreto, que progrediu até o término do experimento. Este comportamento mostrou que a medida adotada para minimizar os efeitos da carbonatação, que foi a colocação de cal sodada na câmara climática para reduzir a concentração de $\mathrm{CO}_{2}$ do ar interno, não foi eficaz no impedimento da ocorrência da carbonatação. Este aumento de massa medido é devido a uma pequena carbonatação, que também se refletiu em aumento da retração a partir do 25ํำ de exposição (Figura 134).

A segunda amostra foi submetida à secagem durante o primeiro período de exposição, com duração de 19 dias. Em seguida, foi submetida à carbonatação acelerada em câmara de carbonatação com concentração de $5 \%$ de $\mathrm{CO}_{2}$ por período de 63 dias (Figura 121). Desta forma foi possível medir isoladamente 0 efeito da retração por secagem, que foi de $2,20 \mathrm{~mm} / \mathrm{m}$ após 19 dias de secagem, e a 
parcela de retração por carbonatação, que foi de 2,74 mm/m após 63 dias de carbonatação (Figura 134).

Quando o fibrocimento foi exposto diretamente às condições programadas para a carbonatação acelerada, com $5 \%$ de $\mathrm{CO}_{2}$ desde o primeiro período de secagem (Figura 121), observou-se que a retração oriunda dos dois mecanismos aconteceu simultaneamente, aumentando a velocidade de retração, que atingiu valor de aproximadamente $5 \mathrm{~mm} / \mathrm{m}$ aos 10 dias de exposição, e retração final de $5,61 \mathrm{~mm} / \mathrm{m}$ após 82 dias de exposição (Figura 134).

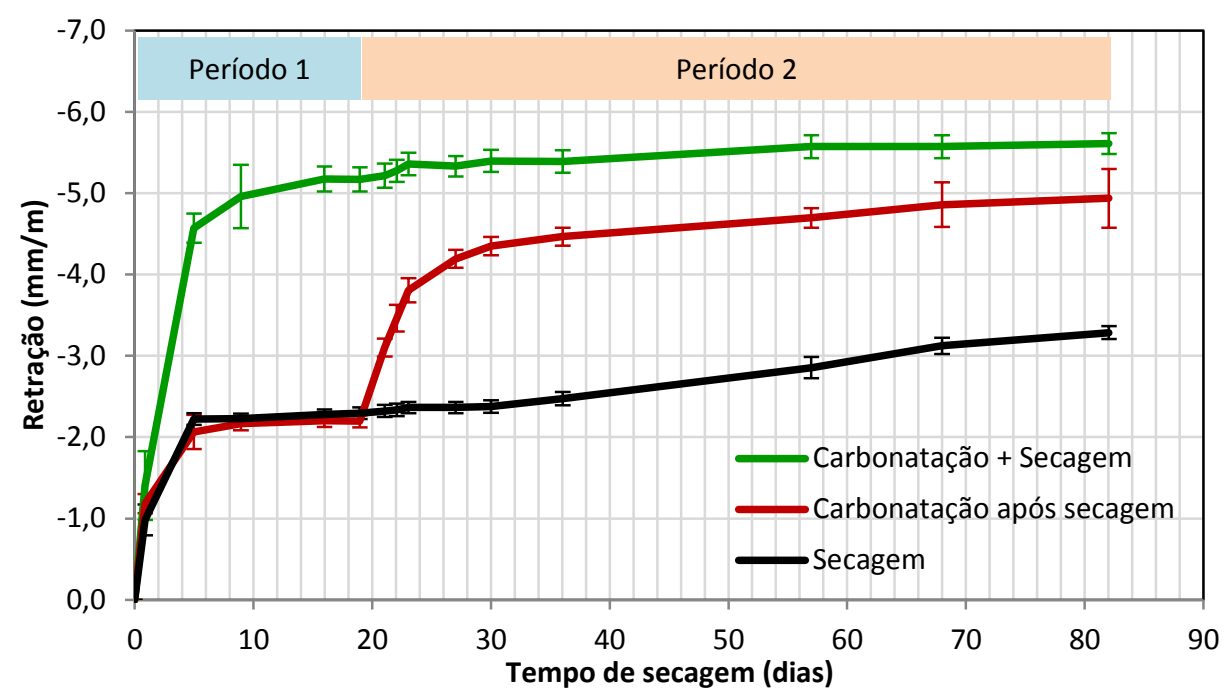

Figura 134 - Retração em função da secagem, carbonatação simultaneamente à secagem, e carbonatação após secagem

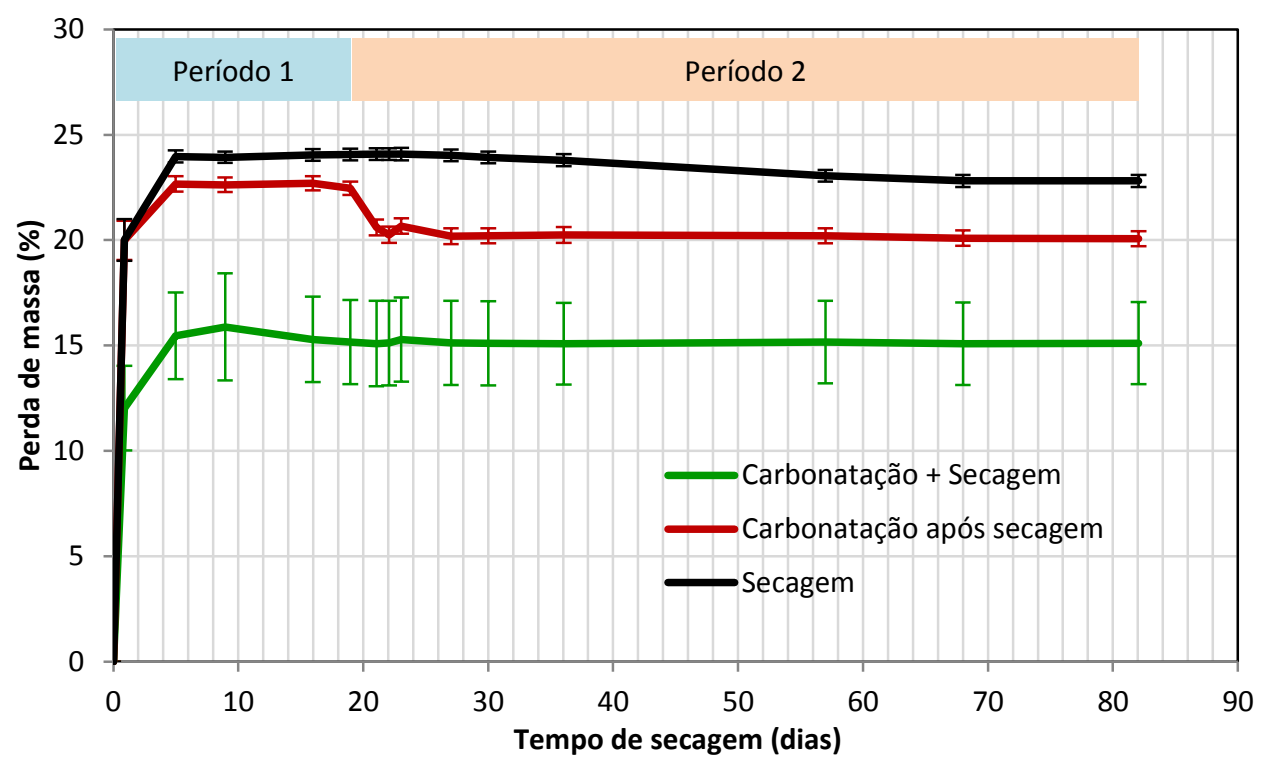

Figura 135 - Perda de massa em função da secagem, carbonatação simultaneamente à secagem, e carbonatação após secagem 
A relação entre a retração e a perda e massa é uma forma de expor a suscetibilidade do material à retração por secagem, uma vez que, independente do valor da retração final, a maior inclinação da curva gerada indica que o compósito é mais suscetível à retração para uma mesma quantidade de água evaporada. No entanto, a Figura 136 apresenta duas curvas referentes a amostras submetidas à secagem, e uma amostra submetida aos efeitos combinados de secagem e carbonatação. Uma vez que a reação de carbonatação envolve o consumo de água, a massa do material sofre um aumento. Desta forma, a curva apresentada na Figura 136 expressa a relação da retração com a variação de massa oriunda da secagem (diminuição da massa) conjuntamente com a variação da massa oriunda da reação de carbonatação (aumento de massa). Observa-se que a quantidade de água evaporada é maior que a quantidade incorporada, uma vez que a resultante é uma perda de massa, que naturalmente é inferior à observada nas amostras submetidas à secagem isolada (Figura 135).

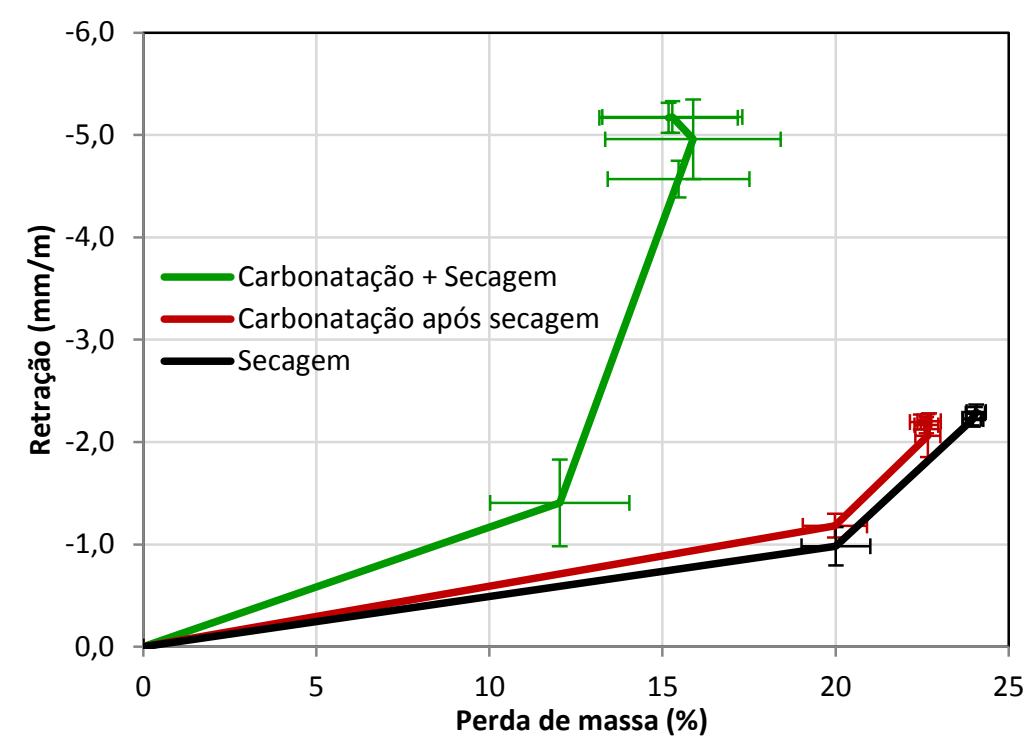

Figura 136 - Relação entre a retração e a perda de massa no primeiro período de exposição (até 19 dias)

\subsubsection{Gradiente de carbonatação nas telhas empilhadas}

Da mesma forma que ocorre para a retração por secagem, onde o arranjo das telhas em estoque, que ficam empilhadas em montes de aproximadamente 90 telhas, favorece a fissuração na borda, uma vez que cria o gradiente de umidade na mesma telha, e que gera uma retração diferencial entre as regiões de borda e de 
miolo da telha; da mesma forma, ocorre um gradiente de retração por carbonatação nas telhas. As bordas ficam expostas diretamente ao meio ambiente, onde a reação de carbonatação ocorre sem restrições, na velocidade da carbonatação natural. Em contrapartida, na região central da telha a carbonatação é mais lenta, tanto pela maior umidade das telhas nesta região, como pela dificuldade de difusão do $\mathrm{CO}_{2}$ até o interior do monte, devido à pequena espessura livre formada entre as telhas.

Como visto anteriormente, a magnitude da retração por carbonatação é significativa, da mesma ordem de grandeza, ou até mesmo superior à retração por carbonatação, e por este motivo optou-se por medi-la em condições reais de exposição. Neste item foram coletadas amostras de telhas expostas no pátio de uma fábrica de fibrocimento, submetidas a esta condição de carbonatação diferencial.

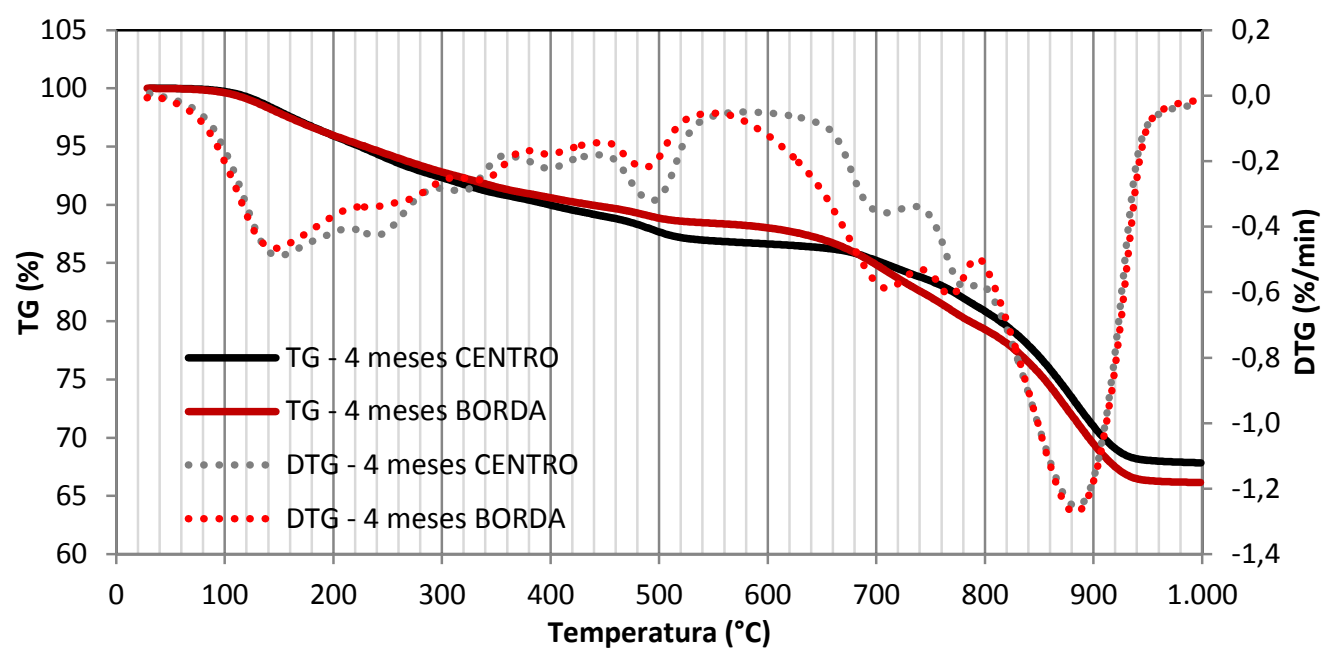

Figura 137 - Termogravimetria da amostra exposta por 4 meses ao meio ambiente. Curvas da amostra da borda e do centro da telha 


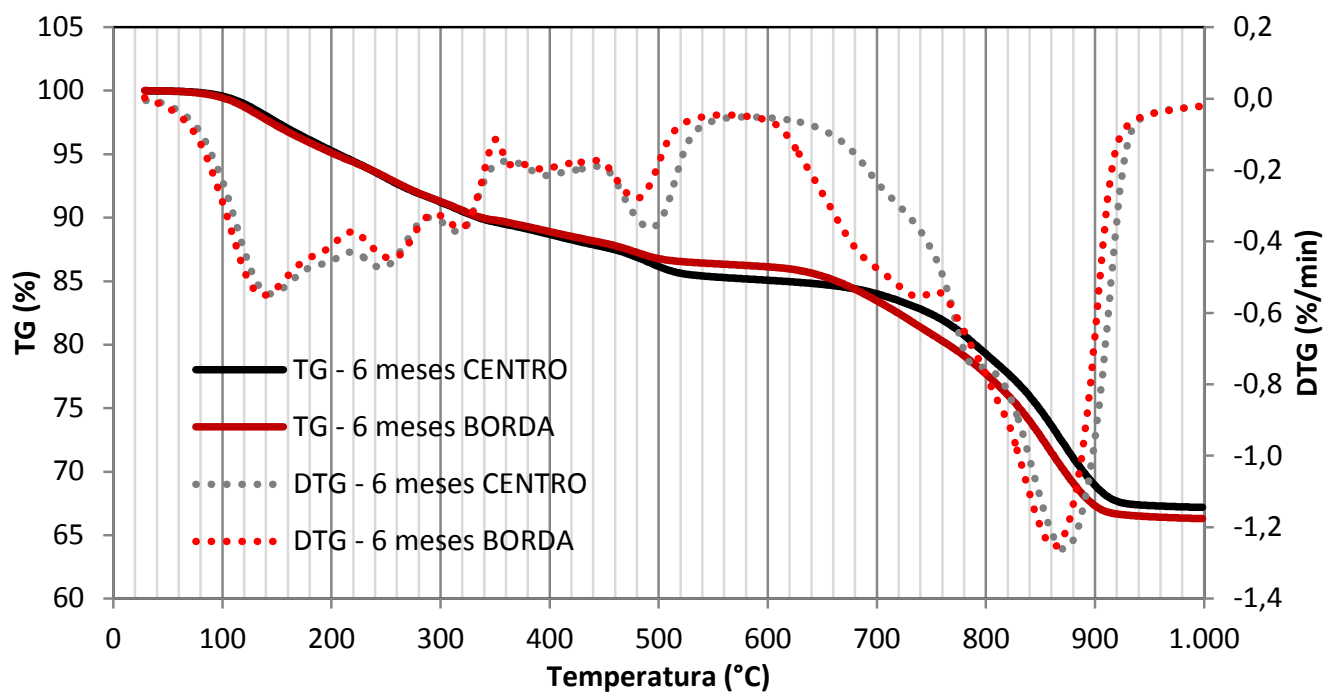

Figura 138 - Termogravimetria da amostra exposta por 6 meses ao meio ambiente. Curvas da amostra da borda e do centro da telha

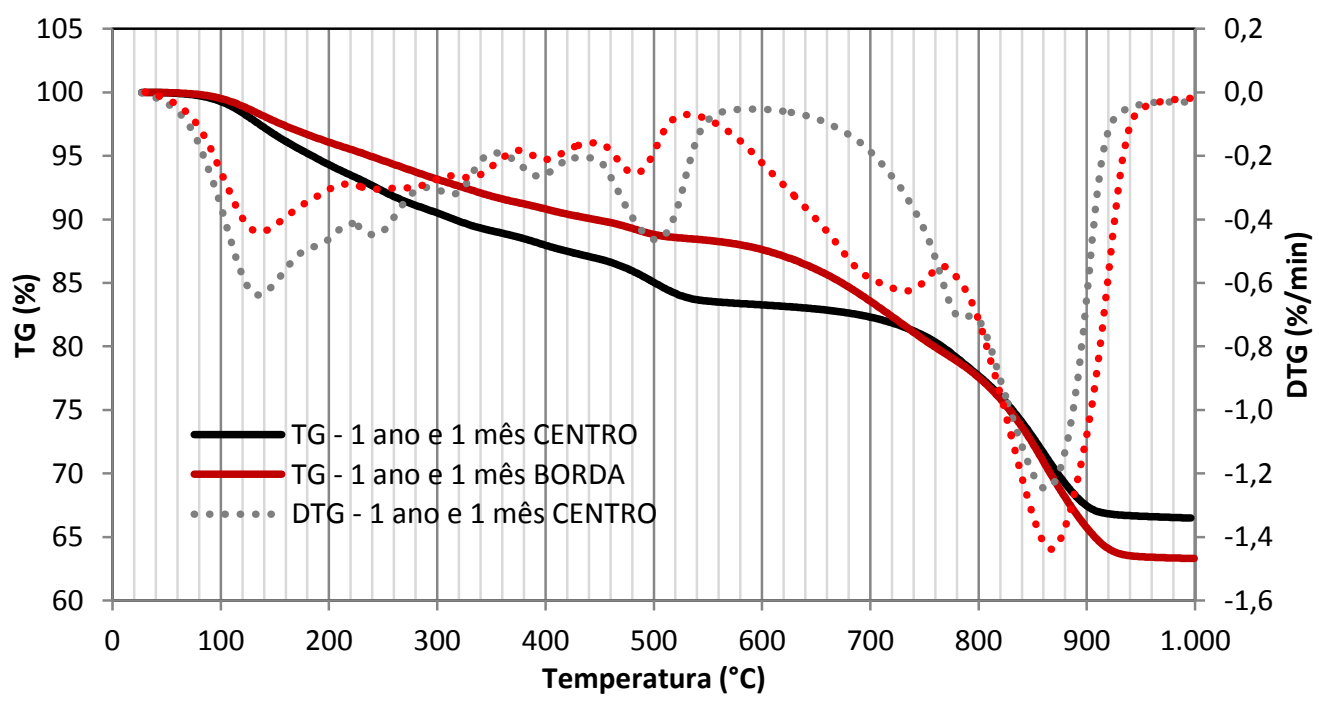

Figura 139 - Termogravimetria da amostra exposta por 1 ano e 1 mês ao meio ambiente. Curvas da amostra da borda e do centro da telha 


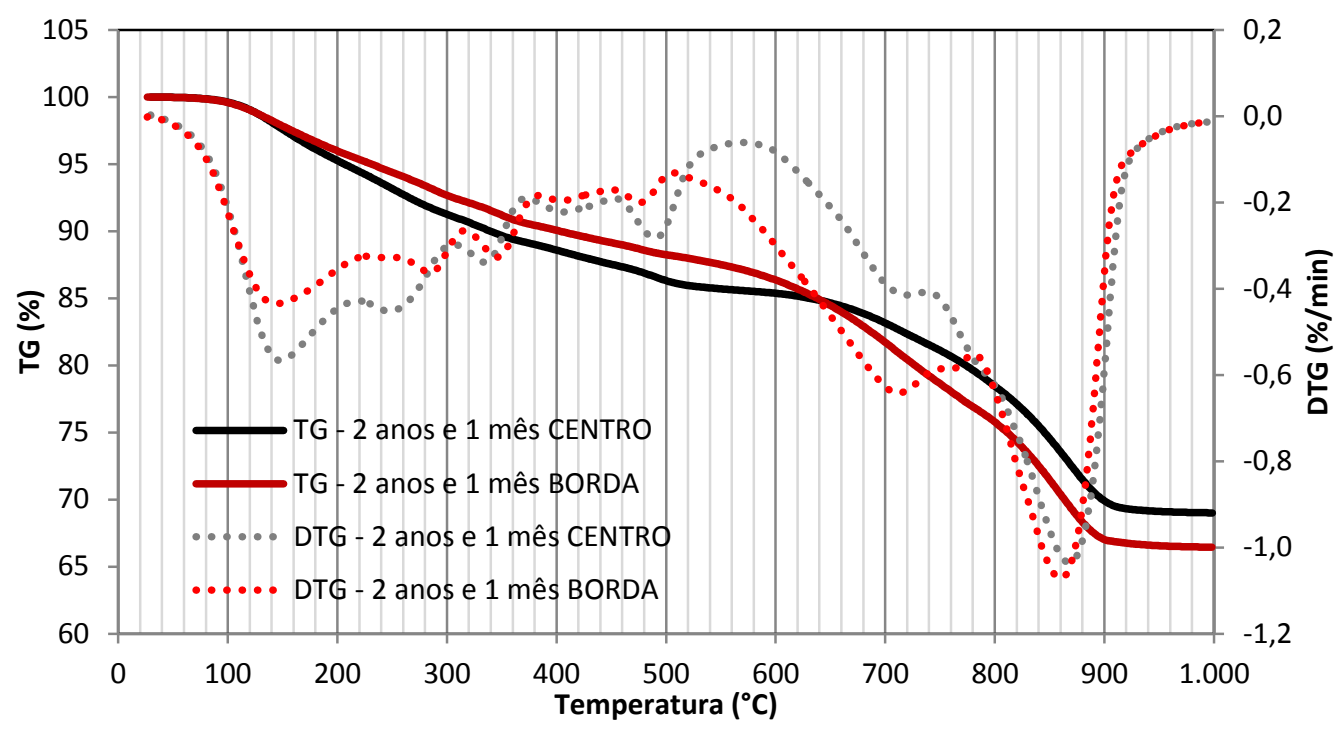

Figura 140 - Termogravimetria da amostra exposta por 2 anos e 1 mês ao meio ambiente. Curvas da amostra da borda e do centro da telha

A Figura 137 mostra que aos 4 meses de exposição ao tempo, ocorre diferença no grau de carbonatação entre a região central e da borda de telhas onduladas de fibrocimento. A quantidade de calcita mal cristalizada, oriunda das reações de carbonatação, é significativamente maior na amostra da borda em comparação com o centro, indicando que a carbonatação ocorre em velocidade muito maior nesta região. O resultado de termogravimetria mostra que a reação de carbonatação envolveu o consumo de portlandita, que diminuiu na amostra mais carbonatada, e a descalcificação do C-S-H, com redução menor perda de massa medida no primeiro pico da DTG.

Os demais resultados expostos na Figura 138, Figura 139 e Figura 140 mostram o mesmo cenário, onde a carbonatação na borda da telha é maior que região central. Com o aumento do tempo de exposição, a quantidade de calcita mal cristalizada determinada pela termogravimetria aumentou com o avanço da carbonatação, com maior redução nas quantidades de portlandita e perda de massa do primeiro pico, que inclui a perda de massa do C-S-H.

Mesmo sendo um artefato com alto potencial de carbonatação, pelo fato da telha de fibrocimento possuir pequena espessura, elevada porosidade e alto consumo de cimento, às condições de exposição nos montes de telhas são aquelas naturais do meio ambiente, o que confere a uma velocidade de carbonatação natural, inferior à medida no estudo feito em laboratório em corpos-de-prova. 
A Figura 141 mostra que a portlandita passa a ter sua quantidade comprometida pela reação de carbonatação somente a partir dos 13 meses de exposição na região central da telha, enquanto que na sua borda a queda foi medida a partir dos 6 meses de exposição. Considerando a perda de massa aos 4 meses de exposição, na região central da telha, que é a medida da termogravimetria da amostra menos afetada pela ação da carbonatação, a quantidade total e portlandita no fibrocimento é de $19,7 \mathrm{~g}$ por $100 \mathrm{~g}$ de amostra (equivale a $8,39 \mathrm{~g}$ de volátil por $100 \mathrm{~g}$ de fibrocimento). A diferença da carbonatação entre a região central e da borda equivale a um consumo de $7,2 \mathrm{~g}$ de portlandita, ou seja, uma redução de $38 \%$. Este valor é superior ao medido para 19 meses de efeito da carbonatação natural do fibrocimento exposto ao ar, com base na redução da quantidade de portlandita entre as idades de 6 e 25 meses de exposição, da região da borda da telha. Neste caso houve uma redução de 6,3 $\mathrm{g}$ de portlandita por $100 \mathrm{~g}$ de fibrocimento. Estes valores calculados são aproximados, uma vez que as formulações entre as amostras não exatamente a mesma, com variação de até $2,2 \%$ no consumo de cimento entre elas.

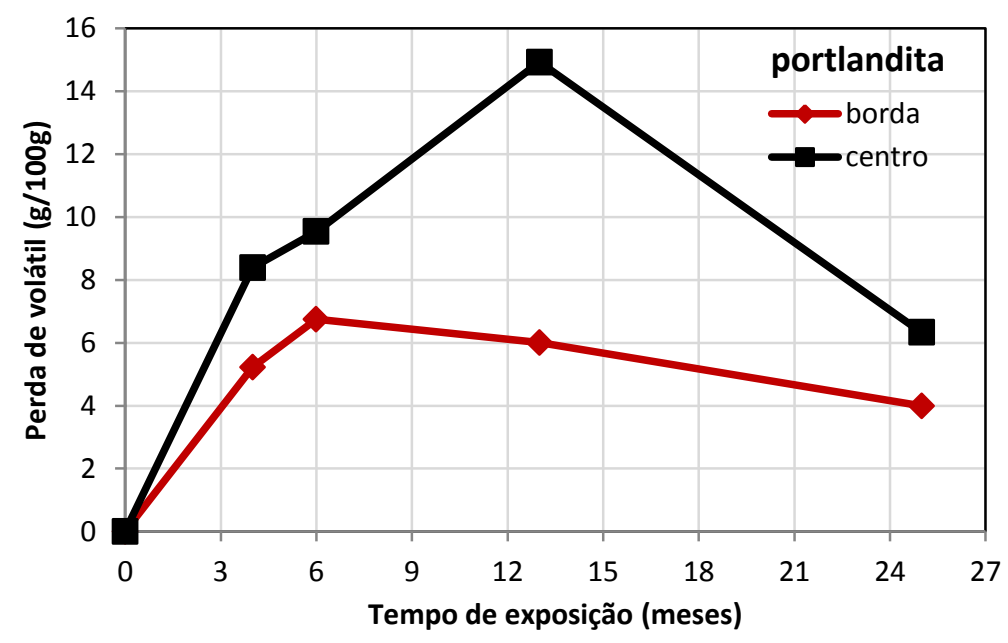

Figura 141 - Perda de massa na faixa de temperatura de aproximadamente $450^{\circ} \mathrm{C}$ a $550^{\circ} \mathrm{C}$, referente à portlandita formada na hidratação do cimento e consumida na reação de carbonatação. Valores calculados na base volátil

A Figura 142 mostra que a carbonatação passou a atuar na descalcificação do C-S-H somente a partir dos 6 meses de exposição, possivelmente devido à menor demanda de portlandita disponível para interação com o dióxido de carbono. Faz-se esta afirmação, uma vez que não houve diferença na perda de massa do primeiro pico da DTG nas idades de 4 e 6 meses de exposição, entre a região central e da borda da telha. A partir de então, mediu-se uma queda na perda de massa na 
região de decomposição do $\mathrm{C}-\mathrm{S}-\mathrm{H}$, indicando a descalcificação deste composto hidratado resistente do cimento. Considerando que neste mesmo pico da DTG também ocorre perda de volátil de outros compostos hidratados do cimento, como os aluminatos, considera-se que a quantidade de C-S-H decomposto na reação de carbonatação foi elevada, uma vez que a redução na perda de massa entre o centro e a borda da telha foi de $34 \%$.

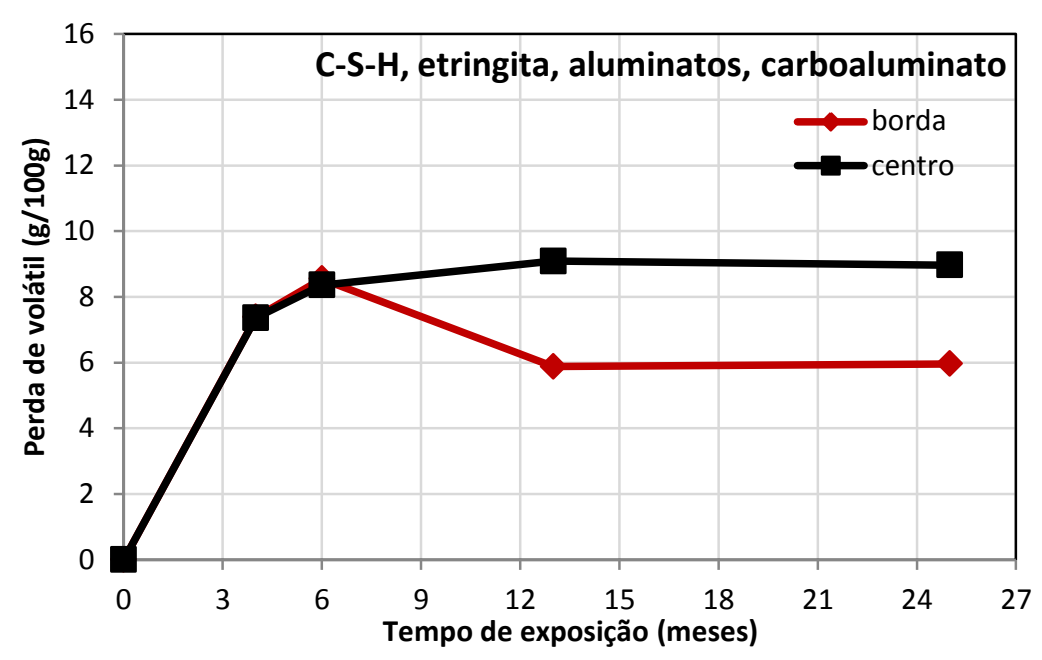

Figura 142 - Perda de massa na faixa de temperatura de aproximadamente $60^{\circ} \mathrm{C}$ a $300^{\circ} \mathrm{C}$, referente ao C-S-H, etringita, aluminatos e carboaluminato. Valores calculados na base volátil

O principal indicador da evolução da evolução da carbonatação nestas amostras foi a evolução na quantidade do composto formado nesta reação química, que é a calcita mal cristalizada. A Figura 143 mostra que há um crescimento na perda de massa do dióxido de carbono decomposto da calcita, em função do tempo de exposição. Uma vez que a perda de massa da calcita mal cristalizada aparece sobreposta na termogravimetria com o pico referente à calcita bem cristalizada, oriunda das adições de filler da formulação, os valores medidos e expostos na Figura 143 podem sofrer influência da quantidade destas adições minerais. Desta forma, para auxiliar na análise, está exposta na mesma figura o consumo de calcário em cada formulação, que variou até $2,4 \%$. Esta variação no consumo de calcário na formulação explica as oscilações nas curvas de evolução da quantidade de calcita mal cristalizada tanto no centro quanto na borda, como a redução nestes teores entre 4 e 6 meses de exposição, e a pequena redução entre 13 e 25 meses de exposição. Fazendo estas considerações, pode-se afirmar que a formação de calcita pela carbonatação correu em maior velocidade até os 13 meses de exposição, conclusão esta que é coerente com a variação observada nas 
quantidades de C-S-H decomposta, que se estabiliza a partir dos 13 meses de exposição.

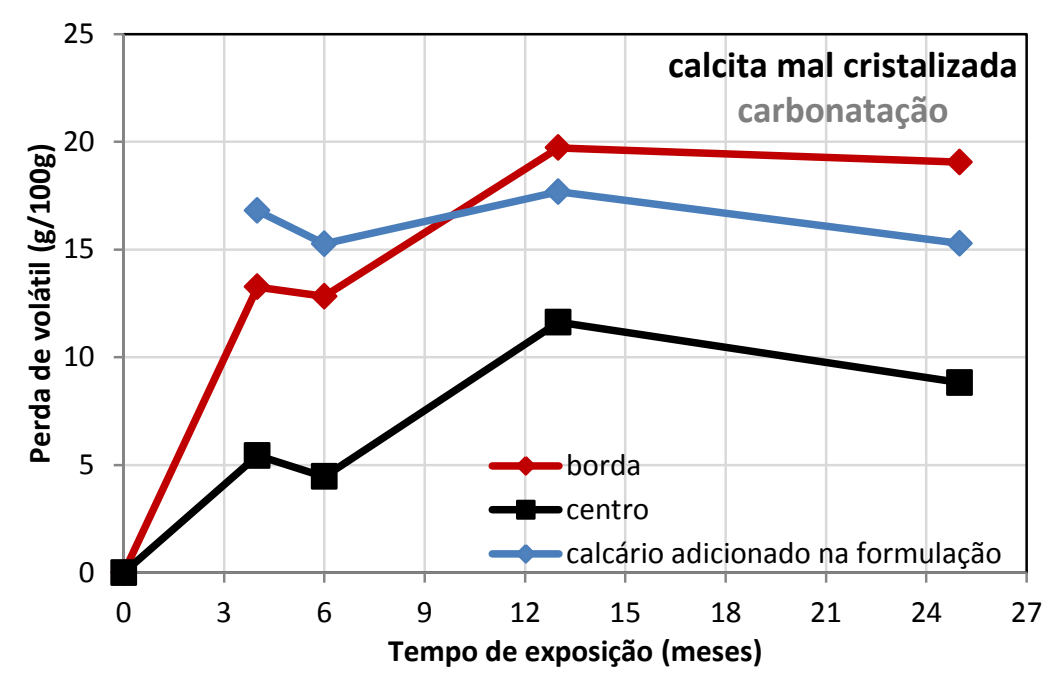

Figura 143 - Perda de massa na faixa de temperatura de aproximadamente $560^{\circ} \mathrm{C}$ a $760^{\circ} \mathrm{C}$, referente à calcita mal cristalizada formada a partir da reação de carbonatação. Valores calculados na base volátil

Como alterações nas propriedades físicas do fibrocimento, a carbonatação reduziu a porosidade do fibrocimento, embora os resultados de porosidade por princípio de Arquimedes tenha apresentado alguma variabilidade (Figura 144.a). O fato das formulações serem diferentes entre as amostras pode ter maior efeito na porosidade e densidade aparente, uma vez que uma pequena quantidade de material de granulometria diferente, por exemplo, pode se refletir em grandes diferenças no empacotamento de partículas. O efeito da carbonatação na densidade aparente foi mais consistente, com a região mais carbonatada (borda) apresentando sempre maior densidade em comparação com a região central, confirmando o efeito de colmatação dos poros relatado na bibliografia (Figura 144.b).

À medida que o tempo de exposição aumenta, a parcela referente à carbonatação é mais efetiva na propagação das fissuras de borda do que a parcela referente à secagem. A Figura 145 mostra que a retração por secagem das amostras do centro é sempre maior do que na borda, e isto se dá por dois motivos: redução da porosidade total da amostra carbonatada reduz a retração por secagem do material e os ciclos de molhagem-secagem aos quais a borda foi submetida, inferiu ao fibrocimento uma retração permanente maior, reduzindo assim a parcela de retração reversível que acontece na secagem. 


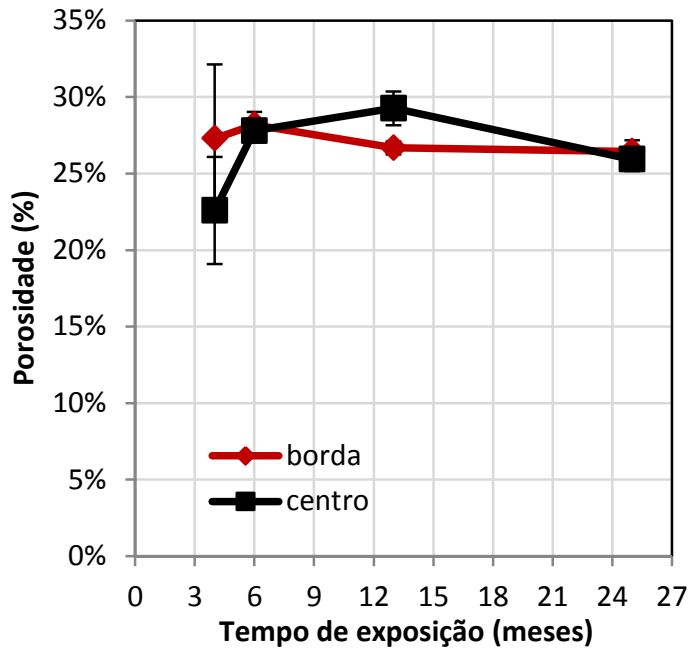

(a)

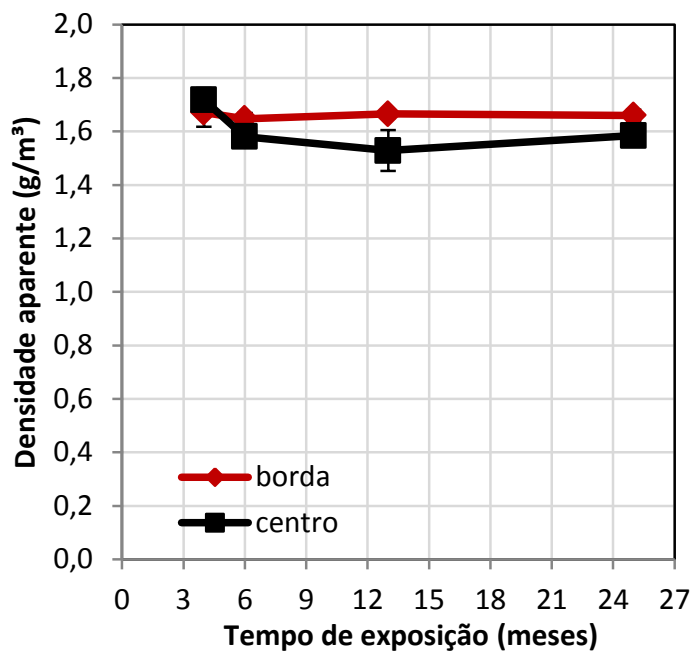

(b)

Figura 144 - (a) Porosidade total e (b) densidade aparente, ambos calculados por princípio de Arquimedes

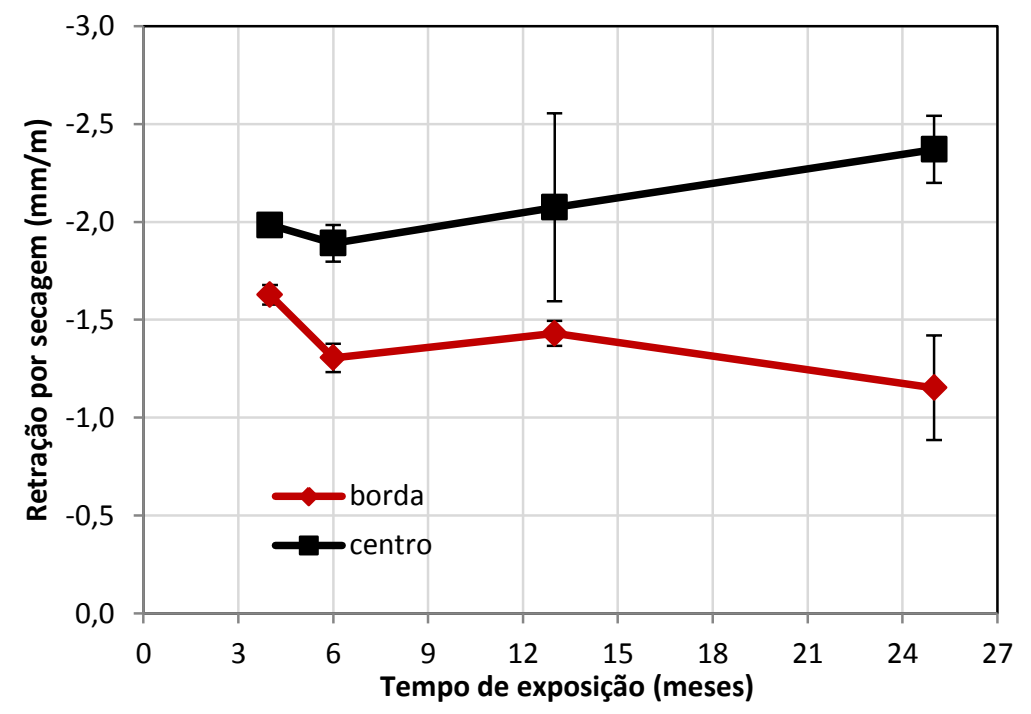

Figura 145 - Retração por secagem do fibrocimento após efeito da carbonatação natural

\subsection{Conclusões}

Este capítulo da tese mostra que a parcela referente à reação de carbonatação é significativa na retração total do fibrocimento, juntamente com a retração por secagem. Haja vista que as telhas de fibrocimento estão sempre submetidas a esta interação com o dióxido de carbono do ar, sempre há influência da retração por carbonatação na variação dimensional do fibrocimento. 
Sobre os resultados e discussões acerca da retração por carbonatação, as conclusões deste capítulo foram:

- A reação de carbonatação se refletiu em aumento na quantidade de calcita mal cristalizada no fibrocimento, visível pela grande perda de voláteis na faixa de temperatura de 550 a $760^{\circ} \mathrm{C}$ na termogravimetria. No entanto, em amostras submetidas à carbonatação após a secagem, a interação do $\mathrm{CO}_{2}$ com a matriz cimentícia não alterou as quantidades de portlandita, sendo identificada que a interação do dióxido de carbono com a matriz ocorreu na redução significativa da quantidade de C-S-H;

- Para amostra exposta à ação conjunta de secagem e carbonatação foi observado acréscimo rápido da quantidade de calcita mal cristalizada, oriunda das reações de carbonatação. Neste caso a reação de carbonatação agiu tanto na descalcificação do C-S-H como no consumo de portlandita;

- Com base nestas observações, pode-se concluir que a carbonatação tem como principal efeito na microestrutura da matriz cimentícia o aumento na quantidade de calcita mal cristalizada e descalcificação do C-S-H;

- Em amostras submetidas à carbonatação após a secagem e submetidas à secagem simultaneamente à carbonatação, apresentaram o mesmo comportamento na fase do avanço da hidratação - aumento no volume de poros na faixa de $3,6 \mathrm{~nm}$ até $0,1 \mu \mathrm{m}$, e redução no volume de poros maiores, na faixa de 0,1 a $4 \mu \mathrm{m}$;

- Quanto à porosidade total, as amostras submetida à carbonatação após a secagem e submetidas à carbonatação e secagem simultaneamente, apresentaram intensidade de redução distinta. Enquanto a primeira apresentou uma pequena redução da porosidade total com o efeito da carbonatação, a segunda apresentou uma redução mais acentuada;

- Em amostras submetidas à secagem simultaneamente à carbonatação, a porosidade total medida por MIP foi menor em comparação com as demais, no entanto, a distribuição de tamanho de poros não foi nítida - ao passo que o cimento forma seus compostos hidratados como o $\mathrm{C}-\mathrm{S}-\mathrm{H}$ e a portlandita, o mecanismo de carbonatação atua consumindo estes 
compostos em suas reações químicas, de modo que não é clara a observação das alterações na microestrutura da matriz cimentícia referente a cada mecanismo isoladamente;

- Os resultados da retração por carbonatação obtidos a partir de amostras de fibrocimento com fibras de PVA comprovam que a retração de carbonatação do compósito cimentício endurecido tem grande magnitude, da mesma ordem de grandeza da retração por secagem;

- A ação conjunta de secagem e carbonatação potencializou a retração no fibrocimento. A retração final sob estas condições foi de $5,60 \mathrm{~mm} / \mathrm{m}$ ao término de 83 dias de exposição. Quando o fibrocimento foi submetido à carbonatação somente após a secagem, a retração máxima foi de $4,94 \mathrm{~mm} / \mathrm{m}$ no mesmo período;

- O empilhamento das telhas cria uma condição onde a região central fica protegida das ações do tempo, sendo menores os efeitos de secagem e de carbonatação nesta região, devido à maior dificuldade de difusão do ar externo até esta região e grau de saturação do fibrocimento;

- A reação de carbonatação envolveu o consumo de portlandita, que diminuiu na amostra mais carbonatada, e a descalcificação do C-S-H, com redução menor perda de massa medida no primeiro pico da DTG. Este efeito é mais intenso em função do aumento do tempo de exposição. A portlandita passa a ter sua quantidade comprometida pela reação de carbonatação somente a partir dos 13 meses de exposição na região central da telha, enquanto que na sua borda a queda foi medida a partir dos 6 meses de exposição;

- A carbonatação passou a atuar na descalcificação do C-S-H somente a partir dos 6 meses de exposição, possivelmente devido à menor demanda de portlandita disponível para interação com o dióxido de carbono. 


\section{Capítulo VI}

\section{Efeito da Tensão Superficial na Retração por Secagem}

\subsection{Introdução}

A retração é certamente uma das maiores causas de deterioração prematura de compósitos cimentícios em geral. Os danos oriundos da retração podem ser observados em todos os tipos de estruturas como concreto, argamassa e demais compósitos cimentícios, como o fibrocimento.

O concreto, que é o material mais importante dentro da construção civil, sofre danos devido à retração. A manifestação patológica mais comumente observada é a fissuração, que pode ocorrer tanto por secagem e retração da estrutura endurecida, como pela retração do concreto ainda no estado plástico. Segundo Yuan (2003), a retração é apontada como uma das propriedades mais significativas na fissuração, uma vez que propicia o acesso de agentes agressivos para o interior do compósito. A fissuração de fachadas de edifícios, com revestimento externo em argamassa, pode resultar de um ou mais fatores, dentre eles a retração. Tensões são geradas na interface de aderência entre a argamassa e o substrato, resultando em fissuração aparente (Bastos et al., 2002).

O fibrocimento é um compósito cimentício com características diferentes do concreto e argamassa, pois as peças e artefatos deste material têm pequena espessura, o que potencializa a troca de umidade com o ambiente. Este compósito é peculiar, pois é composto essencialmente por cimento, com reforço mecânico de fibras, para conferir tenacidade às peças. Pensando no reforço mecânico, a fibra atua favoravelmente contra a retração, resistindo aos esforços gerados pela variação dimensional e postergando o início e a propagação da fissuração. No 
entanto, os altos teores de cimento presente por volume de fibrocimento produzido se refletem em grandes quantidades de compostos hidratados do cimento, como 0 C-S-H. Apesar de conferir resistência mecânica à matriz cimentícia, a distribuição de tamanho de poros deste composto hidratado é formada por grande parcela de poros com dimensões capilares, aumentando a retração.

Em pilhas de telhas onduladas, ou placas cimentícias planas, os elementos superiores algumas vezes apresentam empenamento, se expostos às intempéries. Esta é uma manifestação patológica oriunda de vários ciclos de retração, que ocorre de maneira diferencial entre as faces superior e inferior deste elemento, e que compromete o seu desempenho. Fissuras na direção longitudinal das telhas onduladas, conhecidas no meio produtivo como "gersuras", também podem ocorrer, no entanto, acredita-se que a origem desta fissuração não seja a retração, mas sim a conformação (formação das ondas das telhas) durante o processo produtivo. Podem ocorrer também fissuras na direção transversal às ondas da telha, neste caso podendo ser por causa da retração diferencial que ocorre entre as regiões das cavas (fundo da telha) e das cristas. Por fim, uma manifestação patológica bastante importante e que atualmente incomoda os fabricantes de fibrocimento são as fissuras de borda (Figura 146), que aparecem frequentemente nas telhas onduladas com reforço de fibras de celulose e poliméricas (sem fibras de amianto).

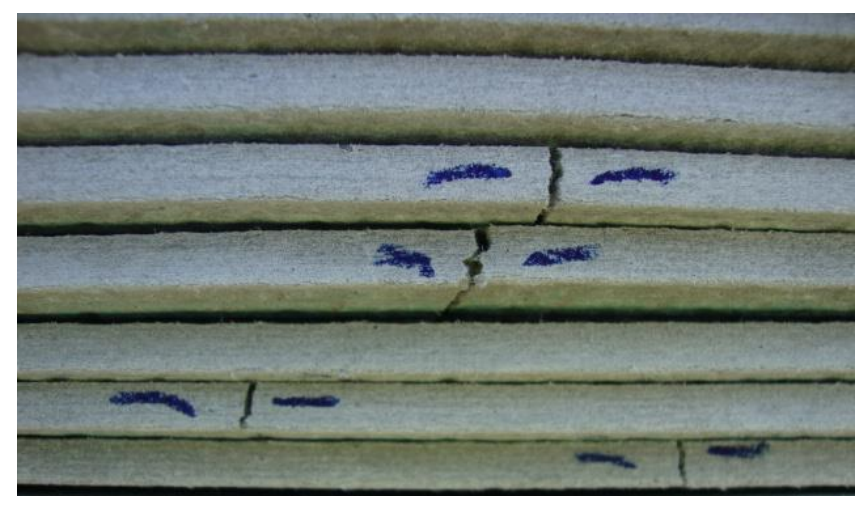

Figura 146 - Fissuras nas bordas das telhas de fibrocimento reforçadas com fibras de PVA

A tecnologia de fabricação de fibrocimento com reforço mecânico de fibras poliméricas, pela tendência do banimento do uso do amianto em materiais de construção, já está bastante avançada em todo o mundo. Já é possível produzir artefatos com boa resistência mecânica, excelente tenacidade e desempenho em uso atendendo aos requisitos exigidos em normas técnicas. No entanto, a fissuração de borda é um problema ainda sem solução, sendo possível a 
observação desta manifestação patológica nos produtos de fibrocimento comercializados pelas principais empresas brasileiras. Relatos de pesquisadores e produtores de fibrocimento de outros lugares do mundo também apontam a existência deste tipo de problema.

Devido à importância desta manifestação patológica, a fissuração de borda em artefatos fibrocimento será objeto do presente estudo, especialmente em telhas onduladas, que respondem pela maior parte do mercado de fibrocimento nacional (Dias, 2011). A principal hipótese deste trabalho é que a fissuração de borda do fibrocimento reforçado com fibras poliméricas advém da retração diferencial, que acontece na borda das telhas onduladas enquanto estas estão empilhadas no estoque. A Figura 147 mostra que após poucos segundos da retirada da telha superior, uma telha do meio da pilha apresenta grande diferença de umidade superficial na região da borda, sendo visível pela diferença de coloração do material.
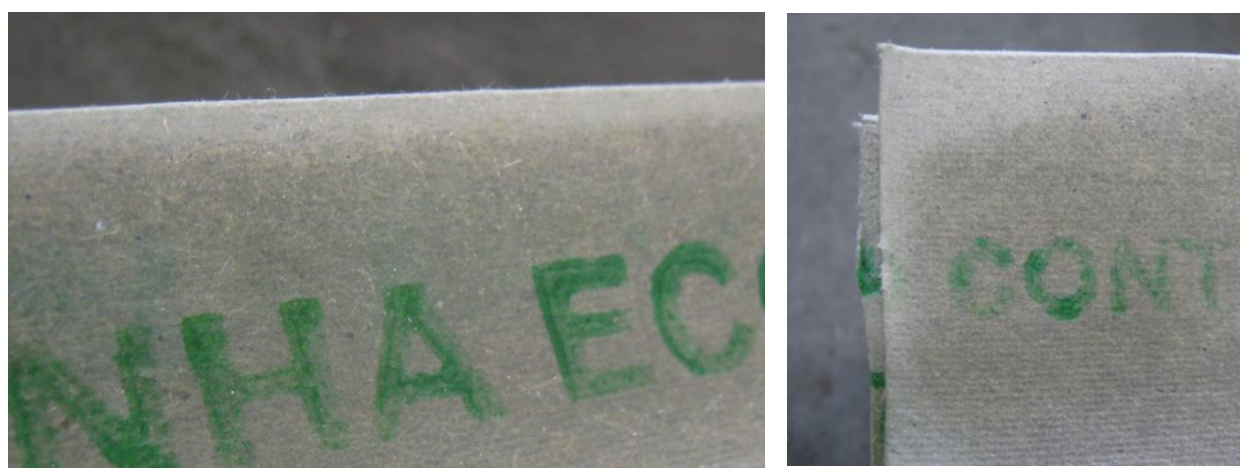

Figura 147 - Região da borda de uma telha de fibrocimento reforçada com fibras de PVA, 30 segundos após a mesma ter sido retirada de uma pilha de 90 telhas

Ao final do processo de produção, as telhas de fibrocimento apresentam umidade bastante elevada, afinal foram submetidas a um processo de cura com o objetivo de manter a umidade do material. Imediatamente após a desforma, as telhas são empilhadas umas sobre as outras em montes de aproximadamente 90 telhas. Esta configuração favorece a condição de manutenção da elevada umidade por quase toda a área da telha, uma vez que as demais telhas da pilha atuam como barreira à perda de umidade. Ocorre que as bordas das telhas ficam expostas ao ambiente, e consequentemente perdem umidade por evaporação, o que causa uma condição crítica nesta região, pois estas tendem a retrair pela secagem, mas há uma restrição à retração pela parte úmida do fibrocimento (Figura 148). Como comentado, a secagem na extremidade da borda causa retração, uma vez que há 
poros capilares no material, no entanto, a região adjacente da telha, ainda úmida, impede a ocorrência da variação dimensional, o que gera tensão interna naquela região. Como normalmente isso ocorre nas primeiras idades de hidratação, o fibrocimento ainda não atingiu um grande ganho de resistência, podendo esta tensão interna citada superar a resistência do material, causando assim a fissuração.

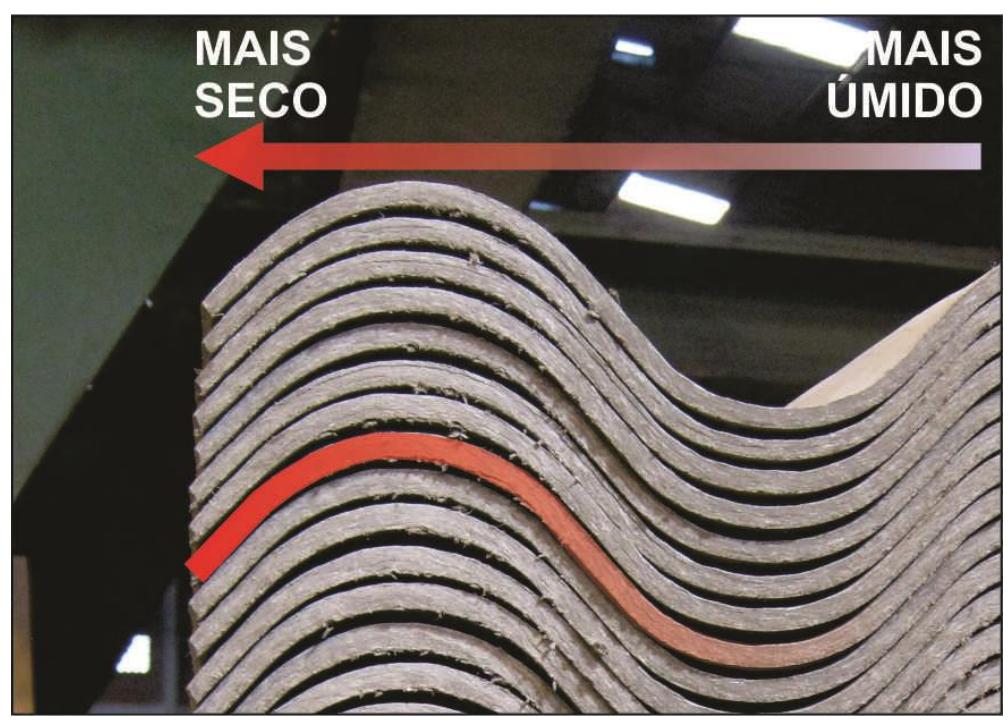

(a)

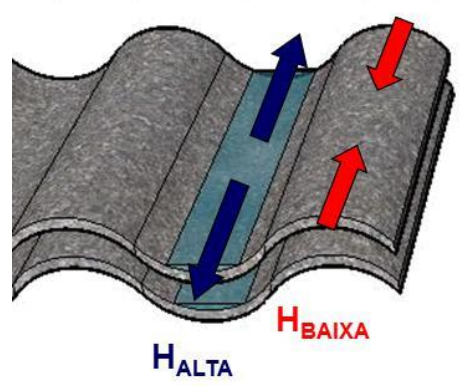

(b)

Figura 148 - (a) Esquema indicando a variação de umidade ao longo da telha empilhada. A borda seca mais rapidamente e a região central da telha permanece mais úmida, devido à restrição à evaporação imposta pelas telhas adjacentes (inferior e superior). (b) Esquema indicando a retração na borda devido à secagem ( $\mathrm{H}_{\mathrm{BAIXA}}$ : umidade baixa), enquanto a região central mais úmida $\left(\mathrm{H}_{\mathrm{ALTA} A}\right.$ : umidade alta) resiste a esta deformação

As propriedades mecânicas e de desempenho do fibrocimento são adequadas ao uso, sendo que a ocorrência da fissuração de borda não interfere nestas propriedades. Entretanto, trata-se de um defeito e o mercado consumidor não aceita o produto ou o avalia como de baixa qualidade. Um fator importante apontado por (Molin, Dal, 1988) é o fato das fissuras de um modo geral atingir o usuário sob o ponto de vista de satisfação psicológica.

O objetivo deste capítulo é realizar um estudo de caso aplicando como estratégia para redução da retração o princípio da redução da tensão capilar causadora da retração, observando os efeitos na redução da retração por secagem e redução da fissuração em telhas de fibrocimento reforçado com fibras de PVA, comercializados pela indústria da construção. 


\subsection{Redução da retração devido à modificação da pressão capilar do líquido}

Com o entendimento do fenômeno envolvido na retração, é natural que a engenharia busque por soluções no sentido de mitigar a retração, e reduzir assim a fissuração das estruturas. Como a retração por secagem é uma propriedade do compósito cimentício, uma das formas de reduzi-la é manipular as matérias-primas de modo a produzir um material com características tais que resultem em pequena retração. São exemplos disso a utilização de baixo teor de celulose, ou não utilizar adições minerais que aumentam a retração, como a sílica ativa.

No entanto, além de ser uma propriedade do fibrocimento, a capacidade de retrair em maior ou menor magnitude, a retração por secagem é um fenômeno que envolve a movimentação de água (movimentação higroscópica) de poros capilares da matriz cimentícia, para poros grandes ou para o ambiente. Desta forma, outra possibilidade de atuação na tentativa da mitigação da retração é a manipulação da movimentação higroscópica no fibrocimento, objetivando a redução da tensão capilar causadora da retração.

Tem sido provado em diversas publicações que vários tipos de aditivos são efetivos na redução da retração autógena. Alguns agentes redutores de retração (SRA), que reduzem a tensão superficial da água capilar, reduzindo consequentemente a pressão capilar, são efetivos na redução da retração autógena. Além dos modificadores de tensão superficial, há aditivos compensadores de retração (SCA), cuja atuação é a formação de compostos expansivos, que também são eficazes na redução da retração por secagem final. Os hidrofugantes também são produtos utilizados para este fim, sendo que há estudos mostrando sua efetividade na redução da retração autógena. Isso ocorre porque o hidrofugante aumenta o ângulo de contato entre o cimento hidratado e a água capilar, e desta forma reduz a tensão capilar.

Os aditivos SRA ${ }^{18}$ (aditivo redutor de retração) são produtos eficazes na mitigação da retração em concretos e argamassas. Estudos recentes mostram que a sua capacidade de redução da retração é grande, especialmente na retração por secagem, uma vez que este tipo de retração tem maior magnitude que a retração

\footnotetext{
${ }^{18}$ Shrinkage Reducing Admixtures
} 
autógena, e o princípio envolvido no mecanismo de retração é a pressão capilar. Por agir na redução da tensão superficial do fluido dos poros, o aditivo SRA tem melhor atuação neste tipo de retração. A retração autógena é menos sensível ao efeito do SRA (Saliba et al., 2011).

Os aditivos SRA atuam reduzindo a tensão superficial da água do poro da matriz cimentícia, reduzindo assim a tensão capilar causadora de retração. Estes aditivos são compostos normalmente por glicóis, como propileno glicol, trietileno glicol e dipropileno glicol (Chindaprasirt; Rattanasak, 2011). Outra opção de aditivo mitigador de retração são os aditivos expansivos EXA ${ }^{19}$, ou aditivos compensadores de retração $S C A^{20}$, que atuam formando compostos expansivos no interior do concreto, compensando a retração sofrida. Os aditivos SCA têm menor efeito, quando comparados com o SRA quando utilizados em argamassas e concretos (Melo Neto, 2008). Mas este tipo de aditivo também se mostra eficaz na redução da retração (Meddah et al., 2011).

O estudo do efeito da cura interna na retração apresenta uma abordagem correta do tema, uma vez que discute diretamente a movimentação higroscópica, que é causa primária da retração. A cura interna altera a movimentação higroscópica do material cimentício, pois consiste em uma reserva de água que é liberada no momento da cura, ou ainda uma barreira contra a evaporação e perda de água para o meio-ambiente (Esteves, 2009). Polímeros superabsorventes são utilizados como reserva de água para a cura interna, deste modo a retração é diminuída uma vez que há redução da autossecagem do concreto (Zhutovsky; Kovler; Bentur, 2011). Como o efeito dos poros do $\mathrm{C}-\mathrm{S}-\mathrm{H}$ e demais compostos hidratados do cimento não foram causa direta de retração no caso do fibrocimento, é possível que este princípio de cura interna não funcione para este compósito, que possui porosidade total muito grande.

Como a cura interna tem se mostrado eficaz no caso de concretos, este tipo de estudo se tornou tão importante que recentemente a RILEM estabeleceu um comitê técnico sobre a aplicação de polímeros superabsorventes em concreto (RILEM TC 225-SAP - Application of superabsorbent polymers in concrete construction). Os polímeros superabsorventes podem armazenar de $10 \mathrm{a} 16 \mathrm{ml}$ de água por grama de

\footnotetext{
${ }^{19}$ Expansive Additive

${ }^{20}$ Shrinkage Compensating Admixture
} 
polímero, dependendo do diâmetro das partículas (Esteves, 2011). Esta quantidade de água faz com que o polímero aumente de volume em torno de $200 \%$.

\subsection{Metodologia}

6.3.1. Efeito dos modificadores da movimentação higroscópica na retração

Objetivando a redução da retração, foram aplicados os seguintes tratamentos ao fibrocimento, sendo que em todos os casos a alteração na movimentação higroscópica é o princípio de atuação dos produtos:

- Aditivo SRA (redutor da tensão superficial da água);

- Propileno glicol (redutor da tensão superficial da água);

- Hidrofugante (hidro-repelente, que aumenta o ângulo de contato entre a água e o fibrocimento).

Este estudo foi realizado com amostras de fibrocimento produzidos industrialmente, por uma fábrica de telhas de fibrocimento reforçado com fibras poliméricas de PVA.

As amostras foram produzidas pelo processo Hatschek, cuja placa pronta de fibrocimento é composta pela sobreposição de várias camadas mais finas. Esta particularidade do processo produtivo permitiu que os produtos modificadores da movimentação higroscópica fossem aplicados entre as camadas que formam o fibrocimento, garantindo a melhor difusão dos produtos no interior do fibrocimento.

A quantidade dos produtos aplicados foi controlada pela vazão de aplicação do produto líquido, que foi de $5,2 \mathrm{~g} / \mathrm{s}$ em todos os casos. Considerando a água livre presente no fibrocimento no estado fresco, a concentração de aditivo aplicado foi de $6 \%$. Os produtos modificadores de movimentação higroscópica foram aplicados apenas na região da borda de cobertura das telhas de fibrocimento, que é a região onde é observada a ocorrência de fissuração. A largura de aplicação foi de $6 \mathrm{~cm}$ a partir da borda. No processo produtivo, a aplicação ocorre em uma faixa de $10 \mathrm{~cm}$, sendo que após o corte da manta fresca para a formação da telha, esta ficou com aproximadamente $6 \mathrm{~cm}$ da região com aplicação de SRA, como mostra a Figura 149. 


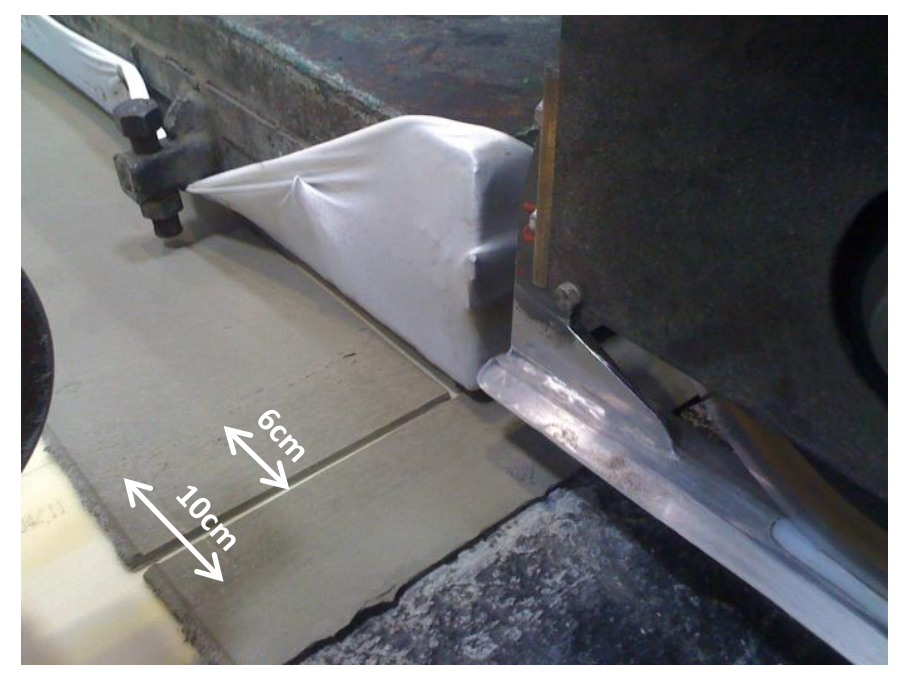

Figura 149 - Faixa de aplicação do aditivo SRA (6cm a partir da borda da telha)

As amostras foram coletadas a partir da manta fresca, antes da conformação das telhas (ondulação). Foram coletadas amostras de aproximadamente $25 \times 25 \mathrm{~cm}$, que foram embaladas com filme plástico para evitar a perda de água por evaporação. A cura das amostras foi realizada em temperatura de aproximadamente $60^{\circ} \mathrm{C}$, juntamente com a cura térmica das telhas produzidas para a comercialização, por período de aproximadamente 10 horas. Após o período de cura térmica, as amostras foram submetidas à cura úmida por mais 10 dias, em câmara úmida.

A concentração de aditivo aplicada foi definida em função da eficiência do SRA diluído em água. A Figura 151 mostra que o aditivo tem eficiência máxima desde o teor $10 \%$ até $100 \%$. Deste modo, aliado a testes exploratórios realizados para comprovar o efeito do aditivo diluído, concluiu-se que o teor ótimo de eficiência do SRA foi de $6 \%$.

O aditivo SRA utilizado foi o Eclipse, da marca Grace Construction, que atua na redução da tensão superficial da água do poro da matriz cimentícia. Um indicador da redução da tensão superficial é o formato da gota pendente de água, como mostra a Figura 150.

O Propileno glicol é a principal matéria-prima dos aditivos SRA utilizados em concreto. Deste modo, ele atua da mesma forma, reduzindo a tensão superficial da água do poro. No entanto, a eficiência na redução da tensão superficial da água é maior do aditivo SRA, como mostra a Figura 151. 
O efeito do aditivo SRA e do propileno glicol na água foi determinada em um goniômetro, através do método da gota pendente. Foram preparadas várias soluções, variando a concentração de aditivo, e foi medida a tensão superficial através do formato da gota pendente, resultando da Figura 151.

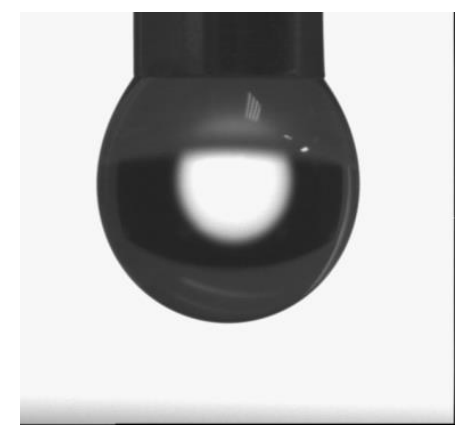

(a)

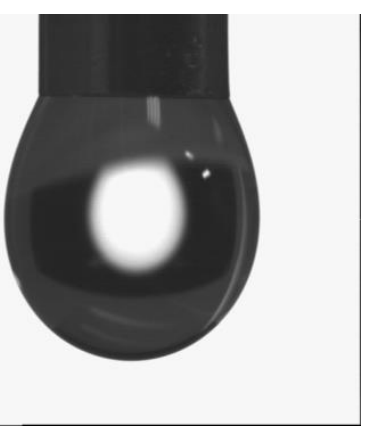

(b)

Figura 150 - (a) Gota de água deionizada e (b) gota de água deionizada com 6\% de aditivo SRA

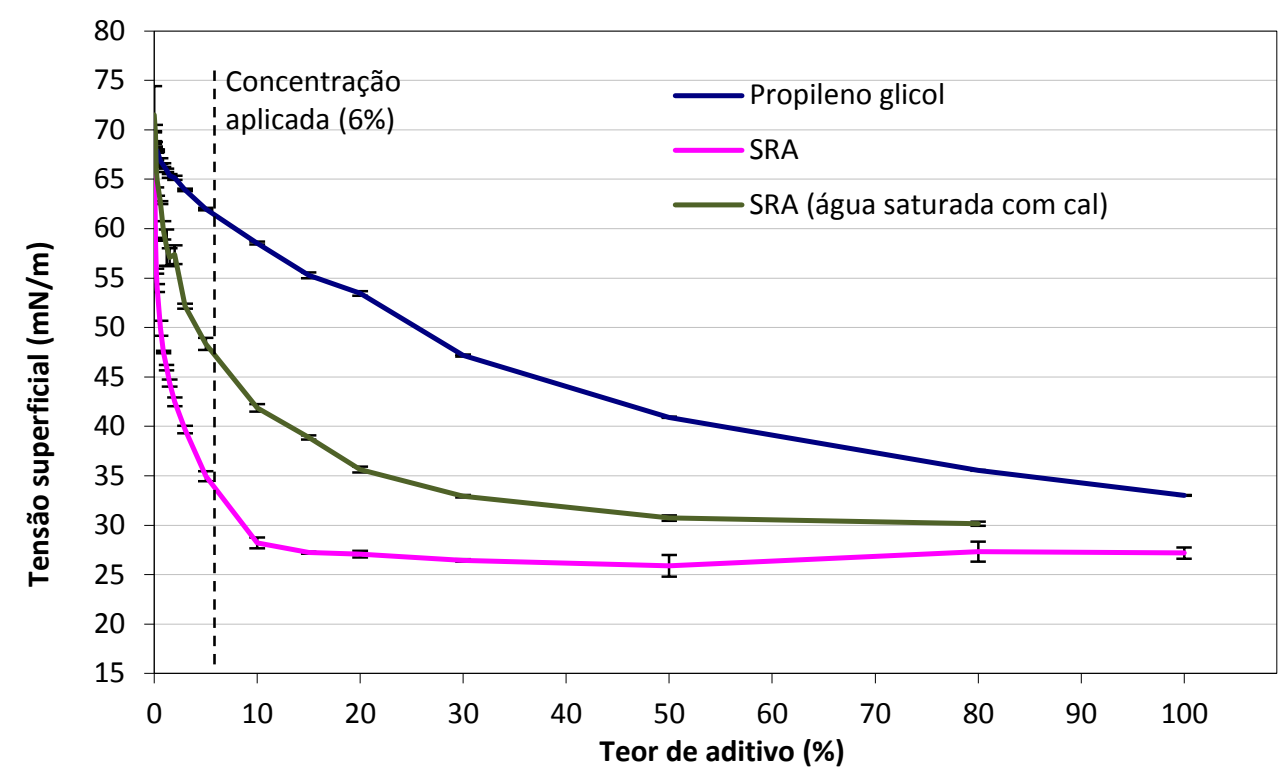

Figura 151 - Efeito do aditivo SRA e propileno glicol na tensão superficial da água

O hidrofugante utilizado foi a base de silicone, da marca Wacker, que atua no aumento do ângulo de contato da água com o fibrocimento, inferindo ao fibrocimento hidro repelência à água. A Figura 152 mostra que o formato da gota sobre o fibrocimento muda com a aplicação do hidrofugante. O ângulo de contato entre a água e o fibrocimento sobe de aproximadamente $80^{\circ}$ nas amostras sem tratamento, para $130^{\circ}$ nas amostras hidrofugadas. 


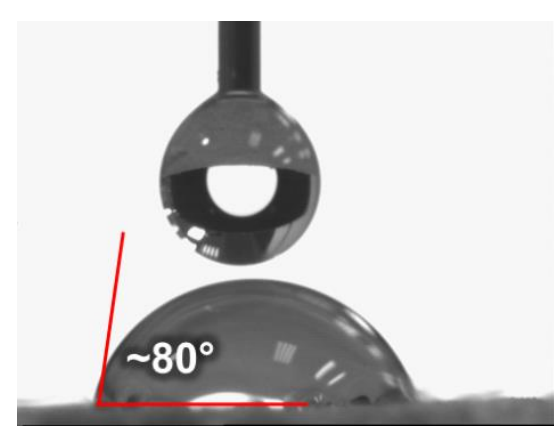

(a)

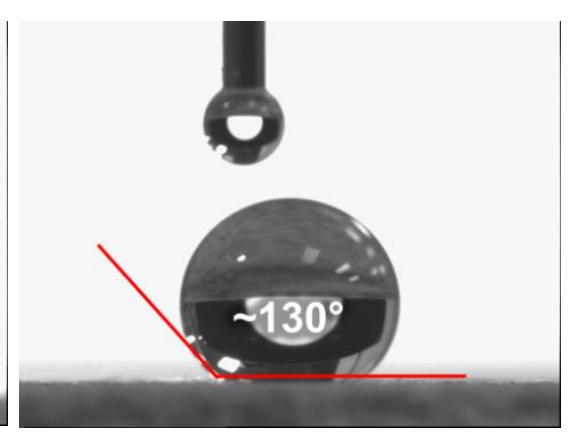

(b)

Figura 152 - Ângulo de contato da água deionizada (a) com um fibrocimento padrão, sem tratamento, e (b) em um fibrocimento hidrofugado, tratado com uma solução de água e $10 \%$ de hidrofugante

\subsubsection{Aplicação em escala industrial do aditivo SRA}

Com base nos testes dos tratamentos com modificadores de movimentação, optou-se por aplicar em escala industrial o aditivo SRA, e avaliar o seu potencial na redução da retração por secagem e suscetibilidade das telhas de fibrocimento à fissuração nas bordas.

O presente estudo é um teste em escala industrial, que busca 0 acompanhamento na fábrica da aplicação do SRA como agente redutor da retração na borda das telhas de fibrocimento, buscando a redução da fissuração nesta região das telhas. Este teste industrial é uma validação dos estudos realizados em escala menor (em laboratório), onde a aplicação do SRA comprovadamente reduziu a retração por secagem do fibrocimento em até $40 \%$.

O teste é composto essencialmente por:

- Aplicação do SRA na borda de cobertura das telhas de fibrocimento durante 1 jornada de produção;

- Caracterização do fibrocimento tratado com SRA através de ensaios de retração por secagem e resistência à flexão. Para isso foram coletadas amostras;

- Medida da retração por secagem diretamente na telha com SRA;

- Acompanhamento do aparecimento de fissuras na borda de cobertura das telhas tratadas, durante 6 meses de exposição nos pátios da fábrica. 
Como o fibrocimento foi produzido pelo processo Hatschek, o SRA foi aplicado entre as camadas que formam o fibrocimento, garantindo a melhor difusão dos produtos no interior do mesmo.

A quantidade dos produtos aplicados foi a mesma do estudo anterior, sendo esta controlada pela vazão de aplicação do produto líquido, que foi de $5,2 \mathrm{~g} / \mathrm{s}$, o que equivale a uma concentração de $6 \%$ de SRA na água do poro do fibrocimento. 0 SRA foi aplicado apenas na região da borda de cobertura das telhas de fibrocimento, com largura de aplicação de $6 \mathrm{~cm}$ a partir da borda.

Este teste realizado dentro da indústria foi realizado durante uma jornada de 24 horas de produção de telhas, sendo que neste período foram produzidos aproximadamente 190 montes com 90 telhas cada. Destes 190 montes, em aproximadamente $10 \%$ deles não foi aplicado o tratamento com SRA, para a retirada das amostras de referência. Deste grupo total de amostras, foram escolhidos aleatoriamente 3 montes de referência e 3 montes com SRA.

A medida da retração na borda da telha foi realizada utilizando um equipamento Tensotast, da marca ELE, modelo Digimat, com precisão de $0,01 \mathrm{~mm}$, que mede a retração lateralmente à amostra (Figura 154). Para tentar simular a condição de secagem a que uma telha é submetida quando empilhada, para cada amostra foi montado um conjunto de duas telhas empilhadas, com uma manta de tecido sobre estas. A evaporação de água da telha testada foi impedida na sua face inferior pela telha posicionada abaixo, e pela face superior foi impedida pela manta de tecido, que estava saturada no início do teste. A retração foi medida a 3, 6, 16, 34 e $62 \mathrm{~cm}$ da borda (crista da onda de cobertura), como mostra a Figura 153. 


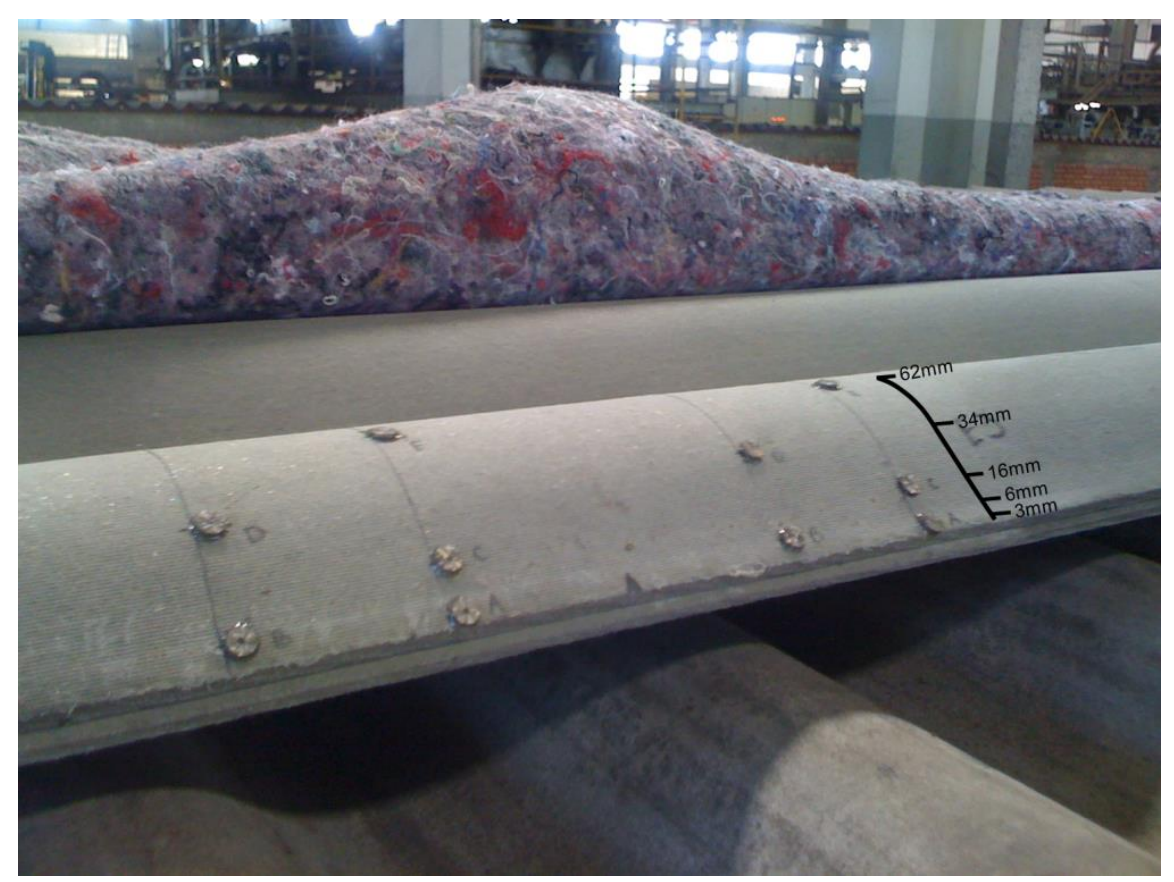

Figura 153 - Região da borda da telha onde foi realizada a leitura da retração por secagem

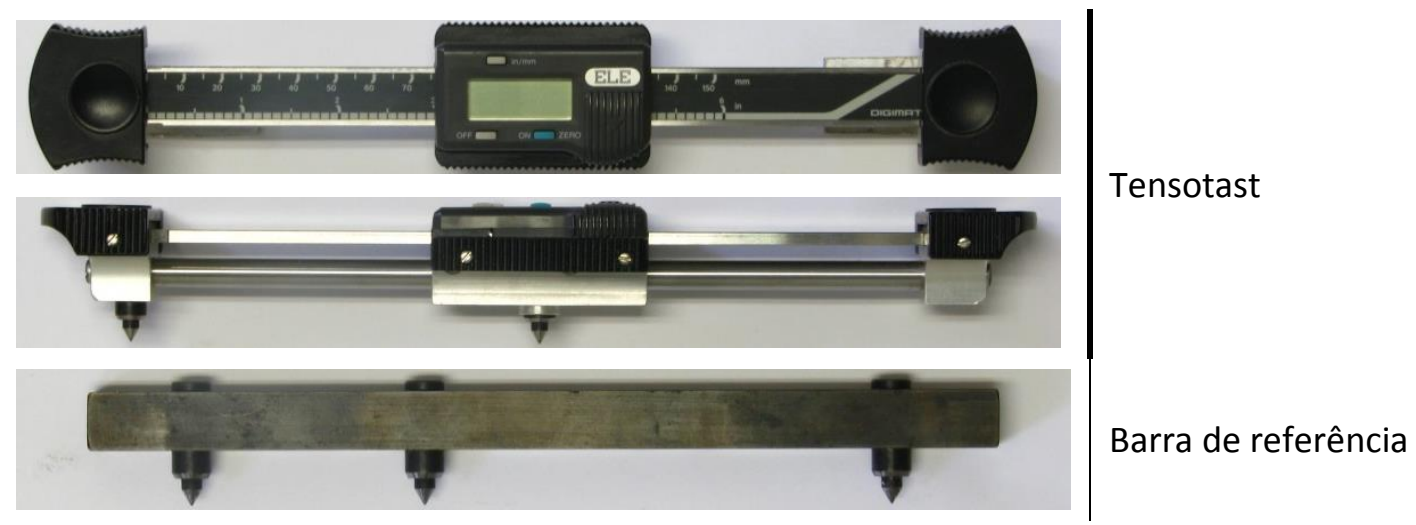

Figura 154 - Equipamento Tensotast

Para o acompanhamento da evolução da fissuração nas telhas em função do tempo de exposição ao meio ambiente, foram monitorados 6 montes de telhas, formados por 90 telhas empilhadas cada, expostas no pátio da uma fábrica de fibrocimento, sendo 3 montes com telhas tratadas com o aditivo SRA e mais 3 montes de referência. Estes montes foram expostos entre os meses de abril e outubro, época com pouca incidência de chuvas na região de exposição, portanto considerada mais crítica do ponto de vista do surgimento de fissuras, uma vez que favorece a secagem. A contagem de fissuras foi realizada na borda da onda de cobertura das telhas, onde há normalmente maior incidência da fissuração de borda, sendo que os montes de telhas foram posicionados para exposição com a face da borda de cobertura voltada para a direção norte, de modo a sofrer maior insolação 
durante o período de monitoramento. A evolução da fissuração nas telhas foi monitorada através de contagem da quantidade de fissuras de borda, realizada em diferentes tempos de exposição. A face lateral dos montes, da onda de cobertura, foi dividida em 9 regiões, como mostra a Figura 155, para a análise da região de maior incidência de fissuração.

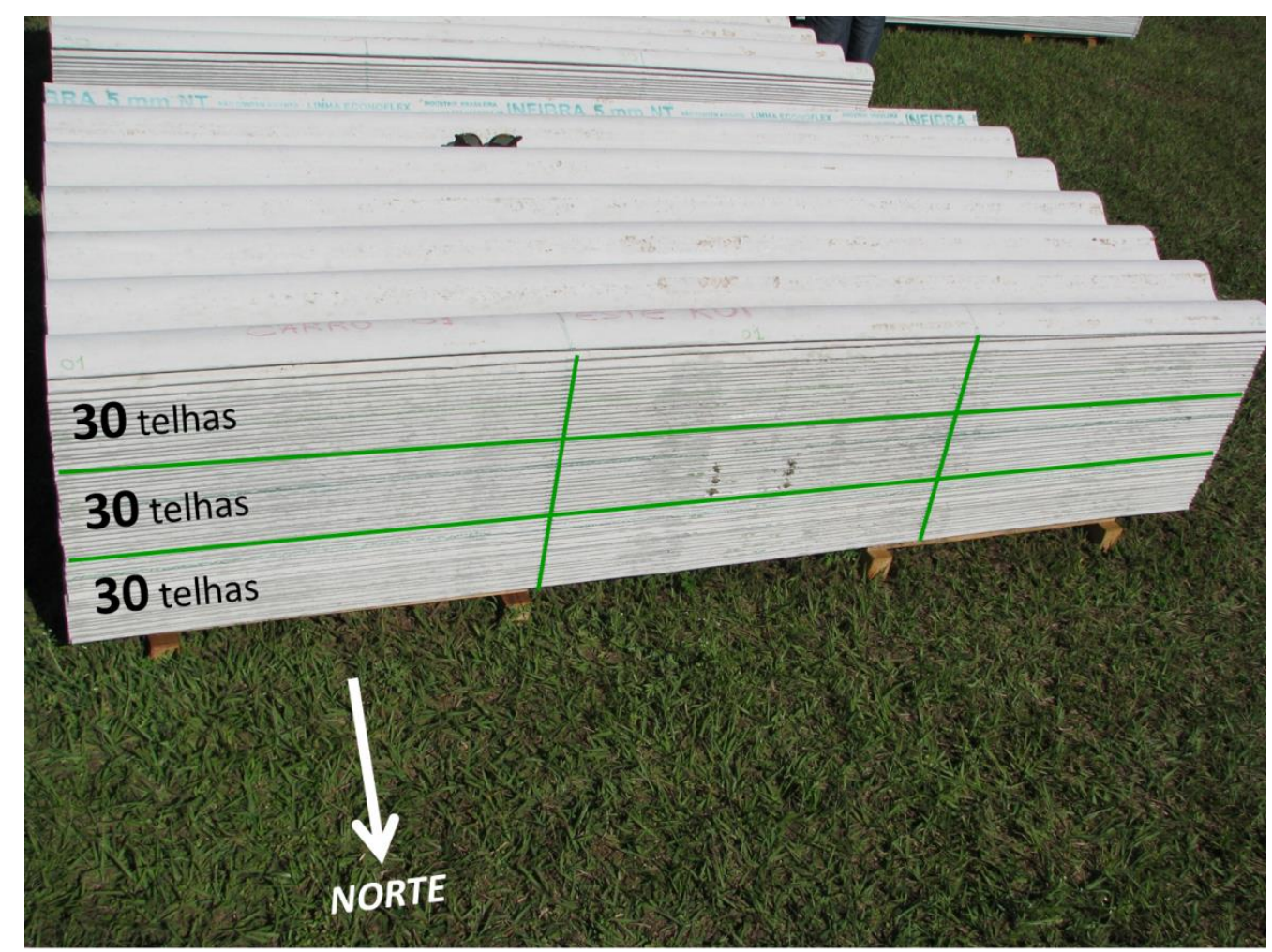

Figura 155 - Monte de telhas expostas ao meio ambiente para monitoramento da evolução da fissuração. Divisão das regiões na face lateral do monte, onde foi contada a quantidade de fissuras na borda da onda de cobertura

Uma vez aplicado o SRA nas telhas de fibrocimento, foi realizado o acompanhamento das suas propriedades mecânicas, de retração e aparecimento de fissuras ao longo do tempo. Para isso foram adotados os seguintes indicadores de desempenho:

\section{Para as amostras coletadas}

- Resistência à flexão (em corpos-de-prova)

- Retração por secagem (em corpos-de-prova e em telhas)

- Perda de massa (em corpos-de-prova)

- Densidade (em corpos-de-prova) 


\section{Para as pilhas de telhas da produção}

- Observação do aparecimento de fissuras na borda de cobertura das telhas empilhadas expostas

Este estudo foi realizado segundo o fluxograma de atividades exposto na Figura 156.

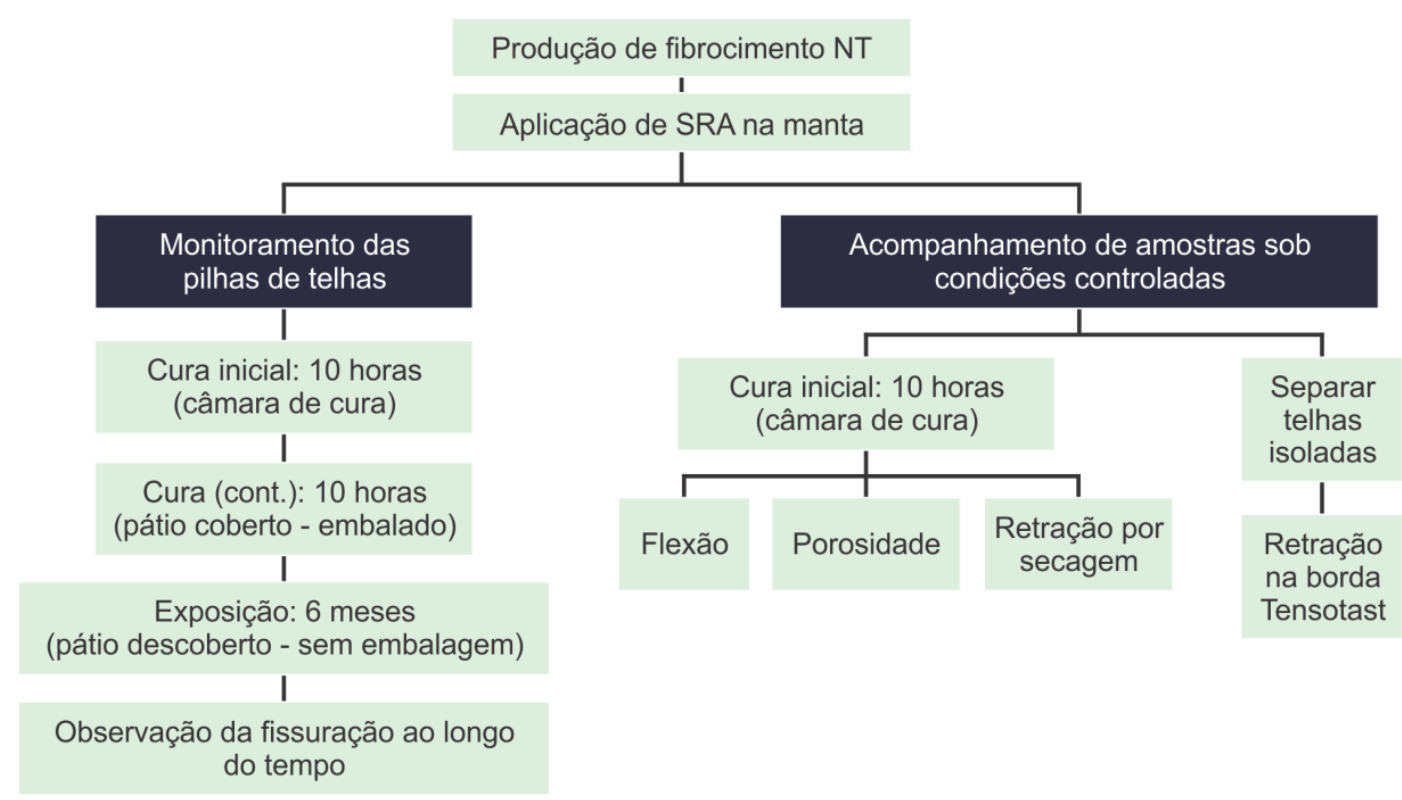

Figura 156 - Fluxograma de atividades do estudo de estratégia para redução da retração e fissuração em telhas de fibrocimento NT produzidas industrialmente

\subsection{Resultados e discussões}

\subsubsection{Modificação da pressão capilar}

Os princípios de atuação dos tratamentos aplicados nas amostras de fibrocimento são diferentes. Porém, em todos os casos a movimentação higroscópica na estrutura de poros da matriz foi modificada. No caso dos produtos que modificam a tensão superficial da água do poro, a Figura 158 mostra que a secagem foi facilitada. Segundo a equação de Laplace (Equação 8), a tensão superficial tem relação direta com a tensão capilar atuante no poro, de modo que a redução da tensão superficial da água do poro conferida pelos aditivos SRA e propileno glicol diminuiu a tensão capilar nos poros, facilitando a secagem destes. Como consequência, a perda de água foi maior nestas amostras aos 14 dias de secagem. Nas amostras tratadas com propileno glicol, a ação deste produto na 
tensão superficial da água do poro foi menor, como mostrou a Figura 151, no entanto a maior perda de massa em função do tempo de secagem também se deu devido ao maior nível de umidade no início da secagem, como mostra a Figura 160.

Os tratamentos modificadores da movimentação higroscópica reduziram a retração em alguns casos, como era esperado. A ação do hidrofugante e do propileno glicol foi uma redução muito discreta da retração, que não apresenta diferença estatística para a amostra de referência (Figura 159). A ação esperada do tratamento com hidrofugante é o aumento do ângulo de contato entre a água e as paredes do poro capilar, e desta forma alterar o formato do menisco e consequentemente a pressão capilar. No entanto, a aplicação deste produto foi feita através da sua diluição na água do poro, o que não garante que este foi adsorvido nas paredes do poro, formando uma película hidrofugada. Por princípio, a água tende a ser adsorvida nas paredes do poro devido sua afinidade com a matriz cimentícia, e isso depende da umidade relativa da fase gasosa. Partindo deste princípio, é possível que o hidrofugante não tenha aderido às paredes do poro, devido sua menor afinidade com a matriz cimentícia, e como consequência menor suscetibilidade à adsorção física. Soma-se a esta discussão, a dificuldade da difusão do hidrofugante até o interior dos poros de menor dimensão, uma vez que este produto contém partículas sólidas em sua composição, que ficam limitadas ao seu tamanho para progresso da difusão até os espaços vazios menores dentro da matriz cimentícia. Por este motivo, acredita-se que o princípio de alteração do ângulo de contato entre a água e as paredes sólidas do poro não ocorreu efetivamente, pois não houve adesão do hidrofugante nas paredes do poro.

A ação do aditivo SRA foi efetiva na redução da tensão capilar da água deionizada, mesmo em diluição com pequena concentração do produto. Quando se simulou uma condição mais representativa da água do poro de uma matriz cimentícia, testando o efeito do SRA na redução tensão superficial de uma solução de água saturada com hidróxido de cálcio, a redução na tensão superficial medida foi menor, em especial na concentração aplicada neste estudo (Figura 151) (redução de 72 para $47 \mathrm{mN} / \mathrm{m}$ ). Apesar disso, o tratamento com aditivo SRA nas telhas de fibrocimento reduziu significativamente a retração por secagem, que aos 15 dias de secagem caiu de aproximadamente $2,9 \mathrm{~mm} / \mathrm{m}$ para $1,8 \mathrm{~mm} / \mathrm{m}$ (redução de $40 \%$ ) (Figura 159), mostrando que a redução da tensão superficial da água do poro é um 
mecanismo eficaz de redução da tensão superficial e consequentemente redução da retração. Os dois efeitos observados no fibrocimento, com o tratamento com aditivo SRA nos poros deste material, comprovam a teoria do efeito da tensão superficial da fase líquida do poro, na tensão capilar atuante neste poro pela formação do menisco. Como mostra a estimativa da tensão capilar atuante nos poros do fibrocimento (Figura 157), aplicando-se a equação de Laplace (Equação 8), a redução da tensão superficial do líquido, que foi em torno de 35\% segundo a Figura 151 para a água saturada com hidróxido de cálcio, tem relação direta com a redução da tensão capilar, medida pela redução de $40 \%$ da retração aos 15 dias de secagem.

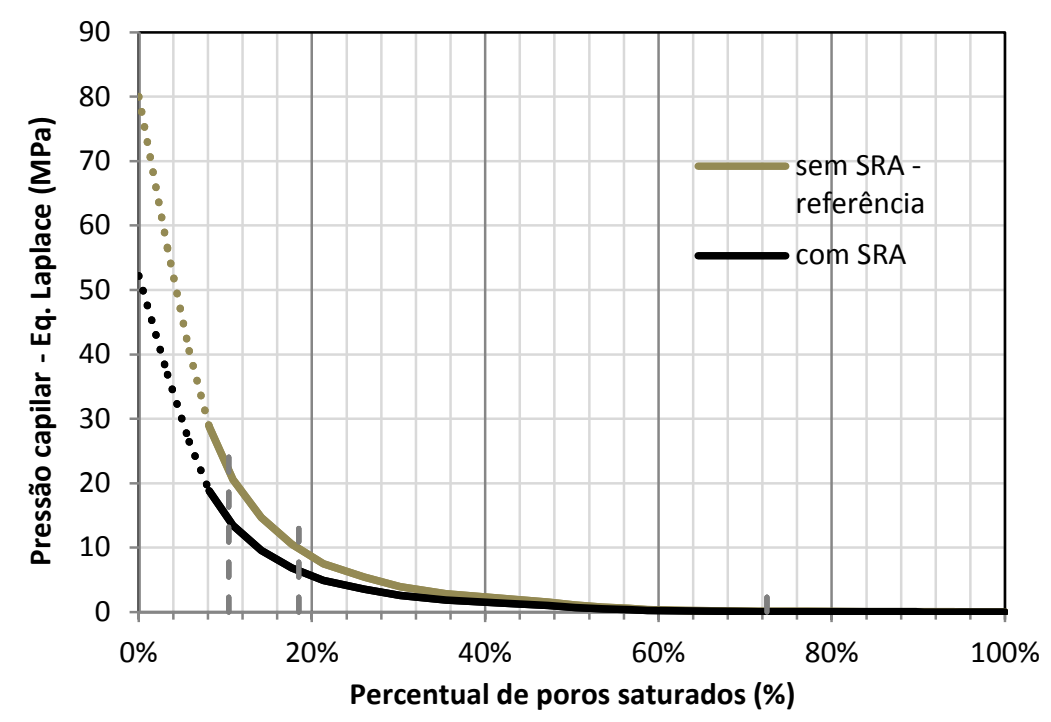

Figura 157 - Pressão capilar estimada, calculada a partir da equação de Laplace, para o percentual de poros saturados. $O$ trecho em pontilhado em ambas as curvas representa a região dos poros de gel e microporos, onde o mecanismo de depressão capilar governado pela equação de Laplace não é válido. A curva com SRA é a estimativa da pressão capilar considerando a concentração deste produto aplicado nas amostras, que foi de $6 \%$ 


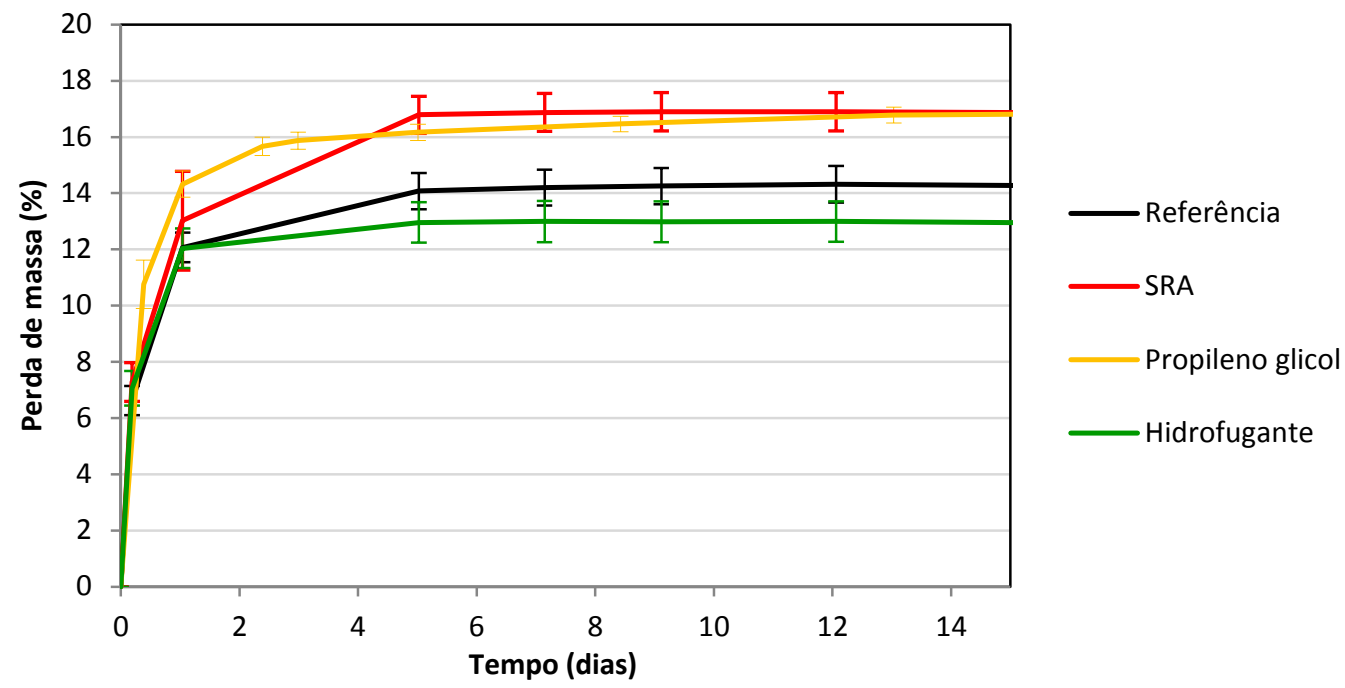

Figura 158 - Perda de massa dos fibrocimentos tratados com modificadores da movimentação higroscópica (SRA, propileno glicol, hidrofugantes)

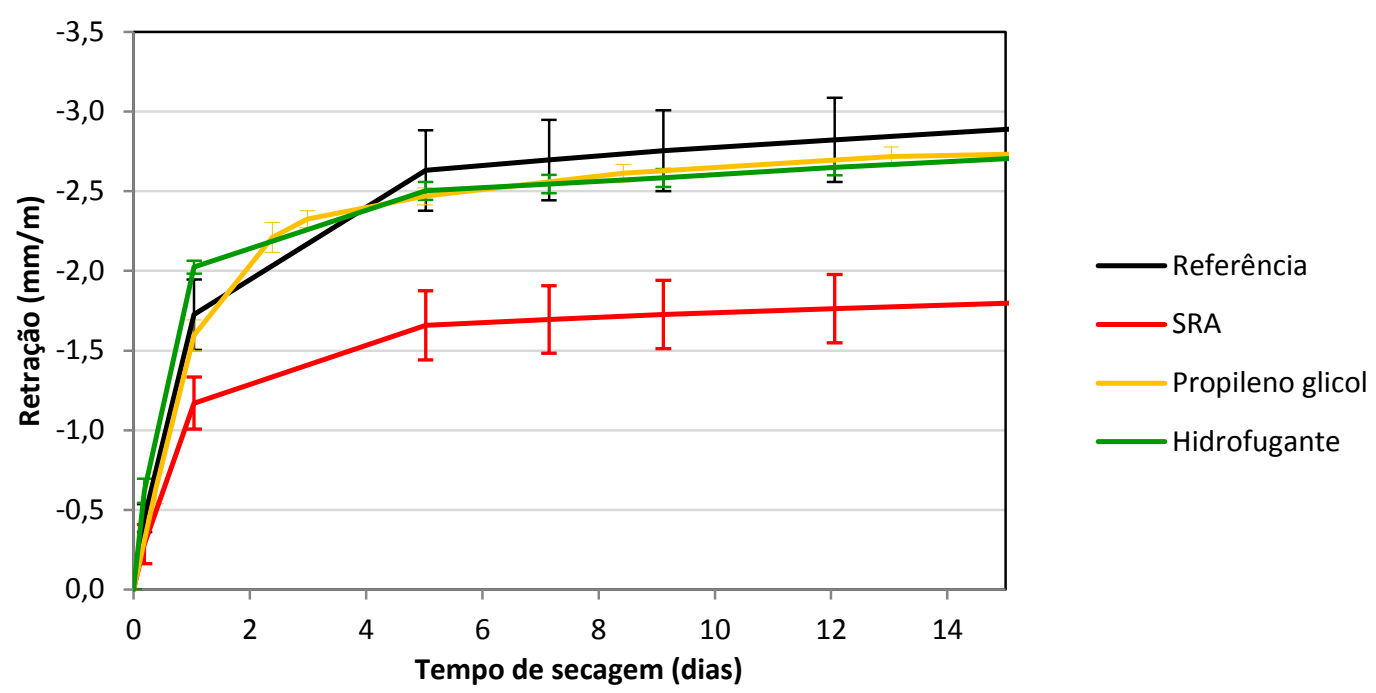

Figura 159 - Efeito dos tratamentos modificadores da movimentação higroscópica (aplicação de SRA, propileno glicol, hidrofugantes) na retração por secagem do fibrocimento reforçado com fibras de PVA

A relação entre a retração e a variação da umidade do fibrocimento na secagem é um indicativo da suscetibilidade do fibrocimento à retração para uma mesma quantidade de água evaporada. Esta diferença é indicada pela inclinação das curvas expostas na Figura 160, que deve ser a menor possível, para representar amostras de fibrocimento que retraem pouco mesmo para os mesmos níveis de perda de água.

A eficácia do tratamento com SRA é observada na Figura 160, onde mesmo para níveis de umidade bastante reduzidos, a retração por secagem foi menor que a medida nas amostras de referência. Este comportamento só foi possível, pois a 
inclinação da curva Retração X Umidade foi a menor entre todos os tratamentos testados.

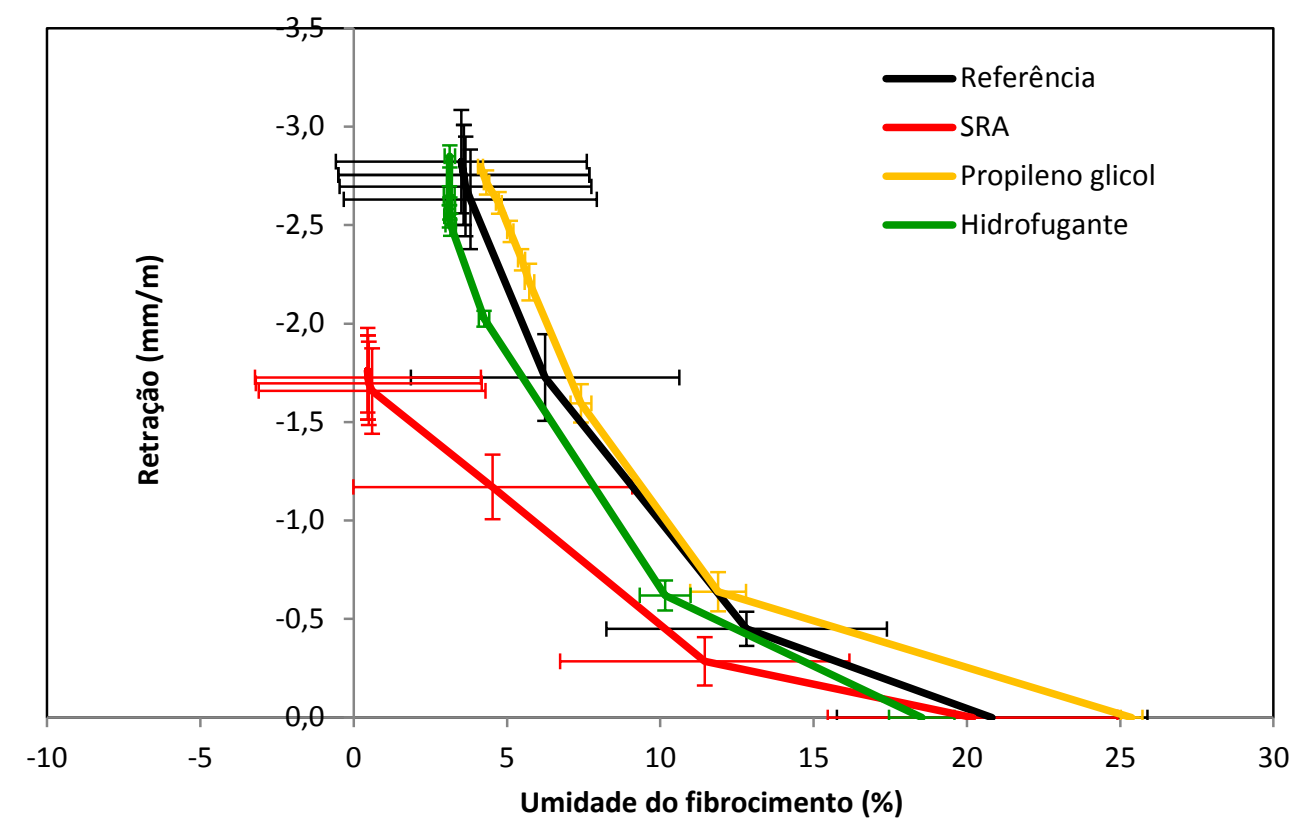

Figura 160 - Relação entre a retração por secagem e a umidade do fibrocimento

Além dos efeitos na movimentação higroscópica e consequentemente na retração por secagem, os produtos aplicados no fibrocimento alteraram as propriedades físicas e mecânicas do compósito.

A influência dos tratamentos modificadores da movimentação higroscópica na porosidade total de modo geral não foi grande, sendo que na maioria dos casos a porosidade aumentou (Figura 161). Uma vez que os aditivos foram incorporados ao fibrocimento, sem a remoção de água livre, a umidade total da manta fresca foi maior na região tratada, aumentando a porosidade total. 


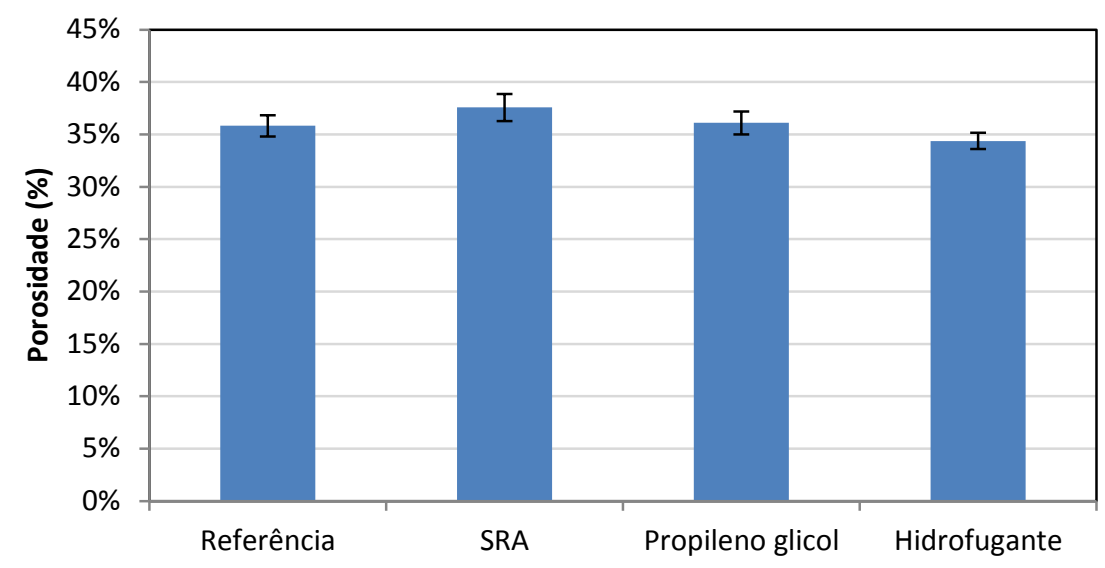

Figura 161 - Porosidade dos fibrocimentos tratados com modificadores da movimentação higroscópica (SRA, propileno glicol, hidrofugantes)

O aditivo SRA altera a cinética de hidratação, retardando as principais reações de hidratação do cimento (Figura 166). No entanto, nas amostras estudadas este efeito na hidratação do cimento não se refletiu em alterações significativas nas propriedades mecânicas do fibrocimento. As curvas médias de tensão $X$ deformação têm perfil muito parecido (Figura 162), apesar da dispersão dos resultados. Os índices calculados a partir do ensaio de flexão, como o MOR, LOP (Figura 164) e energia específica (Figura 165) não se alteraram com a aplicação de SRA.

O propileno glicol atua da mesma forma que o aditivo SRA, retardando as reações de hidratação do cimento. No teor aplicado neste estudo, foi observada uma redução na resistência máxima à flexão, como diminuição de $8 \%$ no MOR. O LOP foi determinado a partir da curva média apresentada na Figura 163.a, e representa a carga máxima do trecho elástico da curva tensão $X$ deformação. Para esta amostra, a identificação do LOP é fácil, com clara distinção entre o término do trecho elástico e início do trecho de deformação permanente. Em comparação com o LOP da amostra de referência, a aplicação de propileno glicol reduziu em 32\% este índice, no entanto, no caso da curva tensão X deformação da amostra de referência, o trecho definido como elástico apresenta uma curvatura que dificulta a determinação do LOP (Figura 162.a). Adotou-se como LOP a resistência de 7,26 MPa, que indica o ponto mais nítido de mudança de inclinação da curva, que caracteriza o LOP. No entanto, a curva permite uma segunda interpretação, com LOP na ordem de 4,3 MPa em ponto onde há uma discreta mudança na inclinação da curva. 
O hidrofugante reduziu consideravelmente a resistência máxima a flexão, com diminuição do MOR de 7,26 para 5,01 MPa (Figura 164). Além de ter influenciado na maneira como a matriz cimentícia adere nas fibras de reforço com a redução do MOR, o hidrofugante também reduziu o LOP, indicando que reduziu também a resistência da matriz, melhor representado por este índice (Figura 164).

Nas amostras onde a resistência à flexão foi menor que a amostra de referência, a energia específica, que é a área sob o gráfico de tensão X deformação (Figura 162 e Figura 163), também decresceu (Figura 165), o que indica que estas amostras têm menor tenacidade.

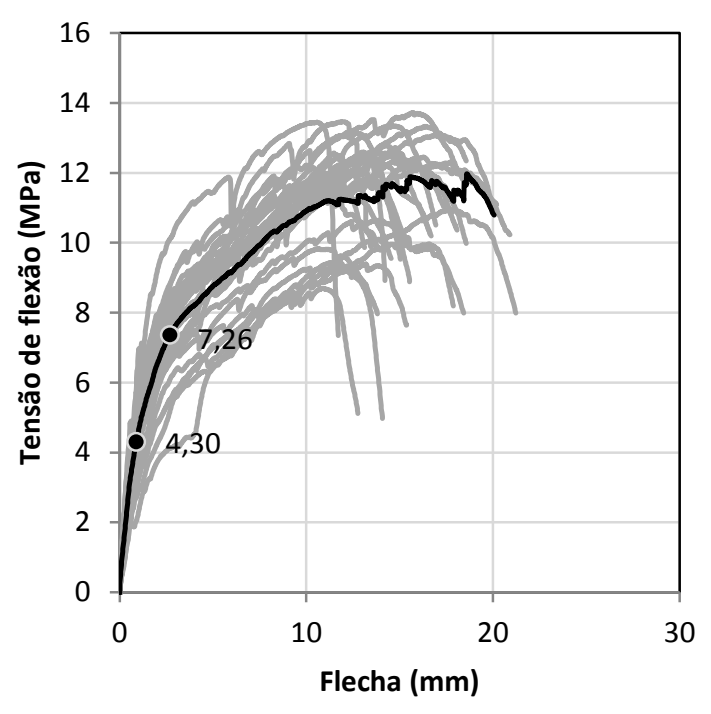

(a)

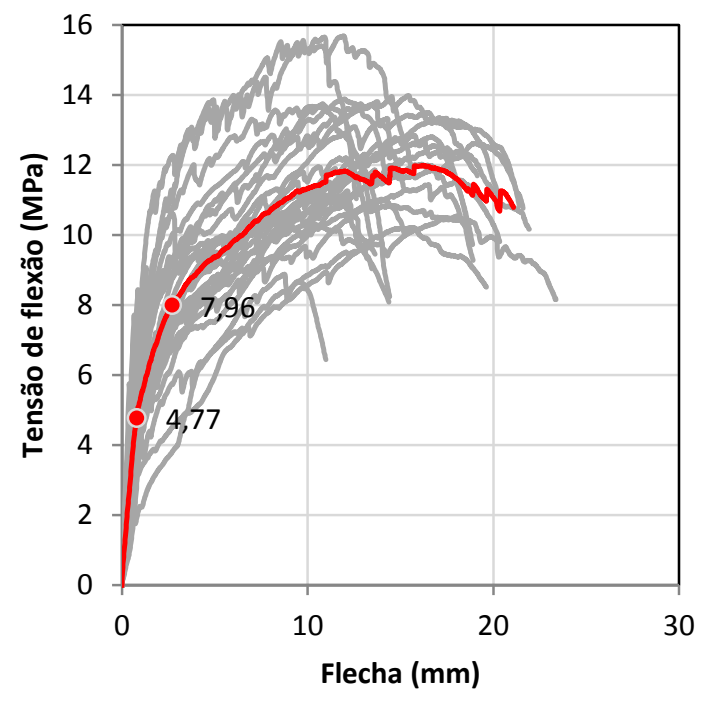

(b)

Figura 162 - Curvas tensão-deformação. (a) Amostras de referência e (b) com aplicação de SRA 


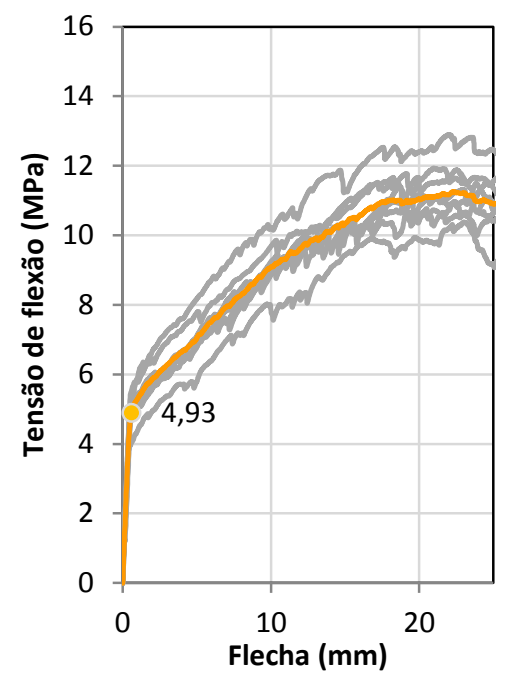

(a)

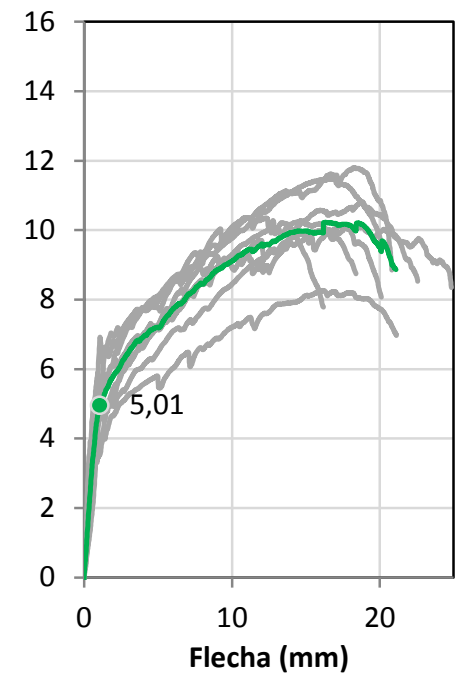

(b)

Figura 163 - Curvas tensão-deformação. Amostras de fibrocimento com aplicação de (a) propileno glicol, (b) hidrofugantes

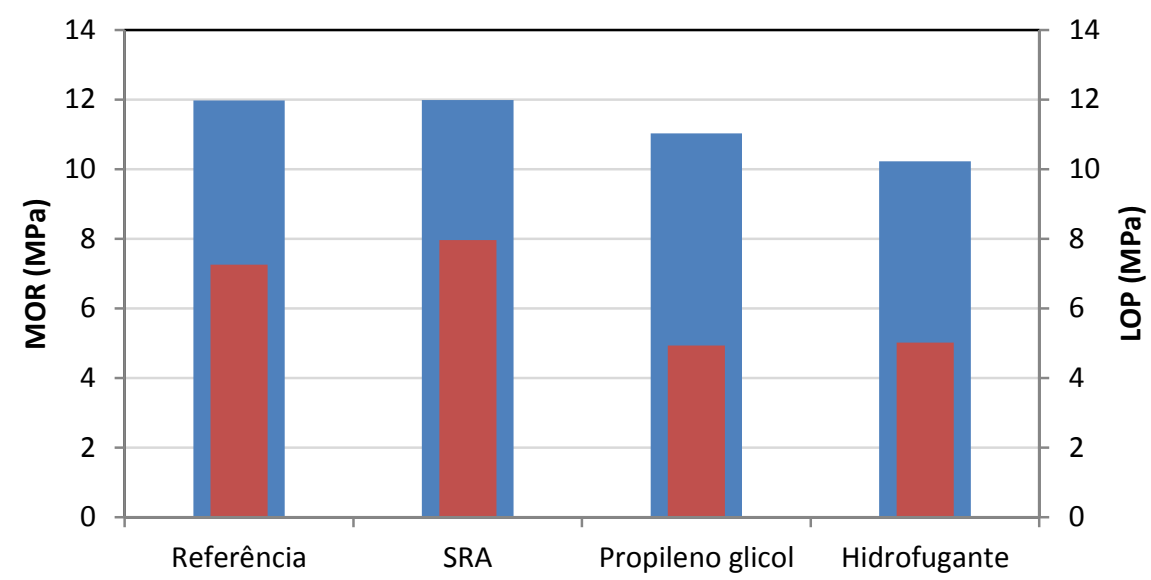

Figura 164 - Propriedades mecânicas (MOR e LOP) dos fibrocimentos tratados com modificadores de movimentação higroscópica (SRA, propileno glicol, hidrofugantes)

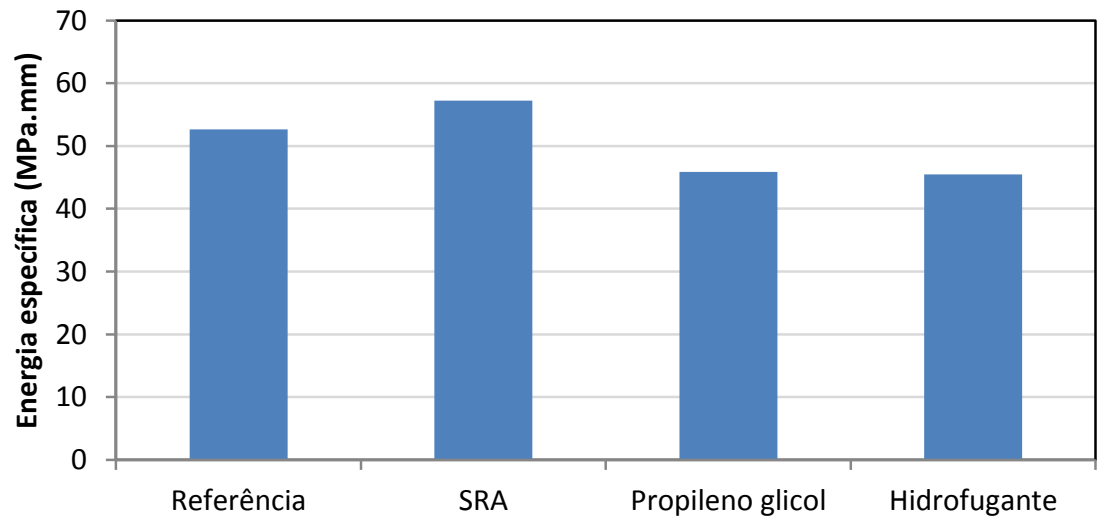

Figura 165 - Energia específica dos fibrocimentos tratados com modificadores de movimentação higroscópica (SRA, propileno glicol, hidrofugantes) 


\subsubsection{Efeito do tratamento com SRA na redução da retração do} fibrocimento produzido industrialmente

O tratamento com SRA reduziu em grande escala a retração do fibrocimento, sem alterar as propriedades mecânicas do mesmo. Embora não tenha modificado a resistência mecânica do fibrocimento, o SRA altera a cinética de hidratação do cimento. A Figura 166 mostra que as reações de hidratação do cimento ocorrem em menor velocidade com o aumento da quantidade de SRA misturado. No teor de $6 \%$, valor aplicado no teste realizado na indústria, a velocidade de formação do C-S-H diminuiu $41 \%$, e o tempo em que o C-S-H começou a ser formado, que tem relação com o tempo de início de pega do cimento, ocorreu quase $1 \mathrm{~h} 45 \mathrm{~min}$ depois da amostra de referência (Figura 167). Estas influências do SRA na cinética de hidratação são grandes, sendo observada também uma redução no calor acumulado após 72 horas de hidratação (Figura 166.b). No entanto, é possível que após 28 dias, as reações químicas tenha se equiparado, e por este motivo a resistência mecânica nesta idade não foi prejudicada.

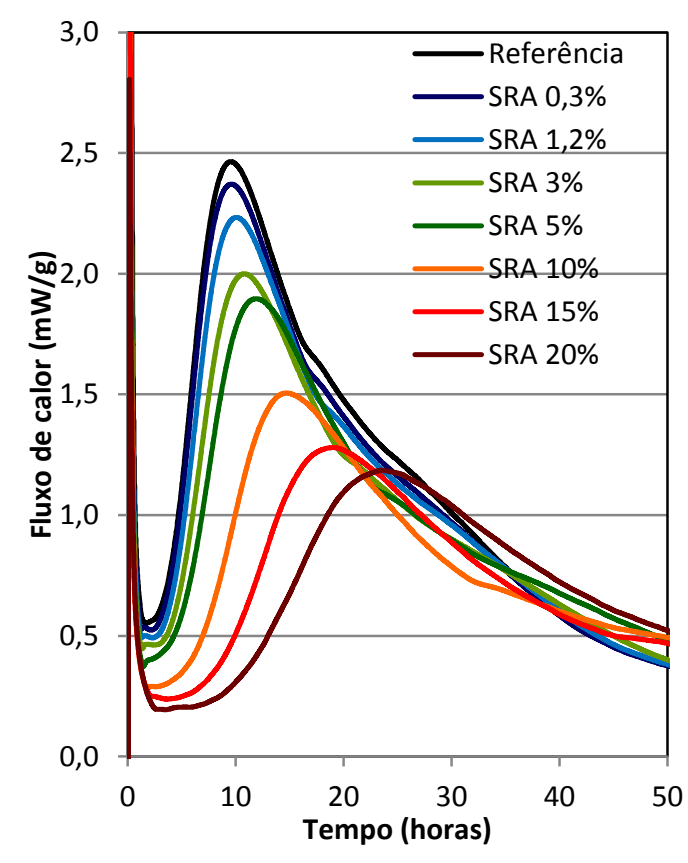

(a)

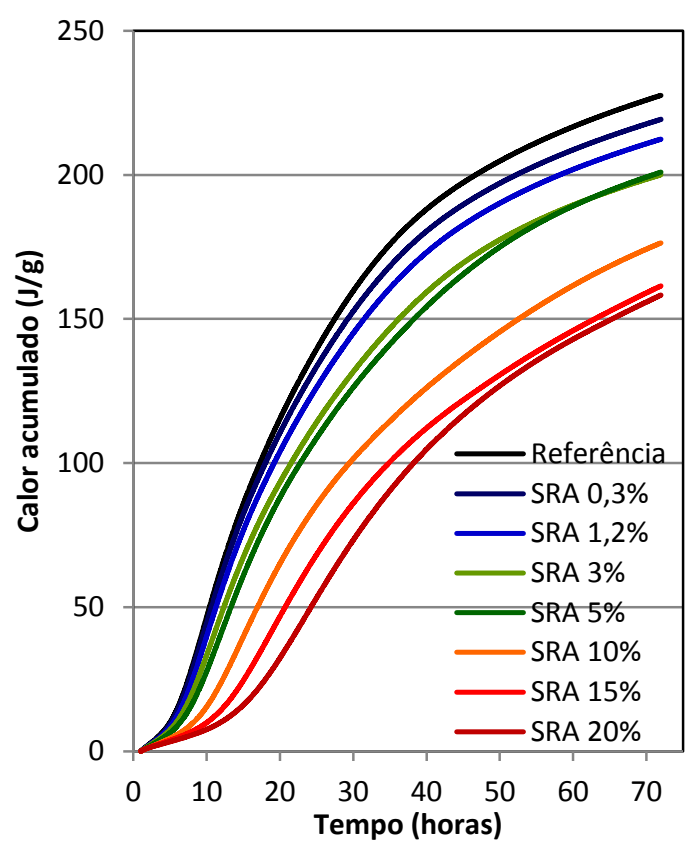

(b)

Figura 166 - Efeito do teor de SRA na cinética de hidratação do cimento 


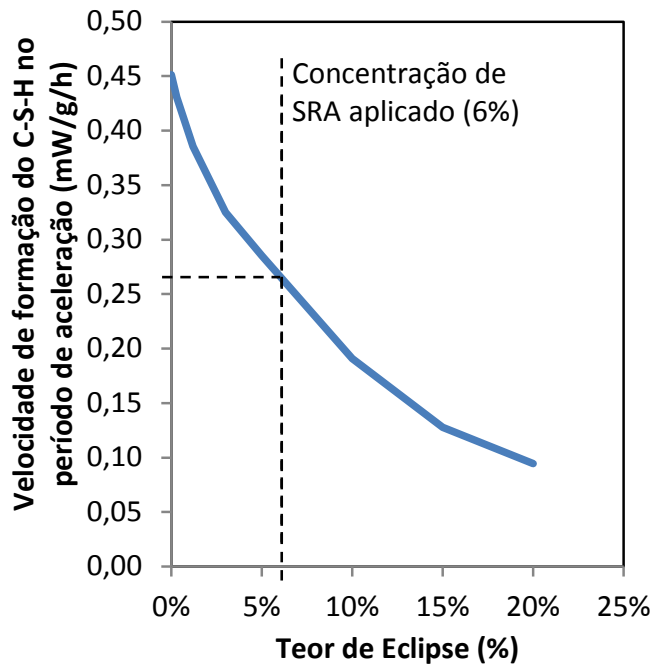

(a)

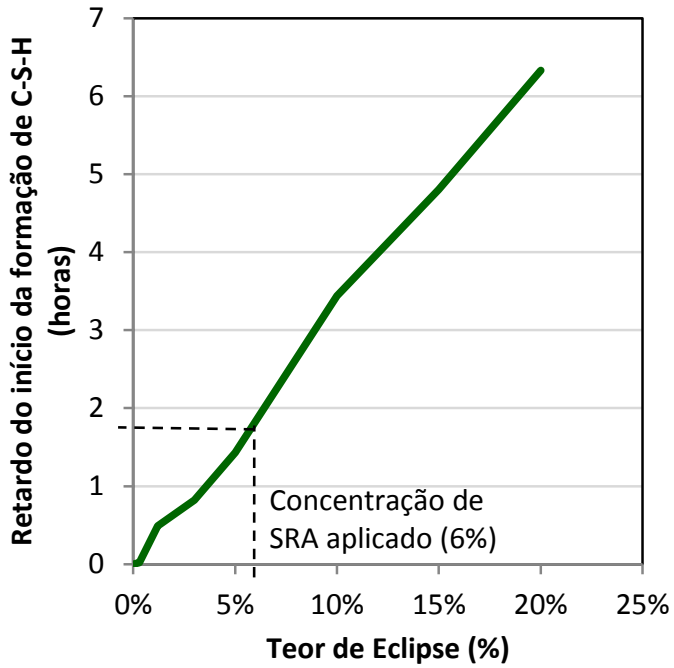

(b)

Figura 167 - Efeito do teor de SRA na (a) velocidade de formação do C-S-H e no (b) tempo de início da formação de C-S-H durante a hidratação do cimento

O efeito da aplicação de SRA na retração por secagem de telhas produzidas industrialmente, primeiramente foi monitorado a partir da medida da retração na borda de telhas expostas à secagem. Neste teste, buscou-se expor a telha sob as mesmas condições de restrição de secagem a que estas são submetidas quando empilhadas, de modo a criar a condição de secagem diferencial. A determinação da retração por secagem na borda das telhas foi medida a partir de $3 \mathrm{~mm}$ da sua extremidade, até a crista da primeira onda, a $62 \mathrm{~mm}$ da extremidade. Os resultados expostos na Figura 168 mostram que a velocidade da retração não se alterou, independente da distância para a borda. No entanto, a retração final aos 14 dias de secagem foi diferente entre a extremidade e a primeira crista da telha, comprovando a ocorrência da retração diferencial em função da secagem mais rápida na borda do que na região central da telha. Para a amostra de referência a retração na crista foi de $2,60 \mathrm{~mm} / \mathrm{m}$, enquanto que na borda foi de $2,71 \mathrm{~mm} / \mathrm{m}$ (Figura 169). A aplicação de SRA foi efetiva na redução da retração na borda da telha, que foi de $2,12 \mathrm{~mm} / \mathrm{m}$ na borda (redução de 22\%).

Estas medidas da retração indicam uma variação volumétrica restringida, uma vez que todo o miolo da telha não está retraindo, pois não ocorre secagem nesta região. Por este motivo, os valores de retração apresentados são inferiores aos determinados em corpos-de-prova livres, expostos nos capítulos anteriores. Em laboratório, normalmente a retração restringida é avaliada em testes específico onde 
é determinada a tensão gerada devido à retração, em situações onde a amostra encontra-se sob restrição (Veiga; Velosa; Magalhães, 2006).

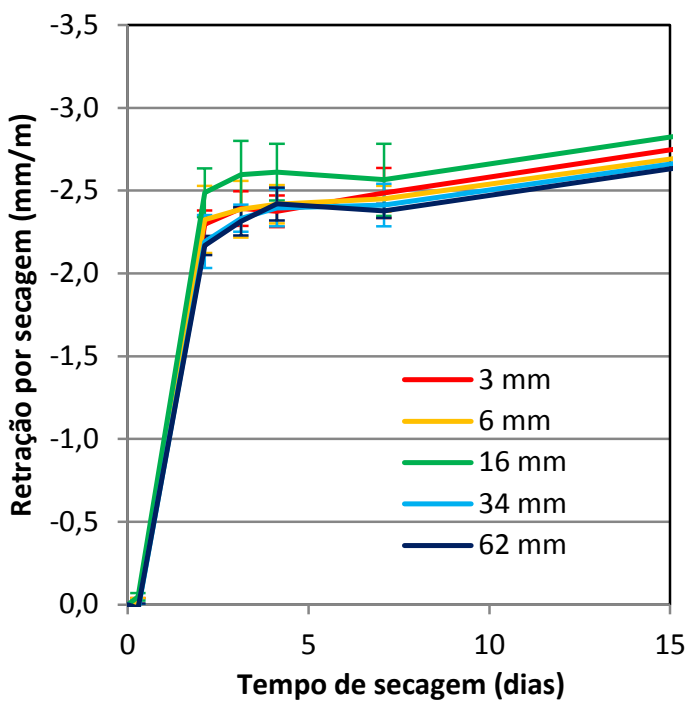

(a)

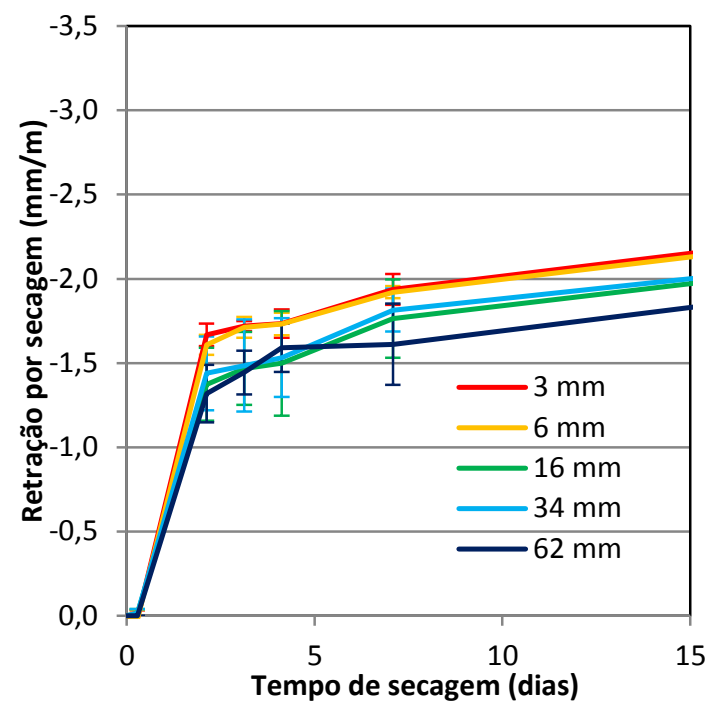

(b)

Figura 168 - Retração por secagem na região da borda de cobertura de telhas de fibrocimento. (a) Amostra de referência e (b) com aplicação de SRA

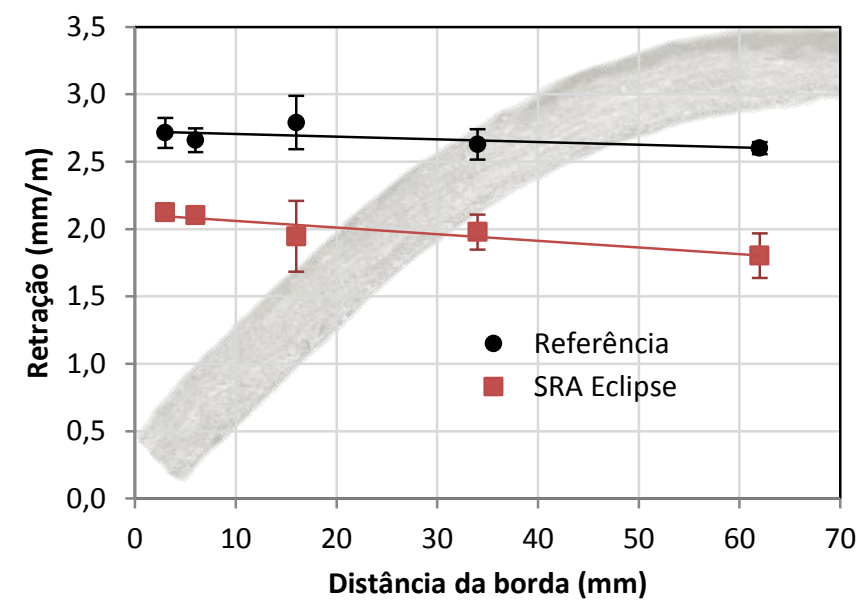

Figura 169 - Retração aos 14 dias de secagem medida na borda de cobertura de telhas de fibrocimento de referência e com aplicação de SRA, em função da distância da borda

O aditivo SRA reduz efetivamente a retração por secagem do fibrocimento, como comprovado nos testes em corpos-de-prova e nas medições nas telhas. No entanto, esta solução tem potencial para aplicação industrial somente no caso de reduzir também a manifestação patológica resultante da retração, que é a fissuração de borda. Para avaliar a eficiência do aditivo SRA na suscetibilidade à fissuração, foi realizada a contagem da quantidade de fissuras em telhas expostas ao tempo. 
Nos 3 montes de telhas onde não houve nenhum tratamento para redução da fissuração (referência), a quantidade de fissuras após 6 meses de exposição foi muito superior ao observado nos montes com a borda tratada com SRA. A quantidade de fissuras que apareceram nas bordas das telhas foi de aproximadamente 560 fissuras por monte de 90 telhas, o que equivale a mais de 6 fissuras por telha após 6 meses de exposição. Em contrapartida, nos montes com aplicação de SRA a quantidade de fissuras nesta região foi de aproximadamente 180 fissuras por monte (redução de 67\%).

Quando a análise é feita em função da quantidade de telhas fissuradas, observase que após 6 meses de exposição quase todas as telhas expostas apresentam fissuras, sendo que das 270 telhas expostas, 255 apresentaram fissuras. Enquanto isso, no caso das telhas tratadas com SRA, observou-se que $41 \%$ das telhas expostas apresentaram fissuras.

A evolução da quantidade de fissuras nas telhas expostas cresceu linearmente com o tempo, como mostra a Figura 170. Considerando a quantidade total de fissuras observadas, a redução da fissuração total foi de $67 \%$, enquanto que a redução na quantidade de telhas fissuradas foi de $57 \%$ quando foi aplicado SRA na borda de cobertura (Figura 170).

Estes valores apresentados foram calculados considerando apenas 2 montes de telhas com aplicação de SRA (montes SRA1 e SRA2), uma vez que foi detectada uma falha na aplicação do produto durante a produção do terceiro monte submetido ao tratamento (monte SRA3). A quantidade de SRA aplicado nas telhas deste monte foi menor, provavelmente por uma menor vazão de produto no momento da aplicação. Durante o período de exposição das telhas, foram coletadas amostras da borda de telhas de referência e de telhas com SRA aplicado, para a análise da concentração de SRA presente. Estes testes foram realizados pela Grace Construction, fabricante do aditivo SRA utilizado, através da técnica de cromatografia líquida de alta eficiência $\left(\mathrm{HPLC}^{21}\right)$, que é uma técnica cromatográfica utilizada para separar as fases de compostos com a finalidade de identificar, quantificar ou purificar os componentes individuais desta mistura. Os resultados mostraram que a concentração de SRA ativo nas amostras do monte SRA3 foi

\footnotetext{
${ }^{21}$ High-performance liquid chromatography
} 
apenas $36,8 \%$ da concentração total aplicada nos demais montes de telhas (Tabela 26).

Tabela 26 - Quantidade de SRA ativo presente na borda das telhas expostas, por HPLC

\begin{tabular}{lc} 
Amostra & Quantidade de SRA ativo (\%) \\
\hline Montes SRA1 e SRA2 & $0,76 \pm 0,01$ \\
Monte SRA3 & $0,28 \pm 0,02$ \\
Montes R1, R2 e R3 & nd
\end{tabular}

Os resultados do acompanhamento da fissuração ao longo do tempo de exposição mostraram que em baixa concentração o SRA não foi eficiente na redução do surgimento de fissuras, através dos resultados do total de fissuras e total de telhas fissuradas após 6 meses de exposição. A quantidade total de fissuras no monte SRA3 foi 3,6 vezes superior à média de fissuras que surgiram nos montes SRA1 e SRA2. Desta forma, nos cálculos médios da quantidade de fissuras, considerou-se que o monte com baixo teor de SRA não representa a condição de tratatamento com SRA.

A Figura 170 mostra a evolução da fissuração das telhas expostas em função do tempo de exposição. Estes resultados mostram que após 28 dias de exposição, data da primeira leitura de fissuração, a quantidade de telhas fissuradas nas amostras de referência já foi grande, com um terço das telhas fissuradas (Figura 170.b). Em contrapartida, as telhas tratadas com SRA apresentaram quantidade bastantes reduzida de fissuras, com média de 4,5 fissuras por monte, com total de $4 \%$ das telhas fissuradas. Aos 92 dias de exposição, mais de $80 \%$ das telhas de referência já apresentaram fissuras, contra $23 \%$ de telhas fissuradas nas telhas com SRA. Como as telhas não ficaram protegidas da ação do $\mathrm{CO}_{2}$ do ar, uma vez que ficaram expostas ao meio ambiente, soma-se ao efeito da retração por secagem como causa da fissuração das telhas, a retração diferencial por carbonatação. 


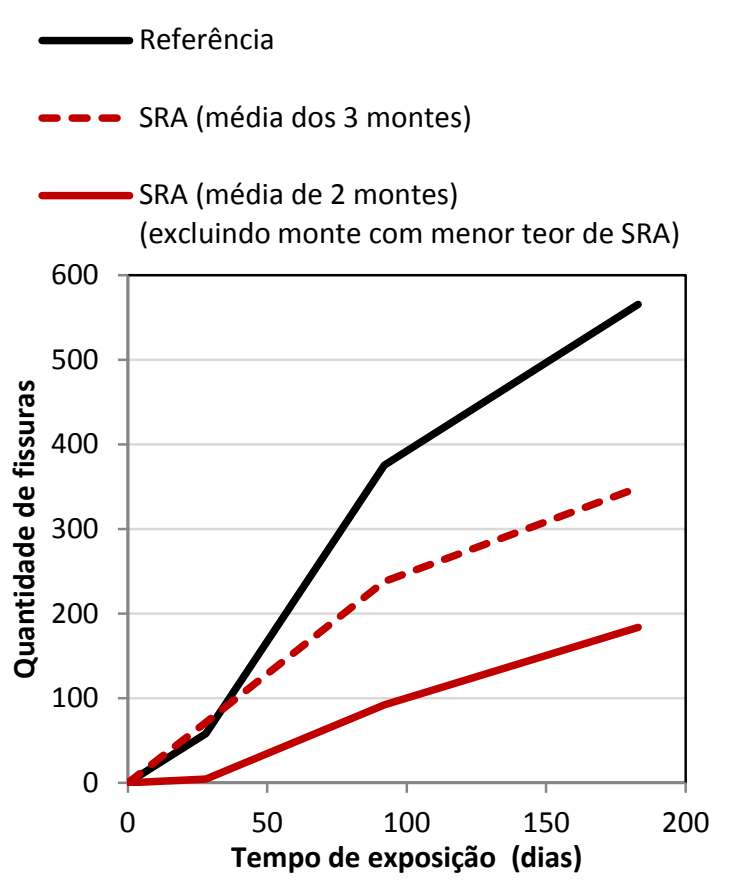

(a)
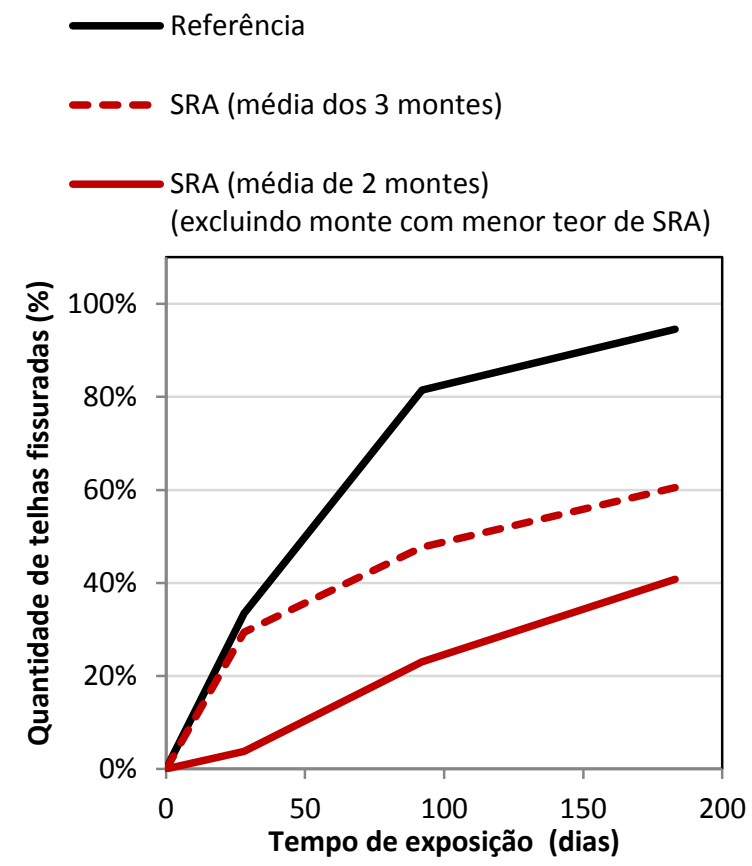

(b)

Figura 170 - Quantidade de fissuras existentes na borda de cobertura de telhas de fibrocimento de referência e com aplicação de SRA, durante 6 meses de exposição. (a) Pilhas em exposição e (b) média das pilhas em exposição

O efeito do tratamento com SRA na fissuração do fibrocimento foi realizado com o acompanhamento do aparecimento de fissuras nos montes expostos, enquanto que o efeito do SRA na retração por secagem foi estudado em corpos-de-prova. Nestes dois experimentos às solicitações as quais o fibrocimento é submetido são diferentes. Os corpos-de-prova ensaiados à retração por secagem foram expostos a condições controladas e constantes de meio ambiente, a $23^{\circ} \mathrm{C}$ e com umidade relativa do ar de 50\%, que é o nível de umidade mais crítico para a ação de tensão capilar; a retração medida é livre de restrições; a secagem é uniforme; o equipamento de medida é de precisão; entre outras condições específicas. Em contrapartida, as telhas empilhadas ao meio ambiente foram expostas a condições naturais de temperatura e umidade, que variaram constantemente, desde dias muito secos comuns na época em que o teste foi realizado, até dias de chuva. Estes ciclos de molhagem e secagem alteram a retração total do fibrocimento, além de inferir efeitos de cristalização de sais que favorecem a fissuração. A região da borda da telha empilhada está sob restrição de movimentação, além da retração ser diferencial na borda e centro da telha, devido à secagem diferencial; o efeito da carbonatação diferencial entre a borda e o centro também favorecem a carbonatação; quando empilhadas, as telhas sofrem solicitações devido ao 
carregamento gerado pelo peso próprio das telhas, que podem favorecer a abertura das fissuras, com influência do posicionamento dos apoios dos montes, além de outras condições específicas. Apesar destas diferenças nas condições de ensaio, a retração por secagem apresentou correlação com a fissuração das telhas de fibrocimento testadas.

\subsection{Conclusões}

Este capítulo da tese mostra as estratégias de alteração na movimentação higroscópica ocorrida no fibrocimento para a redução da retração por secagem, pode ser eficaz na mitigação da fissuração das telhas de fibrocimento NT, com comprovação em teste realizado industrialmente.

Sobre os resultados e discussões acerca do efeito da alteração na movimentação higroscópica, e mais detalhadamente na redução da tensão superficial da agua do poro do fibrocimento na redução da retração e fissuração das telhas onduladas, as conclusões deste capítulo foram:

- A manipulação da movimentação higroscópica do fibrocimento é uma forma eficaz de reduzir a retração deste compósito. A redução da tensão superficial da água do poro certamente diminuiu a tensão capilar causadora da retração, pois esta diminuiu significativamente quando aplicado aditivo SRA nos fibrocimentos;

- Para que a redução da tensão superficial na água do poro se reflita em diminuição da retração por secagem, a eficiência do produto aplicado tem que ser elevada mesmo quando diluído, visto que há muita água nos poros do fibrocimento que se misturam com o produto;

- O aditivo SRA mostrou-se como uma boa solução na redução da retração, o que se refletiu em redução a fissuração medida nas telhas expostas. A redução da fissuração ocorreu na mesma proporção da redução da retração, indicando a correlação direta desta causa e efeito;

- A utilização de hidrofugante misturado à água do poro não apresentou redução na retração por secagem, uma vez que não se garantiu que este produto atuou nos poros capilares, alterando o ângulo de contato da água com as paredes dos poros. 


\section{Capítulo VII}

\section{ANÁLISE SistêMICA}

A retração por secagem é um fenômeno muito estudado em concreto e argamassas, pois é importante na causa de fissuração destes compósitos. No caso do fibrocimento, também há estudos sobre o assunto, mas a abordagem isolada dos diferentes tipos de retração classificados no meio científico dificulta conclusões mais amplas sobre o tema, dificultando também as ações práticas no sentido de mitigar esta manifestação patológica importante, que é a fissuração.

Com a motivação de estudar as causas primárias da retração por secagem, mas também com intuito de trazer inovação tecnológica no sentido de mitigar os efeitos da retração por secagem na fissuração das telhas onduladas de fibrocimento NT, os capítulos desta tese estão relacionados com estratégias passíveis de serem aplicadas industrialmente, no sentido de reduzir a retração por secagem deste material cimentício, como mostra a Figura 171.

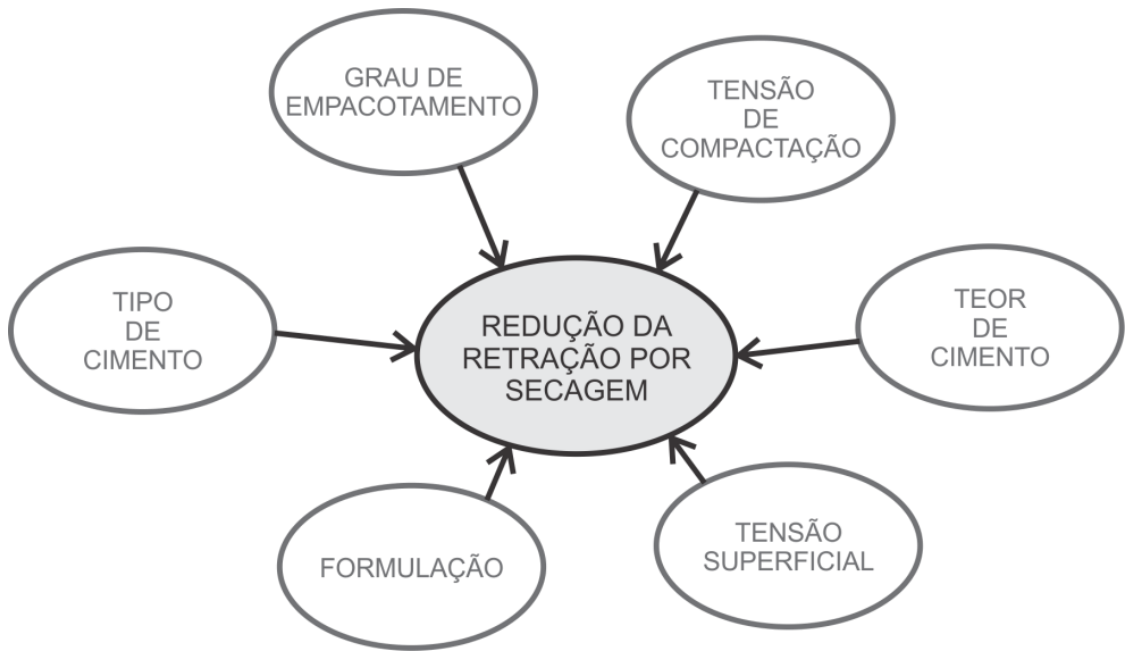

Figura 171 - Estratégias para a redução da retração por secagem no fibrocimento NT 
O fibrocimento é um material de construção poroso cujas características o tornam muito suscetível à retração por secagem. Sua geometria favorece a secagem, uma vez que a área da superfície dos artefatos de fibrocimento é grande em relação ao volume, devido sua pequena espessura. Uma telha ondulada de

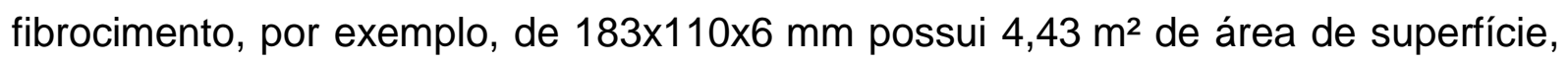
para um volume de $0,013 \mathrm{~m}^{3}$ de fibrocimento. Por este motivo as curvas de secagem apresentadas mostraram a grande velocidade de perda de água, com situações onde em 2 dias, mais de $90 \%$ de toda a água evaporada em todo 0 período de secagem já havia sido perdida. Na maioria dos experimentos, após 5 dias de secagem a perda de massa já estabilizou.

O diagrama de retração por secagem apresentado na Figura 37 é a representação da cinética de retração dos fibrocimentos NT reforçados com fibra de PVA produzidos industrialmente. Estes dados apresentam grande robustez, uma vez que são representativos de uma unidade industrial de produção de telhas onduladas de fibrocimento, em cadência normal de produção. A quantidade de dados associada com o período de coleta permitem que seja observada a variação possível da retração por secagem deste tipo de fibrocimento, sob as diversas influências que envolvem este processo produtivo. Há várias hipóteses para a origem da retração por secagem, como alguns dos parâmetros de processo programados industrialmente, o manejo dos artefatos após a sua produção, além das matérias-primas que o compõe e condições de exposição. A ação conjunta destes diversos fatores simultaneamente resulta em fibrocimentos com valores de retração por secagem que variam em um intervalo de $2 \mathrm{~mm} / \mathrm{m}$, entre aproximadamente 1,5 e $3,5 \mathrm{~mm} / \mathrm{m}$. Fibrocimentos com retração por secagem na parte inferior deste intervalo podem ter bom desempenho sem o surgimento de fissuras, enquanto outros podem sofrer grande tensão interna para os níveis mais altos de retração, resultando em grande quantidade de fissuras.

Fatores que influenciam na retração por secagem do fibrocimento

As amplitudes dos resultados de retração alcançados nos estudos mostram que as estratégias adotadas têm influência na retração por secagem, podendo alterar esta propriedade dentro de um intervalo de até $1,2 \mathrm{~mm} / \mathrm{m}$, que foi o caso da variação do teor de fibra de celulose (Figura 172), o que relevante em comparação com o intervalo de retração obtido no diagrama de retração por secagem, que foi de 
$2 \mathrm{~mm} / \mathrm{m}$. Estas estratégias envolvem os materiais constituintes, com a variação das suas quantidades e propriedades físico-químicas do cimento, e uso de adições minerais; e ações industriais no processo de fabricação, como a compactação da manta fresca, ou a aplicação de aditivo redutor de tensão superficial.

Com relação às estratégias que envolvem os materiais constituintes do fibrocimento, observou-se que todos os materiais que compõe a matriz cimentícia têm o mesmo potencial de alteração da retração, uma vez que atuam basicamente na mudança da distribuição de tamanho de poros da matriz cimentícia. As adições minerais de modo geral propiciam um refinamento de poros, com diminuição da faixa de poros presente em maior quantidade no fibrocimento (faixa entre 2,33 e 0,03 $\mu \mathrm{m}$ de diâmetro), que são poros grandes, mas que contribuem para a retração final. No entanto, este refinamento de poros também é composto por um aumento da faixa de poros que mais sofrem tensão capilar na secagem, que são os mesoporos e a interface entre os mesoporos e os poros de gel. Por este motivo é que a retração em geral aumenta quando se adiciona sílica, pozolana ou escória.

Por ser a matéria-prima mais consumida, o cimento também tem forte influência na retração, especialmente pelo fato das propriedades dos diferentes cimentos também variar muito. Desta forma, não foi possível identificar uma propriedade isolada do cimento que influenciasse diretamente e predominantemente na retração. Isto ocorreu uma vez que, ao se alterar o tipo de cimento, mais de uma variável com potencial de alteração da retração está sendo inferida ao estudo, como:

- Efeito do tamanho de partículas no empacotamento;

- Quantidade de C-S-H formado, que varia em função do ter de clínquer do cimento;

- Efeito da adição mineral incorporada ao cimento, uma vez que a escória favorece a retração (Giordano et al., 2009), diferente do calcário;

- $\quad$ grau de hidratação devido à velocidade de hidratação.

Quando se varia somente o teor de um mesmo tipo de cimento, esta variável influencia as propriedades do fibrocimento de duas formas: primeiro a falta de cimento nos menores teores gera grande quantidade de defeitos (não causa retração), além de aumentar também o volume de macroporos e mesoporos (se 
reflete em retração); e em paralelo ocorre um aumento na quantidade dos poros de gel, que são referentes à maior quantidade de C-S-H presente, no entanto, esta faixa de poros não sofre a ação da tensão capilar, pois são de difícil secagem quando expostos em ambiente com umidade relativa do ar de 50\%. O grande consumo de cimento acaba por gerar grande volume de C-S-H na matriz cimentícia, no entanto, a porosidade gerada entre as lamelas do C-S-H não é a causadora da retração, pois esta tem dimensão da ordem de $1 \mathrm{~nm}$ (Mehta et al., 2008). Na umidade relativa adotada na secagem nos experimentos realizados nesta tese (UR $50 \%$ ), os poros das lamelas do C-S-H não sofrem a ação de pressão capilar, pois estes se encontram saturados. A partir das equações de Kelvin e Laplace, o diâmetro do poro condensável para a umidade relativa de $50 \%$ equivale a $1,55 \mathrm{~nm}$. As lamelas do $\mathrm{C}-\mathrm{S}-\mathrm{H}$ só passarão a sofrer secagem em níveis mais baixos de umidade relativa entre 15 e 35\% (Sato, 1998), e em contrapartida nestes níveis de umidade os microporos e poros de gel, não possuem mais uma fase contínua de umidade de modo a formar meniscos e por consequência retração por mecanismo de depressão capilar (Baroghel-Bouny, 2007b; Taylor, 1997).

As fibras vegetais de celulose apresentaram forte influência na retração, pois além de aumentarem a quantidade de defeitos (faixa de poros tipicamente formada devido à incorporação de fibras de celulose), também aumentaram a quantidade de poros entre 2,33 e 0,03 $\mu \mathrm{m}$ (macroporos e parcela de mesoporos), que causam retração. A fibra de celulose é um retentor de água, adicionado na formulação com esta função específica de retenção de água e finos, necessária para o bom funcionamento do processo Hatschek. Da mesma forma o aumento da umidade da manta fresca se reflete diretamente no aumento da porosidade do compósito. Os resultados mostraram que a retração apresentou correlação direta com a porosidade. As fibras poliméricas têm função de reforço da resistência mecânica do fibrocimento. Estas fibras não influenciam, teoricamente, nas propriedades da matriz cimentícia, que é fase do fibrocimento responsável pela retração por secagem, pois é a fase porosa. Os resultados mostraram que o alto consumo de fibras gera um aumento discreto na porosidade total, sem uma tendência clara na distribuição de tamanho de poros. Em função disso, a retração por secagem variou pouco mesmo dobrando o teor de fibras no compósito, aumentando até $0,26 \mathrm{~mm} / \mathrm{m}$. A principal atuação destas fibras nos efeitos da retração por secagem, não foi 
efetivamente na variação volumétrica do compósito, mas será na redução da propagação das fissuras, por ação mecânica no compósito, evitando o colapso. Esta conclusão é baseada no acréscimo de $25 \%$ no MOR e mais de $30 \%$ na energia específica do fibrocimento.

Outras estratégias envolvem ações industriais no processo de fabricação do fibrocimento, como a aplicação de carga de compactação na manta fresca, ou ações de cura dos artefatos de modo a manter a umidade relativa do ar em níveis elevados, ou ainda a aplicação de produtos que alterem a tensão superficial da água do poro. A aplicação de carga de compactação na manta fresca de fibrocimento resultou em diminuição da retração por secagem, pois além de reduzir grandemente os defeitos (não influem na retração), também reduziram proporcionalmente as quantidade de todas as faixas de poros, incluindo aquelas que causam retração (macroporos menores que 2,33 $\mu \mathrm{m}$ e mesoporos). A umidade de equilíbrio do material é função da umidade relativa do ar, de modo que ações de cura que mantenham a umidade do fibrocimento sempre elevada, manterão os níveis de retração reduzidos. Por fim, a aplicação de produtos que reduzam a tensão superficial da água do poro agem diretamente na diminuição da tensão capilar atuante dos poros, que é a causa primária da retração por secagem.

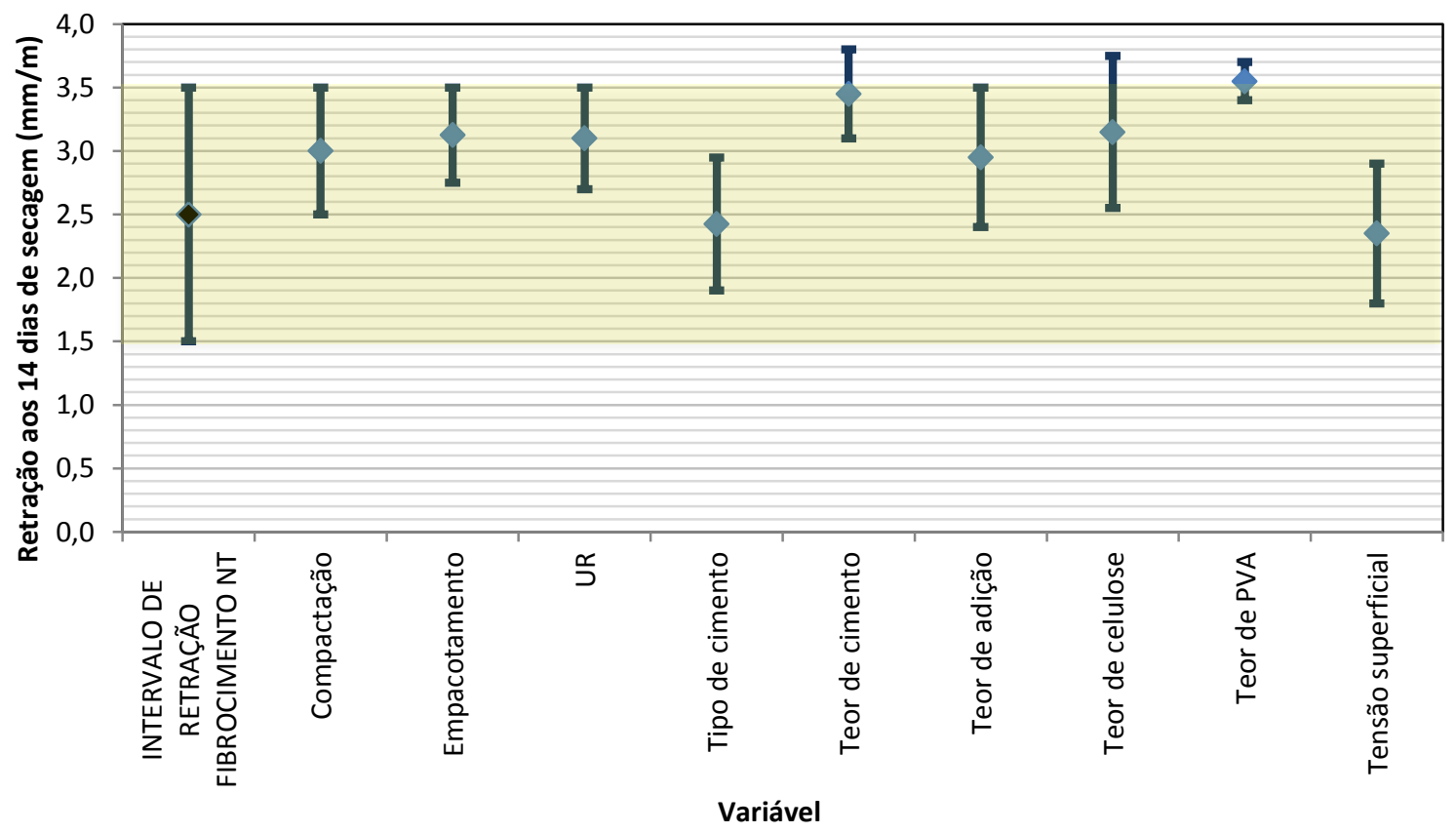

Figura 172 - Intervalo de variação da retração por secagem em função da estratégia aplicada pra a modificação das propriedades do fibrocimento 


\section{Cinética de retração do fibrocimento}

Do grande conjunto de dados que geraram o diagrama de retração por secagem (Figura 37) conclui-se que uma forma adequada de expor a cinética de retração por secagem do fibrocimento é através da relação entre retração e umidade do material. Desta forma é possível observar a retração máxima do material, a umidade de equilíbrio ao final do período de secagem e a suscetibilidade à retração, que é a inclinação da curva. Estes três parâmetros são função das propriedades do fibrocimento, especialmente a porosidade (incluindo a distribuição de tamanho de poros).

A retração máxima do fibrocimento é sem dúvida o valor mais importante a ser considerado, pois em função da sua magnitude será gerada a tensão interna no material, cujas consequências serão refletidas em fissuração do mesmo. A principal conclusão atingida foi que a retração máxima final é função dos 2 fatores:

- Umidade de equilíbrio;

- Cinética de retração (taxa de retração).

A umidade de equilíbrio indica qual é a mínima umidade a ser atingida pelo fibrocimento ao final da secagem. Como a retração ocorre devido à secagem, este índice tem influência direta na retração máxima. Influenciam na umidade de equilíbrio a distribuição de tamanho de poros do fibrocimento, uma vez que poros de tamanho muito reduzido, como os microporos e poros de gel; além das condições de exposição do material, como a umidade relativa do ar. A distribuição de tamanho de partículas pode ser influenciado pelo empacotamento de partículas das matériasprimas ou pelo teor e tipo de cimento utilizado, no sentido de aumentar o volume de poros de gel e microporos, onde os mecanismos de depressão capilar não atuam devido à dificuldade de secagem dependendo do nível de umidade relativa do ar. A carga de compactação da manta fresca durante a produção não tem eficiência na redução dos poros menores, atuando somente na diminuição da quantidade de poros muito grandes, maiores que os macroporos, cuja escala já não é mais capilar. A celulose, matéria-prima que tem grande influência na retração por secagem, tem pouca influência na umidade de equilíbrio, uma vez que os seus lúmens que geram 
porosidade no compósito têm grande dimensão, na escala dos defeitos e macroporos.

A taxa de retração, ou cinética de retração, indicada pela inclinação da curva retração $X$ umidade, indica a velocidade da ocorrência da retração para uma mesma velocidade de redução de umidade. Quanto maior esta taxa, maior será a magnitude da retração para um mesmo intervalo de variação de umidade do material. Este índice também influencia na retração máxima, e é um indicador da quantidade de poros suscetíveis a grandes tensões capilares na secagem, pois para pequenas variações de umidade, os materiais com grande taxa de retração sofrem grande variação volumétrica.

A causa primária da retração por secagem é a tensão capilar atuante nos poros durante a secagem. Este é o fundamento do mecanismo de depressão capilar. A equação de Laplace é o modelo que descreve como varia o nível de tensão capilar nos poros em função do seu tamanho, sendo possível estimar a sua magnitude, após fazer algumas simplificações e considerações. Associado à cinética de retração do fibrocimento e sua distribuição de tamanho de poros, observa-se que a perda de água inicial na secagem não causa retração (Figura 38). Estes resultados mostram que a secagem inicial ocorre predominantemente nos poros maiores, de diâmetro maior que $2,33 \mu \mathrm{m}$, cuja tensão capilar atuante é muito pequena. A quantidade de água evaporada nesta etapa de secagem é grande, equivalente à $9,8 \%$ do volume total do fibrocimento, ou aproximadamente $28 \%$ de toda a água contida em uma amostra saturada. Apesar do grande volume de água evaporada, esta secagem ocorre muito rapidamente, na primeira 1,5 hora de exposição a $50 \%$ de umidade relativa do ar.

A secagem que causa retração no fibrocimento pode ser dividida em duas etapas, sendo a primeira aquela que ocorre em poros relativamente grandes, os capilares grandes, ou macroporos, contendo uma parcela de poros capilares médios, os mesoporos. A tensão capilar atuante em poros deste tamanho não atinge os níveis mais elevados possíveis, mas esta é a faixa de poros presente em maior quantidade dentro do fibrocimento. Por este motivo, uma secagem que é equivalente à aproximadamente $54 \%$ de toda água presente em uma amostra saturada, resulta em grande retração final máxima do fibrocimento. Esta retração 
ocorre nas primeiras idades de secagem, entre 1,5 hora e 2 dias de exposição em ambiente seco, e resulta em valor em torno de $76 \%$ de toda a retração ocorrida.

O período final de secagem é lento, e o volume de água evaporada é pequeno, no entanto, a parcela de retração que ocorre nesta etapa de secagem é elevada, equivalente a aproximadamente $24 \%$ de toda a retração do material. Apenas $10 \%$ de toda a água presente em uma amostra saturada evapora no período final de secagem, no entanto, os poros que sofrem secagem neste período são predominantemente aqueles de tamanho capilar na ordem dos mesoporos, suscetíveis a grande tensão capilar na secagem.

A velocidade de secagem é um fator importante, que interfere na retração final do fibrocimento. Isto ocorre porque a secagem é um processo cuja força motriz é o equilíbrio de umidade entre o meio ambiente e os poros, e entre os diferentes poros que compõem a matriz. Ocorre que para atingir a condição de equilíbrio, é requerido um grande tempo, maior do que o tempo de secagem imposto nos testes de laboratório (Baroghel-Bouny, 2007b), e também na secagem por exposição no meio ambiente, dependendo dos parâmetros ambientais. Quando a secagem ocorre muito lentamente, com tempo suficiente para o equilíbrio da umidade no interior dos poros, a extensão contínua de água dentro da estrutura de poros da matriz é a maior possível com atuação de tensão capilar em todos os poros suscetíveis à formação de menisco. Em contrapartida, quando a secagem ocorre muito rapidamente, há secagem muito pronunciada em alguns poros, e a continuidade da fase líquida é quebrada, sendo esta necessária para a formação de menisco (Taylor, 1997) e ação do mecanismo de depressão capilar (Kovler et al., 2006). Os resultados mostraram que a redução na velocidade de secagem por variação progressiva da umidade relativa do ambiente resultou em aumento na retração por secagem final, mesmo em níveis de umidade muito baixos, como $20 \%$. No caso da secagem mais rápida, com exposição do fibrocimento diretamente em ambiente com umidade relativa de $20 \%$, a retração por secagem final foi muito menor. Isso ocorreu porque a continuidade da fase líquida por entre a estrutura de poros da matriz se quebrou, tornando instável a formação de menisco (Taylor, 1997). Isto equivale dizer que poros de dimensões capilares ficaram com umidade muito baixa, sem formação de uma fase líquida e outra gasosa, enquanto microporos permaneceram saturados. 


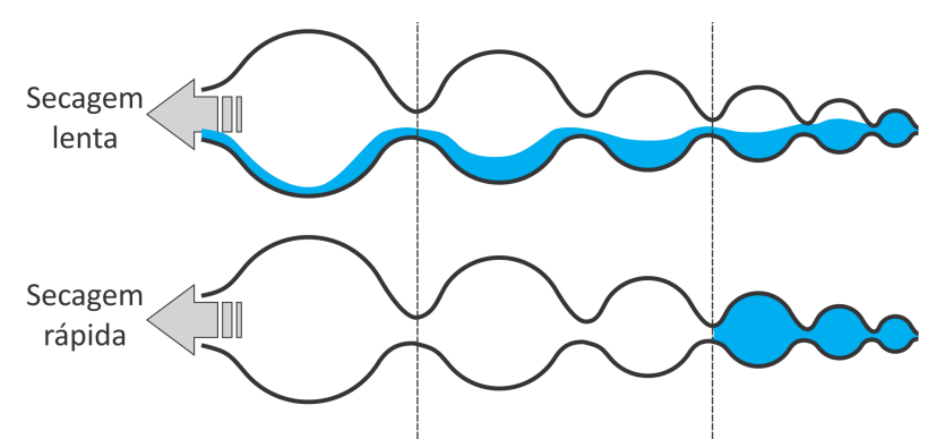

Figura 173 - Esquema destacando a fase líquida contínua formada quando a secagem é lenta

A fissuração de borda em telhas onduladas de fibrocimento - Ação da retração por carbonatação e ação da retração por secagem

O problema industrial enfrentado em vários países em fibrocimentos NT é a fissuração de borda das telhas onduladas. Não somente este tipo de fissuração, mas na maioria das vezes a variação volumétrica é a causa da ocorrência deste típico defeito. Uma vez estudados alguns fatores que influenciam na variação volumétrica deste compósito, podemos concluir que a redução da tensão capilar causadora de retração é uma estratégia em potencial para a redução da retração por secagem. Considerando que a parcela da retração por secagem é em torno de $2,5 \mathrm{~mm} / \mathrm{m}$, e equivale à metade da retração sofrida pelo fibrocimento durante a exposição ao meio ambiente, foi realizado o teste em campo onde se reduziu a tensão capilar que atua nos poros durante a secagem, e foi medido seu efeito na fissuração de borda. Esta estratégia aplicada no estudo de caso foi efetiva na redução da fissuração de borda das telhas de fibrocimento, com queda de $38 \%$ na retração, que se refletiu em redução de $37 \%$ na quantidade de fissuras nas bordas das telhas, ou redução de $57 \%$ na quantidade de telhas fissuradas.

Pelos mesmos motivos apresentados que justificam a elevada e rápida secagem do fibrocimento, servem de justificativa para sua grande suscetibilidade à reação de carbonatação. Este mecanismo, considerado de degradação no caso do concreto armado, envolve primeiramente a difusão do dióxido de carbono para o interior do material. Desta forma, a grande área de superfície dos artefatos, somado à grande porosidade, resultam em grande exposição dos compostos hidratados do cimento aos efeitos da reação química com o dióxido de carbono do ar. As condições ambientais típicas, somado ao alto consumo de cimento, completam a lista de fatores responsáveis pelo alto grau de carbonatação dos artefatos de fibrocimento 
expostos às intempéries. Em apenas 12 dias de exposição ao ambiente com dióxido de carbono, o fibrocimento retraiu aproximadamente $2,2 \mathrm{~mm} / \mathrm{m}$, com aumento de $18,2 \mathrm{~g}$ de $\mathrm{CaCO}_{3}$ para cada $100 \mathrm{~g}$ que compõem o fibrocimento. A retração por carbonatação tem magnitude alta, se configurando com uma parcela importante e muito relevante na retração total do material quando exposto às condições comuns de meio ambiente. Uma vez que uma importante motivação deste trabalho a busca de explicação do fenômeno de fissuração de borda nas telhas de fibrocimento empilhadas, a carbonatação ocorrida nesta condição de exposição potencializa a chance de aparecimento de fissuras nas bordas, uma vez que reúne dois fatores primordiais: retração diferencial entre a borda e o centro da telha e alta magnitude da retração por secagem. A retração diferencial ocorre tanto devido à maior dificuldade de difusão do dióxido de carbono até as regiões centrais das telhas, que estão sob condição confinada, além do grau de saturação dos poros nesta região, que pelo mesmo motivo, permanecem com elevada umidade por mais tempo que a borda. E como a difusão do dióxido de carbono é algumas ordens de grandeza menor na água do que no ar, a reação de carbonatação é retardada. Segundo (Neville, 1997), a difusão do dióxido de carbono na água é de $10^{4}$ a $10^{6}$ vezes menos que no ambiente. Os resultados em telhas expostas empilhadas mostraram que o somatório da retração permanente devido aos ciclos de molhagem e secagem, com a retração por carbonatação que é irreversível, foi uma retração acumulada durante o tempo de 25 meses de exposição de 1,22 mm/m. Fazendo um cálculo aproximado, aplicando a lei de Hooke, e considerando um módulo de elasticidade de $8000 \mathrm{MPa}$ para o fibrocimento produzido industrialmente, esta diferença no comprimento da telha entre a região central e a sua borda, causaria uma tensão de tração de $9,8 \mathrm{MPa}(\sigma=E \cdot \varepsilon=8000 \cdot 0,00122=9,8 \mathrm{MPa})$, que é inferior à tensão máxima à flexão do fibrocimento, que girou em torno de $12 \mathrm{MPa}$ (MOR), no entanto, é acima da resistência máximo no trecho elástico da curva tensão $X$ deformação, que representa o nível de resistência a partir do qual a matriz cimentícia rompe, com aparecimento de fissuras. 


\section{Capítulo VIII}

\section{ConClusões}

A retração por secagem em fibrocimento é um fenômeno multifatorial, ou seja, sofre a influência de diversos fatores inerentes aos materiais constituintes e processo produtivo.

A presente tese conclui ainda que a variação na retração por secagem de fibrocimento NT produzido pelo processo Hatschek é bastante grande, podendo variar em intervalo de $1,5 \mathrm{~mm} / \mathrm{m}$ a $3,0 \mathrm{~mm} / \mathrm{m}$ (intervalo de $80 \%$ em relação à média). Esta grande variabilidade é inerente ao material fibrocimento e ao seu processo produtivo, de modo que podem influenciar nestes valores fatores como: tipo (intervalo de $43 \%$ em relação à média) e quantidade de cimento (intervalo de $20 \%$ em relação à média); tipo e quantidade das demais matérias-primas (intervalo de $38 \%$ em relação à média); tamanho de partículas de todas as matérias-primas (intervalo de 24\% em relação à média); parâmetros de processo; entre outros. Este intervalo de variação indica que é possível produzir fibrocimento com baixo nível de retração por secagem apenas combinando os ajustes inerentes à atual tecnologia de produção.

A retração total no final do fibrocimento é função da umidade de equilíbrio do material e da cinética de retração. Diversos fatores podem influenciar na umidade de equilíbrio do material, como a quantidade de poros muito pequenos, ou os parâmetros ambientais de exposição (umidade relativa do ar). Estes mesmos fatores podem influenciar a cinética de retração.

A retração por secagem tem como influência a tensão capilar atuante nos poros de menor dimensão, que ocorre com a diminuição da umidade relativa do 
fibrocimento. A teoria de Laplace é atendida à medida que o volume de poros de menor dimensão contribui significativamente com a retração no fibrocimento.

Deste modo, os fatores primários causadores de retração em fibrocimento são:

- Sistema de poros;

- O contato entre a fase líquida e a fase sólida nos poros.

Quanto ao sistema de poros, a faixa de tamanho considerada capilar, pois sofrem alguma ação da tensão capilar que pode se refletir de retração em escala macroscópica, é aquela que compreende os mesoporos e a faixa dos poros capilares grandes (macroporos) inferior a 2,33 $\mu \mathrm{m}$. Os poros de gel são suscetíveis a grande tensão capilar, no entanto, devido ao seu reduzido tamanho, sua secagem é mais difícil de modo que sua influência na retração por secagem é mais sentida nos casos onde as condições de exposição são mais severas. Os mesoporos são aqueles que apresentam melhor correlação com a retração, com grande pressão capilar atuante nos níveis de umidade relativa em torno de $50 \%$. Os poros capilares grandes sofrem menor tensão capilar, mas por serem presentes em grande quantidade no fibrocimento, são responsáveis por grande parte da retração total, pois o fator escala aumenta a sua influência na retração por secagem.

Quanto ao contato da fase líquida com a fase sólida dos poros capilares, a redução da tensão capilar ou o aumento do ângulo de contato entre a fase líquida e sólida, reduzem a tensão capilar atuante no poro. Os resultados mostraram que a redução de aproximadamente $35 \%$ da tensão superficial da água do poro do fibrocimento reduz a retração em torno de $40 \%$.

Definidos os fatores primários que influenciam na retração por secagem, ações e estratégias adequadas podem ser adotadas no sentido de reduzir esta variação volumétrica e assim minimizar seus efeitos no surgimento de manifestações patológicas importantes do fibrocimento, como a fissuração de borda.

A redução da porosidade total, desde que acompanhada da redução de poros capilares, é uma estratégia com potencial de redução da retração, de modo que através do aumento da pressão de compactação do fibrocimento, ou ainda com a melhoria do empacotamento de partículas, o potencial de redução da retração foi de até $1,0 \mathrm{~mm} / \mathrm{m}$. 
Outras estratégias podem ser apontadas no sentido da redução da retração por secagem, como alterações na formulação. Neste caso, as variáveis envolvidas são diversas, que surtem na distribuição de tamanho de poros e contato da água do poro e paredes sólidas da matriz cimentícia. Alterações no tipo e teor de cimento, além dos teores de adições minerais e fibras, foram capazes de variar a retração em um intervalo entre $1,9 \mathrm{~mm} / \mathrm{m}$ a $3,8 \mathrm{~mm} / \mathrm{m}$.

A retração por carbonatação apresentou magnitude elevada, da mesma ordem de grandeza da retração por secagem, o que deve ser considerado nos resultados sobre retração de fibrocimento exposto ao ar. Esta grande influência se deu devido à elevada velocidade da reação de carbonatação, uma vez que a área de exposição dos elementos de fibrocimento é normalmente muito grande.

Por fim, diversos fatores influenciam da retração de fibrocimento NT, de modo que alterando alguns destes fatores conjuntamente, é possível reduzir bastante os níveis de retração, eliminando desta forma a ocorrência de manifestações patológicas nos artefatos, como a fissuração de borda. 


\section{Capítulo IX}

\section{Sugestões de Trabalhos Futuros}

A presente tese é um trabalho de pesquisa amplo, com muitos resultados, varrendo um leque grande de análises. Desta forma, a sugestão para trabalhos futuros é no sentido de realizar análises mais aprofundadas em cada uma das linhas de atuação expostas neste texto. Como sugestões para trabalhos futuros, podem ser listados os temas:

- Realização de trabalhos que abordem a pressão capilar como causa da retração, no entanto, com abordagem menos tecnológica e mais científica, com a determinação experimental das tensões capilares, por exemplo;

- Estudo do efeito das fibras na retração por secagem, tanto variando as fibras naturais orgânicas como as poliméricas. Neste caso sugere-se uma abordagem capaz de medir o efeito de restrição das fibras tanto na retração quanto na formação e propagação de fissuras;

- Estudar as alterações microestruturais da matriz cimentícia quando se muda a composição da fase ligante, dividindo dentro da formulação completa da matriz do fibrocimento quais componentes compõe a fase ligante (clínquer, adições que reajam quimicamente na hidratação), e quais compõe a fase inerte, cuja ação é melhorar o empacotamento;

- Realização de trabalhos que isolem as diversas variáveis apontadas nesta tese, como fator influente na retração por secagem do fibrocimento;

- Os novos trabalhos devem modelar os fenômenos envolvidos na retração, sendo alimentados inclusive pelos dados aqui apresentados. 


\section{REFERÊNCIAS}

ABNT, A. B. DE N. T. NBR 5735. Cimento Portland de alto-forno. . 1991 a, p. 5.

ABNT, A. B. DE N. T. NBR 5733. Cimento Portland de alta resistência inicial. . 1991 b, p. 5 .

ABNT, A. B. DE N. T. NBR 11578. Cimento Portland composto. . 1997, p. 5.

ABNT, A. B. DE N. T. NBR 5736. Cimento Portland pozolânico. . 1999, p. 5.

ABNT, A. B. DE N. T. NBR 15210-1. Telha ondulada de fibrocimento sem amianto e seus acessórios. Parte 1 - Classificação e requisitos. . 2013 a, p. 13.

ABNT, A. B. DE N. T. NBR 15498. Placa plana cimentícia sem amianto - Requisitos e método de ensaio. . 2013 b, p. 32.

AKERS, S. Hygral and thermal expansion/shrinkage properties of asbestos-free fibre cement. Cement and Concrete Composites, v. 12, n. 1, p. 19-27, 1990.

AKERS, S. A. S. Cracking in fibre cement products. Construction and Building Materials, v. 24, n. 2, p. 202-207, fev. 2010.

ATIŞ, C. D.; KILIÇ, A.; SEVIM, U. K. Strength and shrinkage properties of mortar containing a nonstandard high-calcium fly ash. Cement and Concrete Research, v. 34, n. 1, p. 99-102, jan. 2004.

BARCELO, L.; MORANVILLE, M.; CLAVAUD, B. Autogenous shrinkage of concrete: a balance between autogenous swelling and self-desiccation. Cement and Concrete Research, v. 35, p. 177-183, jan. 2005.

BARNES, G. Interfacial science: an introduction. 2nd ed ed. Oxford; New York: Oxford University Press, 2011.

BAROGHEL-BOUNY, V. Water vapour sorption experiments on hardened cementitious materials. Cement and Concrete Research, v. 37, n. 3, p. 414-437, mar. 2007a.

BAROGHEL-BOUNY, V. Water vapour sorption experiments on hardened cementitious materials. Part II: Essential tool for assessment of transport properties 
and for durability prediction. Cement and Concrete Research, v. 37, n. 3, p. 438454, mar. 2007b.

BAROGHEL-BOUNY, V.; KHEIRBEK, A. Effect of mix-parameters on autogenous deformations of cement pastes - Microstructural interpretationsProceedings of the international workshop on shrinkage of concrete "Shrinkage 2000". Anais... In: INTERNATIONAL WORKSHOP ON SHRINKAGE OF CONCRETE "SHRINKAGE 2000". Paris, França: V. Baroghel-Bouny and P.-C. Aïtcin, 2000.

BASTOS, P. K. X. et al. Retração e desenvolvimento de propriedades mecânicas em argamassas de revestimento. Ambiente Construído, v. 2, n. 2, p. 57-70, 2002.

BELTZUNG, F.; WITTMANN, F. Dissolition of cement and early chemical shrnkage of cement pastProceedings of the international workshop on shrinkage of concrete "Shrinkage 2000". Anais... In: INTERNATIONAL WORKSHOP ON SHRINKAGE OF CONCRETE "SHRINKAGE 2000". Paris, França: V. BaroghelBouny and P.-C. Aïtcin, 2000.

BELTZUNG, F.; WITTMANN, F. Role of disjoining pressure in cement based materials. Cement and Concrete Research, v. 35, n. 12, p. 2364-2370, dez. 2005.

BENTUR, A. Early age shrinkage and cracking in cementitious systemsProceedings of the international workshop on shrinkage of concrete "Shrinkage 2000". Anais... In: INTERNATIONAL WORKSHOP ON SHRINKAGE OF CONCRETE "SHRINKAGE 2000". Paris, França: V. Baroghel-Bouny and P.-C. Aïtcin, 2000.

BISSONNETTE, B.; PIERRE, P.; PIGEON, M. Influence of key parameters on drying shrinkage of cementitious materials. Cement and Concrete Research, v. 29, n. 10, p. 1655-1662, out. 1999.

BROOKS, J. J.; CABRERA, J. G.; MEGAT JOHARI, M. A. Factors affecting the autogenous shrinkage of silica fume high-strength concreteAutogenous shrinkage of concrete: proceedings of the international workshop on autogenous shrinkage of concrete "Autoshrink' 98". Anais... In: INTERNATIONAL WORKSHOP ON AUTOGENOUS SHRINKAGE OF CONCRETE "AUTOSHRINK' 98”. Hiroshima: Ei-ichi Tazawa, 1999.

BURLION, N.; BOURGEOIS, F.; SHAO, J. F. Coupling damage - Drying shrinkage: Experimental study and modellingProceedings of the international workshop on shrinkage of concrete "Shrinkage 2000". Anais... In: INTERNATIONAL WORKSHOP ON SHRINKAGE OF CONCRETE "SHRINKAGE 2000". Paris, França: V. Baroghel-Bouny and P.-C. Aïtcin, 2000.

BUTT, H.-J. Physics and chemistry of interfaces. Weinheim ;Chichester: WileyVCH;;John Wiley, 2003.

CARDOSO, F. A. Método de formulação de argamassa de revestimento baseado em distribuição granulométrica e comportamento reológico. São Paulo: Escola Politécnica da Universidade de São Paulo, 2009. 
CHAN, Y. W.; LIU, C. Y.; LU, Y. S. Effects of slag and fly ash on the autogenous shrinkage of high performance concreteAutogenous shrinkage of concrete: proceedings of the international workshop on autogenous shrinkage of concrete "Autoshrink' 98". Anais... In: INTERNATIONAL WORKSHOP ON AUTOGENOUS SHRINKAGE OF CONCRETE “AUTOSHRINK' 98”. Hiroshima: Ei-ichi Tazawa, 1999.

CHEN, J. J.; THOMAS, J. J.; JENNINGS, H. M. Decalcification shrinkage of cement paste. Cement and Concrete Research, v. 36, n. 5, p. 801-809, maio. 2006.

CHINDAPRASIRT, P.; RATTANASAK, U. Shrinkage behavior of structural foam lightweight concrete containing glycol compounds and fly ash. Materials \& Design, v. 32, p. 723-727, fev. 2011.

CHOI, S. Y.; PARK, J. S.; JUNG, W. T. A Study on the Shrinkage Control of Fiber Reinforced Concrete Pavement. Procedia Engineering, v. 14, p. 2815-2822, jan. 2011.

CINCOTTO, M. A. Reações de hidratação e pozolânicas. In: Concreto: Ciência e Tecnologia. São Paulo: Geraldo C. Isaia, 2011. v. 1p. 381-413.

COHEN, M. D.; OLEK, J.; DOLCH, W. L. Mechanism of plastic shrinkage cracking in portland cement and portland cement-silica fume paste and mortar. Cement and Concrete Research, v. 20, p. 103-119, jan. 1990.

CUSSON, D.; HOOGEVEEN, T. Internal curing of high-performance concrete with pre-soaked fine lightweight aggregate for prevention of autogenous shrinkage cracking. Cement and Concrete Research, v. 38, p. 757-765, jun. 2008.

DAMINELI, B. L. et al. Measuring the eco-efficiency of cement use. Cement and Concrete Composites, v. 32, n. 8, p. 555-562, set. 2010.

DARQUENNES, A. et al. Early age deformations of concrete with high content of mineral additions. Construction and Building Materials, v. 25, p. 1836-1847, abr. 2011.

DIAS, C. M. R. Efeitos do envelhecimento na microestrutura e no comportamento mecânico dos fibrocimentos. São Paulo: Escola Politécnica da Universidade de São Paulo, 2005.

DIAS, C. M. R. et al. Mixture Screening Design to Choose Formulations for Functionally Graded Fiber Cements. Materials Science Forum, v. 631-632, p. 6570, out. 2009.

DIAS, C. M. R. Fibrocimento com gradação funcional. São Paulo: Escola Politécnica da Universidade de São Paulo, 2011.

DIAS, C. M. R.; GIORDANO, B. L.; JOHN, V. M. Materiais bioinspirados. Uma solução inovadora na tecnologia de produção de telhas de fibrocimento. $\ln : 1^{\mathrm{a}}$ JORNADA DE INOVAÇÃO DA USP. São Paulo: [s.n.].

ESTEVES, L. P. Internal curing in cement-based materials. Aveiro, Portugal: Universidade de Aveiro, 2009. 
ESTEVES, L. P. Superabsorbent polymers: On their interaction with water and pore fluid. Cement and Concrete Composites, v. 33, p. 717-724, ago. 2011.

FOURDRIN, E.; GUIGOU, C.; CHAPPUIS, J. Early age shrinkage of mortars: conception of a new device and detailed analysis of a typical experimental curveProceedings of the international workshop on shrinkage of concrete "Shrinkage 2000". Anais... In: INTERNATIONAL WORKSHOP ON SHRINKAGE OF CONCRETE "SHRINKAGE 2000". Paris, França: V. Baroghel-Bouny and P.-C. Aïtcin, 2000.

GARBOCZI, E. J. Permeability, diffusivity, and microstructural parameters: A critical review. Cement and Concrete Research, v. 20, n. 4, p. 591-601, jul. 1990.

GIORDANO, B. L.; SOUZA, R. B.; JOHN, V. M. Influência do ligante na retração por secagem em fibrocimento. Ambiente Construído, v. 9, n. 4, p. 7-16, 2009.

GONÇALVES, B. J. S. Formulações de argamassas controladoras de humidade ambiente. Aveiro, Portugal: Universidade de Aveiro, 2011.

GROOT, C. J. W. .; LARBI, J. The influence of water flow (reversal) on bond strength development in young masonry. 2. ed. [S.I: s.n.]. v. 44

GROVES, G. W. et al. Progressive Changes in the Structure of Hardened C3S Cement Pastes due to Carbonation. Journal of the American Ceramic Society, v. 74, n. 11, p. 2891-2896, nov. 1991.

GÜNEYISI, E.; GESOĞLU, M.; ÖZBAY, E. Strength and drying shrinkage properties of self-compacting concretes incorporating multi-system blended mineral admixtures. Construction and Building Materials, v. 24, p. 1878-1887, out. 2010.

HALL, C.; HOFF, W. D.; SKELDON, M. The sorptivity of brick: dependence on the initial water content. Journal of Physics D: Applied Physics, v. 16, n. 10, p. 18751880, 14 out. 1983.

HAMMER, T. A. Test methods for linear measurement of autogenous shrinkage before settingAutogenous shrinkage of concrete: proceedings of the international workshop on autogenous shrinkage of concrete "Autoshrink' 98". Anais... In: INTERNATIONAL WORKSHOP ON AUTOGENOUS SHRINKAGE OF CONCRETE "AUTOSHRINK' 98”. Hiroshima: Ei-ichi Tazawa, 1999.

HAMMER, T. A. Effect of silica fume on the plastic shrinkage and pore water pressure of high-strength concretesProceedings of the international workshop on shrinkage of concrete "Shrinkage 2000". Anais... In: INTERNATIONAL WORKSHOP ON SHRINKAGE OF CONCRETE "SHRINKAGE 2000". Paris, França: V. BaroghelBouny and P.-C. Aïtcin, 2000.

HAN, J.; ZHANG, X.; LI, Y. Study on shrinkage of concrete with slag composite admixtureProceedings of the international workshop on shrinkage of concrete "Shrinkage 2000". Anais... In: INTERNATIONAL WORKSHOP ON SHRINKAGE OF CONCRETE "SHRINKAGE 2000". Paris, França: V. Baroghel-Bouny and P.-C. Aïtcin, 2000. 
HANEHARA, S.; HIRAO, H.; UCHIKAWA, H. Relationships between autogenous shrinkage, and the microstructure and humidity changes at inner part of hardened cement past at early ageAutogenous shrinkage of concrete: proceedings of the international workshop on autogenous shrinkage of concrete "Autoshrink' 98". Anais... In: INTERNATIONAL WORKSHOP ON AUTOGENOUS SHRINKAGE OF CONCRETE "AUTOSHRINK' 98”. Hiroshima: Ei-ichi Tazawa, 1999.

HEDLUND, H.; WESTMAN, G. Evaluation and comparison of sealed and nonsealed shrinkage deformation measurements of concreteAutogenous shrinkage of concrete: proceedings of the international workshop on autogenous shrinkage of concrete "Autoshrink' 98". Anais... In: INTERNATIONAL WORKSHOP ON AUTOGENOUS SHRINKAGE OF CONCRETE "AUTOSHRINK' 98”. Hiroshima: Eiichi Tazawa, 1999.

HEWLETT, P. Lea's chemistry of cement and concrete. Oxford:: Elsevier Butterworth-Heinmann,, 2004.

HILLEL, D. Encyclopedia of soils in the environment. 1st ed. ed. Oxford UK ;;Boston: Elsevier/Academic Press, 2004.

HOLT, E.; LEIVO, M. T. Autogenous shrinkage at very early agesAutogenous shrinkage of concrete: proceedings of the international workshop on autogenous shrinkage of concrete "Autoshrink' 98". Anais... In: INTERNATIONAL WORKSHOP ON AUTOGENOUS SHRINKAGE OF CONCRETE "AUTOSHRINK' 98". Hiroshima: Ei-ichi Tazawa, 1999.

HOPPE FILHO, J. Sistemas cimento, cinza volante e cal hidratada: mecanismo de hidratação, microestrutura e carbonatação de concreto. São Paulo: Escola Politécnica da Universidade de São Paulo, 2008.

HORI, A. et al. Influence of expansive additives on autogenous shrinkageAutogenous shrinkage of concrete: proceedings of the international workshop on autogenous shrinkage of concrete "Autoshrink' 98". Anais... In: INTERNATIONAL WORKSHOP ON AUTOGENOUS SHRINKAGE OF CONCRETE "AUTOSHRINK' 98". Hiroshima: Ei-ichi Tazawa, 1999.

HOUST, Y. F.; WITTMANN, F. H. Depth profiles of carbonates formed during natural carbonation. Cement and Concrete Research, v. 32, n. 12, p. 1923-1930, dez. 2002.

HUA, C.; ACKER, P.; EHRLACHER, A. Analyses and models of the autogenous shrinkage of hardening cement paste. Cement and Concrete Research, v. 25, n. 7, p. 1457-1468, out. 1995.

IDIART, A. E. Coupled analysis of degradation processes in concrete specimens at the meso-level. Barcelona: Universitat Politècnica de Catalunya, 2009.

IVANOV, I. D.; STRAIF, K. Prevention of Occupation al Cancer. The Global Occupational Health Network, v. 11, p. 1-15, 2006. 
JENNINGS, H. M. Refinements to colloid model of C-S-H in cement: CM-II. Cement and Concrete Research, v. 38, n. 3, p. 275-289, mar. 2008.

JENSEN, O. M. Influence of cement composition on autogenous deformation and change of the relative humidityProceedings of the international workshop on shrinkage of concrete "Shrinkage 2000". Anais... In: INTERNATIONAL WORKSHOP ON SHRINKAGE OF CONCRETE "SHRINKAGE 2000". Paris, França: V. BaroghelBouny and P.-C. Aïtcin, 2000.

JOHN, V. M. Cimentos de escória ativada com silicatos de sódio. São Paulo: Escola Politécnica da Universidade de São Paulo, 1995.

JOHN, V. M.; AGOPYAN, V. Reciclagem de escória de alto-forno no BrasilAnais do Seminário nacional sobre reuso/reciclagem de resíduos sólidos industriais. Anais... In: SEMINÁRIO NACIONAL SOBRE REUSO/RECICLAGEM DE RESÍDUOS SÓLIDOS INDUSTRIAIS. São Paulo: SEMA-SP/FIESP/CETESB, 2000.

JUSTNES, H.; SELLEVOLD, E. J.; et al. The influence of cement characteristics on chemical shrinkageAutogenous shrinkage of concrete: proceedings of the international workshop on autogenous shrinkage of concrete "Autoshrink' 98". Anais... In: INTERNATIONAL WORKSHOP ON AUTOGENOUS SHRINKAGE OF CONCRETE "AUTOSHRINK' 98". Hiroshima: Ei-ichi Tazawa, 1999.

JUSTNES, H.; HAMMER, T.; et al. Chemical shrinkage of cement paste, mortar and concreteAutogenous shrinkage of concrete: proceedings of the international workshop on autogenous shrinkage of concrete "Autoshrink' 98". Anais... In: INTERNATIONAL WORKSHOP ON AUTOGENOUS SHRINKAGE OF CONCRETE "AUTOSHRINK' 98". Hiroshima: Ei-ichi Tazawa, 1999.

KANSTAD, T. et al. Effect of silica fume on early age crack sensitivity of high performance concreteProceedings of the international workshop on shrinkage of concrete "Shrinkage 2000". Anais... In: INTERNATIONAL WORKSHOP ON SHRINKAGE OF CONCRETE "SHRINKAGE 2000". Paris, França: V. BaroghelBouny and P.-C. Aïtcin, 2000.

KIRCHHEIM, A. P. et al. Analysis of cubic and orthorhombic C3A hydration in the presence and absence of gypsumProceedings of the XIII International Congress on the Chemistry of Cement. Anais... In: XIII INTERNATIONAL CONGRESS ON THE CHEMISTRY OF CEMENT - ICCC. Madrid: Instituto de Ciencias de la Construcción Eduardo Torroja, 2011.

KOVLER, K.; ZHUTOVSKY, S. Overview and Future Trends of Shrinkage Research. Materials and Structures, v. 39, n. 9, p. 827-847, 5 jul. 2006.

KRONLÖF, A.; LEIVO, M.; SIPARI, P. Experimental study on the basic phenomena of shrinkage and cracking of fresh mortar. Cement and Concrete Research, v. 25, p. 1747-1754, dez. 1995.

MAJORANA, C. E. Mathematical modeling of creep and shrinkage of concrete, Edited by Z. P. Bazant, 1988. Wiley, ISBN 0 471920576. Price $£ 65.00$. Communications in Applied Numerical Methods, v. 5, n. 6, p. 423-423, ago. 1989. 
MARUYAMA, I. Origin of Drying Shrinkage of Hardened Cement Paste: Hydration Pressure. Journal of Advanced Concrete Technology, v. 8, p. 187-200, 2010.

MATSUSHITA, F.; AONO, Y.; SHIBATA, S. Calcium silicate structure and carbonation shrinkage of a tobermorite-based material. Cement and Concrete Research, v. 34, n. 7, p. 1251-1257, jul. 2004.

MEDDAH, M. S.; SUZUKI, M.; SATO, R. Influence of a combination of expansive and shrinkage-reducing admixture on autogenous deformation and self-stress of silica fume high-performance concrete. Construction and Building Materials, v. 25, p. 239-250, jan. 2011.

MEHTA, P. Concreto microestrutura, propriedades e materiais. 3 ed. ed. São Paulo: Ibracon, 2008.

MEHTA, P.; MONTEIRO, P. Concreto microestrutura, propriedades e materiais. 3 ed. ed. São Paulo: Ibracon, 2008.

MELO NETO, A. A.; CINCOTTO, M. A.; REPETTE, W. Drying and autogenous shrinkage of pastes and mortars with activated slag cement. Cement and Concrete Research, v. 38, n. 4, p. 565-574, abr. 2008.

MELO NETO, A. A. DE. Influência de aditivos redutores e compensadores de retração em argamassas e pastas com cimento de escória ativada. São Paulo: Escola Politécnica da Universidade de São Paulo, 2008.

MIAO, B. A new method to measure the early-age deformation of cement based materialsProceedings of the international workshop on shrinkage of concrete "Shrinkage 2000". Anais... In: INTERNATIONAL WORKSHOP ON SHRINKAGE OF CONCRETE "SHRINKAGE 2000". Paris, França: V. Baroghel-Bouny and P.-C. Aïtcin, 2000.

MINARD, $\mathrm{H}$. et al. Mechanisms and parameters controlling the tricalcium aluminate reactivity in the presence of gypsum. Cement and Concrete Research, v. 37, p. 1418-1426, out. 2007.

MINDESS, S. Concrete. Englewood Cliffs, N.J: Prentice-Hall, 1981.

MIYAZAWA, S.; TAZAWA, E. Influence os specimen size and relative umidity on shrinkage of high-strength concreteProceedings of the international workshop on shrinkage of concrete "Shrinkage 2000". Anais... In: INTERNATIONAL WORKSHOP ON SHRINKAGE OF CONCRETE "SHRINKAGE 2000". Paris, França: V. BaroghelBouny and P.-C. Aïtcin, 2000.

MOLIN, D. C. C. DAL. Fissuras em estruturas de concreto armado: análise das manifestações típicas e levantamento de casos ocorridos no Estado do Rio Grande do Sul. Porto Alegre: Universidade Federal do Rio Grande do Sul, 1988.

MORA-RUACHO, J.; GETTU, R.; AGUADO, A. Influence of shrinkage-reducing admixtures on the reduction of plastic shrinkage cracking in concrete. Cement and Concrete Research, v. 39, p. 141-146, mar. 2009. 
MOTTA, L. A. C. Melhoria do desempenho de fibras de coco e sisal para reforço de matrizes cimentícias através de tratamento termodinâmico e impregnação de resinas. São Paulo: Escola Politécnica da Universidade de São Paulo, 2005.

MOUNANGA, P. et al. Predicting $\mathrm{Ca}(\mathrm{OH}) 2$ content and chemical shrinkage of hydrating cement pastes using analytical approach. Cement and Concrete Research, v. 34, n. 2, p. 255-265, fev. 2004.

NEGRO, C. et al. Methodology for flocculant selection in fibre-cement manufacture. Cement and Concrete Composites, v. 28, n. 1, p. 90-96, jan. 2006.

NEVILLE, A. M. Propriedades do concreto. São Paulo: Pini, 1997.

NGALA, V. T.; PAGE, C. L. EFFECTS OF CARBONATION ON PORE STRUCTURE AND DIFFUSIONAL PROPERTIES OF HYDRATED CEMENT PASTES. Cement and Concrete Research, v. 27, n. 7, p. 995-1007, jul. 1997.

PASSUELLO, A.; MORICONI, G.; SHAH, S. P. Cracking behavior of concrete with shrinkage reducing admixtures and PVA fibers. Cement and Concrete Composites, v. 31, n. 10, p. 699-704, nov. 2009.

PERSSON, B. Self-desication and it's importance in concrete technology. Lund Sweden: Lund Institute of Technology, 2002a.

PERSSON, B. Eight-year exploration of shrinkage in high-performance concrete. Cement and Concrete Research, v. 32, n. 8, p. 1229-1237, ago. 2002b.

PERSSON, B. S. M. Shrinkage of high-performance concreteAutogenous shrinkage of concrete: proceedings of the international workshop on autogenous shrinkage of concrete "Autoshrink' 98". Anais... In: INTERNATIONAL WORKSHOP ON AUTOGENOUS SHRINKAGE OF CONCRETE "AUTOSHRINK' 98". Hiroshima: Ei-ichi Tazawa, 1999.

QUENARD, D.; SALLEE, H. Water vapour adsorption and transfer in cement-based materials: a network simulation. Materials and Structures, v. 25, p. 515-522, 1992.

RAO, G. A. Long-term drying shrinkage of mortar - influence of silica fume and size of fine aggregate. Cement and Concrete Research, v. 31, n. 2, p. 171-175, fev. 2001.

SALES, A. T. C. Retração, fluência e fratura em compósitos cimentícios reforçados com polpa de bambu. Rio de Janeiro: Pontífica Universidade Católica do Rio de Janeiro, 2006.

SALIBA, J. et al. Influence of shrinkage-reducing admixtures on plastic and long-term shrinkage. Cement and Concrete Composites, v. 33, p. 209-217, fev. 2011.

SATO, N. M. N. Análise da porosidade e de propriedades de transporte de massa em concretos. São Paulo: Escola Politécnica da Universidade de São Paulo, 1998. 
SATO, N. M. N.; AGOPYAN, V. ANÁLISE DA POROSIDADE E DE PROPRIEDADES DE TRANSPORTE DE MASSA EM CONCRETOS. Boletim Técnico da Escola Politécnica da USP, v. 216, 1998.

SAVASTANO JR., H.; SANTOS, S. F. Produtos de fibrocimento. In: Materiais de Construção Civil e Princípios de Ciência e Engenharia de Materiais. São Paulo: Instituto Brasileiro do Concreto IBRACON, 2007. v. 2p. 983-1005.

SAVASTANOJR, H.; WARDEN, P.; COUTTS, R. Microstructure and mechanical properties of waste fibre?cement composites. Cement and Concrete Composites, v. 27, n. 5, p. 583-592, maio. 2005.

SCRIVENER, K. L.; WIEKER, W. Advances in Hydration at Low: ambient and elevated temperaturesProceedings of the INTERNATIONAL CONGRESS ON THE CHEMISTRY OF CEMENT. Anais... In: INTERNATIONAL CONGRESS ON THE CHEMISTRY OF CEMENT. Nova Delhi, Índia: ICCC, 1992.

SHAH, H. R.; WEISS, J. Quantifying shrinkage cracking in fiber reinforced concrete using the ring test. Materials and Structures, v. 39, n. 9, p. 887-899, 20 set. 2006.

SILVA, A. L. G.; ETULAIN, C. R. Avaliação do impacto econômico da proibição do uso do amianto na Construção Civil no Brasil: Convênio de Cooperação Técnica 4416 - ABIFibro/Unicamp. [S.I.] Unicamp, 2010. Disponivel em: $<$ http://inverde.files.wordpress.com/2010/10/estudo-unicamp-impacto-economico-daproibicao-do-amianto.pdf>.

SLOWIK, V. et al. Simulation of capillary shrinkage cracking in cement-like materials. Cement and Concrete Composites, v. 31, n. 7, p. 461-469, ago. 2009.

SLOWIK, V.; SCHMIDT, M.; FRITZSCH, R. Capillary pressure in fresh cement-based materials and identification of the air entry value. Cement and Concrete Composites, v. 30, n. 7, p. 557-565, ago. 2008.

SOUZA, R. B. Suscetibilidade de pastas de cimento ao ataque por sulfatos Método de ensaio acelerado. São Paulo: Escola Politécnica da Universidade de São Paulo, 2006.

SOUZA, R. B.; JOHN, V. M. The influence of silica fume on the drying shrinkage of fiber cement reinforced with PVA fibersProceendings - International inorganicbonded fiber composites conference. Anais... In: INTERNATIONAL INORGANICBONDED FIBER COMPOSITES CONFERENCE. Aalborg: Aalborg University, 2010.

SUN, W. et al. The effect of hybrid fibers and expansive agent on the shrinkage and permeability of high-performance concrete. Cement and Concrete Research, v. 31, p. 595-601, abr. 2001.

TAKADA, K. et al. Experimental evaluation of autogenous shrinkage of lightweight aggregate concreteAutogenous shrinkage of concrete: proceedings of the international workshop on autogenous shrinkage of concrete "Autoshrink' 98". Anais... In: INTERNATIONAL WORKSHOP ON AUTOGENOUS SHRINKAGE OF CONCRETE "AUTOSHRINK' 98". Hiroshima: Ei-ichi Tazawa, 1999. 
TANGTERMSIRIKUL, S. Effect of chemical composition and particle size of fly ash on autogenous shrinkage of pasteAutogenous shrinkage of concrete: proceedings of the international workshop on autogenous shrinkage of concrete "Autoshrink' 98". Anais... In: INTERNATIONAL WORKSHOP ON AUTOGENOUS SHRINKAGE OF CONCRETE "AUTOSHRINK' 98". Hiroshima: Ei-ichi Tazawa, 1999.

TAYLOR, H. F. W. Cement chemistry. 2nd ed. ed. London: T. Telford, 1997.

TAZAWA, E. Autogenous shrinkage of concrete. Hiroshima: Ei-ichi Tazawa, 1998.

TAZAWA, E. et al. Work of $\mathrm{JCl}$ Committee on autogenous shrinkageProceedings of the international workshop on shrinkage of concrete "Shrinkage 2000". Anais... In: INTERNATIONAL WORKSHOP ON SHRINKAGE OF CONCRETE "SHRINKAGE 2000". Paris, França: V. Baroghel-Bouny and P.-C. Aïtcin, 2000.

THEINER, Y.; HOFSTETTER, G. Evaluation of the effects of drying shrinkage on the behavior of concrete structures strengthened by overlays. Cement and Concrete Research, v. 42, n. 9, p. 1286-1297, set. 2012.

TOLEDO FILHO, R. D. et al. Free, restrained and drying shrinkage of cement mortar composites reinforced with vegetable fibres. Cement and Concrete Composites, v. 27, n. 5, p. 537-546, maio. 2005.

VEIGA, M. R.; VELOSA, A. L.; MAGALHÃES, A. C. Evaluation of mechanical compatibility of renders to apply on old walls based on a restrained shrinkage test. Materials and Structures, v. 40, n. 10, p. 1115-1126, 21 dez. 2006.

WEISS, W. J.; YANG, W.; SHAH, S. P. Shrinkage Cracking of Restrained Concrete Slabs. Journal of Engineering Mechanics, v. 124, n. 7, p. 765-774, jul. 1998.

WITTMANN, F. On the action of capillary pressure in fresh concrete. Cement and Concrete Research, v. 6, n. 1, p. 49-56, jan. 1976.

YUAN, Y. Modeling for prediction of restrained shrinkage effect in concrete repair. Cement and Concrete Research, v. 33, n. 3, p. 347-352, mar. 2003.

ZHUTOVSKY, S.; KOVLER, K.; BENTUR, A. Revisiting the protected paste volume concept for internal curing of high-strength concretes. Cement and Concrete Research, v. 41, p. 981-986, set. 2011. 